\title{
Diamonds are a woman's best friend
}

\author{
Citation for published version (APA):
}

Lott, C. (2019). Diamonds are a woman's best friend: broadening measures of women's access to formal political decision-making. [Doctoral Thesis, Maastricht University]. Boekenplan.

https://doi.org/10.26481/dis.20190617cl

Document status and date:

Published: 01/01/2019

DOI:

10.26481/dis.20190617cl

Document Version:

Publisher's PDF, also known as Version of record

\section{Please check the document version of this publication:}

- A submitted manuscript is the version of the article upon submission and before peer-review. There can be important differences between the submitted version and the official published version of record.

People interested in the research are advised to contact the author for the final version of the publication, or visit the DOI to the publisher's website.

- The final author version and the galley proof are versions of the publication after peer review.

- The final published version features the final layout of the paper including the volume, issue and page numbers.

Link to publication

\footnotetext{
General rights rights.

- You may freely distribute the URL identifying the publication in the public portal. please follow below link for the End User Agreement:

www.umlib.nl/taverne-license

Take down policy

If you believe that this document breaches copyright please contact us at:

repository@maastrichtuniversity.nl

providing details and we will investigate your claim.
}

Copyright and moral rights for the publications made accessible in the public portal are retained by the authors and/or other copyright owners and it is a condition of accessing publications that users recognise and abide by the legal requirements associated with these

- Users may download and print one copy of any publication from the public portal for the purpose of private study or research.

- You may not further distribute the material or use it for any profit-making activity or commercial gain

If the publication is distributed under the terms of Article $25 \mathrm{fa}$ of the Dutch Copyright Act, indicated by the "Taverne" license above, 


\section{Diamonds are a Woman's Best Friend Broadening Measures of Women's Access to Formal Political Decision-Making}




\section{Discipline}

political science, gender studies

\section{Key words}

descriptive representation, women's political empowerment, women's political power, gender quotas, composite gender index

(c) 2019 Catie Lott

ISBN 9789086664757

Cover Illustration: Ellie Lott-Clough

Publisher: Boekenplan, Maastricht

All rights reserved. No part of this publication may be reproduced, stored in a retrieval system, or transmitted in any form, or by any means, electronic, mechanical, photocopying, recording, or otherwise, without the prior permission in writing, from the author. 


\title{
Diamonds are a Woman's Best Friend Broadening Measures of Women's Access to Formal Political Decision-Making
}

\author{
DISSERTATION \\ to obtain the degree of Doctor at Maastricht University, \\ on the authority of the Rector Magnificus, Prof. Dr. Rianne M. Letschert \\ in accordance with the decision of the Board of Deans, \\ to be defended in public on \\ Monday June 17th, 2019, at 14.00 hours
}

by

Catie Lott 


\section{Promotor}

Prof. Dr. Mark Bevir

\section{Supervisor}

Prof. Dr. Petra Meier, University of Antwerp

\section{Assessment Committee}

Prof. Dr. Melissa Siegel, Chair

Dr. Ortrun Merkle

Dr. Karen Celis, Vrije Universiteit Brussel

Dr. Melanie Hughes, University of Pittsburgh 


\section{ACKNOWLEDGMENTS}

A heartfelt thanks to Mindel, who fought to get me into the PhD program despite credentials that didn't quite align with those of the typical GPAC2 student. My supervisory duo of Mark Bevir (University of California Berkeley, USA) and Petra Meier (University of Antwerp, Belgium) receive the standing ovation for pushing, praising, and cajoling me across the finish line. Our long dinners, "robust" conversations, and wonderful analogies (here's how you bake a cake and take a vacation in Barcelona) were always a highlight of each Maastricht trip. A big thank you to my fellow GPAC2 student, Richard Martina, for continually encouraging me to finish while ensuring that I saw at least two good movies every year. Let me also acknowledge the United States Agency for International Development and David Yang, former Deputy Assistant Administrator. He heard the pitch for this research project, quickly understood its practical application for the Agency, and gave it a green light. Neil Levine, Director of the USAID Democracy Center, jumped in and championed this initiative, offering his full support and leadership. The USAID Women in Power Project sparked the first round of data collection upon which this research effort was built. Individuals who worked on the Women in Power project are highlighted and thanked throughout the book, but a special note of appreciation is reserved for Dr. Melanie Hughes from Rutgers University and USAID Senior Election Advisor Julie Denham for their unfailing commitment and perseverance. And finally, to my family. Thanks to Joe for his care-taking duties and unparalleled editing skills. Let me also thank my mother. Her oft-uttered phrase - "You can only do what you can do!" - was a reminder that juggling family, work, and school is a constant, never-perfect balancing act. May the women who come after us find the path easier. 


\section{DEDICATION}

To my girls, Berdeen and Ellie, for the many weekends and nights that mom was shut up in her office and missed out on their adventures. While the time can never be recaptured, I hope my dedication to higher education and furthering gender equality may have a positive influence on your lives. 


\section{LIST OF ABBREVIATIONS}

AGDI African Gender and Development Index

CEDAW Convention on the Elimination of All Forms of Discrimination against Women

CIA Central Intelligence Agency

DFID Department for International Development

GDI Gender Development Index

GEM Gender Empowerment Measure

GEPA Gender Equality in Public Administration

IPU Inter-Parliamentary Union

NGO Non-Governmental Organization

OECD Organization for Economic Co-Operation and Development

RESDAL Red de Seguridad y Defensa de América Latina

SDG Sustainable Development Goal (United Nations)

UN United Nations

UNDP United Nations Development Program

UNIFEM United Nations Development Fund for Women

UNSCR United Nations Security Council Resolution

USAID United States Agency for International Development 



\section{TABLE OF CONTENTS}

List of Tables

$\begin{array}{ll}\text { List of Graphs } & 13\end{array}$

$\begin{array}{lll}\text { Chapter } 1 & \text { Introduction } & 15\end{array}$

$\begin{array}{ll}1.1 & \text { Opening the Story } \\ 1.2\end{array}$

1.2 The Evolution of Current Political Gender Measures 17

1.3 The Diamond Index as a Global Gender Measuring Tool 30 in the Political Space $\quad 30$

1.4 Chapter Overviews 33

Chapter 2 Measuring Women in the Political Domain:

$\begin{array}{ll}\text { a Critical Appraisal } & 37\end{array}$

2.1 Introduction 37

2.2 How Current Gender Indexes Conceptualize and Measure 39 Women's Presence in the Political Domain 39

$\begin{array}{lll}2.3 & \text { Conclusion } & 89\end{array}$

$\begin{array}{lll}\text { Chapter } 3 & \text { For Good Measure } & 93\end{array}$

$\begin{array}{lll}3.1 & \text { Introduction } & 93\end{array}$

3.2 Criteria of Quality Data 94

3.3 Using Quality Data to Measure Women's Political Presence 108

$\begin{array}{ll}3.4 & \text { Conclusion } \\ & 126\end{array}$

$\begin{array}{lll}\text { Chapter } 4 & \text { Developing the Diamond Index } & 127\end{array}$

$\begin{array}{ll}4.1 & \text { Introduction } \\ & 127\end{array}$

$\begin{array}{lll}4.2 & \text { Researcher Positionality } & 128\end{array}$

4.3 Indicator Development of the Diamond Index 129

4.4 Construction of the Diamond Index 152

4.5 Conceptual Limitations 164

$\begin{array}{lll}4.6 & \text { Conclusion } & 166\end{array}$

Chapter 5 Gathering Data For the Diamond Index 171

$\begin{array}{lll}5.1 & \text { Introduction } & 171\end{array}$

5.2 The Four Phases of Data Collection 172

5.3 Collecting Data: From Easy to Hard 185

$\begin{array}{lll}5.4 & 192\end{array}$

$\begin{array}{lll}5.5 & \text { Conclusion } & 197\end{array}$ 
Chapter 6 Mapping the Diamond Index in 40 Countries

$\begin{array}{ll}6.1 \text { Introduction } & 201\end{array}$

6.2 Overview of the Diamond Index in 40 Countries 202

6.3 Diamond Index - Executive Domain 209

6.4 Diamond Index - Legislative Domain 214

6.5 Diamond Index - Judicial Domain 222

6.6 Diamond Index - Security Sector Domain 226

6.7 Glass Walls: Horizontal Representation Among 232

Decision-Makers 232

6.8 Glass Ceilings: Vertical Representation Among 238

Decision-Makers 238

$\begin{array}{lll}6.9 \text { Conclusion } & 244\end{array}$

$\begin{array}{lll}\text { Chapter } 7 & \text { Diamond Index Findings and Limitations } & 247\end{array}$

$\begin{array}{lll}7.1 & \text { Introduction } & 247\end{array}$

7.2 Evaluating the Quality Data Framework 248

7.3 Diamond Index Findings and Areas of Interest 267

7.4 Value of the Diamond Index and Areas of Future Research 276

7.5 Limitations of the Diamond Index 282

$\begin{array}{lll}7.6 \text { Conclusion } & 285\end{array}$

$\begin{array}{lll}\text { Chapter } 8 & \text { Conclusion } & 289\end{array}$

8.1 Summary of Results 290

8.2 Limitations of the Research 292

8.3 Added Value of the Research 293

8.4 Future Areas of Research and Practitioner Use 294

$\begin{array}{lll}8.5 & \text { Final Note } & 297\end{array}$

Annexes $\quad 300$

$\begin{array}{lll}\text { Annex A Diamond Index Country Maps } & 300\end{array}$

Annex B Diamond Index Scorecards 348

$\begin{array}{ll}\text { Bibliography } & 396\end{array}$

Addendum on Valorization of the Dissertation 4412

$\begin{array}{ll}\text { Biography } & 416\end{array}$

UNU-MERIT/MGSoG Dissertation Series $\quad 417$ 


\section{LIST OF TABLES}

TABLE 1: Indexes Using Legislative Branch Measures Only

TABLE 2: Indexes Using Legislative and Executive Branch Measures

TABLE 3: Index Using Legislative, Executive, Judicial, and Security Measures

TABLE 4: $\quad$ Political Domain Indicators Used across Six Gender Indexes

TABLE 5: Data Quality Assessment Framework - International Monetary Fund

TABLE 6: European Statistics Code of Practice - Eurostat

TABLE 7: National Quality Assurance Framework - UN

TABLE 8: Data Quality Framework in Relation to Composite Indicators Organization for Economic Co-Operation and Development

TABLE 9: Gender Data Quality Framework - Data2X

TABLE 10: Selected Positions of Formal Political Decision-Makers

TABLE 11: Quality Data Framework for the Diamond Index

TABLE 12: Indicators Measuring Women in the Political Space from Six Gender Indexes

TABLE 13: Diamond Index - 12 Selected Positions

TABLE 14: STEP 1 - Example of Diamond Index Weighting Process

TABLE 15: Yemen's Weighted Judicial Score

TABLE 16: Rwanda's Weighted Judicial Score

TABLE 17: STEP 2 - Example of Albania Diamond Index Scaled from 0 to 100

TABLE 18: Diamond Index Albania Country Scorecard Achieving a Final Score of 18.5

TABLE 19: Final 40 Countries Selected

TABLE 20: Master Spreadsheet Headings and Definitions

TABLE 21: Information Sources for the Diamond Index

TABLE 22: Missing Diamond Index Indicators by Domain

TABLE 23: Average Number of Indicators Collected by Region

TABLE 24: Number/Percentage of Indicators Collected for the Diamond Index

TABLE 25: 20 Countries with Full Diamond Index 2015 Scores

TABLE 26: Diamond Index 2015 Scores of all 40 Countries

TABLE 27: Diamond Index 2015 Weighted Scores by Region and Global Average

TABLE 28: Global Percentage of Women by Horizontal Distribution (Glass Walls)

TABLE 29: Global Percent of Women by Vertical Distribution (Glass Ceiling)

TABLE 30: Percent of Women in the Executive Branch by Tier and Region

TABLE 31: Executive Rankings: Diamond Index 2015

TABLE 32: Diamond Index 2015 - Weighted Executive Scores by Region

TABLE 33: Percent of Women in the Legislative Branch by Tier and Region

TABLE 34: Comparison of 2015 Diamond Index to IPU Legislative Rankings 
TABLE 35: Diamond Index 2015 - Legislative Scores by Region

TABLE 36: Percent of Women in the Judicial Branch by Tier and Region

TABLE 37: Diamond Index 2015 - Judicial Scores

TABLE 38: Diamond Index 2015 - Judicial Scores by Region

TABLE 39: Percent of Women in the Security Sector by Tier and Region

TABLE 40: Diamond Index 2015 - Security Sector Scores

TABLE 41: Asia - Percent of Women by Security Tier and Weighted Security Score

TABLE 42: Middle East \& North Africa - Weighted Security Scores by Individual Tier

TABLE 43: Diamond Index 2015 - Security Scores by Region

TABLE 44: Eastern Europe/Eurasia - Horizontal Distribution

TABLE 45: Latin America/Caribbean - Horizontal Distribution

TABLE 46: Asia - Horizontal Distribution

TABLE 47: Africa - Horizontal Distribution

TABLE 48: Middle East/North Africa - Horizontal Distribution

TABLE 49: Eastern Europe/Eurasia - Vertical Distribution

TABLE 50: Latin America/Caribbean - Vertical Distribution

TABLE 51: Asia - Vertical Distribution

TABLE 52: Africa - Vertical Distribution

TABLE 53: Middle East/North Africa - Vertical Distribution

TABLE 54: Relevance Quality Data Criteria

TABLE 55: Completeness Quality Data Criteria

TABLE 56: Comparability Quality Data Criteria

TABLE 57: Accuracy Quality Data Criteria

TABLE 58: Timeliness Quality Data Criteria

TABLE 59: Cost Effectiveness Quality Data Criteria

TABLE 60: Accessibility Quality Data Criteria

TABLE 61: Granularity Quality Data Criteria

TABLE 62: Diamond Index Quality Data Framework with Quantity of Data Collected

TABLE 63: Average Percentage of Women by Elected or Appointed Position

TABLE 64: Lowest Diamond Index Scores in the Legislative Domain

TABLE 65: Average Percentage of Women in the Diamond Index 40 Countries

TABLE 66: Lowest-Scoring Country by Region 


\section{LIST OF GRAPHS}

GRAPH 1: Diamond Index - Country Score of 50 Representing Parity

GRAPH 2: Example of Domain Exceeding Parity

GRAPH 3: Diamond Index - Country Score of 0 Representing the Absence of Women

GRAPH 4: Diamond Index Albania Country Scorecard $=18.5$

GRAPH 5: Diamond Index with One Dominant Sector

GRAPH 6: Diamond Index Scores for South Africa and Yemen

GRAPH 7: Diamond Index Score for Mali and the 40-Country Average

GRAPH 8: Diamond Index - Iraq and Guatemala 



\section{Chapter 1 \\ Introduction}

\section{Some Leaders are Born Women. ${ }^{1}$}

\subsection{OPENING THE STORY}

Many years ago, looking down at a New York Times freshly dropped on my doorstep, I was struck by a front-page photo chronicling a gathering of world leaders. In a sea of suits and ties, the female sex was glaringly absent, even to a young woman who was more interested in the arts and entertainment section than the political machinations of the day. That photo has remained with me over the years, and in many respects its composition has shifted little. From black-and-white newspaper photo to digital download, the absence of gender equality remains a constant in the political picture.

Other sectors have fared better at incorporating women throughout their ranks. While parity may still be the exception, women are making significant gains as professionals, business leaders, academics, entrepreneurs, and athletes. The field of politics, however, remains stubbornly slow to change, with women's representation in this arena lagging far behind despite decades of concerted effort to increase numbers. In 1960, Sirivamo Bandaranaike became the world's first female elected head of government when she assumed the position of premier minister in Sri Lanka (formerly known as Ceylon). Almost 60 years later, 11 women are elected heads of state and/or government out of 193 countries in the world. ${ }^{2}$ Progress? While not disputing that 11 is better than 1 , at the current rate of expansion the reality of closing the parity gap between men and women holding the highest office in the land remains a visionary exercise in patience.

One question academics and experts have attempted to answer over the years is Why does women's political representation matter? This question does not lend itself to

\footnotetext{
1 Attributed to Geraldine A. Ferraro, the first female vice-presidential candidate to represent a major political party in the United States. In 1984 she ran with Walter Mondale as the Democratic nominee.

2 Inter-Parliamentary Union. "Women in Politics," 2017. (www.ipu.org).
} 
an easy answer. Intuitively it seems self-evident: Of course you need women leaders. But, the "why" surrounding women's political representation remains multi-faceted. During a June 2012 focus group in Nairobi, I asked a group of Kenya's leading gender experts why having women in government mattered. The response was indignation at the question, even anger. But as I pushed for a specific answer it became apparent that participants' rationale behind the need for female representation was quite different. For some it was a matter of justice. Simply put, it was blatantly unfair for men to monopolize political representation: "In the same way as a nation we are different, I think we all need to be at the table," noted one participant. Others cited positive role models for future generations as the main impetus. Still others believed that only women could, or would, push for a "woman's agenda." Another focus group participant stated, "Women need to ensure that the gender equality issues are on top of every agenda and that they're moving forward with them."3

An equally strong contingent argued that the focus should not be increasing the percentage of women in Parliament, but focusing more attention on electing the "right women." Their position stressed that substantive representation - electing women who could and would act for women - was more important than gaining numbers. One of Kenya's most respected and long-standing female politicians is Martha Karua. Principled, tough, and a trained litigator with a talent for debate, I was told repeatedly that she strikes fear into the hearts of male politicians. For things to change "we just need a few more Martha Karua's," was a phrase I heard throughout focus groups and individual interviews. In line with this group's thinking, rather than looking towards neighboring Rwanda and its globally high percentage of women parliamentarians, Kenya should be looking to replicate more Martha Karua's.

Finally, because women's participation in Kenya has traditionally been so low, some argued heatedly: “Just get women elected, don't worry about quality. Quality has never been a criterion for electing men! Get women elected now and then we'll worry about performance later." 4

As with the practical example in Kenya, the academic justification for why women should be represented in political life remains varied: fairness, equality, more

\footnotetext{
3 Three focus groups were held in Nairobi, Kenya, between May and June 2012 to discuss women's political leadership in the country. The different groups were comprised of: 1) NGO leaders, 2) gender experts, and 3) representatives from the international donor community. The discussions took place following the adoption of a new Constitution in $\mathbf{2 0 1 0}$ mandating that no more than two-thirds of all elected and appointed positions could be held by any one gender. Given the lack of women in Kenyan politics, this equated to a one-third quota mandate for women across all of government and the security sector.

4 Echoed by a member of the "gender experts" focus group conducted in Nairobi, Kenya, in June 2012 to discuss the state of women's political leadership in the country.
} 
gender-friendly policies, positive role models, etc. Despite these differences of opinion regarding the underpinning rationale, however, there is growing consensus that women's continued under-representation in the formal political arena should be challenged. As Phillips noted in her classic work: "Though the overall statistics on women in politics continue to tell their dreary tale of under-representation, this underrepresentation is now widely regarded as a problem." 5

Many individuals and organizations have attempted to capture the extent of the problem - women's political under-representation - during the past decades using a variety of tools. This chapter presents a brief overview of prominent actions and research that have led to the wide-spread use of composite indicators to measure the ongoing gender inequality in politics and, specifically, the emergence of legislative representation as a core measure of women's political advancement. While the legislative area is no longer used exclusively to measure progress, a short review of this indicator's historical emergence allows us to better understand its continuing significance in tracking political gender inequality.

The second section of this chapter discusses the research value of this academic work, including a brief introduction to a measurement approach designed to capture women's descriptive representation in formal politics. The third, and final section, presents an overview of all eight chapters contained in this book.

\subsection{THE EVOLUTION OF CURRENT POLITICAL GENDER MEASURES}

\subsubsection{The Rise of Composite Indicators and Indexes}

The ability to accurately measure such an abstract idea - typically labeled women's political "power" or "empowerment" - remains an ongoing challenge. ${ }^{6}$ The volume and quality of data that can now be disaggregated by sex is not only increasing, but also becoming more accessible to the public. One significant challenge of this informational influx is determining how to capture, distill, and present dozens or hundreds of indicators and data points in a meaningful and understandable format.

\footnotetext{
$5 \quad$ Phillips, Anne. The Politics of Presence. Oxford University Press, 1995.

6 Current, popular gender measurement tools use a variety of approaches to capture the concept of women's presence in the political space. The most common definitions that indexes claim to measure are women's political "power" or "empowerment." Throughout this work various authors and experts use these terms as conceptual dimensions that they are measuring. The tool that I propose in this research, however, narrows the definition of women in the political space. It focuses discreetly on measuring descriptive representation across a variety of elected and appointed roles deemed to have decision-making authority inherent in the positions themselves. Rather than political power or empowerment, I limit myself to measuring "women's access to positions of decisionmaking authority in the political space."
} 
Increasingly, policy makers and development practitioners are turning to composite indicators to combine large amounts of data into a single measure that can capture complex ideas. The unitary score resulting from the index - rather than a wide variety of disparate indicators - also creates a simplified way to conduct countryto-country comparisons at the individual, regional, or global level. Typically, in creating a composite index, select indicators are chosen from a variety of domains based on a theoretical argument. The indicators may be quantitative, qualitative, or a mix of both, as appropriate. The indicator data is then drawn into an index using a described methodology with the different domains averaged into one score.

Building on Michela Nardo's work for the Organization for Economic Co-Operation and Development, there are a number of arguments both for and against the use of composite indicators. ${ }^{7}$ Turning first to the "pro" side argument, advocates contend that a well-constructed index can simplify complex concepts into easily understood information. One composite indicator allows for a wide variety of data to be pulled into a manageable stream of information. This information can, in turn, be presented in a simplified format. As a result, composite indicators are easier to interpret (rather than attempting to draw conclusions from a plethora of separate indicators). ${ }^{8}$ This might be especially important when trying to appeal to a wide lay audience. Rather than requiring the reader to cull through a long list of separate indicators, and attempt to intuit a picture from the information, a composite index combines the data points into information that can be more easily grasped, especially for those lacking in-depth expertise in that specific area.

For policy-makers and practitioners, a composite index provides quantitative data that can be used as a basis for making decisions, measuring progress over time, and designing interventions or programs. A composite indicator that measures various countries across a region, or even across the globe, can be easily used to benchmark performance. In this way, government officials, non-government organizations, multi-lateral donors, and advocates have a consistent way of judging progress both at the country level as well as how individual countries fare in relation to their neighbors or the world.

In turning to the "con" side of the argument, while acknowledging that the beauty of a composite indicator may rest with its ability to simplify complex phenomena into easily understood concepts, this is where danger also lies. A sloppily constructed index, or lack of understanding about the underlying data sets, may lead to

7 Nardo, Michela, Michaela Saisana, Andrea Saltelli, Anders Hoffman, and Enrico Giovannini. "Handbook on Constructing Composite Indicators: Methodology and User Guide." OECD publishing, 2005.

8 Nardo, Michela, Michaela Saisana, Andrea Saltelli, and Stefano Tarantola. "Tools for Composite Indicators Building." European Commission, Ispra, 2005. 
confusion about what is, or is not, being measured. In turn, this can make decisionmaking based on flawed data, or a flawed understanding of the data, difficult or even counterproductive. ${ }^{9}$

The construction process of a composite indicator can also lead to misinterpretation or simplification of the problem being measured. Indexes use multiple indicators, which are then typically distilled into a single score against which progress is benchmarked or compared. This one aggregate score, however, can mask underlying problems. A below-average score in one area can be counterbalanced by an aboveaverage score in another domain. Yet both domains may be required in order to make progress against the concept being measured.

Rather than taking a critical look at the lowest-scoring components of the index, countries tend to focus on their overall rating. As a result, a positively increasing score - which leads to claims that the situation is improving - may divert attention away from problematic indicators that could hinder future progress. Because strong country performance in one area can "mask" low performance in another, the final composite score may not reveal the full extent of challenges to be addressed. Unless the stakeholder is willing to take the time and effort to pull apart the data, this can make it difficult to identify specific intervention opportunities. Finally, there is often a significant lag time in the collection of data and construction of a composite indicator, leading to a mismatch of results and on-the-ground reality. This may be especially true for those composite indicators that are not conducted on an annual basis, when years may pass between measurement efforts.

Weaknesses aside, the use of composite indicators has been steadily rising. The most recent count by the United Nations Development Program in 2008 highlighted 178 separate composite indexes varying in range from the Happiness Index to Military Expenditures and Arms Transfers. ${ }^{10}$ One area of composite indexes that has seen significant growth during the past decade is that of measuring aspects of gender inequality.

\footnotetext{
9 Schüler, Dana. "The Uses and Misuses of the Gender-Related Development Index and Gender Empowerment Measure: A Review of the Literature." Journal of Human Development 7, no. 2 (2006): 161-81.

10 Bandura, Romina. "A Survey of Composite Indices Measuring Country Performance: 2008 Update." Office of Development Studies, New York: United Nations Development Program, 2008.
} 


\subsubsection{The Growth of Gender Composite Indicators and Indexes}

Kersti Yllö, in 1984, was the first to develop and use a gender composite index to measure the concept of what she referred to as women's social status. Her Status of Women Index analyzed how structural gender inequality affected domestic violence against women in the United States. ${ }^{11}$ Since Yllö, other social scientists have followed her trend in developing gender composite indexes. In 1988 Sugarman and Straus published their Gender Equality Index, again focused on the United States. In their work they attempt to more accurately define the "status of women" by making a theoretical distinction between "gender attainment" - defined as the extent to which women have achieved "society valued status" such as education, economic resources, physical and mental health, etc., - and "gender equality" - whether women have as much education, earning power, and life expectancy in relation to men. ${ }^{12}$ The purpose behind their construction of the Gender Equality Index was not to measure gains women were making, but to "measure the attainments of women relative to men." 13

The need for improved and more global gender composite indexes received a significant boost in 1995 with the Fourth World Conference on Women in Beijing. As a result of the conference, the Beijing Declaration and Platform for Action was produced and signed by governments around the world. In its own words: "The Platform for Action establishes a set of actions that should lead to fundamental change."14 The document called on governments to ensure women's full participation - on a basis of equality - in every aspect of society. This call for government action included the responsibility to coordinate, monitor, and assess progress on women's advancement in each country. The need to track progress highlighted the gap in data availability on women's status. Serious efforts at measuring gender equality required new, and better, measurement tools.

In 1995 the United Nations Development Program (UNDP) launched the Gender Development Index (GDI) and the Gender Empowerment Measure (GEM), with the aim of including a gender dimension in its annual Human Development Index. There have been numerous criticisms over the years about what the GDI and GEM measured,

\footnotetext{
11 Yllö, Kersti. "The Status of Women, Marital Equality, and Violence against Wives a Contextual Analysis." Journal of Family Issues 5, no. 3 (1984): 307-320.

12 Sugarman, David B., and Murray A. Straus. "Indicators of Gender Equality for American States and Regions." Social Indicators Research 20, no. 3 (1988): 229-70.

13 Ibid.

14 According to its Mission Statement, the Beijing Platform for Action aims to remove obstacles to women's active participation in all spheres of public and private life through a full and equal share in economic, social, cultural and political decision-making. Full text of the Beijing Declaration and Platform for Action can be found at: http://www. un.org/womenwatch/daw/beijing/platform.
} 
or did not measure. ${ }^{15}$ Due to a lack of understanding about what each was capable of doing, both indices were considered marginally effective as policy tools. ${ }^{16}$ Yet each was important, despite their problems and misuses, as the GEM and GDI represent early attempts to aggregate multiple indicators into a common gender score comparable on a regular basis, across multiple countries. ${ }^{17}$ Their introduction spurred other efforts to construct a more reliable index with gender-differentiated data. $^{18}$

The establishment of other global initiatives, such as the Millennium Development Goals in 2000, reinforced the need for gender-disaggregated data across all countries. ${ }^{19}$ Goal number three was specifically devoted to promoting gender equality and empowering women, although many other targets aimed at highlighting gender inequalities were found throughout all eight Millennium Development Goals. ${ }^{20}$ While many countries did not achieve the 2015 targets, the goals were able to establish a more collective, global vision for measuring gender equality.

From 2000 onward there has been a plethora of new gender indexes designed that aim to fill gaps in data. While indicators and methodologies are different, publication frequency is inconsistent, and theoretical underpinnings vary, each attempts to measure in some way the progress of the world's women.

\subsubsection{The Rise of Critical Mass Theory}

As the utility of quantifying women's presence in social and political life has taken root through the use of international instruments, it is useful to understand where the global community has focused its measurement attention. In particular, for the purpose of this research, I am most concerned with the political arena, where women's equitable share of representation has been very slow to materialize.

To speak of representation, one must begin with Hanna Pitkin. In her detailed analysis she clearly articulates what it means to "represent," including by whom

\footnotetext{
15 Klasen, Stephan. "UNDP's Gender-Related Measures: Some Conceptual Problems and Possible Solutions." Journal of Human Development 7, no. 2 (2006): 243-74. Dijkstra, Geske. "Towards a Fresh Start in Measuring Gender Equality: A Contribution to the Debate." Journal of Human Development 7, no. 2 (2006): 275-83.

16 Schüler, Dana. "The Uses and Misuses of the Gender-Related Development Index and Gender Empowerment Measure: A Review of the Literature." Journal of Human Development 7, no. 2 (2006): 161-81.

17 UNDP replaced the GEM and GDI with the Gender Inequality Index in 2010.

18 Hawken, Angela, and Gerardo L. Munck. "Cross-National Indices with Gender-Differentiated Data: What Do They Measure? How Valid Are They?" Social Indicators Research, 2013, 1-38.

19 A self-stated objective of the Millennium Development Goals was to improve the monitoring of commitments made to women during the 1990s through, for example, the Beijing Declaration, as well as other global agreements.

20 “The Millennium Development Goals Report 2015." New York, N.Y.: United Nations, 2015.
} 
and for whom. ${ }^{21}$ Of particular relevance, Pitkin expounds on what it means to have a "representative government." While she does not detail what percentage of minority or opposition views are needed for a government to be considered as "representative," she does make the important theoretical argument that diversity is a core component of representation. A representative government, by Pitkin's definition, underscores the need for a number of minority or opposition views to be officially active in government.

She further delves into the types of representation these minorities may encumber, including descriptive representation, which she generally defines as not acting for others, but standing for them. I am a woman and my legislative representative is a woman. Within the legislative realm, descriptive representation may be seen as "compositional similarity between representatives and represented." 22 The legislature, therefore, becomes a reflection for the whole of society.

While academics such as Pitkin helped further the theoretical and collective understanding of what modern representation should look like, the pressure for achieving that greater diversity of representation was given impetus with the 1979 passage of the United Nations Convention on the Elimination of All Forms of Discrimination against Women (CEDAW). The convention called for women's empowerment and full participation in society. It explicitly included "participation in the decision-making process and access to power." 23 CEDAW helped lay the basis for a global framework, accepted by the majority of countries, outlining the importance of women's political participation and the need to measure progress against this articulated goal.

Following CEDAW's adoption, the term "temporary special measures" enters into wider use. While the term was used in previous UN documents, CEDAW attempted to more clearly define the term, while at the same time delinking it from the concept of discrimination.

Article 4, paragraph 1: Adoption by States parties of temporary special measures aimed at accelerating de facto equality between men and women shall not be considered discrimination as defined in the present Convention, but shall in no way entail as a consequence the maintenance of unequal or separate standards; these

\footnotetext{
21 Pitkin, Hanna Fenichel. The Concept of Representation. University of California Press, 1967.

22 Schwindt-Bayer, Leslie A., and William Mishler. "An Integrated Model of Women's Representation." Journal of Politics 67, no. 2 (2005): 407-28.

${ }^{23}$ United Nations General Assembly. "Convention on the Elimination of All Forms of Discrimination Against Women." United Nations, Treaty Series, vol. 1249, p.13, December 18, 1979.
} 
measures shall be discontinued when the objectives of equality of opportunity and treatment have been achieved. ${ }^{24}$

CEDAW's specific effort to delink temporary special measures from notions of discrimination helped increase their acceptance. As a result, we began to see more women entering the legislative branch through the adoption of such temporary special measures as legislative quotas. At the same time pressure was increasing on states to demonstrate gender progress in line with their international commitments. Counting women in the legislative branch was seen as an easily measured, quantifiable standard against which women's political progress could be judged. As quotas became an accepted tool in many countries for increasing women's legislative representation, a corresponding area of discussion was the number of women perceived as optimal for a legislature. At what number or percentage should you set the quota?

In Kanter's seminal research she sets the following baseline of understanding: when only a few representatives (tokens) are present they have little ability to effect change in the larger group. She argued that it is only at the "tilted" category (with a ratio of approximately 65:35) that the minority can begin to change the institutional culture. ${ }^{25}$ Therefore, according to Kanter's line of reasoning - and as applied to the political arena - having a few women represented in the legislature would not necessarily lead to political change given their minority, token status.

Building on Kanter's work, Dahlerup argued that the size of the minority is important. ${ }^{26}$ Yet even as early as 1988 she expressed her reservations around the argument that women's representation must achieve a "critical mass" ${ }^{27}$ in order for change to occur. She acknowledges that numbers and percentages may have little impact on policy outcomes, and that even a few women - given the right circumstances - can create significant change. In short, given all the social, cultural, and political factors at play, it is extremely difficult to isolate the impact of numbers or percentages of women alone..$^{28}$

Despite her concerns cautioning the acceptance of "critical mass theory" as a panacea to achieving positive change for women, she acknowledges that today the

\footnotetext{
24 Ibid.

25 Kanter, Rosabeth Moss. "Some Effects of Proportions on Group Life: Skewed Sex Ratios and Responses to Token Women." The American Journal of Sociology 82, no. 5 (March 1977): 965-90.

26 Dahlerup, Drude. "From a Small to a Large Minority: Women in Scandinavian Politics." Scandinavian Political Studies 11, no. 4 (1988): 275-98.

${ }_{27}$ The term "critical mass" is borrowed from nuclear physics, and refers to the quantity needed to initiate an irreversible situation or process.

28 Dahlerup, Drude. "The Story of the Theory of Critical Mass." Politics \& Gender 2, no. 4 (2006): 522-30.
} 
idea of critical mass as a precursor to change has shifted from the academic realm to common acceptance:

The "story of the critical mass theory" refers to the actual use of the theory of a critical mass. When feminist movements and female politicians themselves make use of this "theory," it becomes important in itself, in spite of all scholarly reservations. Again and again one hears, as part of conventional wisdom, the research has shown that there must be at least 30\% women, a critical mass, for women to make a difference in politics. ${ }^{29}$

The figure of $30 \%$ representation was codified in the Beijing Platform for Action: "30\% of decision-making positions to be held by women." ${ }^{30}$ Despite reservations surrounding the effectiveness of critical mass, the concept of achieving a minimum block of women - most typically targeting parliamentary representation - has continued to grow in strength. In the last two decades, the United Nations, the Council of Europe, the European Union, the Commonwealth, the African Union, the Southern African Development Community, and the Organization of American States, to name some of the more prominent regional and international organizations, have endorsed the idea of a $30 \%$ critical mass in line with the Beijing Declaration. ${ }^{31}$

For two decades the trend line for adopting quotas to achieve a critical mass has been on the increase. ${ }^{32}$ Most recently, this shift to quotas has been prevalent in developing countries, where many new democracies are mandating the rapid adoption of quotas for women, often through constitutional and legal changes. Dahlerup and Freidenvall contrast the Scandinavian model (an "incremental approach" that has taken decades to achieve) to the more recent "fast track" approach (a process that results in historic leaps in relatively short periods of time, often in only one election). ${ }^{33}$

A number of countries with high historical barriers to women's participation, resulting in continuously low levels of representation, are using new constitutional and legal processes to rapidly mandate changes. These changes are often possible

\footnotetext{
29 Ibid.

30 United Nations. "Beijing Declaration and Platform of Action, adopted at the Fourth World Conference on Women," October 27, 1995.

31 Krook, Mona Lena. "Reforming Representation: The Diffusion of Candidate Gender Quotas Worldwide." Politics and Gender 2(3) 2006. 303-327. Norris, Pippa, and Mona Lena Krook. "Gender Equality in Elected Office: A Six-Step Action Plan." Organization for Security and Cooperation in Europe, September 9, 2011.

32 Inter-Parliamentary Union. "Women in Parliament: 20 Years in Review." Geneva, Switzerland: InterParliamentary Union, 2015.

${ }_{33}$ Dahlerup, Drude, and Lenita Freidenvall. "Quotas as a 'Fast Track' to Equal Representation for Women: Why Scandinavia is No Longer the Model." International Feminist Journal of Politics 7, no. 1 (March 2005): 26-48.
} 
following major political shifts or upheavals, ${ }^{34}$ with Rwanda and South Africa being highly visible examples. One can also look more recently to Kenya. Following massive electoral violence in 2008, a peace agreement was signed that included passage of a new constitution. The drafters included a 30\% quota for women across all elected and appointed positions - that came into full play beginning with national and local elections in 2013. In all three instances political upheaval allowed the country's rules concerning representation levels for women to be substantially rewritten in a condensed timeframe.

Today, the critical mass theory is accepted by multi-lateral and bi-lateral donors, with programs often designed around 30\% women's participation as an acceptable achievement standard. For example, the International Institute for Democracy and Electoral Assistance - at the forefront of advocating for women's increased political representation and tracking the use of quotas globally - continues to highlight the necessity of a critical mass on its website and in publications. ${ }^{35}$

As the use of quotas has grown in acceptance as a means to correct women's underrepresentation in formal government, the literature has also expanded around why and how quotas are adopted by different countries and political systems, including variations in the types of quotas embraced. Krook's analysis outlines four common arguments that have traditionally been used to explain quota adoption: 1) women mobilize to increase descriptive representation, 2) political elites recognize a strategic advantage behind increasing the presence of women, 3) quotas support standards of justice and equality of women's representation, and 4) international norms and pressure help facilitate the spread of quotas. ${ }^{36}$

Explicitly, these four arguments are based on a belief that women's descriptive representation is a positive factor, even as rationales for why may vary. Implicitly, underpinning the quota debate is the belief that increasing women's descriptive participation will increase gender-positive outcomes. For example, research points to evidence that women may be more willing to introduce legislation related to education, health care, children's issues, and welfare policy. ${ }^{37}$ Women, in their predominate role as care-giver and nurturer, can more effectively represent the views and needs of women and children than their male counterparts. Likewise, because of their role as nurturer, women are seen as staunch defenders of the

\footnotetext{
34 Tripp, Aili. "Women's Political Empowerment in Statebuilding and Peacebuilding: A Baseline Study." Madison, Wisconsin: University of Wisconsin-Madison, November 2012.

35 Institute for Democracy and Electoral Assistance. “Gender Quotas Database," 2015.

36 Krook, Mona Lena. Quotas for Women in Politics: Gender and Candidate Selection Reform Worldwide. Oxford University Press, 2010.

37 Paxton, Pamela, Sheri Kunovich, and Melanie M. Hughes. "Gender in Politics." Annual Review of Sociology 33 (2007): 263-84.
} 
underprivileged and less willing to engage in corrupt practices. While the academic literature is mixed on whether men or women are less corrupt, the perception is widespread that women are less willing to engage in rent-seeking behavior as it is not considered to be in their nature. ${ }^{38}$ Research also lends credence to the perception that women practice politics in a feminized manner. ${ }^{39}$ This includes a strong ability to build consensus and effectively negotiate differences in a non-threatening way. ${ }^{40}$

While debates continue regarding the justification for adopting and maintaining quotas, the fact remains that today more than 100 countries have embraced them through legal or voluntary means, with approximately three-quarters of those countries having done so in the past 20 years. ${ }^{41}$ In 1945 women held $2.6 \%$ of all legislative seats. Today, on average, women make up approximately $24 \%$ of all legislatures. ${ }^{42}$ The story of critical mass theory, and its usefulness as an advocacy tool for moving more women into legislative office, has proven successful. In short, the use of quotas is putting more women into politics, in particular within the legislative arena. Therefore, counting women in the legislative branch continues to be seen as an easily quantifiable standard against which women's access to positions of formal political power can be measured.

As a result of the critical mass story, and directed focus on women obtaining more legislative seats, the percentage of women in parliament is an internationally accepted and widely used indicator for tracking women's advancement. While development practitioners and aid organizations remain staunch supporters of legislative quotas as a way to improve women's lives, academic research is increasingly questioning the effectiveness of quotas as a route to greater substantive representation for women. ${ }^{43}$

The idea that women will support women's issues in itself is problematic given that there is no standard definition of what constitutes a "women's issue." Scholars have defined the term narrowly, from issues that increase autonomy and well-being,

\footnotetext{
38 Goetz, Anne Marie. "Political Cleaners: Women as the New Anti-Corruption Force?" Development and Change 38, no. 1 (2007): 87-105.

${ }_{39}$ Childs, Sarah. "A Feminised Style of Politics? Women MPs in the House of Commons." The British Journal of Politics \& International Relations 6, no. 1 (2004): 3-19.

40 Tamerius, Karin L. "Sex, Gender, and Leadership in the Representation of Women." Women, Gender, and Politics: A Reader, 2010, 243-50. Wilson, Marie C. Closing the Leadership Gap. New York: Penguin Books, 2007.

${ }^{41}$ Krook, Mona Lena. Quotas for Women in Politics: Gender and Candidate Selection Reform Worldwide. Oxford University Press, 2010.

42 Inter-Parliamentary Union. "Women in National Parliaments," 2019. (www.ipu.org).

43 Studlar, Donley T., and lan McAllister. “Does a Critical Mass Exist? A Comparative Analysis of Women's Legislative Representation Since 1950." European Journal of Political Research 41 (2002): 233-53. Devlin, Claire, and Robert Elgie. "The Effect of Increased Women's Representation in Parliament: The Case of Rwanda." Parliamentary Affairs 61, no. 2 (February 23, 2008): 237-54. Childs, Sarah, and Mona Lena Krook. "Should Feminists Give Up on Critical Mass? A Contingent Yes." Politics \& Gender 2 (2006): 522-30. Grey, Sandra. "Numbers and Beyond: The Relevance of Critical Mass in Gender Research." Politics \& Gender 2, no. 4 (2006): 492-502.
} 
to more broadly, including issues that affect a woman's everyday life. ${ }^{44}$ Celis's work highlights that attempting to narrow issues neatly into categories defined as belonging to women - and thereby implying a homogeneity to what women want and need - is simply misleading. ${ }^{45}$ Women are not monolithic in their thinking and opinions. Women are black and white, rich and poor, conservative and liberal. Given this diversity of race, education, culture - and numerous other factors - we can not inherently assume that women will support specific issues that advance a feminist cause simply because they are women.

Even if, hypothetically speaking, we were able to define a common number of women's issues upon which all elected and appointed women could rally behind in any particular country, we must be cognizant of the fact that other factors may limit women's words and actions. Political parties, as only one example, may effectively limit women's voice, agency, and willingness to act. ${ }^{46}$ Political parties remain, in most instances, the gate-keepers to political life. ${ }^{47}$ Where a woman is placed on a voting list, how many women are proposed, which constituency, and how seriously the party undertakes its commitment to gender diversity are all important elements involved in getting women elected. ${ }^{48}$ Ethnic- and religious-based parties have strong incentives to see like-minded women candidates in office. Likewise with systems based on patronage or clientelism - the "right" woman (one who will play by the existing rules) is more likely to garner party support. Being recognized and selected as a maverick or agent of change is not the criteria upon which potential candidates are typically selected by established political parties. ${ }^{49}$

If a woman successfully makes it past the numerous political party hurdles that may stand in her way, she often finds her ability to make substantive changes limited by the gender-biased nature of the institution itself in which she serves. ${ }^{50}$ Once appointed or elected to office, positions of influence and power may be closed

44 Childs, Sarah, and Mona Lena Krook. "Analysing Women's Substantive Representation: From Critical Mass to Critical Actors." Government and Opposition 44, no. 2 (2009): 125-45.

${ }_{45}$ Celis, Karen. "Studying Women's Substantive Representation in Legislatures: When Representative Acts, Contexts and Women's Interests Become Important." Representation 44, no. 2 (2008): 111-23. Celis, Karen and Sarah Childs. "The Substantive Representation of Women: What to Do with Conservative Claims?" Political Studies 60 (2012): 213-225.

46 Norris, Pippa, and Joni Lovenduski, eds. Gender and Party Politics. Sage Publications, 1993. Koch, Michael T., and Sarah A. Fulton. "In the Defense of Women: Gender, Office Holding, and National Security Policy in Established Democracies." The Journal of Politics 73, no. 01 (2011): 1-16.

47 Kittilson, Miki Caul. Challenging Parties, Changing Parliaments: Women and Elected Office in Contemporary Western Europe. Ohio State University Press, 2006. Hoekstra, Valerie. "Increasing the Gender Diversity of High Courts: A Comparative View." Politics \& Gender 6, no. 3 (2010): 474-82.

48 Kenworthy, Lane, and Melissa Malami. "Gender Inequality in Political Representation: A Worldwide Comparative Analysis." Social Forces 78, no. 1 (1999): 235-68.

49 Dahlerup, Drude. "The Story of the Theory of Critical Mass." Politics \& Gender 2, no. 4 (2006): 522-30.

50 Puwar, Nirmal. Space Invaders: Race, Gender and Bodies out of Place. Berg, 2004. Wängnerud, Lena. The Principles of Gender-Sensitive Parliaments. Routledge, 2015. Norris, Pippa, and Mona Lena Krook. "Gender Equality in Elected Office: A Six-Step Action Plan." Organization for Security and Cooperation in Europe, September 9, 2011. 
through an institutional structure that prioritizes male-based attributes and styles. ${ }^{51}$ In some legislative institutions, for example, committee chairs are awarded based on longevity of office. With women moving more recently into elected or appointed legislative positions, they are clearly disadvantaged in this process. The ability to link critical mass to substantive representation - given the potentially numerous barriers that exist between and around the two concepts - has been attempted through different modalities and will continue to be debated as new research emerges. ${ }^{52}$

\subsubsection{From Critical Mass to Critical Actors}

As noted earlier, even in the 1980s Dahlerup acknowledged that it was difficult to draw a relation between specific numbers of women and outcomes, proposing that a shift in social attitudes might go further towards explaining evidence of change once greater numbers of women enter the legislature. This change takes place around "critical acts," defined as acts or initiatives that "change the position of the minority and lead to further changes." ${ }^{53}$ Importantly, Dahlerup highlights that critical acts depend on "the willingness and ability of the minority to mobilize the resources of the organization or institution to improve the situation for themselves and the whole minority group." ${ }^{54}$ Success, in short, depends on the ability of certain actors to mobilize the institution to embrace the views of the minority.

More than a decade later Tremblay and Pelletier also argued that individuals may count more than numbers, and that getting higher percentages of women elected may not be the key to substantive representation. The best strategy to advancing a gender-friendly agenda is to get more feminists - both men and women - elected. While greater numbers of women can have positive effects on, for example, symbolism, equality, legitimization of institutions and systems, individual feminists are needed to push forward progressive interests and issues of women. ${ }^{55}$ While more women elected can achieve a descriptive critical mass, more feminists elected - a

\footnotetext{
51 Turquet, Laura. "Progress of the World's Women: In Pursuit of Justice." (2011). Thames, Frank C., and Margaret S. Williams. Contagious Representation: Women's Political Representation in Democracies Around the World. NYU Press, 2012.

52 Celis, Karen. "Substantive Representation of Women: The Representation of Women's Interests and the Impact of Descriptive Representation in the Belgian Parliament (1900-1979)." Journal of Women, Politics \& Policy 28, no. 2 (2007): 85-114. Tremblay, Manon, and Réjean Pelletier. "More Feminists or More Women? Descriptive and Substantive Representations of Women in the 1997 Canadian Federal Elections." International Political Science Review 21, no. 4 (2000): 381-405. Childs, Sarah. "The Complicated Relationship between Sex, Gender and the Substantive Representation of Women." European Journal of Women's Studies 13, no. 1 (2006): 7-21.

53 Dahlerup, Drude "From a Small to a Large Minority: Women in Scandinavian Politics." Scandinavian Political Studies 11, no. 4 (1988): 275-98.

54 lbid.

55 Tremblay, Manon, and Réjean Pelletier. "More Feminists or More Women? Descriptive and Substantive Representations of Women in the 1997 Canadian Federal Elections." International Political Science Review 21, no. 4 (2000): 381-405.
} 
"vocal critical mass" 56 - are needed to substantively represent women's issues. This not only applies to parliamentarians, the focus of most attention, but more recent evidence within the judiciary also points in this direction: feminist men appear to judge in line with feminist women while conservative women's judicial decisions are more closely aligned to those of conservative men. ${ }^{57}$

More recently, Krook and Childs have reiterated the call to focus more attention on individuals, stressing the need to move away from critical mass and direct greater attention towards what they term "critical actors" as a path towards better understanding the substantive representation of women's concerns. ${ }^{58}$ They identify critical actors as legislators, either men or women, who willingly initiate and engage in policy actions to advance women's issues, even as a minority. ${ }^{59}$ A common feature among critical actors is the low threshold at which they are willing to act politically. The objective of critical actors is to garner a substantial following - a critical mass, so to speak - to their cause in order to effect change. Their efforts may fail, however, through a lack of numbers to initiate policy change or provoke a backlash among entrenched elites opposed to fundamental reform. In order to understand how critical actors succeed or fail, the researcher must look retrospectively at the change which did, or did not, occur and why. In essence, deconstruct what happened and the role each actor played. This allows researchers to pay greater attention to how substantive representation of women occurs (rather than focus on how more women make a difference) as well as determine what specific individuals do to advance change (not what "women" as a monolithic group accomplish). ${ }^{60}$

While the idea of shifting greater focus away from critical mass and more towards critical actors is a welcome addition, it is an idea that has not been widely adopted by practitioners. Global indexes used to measure what they define as the progress of women's political power or political empowerment focus on percentages of women. Currently, they are unable to differentiate between critical actors or differing levels of authority women may hold in an institution. Women are considered as a whole, with higher percentages remaining a proxy measure for greater levels of political power.

\footnotetext{
56 Tremblay, Manon. "Do Female MPs Substantively Represent Women? A Study of Legislative Behaviour in Canada's $35^{\text {th }}$ Parliament." Canadian Journal of Political Science/Revue Canadienne de science Politique 31, no. 3 (1998): 435-465.

57 Kenney, Sally Jane. Gender and Justice: Why Women in the Judiciary Really Matter. Routledge, 2013.

58 Childs, Sarah, and Mona Lena Krook. "The Substantive Representation of Women: Rethinking the 'Critical Mass' Debate." Annual Meeting of the American Political Science Association, Washington DC, 2005.

59 Childs, Sarah, and Mona Lena Krook. "Analysing Women's Substantive Representation: From Critical Mass to Critical Actors." Government and Opposition 44, no. 2 (2009): 125-45.

60 Ibid.
} 
Critics have also begun to argue that too much emphasis has been placed on legislative quotas to the detriment of other parts of government. Legislative members do not operate in a vacuum. In functioning democracies, even weak ones, collaboration is required between the executive and legislature to pass bills and follow through on implementation. The best legislation can also be reversed, or not enforced, by the courts. In addition, de-concentrated or decentralized local governments, including local police, are often far from the national policy process. They can ignore dictates from the capital or turn a blind eye when abuses occur.

Members of parliament may successfully draft a new law and have it passed. But the executive also has to be in agreement with the law. If there is tension around the law, or provisions of the law in dispute, the executive can: 1) veto the bill, 2) refuse to fully implement it through ministries, or 3) use budget constraints as a way to "starve" implementation. Likewise, the judiciary has a role to play. Judges have the ability to overturn legislation, refuse to hear cases, or fail to punish violators. When land is illegally taken from a widow or domestic violence occurs, a slap on the wrist to the perpetrator - rather than meting out what the law dictates - sends a strong message to both sexes. The police, as community responders and law enforcers, may hesitate to pursue future prosecutions. Women, giving the anticipated outcome, may decline to report the crime. Focusing the majority of attention on women in the legislature detracts from the other decision-makers who also impact and influence rules, decisions, and policies that may disadvantage women.

\subsection{THE DIAMOND INDEX AS A GLOBAL GENDER MEASURING TOOL IN THE POLITICAL SPACE}

While we should not abandon the idea of a critical mass, we should be asking where other sources of information exist that can expand our understanding of how women are being descriptively represented in the political dimension. For example, while not as widely used as legislative percentages, more gender indexes are including executive branch data, thanks to the efforts of UN Women and the Inter-Parliamentary Union which now track and present this information annually. ${ }^{61}$ These two indicators - percentage of legislators and ministers - remain the most common measures for tracking women's global progress in the political field. What remains unclear is how to collect data representing other parts of government in the same manner. And, if it is possible, would a broader and deeper collection of women's descriptive representation across the political spectrum have additional intellectual or practical value? Would collecting such data be too time consuming

61 The latest Women In Politics report for 2017 can be found at: www.ipu.org. 
(and therefore expensive) to warrant the investment? A common perception one often hears is that better information on women in politics is simply missing and, therefore, we must content ourselves with what we have.

While women's lack of representation in the political field lags behind other areas, as currently measured through gender indexes today, that is not to say that women are not making gains as judges, police officers, mayors, governors, and senior civil servants. We simply do not know to what extent. As the common adage goes: what gets measured gets done. If we want to know whether more women are moving into other political areas, then we should be measuring that movement. And, given the growing use of technology in our daily lives and day-to-day work of government, is the lack of data as true today as it was more than 20 years ago when the InterParliamentary Union first began collecting statistics on women parliamentarians?

Despite the challenges surrounding the idea of what a critical mass can and can not do for women's representation, we should not throw it out the window. What it has clearly done is produce a body of information - representing almost every country for a sustained period of time - thus creating consistent information freely available to any stakeholder interested in this field of study. Our focus should now turn to further supplementing this valuable data. As more, and perhaps different, political doors open for women, there is a need to reflect a more modern view of descriptive representation across and within the various institutions of government.

The majority of gender composite indexes in use today attempt to measure women's relationship to the political arena through a lens of what they label as political empowerment or access to political power. Most global indexes use one to three measures to reflect these concepts. Regional indexes may use more varied but locallevel measures, depending on data availability. ${ }^{62}$

My purpose is to create a new index. Given the fact that a wide variety of excellent gender indexes already exist, my intention in creating yet another one is to expand the possibilities of measurement into new directions. This includes increasing indicators both horizontally and vertically to create a more robust global picture of how and where women are descriptively represented. Specifically, the design

\footnotetext{
62 A total of six gender composite indicators were reviewed in Chapter 2-Measuring Women's Access to Political Power: A Critical Appraisal. Of the six, four were considered global indexes: 1) Gender Inequality Index - United Nations Development Program; 2) Social Institutions and Gender Index - Organization for Economic Cooperation and Development; 3) Global Gender Gap Index - World Economic Forum; and 4) Gender Equity Index - Social Watch. The remaining two were classified as regional indexes: 1) Gender Equality Index - European Institute of Gender Equality; and 2) African Gender and Development Index - United Nations Economic Commission for Africa.
} 
and piloting of what I will call the Diamond Index attempts to answer the following research question:

\section{Can quality data measuring women's positions \\ of formal political decision-making \\ be collected on a global scale?}

The Diamond Index will measure the levels of descriptive representation among a wider variety of positions within the formal government than currently seen in any global measurement tool in use today. While the Diamond Index may have varied applications, I specifically piloted its use towards measuring women's descriptive representation in order to better understand if and where women are gaining access to political decision-making positions. A total of 12 key positions were identified from the executive, legislative, judicial, and security sector domains that are common to all countries. These positions were weighted according to their perceived level of access to decision-making authority.

The Diamond Index is a first attempt to assign varying levels of decision-making authority to different positions, acknowledging that some positions are potentially more important than others. Currently, the articulation of what is called women's access to political power is most often tied to percentages of women in institutions, with a higher percentage equated with more access. Yet straight percentages do not tell the whole story: "Counting the number of women in a parliament ... just tells you how many women are in parliament. It says nothing about their freedom to think and vote as they choose without fear of reprisal."63 Given the numerous positive outcomes associated with women's representation in the political arena, descriptive representational tools that capture their presence play an important role. The Diamond Index, while still focused on descriptive representation like other indexes, may potentially present a more detailed reflection of women's broader formal political representation. Because it focuses on selected positions that are perceived to have greater access to political decision-making, it also is able to differentiate between a block percentage of women and those considered among the elite. While today it appears that most countries still allow for only a small percentage of "superwomen" in these coveted slots, longer-term data gathered through the Diamond Index could either reinforce the "superwoman" phenomenon, or demonstrate that a wider swath of women - more reflective of their country's societal makeup - is making inroads across government and perhaps generating

63 Foust, Joshua, and Melinda Haring. "Who Cares How Many Women Are in Parliament?" Foreign Policy, June 25, 2012. 
benefits in new ways reflective of their presence in positions little recorded with today's tracking tools.

No index to date, including the Diamond Index, can predict how women will choose to vote and their rationale for doing so, in effect, their substantive representation. Over time, however, the Diamond Index holds the potential for highlighting how women are moving horizontally across any political system as well as vertically into more powerful political positions. Understanding this movement is a critical missing piece in the academic literature. Recognizing the differentiation in high, medium, and low levels of access to positions of political decision-making, while using descriptive representational measures to track how women are feeding in and out of these positions, is a valuable contribution towards building our understanding of the access to key political positions and, on the basis of future research, the relation between that access and positive gender gains.

\subsection{CHAPTER OVERVIEWS}

This work consists of eight chapters, including this introduction. Below is a short synopsis of what each attempts to convey to the reader:

\section{Chapter 2 - Measuring Women in the Political Domain: A Critical Appraisal}

Six leading gender indexes (four global and two regional) are examined to better understand the theoretical frameworks, conceptual dimensions, and selected indicators used to measure women's presence in the political arena. The analysis includes a review of the literature that underpins the development of each index and the differing terms and definitions used to reflect women's political presence. As each index is examined, the value associated with measuring women's presence across different branches of government is discussed. This includes an acknowledgement that the lack of appropriate data across the political spectrum is problematic for index measurement purposes.

\section{Chapter 3 - For Good Measure}

This chapter begins with a review of quality data definitions and frameworks proposed by a range of academics. Academic approaches are then compared to quality data use by international organizations, including the different frameworks that have been developed for global use during the past 25 years. Based on academic literature and international development practices, I then develop a quality data framework comprised of eight criteria: relevancy, completeness, comparability, accuracy, timeliness, cost effectiveness, accessibility, and granularity. Each criteria 
is then discussed in detail regarding its definition, the purpose of its inclusion, and nuances in relation to its use in a composite gender indicator.

\section{Chapter 4 - Developing the Diamond Index}

The conceptual framework for developing the Diamond Index is detailed in this chapter, including the four guiding principles that form the foundation of the measurement tool. This includes a detailed explanation of how the 12 decisionmaking positions were selected. Readers are then offered a step-by-step introduction as to how the index will be built. This includes an explanation of the tool's shape, with a full diamond demonstrating approximate parity between the number of men and women holding positions of formal political decision-making. Mapping exercises are highlighted to demonstrate differing aspects and uses of the index. Conceptual limitations of the Diamond Index are also acknowledged and discussed.

\section{Chapter 5 - Gathering Data for the Diamond Index}

This chapter presents a detailed narrative describing the four different stages of data collection. The second part of the chapter then devotes significant attention to outlining the numerous successes and challenges in that data collection process. An expanded section details problems found in attempting data collection within the security sector. After describing the collection process, statistics are then presented to outline where data gaps occur. These gaps are detailed by region, country, and each of the four sectors: executive, legislative, judiciary, security. Highlights around the collection effort are presented in the conclusion.

\section{Chapter 6 - Mapping the Diamond Index in 40 Countries}

The data collected and mapped in the Diamond Index 40-country sample is presented in this chapter. Results are first described globally, including a ranking of all countries from high to low scores. Following this overview, each of the four respective domains - executive, legislative, judicial, security - is presented and scored with regional trends highlighted. The second half of the chapter is devoted to examining women's horizontal and vertical presence (glass walls and glass ceilings) across the different domains. This includes using detailed graphs to present the percentage of women occupying each of the 12 decision-making positions according to regional averages drawn from the countries sampled.

\section{Chapter 7 - Diamond Index Findings and Limitations}

The first part of this chapter focuses on an analysis of the data quality in relation to the decision-making positions selected. Each of the eight criteria outlined in the Diamond Index Quality Data Framework (developed in Chapter 3) is compared against the 12 positions chosen across formal government. A ranking is given 
according to whether the quality of the data is perceived to be high, medium, or low. Compiled into one graph according to these rankings, the reader can easily see where quality concerns emerge across the 96 separate rankings (12 positions X 8 quality data criteria). The second half of this chapter is focused on findings emerging from the data, including a number of themes where the Diamond Index extends our understanding of women's descriptive representation.

\section{Chapter 8 - Conclusion}

A summary of the research project is presented in this final chapter. This includes percentages detailing the total amount of data collected and the perceived quality of that data. This is followed by a brief summation outlining what the research adds of academic value and the limitations associated with this body of work. Additionally, areas of future interest and potential areas of study in the field of women's political representation are highlighted for academics and practitioners alike. 



\title{
Chapter 2
}

\section{Measuring Women in the Political Domain: A Critical Appraisal}

\author{
The number of women in parliaments has doubled in the \\ past two decades. This translates into a global average \\ of $24 \%$ women holding parliamentary seats today. ${ }^{64}$
}

\subsection{INTRODUCTION}

This chapter reviews six prominent gender composite indexes in use today. The purpose of this exercise is to better understand how leading gender composite indexes conceptually frame, articulate, and then specifically measure women's presence in the political area.

I began this analysis by examining the available academic literature underpinning the theoretical development of commonly cited gender global indexes, such as those in use by multi-lateral organizations and non-governmental actors. I then expanded my research to include the literature produced by the organizations responsible for creating the indexes. I also examined a wide variety of gender data sources, to better understand how and where data was being collected for the indexes in use. Finally, I reviewed an extensive number of indexes containing data on women, even if their self-defined purpose was to measure concepts other than gender or women's advancement. ${ }^{65}$

\footnotetext{
64 Inter-Parliamentary Union. "Women in National Parliaments," 2019. (www.ipu.org)

65 The following is not an exhaustive list of resources consulted, but contains the more prominent indexes and data sources examined: African Gender and Development Index; Afrobarometer; Asian Barometer; Bribe Payers Index; Cingranelli-Richards Human Rights Data; Corruption Perceptions Index; Freedom in the World; Gender Equality Index; Gender Equity Index; Gender Inequality Index; Gender, Institutions and Development Database; GlassCeiling Index; Global Gender Gap Index; Human Development Index; Index of Economic Freedom; Key Indicators of the Labor Market; Women in Politics; Ibrahim Index of African Governance; Index of Economic Freedom; No Ceilings Report; Opacity Index; Open Budget Index; Parliaments at a Glance; Political Constraint Index; Polity IV Project; Quota Project; Social Institutions and Gender Index; United Cities and Local Governments Equality Agenda; UN Gender Statistics; UN Millennium Development Goals; UN Sustainable Development Goals; UN Women Facts and Figures: Leadership and Political Participation; WomenStats Project Database.
} 
Based on this review, I narrowed my focus to those indexes whose self-stated purpose is to measure gender. The index also had to have a specific component aimed at measuring women in the political space. Although this was defined across indexes in different ways (women's power, women's political empowerment, etc.), the intent was to track the progress of women's political representation. I originally envisioned analyzing only global indicators, given the focus of my research. I chose, however, to include two regional indexes in order to expand the number of cases, variety of indicators in use, and breadth of approaches to gender measurement in the political space. Individual country indexes were not included due to the specificity of their approach and narrow intentionality of use. I also chose to exclude indexes no longer being updated and published in order to focus on trends emerging from the availability of more recent data. As a result of this process, a total of six indexes were selected for analysis, including four global and two regional indexes. ${ }^{66}$

Each index is then reviewed separately through a number of different lenses. The six are first divided according to the type of indicators used to measure women's political representation. For example, one category contains two indexes that contain only legislative measures. The second category contains three indexes that focus on both legislative and executive measures. The third category contains one index that includes all four domains of interest for this research: legislative, executive, judicial, and security.

Under each index the first sub-section is devoted to introducing the index and its self-stated purpose. Because many of the terms being used are contested or open to interpretation, the second sub-section clarifies how that term is conceptualized (at times differently by various academics and institutions). Empowerment is given a lengthy discussion given that half of the indexes use this term to measure progress, even as their conceptual underpinnings vary. The third sub-section is devoted to the indicators selected by each index to measure their respective concepts of political representation. In total, 20 of the 22 indicators examined in the six indexes are categorized as measuring women's presence in the afore-mentioned sectors of formal government: legislature, executive, judicial, and security. ${ }^{67}$

Finally, a sub-section is provided highlighting some of the arguments as to why each particular domain-legislative, executive, judicial, security-adds value when creating

\footnotetext{
66 The indexes include: Gender Inequality Index, Social Institutions and Gender Index, Global Gender Gap Index, Gender Equity Index, European Union Gender Equality Index, and the African Gender and Development Index.

${ }_{67}$ Of the 22 indicators self-identified by the index designers as measuring women in the political arena, one indicator focused on education (female and male population with at least secondary education) while the second measured women's presence outside of formal government (senior positions in political parties, trade unions, employers' associations, heads or managers of NGOs).
} 
a picture of women's political representation. This includes an acknowledgement by index developers that the lack of appropriate indicator data in the political area is problematic; it is problematic for the development of their respective tools and for their ability to accurately measure the conceptual dimensions identified.

\subsection{HOW CURRENT GENDER INDEXES CONCEPTUALIZE AND MEASURE WOMEN'S PRESENCE IN THE POLITICAL DOMAIN}

The majority of gender indexes in use today attempt to measure equality or inequality between men and women. ${ }^{68}$ On average, they employ components of education, labor, health, and politics. Some of the more common indicators include primary, secondary, tertiary education levels (education); wage earnings, workforce participation rates (labor); and maternal/child mortality rates, life expectancy (health). Health tends to be the highest scoring domain with education and labor, respectively, second and third. Most notably, however, the component intended to track women's advancement in the political arena consistently scores the lowest. This last-place showing of the political category may indicate that it is the toughest dimension to change or, perhaps, the current measurement tools being employed are inadequate.

In order to understand the progression in the political domain, it is useful to understand what is being measured. The analysis below discusses six leading gender composite indexes: four that attempt to measure gender globally and two that limit themselves to one specific region. Each of these indexes takes a holistic view of women across a range of different sectors in order to capture the various facets of gender relations across society. Each index also attempts to measure some aspect of women's political "power" or "empowerment." This specific political dimension - the consistently lowest-scoring component - is my area of interest. Although reasons underpinning the slow rate of change remain outside the scope of this work, better understanding the analytical basis upon which each index is built can help shed light on the validity of indicator selection as representative of the concepts being measured.

\subsubsection{Legislative Measures}

Of the six leading gender composite indicators analyzed, the percentage of women parliamentarians is used in each one. This is the only measure to appear in all

\footnotetext{
68 Bericat, Eduardo. "The European Gender Equality Index: Conceptual and Analytical Issues." Social Indicators Research 108, no. 1 (2012): 1-28.
} 
six. There are many valid reasons as to why this branch of government has been historically used as the political power yardstick. The legislature remains the arena in which laws are debated and passed. The legislature also has varying degrees of budget authority and, therefore, power of the purse. ${ }^{69}$ In many governments the cabinet is formed from members of parliament; the path to the executive branch lies through the legislative branch. ${ }^{70}$ "Outsider" women's organizations need "insider" legislators who can carry their issues forward and act as an advocate in the formal law-making process. ${ }^{71}$ In functioning democracies, legislative institutions are able to act as an oversight and accountability check against other branches of government.

While all six composite indicators use the percentage of women parliamentarians as a core measure of what they identify as women's political power or women's empowerment, two of the global gender indexes go no further than the legislative branch: The United Nations Development Program (UNDP) Gender Inequality Index and the Organization for Economic Cooperation and Development (OECD) Social Institutions and Gender Index, detailed in Table $\mathbf{1 .}$

69 The power of the purse: I refer to how money can be controlled by national, state, and local budgeting and taxation processes that fall within the legislative mandate. The policy agenda can be affected positively (through adequate funding) or negatively (through delayed or withheld funding).

70 Lijphart, Arend. 2012. Patterns of Democracy: Government Forms and Performance in Thirty-six Countries. Yale University Press.

71 Weldon, S. Laurel. 2002. "Beyond Bodies: Institutional Sources of Representation for Women in Democratic Policymaking." Journal of Politics 64 (4): 1153-1174. 
TABLE 1: Indexes Using Legislative Branch Measures Only

\begin{tabular}{|c|c|c|c|}
\hline $\begin{array}{l}\text { Index Name } \\
\text { Organization } \\
\text { Publication }\end{array}$ & $\begin{array}{l}\text { Self-Identified } \\
\text { Overarching Concept } \\
\text { and Value }\end{array}$ & Approach & Indicators \\
\hline $\begin{array}{l}\text { Index Name: } \\
\text { Gender Inequality } \\
\text { Index }^{72} \\
\text { Organization: } \\
\text { United Nations } \\
\text { Development Program } \\
\text { Publication: } \\
\text { Global } \\
\text { Annually } \\
2010 \text { - present }\end{array}$ & $\begin{array}{l}\text { Overarching Concept: } \\
\text { Gender equity is an } \\
\text { intrinsic component of } \\
\text { human development. } \\
\text { Therefore, inequality } \\
\text { between female and } \\
\text { male achievements } \\
\text { results in the loss of } \\
\text { human development. } \\
\text { Value: } \\
\text { Computed annually for } \\
\text { almost every country } \\
\text { so the index provides } \\
\text { a consistent global } \\
\text { measure. }\end{array}$ & $\begin{array}{l}\text { Approach: } \\
\text { Gender-based } \\
\text { disadvantages are } \\
\text { measured across three } \\
\text { dimensions - health, } \\
\text { labor market, and } \\
\text { empowerment - using a } \\
\text { total of five indicators. }\end{array}$ & $\begin{aligned} & \text { Empowerment: } \\
& \checkmark \text { Female and } \\
& \text { male share of } \\
& \text { parliamentary seats } \\
& \checkmark \text { Female and male } \\
& \text { population with } \\
& \text { at least secondary } \\
& \text { education }\end{aligned}$ \\
\hline $\begin{array}{l}\text { Index Name: } \\
\text { Social Institutions and } \\
\text { Gender Index } \\
\text { Organization: } \\
\text { Organization for } \\
\text { Economic Cooperation } \\
\text { and Development } \\
\text { Publication: } \\
\text { Global } \\
\text { 2009, 2012, } 2014\end{array}$ & $\begin{array}{l}\text { Overarching Concept: } \\
\text { Discriminatory social } \\
\text { institutions - social } \\
\text { norms, practices, } \\
\text { formal and informal } \\
\text { laws - have a negative } \\
\text { impact on women's } \\
\text { development outcomes. } \\
\text { Examining social } \\
\text { institutions allows for a } \\
\text { better understanding of } \\
\text { the underlying causes } \\
\text { of gender inequality. } \\
\text { Value: } \\
\text { SIGI compliments other } \\
\text { indices by measuring } \\
\text { the discrimination } \\
\text { levels of social } \\
\text { institutions against } \\
\text { women and girls that } \\
\text { cause gender inequality, } \\
\text { rather than gender } \\
\text { inequality in itself. }\end{array}$ & $\begin{array}{l}\text { Approach: } \\
\text { Gender equality is } \\
\text { measured using ordinal } \\
\text { scales graded by expert } \\
\text { opinion. A total of } 14 \\
\text { indicators are grouped } \\
\text { into } 5 \text { sub-indexes. In } \\
2014 \text { the index included } \\
108 \text { countries classified } \\
\text { by their level of } \\
\text { discrimination. }\end{array}$ & $\begin{array}{l}\text { Political Voice: } \\
\text { Level of discrimination } \\
\text { against women's } \\
\text { political participation } \\
\checkmark \quad \text { Existence of legal } \\
\text { quotas to promote } \\
\text { women's political } \\
\text { participation } \\
\checkmark \text { Share of women in } \\
\quad \text { national parliament }\end{array}$ \\
\hline
\end{tabular}

72 UNDP. “Gender Inequality Index," 2014. www.hdr.undp.org.

73 OECD Development Center. "Social Institutions and Gender Index." 2014. http://genderindex.org. 


\subsubsection{Index \# 1: United Nations Development Program - Gender Inequality Index}

The UNDP index tool is premised on a framework that maintains human development at its core, with gender equity considered an intrinsic dimension of human development. ${ }^{74}$ Evidence points to investments in girls and women as a means for improving human development potential and producing long-term economic growth. ${ }^{75}$ Denying women the same protections and opportunities available to men will, therefore, result in human development potential being negatively affected. UNDP argues that a country cannot achieve its full potential in the face of constrained human development among half the population. ${ }^{76}$

Looking at foreign assistance through a human development lens was first articulated by UNDP in the 1990s. This new approach followed closely on the era of structural adjustment that is widely acknowledged to have exasperated inequalities between men and women rather than minimize inequalities. ${ }^{77}$ This new approach was intended to shift the concept of development advancement based on economic metrics to one that prioritized individuals. "Human development is about putting people at the centre of development. It is about people realizing their potential, increasing their choices and enjoying the freedom to lead lives they value."78

The Gender Inequality Index attempts to capture the disadvantages women may face - and resulting loss in human development - in three areas: 1) health, 2) economic activity, and 3) empowerment. Women's access to the political sphere is captured in the third dimension of empowerment. Focusing on this dimension, it is useful to determine how this concept is interpreted, and the resulting indicators that flow from this interpretation.

\footnotetext{
74 Gaye, Amie, Jeni Klugman, Milorad Kovacevic, Sarah Twigg, and Eduardo Zambrano. “Measuring Key Disparities in Human Development: The Gender Inequality Index." Human Development Research Paper 46 (2010): 1-37.

75 Ibid. Permanyer, Inaki. "A Critical Assessment of the UNDP's Gender Inequality Index." Feminist Economics 19, no. 2 (2013): 1-32.

76 The Gender Inequality Index is closely linked to the United Nations Development Program Human Development Index. This index was created "to emphasize that people and their capabilities should be the ultimate criteria for assessing the development of a country, not economic growth alone." The index measures three dimensions of human development: 1) a long and healthy life, 2) knowledge, and 3) standard of living. Both indexes are published annually. The Human Development Index can be found at http://hdr.undp.org/en/content/human-developmentindex-hdi.

77 Desai, Manisha A. “Hope in Hard Times: Women's Empowerment and Human Development." UNDP, 2010.

78 Ibid.
} 


\section{A. Conceptualizing Empowerment}

Empowerment is a particularly slippery concept to define, despite the fact that it is used extensively as a measure of gender progress. Three of the six gender indexes analyzed in this chapter, for example, identify empowerment as the central tenant for measuring gender progress in the political space. In attempting to identify the challenges associated with measuring empowerment, it is worthwhile to better understand how the term itself has evolved over the years.

The concept of empowerment has a long history, with Batliwala tracing its roots back to $12^{\text {th }}$ and $13^{\text {th }}$ century India where movements for social justice emerged, framed by a central concept that articulated the need to fight against cast and gender oppression. ${ }^{79}$ While language may have differed over the centuries, the concept remained embedded in efforts to achieve more democratic forms of social change well into the second half of the $20^{\text {th }}$ century. By the 1970 s the term was firmly embedded in feminist literature and the fight for gender equality ${ }^{80}$ This fight was articulated not from an individualistic perspective, but rather as a challenge to the underlying structures of subordination that reinforced women's position in relation to men. The goal of women's empowerment, therefore, was to challenge the patriarchal ideology and institutions that perpetuate gender discrimination and social inequality. ${ }^{81}$

By the beginning of the 1990s, however, we see the definition of the word empowerment begin to shift: from a word denoting challenge to existing structures of oppression, to a more instrumentalist form of advocacy that emphasizes freedom of choice and action. ${ }^{82}$ This interpretation applies not only to categories or groups of the disempowered - women, minorities, people with disabilities, etc. - but also to individuals. For example, what type and level of empowerment might emerge from women provided with micro-credit? What are the empowering effects of ensuring women own their land?

Kabeer argues that when women's empowerment was the end in itself, critics viewed empowerment as a zero-sum game in which powerful males were losers. ${ }^{83}$ The

\footnotetext{
79 Batliwala, Srilatha. "Taking the Power out of Empowerment - an Experiential Account." Development in Practice 17, no. 4-5 (2007): 557-65.

80 Desai, Manisha A. "Hope in Hard Times: Women's Empowerment and Human Development." United Nations Development Program, 2010.

81 Batliwala, Srilatha. "The Meaning of Women's Empowerment: New Concepts from Action." 1994.

82 Malhotra, Anju, Sidney Ruth Schuler, and Carol Boender. "Measuring Women's Empowerment as a Variable in International Development." World Bank, 2002.

${ }^{83}$ Kabeer, Naila. "Resources, Agency, Achievements: Reflections on the Measurement of Women's Empowerment." Development and Change 30, no. 3 (1999): 435-64.
} 
ability to articulate arguments that focused on greater women's empowerment as a means to a desirable end - increased economic growth and education, for example was seen as more palatable as an advocacy and policy approach..$^{84}$

The 1995 Fourth World Conferenced on Beijing helped further the spread of women's empowerment as a development goal in itself. Signatory countries committed to "enhancing further the advancement and empowerment of women all over the world...." 85 The World Bank, for example, articulates empowerment as a means to poverty reduction and, therefore, a primary development assistance goal. ${ }^{86}$ UN agencies have followed suit as well, and women's empowerment is littered throughout policies, papers, and language of the 2030 Sustainable Development Goals. ${ }^{87}$ It is this merging of feminist goals with international development priorities that has moved empowerment out of an edgy politically space and into the mainstream consciousness and development / policy vocabulary. ${ }^{88}$

However, critics charge that this popularization in development circles has undermined the concept as one meant to challenge unequal power relations and structures and refocused it on the individual and her ability to act within a set of predetermined development strategies. ${ }^{89}$ In this context, empowerment as a narrative for tackling inherently discriminatory local, national, and international patriarchal structures that disadvantage women has been minimalized to represent a narrow zone of influence where the individual's voice and agency must act within the established status quo. ${ }^{90}$ Shifting the focus away from the larger global and national forces negatively impacting disadvantaged populations - in favor of the individual or community-level engagement - has not only limited its effectiveness but essentially ignores the structural constraints and institutions that allow disempowerment to occur in the first place. ${ }^{91}$ In short, empowerment may still be transformative, but only to the extent it is transformative within existing power structures.

\footnotetext{
${ }^{84}$ Malhotra, Anju, Sidney Ruth Schuler, and Carol Boender. "Measuring Women's Empowerment as a Variable in International Development." World Bank, 2002.

85 Women, U. N. "Beijing Declaration and Platform for Action." In Fourth World Conference on Women, Vol. 15, 1995.

86 Malhotra, Anju, Sidney Ruth Schuler, and Carol Boender. "Measuring Women's Empowerment as a Variable in International Development." World Bank, 2002.

87 https://unstats.un.org/sdgs/report/2017/goal-05/

88 Kabeer, Naila. "Resources, Agency, Achievements: Reflections on the Measurement of Women's Empowerment." Development and Change 30, no. 3 (1999): 435-64.

89 Desai, Manisha A. "Hope in Hard Times: Women's Empowerment and Human Development." United Nations Development Program, 2010.

90 Batliwala, Srilatha. “The Meaning of Women's Empowerment: New Concepts from Action.” 1994.

91 Parpart, Jane L., Shirin M. Rai, and Kathleen A. Staudt. Rethinking Empowerment: Gender and Development in a Global/Local World. Routledge, 2003.
} 
The wide acceptance of empowerment as a term of art in development circles has not only shifted its meaning, but its instrumentalization has also resulted in ongoing efforts to define, quantify, and verify the term. If development organizations and objectives seek to empower women, the progress of this empowerment - and ultimate success - must be measured in a quantifiable way. In order to develop reliable measures of progress, however, it is essential to define the term being measured. There must be alignment between the concept and anticipated outcomes achieved.

Efforts to actually define the concept of empowerment often begin with Amartya Sen's Development as Freedom. ${ }^{92}$ In his classic work he identifies development as linked to expanding people's choices. Well-being must be examined in terms of people's capabilities: true opportunities to do, and be, what they value. Freedom of choice is central to Sen's articulation of individual empowerment.

Kabeer also places choice at the center of her reflections on empowerment and power: "to be disempowered, therefore, implies to be denied choice." the ability to exercise choice as having three dimensions: (1) resources (both the human and social resources required to exercise choice), (2) agency (the ability to define goals and act upon them), and (3) achievements (outcomes, i.e., the decisions or choices made). It is the achievements that allow for a closer measure of empowerment, although Kabeer acknowledges that this is laden with problems. What choices are women actually presented with in a culturally restricted context? What are the social and economic costs of those choices? Do the choices presented simply reinforce women's subordinate status? While articulating the important role choice plays in women's empowerment - and while also positing how the concept might be more accurately measured - Kabeer highlights that indicators can not accurately measure "changes in women's ability to make change." Instead, they only point us in the direction of that change..$^{94}$

Multi-lateral institutions have also turned to the task of defining empowerment over the years as it became an accepted part of their work and objectives. In the 1990s, for example, UNIEFM defined empowerment as the ability to make choices and exercise bargaining power; to have a voice; to have the ability to organize and influence the direction of social change; to create a just social and economic order,

\footnotetext{
92 Sen, Amartya. Development as Freedom. Oxford University Press, 2001.

93 Kabeer, Naila. "Resources, Agency, Achievements: Reflections on the Measurement of Women's Empowerment." Development and Change 30, no. 3 (1999): 435-64.

94 Ibid.
} 
nationally and internationally. ${ }^{95}$ UNIFEM's intention, it appears, is to stretch the concept beyond the individual and draw a vision of empowerment on a much larger scale that encompasses national and global change.

The World Bank, in an effort to bring more clarity to the term empowerment given varied definitions in use, commissioned a background paper in 2002 for a workshop entitled Poverty and Gender: New Perspectives. ${ }^{96}$ This purpose of the paper, it states, was to take a first step towards attempting to outline promising methodological approaches to measuring and analyzing women's empowerment. The authors employ Kabeer's definition of empowerment as one that best captures the commonalities of its use across development assistance: "The expansion in people's ability to make strategic life choices in a context where this ability was previously denied to them." ${ }^{97}$ This definition encompasses two essential elements that help distinguish empowerment from other, commonly cited terms such as gender equality, gender equity, voice, etc. The first element is a focus on process and the understanding that there is a transitional period from one state to another. The second key element is agency, which acknowledges that women themselves are the drivers of choice or change.

Mosedale further refines the term empowerment, although building on many of the same elements. She outlines four characteristics: 1) one must be disempowered as, for example, women are relative to men, 2) empowerment cannot be given by a third party, 3) people make decisions and are able to carry those decisions forward, and 4) it is an ongoing process. ${ }^{98}$ Mosedale raises the interesting point that empowerment is not something that can be given. Empowerment is driven by those disempowered. It is not something bestowed by those in power, donors, or sympathetic stakeholders. For Mosedale it is transformatory - power from within ${ }^{99}-$ and has no definable end. It is continuous and ongoing - one does not wake up in the morning to have arrived at a final state of empowerment.

UNDP's attention to empowerment was refocused in 2010 due, in part, to strong criticism arising from its earlier efforts to measure gender inequality through the

\footnotetext{
95 "ACC Task Force on Basic Social Services for All: Guidelines on Women's Empowerment." New York, N.Y.: UNIFEM, 1997.

96 Malhotra, Anju, Sidney Ruth Schuler, and Carol Boender. "Measuring Women's Empowerment as a Variable in International Development." World Bank, 2002.

97 Kabeer, Naila. "Reflections on the Measurement of Women's Empowerment in Discussing Women's Empowerment Theory and Practice, SIDA Studies No. 3." Stockholm: Swedish International Development Cooperation Agency, 2001.

98 Mosedale, Sarah. 2005. "Assessing Women's Empowerment: Towards A Conceptual Framework." Journal of International Development 17 (2): 243-257.

99 Green, Joanne Helen. "Measuring Women's Empowerment: Development of a Model." International Journal Of Media \& Cultural Politics 4, no. 3 (2008): 369-89.
} 
Gender Development Index and the Gender Empowerment Measure. ${ }^{100}$ Misunderstood and misused, confusion around the purpose of the indexes led UNDP back to the drawing board. The more recent Gender Inequality Index draws upon the work of Sen, ${ }^{101}$ Kabeer, ${ }^{102}$ and Batliwala, ${ }^{103}$ among others. In examining a cross-sector of academic opinions on the term, UNDP attempts to draw conceptual consensus from the various definitions. It posits that consensus does exist around four shared dimensions that underpin empowerment: 1) control over resources and ideology, 2) agency, including the right to determine the most appropriate choices, 3) process, involving change over time, and 4) outcome, as seen through tangible improvement. ${ }^{104}$ While attempting to argue that there is consensus around these terms, UNDP authors also acknowledge that emphasis on women's empowerment varies widely from a focus on the individual (thus the need for local-level interventions) to collective empowerment (aimed at social and structural transformation). Despite differences and commonalities, the one thing which seems in total agreement is that "empowerment is a multidimensional and multilevel concept.".105

While UNDP may propose that there is a growing consensus around specific terminology, others argue that it is this very lack of agreement on the concept of empowerment that continues to hinder better measurement tools. ${ }^{106}$ In point of fact, there is no single definition of "women's empowerment" that has been globally accepted. Thus, we are trying to measure a concept that lacks a common understanding. ${ }^{107}$ The development community perpetuates this confusion of definition by conflating empowerment with other concepts. Women's representation, voice, power, agency, etc., are lumped together as admirable and interchangeable concepts.

Even if common terms are agreed upon, divisions remain in attempting to define and measure empowerment at varying levels. While empowerment as a concept has entered the development lexicon, critics charge that it has remained focused at the local level and on individuals. Thus the emergence of empowerment as a

100 Dijkstra, A. Geske. "Revisiting UNDP's GDI and GEM: Towards an Alternative." Social Indicators Research 57, no. 3 (2002): 301-38 Klasen, Stephan. "UNDP's Gender-related Measures: Some Conceptual Problems and Possible Solutions." Journal of Human Development 7, no. 2 (2006): 243-74.

101 Sen, Amartya. Development as Freedom. Oxford University Press, 2001.

102 Kabeer, Naila. The Conditions and Consequences of Choice: Reflections on the Measurement of Women's Empowerment. Vol. 108. UNRISD Geneva, 1999.

103 Batliwala, Srilatha. "The Meaning of Women's Empowerment: New Concepts from Action." 1994.

104 Desai, Manisha A. “Hope in Hard Times: Women's Empowerment and Human Development.” UNDP, 2010.

105 Ibid.

106 Green, Joanne Helen. “Measuring Women's Empowerment: Development of a Model.” International Journal Of Media \& Cultural Politics 4, no. 3 (2008): 369-89. Malhotra, Anju, Sidney Ruth Schuler, and Carol Boender. “Measuring Women's Empowerment as a Variable in International Development." World Bank, 2002.

107 In a February 2013 conversation with staff members from UNDP, they noted that UN Women was in the process of developing a common definition for women's empowerment. 
development tool linked to terms such as "community," "grass-roots," "individual," and "household." 108 Others view empowerment as nothing less than actions that challenge the existing power relations and structures that oppress women. ${ }^{109}$ While not dismissing the importance of individualistic empowerment, these critics stress that the focus of empowerment should remain on collective change at the national and global levels. The difficulty in selecting global indicators that can bridge this divide between individual and structural empowerment is apparent. Indicators themselves carry information, meaning, and value judgements as to what is important. ${ }^{110}$ Because the concepts of power and empowerment remain controversial in themselves, the validity of any indicators designed to capture these concepts will likely remain open to criticism.

Kabeer attempts to address this tension by identifying three different levels or dimensions of empowerment. The first is "immediate," reflecting change at the individual or group level. The second level, "intermediate," is where the institutional rules, relationships, and resources change. Finally, "deeper" level empowerment speaks to change in the structural relationships that shape resource and power allocation, and reproduction, in the society. ${ }^{111}$ All of these three dimensions interplay with one another, as individual empowerment may require societal change in order to be sustainable. Conversely, rules and structures mean little if disempowered individuals remain un-impacted.

In the World Bank's 2002 attempt to untangle definitions and measures of empowerment, ${ }^{112}$ the authors proposed a new framework to reflect the varying dimensions of empowerment by dividing indicators into three "arenas" or spheres of life. These included: (1) household, (2) community, and (3) broader areas (with this dimension typically reflective of regional and national levels). The authors propose specific empowerment indicators across all three levels. One can easily see at a glance how the targeted level of empowerment being measured produces widely varying proposed indicators. For example, in looking at political measurement, one Household-level measure suggested was "knowledge of political system." At the Broader Arenas level, "women's representation in regional and national bodies of government" was proposed as more reflective of the dimension. The authors

\footnotetext{
108 Parpart, Jane L., Shirin M. Rai, and Kathleen A. Staudt. Rethinking Empowerment: Gender and Development in a Global/Local World. Routledge, 2003.

109 Batliwala, Srilatha. "The Meaning of Women's Empowerment: New Concepts from Action.” 1994.

110 Kabeer, Naila. The Conditions and Consequences of Choice: Reflections on the Measurement of Women's Empowerment. Vol. 108. UNRISD Geneva, 1999.

111 Kabeer, Naila. "Resources, Agency, Achievements: Reflections on the Measurement of Women's Empowerment." Discussing Women's Empowerment 17 (2001).

112 Malhotra, Anju, Sidney Ruth Schuler, and Carol Boender. "Measuring Women's Empowerment as a Variable in International Development." World Bank, 2002.
} 
suggest that in their review of the research literature and development frameworks measuring empowerment, the political/legal dimension is typically at high levels of aggregation (regional or national) while family, social, and economic dimensions occur at the individual or household level. ${ }^{113}$ That is not to infer that combining different levels of empowerment is problematic or advantageous, rather it highlights the numerous ways the concept is being understood, and multiple ways measurable outcomes may be misunderstood. Measuring different understandings of empowerment - as well as at different levels - can easily lead to contradictions in our understanding of how women's empowerment is advancing.

While competing definitions of empowerment point to the most fundamental difficulty in measuring its progress, there are a number of other constraints that also make the development of appropriate indicators extremely challenging. Foremost among these is the lack of data, especially gender-segregated data at the macro level. While researchers and practitioners recognize these limitations, in practical terms it means tools and approaches often need to be modified to accept what there is rather than collect what is needed.

Secondly, empowerment is context specific. A mother's ability to insist on an education for her daughter may be seen as an empowering move in parts of Africa or Asia while considered a non-existent issue across Europe. As laws, policies, and cultural acceptance are modified, so to will notions of empowerment change. Deciding how to select consistent and comparable empowerment indicators across countries, cultures, and time has proven to be a continually developing conversation among index developers and critics.

Finally, in returning to UNDP's four dimensions of empowerment, most efforts today have focused on measuring women's control over resources and the outcomes of empowerment as both offer more tangible results. Less effort has been devoted to measuring process and agency. ${ }^{114}$ Because empowerment is a process - with no static start and finish date - it is difficult to capture with a single measure. Malhotra et al. argue that at least two points in time are required, as well as the specification of which aspects are expected to change (and an acceptable timeframe agreed upon within which this change should occur). Only when these components are combined can success or failure be determined for measuring empowerment. ${ }^{115}$ Measuring agency is equally challenging. Kabeer notes that the term is about the ability to define one's

\footnotetext{
113 Ibid.

114 Desai, Manisha A. “Hope in Hard Times: Women's Empowerment and Human Development.” UNDP, 2010.

115 Malhotra, Anju, Sidney Ruth Schuler, and Carol Boender. "Measuring Women's Empowerment as a Variable in International Development." World Bank, 2002.
} 
goals and act upon them, and is operationalized as "individual decision-making."116 This neglects a range of actions, including the more intangible aspects of reflection and analysis. ${ }^{117}$ How did the woman arrive at a decision point? Were the choices presented actually true choices? How should we envision collective agency?

How to accurately measure such difficult components of empowerment - beyond the individual level and across countries - must be acknowledged as an enormous challenge in light of limited standardized data available on women, especially in the political arena. Given these challenges, we often see indicators repeated claiming to measure empowerment when, in fact, they may be more representative of gender inequality measures. ${ }^{118}$ Given the multiple dimensions of empowerment, however, finding a single indicator, or even set of indicators, that can accurately represent the concept in all its complexity is unlikely.

\section{B. How the UNDP Gender Inequality Index Measures Women's Empowerment}

The Gender Inequality Index's approach to measuring empowerment is somewhat different than other gender composite indexes. The authors have chosen to combine one indicator typically found in the education dimension with one legislative measure. For education the selected measure is: "Population with at least some secondary education: percent ages 25 and older." Education is recognized as a key factor in increasing the health of the individual and her family; creating greater economic opportunity; and strengthening a woman's capacity to increase information, question, and act on conditions. ${ }^{119}$ Education is typically seen as a key factor contributing to women's empowerment. ${ }^{120}$ UNDP especially emphasizes the importance in strengthening the agency of women. ${ }^{121}$ While most composite indexes separate education into another dimension, the Gender Inequality Index focus on secondary education levels reflects the concept of "empowerment" as a means to creating greater economic opportunities, improving health outcomes, and increasing space for public voice. Enhanced educational opportunities are viewed as an end to achieving gender-positive outcomes across a wide range of areas that impact a woman's life.

\footnotetext{
116 Kabeer, Naila. "Resources, Agency, Achievements: Reflections on the Measurement of Women's Empowerment." Discussing Women's Empowerment 17 (2001).

117 Ibid.

118 Desai, Manisha A. “Hope in Hard Times: Women's Empowerment and Human Development.” UNDP, 2010.

119 Permanyer, Inaki. "A Critical Assessment of the UNDP's Gender Inequality Index." Feminist Economics 19, no. 2 (2013): 1-32.

120 Parpart, Jane L., Shirin M. Rai, and Kathleen A. Staudt. Rethinking Empowerment: Gender and Development in a Global/Local World. Routledge, 2003.

121 Gaye, Amie, Jeni Klugman, Milorad Kovacevic, Sarah Twigg, and Eduardo Zambrano. “Measuring Key Disparities in Human Development: The Gender Inequality Index." Human Development Research Paper 46 (2010): 1-37.
} 
The empowerment compliment to the education indicator is a commonly used political measure identified as: "Share of seats in parliament: percent held by women." Little rationale is overtly given by UNDP as to the justification for this measure, aside from the fact that the data is available. "There are other crucial elements of empowerment, but internationally comparable measures do not exist." ${ }^{122}$ Permanyer, in extensively critiquing the Gender Inequality Index following its introduction and publication in 2010, simply states: "On the other hand, PR [parliamentary representation] is a crude, but widely available, measure of women's access to power."123 From her perspective, while not perfect, it is a proxy measure for "access to power." 124 In using it as a measure in the UNDP index, however, it appears that the authors and critics view parliamentary seats as a global proxy for the concept of empowerment as well.

Supporters of this measure argue that using "deeper" level indicators, including political representation of women, tells us something important about the ability of women to make changes in other aspects of their lives. ${ }^{125}$ By focusing on this higherlevel indicator, the logic dictates that in order for women to have arrived at this position other levels of empowerment must have occurred along the way.

Others disagree with this interpretation, pointing out that the percentage of women in parliament should be regarded as a questionable measure of women's empowerment. ${ }^{126}$ While acknowledging the lack of available data in this field, the percentage of female parliamentarians may be construed more as a reflection of political factors (such as type of system, the existence of temporary special measures, etc.) than a reflection of socio-economic and cultural factors that point to women's increasing empowerment. ${ }^{127}$ Following this line of criticism, when parliamentary percentages are used as an empowerment measure, care should be given to understanding how women arrive at their legislative seat.

While both UNDP and Permanyer acknowledge that there may be other measures more appropriate than the percentage of women parliamentarians, this measure is seen to have definitional consistency with the Global Inequality Index's use of

\footnotetext{
122 Ibid.

123 Permanyer, Inaki. "A Critical Assessment of the UNDP's Gender Inequality Index." Feminist Economics 19, no. 2 (2013): 1-32.

124 Ibid.

125 Kabeer, Naila. "Resources, Agency, Achievements: Reflections on the Measurement of Women's Empowerment." Discussing Women's Empowerment 17 (2001).

126 Dijkstra, A. Geske. "Revisiting UNDP's GDI and GEM: Towards an Alternative." Social Indicators Research 57, no. 3 (2002): 301-38.

127 Cueva Beteta, Hanny. "What Is Missing in Measures of Women's Empowerment?" Journal of Human Development 7, no. 2 (2006): 221-41. Desai, Manisha A. “Hope in Hard Times: Women's Empowerment and Human Development." UNDP, 2010.
} 
empowerment, even as the availability of data is noted as a key determinant for the indicator's inclusion. The Gender Inequality Index pulls from the existing InterParliamentary Union database for percentages of women parliamentarians, so the inclusion of legislative seats does not necessarily add any new information in the empowerment arena. When aggregated with the education data, it does create a unique combination for reflecting women's empowerment. Some might argue, however, that aggregating education levels with political representation creates a less clear picture for women's education, access to political power, and empowerment. Because UNDP captures the vast majority of countries on a consistent annual basis, however, the index remains a tool that is widely used due to its global comparability.

\subsubsection{Index \# 2: OECD - Social Institutions and Gender Index}

The Social Institutions and Gender Index was developed by the OECD as a compliment to current composite indexes in use, including the heavily criticized UNDP Gender Empowerment Measure and Gender-Related Development Index tools. It draws from a compilation of the OECD Gender, Institutions and Development Data Base developed in 2006. This database, the authors state, attempts to differentiate between the outcome variables used by most composite indexes (that focus on measuring the extent of male-female inequality) and input variables (the underlying reasons that lead to discrimination against women). ${ }^{128}$ Through its framework, the Social Institutions and Gender Index claims that it does not measure gender inequalities in health, education, labor, etc., but focuses rather on social institutions. ${ }^{129}$ These social institutions are defined as "long-lasting codes of conduct, norms, traditions, informal and formal laws that might contribute to gender inequalities in all spheres of life." ${ }^{130}$ It is discriminatory social institutions that perpetuate women's lower status in society. Sociologists emphasize that these institutions endure and persist over time. Collectively, they may restrict, exclude, and curtail access to opportunities, resources, and power which, in turn, negatively impact development. ${ }^{131}$ As a result, countries with higher inequality of social institutions are associated with lower development outcomes. ${ }^{132}$ In order to improve development outcomes, therefore, unequal social institutions must be challenged and improved. OECD countries

\footnotetext{
128 Jütting, Johannes P., Christian Morrisson, Jeff Dayton-Johnson, and Denis Drechsler. "Measuring Gender (In) Equality: The OECD Gender, Institutions and Development Data Base." Journal of Human Development 9, no. 1 (2008): 65-86.

129 North, Douglass C. "Institutions." The Journal of Economic Perspectives 5, no. 1 (1991): 97-112.

130 Branisa, Boris, Stephan Klasen, and Maria Ziegler. "The Construction of the Social Institutions and Gender Index (SIGI)." Discussion papers, Ibero America Institute for Economic Research, 2009.

131 Cerise, Somali, Gaelle Ferrant, and Jason Gagnon. "2012 Social Institutions and Gender Index: A Methodological and Technical Background Paper." Organisation for Economic Co-Operation and Development, 2013.

${ }^{132}$ Branisa, Boris, Stephan Klasen, and Maria Ziegler. "Why We Should All Care about Social Institutions Related to Gender Inequality," 2010.
} 
are excluded, as measures in the Gender, Institutions, and Development Data Base are viewed as targeting problems more prevalent in the developing world.

Five separate dimensions are captured in the index. Language and indicators have been modified over the course of three iterations, but the most recent publication of the index in 2014 included: 1) discriminatory family code, 2) restricted physical integrity, 3) son bias, 4) restricted resources and assets, and 5) restricted civil liberties. Restricted Civil Liberties is divided into two aspects. The first is access to public space which examines the individual's freedom of movement. For example, laws allowing women to travel alone, choose their residence, apply for a passport, etc. Of greater interest to this research is the second aspect of restricted civil liberties defined as political voice. The intent here is to capture women's participation in the public sphere. ${ }^{133}$

\section{A. Conceptualizing Political Voice}

Voice is defined by Goetz as a metaphor for powerful speech associated with acts or arguments that influence public decisions. It is often used in the context of public decision-making, such as parliament. ${ }^{134}$ We also see voice linked to concepts of democracy and representation. Institutions with a diversity of voices - more reflective of the country's citizenry - are perceived to be more representative of the population's interests and garner higher levels of trust. While being a woman does not guarantee a fixed ideology, it does ensure that a different set of life experiences are included within public institutions. ${ }^{135}$ In this respect, the concept of voice is not only about women having greater say among decision-making bodies, but can equally reflect concepts of democratic freedoms and representation.

Within development circles the term is often linked to agency. Agency is about making and acting on choices while voice articulates those choices. In this respect, voice can be described as the expression of agency. ${ }^{136}$ There seems consensus around the concept that voice, while not considered empowerment in itself, is a necessary component for achieving empowerment. By giving women greater voice, it is suggested that they can achieve empowerment-linked outcomes such as improved policies for services, greater control over reproductive rights, and increased economic opportunities. ${ }^{137}$

\footnotetext{
133 More information about the Social Institutions and Gender Index, including the latest variables and data source, can be found at http://www.genderindex.org.

134 Goetz, Anne-Marie, and C. Nyamu-Musembi. "Voice and Women's Empowerment: Mapping a Research Agenda." Pathways of Women's Empowerment Working Paper 2 (2008).

135 Kenney, Sally J. 2002. "Breaking the Silence: Gender Mainstreaming and the Composition of the European Court of Justice." Feminist Legal Studies 10: 257-270.

136 Buvinic, Mayra, Gayatri Koolwal, and Rebecca Furst-Nichols. “Data 2X: Mapping Gender Data Gaps DRAFT.” UN Foundation, April 2013.

137 Goetz, Anne-Marie, and C. Nyamu-Musembi. "Voice and Women's Empowerment: Mapping a Research Agenda." Pathways of Women's Empowerment Working Paper 2 (2008).
} 


\section{B. How the OECD Measures Political Voice}

The OECD states that the Political Voice dimension of the index: "highlights the importance of women's participation in community actions and public decision making for a range of development outcomes such as governance, health and education."138 Essentially, the OECD posits that allowing women greater voice in the public arena will lead to substantive representation for women. Conceptually, the attempt is being made to link greater political voice to improved development outcomes.

It is worth noting that the Restricted Civil Liberties domain of the SIGI index has proven problematic to measure from the beginning. In the original 2009 version of the index, this dimension was defined as "Civil Liberties" and included two variables: 1) Freedom of Movement (allowing for movement outside the home) and 2) Freedom of Dress (the obligation to wear a veil or burqa). ${ }^{139}$ Since the majority of countries do not restrict movement and dress, out of 123 countries measured, 83 were placed at the shared ranking of 1 . This lack of variation resulted in two-thirds of the countries being clustered in the same quintiles, making it difficult for policy makers or advocates to identify differences.

In 2012, the index was published for a second time. In this version Civil Liberties language was revised to Restricted Civil Liberties. Within this dimension, Freedom of Movement was changed to Access to Public Space (although the same measure was retained) while Freedom of Dress was discarded. In its place, Political Voice was inserted in order to measure "the level of discrimination against women with respect to political participation." 140 This discrimination is seen to reduce access to education and economic opportunities. Women's lower participation rates is also linked with reduced accountability of governments. ${ }^{141}$ This returns to the concept that greater voice for women results in higher levels of trust among formal institutions, such as parliament.

In 2014 the Restricted Civil Liberties, which in the previous version of 2012 linked higher levels of voice to more accountability government, was slightly modified. In its place the importance of voice was noted for leading to positive development

\footnotetext{
138 Cerise, Somali, Gaelle Ferrant, and Jason Gagnon. "2012 Social Institutions and Gender Index: A Methodological and Technical Background Paper." Organisation for Economic Co-Operation and Development, 2013.

139 Branisa, Boris, Stephan Klasen, and Maria Ziegler. "The Construction of the Social Institutions and Gender Index (SIGI)." Discussion papers, Ibero America Institute for Economic Research, 2009.

140 The full OECD 2012 SIGI report can be accessed at https://www.oecd.org/dev/50288699.pdf.

141 Cerise, Somali, Gaelle Ferrant, and Jason Gagnon. "2012 Social Institutions and Gender Index: A Methodological and Technical Background Paper." Organisation for Economic Co-Operation and Development, Paris. Retrieved September, 2013.
} 
outcomes, including governance. ${ }^{142}$ While voice was still viewed as impacting the political dimension, the authors pulled away from claims that it can "increase government accountability" while still acknowledging positive benefits accrued around the more generic term "governance." ${ }^{143}$

Social Watch introduced a new two-measure approach to track the Political Voice indicator: 1) the percentage of women in parliament and 2) the use of legal quotas to promote women's political participation. These two variables, researchers state, are considered proxy measures of "negative attitudes towards women's political and civic participation."144 For the first indicator, as with others, the information comes from the Inter-Parliamentarian Union database. For the second indicator, countries can garner a 0 (national and local quotas are in place), 0.5 (either national or local quotas are in place), or 1.0 (no quotas are in place). This is the only index that uses legislative quotas as a measurement. While an interesting concept, the wide-spread use of quotas around the globe - when differentiated by only three measures - results in multiple similar scores across the 120 countries. This replicates the problem experienced in 2009 with the Freedom of Dress measure, making it difficult to capture country variances due to the lack of differentiation. A quota rating system that further incorporates more detailed information, for example, the type of quota (mandatory or voluntary) and level of adherence (full, partial, noncompliance) would create a more robust measure of political voice and allow for greater differentiation among countries.

Accurately measuring political voice is acknowledged to be difficult. As a result, we again see the numbers of women in legislative seats as a proxy indicator for women's voice - "it is a conveniently simple measure." 145 It is interesting to note that the Gender, Institutions, and Development Data Base, from which the SIGI is primarily constructed, also has available the percentage of women holding ministerial positions. No explanation is given as to why the OECD effort focuses solely on the legislative branch; one must assume that the authors considered the use of quotas and parliamentarian numbers sufficient proxies for adequately measuring political voice.

\footnotetext{
142 Ibid.

143 Comparison of the differing language between the 2012 and 2014 Social Institutions Gender Index can be found at www.genderindex.org.

144 Cerise, Somali, Gaelle Ferrant, and Jason Gagnon. "2012 Social Institutions and Gender Index: A Methodological and Technical Background Paper." Organisation for Economic Co-Operation and Development, Paris. Retrieved September, 2013.

145 Goetz, Anne-Marie, and C. Nyamu-Musembi. "Voice and Women's Empowerment: Mapping a Research Agenda." Pathways of Women's Empowerment Working Paper 2 (2008).
} 


\subsubsection{Value of Legislative Branch Measures}

The role of the legislative branch in ensuring oversight and accountability, shaping public opinion, implementing policy, and representing constituent interests all underlie the justification for measuring women's descriptive representation in this branch. While the existence of quotas and percentage of male and female parliamentarians can paint a broad picture of women's representation, there are a number of cautions that should be highlighted if we only consider this branch of government as a sufficient measure.

Legislative Branches Vary in Political Power: One of the problems in attempting to measure women's political power solely through the legislative branch is the wide disparity seen in individual legislatures and systems. There is a Western presumption that the legislature is the "first power." But this is often not the case in both developed and developing democracies. Not all legislatures are created equally. Using legislative numbers as a proxy measure for women's empowerment or political voice can be an especially flawed approach for illiberal democracies, countries undergoing political transition, or authoritarian regimes. Across much of Sub-Saharan Africa personalized power and clientelism undermine formal institutions. ${ }^{146}$ Political parties are often unstable and appear and disappear from election to election. ${ }^{147}$ Patronage systems and the weak nature of political parties combine to weaken the institutions upon which democracies rest. As a result, in many illiberal or "electoral democracies" we hear references to a "rubber stamp legislature" - one which lacks de facto power and is viewed as simply a validation of executive desires - evident throughout parts of the developing world. ${ }^{148}$ This can be exacerbated by high turnover rates during elections creating a new cadre of novice parliamentarians with each election. This lack of institutional knowledge can affect the professionalism of the body and lawmaking effectiveness. These weak legislatures are often unable or unwilling to play an effective oversight role in curbing other branch powers and may exercise more limited authority in determining the policy direction of the country.

While it may be important to see women represented in parliament from a cultural and perception-changing perspective, practically speaking, parliamentary bodies

\footnotetext{
146 Lynch, Gabrielle, and Gordon Crawford. "Democratization in Africa 1990 - 2010: An Assessment." Democratization 18, no. 2 (April 2011): 275-310.

147 Ibid.

148 The Parliamentary Powers Index (Fish and Kroenig 2009) assesses the strength of national legislatures around the world. The index uses 32 different items that gauge a legislature's sway over the executive, as well as institutional autonomy, authority, and capacity. The index is scored on a zero to one scale, with zero being an absence of power. The average score of OECD high-income economies is .72. The score for low-income economies is almost half of that at .40 .
} 
may wield limited power. ${ }^{149}$ For those legislatures that do wield authority, there is a growing consensus that elements of power are shifting to the executive branch, most notably in the policy area. ${ }^{150}$ Today, globalization is seen as one underlying cause of the power shift. ${ }^{151}$ Interlinked economies and global security concerns are testing the ability of legislatures to respond effectively to changing norms. Parliamentarians are often viewed as ill-equipped to address growing international issues that fall outside of their domestic institution. The reasons for this may be varied, but can include a lack of technical knowledge required for the situation, inability to forge a common response among government coalition partners, or issues are viewed by representatives as counter to the interests of their constituencies.

Legislative Lawmaking Does Not Always Result in Policy Change: The need to focus women's measurement tools on the legislature is often couched in language that describes not only the representative function of this branch of government, but also the policy-setting function. In its capacity as rule-maker, parliaments are charged with establishing the laws of the land. Therefore, having more women in parliament - who can better represent half of the population's interests - in order to pass more gender-neutral laws - that will lead to more gender-friendly policies - that will enhance women's social status - etc., is a chain of logic that makes sense in Western, liberal democracies. Our assumption is that once a law is approved by parliament then executive implementation will follow. If laws are not complied with, one can turn to the courts for enforcement.

If, for example, the goal is to eliminate violence against women, a logical place to start would be with the legislature and legal framework. The premise underpinning the desired change is that once better approaches are passed into law - perhaps focused on stronger deterrence measures, an expansion of women's rights, or greater access to a justice system - then new rules and policies will be implemented that can more effectively tackle the problem. Practical experience of practitioners and academic researchers repeatedly demonstrates that this is, in fact, far from the reality in many countries. ${ }^{152}$

From laws designed to sanction domestic violence, prevent early marriage, and ensure land inheritance for women, we see a consistent pattern of informal

\footnotetext{
149 Devlin, Claire, and Robert Elgie. "The Effect of Increased Women's Representation in Parliament: The Case of Rwanda." Parliamentary Affairs 61, no. 2 (February 23, 2008): 237-54.

150 Borrelli, MaryAnne, and Janet M. Martin. The Other Elites: Women, Politics, and Power in the Executive Branch. Boulder, Colorado: Lynne Rienner Publishers, 1997.

151 Sassen, Saskia. "Beyond Party Politics: The New President and the Growth of Executive Power." Dissent 56, no. 1 (Winter 2009): 5-6.

${ }_{152}$ Sanematsu, Marisa. “Accessing Justice: Models, Strategies and Best Practices on Women's Empowerment (IDLO, 2013)." Ciências 14 (2014): 04.
} 
customary law and norms undermining civil and constitutional law. ${ }^{153}$ Weak police and judicial enforcement are often identified as major detriments to the state's ability, or willingness, to enforce codified formal law. ${ }^{154}$ The executive branch may also be implicated in non-compliance through either an unwillingness to implement new laws or policies or, in some instances, a lack of financial wherewithal to do so. This supposition that passage of a new law will lead to change, and even result in greater gains for women, does not give adequate weight to the challenges surrounding resource allocation, implementation, and enforcement.

Implementing formal laws that contradict cultural gender norms remains a significant challenge around the world, especially in rural areas. That is not to say that fighting for improved legal frameworks should be abandoned. Laws play a positive role by creating new norms that can eventually lead to wider behavioral change in society. ${ }^{155}$ As we look to engender change, however, we must be cognizant that a Westernfocused perception of the legislative branch as the locus of policy transformation through its legislative mandate does not stand up to scrutiny in swaths of the world. We should not be fooled into a simplistic view that the passage of laws is sufficient, i.e., that once the legislature is done with its business, all else will follow. As UN Women notes, "While acknowledging advances in legal reforms, laws mean little unless they are implemented." 156

Legislative Quotas have Unacknowledged Challenges: Despite Dahlerup's early reservations about critical mass, ${ }^{157}$ the critical mass "theory" today is embraced by most multi-lateral and bi-lateral donors, with programs designed around $30 \%$ women's participation as an accepted standard. ${ }^{158}$ While setting targets is laudable - what gets measured gets done - the consensus figure of approximately $30 \%$ women as a parliamentary goal has raised a number of challenges.

\footnotetext{
153 "Mapping the Substantive Representation of Women in the Ugandan Parliament." Center for Women in Government and Civil Service; Rockefeller College of Public Affairs and Policy, University at Albany; Nkumba University, Uganda, September 2014.

154 Scribner, Druscilla, and Priscilla A. Lambert. "Constitutionalizing Difference: A Case Study Analysis of Gender Provisions in Botswana and South Africa." Politics \& Gender 6, no. 01 (2010): 37-61.

Geraghty, Terese. "Gender and State-Building: The Case for Timor-Leste." Volume II, 2014, 121.

155 Turquet, Laura. "Progress of the Worlds Women 2011-2012. In Pursuit of Justice.," 2011.

156 Ibid.

157 Dahlerup, Drude. "From a Small to a Large Minority: Women in Scandinavian Politics." Scandinavian Political Studies 11, no. 4 (1988): 275-98.

158 USAID, the largest bi-lateral donor in the field of democracy promotion, examined more than 100 development programs focused on women's political leadership between 2009-2014. A 30\% women's participation rate was most often cited as the goal. The report, entitled Women's Leadership as a Route to Greater Empowerment, was published in October 2014: https://www.usaid.gov/sites/default/files/documents/1866/Women's\%20 Leadership\%20as\%20a\%20Route\%20to\%20Greater\%20Empowerment\%20Desktop\%20Study.pdf.
} 
First, it undermines the ideal of parity. Early advocates for critical mass may have believed that a ratio of 70:30 was more realistic given the dearth of women at the time. Today, however, we see donors, governments, and political parties using the $30 \%$ target as the end game. Attempts to move beyond accepted minimums may lead to resistance. ${ }^{159}$ In short, 30\% was required; 30\% has been achieved. Efforts to reach parity are stymied due to a coherence of thinking around the acceptability of a lower percentage, rather than 50:50. The idea of a 30\% critical mass becomes in itself a new glass ceiling for women. ${ }^{160}$

Second, the development community remains wedded to the idea that legislative quotas lead to positive substantive change for women. While the greater inclusion of women through temporary special measures continues to gain global acceptance, among academia there is a rising chorus of voices questioning the effectiveness of legislative quotas to measure women's political power. ${ }^{161}$ If we elect women to simply increase numbers, then quotas have been effective. Underpinning the rise in women's parliamentary percentages is the fact that more than 120 countries today have electoral quotas in place. ${ }^{162}$ Yet implicit in the critical mass argument is the notion that greater numbers of women at the table will result in a positive outcome for women: that once the right number of women are elected, they will have access to power and effect changes in gender equality. If descriptive representation is able to further women's interests, then quotas should be a resounding success. The academic research on this point, however, remains inconclusive.

The inability to consistently turn women's numbers into action for women may be multiple and varied. For example, in some instances the party leadership may act as the gate keeper to women's participation. The most appealing female candidates are those who will represent the political position of the party. If the party platform rests on gender inequality, the female candidates selected will likely be expected to uphold these positions in public. In some instances women are appointed to seats without a defined constituency. This may make it more difficult for a quota candidate to argue for or against legislation on behalf of

\footnotetext{
159 Yoder, Janice D. “Rethinking Tokenism: Looking beyond Numbers.” Gender \& Society 5, no. 2 (1991): 178-92.

160 "Social Watch Report 2014: Means and Ends." Uruguay: Social Watch, 2014. http://www.socialwatch.org/ sites/default/files/Social-Watch-Report-Overview2014_eng.pdf.

161 Childs, Sarah, and Mona Lena Krook. "Should Feminists Give Up on Critical Mass? A Contingent Yes." Politics \& Gender 2 (2006): 522-30. Tremblay, Manon. "The Substantive Representation of Women and PR: Some Reflections on the Role of Surrogate Representation and Critical Mass." Politics \& Gender 2, no. 4 (2006): 502-11. Studlar, Donley T., and Ian McAllister. "Does a Critical Mass Exist? A Comparative Analysis of Women's Legislative Representation since 1950." European Journal of Political Research 41 (2002): 233-53.

162 “The Millennium Development Goals Report 2015." New York, N.Y.: United Nations, 2015.
} 
any particular geographic grouping. ${ }^{163}$ Her representative function could be the nation as a whole. Or, in some instances the party itself - which placed her in the seat - may see itself as the constituency to which she is beholding.

Quotas can also be ignored, or not enforced, or purposefully manipulated by political parties. Research in Belgium suggests that parties are hesitant to accept legally imposed quotas that interfere with candidate selection, preferring instead an approach that is less binding. ${ }^{164}$ Voluntary quotas give parties more liberty to decide how women will be selected and where they are placed on the list. As a result, voluntary party quotas may guarantee that women are considered in the election process, but result in fewer women being actually elected. ${ }^{165}$ Legally imposed quotas, on the other hand, are typically mandated through the country's election law or constitution. Parties are required by law to comply. For this reason legally imposed quotas may be more controversial, yet more effective in achieving targets. ${ }^{166}$

Using the existence of a quota policy or law as a mark of women's progress is also problematic when the majority of countries have established quotas. There is an inability to differentiate descriptive representational levels country to country. If everyone is using the same measure of women's descriptive representation, the indicator no longer allows for differentiation

Given the challenges identified, why do we continue to use legislative seats as a measure of women's political power? As UNIFEM succinctly stated almost 15 years ago, "the empowerment of women does not just depend on the elimination of numerical gender disparities." 167 One simple explanation is that we have the data. Long-standing efforts, such as the Quota Project, ${ }^{168}$ allow academics and practitioners to easily gather and analyze parliamentary figures on a global basis. Parliaments across the world are also similar in their functions and composition. So comparing a lower house in Albania is similar to a lower house in Zimbabwe.

163 During a July 2012 interview with a Kenyan women parliamentarian assigned to a reserved seat, the issue of constituency representation was discussed. The parliamentarian was critical of her appointed position that left her without a defined constituency. Her male members could more easily travel to their areas of representation, better represent their smaller constituency, and be more visible in the eyes of "their" voters. She recognized that she could not cover the nation, as one large constituency, in the same way.

164 Meier, Petra. "The Mutual Contagion Effect of Legal and Party Quotas A Belgian Perspective." Party Politics 10, no. 5 (2004): 583-600.

165 Thames, Frank C., and Margaret S. Williams. Contagious Representation: Women's Political Representation in Democracies around the World. NYU Press, 2012.

166 Meier, Petra. "The Mutual Contagion Effect of Legal and Party Quotas A Belgian Perspective." Party Politics 10, no. 5 (2004): 583-600.

167 Elson, Diame, and Hande Keklik. “Progress of the World's Women 2002: Volume 2." UNIFEM, 2002.

168 The Quota Project brings together comparative knowledge and resources on the implementation and impact of quotas. The project was initiated in 2003 by International IDEA and Stockholm University; the Inter-Parliamentary Union joined the effort in 2009. 
We are able to compare apples to apples. The more complicated answer as to why we use this measure is that changing a country's long-standing attitudes towards women is a multi-generational effort. The number of legislative seats is a proxy for societal shifts in attitudes, one that can be measured annually in most countries.

As composite indexes continue to rely on the legislative branch to track women's progress, the ability to compare like units globally should not be minimized. There remains a dearth of public data that can track women's presence in the political arena. As a result, we are reliant on a narrow set of measures that can be gathered. Despite these constraints, we should ask whether focusing the majority of our energy and resources towards the legislative branch is the most effective formal structure for ensuring women's political power. Given the historically male structure of most parliaments, can women have a strong voice once elected? Many of the large, recent legislative gains have been in developing democracies where parliaments are subservient to other parts of government, typically the executive. How strong is the voice and agency of women - or men - when the institution itself is weak?

It is also worth acknowledging that the majority of research that has formed our thinking around women in political leadership has focused on Western democracies. ${ }^{169}$ This research, in turn, has primarily concentrated on the legislative branch. While women in the executive is a growing field, to date it has received less attention. There remains a void of research on critical mass, critical actors, or critical acts in other parts of government. For example, the use of quotas to increase court diversity is almost nonexistent. ${ }^{170}$ When we narrow our focus to one or two positions in government we are saying, by default, that political power held by other branches is unimportant or less important to women. Our exclusionary optic focuses on "fixing this one part of government," and the rest will follow.

Western academics consistently call for greater research in lower-income countries - especially in light of the significant gains many have made using "fast-track" quotas ${ }^{171}$ in the past decade. For example, in 1995 Europe claimed the top 10 spots in world rankings of women in parliament. By January 2015, countries in Sub-Saharan

\footnotetext{
169 Ballington, Julie, and Azza M. Karam. Women in Parliament: Beyond Numbers. Vol. 2. International Idea, 2005.

170 Hoekstra, Valerie. "Increasing the Gender Diversity of High Courts: A Comparative View." Politics \& Gender 6, no. 3 (2010): 474-82.

171 Dahlerup, Drude, and Lenita Freidenvall. “Quotas as a 'Fast Track' to Equal Representation for Women: Why Scandinavia is no Longer the Model." International Feminist Journal of Politics 7, no. 1 (March 2005): 26-48.
} 
Africa held four of those spots. ${ }^{172}$ From South to East Africa, we are seeing large numbers of women entering government and the military through constitutionally or legally mandated quotas. Across Africa the rise in women entering the judiciary has been unprecedented - and mostly undocumented (see Chapter 6: Mapping the Diamond Index in 40 Countries).

The rapid changes being experienced by many of these countries, which are typically "off the academic grid," mean that valuable insights surrounding recent political gains by women remain unknown. The difficulty of traveling to Mongolia, which boasts approximately $60 \%$ women in the judiciary, or gaining access to data on Jordan, with one of the highest percentages of police women in the region, limit our accessibility and understanding of the phenomena taking place. ${ }^{173}$ Access to data, research funding, and sufficient time required in the country being studied are all real constraints. Yet we must acknowledge that a more limited research agenda, inordinately focused on a limited set of countries and one branch of government, can result in narrowed perceptions and understanding of how women are faring in increasing their political power globally and the resulting impacts.

While the legislature remains an important component for ensuring women's political representation, there are other key positions in formal government that provide opportunities as well. The international community's commitment to the concept of a legislative critical mass should not blind it to other opportunities that could be pursued simultaneously.

\subsubsection{Executive Measures}

The second most common area of measurement is the executive branch. Three gender indexes combine indicators from this branch of government with the legislative branch.

\footnotetext{
172 “The Millennium Development Goals Report 2015.” New York, N.Y.: United Nations, 2015.

173 Refer to Chapter 5 for a description on how data was collected in countries such as Mongolia and Jordan. Chapter 6 presents the data collected from 40 countries in total.
} 
TABLE 2: Indexes Using Legislative and Executive Branch Measures

\begin{tabular}{|c|c|c|c|}
\hline $\begin{array}{c}\text { Index Name } \\
\text { Author } \\
\text { Publication } \\
+\end{array}$ & $\begin{array}{c}\text { Self-Identified } \\
\text { Overarching Concept } \\
\text { and Value }\end{array}$ & Approach & Indicators \\
\hline $\begin{array}{l}\text { Index Name: } \\
\text { Global Gender Gap } \\
\text { Index }^{174} \\
\text { Organization: } \\
\text { World Economic Forum } \\
\text { Publication: } \\
\text { Global } \\
\text { Annual } \\
2006 \text { - present }\end{array}$ & $\begin{array}{l}\text { Overarching Concept: } \\
\text { A country's gender gap } \\
\text { should be delinked } \\
\text { from economic or } \\
\text { development measures, } \\
\text { but based rather on } \\
\text { how a state uses its } \\
\text { available resources, } \\
\text { opportunities, and } \\
\text { assets to ensure equality } \\
\text { among all its citizens. } \\
\text { Value: } \\
\text { The GGGI allows } \\
\text { poorer countries to } \\
\text { perform as well as } \\
\text { rich countries. The } \\
\text { focus of measure is not } \\
\text { wealth or resources, but } \\
\text { distribution of available } \\
\text { assets. }\end{array}$ & $\begin{array}{l}\text { Approach: } \\
\text { Benchmark gender- } \\
\text { based disparities } \\
\text { (gender gap) using } 14 \\
\text { indicators in the areas } \\
\text { of economic, education, } \\
\text { health, and political. } \\
\text { The challenges and } \\
\text { opportunities identified } \\
\text { for narrowing the } \\
\text { gender gap can serve } \\
\text { as a basis for designing } \\
\text { effective measures, } \\
\text { policies, and programs. }\end{array}$ & $\begin{array}{l}\text { Political } \\
\text { Empowerment: } \\
\checkmark \quad \text { Ratio: Female with } \\
\quad \text { seats in parliament } \\
\quad \text { over male value } \\
\checkmark \quad \text { Ratio: Females at } \\
\quad \text { ministerial level over } \\
\text { male value } \\
\checkmark \quad \text { Ratio: Number of } \\
\quad \text { years of a female } \\
\text { head of state (last } \\
50 \text { years) over male } \\
\text { value }\end{array}$ \\
\hline $\begin{array}{l}\text { Index Name: } \\
\text { Gender Equity Index }{ }^{175} \\
\text { Organization: } \\
\text { Social Watch } \\
\text { Publication: } \\
\text { Global } \\
2005,2007,2008,2009 \text {, } \\
2012\end{array}$ & $\begin{array}{l}\text { Overarching Concept: } \\
\text { Lack of equity between } \\
\text { men and women is not } \\
\text { based on resources or } \\
\text { differences in income, } \\
\text { but rather inadequate } \\
\text { policies. Thus the index } \\
\text { strives to measure the } \\
\text { gap between women } \\
\text { and men, rather than } \\
\text { their well-being. } \\
\text { Value: } \\
\text { The index makes gender } \\
\text { inequities more visible } \\
\text { by producing a country } \\
\text { classification system } \\
\text { that can be compared } \\
\text { internationally and } \\
\text { easily monitored. }\end{array}$ & $\begin{array}{l}\text { Approach: } \\
11 \text { indicators measure } \\
\text { three dimensions: } \\
\text { 1) education } \\
\text { 2) economic } \\
\text { participation } \\
\text { 3) empowerment } \\
\text { A value is computed } \\
\text { for each dimension on a } \\
\text { scale from } 0 \text { to } 100 \text {. The } \\
\text { index score is a simple } \\
\text { average of the three } \\
\text { dimensions. }\end{array}$ & $\begin{aligned} & \text { Empowerment: } \\
& \checkmark \text { Seats in } \\
& \\
& \quad \text { Parliamentary } \\
& \checkmark \text { Women in } \\
& \\
& \quad \text { ministerial positions } \\
& \checkmark \text { Legislators, senior } \\
& \quad \text { officials, and } \\
& \text { managers } \\
& \checkmark \text { Professional and } \\
& \text { technical positions }\end{aligned}$ \\
\hline
\end{tabular}

\footnotetext{
174 World Economic Forum. “Global Gender Gap Index 2014," 2014. http://reports.weforum.org/global-gendergap-report-2014/

175 Social Watch. "Gender Equity Index," 2012. http://www.socialwatch.org
} 


\begin{tabular}{|c|c|c|c|}
\hline $\begin{array}{c}\text { Index Name } \\
\text { Author } \\
\text { Publication } \\
+\end{array}$ & $\begin{array}{c}\text { Self-Identified } \\
\text { Overarching Concept } \\
\text { and Value }\end{array}$ & Approach & Indicators \\
\hline $\begin{array}{l}\text { Index Name: } \\
\text { Gender Equality } \\
\text { Index }^{176} \\
\text { Organization: } \\
\text { European Institute of } \\
\text { Gender Equality } \\
\text { Publication: } \\
\text { Regional } \\
2013\end{array}$ & $\begin{array}{l}\text { Overarching Concept: } \\
\text { Gender equality is a } \\
\text { fundamental value } \\
\text { of the EU member } \\
\text { states and essential for } \\
\text { sustainable economic } \\
\text { and social growth. } \\
\text { Value: } \\
\text { The GEI provides a } \\
\text { more comprehensive } \\
\text { framework of } \\
\text { gender equality } \\
\text { rather than women's } \\
\text { empowerment. It is a } \\
\text { better, more refined tool } \\
\text { that is tailored for the } \\
\text { challenges faced by EU } \\
\text { members. }\end{array}$ & $\begin{array}{l}\text { Approach: } \\
\text { Measures progress of } \\
\text { EU-27 and Member } \\
\text { States in achieving } \\
\text { gender equality through } \\
\text { eight domains. Only six } \\
\text { of the domains (Work, } \\
\text { Money, Knowledge, } \\
\text { Time, Health, and } \\
\text { Power using a total } \\
\text { of } 27 \text { indicators) are } \\
\text { included in the final } \\
\text { composite score. } \\
\text { The two domains } \\
\text { of "intersecting } \\
\text { inequalities" and } \\
\text { "violence" are seen as } \\
\text { indicative of gender } \\
\text { inequalities but not } \\
\text { given a quantitative } \\
\text { score. } \\
\text { Three main goals: } \\
\text { 1) Measure gender } \\
\text { inequality at a single } \\
\text { point in time. } \\
\text { 2) Highlight causes of } \\
\text { inequality to inform } \\
\text { policy makers. } \\
\text { 3) Enable monitoring of } \\
\text { policy impacts over } \\
\text { time. }\end{array}$ & $\begin{aligned} & \text { Political Power: } \\
& \checkmark \text { Share of members of } \\
& \text { parliament (upper } \\
& \text { and lower houses) } \\
& \checkmark \text { Share of ministers } \\
& \checkmark \text { Share of members of } \\
& \text { regional assemblies }\end{aligned}$ \\
\hline
\end{tabular}

\subsubsection{Index \# 3: World Economic Forum - Global Gender Gap Index}

The introduction of the Global Gender Gap Index in 2006 was developed to measure the level of equality between women and men across four different dimensions: economic, education, health, and political. ${ }^{177}$ Because women continually lag

176 European Institute for Gender Equality. "Gender Equality Index." 2012. http://eige.europa.eu/rdc/eigepublications/gender-equality-index-2015-measuring-gender-equality-european-union-2005-2012-report. Plantenga, Janneke, Chantal Remery, Hugo Figueiredo, and Mark Smith. "Towards a European Union Gender Equality Index." Journal of European Social Policy 19, no. 1 (2009): 19-33.

177 The first Global Gender Gap Index in 2006 covered 58 countries. The 2016 report included 144 countries. 
behind men across these areas, the index attempts to quantify the size of the gap that must be closed if women are to achieve full equality. The authors state that gender equality is not only about political correctness but, in fact, a country can not afford to misallocate half of its human resources and achieve full competitiveness. ${ }^{178}$ Conceptually, the argument posits that equality between men and women can unlock greater economic potential. ${ }^{179}$ Through this lens it is not surprising that the economic dimension (participation and opportunity for women) plays a dominant role in the measurement criteria.

The index framework is premised on three underlying themes. ${ }^{180}$ The first is the inequality that women face irrespective of their country's economic level of development. So, while an economically poor country may have lower overall rates of education and access to health care, what is measured is the difference that women have to those same resources verses the access that men have. If both men and women have limited access to health care and education opportunities, for example, the gender gap may be minimal. Using this framework, more wealthy economies are not given an advantage over under-developed economies. What matters is whether a country allows its citizens equal access to available resources.

The second theme underpinning the index is its focus on outcomes. Variables that are considered "inputs" - those related to policies, cultural, and customs - are not included. Fundamental rights of women are areas of focus, including educational levels, access to political space, and labor force participation rates. In this way focus is pulled away from laws or attitudes that may favor or hinder women's equality, and looks at the impact of country-level institutions on the lives of women.

The third area of distinction is the Global Gender Gap's focus on gender equality rather than empowerment. The term "gender equality" is defined as the stage of human social development at which "the rights, responsibilities and opportunities of individuals will not be determined by the fact of being born male or female."181 According to the authors, countries are rewarded for low levels of inequality (small gaps) but neither rewarded or penalized if women outperform men in specific areas. The objective is not to determine if women are more empowered than men in key

\footnotetext{
178 Lopez-Claros, Augusto, and Saadia Zahidi. "Women's Empowerment: Measuring the Global Gender Gap." World Economic Forum Geneva, 2005.

179 Porter, Michael E., Klaus Schwab, and Jeffrey Sachs. The Global Competitiveness Report 2004-2005. Palgrave Macmillan New York, NY, 2004.

180 Bekhouche, Yasmina, Ricardo Hausmann, L. D. Tyson, and Saadia Zahidi. “The Global Gender Gap Report 2013.” World Economic Forum Geneva, 2013.

181 Lopez-Claros, Augusto, and Saadia Zahidi. "Women's Empowerment: Measuring the Global Gender Gap." World Economic Forum Geneva, 2005.
} 
outcome areas of life, but whether they are reaching commensurate levels with one another.

\section{A. Conceptualizing Political Empowerment}

Given the above conceptual underpinning - that the index is focused on gender inequality and not empowerment - it seems incongruent that the dimension for measuring women's political advancement uses the terminology "political empowerment." This term has been defined as: "the equitable representation of women in decision-making structures, both formal and informal, and their voice in the formulation of policies affecting their societies." 182 This definition veers from earlier discussions of empowerment literature that envision the term as an ongoing process, with choice as a central tenant. While we see the concept of voice coming into play, the term political empowerment means, quite literally for the World Economic Forum, equal representation.

One of the criticisms voiced about the Global Gender Gap Index is its lack of a theoretical rationale which, in turn, makes it difficult to understand the conceptual dimensions included. ${ }^{183}$ Neither early explanatory documents nor subsequent annual reports discuss the overarching concepts behind the index's development. In introducing the index in 2006, the authors do refer to "a stage when both men and women realize their full potential," harking back to Sen's human development framework. ${ }^{184}$ While the general intent of the index is clear - women's equality as a means to improving development outcomes, including competitive economic potential - conceptual clarity on measurement selection is left to speculation. This theoretical gap makes it difficult to understand why variables were chosen and whether they sufficiently cover all aspects of what is being measured.

\section{B. How the Global Gender Gap Index Measures Political Empowerment}

In addition to measuring the ratio of female to male seats in parliament, the Global Gender Gap Index uses two executive branch indicators to capture "political empowerment." These executive measures include: 1) female ministerial positions and 2) years of a female head of state. The percentage of female ministerial positions has increasingly been used as an indicator by indexes since its introduction by the United Nations and the Inter-Parliamentary Union in 2005. Among the indexes reviewed, it appears as the second most frequently used measure after female

\footnotetext{
182 Ibid.

183 Hawken, Angela, and Gerardo L. Munck. “Cross-National Indices with Gender-Differentiated Data: What Do They Measure? How Valid Are They?" Social Indicators Research, 2013, 1-38.

184 Sen, Amartya. Development as Freedom. Oxford University Press, 2001.
} 
parliamentarians. Neither the Global Gender Gap Index, nor other composite indicators, distinguish between the types of ministries held by women. Evidence is clear, however, that women are being appointed to "lower prestige" portfolios. ${ }^{185}$ In the most recent report by the United Nations/Inter-Parliamentary Union Women in Politics 2017, the top five ministries held by women include: 1) Environment, Natural Resources, Energy; 2) Social Affairs; 3) Family, Children, Youth, Elderly, Disabled; 4) Women's Affairs, Gender Equality; and 5) Education. ${ }^{186}$ The percentage of women ministers would make for a more robust indicator if positions were also weighted according to their level of prestige, as attempted by Krook and O'Brien in their 2009 Gender Power Score. ${ }^{187}$

The indicator tracking years of female head of state during the last 50 years is unique to the Global Gender Gap Index. While an interesting data point, it raises some questions around its utility. In 2017, only 11 out of 193 countries had female heads of state. ${ }^{188}$ The number of countries able to register a score is small, just a few percent of all countries. While this measure adds little as a benchmarking - given that the vast majority of countries fail to meet the standards - it certainly highlights the lack of representation among women at this highest level. The proclivity of political dynasties in the Asian region also offers an interesting challenge to interpreting this indicator. The logical assumption is that for a woman to achieve the highest office in the land, women will have made significant inroads throughout political institutions and the party hierarchy. Asian women presidents or prime ministers, however, have typically been elected to the highest office as the wives and daughters of famous male family members (often seen as martyrs in the eyes of the public) who have preceded them. ${ }^{189}$ This path to power, atypical in other regions, could result in increased scores despite, perhaps, low levels of female representation across the country's political institutions. Countries created within the last 50 years would also be hindered, being able to count years only from the date of their independence or creation. A number of countries in Eastern Europe, Central Asia, and Africa would all be disadvantaged with this indicator, given many of their later starting points as independent nations.

\footnotetext{
185 Krook, Mona Lena, and Diana O’Brien. "All the President's Men? The Appointment of Female Cabinet Ministers Worldwide." presented at the Midwest Political Science Association National Conference, Chicago, IL, 2011. http:// krook.wustl.edu/pdf/mpsa_krook_obrien_11.pdf.

186 "Women in Politics." Inter-Parliamentary Union, 2017.

187 Krook, Mona Lena, and Diana O'Brien. "All the President's Men? The Appointment of Female Cabinet Ministers Worldwide." presented at the Midwest Political Science Association National Conference, Chicago, IL, 2011. http:// krook.wustl.edu/pdf/mpsa_krook_obrien_11.pdf.

188 "Women in Politics." Inter-Parliamentary Union, 2017.

189 Paxton, Pamela, and Melanie M. Hughes. Women, Politics, and Power. Pine Forge Press, 2007.
} 


\subsubsection{Index \# 4: Social Watch - Gender Equity Index}

In its 2005 introductory publication of the Gender Equity Index, Social Watch clearly states that this new index is about measuring gender equity, with gender equity considered a necessary condition for development. Achieving a gender equity society will result in equal opportunities for men and women while relations between people will be based on respect for differences. ${ }^{190}$ Conceptually, the Gender Equity Index's claim to new territory was its focus on "measuring the degree of gender equity in different countries without any connection to the average level of socioeconomic development of the population." 191 As previously noted with the Global Gender Gap Index, a similar logic prevails that developed economies should not have an advantage over less-developed countries because they can provide more or better services to their citizens. ${ }^{192}$

Social Watch is a non-governmental organization with a mandate to report independently on how the world's respective governments are living up to their promises and legal obligations. The Gender Equity Index was born out of growing frustration that pledges being made by governments to achieve gender equality and eradicate poverty, particularly through the 2000-2015 UN Millennium Development Goals, were not on track and unlikely to be met at the current rate of progress. The organization's Basic Capabilities Index, and 2005 Gender Equity Index, were developed as citizen information and advocacy tools to better track global progress across as many countries as possible: lower-, middle-, and upper-income. ${ }^{193}$ In this light, it becomes more apparent why the focus of the Gender Equity Index rests on the need for an index that measures the status of women relative to men, independently of income per capita and human development levels. ${ }^{194}$

Critics of the Gender Equity Index note that the theoretical rationale for the index has not been well articulated, thereby making it difficult to analyze the validity of its conceptual dimensions: 1) economic participation, 2) education, and 3) empowerment. ${ }^{195}$ If we consider the Equity Index as a tracking and advocacy tool directly linked to the UN Millennium Development Goals, there is close alignment

\footnotetext{
190 Social Watch. "Social Watch Report 2005: Roars and Whispers." Montevideo: Social Watch, 2005.

191 Ibid.

192 Both the Social Watch and World Economic Forum indexes, developed and published at approximately the same time between 2005 and 2006, can be seen as responses to the heavily criticized UNDP Gender Development Index and Gender Empowerment Measure that were the first composite measures of global gender progress. One of the main criticisms of the UNDP effort was that it unfairly advantaged more developed economies.

193 Social Watch. "Social Watch Report 2005: Roars and Whispers." Montevideo: Social Watch, 2005.

194 Dijkstra, Geske "Towards a Fresh Start in Measuring Gender Equality: A Contribution to the Debate." Journal of Human Development 7, no. 2 (2006): 275-83.

195 Hawken, Angela, and Gerardo L. Munck. "Cross-National Indices with Gender-Differentiated Data: What Do They Measure? How Valid Are They?" Social Indicators Research, 2013, 1-38.
} 
with the latter's first three goals: 1) eradicate extreme poverty and hunger, 2) achieve universal primary education, and 3) promote gender equality and empower women. ${ }^{196}$ While perhaps not satisfactory from a theoretical standpoint, there is coherency to what the Gender Equity Index is measuring, and its intended purpose.

\section{A. Conceptualizing Empowerment}

Social Watch provides no clear definition of empowerment, or references to existing empowerment literature, regarding how it conceptualizes the term. The authors do stress that empowerment and women's political involvement, however, unlike other development dimensions, are not dictated by development levels or wealth. ${ }^{197}$ Less developed countries, such as Rwanda, have some of the highest levels of legislative representation while high-income countries, such as the United States, have low levels of female legislative representation. These factual realities lend credence to Social Watch's argument that women's empowerment can be disassociated with levels of income and development.

Throughout the index's years of publication and reporting, the authors mix language in the descriptive narrative. Sometimes Social Watch refers to the Gender Equity Index as measuring "empowerment" and at times "political empowerment."198 This does cause conceptual confusion when reviewing the variables selected, as two of the four include job roles outside of government. Capturing a number of these positions from the private sector or non-governmental world muddies the waters if the dimension being examined is defined as political empowerment. For example, why heads of corporations but not directors of non-governmental organizations? Why traditional chiefs but not religious leaders? While mixing government and non-government positions is not without precedent, it does open up the conversation as to where power exists outside formal government structures, how it might be captured, and the validity of the positions selected.

\footnotetext{
196 United Nations. "Millennium Development Goals," 2011. http://www.un.org/millenniumgoals/.

197 Elson, Diane, and Hande Keklik. "Progress of the Worlds Women 2002. Gender Equality and the Millennium Development Goals. UNIFEM Biennial Report. Volume 2.," 2002.

198 Social Watch. "Social Watch Report 2005: Roars and Whispers." Montevideo: Social Watch, 2005. Also refer to the various reports authored by Social Watch. For example, in the last Gender Equity Index published in 2012, the website narrative states: "The Gender Equity Index (GEI) measures the gap between women and men in education, the economy and political empowerment." (www.socialwatch.org).
} 


\section{B. How the Social Watch Gender Equity Index Measures Empowerment}

Social Watch clearly states that there is no clear agreement on how to measure gender equity across all countries in a way that allows for comparison. With that statement out of the way, the empowerment dimension is defined as: "the number of women with access to positions of power and decision-making in each country." 199 Four variables were selected. The first is the female members of parliament. As with other indexes, the information is provided by the Inter-Parliamentary Union. The authors justify this choice by referencing international studies supporting the view that at least $30 \%$ of political positions must be held by women in order to exercise any real influence on political processes. ${ }^{200}$

The Gender Equity Index captures three other indicators as it attempts to measure "empowerment." The first of these three is the percentage of women in governmental decision-making positions at ministerial levels. The data for this indicator is provided by the states themselves to UNDP for the annual Human Development Report based on their own definitions of "national executive." It may, therefore, include a variety of positions, depending on individual country interpretation. The first publication of the Women in Politics map also occurred in 2005. This mapping exercise, published jointly by UN Women and the Inter-Parliamentary Union, provides details on the percentage of women ministers for the majority of countries. ${ }^{201}$ Because this data had not been in use prior to 2005, the more convoluted UNDP measure may have been the most appropriate available at the time of the first Gender Equity Index publication, also in 2005.

The data for the remaining two measures - 1) percentage of female legislators, senior officials, and managers, and 2) percentage of female professional and technical workers - is compiled by the International Labor Organization. While the use of indicators beyond parliament and ministries is welcome, the ILO data includes formal government positions as well as those in the private sector. ${ }^{202}$ This makes it difficult to desegregate access to positions of formal political power from labor or economic access. For example, the measure percent of total positions including legislators, senior officials, and managers is defined as: "legislators, senior government

\footnotetext{
199 Social Watch. "Social Watch Report 2005: Roars and Whispers." Montevideo: Social Watch, 2005.

200 Ibid.

201 "Women in Politics: 2005." Inter-Parliamentary Union, 2005. http://www.ipu.org/pdf/publications/ wmnmap05_en.pdf.

202 For example, under the "International Standard Classification of Occupations" (ISCO-88) used by the ILO to identify job categories, "Legislators, senior officials and managers" includes the following: 1) Legislators and senior officials (legislators, senior government officials, traditional chiefs and heads of villages, senior officials of special-interest organizations); 2) Corporate managers (directors and chief executives, production and operations department managers, other department managers); and 3) General managers. For a full listing of classifications: http://laborsta.ilo.org/applv8/data/isco88e.html
} 
officials, traditional chiefs and heads of villages, senior officials of special interest organizations, corporate managers, directors and chief executives, production and operations department managers and other department and general managers." ${ }^{203}$

While increasing percentages in these two measures is laudable, there is no distinction between economic and political domains. When women have a difficult time entering the political arena they may turn to employment in the private or non-governmental sector as an alternative. Or, conversely, women may be underrepresented in the private sector as space is created in the political arena. The combination of indicators with private and public positions makes it impossible to determine. As a result, if the intent of the index is to measure women's access to positions of political power, the parliamentary and ministerial measures alone would appear more suited. If empowerment is conceived as a much broader understanding of accessing power and decision-making positions, writ large, then a wider net should be thrown. Although, given that the index also attempts to measure economic inequality, statistics on business leaders might more appropriately rest with that dimension. Which is all to say that the mixed terminology and lack of conceptual clarity makes it more difficult to understand where the selected indicators fit best, while not diminishing the added value that the Social Watch effort brings to the field of measuring gender equity.

\subsubsection{Index \#5: European Union Institute of Gender Equality - Gender Equality Index}

The European Union Gender Equality Index was conceived as a regional tool to measure gender equality between men and women. It departs from preceding indexes, also designed to measure gender (in)equality, in a number of ways. First, its theoretical underpinnings are based on the universal caregiver model developed by Nancy Fraser. ${ }^{204}$ Her model deconstructs existing gender roles and rules, allowing for acceptable cross-over between men and women in their day-to-day lives as employees, caregivers, and productive contributors to civic and political space. It upends the values attached to "paid" and "unpaid" labor, typically divided along respective male and female gender lines. Fundamentally, Fraser's model charges men to take on an equal share of the caregiver role. Women, in turn, are freed to increase income, whether through the job market or valuation of unpaid labor, while increasing leisure time as caregiver responsibilities are shed. ${ }^{205}$ In short, men are allowed to act more like women, and women are allowed to act more like men.

\footnotetext{
203 United Nations Statistics Division: https://unstats.un.org/home

204 Fraser, Nancy. "After the Family Wage: Gender Equity and the Welfare State." Political Theory 22, no. 4 (1994): 591-618.

205 Ibid.
} 
Second, the index is also described as tailored to the specific context and needs of EU Member States in two regards. First, the index stands on a long series of policy achievements explicitly directed at achieving greater gender equality that includes the balanced participation of men and women in daily life as well as decision-making processes. ${ }^{206}$ As countries are comprised of men and women, both opinions and perspectives must be accounted for in the population. This diversity of viewpoints is seen as inherently positive for society as well as democracy among EU Member States.

And third, previous global indexes already in use were deemed by the index developers as inadequate for the EU given the selected variables. For example, while some inequalities do exist in education and health levels within the EU, they are too small to be significant. ${ }^{207}$ As a result, traditional global indicators produce a clustering of European countries with no real differentiation. This limits the information as an advocacy tool; if everyone is ranked the same it becomes difficult to differentiate which, if any, interventions should be considered and for what purpose. More meaningful measures - that produce differences tailored to EU weaknesses - was a primary rationale for this new index.

\section{A. Conceptualizing Political Power}

The authors state that the framework of the index and its design is intended to move away from a focus on women's empowerment and adopt a gender approach that looks at both men and women through a lens of equality. This effort is hampered to some degree by the lack of agreement on what constitutes gender equality, the outcomes gender equality is intended to achieve, and what data is available to track its progress. ${ }^{208}$ The index builds on three separate gender equality approaches, relying heavily on the work of Walby to intuit how these approaches may be invoked through a gender mainstreaming process. ${ }^{209}$

1) sameness: men and women are afforded equal opportunity and equal treatment

2) difference: different contributions of men and women are valued equally

3) transformative: a new standard is established that transforms gender relations

206 The Gender Equality Index Report 2005, the introductory document describing the index's development, contains an extensive section devoted to EU policies, treaties, and international commitments (pages 16-18) that underpin the EU Member States' numerous commitments to the principle of gender equality.

207 Plantenga, Janneke, Chantal Remery, Hugo Figueiredo, and Mark Smith. "Towards a European Union Gender Equality Index." Journal of European Social Policy 19, no. 1 (2009): 19-33.

208 European Institute for Gender Equality. “Gender Equality Index." European Institute for Gender Equality, 2012.

209 Walby, Sylvia. "Gender Mainstreaming: Productive Tensions in Theory and Practice." Social Politics: International Studies in Gender, State \& Society 12, no. 3 (2005): 321-43. 
The approaches are viewed as interrelated, with no need to operationalize one approach over the other. Again referencing EU policy documents such as the Women's Charter (Strengthening the Commitment to Equality between Women and Men, 2010) and the Commission Strategy for Equality between Women and Men (2010-2015), the authors state that EU policies accommodate and reflect all three approaches towards gender equality. ${ }^{210}$

In choosing dimensions to accurately measure these varying conceptions of gender equality, the index leans heavily on previous work undertaken by Plantenga and existing EU definitions of gender equality. ${ }^{211}$ Based on Fraser's caregiver model, Plantenga defines the term gender equality as: "an equal sharing of assets... conceptualized rather broadly as an equal sharing of paid work, money, decisionmaking power and time." 212 The overarching definition of gender equality is changed in the final index to the following: "equal share of assets and equal dignity and integrity between men and women." ${ }^{213}$ Achievement of gender equality is then measured through six domains. The domain of "power" is of most interest to this research.

The concept of power, as a measurable component of gender equality, is never clearly defined by the index authors. References are made to some of the existing literature (for example, Baker et al.) that identifies the lack of access by marginalized groups to political decision-making as one form of power inequality. ${ }^{214} \mathrm{Using}$ Sen's capabilities framework, the authors also cite Robeyns' research on measuring inequality. Robeyns identifies 14 different capabilities that should be used to measure gender inequality, with 1 of the 14 identified as political empowerment (as measured in the percentage of legislative seats held by women). Her study suggests that wellbeing is less than men's in the political area, and that the inequality in empowerment results from the lack of equal opportunity in the first place. ${ }^{215}$

Power in the EU Gender Equality Index appears to represent the gap between the share of positions of power in the political, economic, and social spheres. More specifically: the representation of women and men in decision-making positions. Not giving women the same level of participation or access to decision-making

\footnotetext{
210 European Institute for Gender Equality. “Gender Equality Index.” European Institute for Gender Equality, 2012. 211 While Plantenga's definition is changed in the final index report, the components of her definition are reflected in the six conceptual dimensions chosen to be measured: 1) work, 2) health, 3) money, 4) knowledge, 5) time, and 6) power.

212 Plantenga, Janneke, Chantal Remery, Hugo Figueiredo, and Mark Smith. "Towards a European Union Gender Equality Index." Journal of European Social Policy 19, no. 1 (2009): 19-33.

213 European Institute for Gender Equality. “Gender Equality Index.” European Institute for Gender Equality, 2012.

214 Baker, John, Kathleen Lynch, Sara Cantillon, and Judy Walsh. Equality: From Theory to Action. Springer, 2016.

215 Robeyns, Ingrid. "Sen's Capability Approach and Gender Inequality: Selecting Relevant Capabilities." Feminist Economics 9, no. 2-3 (2003): 61-92.
} 
positions in these three areas will have "detrimental consequences," while greater gender balance in positions of power is articulated as having a "positive effect" on gender equality. ${ }^{216}$

Further justification for targeting political power rests on the need to provide positive women role models and promote greater political legitimacy, but also to reshape attitudes towards the respective roles of women and men. ${ }^{217}$ This includes moving entrenched attitudes that call for women to overcome numerous social and psychological barriers to enter the world of politics, while not requiring that men make any accommodations themselves. ${ }^{218}$ The index posits that addressing power remains important given the large gaps that still exist in this domain (ranked as having the largest gap of all six domains) as well as the symbolic impact women in positions of power has on other domains. Although no data or literature is cited to back up this statement, if the symbolic impact of increasing descriptive representation in the power domain contributes positively to other domains such as health, education, and economic advancement, it would prove an interesting rationale for focusing increased attention and resources in this area.

The justification for choosing the domain of political power is also reinforced through frequent references to EU policies that emphasize, in particular, political power as a priority in achieving gender equality. This includes the Convention on the Elimination of All Forms of Discrimination against Women (CEDAW, Article 7), the Millennium Development Goals (MDG 3), and the 2005 United Nations World Summit. A gender gap in male/female representation may also be linked to a "democratic deficit" within the EU, a notion outlined in a number of more recent EU policies. ${ }^{219}$

\footnotetext{
216 European Institute for Gender Equality. “Gender Equality Index.” European Institute for Gender Equality, 2012 217 Tremblay, Manon. "Do Female MPs Substantively Represent Women? A Study of Legislative Behaviour in Canada's 35th Parliament." Canadian Journal of Political Science/Revue Canadienne de Science Politique 31, no. 3 (1998): 435-65.

218 Meier, Petra, Emanuela Lombardo, Maria Bustelo, and M. Pantelidou Maloutas. "Women in Political DecisionMaking and Gender Mainstreaming: Obvious Partners?" In 2nd Pan-European Conference on EU Politics of the ECPR Standing Group on the EU. Bologna, June 2004.

${ }_{219}$ Authors cite the 2006-2010 Roadmap for equality between women and men as well as the 2010-2015 Strategy for equality between women and men as important references underpinning the importance of equal representation for democracy.
} 


\section{B. How the Gender Equality Index Measures Political Power}

The index developers acknowledge that the lack of available, harmonized data is an overriding constraint, and the need remains for broader measures of gender equality. ${ }^{20}$ Despite these acknowledged constraints across domains, the measurement approach for "political power" begins with the two indicators relied upon by other indexes: the percentage of women parliamentarians and ministers. The Gender Equality Index also adds one new measure: "share of members of regional assemblies." This is one of the few attempts to capture women's political power at a decentralized level and extremely welcome. The level of women's representation beyond the national level is a yawning gap in the existing data. Although extending this measure beyond Europe is currently difficult - most developing countries do not collect this information - it should be considered as a standard measure for future composite indicators. ${ }^{221}$

\subsubsection{Value of Executive Branch Measures}

In trying to articulate why inclusion of the executive branch is an important aspect of understanding women's political access, it must be acknowledged that quantifying the power of the executive branch - especially vis a vis other parts of government is not a simple indicator that can be gathered globally. Again, like legislatures, every country presents a context grounded in its own cultural and political realities.

Each year Freedom House attempts to classify the countries of the world into "free," "partly free," and "not free" categories. ${ }^{222}$ If we look to the indicators used to define these different categories, the governments ${ }^{223}$ of "partly free" or "not free" countries are typically restricting the civil and political rights of its citizens. While the Freedom in the World index does not directly grade the influence of the executive branch, it does attempt to measure interference and the negative impact of "the state." A careful reading of the 25 questions and 140 sub-questions that inform the index highlights the role of the executive as the locus of power, and thus its ability to curtail individual freedoms. ${ }^{24}$ In "partly free" and "not free" countries, the executive

\footnotetext{
220 European Institute for Gender Equality. “Gender Equality Index.” European Institute for Gender Equality, 2012. 221 UN Women, in recognition of this data gap, organized and convened a workshop (led by Julie Ballington) of gender experts in December 2015 to review what type of sub-national data was currently available, identify what additional information might be reasonably collected, discuss definitions of various sub-national levels of interest. While stressing that mandating the collection of new data points takes time and energy to formalize, UN Women is working towards ensuring that sub-national data on women's political participation be prioritized.

222 Freedom House. 2011. "Freedom in the World." http://www.freedomhouse.org.

223 On occasion, Freedom House notes, terrorist organizations, separatist movements, or foreign governments can impact the freedom score of a country, rather than the government itself.

224 Ibid.
} 
branch is typically regarded as the most powerful government branch according to the index.

Buttressing this finding is Steven Fish and Matthew Kroenig's 2009 Parliamentary Powers Index..$^{225}$ Their index attempts to measure the power of individual legislatures through 32 separate measures. The majority of measures look at a legislature's influence over the executive as well as its institutional autonomy, authority, and capacity. Almost universally, the "partly free" and "not free" countries received the lowest parliamentary power scores, ${ }^{226}$ reinforcing the conclusion that the executive, and not the legislative, is the most powerful government branch in weaker democracies.

Some experts argue that globalization may also be increasing the influence of the executive, in particular within the realms of foreign policy ${ }^{227}$ and financial affairs. Democratically elected bodies, such as legislatures, are often slow to gain consensus and act. This becomes even more apparent in a politically divided congress or parliament. In response to the U.S. financial crisis of 2008, it was the executive technocrats that acted quickly to shore up the global financial system and avoid collapse. ${ }^{228}$ To address European financial ills, the European Central Bank not only maintains control of the Euro, but also acts as the enforcer when requiring national policy changes. 229

There are a number of reasons put forth as to why the executive is gaining ground in the era of globalization. As noted above, central bank managers, treasury executives, and trade representatives are seeing their powers increase in a globally interlinked economy that often calls for a high-level of expertise and speedy response. The major global regulators, such as the International Monetary Fund and the World Trade Organization, also only deal with the executive branches of countries. Legislative bodies around the world are being relegated to managing domestic affairs and playing catch-up to decisions made by the executive in the global arena. ${ }^{230}$

\footnotetext{
225 Fish, Steven, and Matthew Kroenig. "The Handbook of National Legislatures: A Global Survey." Index. New York, 2009.

226 The index is scored on a zero to one scale, with zero being an absence of power. The average score of OECD high-income economies was .72. The score for low-income economies averaged 0.4

227 Borrelli, MaryAnne, and Janet M. Martin. 1997. The Other Elites: Women, Politics, and Power in the Executive Branch. Boulder, Colorado: Lynne Rienner Publishers.

228 Sassen, Saskia. "Beyond Party Politics: The New President and the Growth of Executive Power." Dissent 56, no. 1 (Winter 2009): 5-6.

229 Irwin, Neil. 2013. "Why the Financial Crisis Hurt Democracy." The Washington Post, April 7, sec. B.

230 Sassen, Saskia. 2009. "Beyond Party Politics: The New President and the Growth of Executive Power." Dissent 56 (1): 5-6.
} 
Along with the global economy, national security is another area of growing executive influence. ${ }^{231}$ Over the past 15 years there has been a steady spread of anticonstitutional measures undertaken in the name of fighting terrorism, resulting in strengthened state security and expanded executive authority. ${ }^{232}$ The international nature of terrorism, and with it the increasing perception of a world in a constant state of emergency, has allowed national executives to increase authority, often through the undermining of domestic constitutions. ${ }^{233}$ The growth of technology in warfare is also reshaping the military-executive-legislative relationship. In the U.S., for example, drone strikes from thousands of miles away - requiring rapid decisionmaking - are being approved by the executive and military branches with little to no legislative consultation or democratic debate.

Citing threats to internal security, 2014 alone saw a number of African presidents launch military operations, both internally and into neighboring countries, to combat perceived threats at home. ${ }^{234}$ The reality of porous borders, weak security systems, and international terrorist networks connected through technology are reshaping traditional responses to insecurity. There is no "war" the public can rally behind, no strategy the legislative branch funds with a clear timeframe. Rather the constant state of alert, covert nature of attacks, and increasing sophistication of warfare (both to defend and initiate) is creating a situation that lends itself to ongoing decisionmaking taking place behind closed executive doors to address each day's new threat on a constantly shifting global stage.

The strength of the executive branch also lies in its role as the locus of policy implementation. While the legislative branch is charged with passing the laws, the practical day-to-day application of those laws falls upon the executive, both at the national and local level. The most far-reaching gender-friendly laws have little impact if they are not executed. What access to positions of decision-making authority women leaders have within the executive branch, one could argue, is equally important to that held by the legislative arm of government.

\footnotetext{
231 Scheppele, Kim Lane. "Law in a Time of Emergency: States of Exception and the Temptations of 9/11." University of Pennsylvania Journal of Constitutional Law 6 (2004): 1001-83.

232 Cooley, Alexander. "Countering Democratic Norms." Journal of Democracy 26, no. 3 (2015): 49-63.

233 Scheppele, Kim Lane. "The International State of Emergency: Challenges to Constitutionalism after September 11." Schmooze 'tickets', 2006, 49.

${ }^{234}$ One of the most prominent examples is the joint fight against Al-Shabaab in Somalia. Following the organization's September 2013 Westgate Mall attack in Nairobi that killed approximately 67 people, the attack in Kampala that killed 74 people watching a World Cup match, and threats of an eminent terrorist attack during 2013 in Addis Ababa, all three countries committed increased troops to the African Union Mission in Somalia (UNISOM) to enter Somalia and erase the remaining strongholds of Al-Shabaab. Tekle, Tesfa-Alem. "Somalia: Ethiopia Decides to Join Amisom Force in Somalia." Sudan Tribune. November 12, 2013.
} 
While individual countries can debate the rising or falling influence of the executive, vis a vis other branches of government, the powerful role it plays in executing the law and governing mandates that it be included as a key area of measurement for examining women's access to decision-making in the political space.

\subsubsection{Judicial Measures}

Only one of the six indexes analyzed includes a measure of the judiciary alongside executive and legislative indicators: the African Gender and Development Index.

TABLE 3: Index Using Legislative, Executive, Judicial, and Security Measures

\begin{tabular}{|c|c|c|c|}
\hline $\begin{array}{l}\text { Index Name } \\
\text { Organization } \\
\text { Publication }\end{array}$ & $\begin{array}{l}\text { Self-Identified } \\
\text { Overarching Concept } \\
\text { and Value }\end{array}$ & Approach & Indicators \\
\hline $\begin{array}{l}\text { Index Name: } \\
\text { African Gender and } \\
\text { Development Index }{ }^{235} \\
\text { Organization: } \\
\text { United Nations } \\
\text { Economic Commission } \\
\text { for Africa } \\
\text { Publication: } \\
\text { Regional } \\
2009 \text { Phase I } \\
\text { (12 countries) } \\
2011 \text { Phase II } \\
\text { (30 countries) }\end{array}$ & $\begin{array}{l}\text { Overarching Concept: } \\
\text { Women's full and equal } \\
\text { involvement in society } \\
\text { is critically important } \\
\text { for all aspects of human } \\
\text { development. } \\
\text { Value: } \\
\text { The index focuses on } \\
\text { variables that have } \\
\text { particular salience } \\
\text { for African men and } \\
\text { women. Data is } \\
\text { collected nationally, } \\
\text { and not reliant on } \\
\text { international databases. }\end{array}$ & $\begin{array}{l}\text { Approach: } \\
\text { The index combines } \\
\text { two types of data. The } \\
\text { first uses data on } 44 \\
\text { indicators and combines } \\
\text { the information into a } \\
\text { "Gender Status Index." } \\
\text { The second component } \\
\text { - the "African Women's } \\
\text { Progress Scorecard" - } \\
\text { qualitatively measures } \\
34 \text { areas on government } \\
\text { policy progress and } \\
\text { performance regarding } \\
\text { women's advancement } \\
\text { and empowerment. }\end{array}$ & $\begin{aligned} & \text { Political Power } \\
& \text { "Agency": } \\
& \text { Public Sector: } \\
& \checkmark \text { Members of } \\
& \text { parliament } \\
& \checkmark \text { Cabinet ministers } \\
& \checkmark \text { Higher positions } \\
& \text { in civil service and } \\
& \text { parastatals } \\
& \checkmark \text { Judges } \\
& \checkmark \text { Members of local } \\
& \text { councils } \\
& \checkmark \text { Traditional rulers } \\
& \checkmark \text { Employment in } \\
& \text { security forces } \\
& \text { Civil Society: } \\
& \checkmark \text { Senior positions } \\
& \text { in: political } \\
& \text { parties, trade } \\
& \text { unions, employers' } \text { associations, heads } \\
& \text { or managers of } \text { non-governmental } \\
& \text { organizations }\end{aligned}$ \\
\hline
\end{tabular}

235 United Nations Economic Commission for Africa. “The African Gender and Development Index," 2011. Schüler, Dana. "The Uses and Misuses of the Gender-Related Development Index and Gender Empowerment Measure: A Review of the Literature." Journal of Human Development 7, no. 2 (2006): 161-81. 


\subsubsection{Index \# 6: UN Economic Commission for Africa - African Gender and Development Index}

The UN Economic Commission for Africa presented the African Gender and Development Index in 2004. ${ }^{236}$ The framework upon which the index is based focuses on a range of different concepts, including gender, power, and empowerment. ${ }^{237}$ Beginning with gender, the concept is envisioned in a holistic way with all aspects of concern to women addressed. These areas include: physical, socio-cultural, religious, legal, political, and economic.

Power, while acknowledged as a contested term, is examined in various ways. First, by identifying how power operates. For example, is it oppressive? Is it challenging existing gender relations? Second, under what conditions does power appear? This acknowledges that power relations are pervasive and found at all levels, from the state down to the individual. Third, how is power made visible? Of particular concern is Lukes' third dimension of power where "real interests" are being denied through the presence of biased institutions and structures that do not allow such interests to ever emerge. ${ }^{238}$ Real interests of women are then identified as those contained in the Convention on the Elimination of all Forms of Discrimination against Women and its Optional Protocol. ${ }^{239}$

Empowerment is also included as underpinning the index development. This concept is emphasized as a process containing the following elements: 1) consciousness of the problem or situation, such as discrimination or oppression; 2) real choices or alternatives to address the problem; 3) the necessary resources; 4) voice to discuss grievances in the public and political arena; and 5) agency to act on one's own behalf. These different elements may occur from an individual or collective perspective. ${ }^{240}$

Along with gender, power, and empowerment underpinnings, the opening narrative in the 2004 report introducing the new index states that women's full integration and equal participation in society is also important for human development. And,

\footnotetext{
236 United Nations Economic Commission for Africa. "The African Gender and Development Index," 2014.

237 Charmes, Jacques, and Saskia Wieringa. "Measuring Women's Empowerment: An Assessment of the GenderRelated Development Index and the Gender Empowerment Measure." Journal of Human Development 4, no. 3 (2003): 419-35.

238 Lukes, Steven. Power: A Radical View-The Original Text with Two Major New Chapters. New York: Palgrave Macmillan, 2005.

${ }^{239}$ A full copy of the convention is available at: www.ohchr.org/EN/Professionallnterest/Pages/CEDAW.aspx. While the original researchers cited CEDAW as the overriding document used to identify women's "real interests," the index was developed using a much broader array of international agreements and policy documents.

240 Charmes, Jacques, and Saskia Wieringa. “Measuring Women's Empowerment: An Assessment of the GenderRelated Development Index and the Gender Empowerment Measure." Journal of Human Development 4, no. 3 (2003): 419-35.
} 
finally, the index states that it is designed to measure gender equality. This is defined as equality of rights, participation, opportunities, and access and control over resources. ${ }^{241}$

The compilation and co-mingling of so many different complex concepts makes it difficult to distinguish what exactly the index is trying to accomplish from a theoretical perspective. Conversely, incorporating concepts of power, empowerment, human development, and gender equality into the AGDI framework was perhaps intentional in order to allow for great latitude in choosing the final 78 measures that make up the index. It does lead to the perception, however, that the index is trying to be all things to all stakeholders.

While the theoretical framework may lack precision, the stated purpose of the index seems well articulated. The index aims to accomplish two objectives: 1) measure the gender gap between women and men in Africa and 2) assess the progress made by African governments against national policies and international commitments. The first component is viewed as a quantitative exercise that uses numbers and percentages to arrive at a definitive Gender Status Index score. The second component is viewed as a qualitative exercise that requires expert opinions to judge the progress governments are making against identified policies. This is captured through the African Women's Progress Scoreboard. These two different components together form an individual country's score in the African Gender and Development Index.

Despite the existence of another gender composite index in the UN family, the UN Economic Commission for Africa argued that a new index was needed as lessdeveloped countries were being excluded due to insufficient international data. For example, in the UNDP 2002 Gender Empowerment Measure, Egypt was the only African country to have sufficient data for inclusion. ${ }^{242}$ As a monitoring or tracking tool, therefore, the Gender Empowerment Measure was largely irrelevant for African realities. A new index, based on nationally available data, was required if the intent was to provide policy messages, track measurable progress, and allow for comparisons across the African development landscape.

The introduction of a qualitative component was also a new innovation and remains a unique focus of the index. It was specifically designed to monitor progress against agreements that Africa countries have ratified. Along with standard conventions, such as CEDAW and the Beijing Platform for Action, the index also includes the African Charter on the Rights and Welfare of the Child, the African Charter on Human

241 United Nations Economic Commission for Africa. "The African Gender and Development Index," 2004.

242 Ibid. 
and People's Rights on the Rights of Women in Africa, and the New Partnership for Africa's Development. This qualitative component is specifically designed with policy advocacy in mind, allowing for governments and civil society to shed light on progress being made, draw attention to stasis, and highlight backsliding against self-identified commitments.

\section{A. Conceptualizing Political Power "Agency"}

The index is built on three dimensions, referred to as "blocks" by the index authors: 1) social power (capabilities), 2) economic power (opportunities), and 3) political power (agency). Of most interest to this research is the third block, political power (agency). There is no literature cited that explains how the terms are conceptualized. The authors define the political power block as comparing "the extent to which men and women are participating in decision-making in a country." ${ }^{243}$ The term agency is described as the "ability to influence and contribute to outcomes, organization, bargaining power, or 'voice.'" 244 While the majority of indicators are taken from the formal government public sector, the index also makes room for senior positions in civil society. As an explanation, the authors state that the boundaries between the public sector and civil society are left open as, depending on the individual country context or shifts in political power, one area can spill over into the other. ${ }^{245}$ The component of political power (agency) is, therefore, comprised of the two subcomponents: public sector (reflected through 10 indicators) and civil society (reflected through 4 indicators). While weight is given to the idea that power resides in other spheres beyond formal government, no other explanation is provided as to why the public sector is given significantly more attention nor criteria as to how civil society positions were selected.

\section{B. How the African Gender and Development Index Measures Political Power "Agency"}

The African Gender and Development Index measure of political power (agency) contains the most robust and expansive data of all political power domains. The index goes well beyond the standard legislative and ministerial measures to provide an insightful and in-depth look at individual countries. The index incorporates five new measures, while also including the percentage of female parliamentarians and ministers. They are: 1) higher positions in civil service and parastatals, 2) members of local councils, 3) judges, 4) traditional rulers, and 5) employment in security forces.

243 United Nations Economic Commission for Africa. "The African Gender and Development Index," 2011.
244 United Nations Economic Commission for Africa. "The African Gender and Development Index," 2004.
245 United Nations Economic Commission for Africa. "The African Gender and Development Index," 2011. 
Regarding the first new measure, unlike the Social Watch Gender Equity Index (Table 4), the African index differentiates between senior government and non-governmental roles. Positions to be counted include directors and secretary generals in the various ministers, ambassadors, regional governors, and directors of government institutions. This approach of disaggregating formal government positions from corporate or non-governmental roles makes for a much clearer quantitative picture of women's representation in the private sector as compared to the formal public sector.

Measures of the percentage of women local council members and traditional rulers have also been included, especially appropriate for the African context. As the authors explain: "The number of women in local councils is of particular relevance in a period when decentralization and local development have gained a high priority in most countries of the continent." ${ }^{246}$ In regard to the measure of traditional rulers, the 2011 narrative report states that this is a sub-component measure of civil society. Later calculations of the index in the report, however, show that the "number of male/female traditional rulers" is defined as a sub-component indicator of the "public sector." 247 Perhaps the inconsistency speaks to the difficulty of classifying this category of leader which may be viewed, depending on the country context, as either a formal part of government or a non-governmental actor. Despite this contradiction in classification, attempts to include local-level measures of women's leadership should be applauded. The European-based Gender Equality Index (Table 5 ) is the other index to attempt a sub-national level measure. The fact that the two regional indexes are the only ones reporting sub-national data highlights the lack of globally comparable indicators at this political level.

The indicator measuring judges is also of significant importance given the increasing influence of the judicial branch and the lack of attention to this sector in other gender indexes. The indicator includes a breakdown of the number of women and men in various courts, defined as "higher, lower, and traditional/religious courts." 248 The only criticism of this approach is that no differentiation is made between the levels of judges: a high court judge is given the same weight as a lower court judge.

The greatest strength of the African Gender and Development Index lies in its wide array of measures - a total of 44 quantitative indicators across seven components. This includes nine indicators in the public sector component, most of which must

\footnotetext{
246 Ibid.

247 Ibid.

248 During the Phase 1 pilot only Higher Court judges were included. The addition of other court levels was included for Phase II. No explanation is given for the change, so whether it was due to a greater availability of data than anticipated, or for other reasons not articulated, it remains unknown.
} 
be collected independently within each country. It is this strength, however, which may also be its greatest hindrance. While data is consistently available for the other components through existing reports or data bases, in the political power (agency) component all data is identified as "to be collected." The methodology included selecting independent institutions in each participating country and establishing a national advisory panel (consisting of government, experts, and civil society representatives). The role of each country panel was to support the local institution collecting data and review their work, including oversight of the national country report submitted to the European Commission for Africa as part of the index.

While such a rigorous process helps guarantee the quality of independently collected data, there is an associated cost. A 2002 public budget proposal outlining the support required to prepare and conduct eight country trials ${ }^{249}$ was estimated at more than US $\$ 800,000$, essentially $\$ 100,000$ per country. ${ }^{250}$ A 2003 report by the Economic Commission noted that progress on completing the index had been delayed due to the participatory nature of its development, which was requiring more time than anticipated, as well as funding constraints, which together had postponed the completion of the pilot project targeting 12 countries. ${ }^{251}$

The final results of the Phase I trial were reported in the 2009 African Women's Report. ${ }^{252}$ An additional 18 countries were added as part of Phase II in 2011. The UN states that its intention is to expand to all African countries and report every two to three years. Given that approximately seven years has elapsed since the last round of data collection, questions remain regarding the ability of the Economic Commission for Africa to sustain this index on a regular basis. While costs might be reduced over time, the ability to expand this model to encompass the majority of countries worldwide would appear to be unfeasible. However, putting criticisms and funding difficulties aside, the African Index's broad approach towards capturing a range of positions in the political space is one that should be emulated as it provides important insights into how one might measure women's access to positions of political power.

\footnotetext{
249 The Dutch organization Hivos (Humanistisch Instituut voor Ontwikkelingssamenwerking) agreed to pay the costs associated with the remaining 5 of the 12 countries identified for the Phase I pilot.

250 United Nations. Economic Commission for Africa. "Production of the African Gender and Development Index and the African Women's Report 2002/2004: Project Proposal. Addis Ababa.

251 United Nations Economic Commission for Africa. "Measuring and Reporting Gender Equality: The African Gender and Development Index." Meeting of the Bureau of the Committee on Women and Development (2003, Sep. 16-17: Addis Ababa, Ethiopia). The Dutch NGO HIVOS has agreed to pay the costs for conducting the pilot in the remaining five countries.

252 "African Women's Report: Measuring Gender Inequality in Africa - Experiences and Lessons from the African Gender and Development Index." Addis Ababa, Ethiopia: Economic Commission for Africa, 2009.
} 


\subsubsection{Value of Judicial Branch Measures}

Although only the African Gender and Development Index includes the judicial branch, a strong case can be made for the growing influence of the judiciary, both at domestic and international levels. It is clear that the composition, independence, and authority of courts will vary across regions and countries, and thus general trends will impact each court system differently. Yet, if the goal is to understand women's political access to formal decision-making, and a number of trends point to the increasing global expansion of judicial power, it then becomes important to better understand women's descriptive representation in this branch of government.

Increasing Judicial Review: Constitutions, written by people, are at times unclear, vague, and open to interpretation. Those drafted in an effort to end conflict may be a broad compilation of compromises aimed at bringing peace rather than legal clarity. The ability to review and interpret the meaning and application of the constitution typically falls to the courts, often a specific constitutional court. ${ }^{253}$ In Lijphart's study of 36 democracies, he notes the trend towards more and stronger judicial review. ${ }^{254}$ The newer democracies, without exception, all maintain judicial review of their constitutions. The five older democracies he catalogs, such as Great Britain, do not follow a similar system, either lacking judicial review authority or a constitution to review. Yet all of the older democracies have accepted the supranational judicial review of the European Court of Justice or the European Court of Human Rights. Through this process, supranational courts are able to restrict the power of individual countries and elected individuals within those countries.

Increasing Judicial Activism: Globally, we see a growing trend of judges becoming more willing to enter the political space once dominated by politicians and parliaments. ${ }^{255}$ Around the sphere of women's rights, litigation before the courts is being used to challenge accepted gender norms on economic employment, land ownership, inheritance, and rights of the girl child. Gains are also being made through litigation in the private sphere around issues such as rape, domestic violence, and reproductive rights. ${ }^{256}$ While acknowledging that women's victories in courts can lead to ostracism when she tries to enforce a positive ruling, ${ }^{257}$ there are

\footnotetext{
253 Horowitz, Donald L. "Constitutional Courts: Opportunities and Pitfalls." Towards a New Constitution for Afghanistan, 2003.

254 Lijphart, Arend. Patterns of Democracy: Government Forms and Performance in Thirty-Six Countries. Yale University Press, 2012.

255 Hague, Rod, and Martin Harrop. Political Science: A Comparative Introduction. Sixth Edition. St. Martin's Press, 2010.

256 Turquet, Laura. “Progress of the Worlds Women 2011-2012. In Pursuit of Justice.," 2011.

257 Sanematsu, Marisa. "Accessing Justice: Models, Strategies and Best Practices on Women's Empowerment (IDLO, 2013)." Ciências 14 (2014): 04.
} 
numerous examples where gender-positive rulings have had far-reaching impact on cultural norms.

The increasing reliance on regulation as a form of governance has also encouraged courts to intervene. Rules made through the executive branch, rather than by statutory law, result in more legal challenges. ${ }^{258}$ This in turn lends greater influence to the judiciary in determining policy. As a recent example, state-by-state regulations aimed at denying gay marriage and government benefits to same-sex couples resulted in the U.S. Supreme Court determining one national policy. While not every judicial intervention has such dramatic policy effect on the country as a whole, the increasing power of the executive in relation to the legislative - and the inherent conflicts this is creating - is drawing the judiciary into the role of arbitrator and policy maker in an unpredictable and increasing manner.

Increasing Application of International Law: The move from judicial restraint to judicial activism ${ }^{259}$ has been attributed, in part, to the growing influence and use of international conventions, charters, declarations, and covenants that create domestic obligations. ${ }^{260}$ For example, most countries in the world are signatories to CEDAW. Individuals of participating countries are allowed to refer complaints to a Committee established under the Optional Protocol to the Convention in 2000. The CEDAW Committee will review individual cases when "all available domestic remedies have been exhausted unless the application of such remedies is unreasonably prolonged or unlikely to bring effective relief." 261

While enforcing international obligations at the state level is not without its challenges, there is growing precedent - of both judges and individuals - to use these instruments when local laws or retribution are perceived to be lacking or in conflict with international law. From the judicial perspective, magistrates now have a greater breadth of tools from which to draw. While in the past the country context or legal constraints may have directed a judge's inclination towards restraint, today an increasing body of international law can offer greater protection and justification for a more progressive legal stance.

\footnotetext{
258 Hague, Rod, and Martin Harrop. Political Science: A Comparative Introduction. Sixth Edition. St. Martin's Press, 2010.

${ }^{259}$ Judicial activism has been defined by Hague and Harrop (2010) as the willingness of judges to venture beyond narrow legal reasoning to influence public policy. They define judicial restraint as a more conservative philosophy that maintains that the role of the judge is to apply the letter of the law, leaving politics to elected bodies.

260 Kenney, Sally Jane. Gender and Justice: Why Women in the Judiciary Really Matter. Routledge, 2013.

261 United Nations General Assembly. "Convention on the Elimination of All Forms of Discrimination Against Women." United Nations, Treaty Series, vol. 1249, p.13, December 18, 1979.
} 
Increasing Prestige of the Judiciary: The judiciary, in most liberal democracies, has maintained its prestige in the face of declining trust among other institutions, most notably political parties. ${ }^{262}$ With a reputation as being impartial, there is a greater tendency for all sides of the political spectrum to turn to the courts for adjudication. This process is seen as reinforcing, expanding legal authority as more and varied complainants are referred to the judicial arena. ${ }^{263}$ Globally, judiciaries are also gaining in credibility as the composition of the judicial benches becomes more diversified. ${ }^{264}$

Finally, it is harder to deny that courts play no political role given increasing evidence of national courts shaping public policy as do supranational courts, such as the European Court of Justice and its leading role in such politically charged issues as European integration. ${ }^{265}$ Given the intersection between judicial decisions and societal practices, it is important to better understand how women's descriptive representation is being reflected throughout this area of formal government.

\subsubsection{Security Measures}

The fifth unique measure in the African Gender and Development Index is "employment in security forces" (Table 6). It is the only gender composite index that attempts to measure any type of descriptive representation of women in the security domain. Once again, however, the 2011 report is contradictory in what is being measured; the narrative states "the number of women in security forces" while the actual index states the indicator as "employment in the security forces." This indicator was not included in the 2009 pilot round, but added during the 2011 Phase II in an effort to capture UN Security Council resolutions aimed at ensuring the greater inclusion of women in the peace processes and negotiations. ${ }^{266}$ While the security sector is not a separate branch of government, the influence it wields in the political sphere bolsters the rational for using an indicator of this type.

While we can state that women have made progress in other areas of government, albeit slowly, women have gained limited descriptive representational ground within the military, police, intelligence, and investigative agencies. On continents rife

\footnotetext{
262 Hague, Rod, and Martin Harrop. Political Science: A Comparative Introduction. Sixth Edition. St. Martin's Press, 2010.

263 Sweet, Alec Stone. Governing with Judges: Constitutional Politics in Europe. Oxford University Press, 2000.

264 Doherty, Joshua. “Women's Representation in Judiciaries Worldwide," 2012.

265 Kenney, Sally Jane. Gender and Justice: Why Women in the Judiciary Really Matter. Routledge, 2013.

266 Specifically, The African Gender and Development Index 2011 states (page 25) that this indicator is designed to take into account UN Security Council resolutions 1325, 1820, 1888, and 1889. "An increasing number of women in the security forces can be considered as a guarantee for more peaceful treatment of conflicts whether individual or collective."
} 
with insecurity and conflict, the perceived ability of women to competently handle conflict may be a difficult cultural jump to make - in part because women rarely hold key decision-making positions in the security sector. United Nations Security Council 1325, passed in 2000 in recognition of women's lack of representation, calls on member states to protect women in conflict and include them in peacebuilding, peacekeeping, and peace negotiations. Progress has been slow to date: between the years 2000 to 2008 no woman was appointed as a mediator in the 13 major peace processes and only $2.7 \%$ of the signatories were women. ${ }^{267}$ More than half of all peace agreements fail within the first 10 years. ${ }^{268}$

\subsubsection{Value of Security Sector Measures}

While the security sector is not a separate branch of government, the influence it wields in the political sphere bolsters the rational for using an indicator of this type.

Rising Influence of the Security Sector: If we look at Mills' work on power, he argued that by the 1950s America's military, economic, and political elite were inextricable linked. Personnel shifted interchangeably between all three arenas and economic interests and ties between the trio were tightly bound. A second edition of The Power Elite was published in 2000, with Alan Wolfe contributing an Afterward. In this section Wolfe argues that Mills' theory is faulty as the military never became the political force he envisioned. At the time of the writing, Wolfe states: "Yet it seems clear that in the 1990s, opposition to military adventures abroad has severely curtailed the ability of the military to have its way in both foreign and domestic policy. Their [most Americans] opposition to higher taxes makes it impossible for the military to grow. The rhetoric of emergency - and with it the need for significant personal sacrifice - is not a rhetoric to which they are attracted." 269 And then September 11, 2001 occurred. Followed by London 2005, Mumbai 2008, Uganda 2010, Kenya 2013, Boston 2013... .

With the rise in global terrorism around the world the importance of national security has resumed center stage, increasing both the power and influence of the military. Mills' belief that a permanent military threat was the impetus for this increased influence ${ }^{270}$ rings much truer today than when Wolfe was writing in 2000. At home and abroad, security forces are changing to meet the new global war on terrorism. ${ }^{271}$

\footnotetext{
267 Tirman, John. “UNSCR 1325: Slow Progress, Uncertain Prospects.” Foreign Service Journal, April 2011.

268 United States National Action Plan on Women, Peace, and Security. White House, December 2011.

269 Mills, C. Wright. 1956. The Power Elite. 1956, 2000 ed. New York: Oxford University Press.

270 Ibid.

271 In the United States, for example, the terrorist attacks of 9/11 led to a massive reorganization of the Executive Branch that resulted in the creation of the Department of Homeland Security, the third-largest cabinet with an annual budget of approximately $\$ 40$ billion and 240,000 employees (https://www.dhs.gov/about-dhs).
} 
In some illiberal democracies, especially evident in a number of African countries, the security sector continues to invade and permeate everyday life. ${ }^{272}$ Lynch and Crawford's study of democratization in Africa notes that between 1990 and 2010 there were 50 attempted coups in Africa and 13 were successful. ${ }^{273}$ While the study ends in 2010, the trend has continued in a number of countries, including Madagascar, the Central African Republic, and Mauritania. Direct takeover of the government by the military, or with the support of the military, not only impacts the political power dynamics of today but may have implications for years to come as a pattern of military influence in politics is established (through unfair elections, installed leaders, or successive military interventions). ${ }^{274}$ The third wave of democracy has not resulted in the withdrawal of the military from political life on the continent. In fact, the escalating fight against home-grown insurgent groups has strengthened the role and political influence of the security sector. Whether fighting Al-Shabaab in East Africa or Boko Haram in Nigeria, we increasingly see the call for aggressive military action supported by the political class as well as by affected citizens. And this is not a situation common only to Africa. One need only look at the United Nations "Consolidated List" of 618 individuals and 421 groups that are subject to sanctions to understand the breadth of terrorist organizations and their global reach. ${ }^{275}$ Today, both developed and developing countries are finding it difficult to ignore the rising influence of the security sector as terrorism groups gain footholds in poorly governed countries and almost 60 million people have been forcibly displaced worldwide. ${ }^{276}$

While currently no gender index attempts to measure women's leadership role in the military or police, in a world constantly on "high alert" we must acknowledge the influence of the security sector in addressing both external as well as internal threats to the state. The ongoing destabilization of the Middle East, rise in terrorist organizations, and increasing difficulty in controlling borders in a globalized world all point to trends that will unlikely see the importance accorded the security sector diminish in the foreseeable future.

\footnotetext{
272 Petchesky, Rosalind. “Critical Perspectives on Empowerment." Development 53, no. 2 (2010): 181-83.

273 Lynch, Gabrielle, and Gordon Crawford. "Democratization in Africa 1990 - 2010: An Assessment." Democratization 18, no. 2 (April 2011): 275-310.

274 Ibid.

275 http://www.un.org/sc/committees/list_compend.shtml.

276 Office of the United Nations High Commissioner for Refugees http://www.unhcr.org.uk/about-us/key-factsand-figures.html
} 


\subsection{CONCLUSION}

In analyzing a number of the leading composite gender indexes in use today, each is making a substantive contribution towards tracking women's presence in politics. While relying on a variety of different terminologies and theoretical frameworks, all of the indexes attempt to capture the gap or inequality existing between the presence of men and the presence of women in the formal political space.

The array of indicators used to capsulize this idea of women in the political space varies by index, as summarized in Table 4. It becomes clear that even as theories and dimensions differ across indexes, a number of the same indicators are repeatedly used. Perhaps this is not surprising, however, as attempting to draw a straight line between the theoretical framework, the conceptual dimension, and the final selection of indicators is, for several reasons, a difficult task.

Table 4: Political Domain Indicators Used across Six Gender Indexes

\begin{tabular}{|c|c|c|c|c|c|c|}
\hline & $\begin{array}{l}\text { Gender } \\
\text { Inequality } \\
\text { Index }\end{array}$ & $\begin{array}{c}\text { Social } \\
\text { Institutions } \\
\text { and Gender } \\
\text { Index }\end{array}$ & $\begin{array}{c}\text { Global } \\
\text { Gender Gap } \\
\text { Index }\end{array}$ & $\begin{array}{c}\text { Gender } \\
\text { Equity Index }\end{array}$ & $\begin{array}{l}\text { EU Gender } \\
\text { Equality } \\
\text { Index }\end{array}$ & $\begin{array}{c}\text { African } \\
\text { Gender and } \\
\text { Development } \\
\text { Index }\end{array}$ \\
\hline $\begin{array}{l}\text { Parliamentary } \\
\text { Seats }\end{array}$ & $X$ & $x$ & $x$ & $x$ & $x$ & $x$ \\
\hline $\begin{array}{l}\text { Existence of } \\
\text { Quotas }\end{array}$ & & $X$ & & & & \\
\hline $\begin{array}{l}\text { Ministerial } \\
\text { Positions }\end{array}$ & & & $X$ & $X$ & $x$ & $x$ \\
\hline $\begin{array}{l}\text { Years Female } \\
\text { Head of State }\end{array}$ & & & $X$ & & & \\
\hline $\begin{array}{l}\text { Senior } \\
\text { civil service }\end{array}$ & & & & & & $X$ \\
\hline $\begin{array}{l}\text { Legislators, } \\
\text { Sr. officials/ } \\
\text { managers }\end{array}$ & & & & $x$ & & \\
\hline $\begin{array}{l}\text { Professional } \\
\text { and technical } \\
\text { positions }\end{array}$ & & & & $x$ & & \\
\hline $\begin{array}{l}\text { Regional } \\
\text { Assembly } \\
\text { seats }\end{array}$ & & & & & $X$ & \\
\hline
\end{tabular}




\begin{tabular}{|c|c|c|c|c|c|c|}
\hline & $\begin{array}{l}\text { Gender } \\
\text { Inequality } \\
\text { Index }\end{array}$ & $\begin{array}{c}\text { Social } \\
\text { Institutions } \\
\text { and Gender } \\
\text { Index }\end{array}$ & $\begin{array}{c}\text { Global } \\
\text { Gender Gap } \\
\text { Index }\end{array}$ & $\begin{array}{c}\text { Gender } \\
\text { Equity Index }\end{array}$ & $\begin{array}{l}\text { EU Gender } \\
\text { Equality } \\
\text { Index }\end{array}$ & $\begin{array}{c}\text { African } \\
\text { Gender and } \\
\text { Development } \\
\text { Index }\end{array}$ \\
\hline $\begin{array}{l}\text { Members of } \\
\text { Local } \\
\text { Councils }\end{array}$ & & & & & & $x$ \\
\hline $\begin{array}{l}\text { Traditional } \\
\text { Rulers }\end{array}$ & & & & & & $x$ \\
\hline Judges & & & & & & $x$ \\
\hline $\begin{array}{l}\text { Security } \\
\text { Forces }\end{array}$ & & & & & & $x$ \\
\hline $\begin{array}{l}\text { Senior } \\
\text { Non- } \\
\text { Government }\end{array}$ & & & & & & $x$ \\
\hline $\begin{array}{l}\text { Secondary } \\
\text { Education }\end{array}$ & $x$ & & & & & \\
\hline
\end{tabular}

First, as discussed earlier, there is no global consensus on definitions surrounding the terms being measured. Our collective understanding of power, empowerment, voice, agency, etc., is dependent on context and interpretation. As highlighted with empowerment, how is it possible that one term can be used to describe a reordering of the patriarchal political order as well as greater decision-making in the household? Terms such as power and empowerment remain open to contestation when applied to gender in a global context because they themselves are not definitive.

Second, the unavailability of data remains a driver of indicator selection in the political field, rather than theory or the conceptual dimension itself. Each index speaks to the lack of appropriate global information that is harmonized, collected, and available. Experts repeatedly state that current tools are inadequate and only a proxy for what is being measured to date. The one index that attempts to remedy the problem - the African Gender and Development Index - has made great strides towards increasing information to measure what it terms "political power (agency)." Yet, it is this very granular measurement approach that creates impediments for conducting wider comparisons in terms of cost, data harmonization, and replicability. The index's current approach appears unsustainable beyond a limited number of countries.

This raises the question as to whether one single theoretical approach or index methodology can adequately capture gender differences in formal politics across all 
countries. The global indexes examined in this chapter remain limited in providing information beyond legislative and ministerial percentages. None of the four global measures include data on sub-national governments, the judiciary, or the security sector. Given the limitations to gathering quality data on a global scale, it appears that trade-offs between data relevance and importance have been made to accommodate geographical coverage. ${ }^{277}$ To include as many countries as possible, it is clear that the global indexes have fewer political measures to draw from annually, thus limiting their detailed applicability. In direct response to the generalized nature of global indexes in use, the European Union and African indexes were developed to specifically target the different challenges of their respective regions. Both indexes, as compared to their global counterparts, capture a wider selection of measures. In particular, the African Gender and Development Index makes a valiant attempt at collecting robust data on a country-by-country basis.

The tension remains, however, between this desire to capture a wider range of political measures for women on a global scale and the unavailability of systematically collected data that would allow researchers and practitioners to do so. While regional efforts are pointing in the right direction, they have yet to be replicated beyond a small sub-set of countries.

In this analysis of six leading gender indexes, it is clear from the academic literature, as well as the research undertaken by index developers, that the lack of appropriate data on women's political representation remains problematic. An insufficient number of indicators are systematically collected across countries, in particular within the judiciary and security sectors. Data at the sub-national level in all domains remains incomplete or non-existent. As a result, researchers remain constrained in their ability to reflect theoretical concepts through data. Whether this data scarcity derives from a lack of accessibility, quality, resources, or interest is open to discussion. What is known, however, is that the picture of women's presence in positions of formal political government remains incomplete.

277 Permanyer, Inaki. "A Critical Assessment of the UNDP's Gender Inequality Index." Feminist Economics 19, no. 2 (2013): 1-32. 



\section{Chapter 3 \\ For Good Measure}

\section{What Gets Measured, Gets Done.}

\subsection{INTRODUCTION}

Many names have been attributed to the oft used adage "what gets measured, gets done." The most likely source of its inspiration is Scottish mathematician and physicist William Thomson, also known as Lord Kelvin. During a lecture on May 3, 1883, he stated: I often say that when you can measure what you are speaking about, and express it in numbers, you know something about it; but when you cannot express it in numbers, your knowledge is of a meagre and unsatisfactory kind; it may be the beginning of knowledge, but you have scarcely, in your thoughts, advanced to the stage of science, whatever the matter may be. ${ }^{278}$

Knowing something, according to Lord Kelvin, is not the same as being able to express it through numbers. The numbers provide scientific standing to the idea. We know, for example, that women are underrepresented in the political field as compared to men. But to what extent do we know it with numbers? Numerical data surrounding this field is consistently described as lacking, inadequate, and of poor quality. ${ }^{279}$ This research effort attempts to improve quality data collection efforts in a field where "no data" or "poor data" are often appropriate categorizations. As Herrera and Kapur note, just because data is lacking or bad does not mean researchers must accept the status quo; the improvement of data remains a continuous task. ${ }^{280}$

\footnotetext{
278 Stellman, Jeanne Mager. Encyclopaedia of Occupational Health and Safety. International Labour Organization, 1998.

279 Desai, Manisha A. “Hope in Hard Times: Women's Empowerment and Human Development.” UNDP, 2010. Cueva Beteta, Hanny. "What Is Missing in Measures of Women's Empowerment?" Journal of Human Development 7, no. 2 (2006): 221-41. Corner, Lorraine. Gender-Sensitive and Pro-Poor Indicators of Good Governance. United Nations Development Programme (UNDP), 2005. Gaye, Amie, Jeni Klugman, Milorad Kovacevic, Sarah Twigg, and Eduardo Zambrano. "Measuring Key Disparities in Human Development: The Gender Inequality Index." Human Development Research Paper 46 (2010): 1-37. Economic Commission for Africa. “African Women's Report: Measuring Gender Inequality in Africa - Experiences and Lessons from the African Gender and Development Index." Addis Ababa, Ethiopia, 2009.

280 Herrera, Yoshiko M., and Devesh Kapur. "Improving Data Quality: Actors, Incentives, and Capabilities." Political Analysis 15, no. 4 (2007): 365-386.
} 
This chapter is divided into two sections. The first section begins with a discussion of how the literature defines and frames quality data. It then compares academic definitions with quality data frameworks established by international organizations during the past 25 years. These frameworks set the standard for how international and local organizations, private institutions, and governments define quality data.

Based on established academic and international organization definitions, in section two I develop a quality data framework as it applies to my research. This includes articulating how quality data is defined in relation to 12 key positions identified across different branches of government and the security sector as well as where my framework aligns and departs from current practices. Each of the eight quality data criteria selected is defined, with nuances discussed in relation to the creation of a composite indicator and index that measures women's descriptive representation in formal government.

\subsection{CRITERIA OF QUALITY DATA}

In speaking specifically about the construction and use of data in composite indicators, two fundamental characteristics drive the overall quality of the product, even as concepts may vary in what an indicator is trying to measure. These two characteristics include: 1) the quality of the data being used, and 2) the quality of the process used in constructing the composite indicator. ${ }^{281}$ Turning to the first aspect, how "quality" data is defined remains an ongoing discussion among academics, international organizations, multi-laterals, and governments, as efforts to reach a global consensus merge closer. In the past, quality was often associated with the accuracy of the data. Today there is recognition that the term quality is multi-faceted with no single characteristic effectively defining the concept. ${ }^{282}$ The terms fitness for purpose or fitness for use - in relation to what the consumer actually needs - are today more often used to describe quality data. ${ }^{283}$ Does the data produced meet the requirements of the user to the greatest degree possible? Accuracy, for example, becomes secondary if the data is unavailable in the applicable timeframe or too expensive for the user to procure.

\footnotetext{
281 Nardo, Michela, Michaela Saisana, Andrea Saltelli, Anders Hoffman, and Enrico Giovannini. "Handbook on Constructing Composite Indicators: Methodology and User Guide." OECD publishing, 2005. "Quality Framework and Guidelines for OECD Statistical Activities." Organization for Economic Co-Operation and Development, 2011.

282 Wang, Richard Y., and Diane M. Strong. "Beyond Accuracy: What Data Quality Means to Data Consumers." Journal of Management Information Systems 12, no. 4 (1996): 5-33. Statistical Commission. "Guidelines for the Template for a Generic National Quality Assurance Framework (NQAF)." United Nations Statistics Division, New York 8 (2012).

283 Echoing this concept of "fit for purpose," the United Nations National Quality Assurance Framework Group of Experts defines quality as: The degree to which a set of inherent characteristics fulfills requirements. https:// unstats.un.org/unsd/dnss/docs-nqaf/NQAF\%20GLOSSARY.pdf.
} 
In attempting to better understand "fitness for purpose" in relation to my research around gender composite indexes, I began with a broad search on quality data literature. The variety and diversity of approaches led me to narrow the literature to quality data associated with governance or gender concepts. While interesting theoretically, the literature proved unsatisfactory in advancing an understanding of how quality data frameworks have been applied to composite gender measures in the political space. I next turned to the literature underpinning the development of current gender indexes. Two of six indexes made oblique references to guidance provided by quality data frameworks in use by international bodies. This then led me to an analysis of the major quality data frameworks established by multi-lateral and global organizations.

These frameworks were then examined through several lenses before final criteria selection was made for my own research framework. This included the level of consistency and repetition seen across the reviewed data quality frameworks. For example: were the same criteria being used over and over across instruments? My intent was not to reinvent an entirely new quality data framework, but rather to build on existing frameworks if consensus existed. Secondly, I paid special attention to any framework that was applied to a composite indicator given the special data needs emerging from this type of measurement tool. If different criteria were used, what was the rationale for doing so? Finally, I examined the frameworks through a gender lens, attempting to understand and document how criteria was framed to address issues of gender data and measurement.

In examining the more general literature on measuring quality data, criteria varies fairly dramatically according to different authors and fields of study. For example, rather than taking a theoretical or intuitive approach, ${ }^{284}$ Wang and Strong specifically examined how data consumers themselves identify quality data. Their efforts resulted in the isolation of 179 separate attributes. During the second survey phase, these 179 were collapsed into 20 criteria ranked by importance. Recognizing that even 20 different attributes remain unwieldy as a data-quality framework, the authors further collapsed these attributes into four target categories of quality data: 1) accuracy, 2) relevancy, 3) representation, and 4) accessibility. ${ }^{285}$ While the final research product produced only four target categories in its final summation, these four were derived from 179 different attributes. The breadth and variety of attributes identified by the survey respondents reinforces the concept that data quality is a multi-faceted concept encompassing a wide range of criteria.

\footnotetext{
284 The authors define an intuitive approach as the one most commonly used to identify quality data, resulting from the researchers' experience or intuitive understanding of which attributes are the most important.

${ }_{285}$ Wang, Richard Y., and Diane M. Strong. "Beyond Accuracy: What Data Quality Means to Data Consumers." Journal of Management Information Systems 12, no. 4 (1996): 5-33.
} 
Again highlighting that data quality is a multi-dimensional concept, Pipino et. al. developed usable data quality metrics by examining both subjective and objective aspects of data. ${ }^{286}$ The authors presented a final list of 16 quality criteria for consideration as a framework. While identifying the same four attributes described earlier - accuracy, relevancy, representation, and accessibility - two other criteria were included of particular interest. ${ }^{287}$ These included:

1 Appropriate Amount of Data: The extent to which the volume of data is appropriate for the task at hand.

2 Completeness: The extent to which data is not missing and is of sufficient breadth and depth for the task at hand

The emphasis is not only on valid and accurate data, but also the amount of data. Is there too much data, therefore containing extraneous components? Is the overall volume unwieldly to manage? Conversely, is there sufficient breadth and depth of data - i.e., is there enough information - to achieve what is intended? While these ideas may be inherent in such criteria as validity or coverage, the larger number of criteria in this research capture greater nuance in defining quality criteria, including quality as it relates to the right amount of data.

In comparison to the large number of criteria identified by the previous authors, Herrera and Kapur specify only three quality criteria of data, even as they attempt to examine such complex concepts as democracy and anti-corruption. ${ }^{288}$ Their criteria for measuring data quality include validity, coverage, and accuracy. Validity captures the relationship between the theoretical concepts and the information collected, coverage refers to data set completeness, and accuracy describes the degree of error, or correctness, of the data.

Although these same three attributes can be found in many quality data frameworks, Herrera and Kapur go on to argue that while quality criteria are important, more attention should be focused on the incentives and capabilities of those individuals and organizations implicit in the development and collection of data. Even with validity, coverage, and accuracy at an acceptable level, data actors have acknowledged vulnerabilities, constraints, and biases that can potentially compromise information in ways that are not being adequately examined.

\footnotetext{
286 Pipino, Leo L., Yang W. Lee, and Richard Y. Wang. "Data Quality Assessment." Communications of the ACM 45, no. 4 (2002): 211-218.

287 The 16 dimensions include: accessibility, appropriate amount of data, believability, completeness, concise representation, consistent representation, ease of manipulation, free-of-error, interpretability, objectivity, relevancy, reputation, security, timeliness, understandability, value-added.

288 Herrera, Yoshiko M., and Devesh Kapur. "Improving Data Quality: Actors, Incentives, and Capabilities." Political Analysis 15, no. 4 (2007): 365-386.
} 
In turning to academics as an identified set of data actors, for example, the authors argue that the positive incentives for generating new data sets are limited, thus reflecting an increasing bias towards - and reliance on - existing data sets. ${ }^{289}$ New data collection is costly in terms of time, skills, and finances. Off-the-shelf and downloadable datasets are now easily accessible for anyone with a computer and interest, allowing academics to better understand corners of the world where previously they had little reach. At the same time, the commensurate costs associated with field work have not declined. Given time and funding limitations, if a pre-existing dataset can meet the outlined research needs, common sense dictates that the dataset will likely take precedent over field work. Given the plethora of reputable institutions producing datasets - World Bank, International Monetary Fund, Organization for Economic Co-Operation and Development, Freedom House, and multiple United Nations agencies, to name only a few - the use of data from these organizations is not considered a hindrance but can, in fact, lend credibility to research efforts. ${ }^{290}$

As data users increasingly depend on established datasets, especially those using the information for policy- or decision-making, assurances of data quality gain in importance. Composite indicators that compare country performance are particularly vulnerable, as they rely heavily on statistical information produced by individual governments that is then provided to international or regional organizations for collection and aggregation. The quality of the data generated will be driven by: 1) the quality of national statistics received, and 2) the quality of the receiving organization's ability to collect and analyze what has been provided. ${ }^{291}$ Regarding the first factor, information is typically provided by national statistics offices. This data is then used by multiple stakeholders to conduct research and analysis; develop policy and programs; and undertake individual, regional, and cross-country comparisons. Especially in the case of global benchmarking, it becomes imperative that the government of Andorra is reporting in a consistent and comparable manner to that of Zambia.

Modern efforts to harmonize this collection of data across all countries is based on the Fundamental Principles of Official Statistics, drafted in 1991. The principles were originally conceived as a way to help maintain the quality, reliability, and professionalism of data as Central European countries shifted from centrally planned economies to market-oriented democracies. ${ }^{292}$ The principles were adopted by the

\footnotetext{
289 Ibid.

290 Ibid.

291 Organization for Economic Cooperation and Development. "Quality Framework and Guidelines for OECD Statistical Activities," January 2012.

292 https://unstats.un.org/unsd/dnss/gp/fundprinciples.aspx
} 
United Nations as a global set of standards in 1994 and remain in use today. These principles underpin the concept of quality criteria upon which later frameworks were developed and adopted by other institutional organizations and actors, to which the remainder of this section is devoted.

\section{International Monetary Fund Data Quality Assessment Framework}

Beginning in 1995, the International Monetary Fund executive board noted the need to improve the quality of data being provided by member countries for use in policy analysis. Building off the UN Fundamental Principles of Official Statistics, the IMF developed a Data Quality Assessment Framework that it introduced in 2003. The goal of the framework was to provide a structure for assessing data quality while also clarifying and promoting an understanding of data quality among users and compilers, including: 1) the IMF itself, 2) the respective country authorities providing the data, and 3) private and public data users. Through the IMF Data Quality Assessment Framework, much greater detail was devoted to defining the traits of quality data based on best practices and internationally accepted methodologies. ${ }^{293}$ A total of five criteria were defined as essential to ensuring quality data. ${ }^{294}$

\section{TABLE 5: Data Quality Assessment Framework - International Monetary Fund}

\section{Data Quality Criteria}

\begin{tabular}{l|l} 
Assurances of Integrity & $\begin{array}{l}\text { Data must be collected in an objective manner based on professional, } \\
\text { transparent, and ethical standards. }\end{array}$ \\
\hline Methodological Soundness & $\begin{array}{l}\text { The methodological basis for collecting data reflects internationally } \\
\text { accepted standards and practices. }\end{array}$ \\
\hline Accuracy and Reliability & $\begin{array}{l}\text { Different criteria for which data is collected reflect the reality of the } \\
\text { country's economy. }\end{array}$ \\
\hline Serviceability & $\begin{array}{l}\text { Data is released in a timely manner, is comparable to similar data sets, } \\
\text { and revised on a regular basis. }\end{array}$ \\
\hline Accessibility & $\begin{array}{l}\text { Data must be presented in a clear and understandable way, remain } \\
\text { accessible, and assistance to users made available. }\end{array}$
\end{tabular}

\footnotetext{
293 “Data Quality Assessment Framework and Data Quality Program.” Washington DC: International Monetary Fund, June 25, 2003.

294 “International Monetary Fund's Data Quality Assessment Framework." Helsinki, Finland: International Monetary Fund, January 8, 2018.

295 As would be expected for International Monetary Fund purposes, the focus of data collection is on economic variables.
} 
In the International Monetary Fund Framework there are many direct linkages back to the Fundamental Principles, including the need for impartiality, sound methodological approaches, and an imperative to make data available to the public. In addition, as would be anticipated for purposes of the International Monetary Fund, there is an emphasis on the collection of economic data. Under "Accuracy and Reliability," the data specifically refers to data that reflects the country's economic reality. So while the Fundamental Principles remain the cornerstone of the framework, we also begin to see differentiation among the quality data criteria according to organizational needs, reinforcing the earlier definition that data must be fit for its intended use or purpose.

\section{Eurostat European Statistics Code of Practice}

Building off the work of the International Monetary Fund, the European Statistics Code of Practice was introduced by Eurostat in 2005. ${ }^{296}$ The code sets up a framework, based on 15 principles, to examine the institutional environment, statistical processes, and quality of output produced. Developed for national and community statistical authorities, the stated purpose of the Code is to ensure the quality of statistics produced within the European Statistical System, and to make this information available to anyone for purposes of decision-making, research, or debate. ${ }^{297}$ While one tends to equate a statistics code of practice as being targeted to statistical institutions, we can also see references to the code in non-governmental contexts. As one example, the Gender Equality Index refers to the European Statistics Code of Practice as one of its core criteria for indicator selection. ${ }^{298}$ Like the International Monetary Fund, Eurostat also identifies five principles related to quality data. ${ }^{299}$

\footnotetext{
296 The Code was adopted in February 2005 and revised in 2011.

$297 \mathrm{http}: / /$ ec.europa.eu/eurostat/web/products-manuals-and-guidelines/-/KS-32-11-955

298 European Institute for Gender Equality. “Gender Equality Index.” European Institute for Gender Equality, 2012.

299 European Statistics Committee. European Statistics Code of Practice. Eurostat, 2011.
} 


\section{TABLE 6: European Statistics Code of Practice - Eurostat}

\begin{tabular}{l|l}
\multicolumn{1}{l}{ Data Quality Criteria } & $\begin{array}{l}\text { The statistics produced meet the needs of the users. This includes } \\
\text { Relevance }\end{array}$ \\
\hline Accuracy and Reliability & $\begin{array}{l}\text { Statistics produced accurately and reliably portray reality. This includes } \\
\text { ongoing assessment, validation, error sampling, and revision processes. }\end{array}$ \\
\hline Timeliness and Punctuality & $\begin{array}{l}\text { Statistics are published according to international release standards; } \\
\text { deviations from the schedule are publically explained. }\end{array}$ \\
\hline Coherence and Comparability & $\begin{array}{l}\text { Statistics are internally consistent and comparable both over time and } \\
\text { between regions and countries. }\end{array}$ \\
\hline Accessibility and Clarity & $\begin{array}{l}\text { Statistics are presented in an understandable format, released in a } \\
\text { convenient manner, and accessible with supporting guidance. }\end{array}$
\end{tabular}

In many respects, the Eurostat data quality criteria are similar to those of the International Monetary Fund, again linking back to the UN Fundamental Principles of Official Statistics. There is no specific alignment to economic data, however, as the Eurostat framework is intended for application across all types of data. A second distinction, perhaps of more interest, is the greater amount of attention paid to the data end-user. Specific language is inserted to ensure that the statistics produced: 1) meet the needs of the user, 2) allowed for consultation with the user, and 3) satisfy the user. Any changes in publication should also be publically explained as to why the deviation occurred. The perception emerges that there is little point in producing information for its own sake. More careful consideration must be given to whether the user, in the end, will find utility and satisfaction in what was produced.

\section{UN National Quality Assurance Framework}

With a mandate not to "recreate the wheel," and to continue to build on the existing quality frameworks such as the International Monetary Fund and Eurostat, the United Nations Statistics Division set about building a flexible template to help countries develop their own data quality frameworks. The resulting National Quality Assurance Framework, with accompanying guidelines, was approved by the UN in 2012. ${ }^{300}$ Because it is impossible to determine the uses each country might require for statistical output, extensive guideline questions are provided for each quality dimension with the intention of assuring quality control as individual

300 Statistical Commission. "Guidelines for the Template for a Generic National Quality Assurance Framework (NQAF)." United Nations Statistics Division, New York (2012). 
countries determined their own specific needs. ${ }^{301}$ The UN National Quality Assurance Framework again provides five criteria related to the production of quality data. ${ }^{302}$

\section{TABLE 7: National Quality Assurance Framework - UN}

\begin{tabular}{|c|c|}
\hline Relevance & $\begin{array}{l}\text { Information should meet the most important current and/or emerging } \\
\text { needs of all stakeholders within given resource constraints. This } \\
\text { includes methodological soundness, and the manner in which } \\
\text { particular concepts, definitions, and classifications correspond to user } \\
\text { needs. }\end{array}$ \\
\hline Accuracy and Reliability & $\begin{array}{l}\text { To what degree does the statistical information correctly describe the } \\
\text { phenomena being measured and is it reliably consistent over time. }\end{array}$ \\
\hline Timeliness and Punctuality & $\begin{array}{l}\text { How fast is the information made available in relation to the reference } \\
\text { period and is the data delivered on the dates publically promised. }\end{array}$ \\
\hline Accessibility and Clarity & $\begin{array}{l}\text { Data can be found without difficulty, presented in a clear manner, and } \\
\text { accessible to all users (including for research purposes), either free or at } \\
\text { an affordable price. Explanatory information and metadata should be } \\
\text { made available to properly understand the information uses. }\end{array}$ \\
\hline Coherence and Comparability & $\begin{array}{l}\text { Statistics should be consistent internally and comparable over time } \\
\text { using common standards. It should be possible to combine and make } \\
\text { joint use of data from different sources. }\end{array}$ \\
\hline
\end{tabular}

The UN Framework pulls heavily from Eurostat, with both using the same five criteria. There are some modest changes in language used to describe each of the five criteria, but the intent of each remains the same. The only significant deviation from the International Monetary Fund and Eurostat is the UN framework's specific reference to cost. In the "Relevance" criteria it is clearly acknowledged that competing demands may outstrip available resources - a likely reality in underresourced government institutions. Part of determining "relevance" of quality data is determining which statistics produced target the greatest priority needs. These decisions will be subjective, given differing country contexts. However, the recognition that trade-offs must be made, and that financial limitations exist, is useful to acknowledge given the framework's intention to be used across countries with widely varying levels of economic development and budget resources.

301 The four areas for which questions are provided include: 1) agency level, 2) program design stage, 3) program implementation stage, and 4) post-collection evaluation stage. These questions, entitled "elements to be assured," provide a range of topics for framework developers to consider in their own design process.

302 Statistical Commission. "Guidelines for the Template for a Generic National Quality Assurance Framework (NQAF)." United Nations Statistics Division, New York (2012). 
Along with its own National Quality Assurance Framework, the UN highlights a wide range of other country data quality frameworks, guidelines, principles, protocols, methodologies, etc., (258 reference documents in total) from individual countries as well as multi-lateral organizations. ${ }^{303}$ A cursory review of these frameworks indicates that the majority pull heavily from the earlier work of the International Monetary Fund and Eurostat, leading to a high level of consistency in the identification of criteria used to define quality data.

\section{Quality Data and Composite Indicators}

In looking across academic and practitioner definitions of what constitutes "quality data," there is consistency around the use of a core grouping of criteria. My research interest lies at the intersection of quality data, as it relates to composite indicators and, in particular, the use of composite indicators as a measure of descriptive representation in the formal political arena. I use the term "composite indicator" to indicate a manipulation of individual indicators, and possible weights, to create an aggregate ordinal or cardinal measure of country performance. ${ }^{304}$ Policy-makers and practitioners are increasingly turning to composite indicators to combine large amounts of data and then distill them into a single measure that captures complex ideas. These scores are then used to benchmark or rank country performance, allowing for comparisons at individual country, regional, or global levels.

The Quality Framework and Guidelines of the Organization for Economic Co-Operation and Development was first published in 2003 and revised in 2011. ${ }^{305}$ Of particular interest for my research, Nardo et. al., pulling from the International Monetary Fund, Eurostat, and Organization for Economic Co-Operation and Development quality frameworks, further elaborated on the criteria used to define quality data and how it relates to composite indicators. These have been summarized in Table $8 .^{306}$

\footnotetext{
303 Reference documents can be found at UN STATS: https://unstats.un.org/unsd/dnss/qualitynqaf/nqaf.aspx.

304 Saltelli, Andrea. "Composite Indicators between Analysis and Advocacy." Social Indicators Research 81, no. 1 (2007): 65-77.

305 Organization for Economic Cooperation and Development. "Quality Framework and Guidelines for OECD Statistical Activities," January 2012.

${ }^{306}$ Nardo, Michela, Michaela Saisana, Andrea Saltelli, Anders Hoffman, and Enrico Giovannini. "Handbook on Constructing Composite Indicators: Methodology and User Guide." OECD publishing, 2005.
} 


\section{TABLE 8: Data Quality Framework in Relation to Composite Indicators Organization for Economic Co-Operation and Development}

\begin{abstract}
Data Quality Criteria
Relevance $\quad$ Relevance must be examined in relation to the overall purpose of the composite indicators, including ensuring that the range of domains are covered in a balanced way. "Proxy" series are often used, given data unavailability. If a proxy is used, evidence of its relationship to the "target" series should be produced when possible.

Accuracy

The accuracy and credibility of the data used to constructed a composite indicator must be based on the confidence associated with the producer. Information must be viewed as professional and produced according to statistical standards without manipulation or political pressure. Official sources - national statistical offices or public bodies with clear codes of conduct - are typically preferred as data sources.
\end{abstract}

Timeliness

Accessibility

Because composite indicators pull data from a variety of sources, accessibility to that information can affect the cost of production. Poor accessibility - including the presentation format, manner of dissemination, and availability of metadata and support services - can all affect the index's credibility if others are unable to access basic data and replicate the results. are often released at different times. Attention must be paid to establishing coherence in dates in order to minimize estimations of missing data or revisions once published.
Data covering the various conceptual domains of a composite indicator

How easily users can understand and properly use the data. Given the wide range of data often used to construct composite indicators - and differing methodologies needed to aggregate varied indicators - access to definitions, concepts, classifications, and the underpinning metadata is essential.

Coherence

Coherence over time and across countries is extremely important for composite indicators and their use as a comparison or benchmarking tool. Concepts, definitions, and methodology must be based on a common understanding and any differences allowed for or explained.

Throughout the Organization for Economic Co-Operation and Development Data Quality Framework we see many of the same indicators previously discussed. Nardo, however, highlights that subtle differences emerge when striving for quality data through the lens of a composite indicator. Many of these differences are associated with access to data, given that a typical composite indicator pulls from multiple sources to address varied domains. For example, proxy data may be used in some instances when information isn't available. Evidence of its relevance to the concept being measured must be substantiated if the data is to be considered credible. Because multiple sources are used, establishing coherence in dates can also be problematic. Information may be published annually, bi-annually, or intermittently. The author 
or researcher must then bring coherence to these differences as they attempt to aggregate results. Gaining access to varied data streams may also increase the cost of production, including researcher access to a potentially wide range of data sets or sources. Finally, given the wide range of information often used to construct a composite indicator, special attention must be devoted to ensuring a common understanding of concepts, definitions, and classifications that hold across all entities or countries being measured. Because composite measures are often used as benchmarking or comparison tools, those building the indicator must ensure clarity over time and countries that apples are being compared to apples and oranges to oranges.

While these quality data concerns apply to the majority of frameworks, they do take on special significance given the nature of composite indicators that rely on multiple data streams that often do not often lend themselves to easy collection or aggregation.

\section{Quality Gender Data}

While fully agreeing with the work of Nardo in relation to quality data for composite indicators, several criteria he describes need further elaboration, especially in the context of a gender composite indicator. For example, nowhere in the quality data definitions or frameworks discussed thus far does language about gender or desegregation occur. One might argue that "fitness for purpose" means the ability to segregate by sex, age, race, etc., if that is considered essential to the research. Anumber of recent gender data collection projects would frame the argument differently, however, citing instead that there has been a systematic lack of data collection that affects women and girls due to societal undervaluing of their contributions and status. ${ }^{307}$ These gender biases both impede and distort data collection. ${ }^{308}$

One of the most prominent of these projects is Data2X, launched in July 2012 by then U.S. Secretary of State Hillary Clinton. ${ }^{309}$ Underpinning its genesis was the perceived need to better identify gaps in the availability of gender data and improve collection efforts. ${ }^{310}$ In the project's own words: “Our mission is to improve the quality, availability, and use of gender data in order to make a practical difference

\footnotetext{
307 According to UN Women, only $13 \%$ of countries worldwide dedicate a regular budget to collecting and analyzing gender statistics.

308 Buvinic, Mayra, Rebecca Furst-Nichols, and Gayatri Koolwal. “Data 2X: Mapping Gender Data Gaps.” United Nations Foundation, Washington, D.C. 2014. Clinton Foundation, and Gates Foundation. "No Ceilings: The Full Participation Report," 2015.

309 The name "Data2X" was chosen to represent the power women have to multiply progress in their societies.

310 Data2X developers note that this mapping exercise builds off the framework developed by Amartya Sen in the early 1990 s.
} 
in the lives of women and girls worldwide." 311 The rise of Data2X coincides with the development of the 2015-2030 UN Sustainable Development Goals and the need for gender data to effectively monitor progress and achievement. Currently, more than $80 \%$ of the indicators housed under the Sustainable Development Goal 5: Gender Equality cannot be measured. In addition, less than one-quarter of the key gender indicators across all Sustainable Development Goals have adequate information for tracking. ${ }^{312}$

Of particular relevance to my research, one of the project's four objectives in gathering gender data is to: "Quantify and make visible women's participation in society and their contributions to development." 313 To accomplish this, five domains are mapped to identify what information is available, where gaps occur, and what constraints exist around the use of specific variables. The five domains include: health, education, economic opportunities, human security, and political participation. Data2X is housed at the United Nations Foundation and coordinates with a mix of 27 partner organizations and government entities. Because data helps drive decision-making, the project posits that incomplete or missing data about women and girls does not allow for an accurate depiction of their lives or realities. This, in turn, negatively affects policy and decision-making. ${ }^{314}$

The Data2X project authors further articulate between data and "gender data." Gender data includes data that pertains specifically to women and girls as well as data that is disaggregated by sex. The first might include, as an example, maternal mortality rates; primary education rates, disaggregated by girls and boys, is an example of the latter. The concept of quality gender data is also defined in the Data2X research. This definition outlines quality gender data as having five desirable features. ${ }^{315}$

\footnotetext{
311 www.Data2X.org.

312 UN Women, 2016. “UN Women launches flagship programme initiative, Making Every Woman and Girl Count," http://www.unwomen.org/en/news/stories/2016/9/un-women-launches-flagship-programme-initiative-makingevery-woman-and-girl-count

313 Buvinic, Mayra, Rebecca Furst-Nichols, and Gayatri Koolwal. "Data 2X: Mapping Gender Data Gaps.” United Nations Foundation, Washington, D.C. 2014.

314 Ibid.

315 Ibid.
} 
TABLE 9: Gender Data Quality Framework - Data2X

\begin{tabular}{l|l}
\hline Gender Data Quality Criteria & \\
\hline Quality & Sources should be reliable, valid, and representative. \\
\hline Coverage & The extent of countries covered and regular production of data. ${ }^{316}$ \\
\hline Standards & Data is comparable in terms of concepts, definitions, and measures. \\
\hline Complexity & $\begin{array}{l}\text { The same source of data covers different domains, or data between } \\
\text { different domains is interrelated. }{ }^{317}\end{array}$ \\
\hline Granularity & $\begin{array}{l}\text { The ability to disaggregate the data into smaller units, for example, sex, } \\
\text { race and ethnicity, age, geographic location, etc. }\end{array}$ \\
\hline
\end{tabular}

Among the international frameworks, Data2X is the first to define one of the quality data criteria as granularity - the ability to disaggregate the data into smaller units. The authors do not limit themselves to sex disaggregation alone, but also highlight other units that should be considered. While not explicitly defined as one of the five "desirable features" of quality data, Data2X also notes that quality data must be free from gender biases. For example, indicators that account only for formal paid labor as a measure of work, while discounting or undervaluing the contribution of unpaid and informal labor, which is predominantly undertaken by women, would be considered problematic.

Along with the Data2X project, a second gender data project - No Ceilings - was also initiated at approximately the same time through a joint venture of the Clinton and Bill and Melinda Gates foundations. ${ }^{318}$ The project was undertaken to commemorate the $20^{\text {th }}$ anniversary of the 1995 UN Fourth World Conference on Women in Beijing. Its goal was to collect and analyze data on the status of girls and women over two decades to try and evaluate the progress made since Beijing and to identify where gaps still exist. These gaps were then used to create recommendations and a blueprint for action. No Ceilings aggregated 850,000 data points on approximately 1,000 indicators across 197 countries, releasing the data on March 2015. ${ }^{319}$ The No Ceilings project was less a commentary on the quality of gender data, and more an

\footnotetext{
316 Coverage is considered "good" when data is available and regularly produced for more than 80 countries.

317 Ideal data sets, authors state, should allow for interaction between different domains that can be crossreferenced and cross-tabulated. For example, a woman's economic participation in relation to her home life.

318 Primary collaborators on the project also included the Economist Intelligence Unit and the University of California Los Angeles World Policy Analysis Center.

319 Clinton Foundation, and Gates Foundation. "No Ceilings: The Full Participation Report," 2015.
} 
exercise on understanding what gender data is actually available in order to gauge the gains women have made during the past two decades.

Of particular interest to my research, the "political and civic preparation" category comprised approximately $2 \%$ of all indicators collected. ${ }^{320}$ The report notes that indicators remain missing in key areas of women's political and civic representation, "including participation in local government, public administration, the judiciary, political parties, unions, and civil society organizations." 321 In an examination of the 1,000 indicators, $^{322}$ eight indicators attempt to capture women's representation in formal political positions. ${ }^{323}$ While all categories contain gaps in data, the political arena seems particularly stark when compared to the quantity of gender data recorded in health, education, economics, and the environment. For example, in drilling down into the eight indicators, the data deficit becomes quickly apparent. In measuring the percentage of women's representation on local/municipal councils, the data sources used vary in definition (thus making the consistency of the measure difficult). Of the 61 countries included in this measure, approximately half were able to provide 10 or more of the 17 data points between 1995 and 2013.

The number of indicators is neither a measure of high- or low-quality data. Rather, the question is: Do the eight indicators identified accurately capture women's progress in the political arena? While eight out of 1,000 indicators may seem trivial, in point of fact it is progress. Attempting to collect 20 years of data on the overall percentage of women in the judiciary, on local councils, and at the central bank has not been done. While recognizing that significant gaps occur in data availability, and definitional problems exist, No Ceilings remains an ambitious attempt to capture more information in areas where international organizations, gender experts, and academics agree that insufficient quality gender data exists.

$$
* * *
$$

\footnotetext{
320 There are a total of 10 categories in the report across which approximately 1,000 indicators were collected. The 10 categories, followed by the approximate percentage of indicators assigned to each respective category, include the following: (1) economic opportunity $-37 \%$, (2) health $-17 \%$, (3) environment $-15 \%$, (4) education - 14\%, (5) background data $-9 \%$, (6) communications - 3\%, (7) conflict $-2 \%$, (8) the girl child - $2 \%$, (9) political and civic preparation $-2 \%$, and $(10)$ violence against women $-1 \%$.

321 Clinton Foundation, and Gates Foundation. “No Ceilings: The Full Participation Report," 2015.

322 Indicators can be located at: https://www.noceilings.org

323 These include: (1) Female representation in national parliaments, (2) women's share of government ministerial positions, (3) central bank governor (male or female), (4) \% of total seats held by women in central banks, (5) Chief Justice (male or female), (6) women justices on the Constitutional Court, (7) \% of total women in the judiciary, (8) $\%$ of women's representation on local/municipal councils.
} 
In examining the concept of quality data, there is definitional consistency around a core group of three to four criteria, whether the data is used for research, policy, or advocacy purposes. Differences emerge, however, depending on the specific uses of the data. For example, quality data for business planning, information systems, or humanitarian assistance might preference different criteria of quality depending on priorities and intended outcomes. Composite indicators also have their own set of challenges. While core quality data criteria are still applicable, the nature of composite construction - which typically draws upon a wide variety of indicators across different criteria - creates unique quality data challenges.

In turning to my own research, how quality data is defined as applicable to global gender composite indicators is of most interest. Figuring prominently in this discussion is the element of data granularity - defined as the ability to disaggregate data into smaller units. The concept of granularity is missing in the more established international frameworks and appears only recently as a definitional element in relation to quality gender data specifically. As a practical example of application, the following section will focus more explicitly on quality data considerations used when constructing a composite indicator to measure women's descriptive representation in the area of formal politics.

\subsection{USING QUALITY DATA TO MEASURE WOMEN'S POLITICAL PRESENCE}

In returning to the opening quote of this chapter-"what gets measured, gets done"- much of the impetus behind my research stems from perceived weaknesses in the ability to measure women's political participation "and express it in numbers," as stated by Lord Kelvin at the beginning of this chapter. Qualifying standards associated with high-quality data, poor-quality data, or mediocre-quality data can only be applied when data actually exists. One can't help but question such exhaustive efforts as the No Ceilings project which, out of 1,000 indicators, was able to collect $0.8 \%$ of the measures as a reflection of women's presence in politics, given general consensus on its importance. ${ }^{324}$ And even within the $0.8 \%$ collected, the majority of countries were unable to provided adequate data. It remains difficult to examine gender issues and data quality - in particular the wide male/female disparities in availability without engaging in efforts to "generate improved measures."

\footnotetext{
324 Phillips, Anne. The Politics of Presence. Oxford University Press, 1995.

325 Hawken, Angela, and Gerardo L. Munck. "Cross-National Indices with Gender-Differentiated Data: What Do They Measure? How Valid Are They?" Social Indicators Research, 2013, 1-38.
} 
My research is one effort to "generate improved measures." I propose a modified approach towards measuring descriptive representation in the formal political space using a composite indicator and index approach. I apply this methodology to specifically measure women's descriptive representation, building off the previous work of composite indexes detailed in Chapter 2 -Measuring Women in the Political Domain: A Critical Appraisal. ${ }^{326}$ The main research question being explored is framed as follows:

Can quality data measuring women's positions

of formal political decision-making be collected

on a global scale?

My research intention is to move the work completed to date another step forward by testing whether a greater amount of quality gender data can be collected effectively and efficiently, on a global scale, focusing on women's presence in 12 decisionmaking positions. These positions are divided into four different conceptual criteria (legislative, judicial, executive, security), weighted according to their perceived decision-making authority, and aggregated into one composite indicator score. From individual country scores the Diamond Index will be created, with four points reflecting the four criteria measured. In attempting to create a composite indicator and index focused on the formal political arena, a framework comprising eight quality data criteria was defined and applied to women's political descriptive representation.

\subsubsection{Theoretical Framework}

I began the index construction by borrowing from theoretical frameworks, conceptual dimensions, and practical applications already at play. I continue to build off the majority of gender composite indicators, and resulting indexes, that use (in)equality as a framework. I am interested specifically in the conceptual dimension of descriptive political equality. Adhering to the Social Watch Gender Equity Index definition reflected in the dimension of "women's empowerment,"327 I define the concept of political equality in a similar manner: "The number of women holding positions of formal political decision-making in each country." ${ }^{328}$ Of the six leading gender

326 The indexes include the following: (1) Gender Inequality Index, (2) Social Institutions and Gender Index, (3) Global Gender Gap Index, (4) Gender Equity Index, (5) European Union Gender Equality Index, and (6) African Gender and Development Index.

327 Social Watch. "Social Watch Report 2005: Roars and Whispers." Montevideo: Social Watch, 2005.

328 The Social Watch Gender Equity Index used the following definition: "The number of women with access to positions of power and decision-making in each country." Social Watch does not distinguish between formal or informal political power, but attempts to capture aspects of both forms by mixing government with non-government positions. For that reason I have inserted the word "formal" to clarify that the focus is on government institutions 
indexes I reviewed, Social Watch is the only one to incorporate the term "position" into its political definition. The terminology and use of position most appropriately reflects my research and index development intent. By choosing to focus on position I immediately pull back from discussions or expectations about substantive representation. A woman holding a specific position in formal government does not constitute a mandate for acting on behalf of women, representing women's interests, or ensuring that a critical mass of women leads to change. ${ }^{329}$ It does, however, open the door to all of those possibilities, as women occupying such positions may be able to increase their voice, exercise agency, or institute gender-positive change. Access to specific positions is about giving women the same opportunities as men: the political equality of numbers to sit at the decision-making table.

This research is focused on political equality, with respect to the institutions that comprise the formal state. It does not attempt to look at political equality through an individual lens (for example, percentage of women voters) nor within international structures (supranational courts, joint military forces, etc.). Political equality is examined at the individual country level focused on common national institutions that exist across the vast majority of states.

Finally, building off the work of Sen, the index I propose does not include any well-being indexes that reflect the individual's level of health, welfare, etc. ${ }^{330}$ Indexes focused on measuring inequality, such as the Global Gender Gap Index, have been criticized for mixing well-being indicators with those that measure access to resources that can lead to empowerment. ${ }^{331}$ While recognizing that well-being measures are important to the lives of individuals, they do not measure women's access to resources that can impact or sustain one's social status. For this reason well-being measures have been excluded as viable measures within a gender political equality framework.

\subsubsection{Twelve Positons of Formal Political Decision-Making}

To date, practical application leads us to believe that "the greater the number of countries, the less comparable empirical data there will be available." ${ }^{332}$ This has proven to be particularly relevant for the political dimension, where globally available data is consistently cited as problematic. There is no clear evidence on

\footnotetext{
and not the non-governmental sector. While these political positions are deemed to have both power and decisionmaking authority, the focus of my definition is on the positions themselves, rather than how that position will be used and for what purposes.

${ }^{329}$ Phillips, Anne. The Politics of Presence. Oxford University Press, 1995.

330 Sen, Amartya. Development as Freedom. Oxford University Press, 2001.

331 Bericat, Eduardo. "The European Gender Equality Index: Conceptual and Analytical Issues." Social Indicators Research 108, no. 1 (2012): 1-28.

332 Ibid.
} 
the need for a minimum number of indicators to measure a concept. When dealing with complex ideas, however, a review of the evidence by Malhotra et al. suggests that single indicators, and even composite indictors, ${ }^{333}$ are inadequate for the task at the aggregate level. ${ }^{334}$ She suggests as one remedy the formation of a strong cluster of aggregate level indicators on one specific dimension. ${ }^{335}$ The authors see this approach as an exercise in triangulation, as multiple measures within the same dimension provide greater opportunity to either confirm or contradict. One of the major constraints to this approach, the authors note, has been the lack of gender disaggregated data for developing countries that can form an adequate cluster. ${ }^{336}$

The composite indicator I will propose, and develop in more detail in the next chapter, adopts this approach by attempting to form a more robust cluster of indicators around the measurement of political equality, defined as equal access to formal political decision-making positions. This includes 12 separate variables identified as having formal decision-making authority. ${ }^{337}$ Table 10 outlines the selected decisionmaking positions in the formal political arena.

TABLE 10: Selected Positions of Formal Political Decision-Makers

\begin{tabular}{l|l|l|l|}
\hline DIMENSION & \multicolumn{1}{|c|}{ TIER 1 } & \multicolumn{1}{c|}{ TIER 2 } & \multicolumn{1}{c|}{ TIER 3 } \\
\hline EXECUTIVE & Ministers & Top-Level Bureaucrats & Mayors 10 Largest Cities \\
\hline LEGISLATIVE & Political Party Leaders & Committee Chairpersons & Legislative Members \\
\hline JUDICIAL & $\begin{array}{l}\text { Judges } \\
\text { Highest Court }\end{array}$ & $\begin{array}{l}\text { Judges } \\
\text { Second-Level Court(s) }\end{array}$ & $\begin{array}{l}\text { Judges } \\
\text { Third-Level Courts }\end{array}$ \\
\hline SECURITY & $\begin{array}{l}\text { Security Officers } \\
\text { Top-Level }\end{array}$ & $\begin{array}{l}\text { Security Officers } \\
\text { Mid-Level }\end{array}$ & $\begin{array}{l}\text { Security Officers } \\
\text { Lower-Level }\end{array}$ \\
\hline
\end{tabular}

\footnotetext{
333 The authors specifically cite the UNDP Gender Empowerment Measure index as inadequate. As noted earlier, this index was replaced in 2010 by the Gender Inequality Index by UNDP due, in large part, to criticism of the index's construction and bias towards high-income economies.

334 Malhotra, Anju, Sidney Ruth Schuler, and Carol Boender. "Measuring Women's Empowerment as a Variable in International Development." World Bank, 2002. Bardhan, Kalpana, and Stephan Klasen. "UNDP's Gender-Related Indices: A Critical Review." World Development 27, no. 6 (1999): 985-1010.

335 Malhotra was specifically looking at the concept of "women's empowerment" and its use and measurement among international development partners.

336 What constitutes an adequate cluster is not defined. Malhotra does note that using this approach should also be done across at least two points in time.

337 Further definitions for each of the 12 decision-making positions is detailed in Chapter 4: Developing the Diamond Index.
} 
Data collected from these 12 positions is weighted and aggregated to form one country score. These scores are then placed in an index (the Diamond Index) consisting of four axes to reflect each of the four conceptual dimensions measured. When final scores are graphed for each of the conceptual dimensions, a full diamond approximates gender equality among political decision-makers. Countries can then be ranked according to their final composite score or by each respective conceptual dimension: executive, legislative, judicial, security. The quality data criteria considered when selecting the 12 positions and constructing the composite indicator and index are discussed below.

\subsubsection{Quality Data Framework for the Diamond Index}

\section{Relevance}

Relevancy, sometimes referred to as validity, appears in every data quality framework I examined as an essential criteria. It captures the relationship between the information collected and the concept being measured. Does the data, in short, measure what it claims to be measuring? For a composite indicator, balancing the different domains is also a consideration. For example, are the different conceptual domains measured in an equal manner, either through the number of indicators selected, weighting methodology applied, or a combination of both? This balance can be difficult to achieve as composite indicators typically use varied datasets to measure different concepts. Each concept may have a unique methodology and, therefore, a distinctive way of collecting and presenting information using a small number, or extensive array, of variables. Rather than trying to mix apples and oranges, composite indicators often resemble an elaborate fruit bowl. Efforts to harmonize the validity and weight of disparate and varied number of measures across dimensions, often in the face of data unavailability, can be extremely challenging.

In attempting to broaden and deepen measures of women's political descriptive representation, I took care in selecting each of the 12 decision-making positions comprising the Diamond Index. It was imperative that there be logical coherence and balance - both horizontally and vertically - across the four domains. For these reasons, three positions were selected from each branch of government and the security sector. This consistency in the same number of positions across domains was intended to allow for equality of weighting between each domain.

Of equal concern was the vertical selection of decision-making positions. Three tiers of decision-maker were chosen within each sector, with each tier intended to be approximately equivalent in its perceived level of decision-making authority across 
each of the four domains. Problems arise, however, in trying to compare levels of authority. Does a regional court judge have the same level of decision-making authority as a police captain or city mayor? Difficult to prove or disprove, as each country context will likely present different results. Of more relevance is the focus on increasing levels of decision-making authority. A high court judge will have more authority than a regional court judge. A police captain will have more authority than a police sergeant. While efforts have been made to compare authority level to authority level across sectors to the greatest extent possible, a vertical examination of positions reflects increasing decision-making authority. So while a low-level police sergeant may not match exactly to a district judge, within each sector they are considered at a third level of decision-making authority, with two higher levels clearly identified.

Also constraining the selection process was the limited number of political decisionmaking levels available that might be captured on a global basis. In the judicial system there are a finite number of court levels. In the security sector a finite number of leadership ranks. Constraints also exist in the legislative and executive branches. For example, the president or prime minister, as head of the executive branch, might at first glance seem a logical choice to include as a decision-maker. The difficulty in choosing this level of leader, however, is that no equivalent position exists in other parts of government. A cabinet of ministers reflects greater decisionmaking equity with a court of judges, grouping of party leaders, or a collective of police commanders.

My research was aimed at targeting influential leaders - those with decision-making authority - across differing government structures and the roster of political positions. In examining formal governments, we may agree that no single institution, branch, or individual holds full decision-making authority, with perhaps the exception of a few notable countries. This decision-making authority shifts within the structure of each state and, when attempting to compare across almost 200 governments, one must look to common denominators. As a result, there will be positional selection limitations.

While acknowledging that limitations exist around the selection of equivalent decision-making positions across all countries, the question remains as to whether what I intend to measure is being measured? Do the 12 selected positions actually measure political equality? My definition of political equality - equal access to positions of formal political decision-making - is purposefully narrow. While my intention is to broaden and deepen how we think about women's political descriptive representation, it does not propose any drastic changes to current descriptive 
representational efforts. What is new is attempting to systematically broaden the formal institutions being measured - horizontal representation - and then focusing greater value on the specific positions women hold - vertical representation. Despite these nuances, however, the focus is still on counting numbers of women. And, specifically, women in formal government.

According to Dahl, power is dispersed across society; government is only one locus of power. ${ }^{338}$ Civil society organizations, lobby groups, trade unions, advocacy organizations, private sector, and the media may all play a role in setting the political agenda and in shaping government decisions. One could argue that by ignoring these other sources of influence, I am only capturing a piece of the political decision-making. Excluding outside political influences and decision-makers was intentional.

In returning to the Data2X project, one of its main objectives was to "quantify and make visible women's participation in society." For my purposes this includes quantifying the senior-level cadre of women political decision-makers in each country. That is not to say that these leaders are immune from other forces of persuasion. That is not to imply that other political pressures and actors have no influence on their decisions. A wide array of power brokers may have significant impact on political deals struck. This is true for both men and women in these positions. But my research interest is not related to how decisions are made or whether substantive representation occurs when women are placed in these positions. My interest, because current measurement tools are viewed as insufficient, is to adequately capture the face of final decision-makers in formal politics. The Diamond Index is an attempt to more robustly capture who voices the final decision, regardless of power dynamics at play. In this regard, the validity between the 12 selected positions and political equality of decision-making positions is coherent.

\section{Completeness}

One of the greatest challenges associated with building a composite indicator is collecting the appropriate breadth and depth of data for use as a global measure. This concept is embedded in quality data frameworks as completeness or, in some instances, it is included as a component of relevance. What differs with a global composite indicator is, however, indicators selected must typically cover the majority of countries in the world, be publically accessible, and reliably produced. These difficult criteria can often be incompatible with what is being measured,

338 Dahl, Robert Alan. Who Governs?: Democracy and Power in an American City. Yale University Press, 2005. 
forcing researchers to rely on what is available or to use proxy data. ${ }^{339}$ "Choices of convenience" - using the data at hand - can result in weaknesses, a failure to capture the full meaning of the conceptual dimension being measured, or a lack of validity between data and concept. ${ }^{340}$ As one example, this lack of conceptual reflection was one of the main failings of UNDP's first effort to create a gender composite index, as the indicator used (parliamentary seats held by women) was considered too narrow a measure of the political empowerment dimension. ${ }^{341}$ As a result, the Gender Empowerment Measure was not well understood, misused, and (after coming under heavy criticism) eventually replaced. ${ }^{342}$ It was essentially deemed insufficient to measure what it claimed to measure. The ability to collect the amount and type of appropriate quality data on a global level, given the lacuna of information in many parts of the world, should not be minimized. This tension between validity of data and accessibility of data remains at the heart of global composite indicator construction.

Increased Horizontal Representation (Glass Walls): The trend line for numbers of women in parliament has steadily increased during the past two decades, which is partly attributable to the growth of quotas that we now see in more than 100 countries. In January 2005 the global average of women in the lower house of parliament was $15.9 \%$. By January 2015 that number had risen to $22.1 \%$, an increase of 6.2 percentage points. ${ }^{343}$ Other branches of government have not benefitted from the application of the same quota pressures. For example, during the same 10 -year period the number of women holding ministerial positions - the second most commonly tracked political gender indicator - increased by only 4 percentage points. $^{344}$ There are no figures available for the judiciary, security sector, or local government. Given the greater focus on legislative quotas in both academia and among development practitioners, it is possible that research and advocacy efforts are creating a bias towards one branch of government and potentially limiting our understanding of what is occurring in other areas. Could our overemphasis on the legislative branch, for example, be creating glass walls that result in the horizontal segregating of women ${ }^{345}$ into specific parts of government over others?

\footnotetext{
339 Nardo, Michela, Michaela Saisana, Andrea Saltelli, Anders Hoffman, and Enrico Giovannini. "Handbook on Constructing Composite Indicators: Methodology and User Guide." OECD publishing, 2005.

340 Hawken, Angela, and Gerardo L. Munck. "Cross-National Indices with Gender-Differentiated Data: What Do They Measure? How Valid Are They?" Social Indicators Research, 2013, 1-38.

341 Desai, Manisha A. "Hope in Hard Times: Women's Empowerment and Human Development." UNDP, 2010. Klasen, Stephan. “UNDP's Gender-Related Measures: Some Conceptual Problems and Possible Solutions." Journal of Human Development 7, no. 2 (2006): 243-74.

342 Schüler, Dana. "The Uses and Misuses of the Gender-Related Development Index and Gender Empowerment Measure: A Review of the Literature." Journal of Human Development 7, no. 2 (2006): 161-81.

343 Inter-Parliamentary Union www.ipu.org.

344 Ibid.

345 W Charles, Maria. "Deciphering Sex Segregation Vertical and Horizontal Inequalities in Ten National Labor Markets." Acta Sociologica 46, no. 4 (2003): 267-87.
} 
Greater breadth of measurement is also important in the face of indications pointing to a parliamentary slowdown in the growth of women. The days of "fast track" quotas, that were seen particularly in the developing world and which drove significant increases during the past decade, may have peaked. ${ }^{346}$ We also continue to see extremely slow gains in majority systems with single-member districts where it continues to be especially challenging to get women elected. ${ }^{347}$ In these types of polity, better efforts to track women's representation across government - in the face of slow or stalled growth in one branch - can help shed light on whether women are finding opportunities in other institutions.

Increased Vertical Representation (Glass Ceilings): Along with horizontal breadth of measurement, there is a significant gap in today's gender composite indicators in the differentiation between political positions within specific institutions, i.e., depth of measurement. Research indicates that the more prestige and power associated with a position, the more difficult it becomes for women to encumber that position. ${ }^{348}$ This may be due to inequalities in: 1 ) social structure - women's access to education or relevant work experience, 2) political structure - type of electoral system or absence of quotas, and 3) cultural attitudes - views that disfavor women's acceptance in the public sphere. ${ }^{349}$

While earlier attempts to quantify the existence of a glass ceiling for women were focused on the labor market, ${ }^{350}$ the same concept and language were adopted early by academics to describe women's lack of advancement in the political arena. ${ }^{351}$ The impediments that hinder women's entrance into senior leadership positions (allowing them to rise above the glass ceiling) have been identified as wide-ranging and numerous, from strong cultural preferences for male candidates to gender biases built into institutions. Rule lists these obstacles as: "narrow gender roles; restrictive religious doctrines; unequal laws and education; discriminatory socioeconomic conditions; male-biased party leaders, other political elites, and voters; and "women

\footnotetext{
346 The Millennium Development Goals Report 2015." New York, N.Y.: United Nations, 2015.

347 Thames, Frank C., and Margaret S. Williams. Contagious Representation: Women's Political Representation in Democracies Around the World. NYU Press, 2012. Reynolds, Andrew. "Women in the Legislatures and Executives of the World: Knocking at the Highest Glass Ceiling." World Politics 51, no. 4 (July 1, 1999): 547-72.

348 Thames, Frank C., and Margaret S. Williams. Contagious Representation: Women's Political Representation in Democracies Around the World. NYU Press, 2012. Krook, Mona Lena, and Diana O'Brien. “All the President's Men? The Appointment of Female Cabinet Ministers Worldwide." Presented at the Midwest Political Science Association National Conference, Chicago, IL, 2011. Williams, Margaret S., and Frank C. Thames. "Women's Representation on High Courts in Advanced Industrialized Countries." Politics \& Gender 4, no. 03 (2008): 451-71.

349 Kenworthy, Lane, and Melissa Malami. "Gender Inequality in Political Representation: A Worldwide Comparative Analysis." Social Forces 78, no. 1 (1999): 235-68. doi:10.2307/3005796.

350 Cotter, David A., Joan M. Hermsen, Seth Ovadia, and Reeve Vanneman. "The Glass Ceiling Effect." Social forces 80, no. 2 (2001): 655-681.

351 Borrelli, MaryAnne, and Janet M. Martin. The Other Elites: Women, Politics, and Power in the Executive Branch. Boulder, Colorado: Lynne Rienner Publishers, 1997. Reynolds, Andrew. "Women in the Legislatures and Executives of the World: Knocking at the Highest Glass Ceiling." World Politics 51, no. 4 (July 1, 1999): 547-72.
} 
unfriendly" election systems. ${ }^{352}$ When women are elected or appointed to the legislature, for example, evidence points to women being blocked from higher-level positional power due to institutional bias towards men's experiences and authority. ${ }^{353}$

In a 2008 study of women's representation on high courts in the OECD, findings highlighted that the most statistical significant variable for predicting women's representation on the court was the total number of seats available. ${ }^{354}$ The greater the number of seats, the greater the percentage of women represented. As the prestige of the court rose, the number of judicial seats and the percentage of women declined, leaving men predominant on those courts with the greatest authority.

In current gender indexes, the percentage of women is prioritized over the occupation of specific positions. They fail to differentiate between varying levels of authority associated with specific elected and appointed roles. Indexes are constructed upon the premise that one seat in the legislature is as powerful as the next and judicial seats are equivalent on any court; therefore, they are weighted the same. Institutionally, however, some seats in any parliament or congress wield more influence than others. This may be especially true in a legislature with a strong committee system. ${ }^{355}$ Likewise, this differentiation of power applies to judicial courts, command structures within the security sector, and positions within the executive. ${ }^{356}$

If we think of powerful positions aligned within a pyramid, with the most influential rising to the top, we should be cognizant of not only what parts of government we see women being elected and appointed to, but where they reside in the pyramid at the top, clustered in the middle, or consigned to the bottom ranks. In recognizing that some government positions are higher in the hierarchy than others, we must acknowledge that it matters which seats women access. Large numbers of women

\footnotetext{
352 Rule, Wilma. "Parliaments of, by, and for the People: Except for Women?" Contributions in Political Science 338 (1994): 15-15. Lindberg, Staffan I. "Women's Empowerment and Democratization: The Effects of Electoral Systems, Participation, and Experience in Africa." Studies in Comparative International Development 39, no. 1 (2004): 28-53. Matland, Richard E. "Women's Representation in National Legislatures: Developed and Developing Countries." Legislative Studies Quarterly (1998): 109-125. Kenworthy, Lane, and Melissa Malami. "Gender Inequality in Political Representation: A Worldwide Comparative Analysis." Social Forces 78, no. 1 (1999): 235-68. Norris, Pippa, and Joni Lovenduski. "'If Only More Candidates Came Forward': Supply-Side Explanations of Candidate Selection in Britain." British Journal of Political Science 23, no. 3 (1993): 373-408.

353 Childs, Sarah, and Mona Lena Krook. “Analysing Women's Substantive Representation: From Critical Mass to Critical Actors." Government and Opposition 44, no. 2 (2009): 125-45.

354 Williams, Margaret S., and Frank C. Thames. "Women's Representation on High Courts in Advanced Industrialized Countries." Politics \& Gender 4, no. 03 (2008): 451-71.

355 Lijphart, Arend. Patterns of Democracy: Government Forms and Performance in Thirty-Six Countries. Yale University Press, 2012.

356 Krook and O'Brien undertook an excellent study in 2009 that documented the overall distribution of ministry portfolios in 118 countries. This was followed by: 1) rating each minister position as masculine, neutral, feminine and 2) ranking each position as low-, medium-, or high-prestige. Krook, Mona Lena, and Diana O'Brien. “All the President's Men? The Appointment of Female Cabinet Ministers Worldwide." Presented at the Midwest Political Science Association National Conference, Chicago, IL, 2011.
} 
in legislative seats may, in fact, be less desirable than having smaller numbers in more powerful positions, such as chairwomen of influential committees.

In an attempt to capture this nuance of positional location, I have weighted the three positions identified in each dimension. Positions are assigned a different value according to the perceived level of access to political decision-making each holds. As with all weighting efforts, normative choices are made based on an overall judgement and an individual's perception of the context. ${ }^{357}$ This is a first attempt to better delineate the concept that positional differences matter. If there is value in the concept that not all positions are equal, then there is value in understanding where women are finding space in relation to positions deemed as having greater decisionmaking authority.

The 12 positions selected attempt to provide a more complete picture of women's descriptive representation in politics through greater depth and breadth of measurement. The ability to include even a wider range of decision-making positions is tempered, however, by collection constraints on a global level. The Diamond Index attempts to be realistic in what information can be garnered, while at the same time doing justice to definitions of quality data completeness.

\section{Comparability}

In grappling with data availability across all countries, composite indicators must pay equal attention to the consistency of concepts and definitions. In some frameworks this is incorporated under the terms relevancy or coherence. At its core lies the ability to consistently measure the same thing, across time, and across all countries included. It is this comparability, or external validity, that allows composite indicators to be used as a benchmarking tool.

Lijphart points out in his extensive study on patterns of government that variations in democracies are wide ranging, and the type of political system greatly influences the strength of the legislature, judiciary, and executive vis a vis one another. ${ }^{358}$ The variation Lijphart documents is based on 36 countries, all classified as liberal democracies. If we extend our view globally, the variations in how decision-making authority is dispersed and wielded among liberal, illiberal, and authoritarian regimes offers an extraordinary and imaginative range of possibilities.

\footnotetext{
357 Robeyns, Ingrid. "Sen's Capability Approach and Gender Inequality: Selecting Relevant Capabilities." Feminist Economics 9, no. 2-3 (2003): 61-92.

358 Lijphart, Arend. Patterns of Democracy: Government Forms and Performance in Thirty-Six Countries. Yale University Press, 2012.
} 
Trying to measure how and where authority rests across such a wide spectrum of systems does not lend itself to a one-size-fits-all approach. One cannot assume that decision-making authority in a liberal democracy mirrors that of an authoritarian government. And even countries within the same classification strata vary widely, as Lijphart illustrates. Each different regime type will affect opportunities for women. ${ }^{359}$

The percentage of women in the legislative branch can be challenging in trying to compare countries as diverse as Switzerland and Swaziland. For example, in Fish and Kroenig's Legislative Powers Index, on a scale from zero to 1, with zero being an absence of power, the Parliament of Swaziland receives a score of .25 while the Federal Assembly of Switzerland achieves .72, almost triple the score. Using this indicator alone as the basis for measuring women's access to political decisionmaking tells a very different story of access to power and authority levels that the men and women that comprise these institutions have in these two countries.

While the example I use is for the legislative branch, it could equally be applied to the executive. One would expect to see stronger executive branches in countries with weaker parliaments and weaker executives paired with stronger legislatures. In looking only at the executive branch, therefore, the decision-making authority of ministries may also vary considerably in relation to other parts of government. And, systems change as old constitutions are voted out and new leaders voted in. Formal government power is not static, but a constantly shifting commodity. As a result, both appointed and elected positions can gain or lose authority over time. How then, given the importance of comparability across the globe, can we reconcile the need for data coherence with data availability?

First, we concede that there is no one perfect measure to track women in the political space. Second, we acknowledge that structural differences exist across the world's varied systems of government. From liberal to authoritarian, and from presidential to parliamentary, the distribution of formal decision-making positions will vary significantly. ${ }^{360}$ These two facts allow us to recognize that trying to measure one or two data points - given shifting authorities across and within institutions - may minimize, or overemphasize, actual reality.

By casting a wider net across a range of political decision-making positions, we attempt to mitigate individual country variations. While not ideal, the alternative

\footnotetext{
359 Reynolds, Andrew. "Women in the Legislatures and Executives of the World: Knocking at the Highest Glass Ceiling." World Politics 51, no. 4 (July 1, 1999): 547-72.

360 Lijphart, Arend. Patterns of Democracy: Government Forms and Performance in Thirty-Six Countries. Yale University Press, 2012.
} 
is to analyze each country's political system on its own merit, detail how decisionmaking authority functions across its varied institutions, then devise a methodology that horizontally weights those variations. For example, in a country I know well, Tanzania, the legislative branch would receive less weight than the executive but more than the judicial branch, with the security sector wedged just below the executive but above the legislative. While this approach might be possible for a limited number of countries, it presents a much larger challenge to accomplish this globally.

Using comparable leadership positions across governments has been the accepted practice for gender composite indexes to date. That is not to say that just because others approach measurement this way makes it right. The 12 positions I have selected, however, are consistently represented in almost every country in the world. While variations in their authority do exist depending on the type of political system, they are stable variables across countries and time.

\section{Accuracy}

Composite indicators are particularly dependent on other entities for supplying data. This includes the data collection agencies in individual countries as well as the international and non-governmental organizations receiving, collating, analyzing, presenting, and distributing the information. These institutions are the gateways for accessing global data typically used in gender composite indicators. Captured in other frameworks as data accuracy, credibility, or timeliness, composite indicators may face particular challenges in this regard, especially in less-developed countries. Governments across many regions face limited budgets and lack qualified personnel. National statistics offices, as part of government, are not immune to these problems. ${ }^{361}$ Poor working conditions, funding availability, few work incentives, low salaries, and poor education systems can all intentionally, or unintentionally, impact the production and release of quality data.

The UN National Quality Assurance Framework is one of the few tools to make a specific reference to generating information "within given resource constraints." 362 This signals to partner countries using the framework template that recognized limitations may come into play when deciding data priorities and production. While more difficult to document, a lack of political independence can also

\footnotetext{
361 Herrera, Yoshiko M., and Devesh Kapur. "Improving Data Quality: Actors, Incentives, and Capabilities." Political Analysis 15, no. 4 (2007): 365-386.

362 UN Statistical Commission. "Guidelines for the Template for a Generic National Quality Assurance Framework (NQAF)." United Nations Statistics Division, New York 8 (2012).
} 
compromise data quality. ${ }^{363}$ For example, closed governments may refuse to share information with international organizations. Low-performing governments may be unwilling to acknowledge their own failings out of embarrassment or negative incentives for doing so. As policy-makers turn to composite indicators to benchmark performance, there are strong incentives for an individual country to put forward a positive reflection of progress. A UNDP analysis in 2003 of indicators selected for the Millennium Development Goals found "not only are there significant gaps for every indicator, there are also extensive problems in relevance, accuracy, consistency and reliability." 364

The inherent difficult in assuring data quality along the entire spectrum of production makes composite indicators vulnerable to potential bias, errors, and gaps. While we assume that countries and international organizations are attempting to provide quality data to the best of their abilities, given their respective constraints, for researchers using this data there is little to no recourse for addressing data gaps, inaccuracies, or the type and quantity of data collected on a country-by-country basis. One must make the most of the data that is provided, given the cost, effort, and difficulty in replicating these international efforts. While safeguards are in place to help alleviate the problem - including the international codes of practice and frameworks highlighted earlier - the continued reliance on constrained agencies for quality data remains a point of tension for global composite indicators.

The 12 positions were selected to specifically test whether the new information being sought could be collected independently by researchers or interested stakeholders. By choosing to measure individual government positions - a descriptive representational head count - the chance of injecting bias or error from either the researcher or respondent is reduced. It is a simple binary measure that indicates the presence of a man or woman in a specific decision-making position. The determination of male or female is left to the individual encumbering that seat.

The intention was not to "by-pass" government agencies or offices. Rather, the research effort was a test as to whether new data on women's political representation could be accurately collected, and the extent of formal government involvement required. With the growing use of technology throughout all countries, and the increasing amount of information now accessible electronically, this research aimed to explore the data available in the area of women's descriptive representation in formal government, and to identify the sources used. The benefit of this

363 Herrera, Yoshiko M., and Devesh Kapur. "Improving Data Quality: Actors, Incentives, and Capabilities." Political Analysis 15, no. 4 (2007): 365-386.

364 United Nations Development Program. “Human Development Report 2003: Millennium Development Goals: A Compact Among Nations to End Human Poverty." New York: United Nations Development Program, 2003. 
approach could potentially minimize inaccuracies introduced by overwhelmed and underfunded government agencies; collect information that governments and independent organizations are unable, unwilling, or uninterested in gathering; and increase the amount of independently collected data in a field noted for its significant information gaps.

\section{Timeliness}

Trying to gather all the appropriate data at the same time into one composite measurement tool often brings to mind the idiom "herding cats." By the very nature of being a composite indicator, there is typically no single source of information. Researchers, therefore, are reliant on the release dates determined by the various collecting organizations according to their priorities. Different conceptual dimensions can require substantially different data collection approaches and sources. Datasets produced by international or non-governmental organizations may be published annually, bi-annually, or when resources allow. There also exists a "data lag" between the time of collection, publication, and the actual state-of-play on the ground. Fast-moving changes resulting, for example, from a snap election, may take significant time to register in a composite indicator depending on the data collection schedule. Data gathered before the election in one dimension, versus data collected after the election in another dimension, may be difficult to reconcile. As a result, a number of timing factors, either separately or combined, can potentially create incoherence in aggregate measures.

This research effort examines the possibility of collecting data on women's political descriptive representation across a single-year time frame. While data collection in "real time" would be the ideal objective, realistically gathering information across 12 different data points - many of them new areas of collection - seems unlikely. Moving the data points closer to one calendar year, however, was deemed more feasible.

\section{Cost Effectiveness}

Little attention in the literature or international frameworks is devoted to the quality data element of cost. ${ }^{365}$ Accessibility of data is the element most closely corresponding to this concept. Definitions of accessibility, however, are more focused on how the data is presented for consumption, whether it is understandable to researchers or the

\footnotetext{
365 Nardo et al., does mention that accessibility to a variety of sources can have cost implications. The UN National Quality Data Framework states that data should be accessible to all users (including for research purposes) either free or at an affordable price.
} 
public, and if interested parties can access the data and understand its application. While all of those criteria hold true for composite indicators, cost implications may be an additional vulnerability. Composite indicators gather an array of information from multiple sources, relying on pre-collected data sets that are often incomplete. Typically, gaps occur in lower-income and information-scarce countries. Researchers and practitioners using this data have two options: 1) devise a mathematical formula to fill the gaps based on the data available, or 2) attempt to collect the data through other means. The sheer number of variables typically selected to construct a composite indicator compounds this problem. While the affordability of filling in one data point might be feasible, multiple dimensions equate to multiple costs. The use of private data collection firms may further compound this problem. Finally, the very countries lacking data may be more costly in which to operate, gain access, or establish partnerships due to their political situation and/or ongoing security concerns.

It is surprising how little cost is addressed in most international data quality frameworks, given it remains a constraint for researchers, organizations, and governments. Most quality data criteria - completeness, accessibility, timeliness, etc. - all have cost implications. International and multi-lateral organizations collecting data may be driven in specific directions by what donors or member states prioritize and show a willingness to fund. ${ }^{366}$ The No Ceilings data collection effort relied on the deep pockets of the Clinton and Gates foundations, a financial powerhouse duo most ordinary researchers and stakeholders are unlikely to call upon as partners. As a result, researchers must make the best use of available datasets, even in the face of validity and completeness challenges. The other option is the production of their own data, either individually or through partnerships, as resources allow. ${ }^{367}$ As noted, composite indicators may be particularly vulnerable as they typically pull from a variety of data sources.

This research effort attempts to collect a broader array of sustainable and replicable data around women's formal political representation in a cost-effective manner. This includes an attempt at data collection in some of the most difficult "data-scarce" countries. These countries are typically challenging for international organizations and researchers to include due to the lack of data availability and the cost of working in these countries, often exacerbated by difficult travel and living conditions as

\footnotetext{
366 Herrera, Yoshiko M., and Devesh Kapur. "Improving Data Quality: Actors, Incentives, and Capabilities." Political Analysis 15, no. 4 (2007): 365-386.

367 As noted in Chapter 2, the United Nations African Gender and Development Index - an exemplary data collection effort upon which I build - appears from program documents and budgets to be an expensive endeavor. While the country-by-country data collection effort produced information unseen previously, the ability to replicate this model beyond a sub-set of African countries seems unsustainable.
} 
well as potentially higher levels of insecurity. Public information sources, with no attached cost, were targeted as the primary data collection methodology. Most of the 12 positions selected were considered high-profile political actors, prominent either nationally or at regional levels. Choosing easily identifiable and influential positions was expected to increase the likelihood that coverage would occur through such public sources as government websites, media, social media, official reports, and grey literature.

\section{Accessibility}

In previous frameworks reviewed, accessibility is articulated as data presentation to the public. For example, what is the format, the timing of the release, and how is it disseminated to the public? This definition also includes whether researchers and the public have the ability to use the information. In other frameworks the term used is interpretability. This aligns more with the ability of the researcher or public to understand, use, and replicate the results. Accessibility for women's political description representation encompasses both meanings.

My research, like the UN African Gender and Development Index, was designed as clearly as possible "to democratize and simplify statistics." 368 Complicated mathematical processes seen in other gender indexes were eschewed in favor of more easy replicability by interested governments, non-governmental organizations, and individual stakeholders who do not have the expertise to handle complicated mathematical formulas. As will be explained in the next chapter, the logical layout of the Diamond Index, and the data creating the composite indicator underpinning the index, were designed with full public access and ease of use as foundational principles. The goal was to present the data in a clear and understandable way while, at the same time, creating a template easily replicable within any countryspecific context.

\section{Granularity}

As discussed earlier in relation to Data2X, the ability to disaggregate statistics into smaller units should be considered an element of quality data. The common international frameworks discussed make no explicit reference to this element. For my purposes, the ability to disaggregate information remains fundamental to the research given the need to differentiate women's access to political positions. Quality data, therefore, must encompass this concept of granularity.

368 United Nations Economic Commission for Africa. "The African Gender and Development Index," 2011. 
Each of the 12 positions selected for the Diamond Index can be disaggregated according to sex - whether a man or woman occupies that position. These positions also hold the possibility of disaggregation in other ways, depending on the availability of information. Age, for example, is one level of granularity that could be of interest to researchers. Tribal, religious, or geographic affiliation may be other ways to examine granularity, cultural sensitivities and data availability not withstanding. For my research purposes, however, the ability to differentiate by sex was the minimum level of disaggregation required.

These eight criteria form the basis for defining quality data as conceptualized in the design of the Diamond Index. While pulling extensively from the established and tested quality data frameworks previously discussed, I also expand on several criteria in relation to my research. These criteria include, in particular, completeness (sufficient depth and breadth), timeliness, cost effectiveness, and granularity. Table 11 brings all eight quality data criteria together.

TABLE 11: Quality Data Framework for the Diamond Index

\begin{tabular}{l|l} 
Quality Data Criteria & \\
Relevance & $\begin{array}{l}\text { Data adequately captures the theoretical concept or ideas that it claims to be } \\
\text { measuring. }\end{array}$ \\
\hline Completeness & Data provides sufficient breadth and depth of information on a global scale. \\
\hline Comparability & Data definitions and concepts are consistent across countries and over time. \\
\hline Accuracy & Data has limited bias, inaccuracies, and data gaps. \\
\hline Timeliness & Data is collected across a single-year timeframe. \\
\hline Cost Effectiveness & $\begin{array}{l}\text { Data can be collected in a cost-effective manner that is sustainable and } \\
\text { replicable on a regular basis. }\end{array}$ \\
\hline Accessibility & $\begin{array}{l}\text { Data is presented in a format that is easy to understand, access, and replicate } \\
\text { by the general public. }\end{array}$ \\
\hline Granularity & $\begin{array}{l}\text { Data can be disaggregated into smaller information units including, at a } \\
\text { minimum, by sex. }\end{array}$ \\
\hline
\end{tabular}




\subsection{CONCLUSION}

I began this chapter by describing the different criteria used to define quality data, first examining the academic literature around quality data and then moving on to frameworks used by global practitioners. This included examining a range of quality data criteria developed by multi-laterals and the United Nations. From these two literature streams I then developed a quality data framework that forms the foundation for the Diamond Index.

The Diamond Index framework developed contains eight separate quality data criteria, including: relevance, completeness, coherence, accuracy, timeliness, cost effectiveness, accessibility, and granularity. Each of these criteria is defined in relation to its use in the Diamond Index and, in particular, definitional nuances that occur when applied to a composite indicator. My quality data framework does not deviate significantly from other frameworks developed during the past 25 years, although additional insights were added around the criteria of completeness, timeliness, cost effectiveness, and granularity.

With a quality data framework clearly defined to develop the Diamond Index, I now move to the development of the index itself in the next chapter. The purpose in creating the Diamond Index is to shed greater light on political descriptive representation by identifying the faces of leading decision-makers and then, as Lord Kelvin stated, express it in numbers. 


\title{
Chapter 4 \\ Developing the Diamond Index
}

\author{
The global proportion of women elected to \\ local government is currently unknown. ${ }^{369}$
}

\subsection{INTRODUCTION}

Among donors and democracy practitioners, there is an interest in developing better, user-friendly measurement tools that provide a more nuanced understanding of women's presence in the formal political arena. Academics as well continue to highlight the lack of robust data available for use on a global basis. ${ }^{370}$ It is in this space where society's rules and laws are debated, passed, implemented, and enforced. "The terrain in which to gain and share power is in the political process. Once active, policy and budgetary levers from that process can be evoked and accessed to negotiate gender equality outcomes. ${ }^{\prime 371}$ In that respect, according to Parpart et al., what happens in the political area affects all other sectors and areas of women's daily lives. ${ }^{372}$

In attempting to capture more data in the political space, neither academics nor practitioners are typically in a position to create their own tool that would broaden measures. The methodology of developing a framework, selecting indicators, collecting information, normalizing the data, weighting it appropriately, aggregating scores, and ensuring the data is published on a regular basis is beyond the scope of most government civil servants, development workers, local non-governmental organizations, and individual researchers. Lacking the ability to create individual country measuring tools, interested stakeholders rely on what is published. As a

\footnotetext{
369 UN Secretary-General's Report on Women and Political Participation (2013). "Measures taken and progress achieved in the promotion of women and political participation," A/68/184.

370 The Diamond Index has been presented on three different occasions to mixed groups of experts comprised of bi-lateral and multi-lateral donors, academics, and democracy practitioners (United States Agency for International Development, Washington D.C., November 2014; Organization for Economic Co-Operation and Development, Paris, February 2015; United Nations Development Program, New York, June 2015.) Positive feedback from all audiences emphasized the clear logic in the development of the measurement tool, its replicability, and incorporation of new data points as valuable contributions to the field of study.

371 Parpart, Jane L., Shirin M. Rai, and Kathleen A. Staudt. Rethinking Empowerment: Gender and Development in a Global/Local World. Routledge, 2003.

372 Ibid.
} 
result, we see a disproportionate amount of resources and attention on the electoral cycle and getting women into parliament, as the legislative branch has produced the most reliable, annually reported data to date.

In this chapter I build on the work of existing gender composite indicators to increase measures of women's political descriptive representation. The Diamond Index is an attempt to broaden and deepen the relatively narrow set of global indicators currently being used to track women's access to positions of decision-making authority in formal government. This chapter discusses the conceptual framework behind the Diamond Index, including four identified principles that underpin the construction of the measurement tool. This is followed by a discussion of the different domains to be measured and rationale for indicator selection within each of those domains. Detailed steps for building the index then follow.

At the conclusion of this chapter the reader will have a complete picture of the Diamond Index and how it was constructed, a clear understanding of how it might be used, a step-by-step guide as to how it can be replicated and applied, and an awareness of conceptual limitations surrounding the tool.

\subsection{RESEARCHER POSITIONALITY}

The intent in developing this research tool for measuring women in the political space was to create an applicable and usable tool for any country in the world. The majority of the research was, however, piloted in economically developing and democratically weak countries. As a white, educated woman from a high-income economy, I am positioned as an outsider in the pilot countries. This is less of a concern given I have spent most of my adult life living as an expatriate, working in a wide array of languages, cultures, and economic circumstances. Of more concern is a set of strong principles that I hold regarding what a democracy should "look like," certainly influenced by my home country, education, and cultural exposure.

The ongoing work that I undertake on a daily basis also continues to shape opinions in relation to this research. I have spent the last 20 years as a development practitioner in the field of democracy promotion. This work has been undertaken with nongovernmental organizations and the United States government. A significant amount of my time is spent working on countries experiencing democratic backsliding, growing authoritarianism, flawed elections, and an increasing risk of intrastate violence. As a result, personal and professional comparisons and judgements are 
made across countries regarding the "preferred" type of government, how it should function, and its member composition.

This includes intimate work with legislatures, parliamentarians, political parties, and election bodies. In most of the focus countries where I work, quotas for women's legislative representation have been instituted. How the quotas have been operationalized has been insufficient or detrimental to advancing women in the political space, in my opinion. Women's placement in other parts of government, as a counterpoint to what is taking place in the legislative arena, is considered of less relevance. My perception is colored, certainly, by the individual circumstances and context of the selected countries framed by my work. I do not have the similar breadth of experience working with Western and high-income countries where the implementation and use of quotas may be perceived quite differently.

While attempting to maintain a dispassionate distance when constructing my measurement tool for this research, I acknowledge that my reflections of "political equality" rest on preconceived professionally and culturally constructed notions based on Western democratic ideals. Attempts were made to mitigate this by using the current literature and established indexes as a foundational base for globally accepted best practices upon which to build. National experts from Latin America, Africa, the Middle East, Asia, and Eastern Europe were employed in their respective countries to ground-truth the construction of the tool and piloting effort. Finally, the information was also vetted in a public forum by a cross-section of approximately 100 academic and development experts prior to publication. While these collective efforts do not dispel researcher bias, they can highlight its presence and potential effect on the research product.

\subsection{INDICATOR DEVELOPMENT OF THE DIAMOND INDEX}

Indexes are used by different groups for different purposes. While impossible to create a measurement tool that is all things to all people, there is agreement on some basic principles. Building off Haq's ${ }^{373}$ work in designing the UNDP Human Development Index, as well as Dijkstra' $\mathrm{s}^{374}$ work on proposing an improved alternative to UNDP's Gender-related Development Index and the Gender Empowerment Measure, the following four principles guided the construction of the Diamond Index:

\footnotetext{
373 Haq, Mahbubul. Reflections on Human Development. New York: Oxford University Press, 1995.

374 Geske Dijkstra, A. "Towards a Fresh Start in Measuring Gender Equality: A Contribution to the Debate." Journal of Human Development 7, no. 2 (2006): 275-83.
} 
1. Indicators should be limited in number, yet sufficient to cover as many dimensions of decision-making authority in formal government as reasonably possible.

2. The index should be simple to calculate and understand.

3. The index should be easily replicable by interested parties, including nongovernmental organizations, governments, donors, and stakeholders.

4. Quality data considerations should underpin the selection of all variables. ${ }^{375}$

While these four principles may be more easily applied to a select number of countries, the challenge lies in making them work for countries on a global scale. If we examine the major gender composite indexes in use today, the difficulty becomes more apparent. The six commonly used gender composite indicators and indexes (reviewed in Chapter 2-Measuring Women in the Political Domain: A Critical Appraisal) can be divided into two general categories. ${ }^{376}$

Global and Annual: These global indexes produce annual results but at a cost to the number and breadth of the indicators. The same indicators are replicated from index to index, as the frequent nature of publication demands that they rely on pre-collected data from the same institutions. Index builders return to the InterParliamentary Union database ${ }^{377}$ to measure a wide variety of theoretical concepts. "In short, the greater the number of countries, the less comparable empirical data there will be available; and the more heterogeneous the social reality of the countries being compared, the less descriptively relevant empirical data there will be." ${ }^{\prime 378}$ While these annual indexes remain a valuable tool for tracking ongoing progress on a global scale, the higher the number of countries included, the less customized the data becomes.

Focused and Infrequent: Some of the best indexes, noted for their breadth of indicator coverage beyond the percent of women legislators and ministers, focus solely on one geographic region. A smaller number of countries allows for more tailored indicators in addition to the standard global measures used. This creates

\footnotetext{
375 Chapter 3 - For Good Measure, describes the quality data framework designed for the Diamond Index. The framework includes eight elements used to define quality data: relevance, completeness, comparability, accuracy, accessibility, timeliness, cost effectiveness, and granularity.

376 The gender composite indicators reviewed in Chapter 2 - Measuring Women's Access to Political Power: A Critical Appraisal, included the following: 1) Gender Inequality Index - United Nations Development Program; 2) Social Institutions and Gender Index - Organization for Economic Cooperation and Development; 3) Global Gender Gap Index - World Economic Forum; 4) Gender Equity Index - Social Watch; 5) Gender Equality Index - European Institute of Gender Equality; and 6) African Gender and Development Index - United Nations Economic Commission for Africa.

377 Inter-Parliamentary Union. "Parliaments at a Glance," 2017.

378 Bericat, Eduardo. "The European Gender Equality Index: Conceptual and Analytical Issues." Social Indicators Research 108, no. 1 (2012): 1-28.
} 
better linkages between the theories articulated and what is measured. It also provides a wealth of data for advocates and development practitioners in a targeted country.

However, using custom indicators also comes at a cost, both in financial and labor intensive terms. The European Equality Index and the African Gender and Development Index are published infrequently: once (2013) for the former and twice (2009 pilot, 2011) for the later. ${ }^{379}$ It remains unclear when future index results will be released. While the indexes provide a snapshot in time of an individual country's gender status, their utility as a global tool is hampered by their infrequent publication and inability to make in-country and cross-country comparisons over time.

The Africa Gender and Development Index is especially vulnerable. Part of the selfidentified value of the index, according to its authors, is that data is collected nationally and not reliant on international databases. ${ }^{380}$ While laudable, this also makes the index more difficult to replicate, especially in regions with serious information-access constraints. Perhaps this has contributed to the limited number of countries and publication frequency, which in turn lessons its utility to undertake longitudinal analysis, track trends, or document individual country changes. ${ }^{381}$ The number of indicators, level of expertise, and time required to construct this index means, for all practical purposes, interested parties may find it difficult to collect the same data or replicate it on a consistent basis.

Table 12 highlights the tension between global and regional measures, including the heavy reliance of global indexes on one to two measures. Beyond "female members of parliament" and "female members of cabinet" the number and indicator use begins to decline, and stratification occurs by region. ${ }^{382}$

\footnotetext{
379 The African Gender and Development Index has included 12 countries twice and 18 countries once.

380 United Nations Economic Commission for Africa. “The African Gender and Development Index," 2011.

381 The Economic Commission for Africa states in the 2011 report that its medium- and long-term plans include expanding the use of the African Gender and Development Index to all 52 African countries and publishing the results every two years (page 62).

382 I have included only those indicators whose stated purpose is to measure the political domain.
} 
TABLE 12: Indicators Measuring Women in the Political Space from Six Gender Indexes

\begin{tabular}{|c|c|c|c|}
\hline Measurement & Global & Europe & $\begin{array}{l}\text { Select } \\
\text { Countries } \\
\text { in Africa }\end{array}$ \\
\hline $\begin{array}{l}\text { Female members of parliament } \\
\text { 1. Female and male share of parliamentary seats } \\
\text { 2. Percent of women in parliament } \\
\text { 3. Members of parliament } \\
\text { 4. Share of members of parliament } \\
\text { 5. Seats in parliament } \\
\text { 6. Female with seats in parliament over male value }\end{array}$ & $\begin{array}{l}X \\
X \\
X \\
X \\
X \\
X\end{array}$ & & \\
\hline $\begin{array}{l}\text { Female members of cabinet } \\
\text { 1. Women in ministerial positions } \\
\text { 2. Share of ministers } \\
\text { 3. Cabinet ministers } \\
\text { 4. Females at ministerial level over male value }\end{array}$ & $\begin{array}{l}X \\
X \\
X \\
X\end{array}$ & & \\
\hline $\begin{array}{l}\text { Senior-level government officials } \\
\text { 1. Higher positions in civil service and parastatals } \\
\text { 2. Legislators, senior officials, and managers }\end{array}$ & $X$ & & $X$ \\
\hline $\begin{array}{l}\text { Senior-level non-government professionals } \\
\text { 1. Senior positions in political parties, trade unions, } \\
\text { employers' associations, heads or managers of } \\
\text { NGOs } \\
\text { 2. Professional and technical positions }\end{array}$ & $X$ & & $X$ \\
\hline $\begin{array}{l}\text { Local government officials } \\
\text { 1. Share of members of regional assemblies } \\
\text { 2. Members of local councils }\end{array}$ & & $X$ & $X$ \\
\hline $\begin{array}{l}\text { Head of State } \\
\text { 1. Number of years of a female head of state (last } \\
50 \text { years) over male value }\end{array}$ & $X$ & & \\
\hline $\begin{array}{l}\text { Judges } \\
\text { 1. Judges higher, lower, traditional, religious courts }\end{array}$ & & & $X$ \\
\hline $\begin{array}{l}\text { Legislative Quotas } \\
\text { 1. Existence of quotas }\end{array}$ & $X$ & & \\
\hline $\begin{array}{l}\text { Security } \\
\text { 1. Employment in security forces }\end{array}$ & & & $X$ \\
\hline $\begin{array}{l}\text { Education } \\
\text { 1. Female and male population with at least } \\
\text { secondary education }\end{array}$ & $X$ & & \\
\hline
\end{tabular}

We can see the tension between the ability to measure women's political presence using a variety of indicators and the global data we have available to do so. Gathering a wider array of indicators has typically required a country-by-country 
collection effort, especially in less-developed countries, as there is no standardized effort to capture much of this information. As a result, for most composite gender indicators in the political domain, little attention has been devoted to examining women's breadth and depth of leadership across government and especially within the security sector. In the leading gender indexes in use today, there is no attempt to identify any variation in specific positions women hold in formal government. In essence, the focus has been more generally directed at tracking percentages of women in institutions with less attention to the levels of decision-making authority inherent in the political positions women are garnering.

Indicator selection was based on measures of progress towards equality between men and women verses what women have attained in society or women's wellbeing. ${ }^{383}$ As an example, the percentage of women who have access to health care (attainment) and low rates of maternal mortality (well-being) are important measures of women's status. But neither measure equality. Likewise in the political arena, the number of women running for election or nominated by parties as candidates do not always translate into women in office. The Diamond Index focuses on outcome indicators that directly measure the equality relationship between men and women in the formal political sphere.

When measuring equality, it is also necessary to make the clear distinction between the "status of attainment" verses the "status of equality." 384 Attainment indices measure levels reached by women or men in the country. In Bangladesh, for example, the male literacy rate is $62 \%$ while the female literacy rate is $53 \%$. Levels are compared against full attainment, rather than against one another. Inequality or equality indices, on the other hand, measure the level of status women have in relation to men. ${ }^{385}$ To measure inequality, indicators must look at the relation of women's status compared to that of men's. ${ }^{386}$ Some indexes mix both attainment and equality indicators. For purposes of conceptual clarity, the Diamond Index only measures political inequality between men and women in the formal political sphere. I define political equality as "an equal number of women holding positions of formal political decision-making."

\footnotetext{
383 Bericat, Eduardo. "The European Gender Equality Index: Conceptual and Analytical Issues." Social Indicators Research 108, no. 1 (2012): 1-28.

384 Sugarman, David B., and Murray A. Straus. "Indicators of Gender Equality for American States and Regions." Social Indicators Research 20, no. 3 (1988): 229-70.

385 Di Noia, Jennifer. "Indicators of Gender Equality for American States and Regions: An Update." Social Indicators Research 59, no. 1 (2002): 35-77.

386 Permanyer, Iñaki. "The Measurement of Multidimensional Gender Inequality: Continuing the Debate." Social Indicators Research 95, no. 2 (2010): 181-98. Bericat, Eduardo. "The European Gender Equality Index: Conceptual and Analytical Issues." Social Indicators Research 108, no. 1 (2012): 1-28.
} 
Horizontal Measures: Measuring access to political decision-making horizontally includes all three branches of government and the security sector. As a result, the four different dimensions of formal political decision-making that define the Diamond Index include components of the legislative, executive, judicial, and security sector.

Vertical Measures: Vertical measures attempt to capture three tiers of senior decision-makers within each horizontal dimension. Tier 1 leaders are considered to have the greatest decision-making authority, Tier 2 moderate decision-making authority, and Tier 3 lower decision-making authority. Despite this stratification into tiers, all positions selected are perceived as influential in formal government.

With three indicators selected for each dimension, and four dimensions included (executive, legislative, judicial, security), the Diamond Index contains a total of 12 positions identified as decision-makers. Decision-makers are defined as individuals who have the potential to achieve impact based on the authority and agency inherent in the position they hold. In selecting and weighting these positions, I have attempted to choose those having common definitions and duties applicable to the broadest range of countries possible.

\subsubsection{Executive Branch}

Tier 1 - Cabinet Ministers: Although the executive branch has been described as the most male branch of government, ${ }^{387}$ women are making headway in gaining ministerial positions. While the literature and documentation to date by the InterParliamentary Union and UN Women indicate women hold up to $17 \%$ of all cabinet positions, ${ }^{388}$ they are often shunted into lower prestige posts, such as education, culture, and women's affairs. ${ }^{389}$ Whether controlling the foreign affairs or health docket, however, ministers may hold enormous sway in overseeing budgets, staff, and policy direction. In some countries the individual "line" ministries themselves develop laws. ${ }^{390}$ Once vetted by cabinet, they are introduced into Parliament thereby influencing both the law-making and policy-implementation functions. In Parliamentarian systems this ensures that the executive and legislative branches are

\footnotetext{
387 Borrelli, MaryAnne, and Janet M. Martin. The Other Elites: Women, Politics, and Power in the Executive Branch. Boulder, Colorado: Lynne Rienner Publishers, 1997.

388 According to the Inter-Parliamentary Union and UN Women: "The total includes deputy prime ministers and ministers. Prime ministers/heads of government were also included when they held ministerial portfolios. Vicepresidents and heads of governmental or public agencies have not been included." I have included only ministers in the Tier 1 category.

389 Inter-Parliamentary Union. "Women in Politics," 2017. Krook, Mona Lena, and Diana O’Brien. "All the President's Men? The Appointment of Female Cabinet Ministers Worldwide." Presented at the Midwest Political Science Association National Conference, Chicago, IL, 2011.

390 Devlin, Claire, and Robert Elgie. "The Effect of Increased Women's Representation in Parliament: The Case of Rwanda." Parliamentary Affairs 61, no. 2 (February 23, 2008): 237-54.
} 
closely aligned in policy priorities. ${ }^{391}$ That is not to imply that ministers have complete freedom to dictate the direction of their ministries. Factors such as legislative and judicial oversight, a strong president, party platforms, public opinion, etc., all come into play in the decision-making process.

There is a growing body of literature that has looked at women ministers across countries and an increasing recognition that the percentage of women ministers is a useful indicator in measuring women's access to political power. While this branch of government still remains understudied in comparison to the legislative branch, annual data on the percentage of women ministers is now more readily available. Individual countries have official websites identifying ministers. The names and portfolios of all cabinet ministers are available through the U.S. Central Intelligence Agency. ${ }^{392}$

$\checkmark$ The Diamond Index incorporates the position of minister only as the Tier 1 position in the executive domain.

\section{$\checkmark$ Indicator: The percentage of women ministers in the executive cabinet.}

Tier 2 - Senior Executives: As in other domains, women have been making steady, although slow, progress in obtaining senior executive positions. Research by Mathiason and Kookhony, for example, points to women's representation in sub-ministerial positions doubling from $7 \%$ to $15 \%$ between 1994 and 2005. ${ }^{393}$ The Diamond Index captures the composition of staff located directly below the minister. This includes deputy ministers, vice ministers, under secretaries, and permanent secretaries. While titles will vary across countries, these individuals sit at the highest levels of the ministry. These positions may be appointed by the executive or held by career members of the civil service. Positions may be inherently political in nature or demand technically strong expertise. While each country will differ, this cadre of officials may be somewhat more insulated from the political fray being viewed as the leadership behind the minister. Whether political or technocratic in nature, however, these senior executives both support and report to the Minister.

A more robust measure for Tier 2 - Senior Executives would have also included one lower bureaucratic level that captures heads of agencies or divisions within each ministry. This head of an agency or director of a division captures more technocratic

\footnotetext{
391 Lijphart, Arend. Patterns of Democracy: Government Forms and Performance in Thirty-Six Countries. Yale University Press, 2012.

392 https://www.cia.gov/library/publications/world-leaders-1.

393 Mathiason, John, and Loveena Kookhony. 2006. Women in Governmental Decision-Making in the Early $21^{\text {st }}$ Century: What Has - and Has Not - Been Achieved in the Post-Beijing Period.
} 
individuals given their greater distance from the minister. Unfortunately, this layer of data within formal government does not exist across countries. It is also difficult to gather on a country-by-country basis using public data. For example, while ministerial organizational charts identify the different divisions led by a director or agency head, staff profiles are often not provided to this level. It would require indepth research to unearth the various directorships through non-public data sources. Even in smaller, less developed countries, the number of these positions may add into the hundreds when compiled across multiple ministries. For these reasons, the positional line was drawn at a higher level in hopes of gathering consistent data within the executive. While recognizing that politics continues to infuse this level of appointee, managerial and technocratic expertise is also likely to emerge to ensure the day-to-day running of the ministry. How the government's vision and policy is put into place - in very practical terms - often resides with these top-level executive branch positions.

$\checkmark$ Data on women's share of senior executive positions across countries is currently not available.

\section{$\checkmark$ Indicator: The percentage of women holding top executive positions. Positions} include deputy ministers, vice ministers, under secretaries, and permanent secretaries.

Tier 3 - Mayors of the 10 Largest Cities: This measure attempts to capture senior decision-makers of the executive branch at the sub-national level. This is a challenging proposition for a number of reasons. First, there is no consistent definition of local political leadership at the sub-national level and, therefore, no consistent methodology or approach for organizations or governments collecting this data. Comparability has been defined as a key element of quality data underpinning the Diamond Index. In this respect, indicators should consistently measure the same definitional concept, across time, and for all countries.

In attempting to include a sub-national unit of the executive, I began by looking at decision-makers within the top administrative level of government below the national level. This stratification is often defined as a state, region, or province, although contradictions quickly emerge when comparing federal and unitary structures. A federal system accommodates the differing constituent units of the state, allocating specific functions and authorities to each tier through the constitution. ${ }^{394}$ The national and sub-national government structures legally exist, with neither able to eliminate the other. In a unity system, sovereignty resides

394 Burgess, Michael. Comparative Federalism: Theory and Practice. Routledge, 2006. 
with the central government. ${ }^{395}$ That is not to impugn, however, that sub-national governments wield no authority under a unity system. The increased focus on decentralization during the past decades has resulted in regional bodies taking on greater formal authority, ${ }^{396}$ including administrative responsibility for the delivery of services, economic development, and planning. However, the political significance of regions, even as it may be increasing in some systems, remains highly variable. ${ }^{397}$ While one country may use a region or province as a territorial marker, another country will decentralize significant autonomy to this level of government. For example, both Canada and China identify provinces as their first level of governance below the national level. The resulting political decision-making authority residing with each country's respective elected and appointed provincial leaders, however, diverges considerably. ${ }^{398}$ This inconsistency in how each country defines this level of government - including the range of decision-making authority held by this level of sub-national leader - makes for challenging comparisons.

A second difficulty is the lack of consistency in the number of sub-national government levels. Kenya, for example, has two levels below the national government: 47 districts followed by local government. In three-tiered South Africa, by comparison, the firstlevel administrative division below the national level is a province. The country's nine provinces are divided into 52 districts. Given similarities in population and size, Kenya's 47 districts (and first sub-national administrative tier) are more closely aligned to South Africa's 52 districts (the country's second sub-national administrative tier).

Third, a number of countries have opaquely defined sub-national levels alongside clearly defined levels of government. For example, we see the term "territory" used across a range of countries and definitions. Territory might refer to a capital, dependent, federal, disputed, or occupied geographic area, to name some of the different classifications used around this term. "Autonomous region" is another classification in use, from the Åland islands in Finland to the Zanzibari islands in Tanzania, the wide range of countries applying this term to a level of administration does not allow for consistency of definition. The level of autonomy and decisionmaking authority held by these more specialized sub-levels, again varying

\footnotetext{
395 Hague, Rod, and Martin Harrop. Political Science: A Comparative Introduction. Sixth Edition. St. Martin's Press, 2010.

396 Marks, Gary, and Liesbet Hooghe. "Types of multi-level governance." European Integration online Papers 5, no. 11 (2001): 31.

397 Hague, Rod, and Martin Harrop. Political Science: A Comparative Introduction. Sixth Edition. St. Martin's Press, 2010.

398 Hooghe, Liesbet, and Gary Marks. “Types of Multi-Level Governance," 2001. Zhang, Xiaobo. “Fiscal Decentralization and Political Centralization in China: Implications for Growth and Inequality." Journal of Comparative Economics 34, no. 4 (2006): 713-726.
} 
significantly country-by-country, makes it difficult to classify, harmonize, and compare leadership positions in a consistent manner.

Given this range of administrative levels and authorities, the quality data choices seem limited. One option is to try and match like units of sub-national government across countries. So, in returning to our example, Kenya's first-tier districts would be collected and compared to South Africa's second-tier districts. In reality, this would create an unwieldly and highly subjective range of data if attempted on a global scale. A second option might include picking one administrative tier and tracking its leadership consistently, knowing that provinces of Cuba and Indian states have little in common besides their definition as the first sub-national geographic unit of their respective countries. What to do with autonomous regions or territories - such as Tibet and the Navajo Nation of the U.S. - also complicates efforts to compare similar units. While acknowledging that variations will be the status quo when attempting worldwide comparisons, given the differences in sub-national levels, authorities, roles, and definitions, comparing decision-makers directly below the federal level was deemed inadequate.

Local government, however, is universally found in all types of political systems federal or unitary, authoritarian or democratic, presidential or parliamentarian - and each local government is divided into rural and urban centers. ${ }^{399}$ In grappling for a meaningful, yet common decentralized unit of measure, I have chosen to look at the composition of mayors across the largest urban centers of each country. Although titles will vary, the top official at this municipal or city level has many similarities across countries and continents. For example, each is responsible for the day-to-day functioning of a defined, generally legally recognized, geographic area. ${ }^{400}$ Each is elected or appointed to represent the interests of citizens within the boundaries of that city. Each oversees some capacity to generate revenue. Finally, each mayor typically represents the executive branch of government. As leader of a major urban area, mayors can wield significant sway over resources and staff. Innovative mayors from the largest cities are often influential in helping shape the national agenda. In this respect, a popular mayor can also use his or her position as a launching pad into national politics. ${ }^{401}$

\footnotetext{
399 Teune, Henry. "Local Government and Democratic Political Development." The Annals of the American Academy of Political and Social Science 540, no. 1 (1995): 11-23.

400 Ibid.

401 National Democratic Institute. "Women and Local Executive Office," 2015. Murray, Rainbow. Parties, Gender Quotas, and Candidate Selection in France. New York: Palgrave, Macmillan Basingstoke, 2010. Hague, Rod, and Martin Harrop. Political Science: A Comparative Introduction. Sixth Edition. St. Martin's Press, 2010.
} 
This is not to assert that mayors are the perfect sub-national level measure. The level and type of decentralized authority allocated to an urban leader will vary significantly. Also the size of cities is a factor that can determine the role it plays in relation to other administrative levels. In some states the major urban centres (Tokyo, Beijing, and São Paulo, for example) encapsulate populations exceeding that of many countries. In less developed economies, urban centres beyond the capital often have a very rural feel with a small population to match. Ideally, the executive head of all cities above a specified population, for example 50,000 residents, would help average variations in size and population. Because this data is not collected in any systemic way, however, and could include hundreds or thousands of cities for larger countries, it was seen as extremely difficult to gather this level of detailed data, especially in more information-scarce countries.

Given the quality data constraints surrounding issues of completeness, coherence, accessibility, and cost effectiveness, I chose to attempt to collect the gender composition of only the top 10 urban leaders. While not ideal, adding new data at this level can at least begin to paint a picture about women's decision-making authority below the national executive level.

$\checkmark$ Data on women's share of mayoral positions across countries is currently not available.

\section{$\checkmark$ Indicator: The percentage of women who hold the top executive position of authority among the country's 10 largest cities.}

\subsubsection{Legislative Branch}

Tier 1 - Political Party Leaders: I have selected the top leadership position of each party with representation in the lower house of the national parliament as the Tier 1 measure in the legislative area. Given the variety of party structures across the globe, however, it must be acknowledged that where decision-making authority actually resides within a political party is not consistent. Another factor making it difficult to draw meaningful comparisons across party typologies has been the research emphasis placed on Western European parties over the past century and a half, and the lack of data associated with developing countries. ${ }^{402}$

Global trends do indicate, however, that the redistribution of power within the party is shifting towards the leadership as parties move away from mass, dues-paying

402 Basedau, Matthias, Gero Erdmann, and Andreas Mehler. Votes, Money and Violence: Political Parties and Elections in Sub-Saharan Africa. South Africa: Nordiska Afrikainstitutet; Kwazulu-Natal Press, 2007. 
members and towards "electoralist" typologies. ${ }^{403}$ Electoralist parties, i.e., those whose primary function is to conduct campaigns, are typically organizationally thin, maintaining only a skeletal staff between elections. During the election period these parties rely on professional experts to direct the campaign and mass communication to mobilize voters. ${ }^{404}$ While Gunther and Diamond go further to sub-divide electoralist parties into three sub-genres, ${ }^{405}$ within each type of party structure power gravitates towards leadership's prominent role. In some more extreme cases, the rationale for the party's existence is simply to act as a vehicle for the party leader to win the election and exercise power. ${ }^{406}$ Most of the newer democracies, for example across Eastern Europe, are more aligned towards the electoralist party model, lacking the traditionally large, dues-paying membership historically seen in Western Europe. ${ }^{407}$

In looking at other parts of the world, attempts to categorize African and Asian political parties into western-developed party models can prove challenging, given the different historical and societal contexts from which they arose. "Mass," "catchall," "cartel," etc., are derived from experiences in Europe and the United States, and may not adequately account for the tribal, regional, and religious differences overlaid across many parts of the world. Research does, however, point to the strong personalism that dominates formal party structures, as well as informal systems (without written rules), that exist across parties in Africa, Asia, and Latin America. ${ }^{408}$ While more research is called for on party typologies throughout the developing world, the accumulation of power attached to strong personality-based party leadership is a common thread across regions.

Political parties also serve as the gatekeepers to political life. ${ }^{409}$ Even as the size and membership of parties has slipped in numbers, they still hold the keys to office for both men and women. In most countries, parties determine who runs for

\footnotetext{
403 Katz, Richard S., and Peter Mair. "The Cartel Party Thesis: A Restatement." Perspectives on Politics 7, no. 4 (2009): 753-766. Katz, Richard S., and Peter Mair. "Changing Models of Party Organization and Party Democracy: The Emergence of the Cartel Party." Party Politics 1, no. 1 (1995): 5-28.

404 Gunther, Richard, and Larry Diamond. "Species of Political Parties: A New Typology." Party Politics 9, no. 2 (2003): 167-199.

405 These are identified as: 1) catch-all party, 2) personalistic party, and 3) programmatic party.

406 Gunther and Diamond define this as the personalistic party: "Its electoral appeal is not based on any programme or ideology, but rather on the personal charisma of the leader/candidate, who is portrayed as indispensable to the resolution of the country's problems or crisis."

407 Costa Lobo, Marina. "Parties and Leader Effects: Impact of Leaders in the Vote for Different Types of Parties." Party Politics 14, no. 3 (2008): 281-298.

408 Basedau, Matthias, Gero Erdmann, and Andreas Mehler. Votes, Money and Violence: Political Parties and Elections in Sub-Saharan Africa. South Africa: Nordiska Afrikainstitutet; Kwazulu-Natal Press, 2007. Costa Lobo, Marina. "Parties and Leader Effects: Impact of Leaders in the Vote for Different Types of Parties." Party Politics 14, no. 3 (2008): 281-298.

409 Norris, Pippa, and Joni Lovenduski. Gender and Party Politics. Sage Publications, 1993. Dahlerup, Drude, and Lenita Freidenvall. “Quotas as a 'Fast Track' to Equal Representation for Women: Why Scandinavia Is No Longer the Model." International Feminist Journal of Politics 7, no. 1 (2005): 26-48. Hoekstra, Valerie. "Increasing the Gender Diversity of High Courts: A Comparative View." Politics \& Gender 6, no. 3 (2010): 474-82.
} 
office. Typically, each party is free to make its own rules, with few national laws dictating how a party will choose its candidates. ${ }^{410}$ Parties decide not only who will run, but the candidate's chances of winning depending on whether they are selected to represent a safe seat in a majoritarian race or a safe slot on a proportional representation list. ${ }^{411}$ Rahat refers to this as the "selectorate" - the individuals or members that decide who gets to run for office. ${ }^{412}$ He likens it to a restaurant menu where, as the customer (or voter), you are allowed to select what you would like to eat (or who to vote for), but your choice is already constrained by what the chef (selectorate) has decided to offer. Because few rules guide the selection, the process may range from a single individual hand-picking his successor to an open primary where any eligible voter has a say in determining the candidate. Both of these extremes are rare, with most countries falling somewhere in the middle of the continuum. ${ }^{413}$ This would include selectorates such as a central or nominating committee, party agency, use of appointed delegates, or a convention. Despite differences in selectorate composition, party leadership still plays an important role in determining who will run and where. This includes allowing candidates access to party resources, expertise, and support. The trending rise of candidate-centered politics - away from the mass parties of the past - has increased the importance of candidate selection as well as the party leadership guiding those choices.

Within the legislative framework, party leadership and influence are instrumental in determining which issues take precedence, how they are framed for the wider public, and what actions must be taken to bring about the party's vision. When in power, leaders can encumber both parliamentary and party leadership spaces concurrently, playing an influential role in determining policy while steering the direction of government. Legislative agendas typically reflect the hierarchy of ruling party priorities, with specific pieces of legislation or themes targeted throughout the parliamentary or congressional term. While some individual members of parliament may have latitude in how they vote on any particular piece of legislation, in other systems voting against the party position can negatively impact a candidate's future funding and support. In some instances, breaking from the party ranks can result in members being removed from their seat. In the most extreme cases, particularly in less developed democracies or fragile states, voting against the party can result in threats to the member's economic interests and/or personal safety. While voting discipline may vary across parties and countries, the leadership in most political

\footnotetext{
410 Rahat, Gideon. "Candidate Selection: The Choice before the Choice." Journal of Democracy 18, no. 1 (2007): 157-170.

411 Lindberg, Staffan I. "Women's Empowerment and Democratization: The Effects of Electoral Systems, Participation, and Experience in Africa." Studies in Comparative International Development 39, no. 1 (2004): 28-53. 412 Rahat, Gideon. "Candidate Selection: The Choice before the Choice." Journal of Democracy 18, no. 1 (2007): 157-170.

413 Ibid.
} 
parties will play a significant role in crafting the organization's platform on which to run and priorities to be achieved.

The position of the political party takes on special significance with the establishment of quotas for women. Throughout the world temporary special measures have been implemented to ensure that women have greater representation. The party is typically responsible for selecting the women, providing training and resources, and determining her position on the candidate list (either high or low) and thus her viability of winning. ${ }^{414}$ This can create a dilemma for women placed into elected office by her party leaders. She often has no directly elected constituency to answer to aside from the party itself. In these instances, incentives to maintain the party line may be especially compelling.

Given the variable roles that party leadership can play as gatekeepers, candidate selection, and in crafting policy priorities, these positions are considered high-level decision-makers. That is not to say that power vested in the party leader does not vary. Throughout Africa, for example, we see instances where the leader is the embodiment of the party; the party and personality are inextricably linked. Yet, even in countries where the head of the party maintains a lower-profile away from the political limelight, one could argue that they still wield influence. In looking to the U.S., where party leaders do not compete as candidates for elected office and maintain a lower public profile, the chairperson plays an influential role in developing the party platform, raising funds, and developing election strategies. The recent chairman of the U.S. Republican Party Reince Priebus was, for example, selected in 2016 by President Trump as his first Chief of Staff upon entering the White House, echoing the influential link between party leadership and political influence. ${ }^{415}$

To ensure greater data accuracy and coherence across all political systems, only those political parties with representation in the lower house of the national legislature were included. As many countries do not have a bi-cameral system, collection at the lower-house level was deemed more consistent rather than attempting to aggregate the composition of upper and lower chambers for some countries and not others. Limiting the leadership measure to only those parties with national-level presence was done to weed out smaller parties that have minimal representation in the general population. That is not to state that parties outside of parliament have no influence

\footnotetext{
414 Paxton, Pamela, and Melanie M. Hughes. Women, Politics, and Power. Pine Forge Press, 2007.

415 The formal governing body of the Republican Party is the Republican National Committee, headed by a chairperson. Reince Priebus' official title was Chairman of the Republican National Committee. The other major U.S. party is, likewise, governed by the Democratic National Committee and led by a chairperson.
} 
on the political environment. However, their ability to craft, vote, and pass laws and policies is constrained in the political sphere without formal representation or seats.

$\checkmark$ Data on women's share of political party leadership across countries is currently not available.

\section{$\checkmark$ Indicator: The percentage of women occupying the top leadership position of a party with representation in the lower legislative house.}

Tier 2 - Committee Chairs: The chairmen and chairwomen leading permanent parliamentary committees have been selected as the position represented at the second level of the legislative domain. Parliamentary committees appear on all continents and, in most countries, serve as the organizing structure responsible for legislation and government oversight. ${ }^{416}$ Whether legislation is introduced by the executive, party leadership, individual member, or other, it is typically referred to an appropriate committee for review. During the review process laws may be changed. It is here that recommendations are made and bargains struck. Some laws may never make it out of committee. Woodrow Wilson, the $28^{\text {th }}$ President of the United States, once said, "... it is not far from the truth to say that Congress in session is Congress on public exhibition, whilst Congress in its committee rooms is Congress at work." ${ }^{\prime 17}$ As issues become increasingly complex, committees are being viewed as venues for addressing political conflict and achieving policy resolution. ${ }^{418}$

Along with influencing the legislative review process, including how legislation is shaped, the committee chairperson is typically recognized as having enhanced status and access to more resources. ${ }^{419}$ That is not to imply that all committees, and therefore their chairs, wield the same amount of decision-making authority. The Scandinavian countries and the United States, at one end of the spectrum, are vested with significant power to negotiate and change the bills on which the full assembly will later vote. However, even in party-dominated legislatures such as Britain's House of Commons, there has been a more recent expansion of its system of select committees. ${ }^{420}$

\footnotetext{
416 Mattson, Ingvar, and Kaare Strøm. "Parliamentary Committees." Parliaments and Majority Rule in Western Europe, 249-307, 1995.

417 Woodrow Wilson, Congressional Government, 1885, quoted in the Joint Committee on the Organization of Congress Final Report.

418 Longley, Lawrence D., and Roger H. Davidson. "Parliamentary Committees: Changing Perspectives on Changing Institutions," The Journal of Legislative Studies 4, no. 1 (1998): 1-20.

419 Kathlene, Lyn. "Position Power versus Gender Power: Who Holds the Floor?" Gender Power, Leadership, and Governance, 1995, 167-94.

420 Hague, Rod, and Martin Harrop. Political Science: A Comparative Introduction. Sixth Edition. St. Martin's Press, 2010.
} 
Committees can also play an important role in bi-cameral systems of government, where differing versions of proposed legislation will be reconciled through a committee system. While not all committee systems wield the same clout as those in Sweden's Riksdag or the U.S. Congress, the global trend has been a growth in the centrality of committees to legislative work and an increase in committee numbers and significance. ${ }^{421}$ In newer democracies this has included experimentation with more elaborate committee structures; in legislatures with highly developed committee systems there has been a move to increase their variety and flexibility. ${ }^{422}$

To ensure data coherence across all political systems, only standing or permanent committees, rather than temporary or ad hoc committees, were considered. Again, the lower house was prioritized across countries given that many systems lack an upper legislative chamber.

$\checkmark$ Data on women's share of committee leadership positions across countries is currently not available.

\section{$\checkmark$ Indicator: The percentage of women holding permanent committee head positions.}

Tier 3 - Members of the Legislature: For the third tier in the legislative domain, the position of parliamentary member in the lower house was selected. The intent of this measure was to capture women's access to senior elected positions at the subnational level. Recent efforts to consistently collect comparable data at this level of government, however, continue to highlight the difficulties of such an exercise. For example, the No Ceilings Report, one of the most ambitious data collection efforts recently undertaken on the status of women, attempts to gather the percentage of "women's representation on the local/municipal councils." Using data from the European Commission, the UN Economic Commission for Women, and the UN Economic Commission for Latin America and the Caribbean, the report notes that definitions vary by source with some capturing women members of municipal councils, some measuring women elected to city councils, while others record members of local area governing bodies. ${ }^{423}$ The number of countries collecting and reporting this data on a regular basis is also insufficient for use as a global indicator. ${ }^{424}$ Given that many countries are not currently collecting this data in any

\footnotetext{
${ }^{421}$ Longley, Lawrence D., and Roger H. Davidson. "Parliamentary Committees: Changing Perspectives on Changing Institutions." The Journal of Legislative Studies 4, no. 1 (1998): 1-20.

422 Ibid.

423 Clinton Foundation, Gates Foundation, The Economist Intelligence Unit, World Policy Analysis Center, Maternal and Child Health Equity Research Program. “No Ceilings: The Full Participation Report," 2015.

${ }^{424}$ The No Ceilings Report was able to gather some form of this data from a total of 61 countries over a 17-year period. Approximately half of the 61 countries were able to report consistently throughout the timeframe. The
} 
consistent way, and the ongoing lack of definitional consistency, I determined that the ability to find this information in a comparable, timely, and cost-effective manner was not possible on a global scale. With no ability to use locally elected positions as a Tier 3 indicator - either at the state, regional, district, or municipal levels - I turned to individual legislators as a viable option. A fundamental function of a legislator is to represent the views and opinions of their constituency. In instances where legislators have a defined geographic constituency, they may spend a significant amount of time at the sub-national level in their area of representation.

Women's representation in parliament becomes extremely important in systems drawing cabinet positions from that body; the lack of experienced women parliamentarians limits the selection pool of potential women cabinet members. Likewise, long-term and robust representation as an individual legislator may be a requirement for parliamentarians to advance to positions as committee chairs and ultimately party leaders.

To ensure greater data consistency across all political systems, only parliamentarians in the lower house were counted in bi-cameral systems.

$\checkmark$ This indicator is reported annually by the Inter-Parliamentary Union. ${ }^{425}$

\section{$\checkmark$ Indicator: The percentage of women in the lower or single house of the national legislature.}

\subsubsection{Judicial Branch}

Tier 1 - Judges Highest-Level Court: Whether based on a common law or civil law tradition, the judiciary plays a valuable role in interpreting and enforcing laws. ${ }^{426}$ In many countries the judicial branch can also act as an effective check against the misuse of executive and legislative powers. Increasingly since 1945 there has been a global tendency away from judicial restraint and towards greater judicial activism. ${ }^{427}$ This is due, in part, to the increasing proliferation of international conventions that allow judges more latitude to step outside their domestic constraints. With the wide acceptance of principles outlined in such documents as the UN Universal

\footnotetext{
African Gender and Development Index has collected this information once for 30 countries using local expertise. The Gender Equality Index is able to collect this data from EU member states.

425 Inter-Parliamentary Union. "Parliaments at a Glance," 2017.

426 Borrelli, MaryAnne, and Janet M. Martin. The Other Elites: Women, Politics, and Power in the Executive Branch. Boulder, Colorado: Lynne Rienner Publishers, 1997.

427 Hague, Rod, and Martin Harrop. Political Science: A Comparative Introduction. Sixth Edition. St. Martin's Press, 2010.
} 
Declaration of Human Rights ${ }^{428}$ and the Convention for the Elimination of All Forms of Discrimination against Women, ${ }^{429}$ judges and aggrieved parties can turn to regional or supra-national bodies and frameworks to build legal decisions. The past decades have also seen the stature of judges rise in relation to members of parliament and executive branch ministers. ${ }^{430}$ When courts are seen as fair arbitrators, there is increased confidence in using the judicial system as a way to address political issues. The process becomes reinforcing as, for example, interest groups, citizens, and political parties, vest increased faith in the courts and, therefore, more readily turn towards them as a way to resolve struggles. ${ }^{431}$

This global expansion of judicial powers - what Tate and Vallinder refer to as the "judicialization of politics" 432 - reinforces the importance of understanding who is representing citizens and, increasingly, helping to determine policy direction. The select group of Tier 1 judges constitutes the country's ultimate repository of legal authority; the court where they sit is considered the most prestigious as its decisions and influence are felt throughout the country. ${ }^{433}$

In attempting to differentiate three tiers within the judiciary across all countries the issue of data comparability emerges, especially at the Tier 3 level. Judicial systems vary by structure, mandate, authority, and geographic coverage. The Tier 1 category in the judiciary is more consistent in what it captures, specifically the percentage of women sitting on the highest-ranking court in the country. While often identified as the constitutional court, in other instances this may be a supreme court. A more recent phenomenon has been the creation of a special constitutional court that stands apart from the ordinary judicial system. ${ }^{434}$ Between 1978 and 2005 the number of countries with constitutional provisions for such a court increased from $26 \%$ to $44 \% .{ }^{435}$ In instances where both supreme courts and constitutional courts were present, the constitutional court was considered superior unless specific information was provided detailing otherwise.

\footnotetext{
428 United Nations General Assembly. "Universal Declaration of Human Rights, Resolution 217 A (III)." United Nations, December 10, 1948.

${ }^{429}$ United Nations General Assembly. "Convention on the Elimination of All Forms of Discrimination Against Women." United Nations, Treaty Series, vol. 1249, December 18, 1979.

430 Tate, C. Neal, and Torbjorn Vallinder. The Global Expansion of Judicial Power. NYU Press, 1995.

431 Sweet, Alec Stone. Governing with Judges: Constitutional Politics in Europe. Oxford University Press, 2000.

432 Tate, C. Neal, and Torbjorn Vallinder. The Global Expansion of Judicial Power. NYU Press, 1995.

433 Williams, Margaret S., and Frank C. Thames. "Women's Representation on High Courts in Advanced Industrialized Countries." Politics \& Gender 4, no. 3 (2008): 451-71.

434 Hague, Rod, and Martin Harrop. Political Science: A Comparative Introduction. Sixth Edition. St. Martin's Press, 2010

435 Horowitz, Donald L. “Constitutional Courts: A Primer for Decision Makers.” Journal of Democracy 17, no. 4 (2006): 125-137.
} 
$\checkmark$ The World Bank maintains a database of constitutional judges. ${ }^{436}$ Gaps occur, however, as data is not available for all countries or for courts not identified as "constitutional." When possible, the World Bank database is used.

$\checkmark$ Indicator: The percentage of women judges seated on the highest-level court.

Tier 2 - Judges Second-Level Court(s): Names and mandates of this court will vary, but this judicial level sits directly below the highest court in the country. Judges from this court, or at times multiple courts, are selected as Tier 2 representatives. For countries maintaining a constitutional court, this court is often labeled as supreme, high, or appellate. While no definitive statements can be made about what this court can or can not do, it typically does not have constitutional review and more often serves as a court of appeal. In some instances, this level of court may have a bifurcation of duties. For example, different branches to deal with criminal, civil, and administrative cases. If the courts are considered of equal stature then judges from each branch are included. Most courts at this level are present at the national level only.

$\checkmark$ Data on women's share of judicial seats allocated at the second-level of the court system across countries is currently not available.

\section{$\checkmark$ Indicator: The percentage of women judges seated on the second-level court(s).}

Tier 3 - Judges Third-Level Courts: Judges from the third-highest level of the judicial system were selected for this judicial measurement. Differences among courts at this classification of the judiciary begin to emerge and quality data concerns around the comparability of information are raised. This third tier is an effort to measure the presence of women judges directly below the national level although, again, variations are rife. Depending on the size of the country and structure of the judicial system, this may be a state, regional, or district court. It often has appellate authority over lower courts with original jurisdiction or courts of first instance. In some countries the numbers of judges at this level may be quite limited. In others, especially countries reaching down into district-level courtrooms, there may be hundreds of magistrates across its collective benches. While authorities and numbers of judges at this level vary across the globe, the consistency of this measure is its focus on the third tier of courts within the country's overall judicial system.

436 World Bank. “Women, Business and the Law," 2015. 
$\checkmark$ Data on women's share of judicial seats allocated at the third-level of the court system across countries is currently not available.

\section{$\checkmark$ Indicator: The percentage of women judges seated on third-level courts.}

\subsubsection{Security}

Tier 1 - Security Officers Top Level: The security sector has been slow to embrace women, despite the passage in 2000 of UN Resolution 1325, which called for the greater inclusion of women in all aspects of peace and security. ${ }^{437}$ Due to the hierarchical nature of this sector, command lines are clear and authority derives from above. It becomes imperative, therefore, to understand who has decisionmaking authority and to what extent other voices are being reflected as priorities are set and orders issued.

How and where to measure women's presence in the security sector is not straightforward. The range of agencies and institutions charged with a country's internal and external security is wide and open to interpretation. Along with the military and police institutions that immediately come to mind when cataloguing security actors, other players could include the intelligence services, parliamentary committees, and ministries in the executive branch. Expert organizations, for example the Geneva Centre for the Democratic Control of Armed Forces, also works with non-state actors such as civil society and the media given their oversight role in ensuring security governance. ${ }^{438}$

Attempts to detail the differing levels of female leadership across such a wide array of agents is difficult and complicated. For example, including parliamentary members within the security sector - even while acknowledging their oversight and funding role - would entail double counting in the Diamond Index. Legislators or members of parliament are currently included under the legislative domain, Tier 3. Information surrounding intelligence service personnel is unlikely to be found in the public domain, or willingly shared, given the inclination of these agencies to avoid public scrutiny. Drawing a clear distinction between the day-to-day work of civil society and their oversight role of the security sector would be difficult, especially for the media. What constitutes investigative or news reporting, vis-à-vis attempts at defining this work as an oversight function, seems a difficult distinction to make with any consistency.

\footnotetext{
437 United Nations Security Council. Resolution 1325 (2000), 2000.

438 The security sector government and non-governmental actors with whom the Geneva Center engages, and the approaches used, are detailed on its website: www.DCAF.ch
} 
Given this initial range of hurdles that negatively impact quality data considerations, I narrowed the focus to identifying leading decision-makers in the military. The immediate problem was the inconsistency among countries in they types of forces they maintain. A significant number of countries have neither a navy nor an air force. To ensure comparability, emphasis shifted to the army only, which the overwhelming majority of countries in the world maintain.

Within the military, the difficulty in defining an "officer" became apparent given its different definitional use across militaries. Women often hold non-commissioned positions, typically in the fields of health, logistics, or administrative services. In some countries, non-commissioned officers include enlisted military personnel who rise to leadership ranks. In other countries the ability to move into an officer position from a support position is difficult or impossible. In Mexico, for example, "The command corps includes officers who have been educated at military academies from the beginning of their careers, as opposed to those who develop a career in the civilian sphere and are then incorporated into the military." 439 This blurring of military categories is perhaps less of an issue at the top echelons where leaders are commissioned officers. The ability to differentiate between a commissioned and non-commissioned army officer, however, becomes more salient in the middle and bottom third of the command structure. Given data limitations in this field, it was impossible to segregate officers by male/female and then again by commissioned/ non-commissioned.

At this point, many quality data issues emerge around the use of an indicator incorporating army officers. Foremost was the issue of comparability: the ability to measure the same concept across all countries. While the difference between commissioned and non-commissioned officers might be palatable, the extent and means by which women (and men) are able to gain differing levels of officer positions varied significantly. Accuracy was also a concern. The security sector data, more than the other domains, inherently relies on the government to produce some level of information for public consumption. Given more restrictive attitudes typically found concerning public information on military work and operations, there was concern that governments may not be in a position, or willing, to share accurate data to the level needed. This included the quality data need for granularity, differentiating male and female officers across all levels.

439 "A Comparative Atlas of Defence in Latin America and Caribbean." Latin American Network of Security and Defence, 2014. http://www.resdal.org/ing/assets/resdal-2014_complete2.pdf. 
Given these concerns, ${ }^{440}$ I then examined including police as an appropriate measure. Selecting those with decision-making authority in the police, however, was not without challenges. The different types and levels of police enforcement vary considerably by country. Policing by community, city, district, state, region, tribal area, etc., are all different stratifications that may (or may not) be used. Again with an eye to quality data - with concerns surrounding data comparability and accessibility - I determined that a focus on decision-making leadership within the national police force was the most equitable measure across countries and the most realistic level of information that might be gathered.

In looking specifically at the national police, the next challenge was to delineate equitable ranks among these organizations for cross-country comparisons. The difficulty in this regard is the variety in the number and types of officers. Each police force has its own hierarchical system of command. While a number of positions are similar - commander, inspector, sergeant - the range of listed officer positions between these categories varies considerably. In attempting to ensure comparability to the greatest extent, all police officer ranks were collected from high to low and then divided into three tiers. The top one-third of these command structures are considered Tier 1 positions.

$\checkmark$ Data on women's share of police officer positions is currently not available. To ensure greater data consistency across all political systems only positions from the national police force were included.

\section{$\checkmark$ Indicator: The percentage of women occupying the top one-third of police officer ranks.}

Tier 2 -Security Officers Middle Level: There are no globally comparative statistics on women's share of leadership positions in the police forces. ${ }^{441}$ When estimates of women's presence are given, they typically represent an overall percentage of women in the organization. For example, the UN estimates that women comprise approximately $9 \%$ of police globally. ${ }^{42}$ This statistic is based on individual country estimates of the overall number of women in their respective policing organizations. In most instances, there is no differentiation for the rank or role of those women. Although command structures vary to a large degree, this tier is typically three to four officer positions and will likely include positions varying across the ranks of

\footnotetext{
440 A detailed description surrounding the process and challenges of data collection in the security sector can be found in Chapter 5 - Gathering Data for the Diamond Index.

441 Hughes, Melanie M. “Women's Leadership As A Route To Greater Empowerment: Report on the Diamond Leadership Model." Washington DC: USAID, December 2014.

442 Turquet, Laura. "Progress of the World's Women: In Pursuit of Justice." (2011).
} 
superintendent and inspector. While Tier 1 positions total a relatively small number of individuals, Tier 2 positions more typically include hundreds of officers. In larger countries, this level may reach into the thousands.

$\checkmark$ Data on women's share of police officer positions is currently not available. To ensure greater data consistency across all political systems only positions from the national police force were included.

\section{$\checkmark$ Indicator: The percentage of women occupying the middle one-third of police officer ranks.}

Tier 3 -Security Officers Lower Level: This includes the bottom one-third of all officer ranks for the police. While these officers may not be dictating high-level policy, they are closest to the rank-and-file and instrumental in setting the tone and culture in which employees operate. Officers at this level may be charged with the training of new-entry and lower-level officers. In many countries these positions are likely to be deployed to the sub-national level. Throughout Africa, for example, smaller district and provincial police stations will be staffed by officers at this level. Even in smaller countries, the number of positions in Tier 3 will likely include several thousand officers. Lower-level inspector, sergeant, and corporal are ranks typically found within the corps at Tier 3 .

$\checkmark$ Data on women's share of police officer positions is currently not available. To ensure greater data consistency across all political systems only positions from the national police force were included.

\section{$\checkmark$ Indicator: The percentage of women occupying the bottom one-third of police officer ranks.}

In combining all four domains, each containing three tiers, the final Diamond Index contains 12 decision-making positions in total. I deemed this number sufficient to meet the first principle of the index framework: a limited number of indicators, yet able to cover a variety of formal government dimensions. While there is interest in casting a wider net to better capture the percentage of women's representation holistically across the political sphere, the Diamond Index is equally focused on tracking women's access to key leadership positions imbued with decision-making authority. Moving below the Tier 3 level would likely result in higher percentages of women and also less-influential positions. The decision to stop at Tier 3 was made 
to best maintain the focus on greater breadth and depth of measurement, while still maintaining a focus on important positions. Moving below the Tier 3 level also begins to raise serious quality data concerns in terms of information completeness, accuracy, cost-effectiveness, and granularity. In the future, as more information on women's political leadership becomes publically available, it may be possible to collect this information while at the same time ensuring quality data principles. Table 13 details the final 12 positions selected for the Diamond Index.

TABLE 13: Diamond Index - 12 Selected Positions

\begin{tabular}{|c|c|c|c|}
\hline SECTOR & TIER 1 & TIER 2 & TIER 3 \\
\hline EXECUTIVE & Ministers & Senior Executives & Mayors 10 Largest Cities \\
\hline LEGISLATIVE & Political Party Leaders & Committee Chairpersons & Legislative Members \\
\hline JUDICIAL & $\begin{array}{l}\text { Judges } \\
\text { Highest Court }\end{array}$ & $\begin{array}{l}\text { Judges } \\
\text { Second-Level Court(s) }\end{array}$ & $\begin{array}{l}\text { Judges } \\
\text { Third-Level Court(s) }\end{array}$ \\
\hline SECURITY & $\begin{array}{l}\text { Security Officers } \\
\text { Top Level }\end{array}$ & $\begin{array}{l}\text { Security Officers } \\
\text { Middle Level }\end{array}$ & $\begin{array}{l}\text { Security Officers } \\
\text { Lower Level }\end{array}$ \\
\hline
\end{tabular}

\subsection{CONSTRUCTION OF THE DIAMOND INDEX}

\subsubsection{Step 1: Calculation and Weighting}

The purpose behind the design and construction of the Diamond Index is to allow any interested stakeholder the opportunity to easily discern women's presence in key decision-making positions across government, including how each particular part of government fares in relation to the other dimensions. From a horizontal perspective, all four domains of the Diamond Index - executive, legislative, judicial, security are accorded the same value. Conceptually, authority is distributed equally among the four domains. In practicality, this inter-relation among branches will vary not only by country, but also over time. As the country context changes, so also will the formal rules and inter-governmental relationships. While the Diamond Index is unable to measure the relative strengths and weaknesses vis-à-vis one domain to another, great care was taken in considering which decision-making positions to include in order to offer the most equitable balance among the four areas. 
From a vertical perspective, the Diamond Index makes a clear distinction between all three tiers. Other gender composite indicators do not differentiate between positions; all are assigned the same value. ${ }^{43}$ Yet evidence indicates that the more powerful the leadership position, the harder it becomes for women to gain access. ${ }^{44}$ Not all positions are the same, nor should they be weighted equally.

Across all four sub-components the Tier 1 positions are valued at three times the weight of Tier 3 positions. Tier 2 positions are valued at two times that of Tier 3 . Tier 3 positions are not weighted, and the straight percentage of women is used at this level. This formula is followed consistently across the executive, legislative, judicial, and security. The rationale being that increasingly powerful positions exist in each of these sub-components.

Once a percentage is arrived at for each of the three tiers, the scores are added together and then divided by 6 , achieving a single weighted score for each domain. The following formula is used to weight each position:

Executive $=\underline{(3 \times \% \text { ministers })+(2 \times \% \text { senior executives }+(1 \times \% \text { mayors top } 10 \text { cities })}$ 6

Legislative $=\frac{(3 \times \% \text { party leaders })+(2 \times \% \text { committee chairs })+(1 \times \% \text { legislators })}{6}$

$J u d i c i a l=\underline{(3 \times \% \text { top-level judges })+(2 \times \% \text { second-level judges })+(1 \times \% \text { third-level judges })}$ 6

Security $=\underline{(3 \times \% \text { top-level officers })+(2 \times \% \text { mid-level officers })+(1 \times \% \text { low-level officers })}$ 6

It is worth reiterating that the number arrived at for each domain is no longer a percentage of women, but a weighted score derived from the percentages of women in Tier 1, Tier 2, and Tier 3. This can be confusing as it varies from other gender composite indexes that maintain the percentage of women as the final score because all positions are weighted equally. So, for example, the second phase of the African Gender and Development Index developed by the UN included a breakdown of the number of women and men in various courts defined as "higher, lower, and

\footnotetext{
443 Nardo, Michela, et al. Handbook on constructing composite indicators: methodology and user guide. No. 2005/3. OECD publishing, 2005.

444 Williams, Margaret S., and Frank C. Thames. "Women's Representation on High Courts in Advanced Industrialized Countries." Politics \& Gender 4, no. 03 (2008): 451-71.
} 
traditional/ religious courts." 445 In the final aggregation, however, no differentiation is made between the different levels of judge, so a high court judge is given the same weight as a lower court judge. ${ }^{446}$ In the case of the Diamond Index, clear distinctions are made between different positions, and thus the need for a weighting process that does not conflate all positions as equal. Table 14 shows an illustrative Country Scorecard demonstrating the Diamond Index weighting and calculation process.

\section{TABLE 14: Step 1 - Example of Diamond Index Weighting Process}

\begin{tabular}{l|l|l}
\multicolumn{2}{l}{ Executive weighted score $=$} & \\
\hline TIER 1 & Ministers & $30.0 \%$ women \\
\hline TIER 2 & Senior Executives & $29.0 \%$ women \\
\hline TIER 3 & Mayors of 10 largest cities & $0.0 \%$ women \\
\hline
\end{tabular}

TOTAL: $(3 \times 30.0)+(2 \times 29.0)+(1 \times 0.0) \div 6=24.6$

Legislative weighted score $=$

\begin{tabular}{l|l|l} 
TIER 1 & Political Party Leaders & $0.0 \%$ women \\
\hline TIER 2 & Committee Chairs & $43.0 \%$ women \\
\hline TIER 3 & Legislators & $20.0 \%$ women
\end{tabular}

TOTAL: $(3 \times 0.0)+(2 \times 43.0)+(1 \times 20.0) \div 6=17.6$

Judiciary weighted score $=$

\begin{tabular}{l|l|l} 
TIER 1 & Constitutional Court & $22.2 \%$ women \\
\hline TIER 2 & Supreme Court & $23.5 \%$ women \\
\hline TIER 3 & Appellate Court & $27.1 \%$ women \\
\hline
\end{tabular}

TOTAL: $(3 \times 22.2)+(2 \times 23.5)+(1 \times 27.1) \div 6=23.5$

\section{Security weighted score $=$}

\begin{tabular}{l|l|l} 
TIER 1 & Top-level officers & $7.0 \%$ women \\
\hline TIER 2 & Mid-level officers & $11.0 \%$ women \\
\hline TIER 3 & Lower-level officers & $6.0 \%$ women \\
\hline
\end{tabular}

TOTAL: $(3 \times 7.0)+(2 \times 11.0)+(1 \times 6.0) \div 6=8.1$

445 During the Phase 1 pilot only Higher Court judges were included. The addition of other court levels was included for Phase II. No explanation is given for the change, so whether it was due to a greater availability of data than anticipated, or for other reasons not articulated, it remains unknown.

446 United Nations Economic Commission for Africa. "The African Gender and Development Index," 2011. 
The Diamond Index emulates the African Gender and Development Index by ignoring population-weighed harmonic means as a basis for computation in an effort to "democratize and simplify statistics." ${ }^{447}$ One might argue that in measuring levels of education or health statistics it is important to account for differences in the overall percentage of men and women in the population. This also becomes important in those indexes using the ratio of achievement rates, such as the Global Gender Gap Index. The index attempts to better understand the proportion of women who have reached a specific achievement in relation to males who have reached that same achievement. ${ }^{448}$

The focus of the Diamond Index, however, varies from other gender composite indicators. First, it is focused in one specific area: the political space. Second, it is a very deliberate attempt to track key positions that are associated with greater access to decision-making authority. These positions are set in the legal framework of each individual country, and not subject to change based on variations in male to female population ratios. The Diamond Index focuses less on the population as a whole and more on equality of representation among political elites. For this reason a straight percentage (percentage of women occupying decision-making positions) was identified as most appropriate - both in terms of its simplicity and accuracy for calculating Diamond Index scores prior to weighting.

The weighting method devised, no matter how straightforward, still remains an individual value judgement. ${ }^{49}$ One might try to argue that the authority of the mayor from a capital city (Tier 3 - Executive) outstrips that of an appellate court judge (Tier 3 - Judiciary). Or, that the authority of a Supreme Court judge (Tier 1 - Judiciary) is superior to that held by a Minister of Gender (Tier 1 - Executive). Attempting these comparisons on a global scale will always produce outliers or examples that deviate from the trend. But by distinguishing different domains of government, and then tiers within, we attempt to capture and understand, in a less biased way, women's positioning in the system as a whole.

In examining how the weighting system translates into scores, two examples are provided. In Table 15 Yemen's "Tier 3 - Judicial" score can be seen as reflecting that $2.1 \%$ of District Court judges are women. Because this tier is not weighted as heavily as Tier 1 or Tier 2, the final score is $.35-\underline{\text { not }} 2.1 \%$ if the purpose were to measure straight percentages of women in the judiciary. Again, the score of .35

\footnotetext{
447 United Nations Economic Commission for Africa. "The African Gender and Development Index," 2011.

448 World Economic Forum. “Global Gender Gap Index 2015,” 2015.

449 Nardo, M., M. Saisana, A. Saltelli, and S. Tarantola. "Tools for Composite Indicators Building. European Commission Joint Research Centre." Institute for the Protection and the Security of the Citizen, Econometrics and Statistical Support to Antifraud Unit, I-21020 Ispra (VA) Italy, Report Number: EUR 21682 (2005).
} 
is a weighted score rather than a percentage. Likewise for Rwanda in Table 16. Despite the country's admirable Tier 3 percentage of $63.8 \%$ legislators, the final score equates to 31.1 due to the more heavily weighted Tier 2 and Tier 1 scores where lower percentages of women are present.

TABLE 15: Yemen's Weighted Judicial Score

\begin{tabular}{l|l|l}
\multicolumn{2}{l}{ Judiciary weighted score $=\mathbf{0 . 3 5}$} & \\
\hline TIER 1 & Supreme Court & $0.0 \%$ women \\
\hline TIER 2 & Appeals Court & $0.0 \%$ women \\
\hline TIER 3 & District Courts & $2.1 \%$ women \\
\hline
\end{tabular}

TOTAL: $(3 \times 0.0)+(2 \times 0.0)+(1 \times 2.1) \div 6=0.35$

TABLE 16: Rwanda's Weighted Judicial Score

\begin{tabular}{l|l|l}
\multicolumn{2}{l}{ Legislative weighted } & score $=\mathbf{3 1 . 1}$ \\
\hline TIER 1 & Political Party Leaders & $14.3 \%$ women \\
\hline TIER 2 & Committee Chairs & $40.0 \%$ women \\
\hline TIER 3 & Legislators & $63.8 \%$ women
\end{tabular}

TOTAL: $(3 \times 14.3)+(2 \times 40.0)+(1 \times 63.8) \div 6=31.1$

\subsubsection{Step 2: Aggregation of the Different Indicators into One Index}

Because no distinction is made between the four different domains, with each accorded the same weight across different political systems, the domains are simply added together to achieve a final score. Were the process to end there, the overall Diamond Index could potentially have a score ranging from 0 to 400 . A score of 400 would indicate all positions are held by women while 0 would indicate women are completely absent. Within each of the four domains the scores could vary between 0 and 100. Here again, a maximum score of 100 would indicate that women hold all leadership positions in that particular domain. A score of 0 would indicate that women do not hold any of the identified decision-making positions in that domain. 
For reasons of readability, we locate the Diamond Index on a 0 to 100 scale. This is done by dividing each individual domain score by four. As a result, rather than final scores ranging between 0 to 100 for each domain, all have been rescaled by onefourth to create a range from 0 to 25 . With each of the four domains able to achieve a total of 25, the maximum score for the entire index is 100 . Table 17 presents an example of the Diamond Index Scorecard which is weighted and rescaled.

\section{TABLE 17: Step 2 - Example of Albania Diamond Index Scaled from 0 to 100}

\begin{tabular}{l|l|l}
\multicolumn{2}{l}{ Executive weighted score $=\mathbf{6 . 2}$} & \\
\hline TIER 1 & Ministers & $30 \%$ women \\
\hline TIER 2 & Senior Executives & $29 \%$ women \\
\hline TIER 3 & Mayors of 10 largest cities & $0 \%$ women \\
\hline
\end{tabular}

TOTAL: $(3 \times 30.0)+(2 \times 29.0)+(1 \times 0.0) \div 6=24.6 \div 4=6.15$

\begin{tabular}{l|l|l} 
Legislative weighted & score $=4.4$ & \\
\hline TIER 1 & Political Party Leaders & $0.0 \%$ women \\
\hline TIER 2 & Committee Chairs & $43.0 \%$ women \\
\hline TIER 3 & Legislators & $20.0 \%$ women \\
\hline
\end{tabular}

TOTAL: $(3 \times 0.0)+(2 \times 43.0)+(1 \times 20.0) \div 6=17.6 \div 4=4.40$

Judiciary weighted score $=5.9$

\begin{tabular}{l|l|l} 
TIER 1 & Constitutional Court & $22.2 \%$ women \\
\hline TIER 2 & Supreme Court & $23.5 \%$ women \\
\hline TIER 3 & Appellate Court & $27.1 \%$ women \\
\hline
\end{tabular}

TOTAL: $(3 \times 22.2)+(2 \times 23.5)+(1 \times 27.1) \div 6=23.5 \div 4=5.88$

\begin{tabular}{l|l|l}
\multicolumn{2}{l}{ Security weighted score $=\mathbf{2 . 0}$} & \\
\hline TIER 1 & Top-level officers & $7.0 \%$ women \\
\hline TIER 2 & Mid-level officers & $11.0 \%$ women \\
\hline TIER 3 & Lower-level officers & $6.0 \%$ women \\
\hline
\end{tabular}

TOTAL: $(3 \times 7.0)+(2 \times 11.0)+(1 \times 6.0) \div 6=8.1 \div 4=2.03$

Once the Diamond Index has been adjusted to the 100-point scale, aggregation follows. The maximum score of 100 (4 sectors X 25 each) would indicate that women hold all critical decision-making positions in all sectors; a score of 0 would reflect a total lack 
of women in any critical decision-making positions. Likewise, a score of 50 would indicate that some level of parity between men and women has been achieved. In our example the aggregate score would be calculated as follows:

\section{$6.15($ Executive $)+4.40($ Legislative $)+5.88($ Judiciary $)+2.03($ Security $)=18.5$}

Of course, as with any composite indicator, a score that appears to achieve parity may be camouflaging inequalities among the different domains. An exceptionally high score in one branch, the Judiciary for example, could help balance out a particularly low score in the Security. For this reason, all Diamond Index Country Scorecards clearly reflect how each sector fares according to the weighting system before the aggregation process, as can be seen in Table 18 demonstrating an example of a completed Country Scorecard.

\section{TABLE 18: Diamond Index Albania Country Scorecard Achieving a} Final Score of 18.5

\begin{tabular}{l|l|l}
\multicolumn{2}{l}{ Executive weighted score $=\mathbf{6 . 2}$} & \\
\hline TIER 1 & Ministers & $30 \%$ women \\
\hline TIER 2 & Senior Executives & $29 \%$ women \\
\hline TIER 3 & Mayors of 10 largest cities & $0 \%$ women \\
\hline
\end{tabular}

TOTAL: $(3 \times 30)+(2 \times 29)+(1 \times 0) \div 6=24.6 \div 4=6.15$

\begin{tabular}{l|l|l}
\multicolumn{2}{l|}{ Legislative weighted score $=\mathbf{4 . 4}$} & \\
\hline TIER 1 & Political Party Leaders & $0.0 \%$ women \\
\hline TIER 2 & Committee Chairs & $43.0 \%$ women \\
\hline TIER 3 & Legislators & $20.0 \%$ women \\
\hline
\end{tabular}

TOTAL: $(3 \times 0)+(2 \times 43)+(1 \times 20) \div 6=17.6 \div 4=4.40$

Judiciary weighted score $=5.9$

\begin{tabular}{l|l|l} 
TIER 1 & Constitutional Court & $22.2 \%$ women \\
\hline TIER 2 & Supreme Court & $23.5 \%$ women \\
\hline TIER 3 & Appellate Court & $27.1 \%$ women \\
\hline
\end{tabular}

TOTAL: $(3 \times 22.2)+(2 \times 23.5)+(1 \times 27.1) \div 6=23.5 \div 4=5.88$

Security weighted score $=2.0$

\begin{tabular}{l|l|l} 
TIER 1 & Top-level officers & $7.0 \%$ women
\end{tabular}




\begin{tabular}{l|l|l}
\hline TIER 2 & Mid-level officers & $11.0 \%$ women \\
\hline TIER 3 & Lower-level officers & $6.0 \%$ women \\
\hline
\end{tabular}

TOTAL: $(3 \times 7)+(2 \times 11)+(1 \times 6) \div 6=8.1 \div 4=2.03$

$6.2($ Executive $)+4.4($ Legislative $)+5.9($ Judiciary $)+2.0($ Security $)=18.5$

As we can see in Albania's example, the country's relatively high score is bolstered by representation in the judiciary and executive branches. The aggregate score is important, however, as it allows for ranking within the larger index and provides a simple benchmark for each particular country. In this respect, advocates, members of government, women's organizations, and any interested stakeholder can see at a glance both overall country achievement and specific domains where more attention is required.

\subsubsection{Step 3: Mapping Diamond Index Scores}

Given valid criticisms that composite indicators can mask weaknesses through the aggregation process, ${ }^{450}$ it was important that the Diamond Index allow for a nuanced understanding of women's political representation in one glance. This concern was also in line with quality data concerns of "accessibility," defined as an index that, in terms of its construction and presentation, is easily understandable to a lay audience. After experimenting with a variety of different options, I followed the lead of the World Economic Forum's Global Gender Gap Index. ${ }^{451}$ This index uses a spider graph to map four measurement domains: health, education, economy, politics. I use this same style to map the findings of the Diamond Index, with each dimension - executive, legislative, judicial, security - creating a different point on the diamond. The four points of the diamond graph represent the four domains of the index.

Each side of the diamond is placed on a scale ranging from 0 to 12.5 . This represents half of the 25-point total score possible. Thus, a score extending out to the end of any individual diamond point would represent approximate parity in that domain. As shown in Graph 1, a full blue diamond - which would equal a score of 50 represents complete parity in all domains.

\footnotetext{
450 Nardo, Michela, Michaela Saisana, Andrea Saltelli, Anders Hoffman, and Enrico Giovannini. "Handbook on Constructing Composite Indicators: Methodology and User Guide." OECD publishing, 2005. Saltelli, Andrea. "Composite Indicators between Analysis and Advocacy." Social Indicators Research 81, no. 1 (2007): 65-77.

451 World Economic Forum. "Global Gender Gap Index," 2017.
} 


\section{GRAPH 1: Diamond Index - Country Score of 50 Representing Parity}

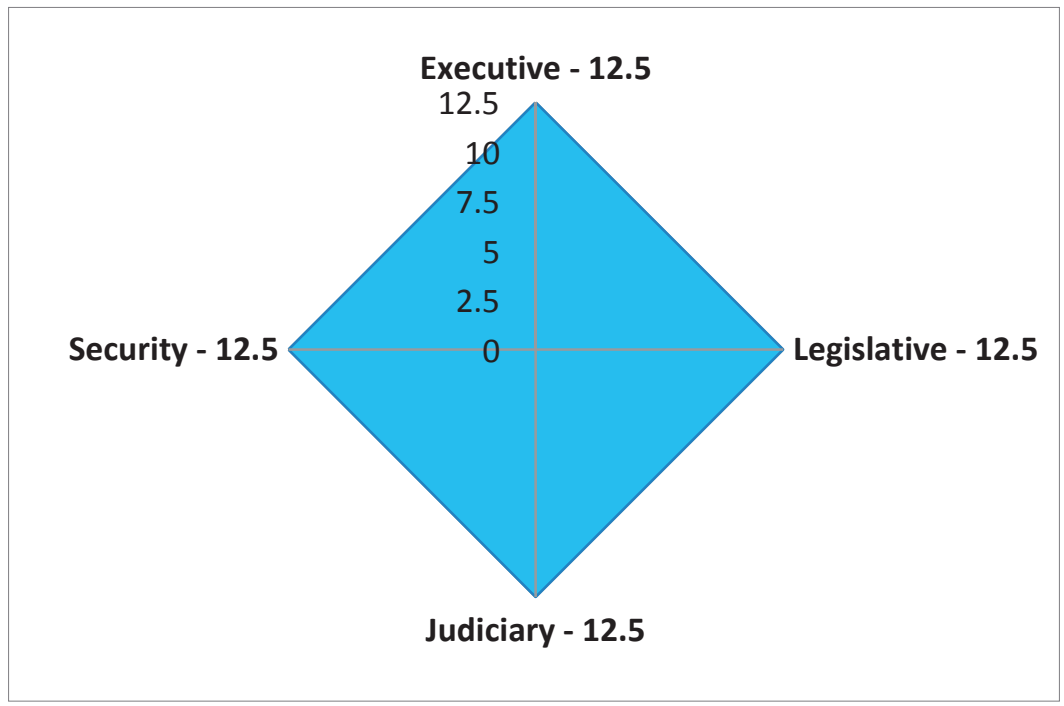

This style of presentation deconstructs the composite nature of the index into its component parts. Through the mapping exercise, weaknesses and strengths for all four domains become visually apparent and the overall country context can be readily grasped.

The Diamond Index graph stops at a representation of parity in any particular domain. A country exceeding a score of 12.5 in any domain would be captured numerically on its scorecard, although visually any area exceeding parity becomes truncated. If, for example, a country were to exceed 12.5 in the judicial domain, the Diamond Index Scorecard would reflect the score, but the full extent of the domain would not be captured by the current scale of 1 to 12.5 . For example, a score of 15.0 in the judiciary is seen in Graph 2. 
GRAPH 2: Example of Domain Exceeding Parity

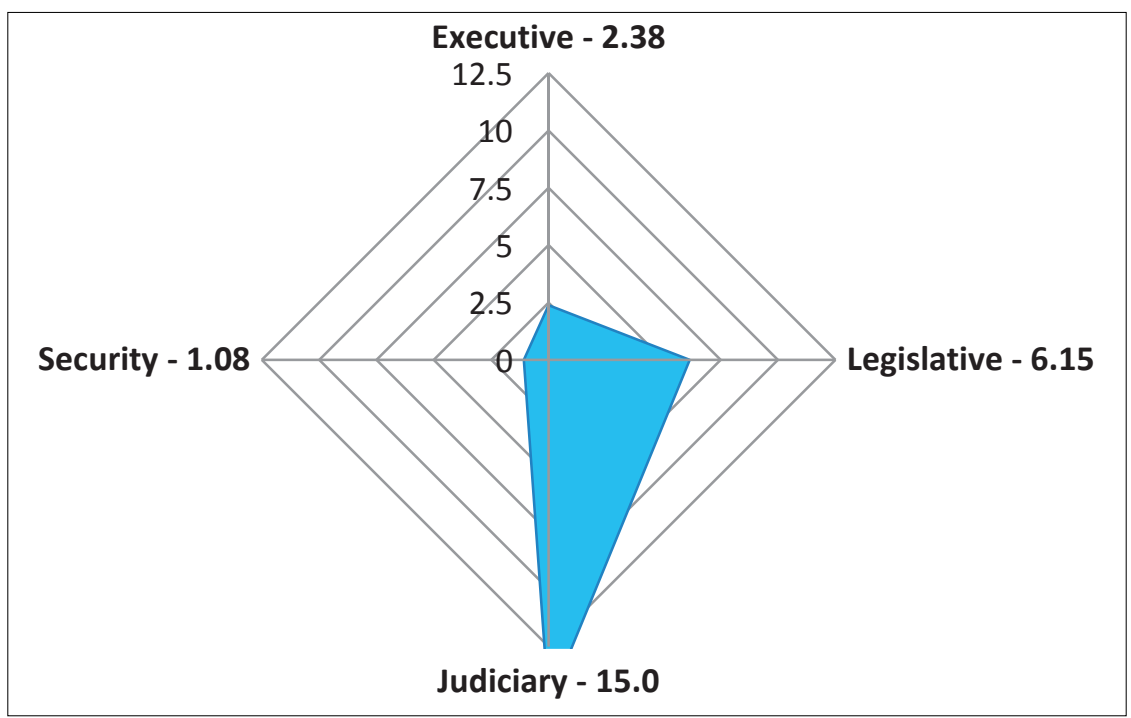

While clear that the point representing the judiciary continues past the end of the diamond, the viewer can not see its final end point. Looking at the reverse situation of parity, the total absence of women from the identified critical decision-making positions would fail to register on any part of the diamond graph, as seen in Graph 3. 
GRAPH 3: Diamond Index - Country Score of 0 Representing the Absence of Women

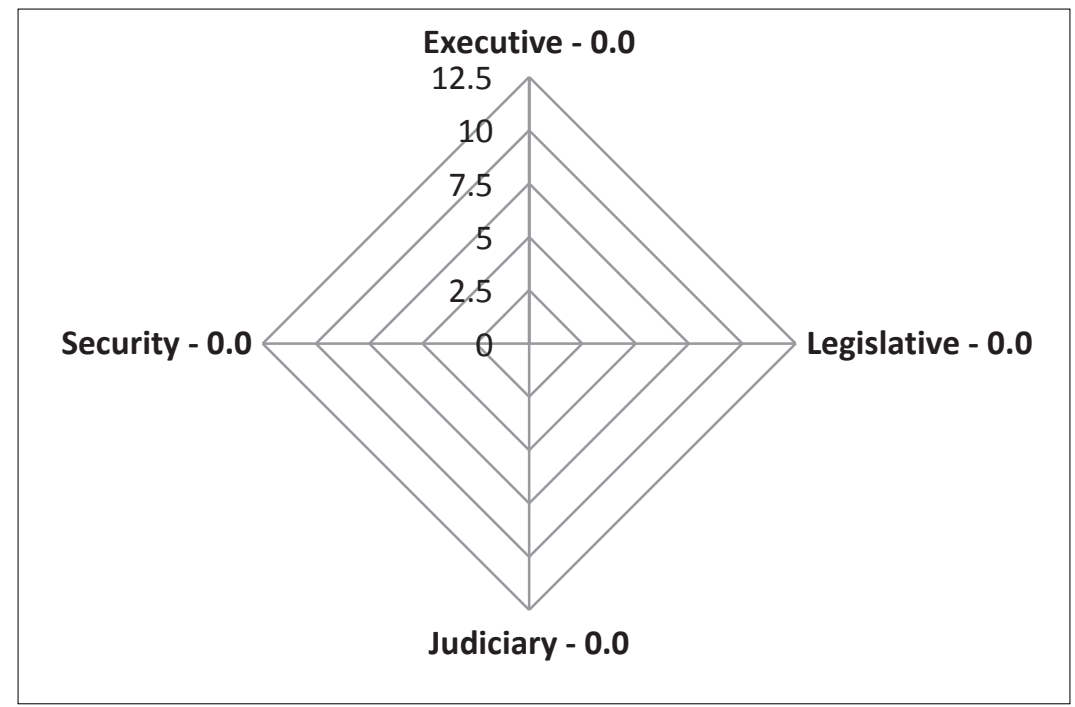

More typically, a variety of representation occurs across the four points of the diamond. If we return to our earlier example of Albania scoring a total of 18.5, the Diamond Index in Graph 4 clearly shows the additional gains made in the executive and judiciary branches, and to some extent the legislative, as opposed to the security domain that lags significantly behind the other domain scores. 
GRAPH 4: Diamond Index Albania Country Scorecard = 18.5

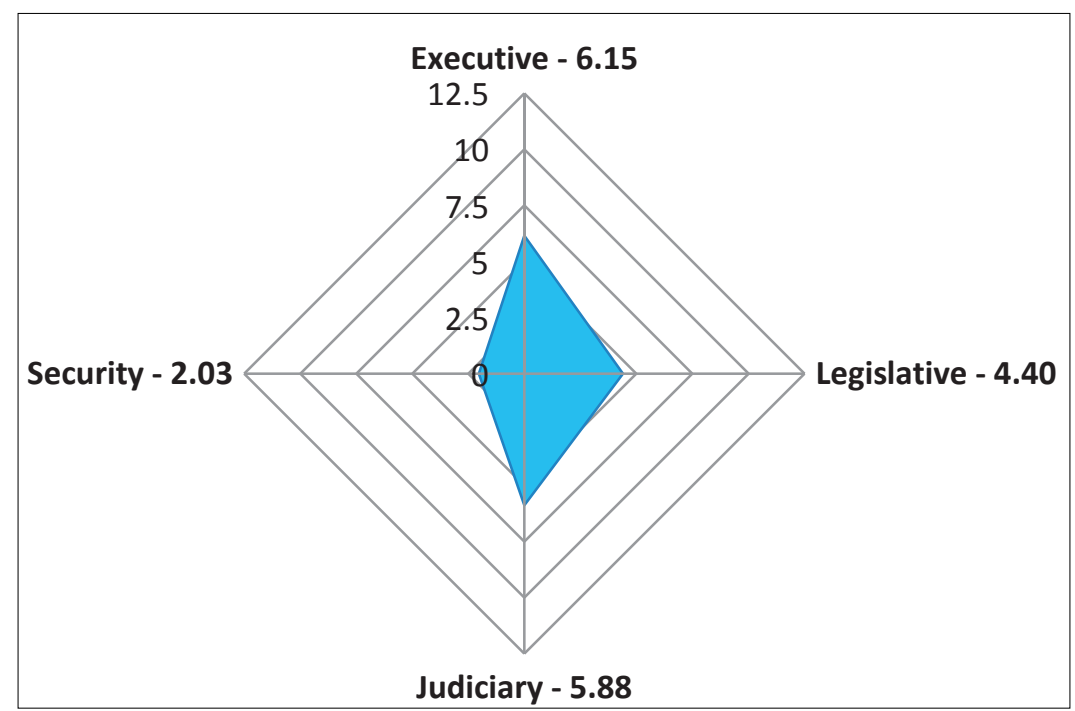

Countries might also vary quite dramatically in women's representational areas, resulting in a triangular shape when one sector dominates. In the Graph 5 example, we can see that the legislative branch outscores all other domains combined. In this country context women are over-represented in one sector in comparison to the other three domains. 


\section{GRAPH 5: Diamond Index with One Dominant Sector}

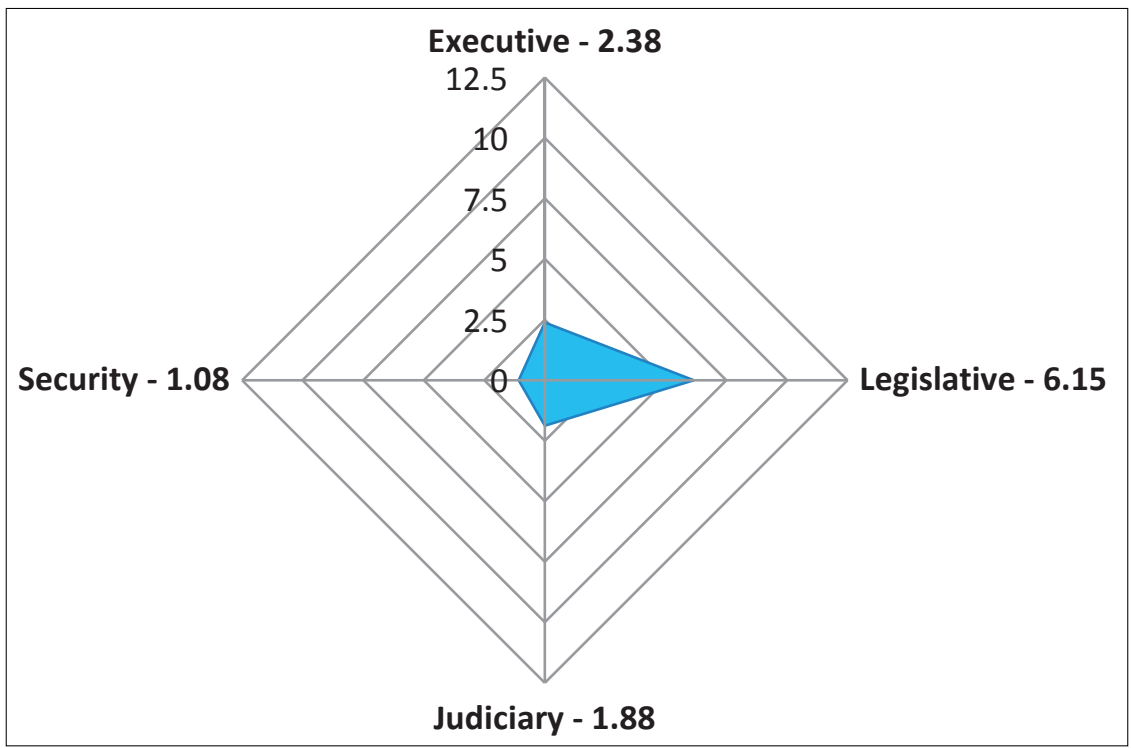

While difficult to imagine today, the future may bring us to a point where women are over-represented in the political sphere. The simplicity of the model allows for it to be "flipped" by reversing the calculations to demonstrate men's lack of political access.

Our reality today, however, brings us back to female-focused calculations of Country Scorecards and maps to accurately show where women are gaining access - both vertically and horizontally - in a transparent and clear format. For example, we can easily intuit if women are being ghettoized into one particular sector, and better understand through a vertical approach whether women are being marginalized or over-represented within the specific tiers of that sector.

\subsection{CONCEPTUAL LIMITATIONS}

Efforts to create a model that is logically coherent, drawn from public data, and simple to calculate have also given rise to a number of conceptual limitations. While each sector is designed to weight power between the different tiers, within the individual tiers themselves (Tier 1, Tier 2, or Tier 3) there is no distinction made between levels of decision-making authority. An obvious case exhibiting this lack of nuance would be among ministry positions. Evidence shows that women are often shunted towards the least powerful ministries and rarely appointed to the most 
powerful, such as economy and defense. ${ }^{452}$ In the Tier 1 ranking under the executive branch, however, the Minister of Youth and Sports is given the same weight as the Minister of Defense. In examining the role of mayors under the executive domain, one could argue that the responsibility and role of the mayor at the capital level exceeds that of a mayor in most other cities. In some countries, especially those with highly ruralized societies, the lower-ranked cities might be more akin to a large town. In the Diamond Index, however, the mayor of the most populous city, the capital city, and the $10^{\text {th }}$ largest city are given the same value.

Turning to the legislative branch, neither party leaders nor committee chairs are weighted differently: so a woman leading a political party with three seats in parliament has the same value as a party leader with 30 or 300 seats. Tier 2 committee chairs are also given equal weight, despite the recognition that some committees may be considered more influential than others depending on their subject matter and parliamentary authorities.

Conceptual problems within the judiciary are more confined to the Tier 3 level, as this is where the greatest differentiation arises. Depending on the structure of the judicial branch and court system, judges at this tier might be small in number and wield significant authority over a range of matters. In most countries a Tier 3 court is at the level of an Appellate Court with the second most popular classification being a High Court. In some countries (for example, Haiti, Benin, and Nepal) this tier resides at the district level. There may be dozens, or even hundreds, of district judges appointed. Again, whether there are 300 or 30 judges appointed to the bench at the Tier 3 level, all are given equal value.

While police forces will vary across countries in terms of status and authorities, their individual command structures appear analogous to one another. A police inspector in Brazil, for example, appears at a similar level as a police inspector in South Africa. While some countries will vary in the number of ranks they include in their chain of command, when analyzed across countries the leadership structures are consistently comparable. The Diamond Index gathers the entire command structure then divides it into thirds; it does not attempt a side-by-side comparison of officer ranks. So if the entire number of officer rankings is 21 in Brazil but 24 in South Africa, Brazil will include seven officer rankings for each third while South Africa will include eight. Looking at the command structure as a whole, rather than comparing them rank-byrank, helps obviate individual country differences.

\footnotetext{
452 Krook, Mona Lena, and Diana O'Brien. “All the President's Men? The Appointment of Female Cabinet Ministers Worldwide." Presented at the Midwest Political Science Association National Conference, Chicago, IL, 2011. InterParliamentary Union. "Women in Politics," 2015.
} 
Along with limitations in each sector, it must be acknowledged that each sector itself will vary in relation and power to others in the model. Although the Diamond Index gives each sector equal weight, illiberal democracies will likely see a legislative and judicial branch more subservient to the executive. In liberal democracies, these same branches may play a stronger oversight role, significantly limiting executive power. Likewise, the police may be firmly under civilian control in the majority of countries while in weaker democracies security may constitute a separate sphere of influence acting as a positive or negative force against other branches. Despite these limitations, the Diamond Index does provide a more holistic view of women's decision-making representation across the political spectrum than current indexes and data have been able to provide.

\subsection{CONCLUSION}

In this chapter I have described how the Diamond Index was constructed as a means towards creating a more nuanced picture of where women are accessing decisionmaking authority through formal government structures. To date, the majority of focus on women's political access has been on increasing percentages while the question of where decision-making authority resides in formal structures has been sidelined. Fundamental to the Diamond Index is the following concept: there should be less focus on the percentages of women and more focus on which positions women hold that allow for greater access to decision-making authority across a range of formal government branches and positions. The index was developed following four guiding principles.

Number 1: Indicators should be limited in number, yet sufficient to cover as many dimensions of decision-making authority in formal government as reasonably possible.

In an effort to broaden the number and variety of indicators currently used to measure gender inequalities in the political power domain, indicators were selected among four different parts of government: executive, legislative, judicial, and security. A broader horizontal selection of indicators is conditioned on the premise that the locus of decision-making authority is variable according to different polities. It is a constantly shifting intangible, difficult to measure in any one place at any one point in time.

Also important, the Diamond Index attempts to focus less on the overall percentages of women in any particular institution. It places greater attention on decision-makers, i.e., individuals who have the potential to achieve impact based on the authority and 
agency inherent in the positions they hold. Three decision-making positions were selected within each domain. All three positions have been weighted differently, according to their levels of authority.

Interlinking these two concepts - broader and deeper measures of decision-makers - resulted in the selection of 12 different indicators around which the Diamond Index is built. The ability to differentiate where women are situated in the formal political system, both from a wider horizontal and deeper vertical perspective, allows us to evaluate more holistically where women are finding representational opportunities and where they are being denied those opportunities.

Number 2: The index should be simple to calculate and understand.

One aim in developing the Diamond Index was to specifically build a tool that any interested party could pick up and easily understand the logic behind indicator selection, weighting, aggregation methodology, and math used to produce the final score. With this principle in mind, three tiers of measurement were selected from each domain. Therefore, no domain contributed more indicators (or fewer) than any other. As much as possible, equivalent decision-makers were selected across the different tiers to ensure like comparisons both horizontally and vertically. The same unit of measure - percentage of women - was used in all indicators to minimize standardization differences. Each tier was weighted identically across domains to maintain consistency of process. Final domain scores were divided by four to maintain a 0 to 100 scale. Each domain score was then added together to achieve an overall Diamond Index score. While basic math skills are required to complete these steps, individual Country Scorecards provide a template that is easy to follow for most interested stakeholders.

Number 3: The index should be easily replicable by interested parties, including non-governmental organizations, governments, donors, and other stakeholders.

The intuitive and simple calculation process involved in the development of the Diamond Index offers local organizations and government officials an opportunity to recreate a similar effort at their own country level. Rather than relying on one or two global measures currently available, a country-led process using the Diamond Index methodology could potentially capture a more in-depth picture of women's decision-making authority. For the donor community, the Diamond Index can easily be generated as part of a larger political economy analysis or gender assessment to provide a more holistic snapshot in time on women's relationship to key decisionmaking positions in formal government. 
Number 4: Quality data considerations should underpin the selection of all variables.

The lack of quality data on women's political representation is the often unspoken lacuna in the room. How do you create a robust index around women's political representation when limited data exists on a global scale? The goal was not to create another regional index - for example, picking one region where data is readily available - but to select a range of countries across the globe that face differing data limitations.

Great effort was exerted in selecting relevant indicators for measuring political decision-making authority. This included indicators that could capture sufficient depth and breadth on a global scale as well as positions having common definitions that would hold for comparison across all countries. Additionally, the information had to be seen as relevant, accurate and without bias, accessible to the public across a reasonably consistent timeframe, and available to interested parties in a cost-effective manner. Finally, the data had to be disaggregated into smaller information units by sex. While not perfect, the 12 indicators attempt to meet the quality data criteria outlined to the greatest extent possible. As more data becomes available globally, especially at the sub-national level and across a broad range of government positions, there may be new opportunities to include other decision-making positions that, for now, we are unable to capture in any consistent and reliable form.

The ability to collect robust, worldwide data every year has been a challenge with current measurement tools. The greater the number of countries included, when paired with the need for frequent data publication, has resulted in the use of limited global indicators being available. Inversely, the selection of a wide range of political indicators has typically resulted in a more narrow collection of countries being measured and infrequent publication of the data. The Diamond Index attempts to thread that needle. It provides a robust number of indicators across the political spectrum common to almost every country in the world. Once the initial data is collected, annual updates would appear to be feasible with a minimal level of effort. Regular reporting for a robust set of countries should increase the reliability in the way we record women's political access across time.

While the Diamond Index is by no means the definitive answer to all descriptive representation ills, it does move beyond what current gender indexes have been able to achieve in the political domain. Its wider range of indicators, and attempts to differentiate varying levels of political access, add new dimensions to ongoing efforts to track gender inequality. Equally important, the Diamond Index offers a tool that interested stakeholders will find logical in its construction and easy to use. The 
hope is that its simplicity will inspire governments and advocates alike to make use of the index at a country level to improve analysis and understanding around the challenges women are facing, as well as the hard-won progress women are making, to gain an equal footing with men in the political arena. 



\title{
Chapter 5 \\ Gathering Data for the Diamond Index
}

\author{
Women's average representation in the police \\ does not exceed $13 \%$ in any region of the world. ${ }^{453}$
}

\subsection{INTRODUCTION}

In this chapter I describe the application of the Diamond Index, including how information was gathered in 40 countries, many of which are perceived as "datascarce." The collection effort focused on capturing women's breadth of representation across the three branches of government and the security sector. The Diamond Index is premised on the belief that in order to more accurately capture women's descriptive representation among diverse polities, this wider selection of indicators - gathered both horizontally across institutions and vertically within institutions - can create a more nuanced picture while minimizing measurement risk of over-attributing or under-attributing women's presence in the political space. By melding these two concepts - broader and deeper measures of decision-makers - the intent is to draw a clearer picture of women in the political arena globally, regionally, and within individual countries.

Along with selecting conceptually relevant indicators, a second aim of the Diamond Index is to create a tool that is replicable by any interested party for whatever measurement purposes envisioned: advocacy, programming, or simply tracking women's progress. One of the main constraints to understanding women's political access to decision-making positions is the lack of reliable data at both national and sub-national levels. The Diamond Index attempts to be creative by using an array of tools available to gather the information being sought, with or without individual government's willingness or ability to do so. Leading decision-makers, given their typically higher-profile in government, are often cited in independent or state media, official government sources, grey literature, and social media. This chapter will explore the research question:

453 Turquet, Laura. “Progress of the World's Women: In Pursuit of Justice.” (2011). 
Can quality data measuring women's positions

of formal political decision-making

be collected on a global scale?

In order to answer this question, the chapter is organized into two major sections. The first includes each stage of data collection: individuals involved, methodology used, and description of what was accomplished. The second section discusses in detail the successes and challenges encountered: what information proved easy, difficult, or impossible to collect. Given that 9 of the 12 indicators are new data points, it is important for future researchers and practitioners to understand what was required in the collection effort if the goal is to replicate the index. The chapter concludes with a discussion of how missing data was handled and a compilation of what was collected in each of the 40 countries.

\subsection{THE FOUR PHASES OF DATA COLLECTION}

The first round of data collection for the Diamond Index was undertaken as part of a larger research project - Women's Leadership as a Route to Greater Empowerment that I developed and led. The project received generous funding from the United States Agency for International Development (USAID) and took place between October 2013 and December 2014. The project was a joint undertaking between USAID's Center of Excellence in Democracy, Human Rights, and Governance and the U.S.-based Management Systems International. Leading U.S. academics were also included as part of the core team. ${ }^{454}$ The goal of the project was threefold: 1) document the challenges and lessons learned from approximately 100 USAID projects supporting women's political empowerment, 2) create an Agency map detailing support for women's empowerment across all USAID technical sectors, and 3) test the feasibility of the Diamond Index as a viable measure of women's access to political power. ${ }^{455}$

\footnotetext{
454 An enormous tribute of thanks goes out to all who helped work on the project. At USAID, this included David Yang (who gave the project a green light), Julie Denham, Summer Lopez, Lauren Siegfried, and Johanna Wilkie. The MSI team was led and directed with aplomb by Darcy Ashman. Academic researchers included Melanie Hughes, Aili Tripp, and Mona Lena Krook. A special thanks as well to the expertise of Brittany Duncan, Milad Pournik, and Layla Moughari for their relentless research.

455 A summary report of the USAID Women in Power Project can be found at: https://www.usaid.gov/sites/ default/files/documents/2496/USAID-WiP\%20summary\%20report_FINAL.pdf
} 


\section{Country Selection}

A day-long workshop was held with all parties in October 2013 to develop a common understanding of the project's objectives, as well as determine in which countries the Diamond Index would be tested. As USAID was funding the pilot, its interest was primarily in those countries where it provided development assistance. Therefore, the first criteria for country selection was to examine only those (approximately 100 countries) where USAID works. It was clear from the beginning that there was neither sufficient time nor resources to pilot all 100 countries with USAID programming. Therefore, a second criteria used to influence the selection process was prioritization of those countries likely to have ongoing, future activities, especially those in the political arena - so that the data produced could be made available for consideration in the development and monitoring of new programs. Decision-making up to this point was primarily driven by the USAID team given its unique understanding of institutional priorities and future funding.

In the second phase the wider team played a more active role, debating the merits of including or excluding specific countries. While USAID primarily works in Low- or Lower-Middle Income countries ${ }^{456}$ and Partly Free democracies, ${ }^{457}$ the team agreed that a wider range of countries, better reflecting the global spread of differences, was preferred. In addition, the team sought to select countries from varying parts of the world, again to ensure that no specific region was excluded. These selection criteria would allow for the model to be tested across economic, democratic, and regional variations. Ultimately, 40 countries were chosen. Because the level of access to information was unknown at this point, the premise moving forward was that of the 40 countries identified, approximately 25 to 30 of them would yield sufficient data for adequately mapping the Diamond Index. Table 19 lists the final 40 countries selected, including their World Bank and Freedom House rankings.

456 World Bank 2013 (http://data.worldbank.org/country).

457 Freedom House 2013 (https://freedomhouse.org/report/freedom-world/freedom-world-2013). 
TABLE 19: Final 40 Countries Selected

\begin{tabular}{|c|c|c|}
\hline REGION - COUNTRY & WORLD BANK 2013 & FREEDOM HOUSE 2013 \\
\hline \multicolumn{3}{|l|}{ Asia } \\
\hline Bangladesh & Low Income & Partly Free \\
\hline Cambodia & Low Income & Not Free \\
\hline India & Lower-Middle Income & Free \\
\hline Indonesia & Lower-Middle Income & Partly Free \\
\hline Mongolia & Lower-Middle Income & Free \\
\hline Nepal & Low Income & Partly Free \\
\hline Philippines & Lower-Middle Income & Partly Free \\
\hline Thailand & Lower-Middle Income & Partly Free \\
\hline Timor-Leste & Lower-Middle Income & Partly Free \\
\hline \multicolumn{3}{|l|}{ Eastern Europe/Eurasia } \\
\hline Albania & Upper-Middle Income & Partly Free \\
\hline Bosnia-Herzegovina & Upper-Middle Income & Partly Free \\
\hline Georgia & Lower-Middle Income & Partly Free \\
\hline Kyrgyzstan & Low Income & Partly Free \\
\hline Ukraine & Lower-Middle Income & Partly Free \\
\hline \multicolumn{3}{|l|}{ Latin America/Caribbean } \\
\hline Brazil & Upper-Middle Income & Free \\
\hline Colombia & Upper-Middle Income & Partly Free \\
\hline Guatemala & Lower-Middle Income & Partly Free \\
\hline Haiti & Low Income & Partly Free \\
\hline Mexico & Upper-Middle Income & Partly Free \\
\hline \multicolumn{3}{|l|}{ Middle East/North Africa } \\
\hline Algeria & Upper-Middle Income & Not Free \\
\hline Iraq & Lower-Middle Income & Not Free \\
\hline Jordan & Lower-Middle Income & Not Free \\
\hline Lebanon & Upper-Middle Income & Partly Free \\
\hline Morocco & Lower-Middle Income & Partly Free \\
\hline Tunisia & Lower-Middle Income & Partly Free \\
\hline Yemen & Lower-Middle Income & Not Free \\
\hline \multicolumn{3}{|l|}{ Africa } \\
\hline Benin & Low Income & Free \\
\hline Burkina Faso & Low Income & Partly Free \\
\hline Cote d'Ivoire & Lower-Middle Income & Partly Free \\
\hline Ghana & Low Income & Free \\
\hline
\end{tabular}




\begin{tabular}{l|c|c}
\multicolumn{1}{c|}{ REGION - COUNTRY } & WORLD BANK 2013 & FREEDOM HOUSE 2013 \\
\hline Kenya & Low Income & Partly Free \\
\hline Liberia & Low Income & Partly Free \\
\hline Madagascar & Low Income & Partly Free \\
\hline Mali & Low Income & Partly Free \\
\hline Mozambique & Low Income & Partly Free \\
\hline Niger & Low Income & Partly Free \\
\hline Nigeria & Lower-Middle Income & Partly Free \\
\hline Rwanda & Low Income & Not Free \\
\hline Senegal & Lower-Middle Income & Free \\
\hline South Africa & Upper-Middle Income & Free \\
\hline
\end{tabular}

Because USAID was funding the first step in the data collection effort, using a random sampling approach to the research was not considered. The development agency, while flexible, required a minimum set of selected countries be mapped. As a result of where USAID works, there is no inclusion of Middle- or High-Income countries. No countries, for example, from Western Europe were included. Likewise, of the 40 countries selected only seven are designated Free. Had a random sampling approach been pursued, a greater number of mature democracies and economically advanced states would have likely been included.

\subsubsection{Phase One-Public Resources}

The first phase of data collection was led by Dr. Melanie Hughes, University of Pittsburgh, with the assistance of researchers Brittany Duncan and Milad Pournik. The goal was to see how much data could be found using only publicly available resources. Four Excel spreadsheets were created, one for each branch of government and one for the security sector. Within these sectoral matrixes a page was created for each of the 40 countries and organized alphabetically. Within each country spreadsheet the source for every data point, and the information provided, was painstakingly coded. When possible, a link was created leading back to the source of data. This became extremely important as the research progressed, as different sources often provided conflicting information. Being able to return to each source was critical in trying to triangulate and resolve variations in the numbers provided.

Beyond simply collecting the numbers or percentages of women, coders recorded the actual names, positions, dates of elections, appointments, and age of the data. Each coder also made extensive notes on any concerns and how they interpreted 
conflicting information that emerged from multiple data sources. Because a fundamental purpose of the exercise was to see what public data could be collected, we were unsure from the beginning what would be useful, the level of detail available, and what gaps we might find by sector, tier, or region. The team was keenly aware that this was, to its knowledge, the first effort to collect data in different areas of government and the security sector, at specific leadership levels, on such a wide scale, and in primarily developing countries. As a result, the team attempted to collect as much data as possible knowing that not everything would be used but unsure of what might be valuable as the research continued. Again, this became extremely important as the research progressed. So, in total, four spreadsheets were developed. Each spreadsheet contained 40 countries and each country recorded a minimum of 15 sources of information (three for each category - executive, legislative, judiciary, police, and military). In total, more than 600 points of were collected. ${ }^{458}$

Once all four spreadsheets (executive, legislative, judicial, security) were completed, the percentages for each tier and sector were combined into one master spreadsheet with individual countries grouped by region. Showing all the percentages of women by sector, and leadership tiers in one document, allowed for easier country analysis. Regional differences and similarities could also be more clearly highlighted in this format. Coding categories contained in the master spreadsheet, as well as definitions, are presented in Table 20.

458 In fact, there were multiple data sources for numerous indicators; 600 points of data collection is a low estimate. 
TABLE 20: Master Spreadsheet Headings and Definitions

\begin{tabular}{|c|c|}
\hline HEADING & DEFINITION \\
\hline Country & Name of the individual country. \\
\hline Freedom Status & Status as classified by Freedom House. \\
\hline Region & $\begin{array}{l}\text { Countries were classified into one of five regions: } \\
\text { 1) Eastern Europe \& Eurasia, 2) Latin America \& the Caribbean, } \\
\text { 3) Asia, 4) Africa (Sub-Saharan), 5) Middle East \& North Africa. }\end{array}$ \\
\hline Priority & $\begin{array}{l}\text { As part of the research agenda five case studies were conducted. } \\
\text { These countries were labeled as Category I, meaning researchers } \\
\text { attempted to gather as much data as early as possible before teams } \\
\text { left for their respective countries to conduct field work. Category } \\
\text { II countries were those perceived to have substantial information } \\
\text { available, and had the best chance of being included in the final } \\
\text { countries that could be robustly mapped. Categories III and IV } \\
\text { were perceived as being data scarce and more time intensive. } \\
\text { While not excluded from efforts to gather data, the team focused } \\
\text { on the higher categories first to ensure that funding and time was } \\
\text { not exhausted attempting to gather data on Category III and IV } \\
\text { countries. }\end{array}$ \\
\hline Coder & $\begin{array}{l}\text { Identified Brittany Duncan or Milad Pournik as the principle coder } \\
\text { for the country. }\end{array}$ \\
\hline $\begin{array}{l}\text { Status Overall (*indicates } \\
\text { reservations; indicates } \\
\text { complete without security data; } \\
\text { I indicates incomplete) }\end{array}$ & $\begin{array}{l}\text { Once all the data was gathered into the master spreadsheet, an } \\
\text { evaluation could be made as to the overall quality of the data and } \\
\text { identify those countries where it would be difficult to draw a final } \\
\text { score given incomplete data. }\end{array}$ \\
\hline $\begin{array}{l}\text { \# Missing Legislative, Executive, } \\
\text { Judicial Indicators }\end{array}$ & $\begin{array}{l}\text { Because the security sector was proving so problematic to gather for } \\
\text { almost every country, the end of phase one focused on identifying } \\
\text { missing data in the three branches of government, leaving the } \\
\text { security sector aside. The number indicates missing indicators from } \\
\text { a total of nine measures (three Executive, three Legislative, and } \\
\text { three Judicial). }\end{array}$ \\
\hline Sample 30 & $\begin{array}{l}\text { This indicated which countries should be included in the final } 30 \\
\text { countries for analysis under the auspices of the USAID project. } \\
\text { Those countries with the most complete data set were selected. }\end{array}$ \\
\hline Legislative Status & $\begin{array}{l}\text { Data within the Legislative Branch was identified as one of the } \\
\text { following: } \\
C=\text { Complete; } C^{*}=\text { Complete with Reservations; } \\
\text { C = Complete without security data; I = Incomplete }\end{array}$ \\
\hline$\%$ Party & $\begin{array}{l}\text { The percentage of women occupying the top party leadership } \\
\text { position. Only those parties with representation in the lower house } \\
\text { of the national legislature are included. }\end{array}$ \\
\hline$\%$ Committee & $\begin{array}{l}\text { The percentage of committees in the lower or single house of the } \\
\text { national legislature that are chaired by women. }\end{array}$ \\
\hline $\begin{array}{l}\% \text { of Women in Lower or Single } \\
\text { House }\end{array}$ & $\begin{array}{l}\text { The percentage of women in the lower or single house of the } \\
\text { national legislature. }\end{array}$ \\
\hline
\end{tabular}


Notes

Any information considered pertinent for understanding challenges encountered, and how percentages were calculated, is explained in this section.

Executive Status

Data within the Executive Branch was identified as one of the following:

$\mathrm{C}=$ Complete; $\mathrm{C}^{*}=$ Complete with Reservations;

$\mathrm{C} \sim=$ Complete without security data; I = Incomplete

$\%$ Women in Cabinet

The percentage of women in the Executive Cabinet.

$\%$ Senior Executives

The percentage of women's share of lower-level leadership in executive cabinet. Positions include deputy minister, vice minister, under secretary, and permanent secretary.

$\%$ Top 10 Mayors

The percentage of women who hold the top executive position of authority among a country's 10 largest cities.

Notes

Any information considered pertinent for understanding challenges encountered, and how percentages were calculated, is explained in this section.

Judicial Status

Data within the judicial branch varied slightly due to difficulties in determining the three top tiers of courts within the country's judicial system:

$\mathrm{C}=$ Complete; $\mathrm{C}^{*}=$ Complete with Reservations; $\mathrm{C}^{\wedge}=$ Data

rearranged because there is no constitutional court; $C$ ? = there is no constitutional court so unsure of $3^{\text {rd }}$ tier of the judiciary.

$\%$ Constitutional

Women's percentage of seats on the Constitutional Court.

\begin{tabular}{l|l}
$\%$ Supreme & Women's percentage of seats on the Supreme Court.
\end{tabular}

$\%$ Appellate

$\%$ Magistrate

Women's percentage of seats in all second-tier appellate courts.

In an effort to collect as much judiciary data as possible, the percentage of magistrates, typically from courts of first instance, was collected when available.

$\%$ Total

Total percentage of female judges in a country. While not specifically a measure of the Diamond Index, it was collected when available.

Notes

Any information considered pertinent for understanding challenges encountered, and how percentages were calculated, is explained in this section.

Military Status

Data within the Military was identified as one of the following: $\mathrm{C}=$ Complete; $\mathrm{C}^{*}=$ Complete with Reservations;

$\mathrm{C} \sim$ = Complete without security data; I = Incomplete

$\%$ Upper

Women's share of positions in the top one-third of officer ranks in the army. While not specifically a measure of the Diamond Index, it was collected when available.

$\%$ Middle

Women's share of positions in the middle one-third of officer ranks in the army. While not specifically a measure of the Diamond Index, it was collected when available. 


\begin{tabular}{|c|c|}
\hline$\%$ Lower & $\begin{array}{l}\text { Women's share of positions in the bottom one-third of officer ranks } \\
\text { in the army. While not specifically a measure of the Diamond Index, } \\
\text { it was collected when available. }\end{array}$ \\
\hline$\%$ Officers & $\begin{array}{l}\text { Total percentage of women officers in the army. While not } \\
\text { specifically a measure of the Diamond Index, it was collected when } \\
\text { available. }\end{array}$ \\
\hline$\%$ Total & $\begin{array}{l}\text { Total percentage of women serving in the army. While not } \\
\text { specifically a measure of the Diamond Index, it was collected when } \\
\text { available. }\end{array}$ \\
\hline Notes & $\begin{array}{l}\text { Any information considered pertinent for understanding challenges } \\
\text { encountered, and how percentages were calculated, is explained in } \\
\text { this section. }\end{array}$ \\
\hline Police Status & $\begin{array}{l}\text { Data within the Police only was identified as one of the following: } \\
\mathrm{C}=\text { Complete; } \mathrm{C}^{*}=\text { Complete with Reservations; } \\
\text { C } \sim \text { = Complete without security data; I = Incomplete }\end{array}$ \\
\hline$\%$ Upper & $\begin{array}{l}\text { The women's share of positions in the top one-third of officer ranks } \\
\text { in the national police force. }\end{array}$ \\
\hline$\%$ Middle & $\begin{array}{l}\text { Women's share of positions in the middle one-third of officer ranks } \\
\text { in the national police force. }\end{array}$ \\
\hline$\%$ Lower & $\begin{array}{l}\text { Women's share of positions in the bottom one-third of officer ranks } \\
\text { in the national police force. }\end{array}$ \\
\hline$\%$ Total & $\begin{array}{l}\text { Total percentage of women officers in the national police force. } \\
\text { While not specifically a measure of the Diamond Index, it was } \\
\text { collected when available. }\end{array}$ \\
\hline Notes & $\begin{array}{l}\text { Any information considered pertinent for understanding challenges } \\
\text { encountered, and how percentages were calculated, is explained in } \\
\text { this section. }\end{array}$ \\
\hline
\end{tabular}

\subsubsection{Phase Two - Case Studies}

As part of the USAID Women in Power research project, five case studies were selected in an effort to better understand the challenges and impact of programs aimed at politically empowering women. As noted earlier, while Dr. Hughes and her team focused broadly on collecting publicly available data for all 40 countries selected, they immediately prioritized the five case-study countries so that the teams would have the latest data before traveling to each location. The countries selected included: Georgia, Cambodia, Mexico, Jordan, and Kenya. ${ }^{459}$ Each country team had specific terms of reference for their case study. This included the mandate to collect as much information as possible for the 12 Diamond Index indicators. The

459 In addition to leading the overall research project, I was also the team leader for the Kenya case study. 
rationale behind this approach was to test if having an in-country presence, and direct access to government decision-makers, would allow for the collection of additional information not available through public resources.

Each team consisted of at least three experts on women's political leadership, including one development professional from USAID, one academic, and one hostcountry national. The teams were frequently supplemented by in-country staff from USAID. Each group spent between seven to 10 working days in their assigned country. During this time they met with a wide range of experts in this field, including staff from the UN, local and international non-governmental organizations, donors, U.S. Government personnel, and country officials from each branch of government, including the security sector when possible. All information and data collected to date for the Diamond Index was openly discussed and shared.

The success in gathering additional data through in-person interviews and local contacts was mixed. For most of the five countries, the largest gap in data revolved around the security sector and Tier 3 of the judiciary. In Georgia, the team successfully obtained a full security sector data set. A Georgian national working at USAID introduced the team to the Deputy Minister of Defense. The locally employed expert met personally with the Deputy Minister, asked for the data in her meeting, and was immediately given the information. Georgia proved to be the best example of accessing additional information through person-to-person interventions.

There are several factors worth considering in this example. First, both the Minister of Defense and the Deputy Minister (with whom the team member met) were women. Perhaps equally important, the team member herself is a well-respected gender expert in the country. The Ministry has published a Gender Equality Strategy of the Ministry of Defence, and this document was also shared with the case-study team. The strategy specifically states that the Ministry, in line with the Constitution of Georgia, "defines the main guarantees for providing equal rights, freedoms and opportunities to men and women. It takes into account Georgia's international obligations and is obligatory for the Ministry of Defence of Georgia, Armed Forces of Georgia, their Structural Units, and the Legal Entities of Public Law (LEPLs) within the defence system." ${ }^{660}$ The seriousness with which the Ministry appears to be embracing gender, the willingness to openly discuss the challenges, the presence of women at the highest levels of the Ministry, the positive relationship between the governments of Georgia and the United States,

\footnotetext{
460 A hard copy of the document was given to the team while in country. It appears to be unavailable on the Georgia Ministry of Defense website.
} 
and the recognized technical expertise of the local Georgian expert were all likely influential factors in being able to procure the needed data. ${ }^{461}$

Cambodia ${ }^{462}$ and Jordan ${ }^{463}$ were at the opposite end of the spectrum with officials refusing to share any information on the security sector. One Cambodia government official went so far as to state that this type of information was not released publically as it was a matter of "national security." Government experts did not deny having the information. The perception among the country experts was that information was available, but officials were unwilling to share it with the case-study teams.

Kenya ${ }^{464}$ and Mexico ${ }^{465}$ fell between the two extremes. In-country publications, experts, and NGOs were able to fill in missing data gaps within the three branches of government. Judicial officials in Kenya were, in fact, proud of the gains women were making in the sector and willing to share what information was available to demonstrate their progress towards greater gender equality on the bench. The security sector, however, once again proved the most challenging. In general, there was a hesitation to share the data. As might be expected with a hierarchical organization, the critical factor in gaining access to the information was to find and ask the "right" person. While lower-level officers seemed open to sharing the data, they did not view themselves as having the authority to do so. The short time in country did not allow for the teams' requests to work their way up to the appropriate decision-maker. With more time and a sustained effort to gather the data, there was the perception that the information would - eventually-be provided. The resistance seemed to stem more from a bureaucratic nature verses one of transparency.

While the teams were able to make more headway on filling in data gaps through access to in-country publications and experts, both government and nongovernmental, it was by no means without using some level of U.S. government

461 Heartfelt thanks to Lauren Seyfried (who crawled out of her sick bed to join the team), Phyllis Dininio, Khatuna Khvichia, and Nana Sumbadze. Their full report - Women's Leadership as a Route to Greater Empowerment: Georgia Case Study - can be found at: https://www.usaid.gov/sites/default/files/documents/1866/WiP\%20 Georgia\%20Case\%20Study.pdf

462 Johanna Wilkie, Darcy Ashman, Sopeat Mer, and Sopheap Sreng comprised the Cambodian team of experts that forged on in the heat of Cambodia despite hitting many roadblocks. Their report can be found at: https:// www.usaid.gov/sites/default/files/documents/1866/WiP\%20Cambodia\%20Case\%20Study.pdf

463 Working in a difficult environment, the Jordan team of Summer Lopez, Kai Spratt, Dima Toukan, and Namar Kayed produced an excellent report found at: https://www.usaid.gov/sites/default/files/documents/1866/ WiP\%20-\%20Jordan\%20Case\%20Study.pdf

464 The Kenya team consisted of myself, Aili Tripp, and Louise Khabure. Despite a tense security situation in the country during the team's field trip, which mandated my early departure, the remaining Kenya team members forged on and finished the report on time. It can be found at: https://www.usaid.gov/sites/default/files/ documents/1866/WiP\%20-\%20Kenya\%20Case\%20Study\%20Report.pdf

465 The self-sufficient Mexico case-study team members included Julie Denham, Mona Lena Krook, and Silvia Gurrolla Bonilla. With little support but a lot of ingenuity, they were able to capture excellent data. Find their report at: https://www.usaid.gov/sites/default/files/documents/1866/WiP\%20-\%20Mexico\%20Case\%20Study. pdf 
influence. The teams were all identified as being led by USAID. In some countries, USAID experts were used to provide references or even make phone calls to set up appointments. Official letters on USAID letterhead were also used to ask for meetings when requested. While USAID could help open doors, however, that was no guarantee that governments would share their information. In countries such as Jordan and Cambodia, for example, the presence of the American flag might, in fact, make a wary official less inclined to share data. What was clearly highlighted in all five case studies, however, was the fact that governments did not deny having the information. In explaining that we were interested in a breakdown of all army and police officers by rank and gender, there was typically a knowing nod followed by excuses. No one ever stated that the information was not collected, tracked, or available.

By September 2014 the data collection effort supported by USAID ended. With the exception of the security sector, which will be discussed separately, the majority of data for the Diamond Index was collected through public records and meetings. At the end of Phase II, Dr. Melanie Hughes and the case study team were able to collect all 9 indicators ( 3 each in the executive, legislative, and judicial sectors) for 25 of the 40 pilot countries $(62.5 \%)$. They were able to collect 8 of the 9 indicators for 30 of the 40 countries $(75 \%)$. A full data set for the police was collected in 16 out of 40 countries $(40 \%) .466$

\subsubsection{Phase Three-Other U.S. Government Agencies, Donors, and Implementing Partners}

At the conclusion of Phase Two, I took over the data collection effort to see if I could fill in more of the remaining gaps. In my role as the Deputy Director for the USAID Center of Excellence on Democracy, Human Rights, and Governance, I had access to a number of U.S. experts and offices working in this field. I queried other colleagues and offices to ask if they had ever seen information or reports on the type of data we were trying to find. In particular I was looking for security sector data, although significant gaps still existed in the lower tiers of the judiciary and mayors of the 10 largest cities. I reached out to colleagues within USAID/Washington, as well as the Department of Justice, State Department, and Department of Defense. I also spoke with colleagues from the Department for International Development (DFID), UN Women, United Nations Development Program, and Swedish International

\footnotetext{
466 Hughes, Melanie M. “Women's Leadership As A Route To Greater Empowerment: Report on the Diamond Leadership Model." Washington DC: USAID, December 2014. https://www.usaid.gov/sites/default/files/ documents/1866/Diamond\%20Model\%20Report.pdf
} 
Development Cooperation to verify whether they were collecting this type of information. ${ }^{467}$

While none of the organizations are replicating the data, both UN Women and UNDP had begun complementary efforts that could enhance data collection efforts for the Diamond Index. UN Women is working to define and measure women's presence in local leadership positions. This includes identifying what information is available, documenting the existing gaps, and determining how a global and systematic data collection effort would best be initiated. ${ }^{468}$ Standardized data collected and available for local leaders at the sub-national level might neatly replace the Diamond Index "Tier 3 - Mayors" indicator in the future.

UNDP's efforts have focused on the executive branch through its Gender Equality in Public Administration project. This activity is collecting data on the overall number of women in the executive branch, including women in "decision-making positions in public administration." The Gender Equality in Public Administration project has currently collected data on 35 countries from five different regions. ${ }^{469}$ While definitions vary to some degree, "decision-making positions in public administration" could supplement the Diamond Index "Executive Tier 2 - Senior Executives" measure if globally available. At present, it is unclear whether the UNDP project will be expanded to cover additional countries. Both UN efforts are promising in their datagathering potential, and could add significant information to the Diamond Index. Apart from these two projects, however, there appears to be no other global efforts to disaggregate data on mayors, political party leadership, legislative committees, or judicial seats beyond the constitutional court. The security sector might best be described as a black hole of information. A number of the other donors noted: "If you find it, be sure to share it!"

\footnotetext{
467 At the field level, as part of the data collection process, all case study teams met with the major donors and NGO organizations in the country to ask about their research and available data. The larger USAID project findings, including those of the Diamond Index, were presented in November 2014 in Washington, D.C. Attending the twoday event were leading academics, implementers, and donor partners working in this field. This was also used as an opportunity to verify if we were missing any duplicative work or available data in this area.

468 A workshop held in December 2014, led by Julie Ballington, brought together leading gender experts to discuss the descriptive representation of women at the sub-national level and better explain the long-term process of how such an indicator would be mandated and collected. While UN Women continues to move forward with this global measurement effort, there is no timeframe as to when the data might be available.

469 "Global Report on Gender Equality in Public Administration." New York, N.Y.: United Nations Development Programme, 2014.
} 


\subsubsection{Phase Four - Individual Contacts}

Reasonably certain that the remaining data gaps would not be filled through public documents, U.S. government agencies, or other donor knowledge, the final phase of collection entailed reaching out to expert individuals in specific countries. Again, as Deputy Director of USAID's Democracy, Human Rights, and Governance Center in 2014, I had access to a cadre of USAID democracy experts located around the world. Cognizant of the fact that I could spend years trying to dig up non-public data - and also aware of my colleagues' busy schedules - I chose to focus on some of the most glaring country gaps, especially those presenting extreme contradictory evidence. In preparation for peer-to-peer requests, I spent July and August of 2015 reviewing every data source used, verifying numbers, considering the rationale for how selections were made when numbers did not match, and ensuring that I fully understood the gaps or contradictions. I then focused on those countries where I had close contacts, thought it probable that the information would be available, and believed that the U.S. relationship with the host government might allow for sharing.

Liberia is a classic case in point on how individual USAID experts were used. The Tier 3 Executive measurement - mayors of the 10 largest cities in each country - was surprisingly difficult to collect on a global level and revealed an enormous gap in women's representation. Out of 400 mayors (10 mayors for each of the 40 countries), the Diamond Index identified 25 women (6.3\%). Equally surprising, information from Liberia seemed to indicate that most of the 10 mayors were women. No other country came close to this level of representation. I contacted the Democracy Officer in the USAID / Liberia Mission to ask her to verify the state of play in the country. Her team explained that 7 out of the 10 mayors were, indeed, women. These women had been appointed by President Ellen Johnson Sirleaf as mayoral terms had expired and local elections have not taken place to date. One expert also highlighted that these mayors had less authority, both in terms of decision-making and fiscal spending, than one would anticipate of a mayor in charge of a large urban center. ${ }^{470}$

In some instances, Mali and Madagascar ${ }^{471}$ for example, the USAID experts were able to reach out to their contacts and gather data published locally or provided in a briefing. Any corrections or additions made to a country's data set were recorded in red on the appropriate sectoral matrix, under the country's individual tab. So, in the "Executive" matrix, "Liberia" tab, I added in red text the list of the 10 largest

\footnotetext{
470 Many thanks to Nina Bowen and her team for providing the back story on women's mayoral leadership in Liberia.

471 Also thanks to Valerie Hovetter in Mali and Corinne Rafael in Madagascar for providing such detailed data.
} 
cities, names and sex of each mayor, and a note explaining how this information was obtained and contextual insights offered from local field experts.

In total, I worked with approximately 30 different USAID field staff. In most instances, several rounds of e-mails were required to gather the full amount of information needed. For example, in Timor-Leste ${ }^{472}$ the number of female officers was quickly provided. It was not clear to staff, however, that I needed to calculate percentages, so additional rounds of e-mail went back and forth asking for the overall number of officers, then officers separated by rank. Precise, clear e-mails detailing EXACTLY what was being requested were essential. Aside from the five case-study countries, USAID field officers were not intimately involved in the dayto-day ongoing research and the findings had not been made public to allow for a greater understanding of our goals. As a result, staff members were unaware of the larger research context being undertaken by USAID and were operating only on the instructions they received, thus the need for detailed, specific directions.

\subsection{COLLECTING DATA: FROM EASY TO HARD}

Of the final 12 Diamond Index decision-makers identified, only three (Tier 1 -Executive Ministers; Tier 3 - Legislative Members; and Tier 1 - Constitutional Court Judges) are collected in a systematic way and desegregated by sex. The remaining nine indicators required various approaches to gather. Table 16 is an effort to capture what was required and the level of difficulty. It details: 1) sources used to gather data in the three branches of government, 2) rating as to the level of difficulty in procuring the information, and 3) explanatory notes about the challenges. Coders tried to collect the most recent information available in the summer and early fall of 2014. I added and adjusted data in the spring and summer of 2015. Whenever possible, the most recent data was used to build the index. Dates are recorded for each source of information on the sectoral matrixes under each individual country tab. Because the challenges of data collection in the security sector posed a number of additional challenges, this sector was not included in Table 21, but will be discussed separately.

472 Thanks to Lisa Whitney and Eugenio dos Santos Marcal at USAID/Timor-Leste for their patience in getting me just what was needed. 
TABLE 21: Information Sources for the Diamond Index

No color indicates access to information was easy; light shade of medium difficulty; and dark shade difficult

\begin{tabular}{|c|c|c|}
\hline TIER LEVEL & SOURCES & NOTES \\
\hline \multicolumn{3}{|c|}{ EXECUTIVE } \\
\hline Tier 1: Cabinet Members & $\begin{array}{l}\text { - Central Intelligence } \\
\text { Agency }{ }^{473} \\
\text { - Inter-Parliamentary } \\
\text { Union }{ }^{474}\end{array}$ & $\begin{array}{l}\text { - The CIA provides the names of all cabinet } \\
\text { members, although the sex of individuals is } \\
\text { not identified. } \\
\text { - Many countries host official ministry } \\
\text { websites that feature information about } \\
\text { individual ministry staff, including its } \\
\text { leadership. } \\
\text { - The Inter-Parliamentary Union, in } \\
\text { conjunction with UN Women, publishes } \\
\text { the percentage of women in ministerial } \\
\text { positions by country bi-annually. This data, } \\
\text { however, combines deputy ministers with } \\
\text { ministers. }\end{array}$ \\
\hline Tier 2: Senior Executives & $\begin{array}{l}\text { - Government websites, } \\
\text { individual experts }\end{array}$ & $\begin{array}{l}\text { Recent cross-national data on women in sub- } \\
\text { ministerial positions is not available. The } \\
\text { Diamond Index focuses on deputy ministers, } \\
\text { vice ministers, and permanent secretaries. } \\
\text { The majority of these positions - verses a } \\
\text { broader definition of senior executives - can } \\
\text { typically be found on-line. }\end{array}$ \\
\hline $\begin{array}{l}\text { Tier 3: Mayors of } 10 \\
\text { Largest Cities }\end{array}$ & $\begin{array}{l}\text { - News stories, } \\
\text { government websites, } \\
\text { reports, individual } \\
\text { experts } \\
\text { - Citymayors.com }{ }^{475}\end{array}$ & $\begin{array}{l}\text { There is no systematic collection of data } \\
\text { on mayors. Public references to mayors } \\
\text { are frequent for the larger cities and/or the } \\
\text { capital. As anticipated, moving away from } \\
\text { the main urban center to the less populated } \\
\text { resulted in less media coverage. } \\
\\
\text { - This website does have some limited utility. } \\
\text { It lists the mayors, by country, of the largest } \\
600 \text { cities in the world. Smaller countries, } \\
\text { however, may see only their capitals appear } \\
\text { on the list. There are also extensive gaps } \\
\text { in identifying the mayors of cities in less } \\
\text { developed countries. }\end{array}$ \\
\hline
\end{tabular}

473 Central Intelligence Agency. 2015. "Chiefs of State and Cabinet Members of Foreign Governments." (https:// www.cia.gov/library/publications/resources/world-leaders-1/)

474 Inter-Parliamentary Union. 2015. “Women in Politics: 2015." (http://www.ipu.org/pdf/publications/ wmnmap15_en.pdf)

475 City Mayors. 2011. "Largest Cities and their Mayors 2011." (http://www.citymayors.com/statistics/largestcities-mayors-el2.html) 


\begin{tabular}{|c|c|c|}
\hline TIER LEVEL & SOURCES & NOTES \\
\hline \multicolumn{3}{|c|}{ LEGISLATIVE } \\
\hline $\begin{array}{l}\text { Tier 1: Political Party } \\
\text { Leaders }\end{array}$ & $\begin{array}{l}\text { - Inter-Parliamentary } \\
\text { Union }{ }^{476} \\
\text { - Central Intelligence } \\
\text { Agency }^{477}\end{array}$ & $\begin{array}{l}\text { The IPU provides some narrative of party } \\
\text { leaders, although it is not consistent for all } \\
\text { countries and all parties. } \\
\text { - The CIA lists all parties, percent of vote } \\
\text { received, number of seats allocated, and } \\
\text { party leaders. This makes it easy to verify } \\
\text { which parties have gained parliamentary } \\
\text { representation. Difficulties can arise in } \\
\text { determining if the party leader is male or } \\
\text { female, as only the name is listed, not the sex } \\
\text { of the individual. Verification by an expert } \\
\text { within the country may be required. }\end{array}$ \\
\hline Tier 2: Committee Chairs & $\begin{array}{l}\text { - Individual legislative } \\
\text { and party websites }\end{array}$ & $\begin{array}{l}\text { There is no dataset of legislative committee } \\
\text { leaderships. Public websites, in general, } \\
\text { provide this information. }\end{array}$ \\
\hline Tier 3: Representatives & $\begin{array}{l}\text { - Inter-Parliamentary } \\
\text { Union }{ }^{478}\end{array}$ & $\begin{array}{l}\text { - The Diamond Index also makes use of this } \\
\text { global standard for measuring women's } \\
\text { legislative representation. }\end{array}$ \\
\hline \multicolumn{3}{|c|}{ JUDICIAL } \\
\hline $\begin{array}{l}\text { Tier 1: Judges Highest } \\
\text { Court }\end{array}$ & $\begin{array}{l}\text { - Government } \\
\text { websites }\end{array}$ & $\begin{array}{l}\text { - The World Bank tracks the number of } \\
\text { women on "constitutional courts" for each } \\
\text { country. This is a somewhat problematic } \\
\text { definition as a number of countries do } \\
\text { not have separate constitutional courts. } \\
\text { In some countries, constitutional review } \\
\text { is granted to, for example, the Supreme } \\
\text { Court. The intent of the Diamond Index is } \\
\text { to capture the judicial body with the power } \\
\text { of constitutional review and the country's } \\
\text { highest-level court. } \\
\text { - Governments typically have information } \\
\text { about their highest court and judges posted } \\
\text { on an official website. }\end{array}$ \\
\hline
\end{tabular}

\footnotetext{
476 Inter-Parliamentary Union. 2014. "PARLINE database on National Parliaments." (http://www.ipu.org/parline-e/ parlinesearch.asp)

477 Central Intelligence Agency. 2015. CIA Factbook. (https://www.cia.gov/library/publications/the-worldfactbook/geos/ic.html)

478 Inter-Parliamentary Union. 2015. (http://www.ipu.org/wmn-e/classif.htm)

479 World Bank. 2015. "Women, Business, and the Law." (http://wbl.worldbank.org/data/exploretopics/going-tocourt)
} 
TIER LEVEL

Tier 2: Judges SecondLevel Court(s)

\section{SOURCES}

NOTES

\begin{tabular}{|c|c|c|}
\hline & $\begin{array}{l}\text { donor reports, NGO } \\
\text { reports, individual } \\
\text { experts }\end{array}$ & $\begin{array}{l}\text { difficult beyond the constitutional level to } \\
\text { determine what is considered a second-level } \\
\text { court. In some countries this is the supreme } \\
\text { court, in others an appellate court. Some } \\
\text { countries have multiple courts at this level, } \\
\text { divided into civil, criminal, and administrative } \\
\text { branches. In the case of a country having } \\
\text { multiple courts at the Tier } 2 \text { level, all judges } \\
\text { were included. } \\
\text { Interpretations of judicial authority are not } \\
\text { always clear. For purposes of future research, } \\
\text { every Country Scorecard explicitly notes the } \\
\text { title of the court being considered at each tier } \\
\text { level. }\end{array}$ \\
\hline $\begin{array}{l}\text { Tier 3: Judges Third- } \\
\text { Level Courts }\end{array}$ & $\begin{array}{l}\text { Government } \\
\text { websites, articles, } \\
\text { donor reports, NGO } \\
\text { reports, individual } \\
\text { experts }\end{array}$ & $\begin{array}{l}\text { This data has been little studied or collected. } \\
\text { Different systems result in different court } \\
\text { structures at this level. In some countries this } \\
\text { might be an appellate court, in others a regional } \\
\text { court, and in some of the less-developed or } \\
\text { populated countries a district court. District } \\
\text { courts may be staffed by hundreds of } \\
\text { magistrates across the country. Coders were } \\
\text { able to find a number of government websites } \\
\text { with lists of judges and then identify each by } \\
\text { sex. In some countries local expertise may be } \\
\text { required to distinguish male/ female names. } \\
\text { Magistrates' names and profiles were not } \\
\text { always available. Following on the Phase I-II } \\
\text { work, I was able to add additional countries } \\
\text { by using judicial experts to gather data in the } \\
\text { selected country. For most countries there was } \\
\text { no perceived intent to hide the data. It seemed } \\
\text { more an issue of having it available in a single- } \\
\text { source format that could be publicly shared. }\end{array}$ \\
\hline
\end{tabular}

\subsubsection{The Security Sector and its Challenges}

The original intent of the Diamond Index was to capture two aspects of the security sector and average them together into one score. These two components were: 1) the military apparatus, which generally looks outwards towards ensuring national security and 2) the national police, which is focused more towards internal security concerns. If the security sector were to be color-coded according to level of effort required to collect the data, you would see a solid block of red for both the police and army. 


\section{Military Data Collection}

The team understood that gathering data in the security sector would be difficult. Dr. Hughes and her team began by collecting data for all branches of the military army, navy, and air force. ${ }^{480}$ It soon became apparent, however, that gathering this information was going to be more difficult and time consuming than anticipated. Given that a number of countries lack an air force and navy, issues of comparability were soon evident. The project also had limited resources, and the time required to hunt down military data was quickly eating into the allocated budget. As a result of quality data concerns around comparability, completeness, and cost-effectiveness, the team decided to focus only on the army branch of the military.

There are currently no globally comparable statistics on the number of women in the military. We also know little about which leadership positions women are encumbering in this field. The UN does track the overall percentage of women peacekeepers on mission, and has pushed to increase that number globally. ${ }^{481}$ This stems, in part, from the passage of UN Security Council resolution 1325 reaffirming the important role women play in the promotion of peace and security. ${ }^{482}$ The team could often find overall percentages of women in the military. In Mozambique, for example, women's overall participation in the military is reported at $5 \% .{ }^{483}$ While peacekeeping figures and general statistics can help paint a broad picture of women's representation, the Diamond Index is focused on decision-makers. Because the military and police are hierarchical in their decision-making, it was important to try and capture the varying levels of leadership and women's representation within the command structure.

The most advanced work in this area has been undertaken by the Latin American Security and Defense Network (Red de Seguridad y Defensa de América Latina RESDAL). RESDAL describes itself as: "A network that creates, strengthens and links the capacities and efforts of decision-makers, academics and members of civil society within the field of security and defence...." 484 Marcela Donadio, RESDAL Executive Secretary, and Paz Tibiletti, President of the Executive Secretariat, have spent years cultivating strong relations and high levels of trust between military

\footnotetext{
480 While I also thought it would be extremely interesting to include the intelligence agencies, I was not so naïve as to believe that this information would be made available.

${ }^{481}$ United Nations. 2015. "UNPOL: Sustainable Peace through Justice and Security." (http://www.un.org/en/ peacekeeping/sites/police/initiatives/globaleffort.shtml)

482 Kuehnast, Kathleen. "Why Women's Involvement in Peacebuilding Matters." Foreign Service Journal, April 2011.

483 Nomthandazo, Mankazana. "SADC Gender Protocol 2015: South Africa." Gender Links, 2014.

484 Donadio, Marcela, and Maria de la Paz Tiblietti. A Comparative Atlas of Defence in Latin America and Caribbean. Red de Seguridad y Defensa de America (RESDAL), 2010.
} 
leaders throughout Latin America and the Caribbean. ${ }^{485}$ According to Donadio, there remains significant mistrust between the security sector and outsiders. "You must know someone personally within the military, and they must trust that the data will not be misused. Only then will they share information." ${ }^{486}$

RESDAL's 2014 atlas published on security and defense is the definitive public voice on military budgets, structural organization, legal framework, and personnel in Latin America and the Caribbean. ${ }^{487}$ For many of the countries covered in the atlas, RESDAL provides a breakdown of personnel by rank and sex, including officers in command positions. In fewer instances they are able to desegregate by commissioned or non-commissioned personnel. ${ }^{488}$ Financial limitations make it difficult for RESDAL to publish the atlas on an annual basis and extend significantly beyond its current regional coverage. The organization has clearly shown, however, that with the right expertise and long-term commitment, gathering excellent, systematic, and replicable data on women in the security sector is possible.

\section{Police Data Collection}

Determining the division of duties between army and police is not without its challenges. In many countries there are organizations that have overlapping responsibilities between internal and external security. We see this dual role in the plethora of national guard units found across most regions and the gendarmerie that is predominant in many Francophone countries. Given the grey area that these entities straddle between the army and police, and the variation in their range of duties from country to country, the leadership ranks of these dual-hatted unit types were not included.

Countries also maintain a range of security forces, at times making it difficult to clearly define what constitutes "the police." Mexico, for example, has a state police system that reports to each respective state governor. It also maintains a federal police system, accountable to the Secretariat of Public Security. Looking at a range of quality data concerns - comparability, accuracy, and cost effectiveness - the team decided to narrow its focus to national police forces only. So again returning to the case of Mexico, only data on the federal police - with national jurisdiction and a presence across the country - became the focus of attention.

\footnotetext{
485 The process of how RESDAL collects its data was discussed in a meeting between myself, Donadio, and Tibiletti at USAID, Washington D.C., June 2014.

486 Interview with RESDAL director, Washington D.C., May 2015.

487 "A Comparative Atlas of Defence in Latin America and Caribbean." Latin American Network of Security and Defence, 2014.

488 The atlas defines the command corps as officers who have been educated at military academies from the beginning of their professional careers.
} 
Information on the police, while by no means easy, was more available than information on the military. Of the 40 countries, the team was able to gather full data sets for the police in 20 countries $(50 \%)$ and overall percentages of women in the police force in an additional 12 countries $(30 \%)$. Military figures, in comparison, were significantly lower with nine countries having full data sets (23\%); overall figures for women in the military were gathered in another eight countries (20\%). To date, there is no systematic collection of police data globally, including their representation in leadership positions.

A typical example of information provided is the case of Jordan: "Women's participation in police service was increased to $7 \%$, divided between military and administrative functions." ${ }^{\prime 49}$ While $7 \%$ might seem an impressive figure in light of neighboring countries, we have no sense of how women's roles are divided (military verses administrative), nor if women are under- or over-represented in a particular level of officer rank.

In general, the perception of the case study teams was that governments and sources were more willing to talk about women in the police than the military. In the case of the Kenya team, for example, changes in the 2010 Constitution have led to an increase in women police officers. While their presence is nowhere near parity, or even 30\%, a number of interviewees acknowledged that progress was being made. The local press also reported that the most recent tranches of recruits had yielded significantly higher numbers of females. In this instance, the openness to meet with the case study team and discuss women in the police may have been based on being able to report a "good news" story.

It is also possible that police data is culturally considered a part of the public domain in a way that military data is not. The reluctance to share police data seemed to stem more from the interviewee's lack of authority to meet the request (thus higher-level approval was required) or that the information was not readily available in a single spreadsheet or fact sheet for public consumption. ${ }^{490}$

In attempting to collect data on the security sector, both police and army, no proverbial rock was left unturned. Along with RESDAL, an important source of information was the Geneva Centre for the Democratic Control of Armed Forces

\footnotetext{
489 “National Report: Progress of Jordanian Women In Pursuit of Justice, Participation and Equality 2010-2011." Amman, Jordan: The Jordanian National Commission for Women (JNCW), 2011.

490 Of course, it is also possible that excuses such as lack of authority or publically presentable data are another way, although perhaps more diplomatically, of simply saying no.
} 
and its country reports. ${ }^{491}$ These reports often provided both overall and detailed figures for women's participation in the military and police for the individual country analyzed. Other sources consulted to try and glean insights into the security sector world included: United Nations Office on Drugs and Crime, United Nations Democracy Fund, Organization for Security and Co-operation in Europe, United Nations Development Program, UN Women, Central Intelligence Agency, Southern African Development Community, government reports and websites, nongovernmental organization reports and websites, journals, media articles, speeches, and blogs.

Once all sources and documents had been tapped for information, the security sector demonstrated how on-the-ground experts could be extremely valuable. In several instances, Timor-Leste for example, the USAID staff was able to find exactly what was required. In others, such as Mali, the USAID gender expert found data for the police but not the military. Finally, in some of the most difficult countries, such as Tunisia, in-country experts confirmed that the door on this data was firmly shut and time would be better spent on other countries.

It should be noted that the data collected in the security sector varies greatly by date, source, and reliability. The team undertook a heroic effort in attempting to gather information never before collected, using every public tool available, individual contacts, as well as large doses of patience and persistence. Rather than being discouraged by the gaps in data, I was encouraged by the significant amount we were able to find. The Diamond Index sets a baseline for what data is available, and underscores that even developing countries, in data-scarce environments, can provide the needed information if there is the will to do so.

\subsection{MISSING DATA}

There were a number of challenges associated with accessing data, especially given the type of information required and countries targeted. Like other indexes, the Diamond Index remains interested in tracking the descriptive representation of women in government. This includes measuring percentages of women within formal institutions. Unlike other efforts, however, the model dictates that data be collected on identified decision-making positions within each sector.

491 Thanks to Anja Ebnöther from DCAF whose keen interest in this work included her participation in the project's final two-day conference where all results were reported. (http://www.dcaf.ch). 
Of the 480 data points attempted for the 40 countries (12 per country) a total of 416 were collected $(86.7 \%)$. The team anticipated that data collection would be the most difficult in the security sector as it attempted to disaggregate data on the command structure rather than overall percentages of women in the police. Team members were not disappointed in their expectations. Of the missing 64 indicators, 2 remained uncollected in the legislative branch, 6 in the executive branch, 12 in the judiciary, and 44 in the security sector. Table 22 highlights the missing indicators per sector for each of the 40 countries.

TABLE 22: Missing Diamond Index Indicators by Domain

\begin{tabular}{|c|c|c|c|c|c|}
\hline COUNTRIES & EXECUTIVE & LEGISLATIVE & JUDICIAL & SECURITY & $\begin{array}{c}\text { TOTAL } \\
\text { MISSING }\end{array}$ \\
\hline 1. Kyrgyzstan & - & - & 3 & 3 & 6 \\
\hline 2. Tunisia & - & - & 2 & 3 & 5 \\
\hline 3. Algeria & 1 & 1 & 1 & 2 & 5 \\
\hline 4. Senegal & 1 & - & 1 & 2 & 4 \\
\hline 5. Mongolia & 1 & - & - & 3 & 4 \\
\hline 6. Niger & 2 & - & 2 & - & 4 \\
\hline 7. Ukraine & - & - & - & 3 & 3 \\
\hline 8. Benin & - & 1 & - & 2 & 3 \\
\hline 9. Madagascar & - & - & 1 & 2 & 3 \\
\hline 10. Mozambique & - & - & 1 & 2 & 3 \\
\hline 11. Iraq & - & - & - & 3 & 3 \\
\hline 12. Morocco & - & - & - & 3 & 3 \\
\hline 13. Jordan & - & - & - & 2 & 2 \\
\hline 14. Lebanon & - & - & - & 2 & 2 \\
\hline 15. Yemen & - & - & - & 2 & 2 \\
\hline 16. Colombia & - & - & - & 2 & 2 \\
\hline 17. Cambodia & - & - & - & 2 & 2 \\
\hline 18. Philippines & - & - & - & 2 & 2 \\
\hline 19. Ghana & - & - & - & 2 & 2 \\
\hline 20. Liberia & - & - & - & 2 & 2 \\
\hline
\end{tabular}




\begin{tabular}{l|l|l|l|l|l}
\hline 21. India & - & - & 1 & - & 1 \\
\hline 22. Burkina Faso & 1 & - & - & - & 1 \\
\hline 23. Albania & - & - & - & - & 0 \\
\hline $\begin{array}{l}\text { 24. Bosnia- } \\
\text { Herzegovina }\end{array}$ & - & - & - & - & 0 \\
\hline 25. Georgia & - & - & - & - & 0 \\
\hline 26. Brazil & - & - & - & - & 0 \\
\hline 27. Guatemala & - & - & - & - & 0 \\
\hline 28. Haiti & - & - & - & - & 0 \\
\hline 29. Mexico & - & - & - & - & 0 \\
\hline 30. Bangladesh & - & - & - & - & 0 \\
\hline 31. Indonesia & - & - & - & - & 0 \\
\hline 32. Nepal & - & - & - & - & 0 \\
\hline 33. Timor-Leste & - & - & - & - & 0 \\
\hline 34. Thailand & - & - & - & - & 0 \\
\hline 35. Cote d'Ivoire & - & - & - & - & 0 \\
\hline 36. Kenya & - & - & - & - & 0 \\
\hline 37. Mali & - & - & - & - & 0 \\
\hline 38. Nigeria & - & - & - & - & 0 \\
\hline 39. Rwanda & - & - & - & - & 0 \\
\hline 40. South Africa & - & - & - & - & 0 \\
\hline TOTAL MISSING & $\mathbf{2}$ & - & - & - & 0 \\
\hline
\end{tabular}

In terms of indicator collection by region, Latin America/Caribbean was the most successful with an average of 11.6 indicators gathered out of a possible 12, as seen in Table 23. This is due primarily to the excellent work of RESDAL, which partnered on this project. Through its extensive network, RESDAL was able to gather security sector data on four of the five countries in the region. ${ }^{492}$ The organization appears unique in its mandated focus on the security sector and ability to collect this type of information annually. Unfortunately, due to financial and human resource constraints, the organization remains geographically limited in its coverage.

492 "A Comparative Atlas of Defence in Latin America and Caribbean." Latin American Network of Security and Defence, 2014. 
TABLE 23: Average Number of Indicators Collected by Region

\begin{tabular}{|c|c|c|c|c|}
\hline $\begin{array}{c}\text { Latin America } \\
\text { Caribbean }\end{array}$ & Asia & Africa & $\begin{array}{c}\text { Eastern Europe } \\
\text { Eurasia }\end{array}$ & $\begin{array}{c}\text { Middle East } \\
\text { North Africa }\end{array}$ \\
\hline 11.6 & 11.0 & 10.5 & 10.2 & 8.9 \\
\hline
\end{tabular}

Excluding the expertise of RESDAL, there was more uniformity in collection, with Asia, Africa, and Eastern Europe/Eurasia collecting 11.0, 10.5, and 10.2 indicators, respectively. The Middle East/North Africa region proved the most difficult region in which to gather information, with an average of 8.9 indicators across the seven countries. Somewhat surprisingly, information was quite accessible in the three main branches of government in this region. Out of 63 possible indicators ( 3 indicators in 3 domains $x 7$ countries), only 5 data points were unavailable (7.9\%). The difference in scoring between the Middle East / North Africa and other regions results from the dearth of public information in the security sector. Even having strong contacts in a number of the countries - and sending a team into Lebanon to specifically ask experts and government officials - cumulatively turned up little data.

How to handle missing data - in particular within the security sector - required extensive thought and deliberation. In some composite indicators, data gaps result in a country's exclusion. Plantenga alternatively proposed, when developing the framework for the Gender Equality Index, to insert the average European Union score for data gaps. ${ }^{493}$ So if Portugal, as an example, was missing the data point for women's share of regional assembly member seats, the overall European average score would be inserted to allow for a full data set and inclusion of the country. This is a reasonable approach given the availability of information for most EU countries and confidence that once all countries are averaged you would have an accurate reflection of the missing data.

Using this methodology with the Diamond Index is not as straightforward. First, Plantenga averages among countries all within the same region, even if countries varied widely in their scores. The Diamond Index looks at a total of 40 countries across five different regions. Africa has the largest number of countries included (14), followed by Asia (9), the Middle East and North Africa (7), Latin America and the Caribbean (5), and Eastern Europe and Eurasia (5). Given the limited number of countries included from several of the regions, it is difficult to say with any certainty that an "average" score is fully reflective. In the Latin America/Caribbean

493 Plantenga, Janneke, Chantal Remery, Hugo Figueiredo, and Mark Smith. "Towards a European Union Gender Equality Index." Journal of European Social Policy 19, no. 1 (2009): 19-33. 
region, five countries in total were mapped (Brazil, Colombia, Guatemala, Haiti, and Mexico). Of the five countries, only Colombia was missing a full data set in the security sector. While one might argue that from the other four countries a reasonable average could be ascertained, one might also argue that the five-country set used is absent numerous important states which, if included, might influence the final score in either direction.

As seen from Table 22, the vast majority of data gaps occurred in the security sector. Focusing on the executive, legislative, and judicial domains only, 20 data points $(6.0 \%)$ were missing out of a possible 333 (37 countries $\times 9$ data points = 333). In looking only at the security domain, 20 countries in total (50.0\%) included all three security data points (Tier 1 , Tier 2, and Tier 3). Scores were weighted and calculated if only one data point was missing from any domain. I did not attempt to insert a regional average given the limited number of countries used in three of the regions (Latin America / Caribbean, Middle East/ North Africa, and Eastern Europe / Eurasia) and lack of confidence that any average calculated was reflective of the larger region. If more than one data point was missing from any domain, then no score was calculated for either that domain nor a final country score. Each Country Scorecard (Annex B) clearly indicates, by tier and domain, where data gaps exist.

All of the Middle East/North Africa countries were a "black hole" of security sector information. Despite the teams' best efforts, little data emerged. Overall percentages of women in the police force were found for four of the seven countries: Algeria, Jordan, Lebanon, and Yemen. This overall percentage was used as the Tier 3 measure as a reasonable approximation reflecting the percentage of LowerLevel Officers. This methodology was used for the Middle East as well as the other regions. ${ }^{494}$ If the overall percentage of women in the police force was the only data point available, however, no score was achieved in the domain (as the percentage of Mid-Level Officers - Tier 2 and Top-Level Officers - Tier 1 could not be calculated without more specific information). As a result, only 20 countries out of the 40 met the high bar of reporting sufficient data in the security sector to warrant a final score.

While commitments to increase women's participation (codified in such international documents as the Beijing Platform for Action and Resolution 1325) require reporting information be made available on a country, regional, and international basis, reporting expectations have not been realized to date. As more police and military open their doors to women's participation, we would expect to see better

\footnotetext{
494 This methodology was selected based on the close correlation between the overall percentage of women in the police force and Tier 3 (female Low-Level Officers). A total of 13 countries recorded both percentages. Averaged together, Tier 3 female officers totaled $9.4 \%$ while overall number of women in the police force totaled $8.6 \%$.
} 
disaggregated data emerge and more accurate modeling of women's leadership status in security sector institutions. Until that time, however, the Diamond Index at least provides a starting point for further discussion.

\subsection{CONCLUSION}

The Diamond Index focuses on capturing a greater bread th of descriptive representation across the three branches of government and the security sector while also paying greater attention to specific decision-making positions in formal government. This wider selection of indicators - gathered both horizontally across institutions and vertically within institutions - can together help create a more nuanced picture of women's representation throughout government and access to decision-making positions of authority.

At the end of all four collection phases, significant headway was made in gathering new data for the Diamond Index. In total, a full data set was collected for $18(45 \%)$ of the 40 countries. Examining only the executive, legislative, and judicial branches resulted in a full data set for $29(72.5 \%)$ of the 40 countries. Within these same three domains the collection teams were able to gather 8 out of 9 indicators for $35(87.5 \%)$ of the 40 countries. Table 24 details percentages of countries in relation to the number of indicators collected.

TABLE 24: Number/Percentage of Indicators Collected for the Diamond Index

\begin{tabular}{c|c|c}
\hline NUMBER OF COUNTRIES & INDICATORS COLLECTED & \% OF TOTAL 40 COUNTRIES \\
\hline 18 & 12 & $45.0 \%$ \\
\hline 2 & 11 & $5.0 \%$ \\
\hline 6 & 10 & $20.0 \%$ \\
\hline 3 & 9 & $15.0 \%$ \\
\hline 2 & 8 & $7.5 \%$ \\
\hline 1 & 7 & $5.0 \%$ \\
\hline
\end{tabular}


In summarizing the 40-country pilot data collection effort, there are several themes worth highlighting:

- The breadth and depth of data required to build the Diamond Index - as a more nuanced measure of women's formal political leadership - was successfully collected across the 40-country sample in the executive, legislative, and judicial sectors primarily through access to public data. In using public data, however, quality data concerns around the accuracy of the data must be taken seriously. Public sources are often contradictory and require a methodology for reconciling different information.

- Security sector information was not collected at the level of detail required in the majority of instances, either through public data or the use of personal contacts. This was especially true for military data. Attitudes do, however, seem more open towards discussing and sharing information about women in the police. Relevant data was found in 34 of the $40(85 \%)$ countries, although this information was often limited to the overall percentage of women represented in an individual country's police or military force. Quality data concerns around the accuracy, timeliness, and disaggregation of decisionmaking positions remain relevant for the security sector.

- The capacity to reach back to an extensive network of on-the-ground global experts in the democracy field was useful when trying to gather targeted data points, in particular security sector information, in the most challenging datascarce environments. While very specific questions or clarifications could be addressed, relying on individuals to gather wider levels of information was not deemed cost efficient.

- The ability to find significant levels of data for the 40 pilot countries - while not without is challenges - speaks to its availability. Cultural constraints, mistrust of institutional "outsiders," and weak demand for greater transparency are all stifling access to information, rather than the lack of information itself.

The current perception exists that data on women's political representation is extremely limited. This research effort, while not without its challenges, demonstrated that more data exists in the public domain than has been previously recognized. There is also an acknowledgement by governments that much, if not all, of the data on the identified 12 decision-makers, disaggregated by sex, already exists. The difficulty lies in its lack of availability to the public to allow for its transparent and systematic collection. 
The ultimate objective, either through the Diamond Index approach or others, is to improve descriptive representational efforts in order to shed more light and understanding around women's political access and inequality. If the data already exists, as was perceived through this academic exercise, then future efforts must increasingly focus on how to make that information publically available. 



\title{
Chapter 6 \\ Mapping the Diamond Index in $\mathbf{4 0}$ Countries
}

\author{
Women hold approximately $18 \%$ of the ministerial \\ positions, with the majority overseeing social sectors, \\ such as education and the family. ${ }^{495}$
}

\subsection{INTRODUCTION}

In an effort to increase understanding of women's descriptive representation in the formal political arena, I developed the Diamond Index as a tool to test whether global quality data can be collected to broaden the current set of indicators being used in this space. The index identifies a total of 12 decision-making positions from the executive, legislative, judicial, and security domains that are consistently found across the majority of countries. A total of 40 pilot countries were selected and then mapped according to the Diamond Index methodology.

This chapter presents the data collected in an 18-month period between 2014 to 2015. The research is designed to answer the overarching question: Can quality data measuring women's positions of formal political decision-making be collected on a global scale? In addition, two sub-components of the research question are also explored through the data:

1) To what extent are women accessing decision-making positions horizontally across formal government and the security sector?

2) To what extent are women accessing decision-making positions vertically across formal government and the security sector?

While the main research question attempts to examine the quality and quantity of global data, the sub-questions shed more nuance on women's descriptive political representation both horizontally across institutions and vertically within institutions. Looking only at percentages of women, these two questions attempt to further

495 Inter-Parliamentary Union. “Women in Politics." 2017. 
examine the phenomenon of glass walls and glass ceilings within the political sector. While the main research question uncovers global trends regarding the availability of political data on women, the two sub-questions present an unweighted representational picture of how that data is dispersed across governments.

The chapter begins with a rank ordering of all 40 countries according to their scores from highest to lowest. Separate indexes were then created according to each of the four domains in order to visualize how countries compared to one another in relation to each selected branch of government. Countries were then examined by geographical clustering. This allowed for an examination of similarities and differences across the five regions selected. Finally, horizontal and vertical representation were examined. This included looking first at the percentage of women encumbering different positions and then at trends emerging from geographic clusters of countries.

Because the Diamond Index represents only one moment in time, it is impossible to conclude whether women are moving across varying levels of decision-making authority. One data collection point can only present the current state-of-play in any respective country. Looking at the data across 40 countries and five regions, however, does allow for certain patterns to emerge for further consideration.

\subsection{OVERVIEW OF THE DIAMOND INDEX IN 40 COUNTRIES}

Of the 40 countries analyzed for the Diamond Index, 18 (45\%) of those countries collected $100 \%$ of the selected indicators across all four dimensions. An overall score of 50 (12.5 in each sector) represents approximate parity between men and women among the identified decision-making positions. A maximum score of 100 indicates all decision-making positions are held by women while a score of zero would indicate women are not present in any of the positions. Table 25 highlights the 18 countries with full scores in rank order from highest to lowest.

TABLE 25: 20 Countries with Full Diamond Index 2015 Scores

\begin{tabular}{|c|c|c|c|c|c|}
\hline \multirow{2}{*}{$\begin{array}{l}\text { COUNTRY } \\
\text { RANKING }\end{array}$} & \multicolumn{4}{|c|}{ WEIGHTED SCORES } & \multirow{2}{*}{$\begin{array}{l}\text { TOTAL } \\
\text { SCORE }\end{array}$} \\
\hline & EXECUTIVE & LEGISLATIVE & JUDICIAL & SECURITY & \\
\hline 1. South Africa & 9.5 & 7.6 & 6.0 & 7.0 & 30.1 \\
\hline 2. Rwanda & 9.5 & 7.8 & 9.2 & 1.4 & 27.9 \\
\hline 3. Kenya & 6.4 & 4.1 & 8.0 & 2.0 & 20.5 \\
\hline
\end{tabular}




\begin{tabular}{l|l|l|l|l|l}
\hline 4. Albania & 6.2 & 4.4 & 5.9 & 2.0 & 18.5 \\
\hline 5. Bosnia-Herz. & 2.6 & 2.5 & 11.6 & 1.1 & 17.8 \\
\hline 6. Timor-Leste & 3.0 & 4.0 & 8.9 & 1.8 & 17.7 \\
\hline 7. Georgia & 5.0 & 2.5 & 8.4 & 1.5 & 17.4 \\
\hline 8. Guatemala & 4.8 & 4.0 & 6.4 & 1.8 & 17.0 \\
\hline 9. Cote d'Ivoire & 3.1 & 3.1 & 6.9 & 2.2 & 15.3 \\
\hline 10. Nigeria & 5.0 & 1.7 & 6.7 & 1.5 & 14.9 \\
\hline 11. Mexico & 4.4 & 3.5 & 4.5 & 1.5 & 13.9 \\
\hline 12. Brazil & 4.5 & 0.8 & 4.4 & 3.6 & 13.3 \\
\hline 13. Mali & 2.5 & 2.5 & 6.6 & 1.1 & 12.7 \\
\hline 14. Indonesia & 3.1 & 3.7 & 2.0 & 1.7 & 10.5 \\
\hline 15. Bangladesh & 1.7 & 4.3 & 2.7 & 1.3 & 10.0 \\
\hline 16. Nepal & 1.9 & 3.6 & 1.3 & 0.3 & 7.1 \\
\hline 17. Haiti & 3.6 & 0.2 & 2.9 & 0.2 & 6.9 \\
\hline 18. Thailand & 1.1 & 0.7 & 1.4 & 0.4 & 3.6 \\
\hline
\end{tabular}

Of the remaining countries not fully scored, the security sector proved a data collection impediment for 19 of the 20 countries. The countries of Tunisia and Kyrgyzstan also lacked data in the judiciary and no score was calculated for either. Niger was the single country, out of 40 , to have a full security data set but lack sufficient information in other domains (executive and judicial) to calculate a score. ${ }^{496}$ Table 26 shows all 40 countries. Scores were calculated if only the security sector was missing.

TABLE 26: Diamond Index 2015 Scores of all 40 Countries

\begin{tabular}{|c|c|c|c|c|c|}
\hline \multirow{2}{*}{$\begin{array}{l}\text { COUNTRY } \\
\text { RANKING }\end{array}$} & \multicolumn{4}{|c|}{ WEIGHTED SCORES } & \multirow{2}{*}{$\begin{array}{l}\text { TOTAL } \\
\text { SCORE }\end{array}$} \\
\hline & EXECUTIVE & LEGISLATIVE & LEGISLATIVE & SECURITY & \\
\hline 1. South Africa & 9.5 & 7.6 & 6.0 & 7.0 & 30.1 \\
\hline 2. Rwanda & 9.5 & 7.8 & 9.2 & 1.4 & 27.9 \\
\hline 3. Kenya & 6.4 & 4.1 & 8.0 & 2.0 & 20.5 \\
\hline 4. Albania & 6.2 & 4.4 & 5.9 & 2.0 & 18.5 \\
\hline 5. Bosnia-Herz. & 2.6 & 2.5 & 11.6 & 1.1 & 17.8 \\
\hline 6. Timor-Leste & 3.0 & 4.0 & 8.9 & 1.8 & 17.7 \\
\hline 7. Philippines & 6.2 & 5.1 & 6.3 & - & 17.6 \\
\hline
\end{tabular}

496 Individual Diamond Index Country Scorecards (Annex B) detail how scores were calculated and where data gaps exist. 


\begin{tabular}{|c|c|c|c|c|c|}
\hline \multirow{2}{*}{$\begin{array}{l}\text { COUNTRY } \\
\text { RANKING }\end{array}$} & \multicolumn{4}{|c|}{ WEIGHTED SCORES } & \multirow{2}{*}{$\begin{array}{l}\text { TOTAL } \\
\text { SCORE }\end{array}$} \\
\hline & EXECUTIVE & LEGISLATIVE & LEGISLATIVE & SECURITY & \\
\hline 8. Georgia & 5.0 & 2.5 & 8.4 & 1.5 & 17.4 \\
\hline 9. Burkina Faso & 2.6 & 2.5 & 10.4 & 1.7 & 17.2 \\
\hline 10. Guatemala & 4.8 & 4.0 & 6.4 & 1.8 & 17.0 \\
\hline 11. Mongolia & 3.1 & 3.6 & 9.7 & - & 16.4 \\
\hline 12. Liberia & 8.4 & 1.5 & 6.4 & - & 16.3 \\
\hline 13. Colombia & 6.8 & 4.3 & 4.8 & - & 15.9 \\
\hline 14. Ghana & 5.5 & 2.1 & 7.8 & - & 15.4 \\
\hline 15. Cote d'Ivoire & 3.1 & 3.1 & 6.9 & 2.2 & 15.3 \\
\hline 16. Nigeria & 5.0 & 1.7 & 6.7 & 1.5 & 14.9 \\
\hline 17. Madagascar & 4.3 & 4.6 & 5.9 & - & 14.8 \\
\hline 18. Mozambique & 5.2 & 4.7 & 4.4 & - & 14.3 \\
\hline 19. Benin & 4.6 & 2.1 & 7.2 & - & 13.9 \\
\hline 20. Mexico & 4.4 & 3.5 & 4.5 & 1.5 & 13.9 \\
\hline 21. Brazil & 4.5 & 0.8 & 4.4 & 3.6 & 13.3 \\
\hline 22. Mali & 2.5 & 2.5 & 6.6 & 1.1 & 12.7 \\
\hline 23. Algeria & 2.3 & 2.0 & 7.4 & - & 11.7 \\
\hline 24. India & 2.4 & 6.2 & 1.9 & 1.1 & 11.5 \\
\hline 25. Ukraine & 2.8 & 3.0 & 5.0 & - & 10.8 \\
\hline 26. Indonesia & 3.1 & 3.7 & 2.0 & 1.7 & 10.5 \\
\hline 27. Senegal & 3.0 & 5.6 & 1.0 & - & 10.4 \\
\hline 28. Cambodia & 2.2 & 3.6 & 4.4 & - & 10.2 \\
\hline 29. Bangladesh & 1.7 & 4.3 & 2.7 & 1.3 & 10.0 \\
\hline 30. Morocco & 3.0 & 2.6 & 3.8 & - & 9.4 \\
\hline 31. Nepal & 1.9 & 3.6 & 1.3 & 0.3 & 7.1 \\
\hline 32. Haiti & 3.6 & 0.2 & 2.9 & 0.2 & 6.9 \\
\hline 33. Jordan & 2.2 & 1.9 & 1.6 & - & 5.7 \\
\hline 34. Lebanon & 0.9 & 1.2 & 1.5 & - & 3.6 \\
\hline 35. Iraq & 0.8 & 2.3 & 0.5 & - & 3.6 \\
\hline 36. Thailand & 1.1 & 0.7 & 1.4 & 0.4 & 3.6 \\
\hline 37. Yemen & 2.2 & 0.0 & 0.1 & - & 2.3 \\
\hline 38. Tunisia & 4.4 & 3.4 & - & - & - \\
\hline 39. Kyrgyzstan & 3.0 & 2.2 & - & - & - \\
\hline 40. Niger & - & 3.6 & - & 0.9 & - \\
\hline
\end{tabular}

\section{- Insufficient Data to Calculate Score}


Of the 40 countries selected, more than 26 points separate the highest-scoring country, South Africa, from the lowest scoring country, Yemen. Visually, the difference is quite dramatic when mapped. South Africa has all 12 data points included. Yemen includes all data points for the executive, legislative, and judicial branches. Both countries' Diamond Index scores are presented in Graph 6.

\section{GRAPH 6: Diamond Index Scores for South Africa and Yemen}

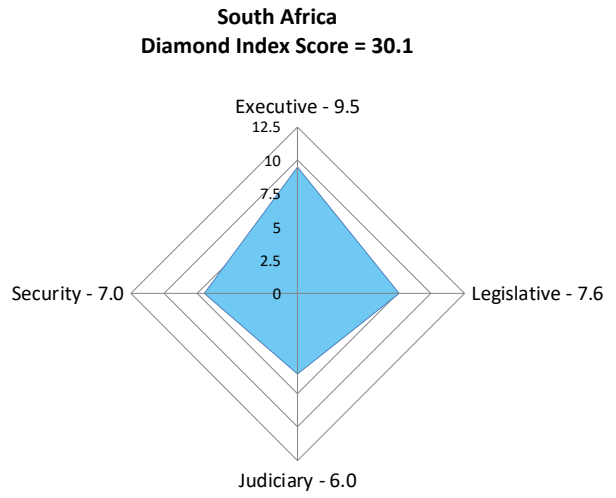

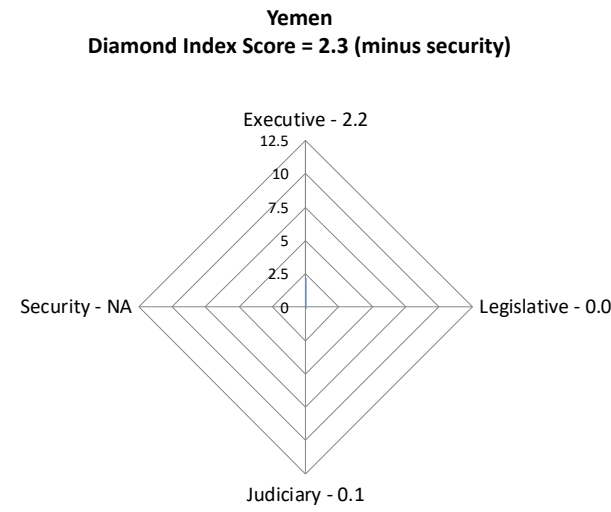

While the security sector is not calculated in the current Yemeni score, given the stark absence of women throughout the government and police, ${ }^{497}$ it is unlikely that there would be a significant boost in score if all officer positions in the police were weighted and included. South Africa, on the other hand, was the only country to exhibit the strong representation of women in the security sector and the semblance of a robust diamond representing progress towards parity in all four domains. A much more typical configuration for a country was a triangle shape with the judiciary score often exceeding other domains, as seen in Mali, paired with a low security score. The combined 40-country average exhibits as a small diamond, although again the judiciary outscores the other three domains. Scores for Mali and the 40-country Diamond Index average are presented in Graph 7.

497 Yemen's police forces contained 168,996 men and 2,868 women (1.7\%): Al-Methaq. "Yemen: female police surveillance of terrorists in the security points and at the entrances to major cities." 14 October 2010. 
GRAPH 7: Diamond Index Score for Mali and the 40-Country Average ${ }^{498}$
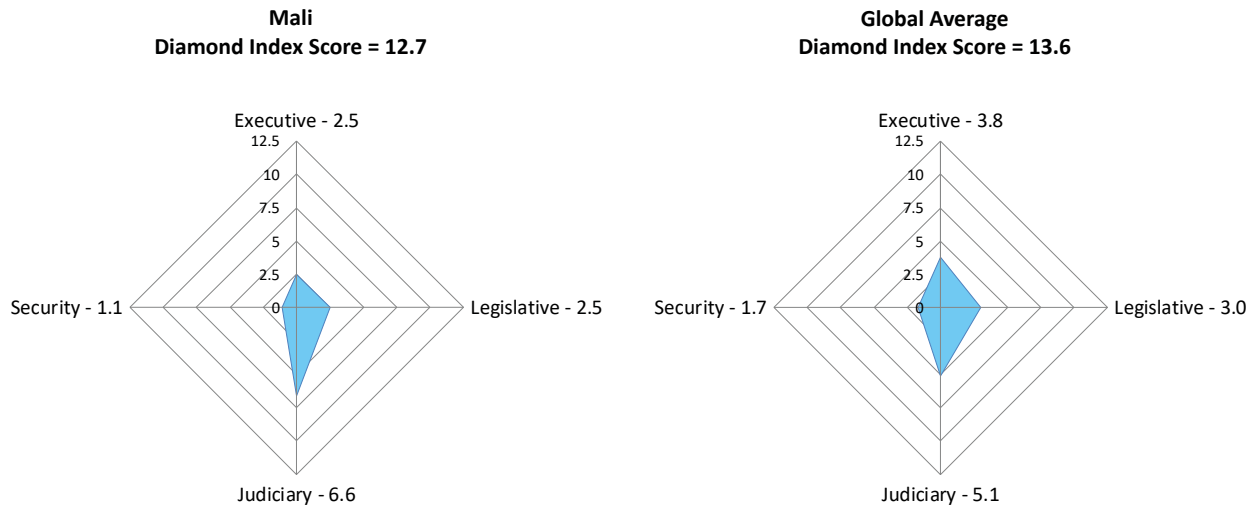

The global average score of 13.6 - with conversely a male global average of 86.4 indicates that women's representation in decision-making positions is less than onesixth men's representation according to the Diamond Index scoring methodology, with the concept of parity a futuristic vision rather than today's reality. Table 27 highlights regional and global average scores in each of the model's four domains across the 40-country sample. Again, a score of 12.5 in each domain would approximate male-female parity.

TABLE 27: Diamond Index 2015 Weighted Scores by Region and Global Average

\begin{tabular}{l|c|c|c|c}
\hline REGIONAL AVERAGE SCORES & EXECUTIVE & LEGISLATIVE & JUDICIAL & SECURITY \\
\hline Eastern Europe/Eurasia & 3.9 & 2.9 & 7.7 & 1.5 \\
\hline Latin America/Caribbean & 4.8 & 2.6 & 4.6 & 1.8 \\
\hline Asia & 2.7 & 3.9 & 4.3 & 1.1 \\
\hline Africa & 5.4 & 3.8 & 6.7 & 2.2 \\
\hline Middle East/North Africa & 2.3 & 1.9 & 2.5 & NA \\
\hline TOTAL & 19.1 & 15.1 & 25.7 & 6.6 \\
\hline GLOBAL AVERAGE SCORES & 3.8 & 3.0 & 5.1 & $\mathbf{1 . 7}$
\end{tabular}

498 Diamond Index graphs of all countries and regions can be found in Annex A. 


\section{Glass Walls - Overview}

Looking horizontally across government, with the exception of security, we see significant numbers of women represented in all three branches. In no area, however, have women decision-makers achieved the popular $30 \%$ critical mass benchmark when reviewing averages across all 40 countries. Overall, appointments within the judiciary are moving closest to $30 \%$, and all three tiers in this branch outscored their equivalents in the other domains. Tier 3 judicial positions scored especially high, with an average of $27.1 \%$ women occupying this decision-making position. The judiciary was also the only area to have all three tiers of women's representation exceed 10\%. Conversely, strong glass walls would appear to be erected around the security sector. All three tiers of security scored below 10\% representation. The distribution of women by percentage across the four domains is highlighted in Table 28.

TABLE 28: Global Percentage of Women by Horizontal Distribution (Glass Walls)

\begin{tabular}{|c|c|c|c|c|c|c|c|c|c|c|c|c|}
\hline \multirow[t]{2}{*}{ Percent } & \multicolumn{3}{|c|}{ Executive } & \multicolumn{3}{|c|}{ Legislative } & \multicolumn{3}{|c|}{ Judicial } & \multicolumn{3}{|c|}{ Security } \\
\hline & Tier 1 & Tier 2 & Tier 3 & Tier 1 & Tier 2 & Tier 3 & Tier 1 & Tier 2 & Tier 3 & Tier 1 & Tier 2 & Tier 3 \\
\hline $0-5$ & & & & & & & & & & $X$ & & \\
\hline $6-10$ & & & $X$ & $X$ & & & & & & & $X$ & $X$ \\
\hline \multicolumn{13}{|l|}{$11-15$} \\
\hline $16-20$ & $x$ & $x$ & & & $x$ & $X$ & $x$ & $X$ & & & & \\
\hline \multicolumn{13}{|l|}{$21-25$} \\
\hline $26-30$ & & & & & & & & & $X$ & & & \\
\hline \multicolumn{13}{|l|}{$31-35$} \\
\hline \multicolumn{13}{|l|}{$36-40$} \\
\hline \multicolumn{13}{|l|}{ 41-45 } \\
\hline \multicolumn{13}{|l|}{$46-50$} \\
\hline Average & 16.8 & 18.3 & 6.0 & 6.0 & 18.2 & 19.2 & 18.0 & 20.1 & 27.2 & 4.8 & 7.6 & 8.3 \\
\hline
\end{tabular}

\section{Glass Ceilings - Overview}

In all regions there appears to be the existence of a "glass ceiling," with higher percentages of women inhibiting Tiers 2 and 3. Most noticeably, women are clustered in lower levels within the judicial and security domains. Within the executive, the contrast between Tier 1 positions and Tier 2 positions was less apparent. Percentages 
are closer between senior executives (Tier $2-18.3 \%$ ) and ministerial positions (Tier 1 $-16.8 \%$ ). In the legislative branch, the percentage of women parliamentarians (Tier $3-19.2 \%$ ) aligns closely with the percentage of committee chairs (Tier $2-18.2 \%$ ). It would appear that women elected or appointed to parliament are also being elected or appointed to head committees in roughly equal measure.

An exception to the appearance of the glass ceiling is found within the executive. For a glass ceiling to be present, the expectation is that Tier 3 and Tier 2 positions - those with lesser authority - would have higher percentages of women than Tier 1 positions. This pattern holds true for the legislative, judicial, and security domains. Within the executive branch, however, there is a stark absence of women in the Tier 3 category of mayoral positions. Globally, out of 385 top urban centers measured, women were found to occupy 23 positions. ${ }^{499}$ If you subtract Liberia's unique situation, in which eight mayors were appointed by the president due to delayed local elections, there are 15 women mayors or 3.9\%. The story is similar for political party leadership (Legislative, Tier 1) where numbers of women present were strikingly low. In total, women led $6.0 \%$ of the parties that hold seats in lower houses.

As noted earlier, the percentage of women in the security sector falls below $10 \%$ in all three tiers. This was anticipated given the small overall percentage of women in police institutions as a whole. Women seem to be making the most gains in the lower-level officer ranks of police forces. The distribution of women by percentage across the three tiers within each domain is highlighted in Table 29.

499 No Tier 3 data was found for Niger; only data on the top five cities for Ghana was available. This resulted in a total of 385 available data points out of a possible 400 . 
TABLE 29: Global Percent of Women by Vertical Distribution (Glass Ceiling)

\begin{tabular}{|c|c|c|c|c|c|c|c|c|c|c|c|}
\hline & $0-5$ & 6-10 & 11-15 & $16-20$ & 21-25 & $26-30$ & $31-35$ & $36-40$ & 41-45 & $46-50$ & $51+$ \\
\hline \multicolumn{12}{|l|}{ Executive } \\
\hline \multicolumn{12}{|l|}{ Ministers } \\
\hline Senior Executives & & & & $x$ & & & & & & & \\
\hline \multicolumn{12}{|l|}{ Top 10 mayors } \\
\hline \multicolumn{12}{|l|}{ Legislative } \\
\hline \multicolumn{12}{|l|}{ Party Leaders } \\
\hline \multicolumn{12}{|l|}{ Committee Chairs } \\
\hline Legislators & & & & $x$ & & & & & & & \\
\hline \multicolumn{12}{|l|}{ Judicial } \\
\hline \multicolumn{12}{|l|}{ Constitutional } \\
\hline \multicolumn{12}{|l|}{ Supreme Court } \\
\hline High Court & & & & & & $x$ & & & & & \\
\hline \multicolumn{12}{|l|}{ Security } \\
\hline \multicolumn{12}{|l|}{ Sr.-level officers } \\
\hline \multicolumn{12}{|l|}{ Mid-level officers } \\
\hline Low-level officers & & $x$ & & & & & & & & & \\
\hline
\end{tabular}

EXECUTIVE: 16.8-18.3-6.0 LEGISLATIVE: 6.0-18.2-19.2 JUDICIARY: 18.0-20.1-27.2 SECURITY: 4.8-7.6-8.3

\subsection{DIAMOND INDEX - EXECUTIVE DOMAIN}

\section{Overview}

Within the executive domain, the 40-country average score was 3.8 on the Diamond Index (based on a maximum score of 25, with 12.5 approaching parity). Women appear in significant percentages at the Tier 1 Ministers level (16.8\%) as well as Tier 2 Senior Executives (18.3\%). Both Tier 1 and Tier 2 decision-makers are typically appointed through an executive process. While both may be open to further confirmation procedures, through the legislative branch for example, they are not voted on by the general populace. This stands in sharp contrast to the number of Tier 3 Mayors $(6.0 \%)$, a position that may be gained through appointment, a voting process, or combination of the two. 
Despite low percentages and scores in mayoral positions, the executive was the second highest-scoring domain. A total of 15 executive scores $(41 \%)$ outperformed judicial scores in the 37 countries that allowed for comparison (no judicial scores were calculated for Tunisia, Kyrgyzstan, or Niger). However, the executive outscored the legislative domain in $27(69 \%)$ of the 39 countries compared (no executive score was calculated for Niger). Countries from the Asia region in my sample proved to be the exception to this trend. Of the nine Asian countries measured, seven legislative scores outperformed the executive. ${ }^{500}$

Conversely, Africa seems to be making the most significant headway in accessing executive branch political power with the leading average score of 5.2 compared to the 40-country average of 3.8. In total, African countries in my sample hold six of the top ten slots in the executive domain of the Diamond Index. Countries within my sample from Asia and the Middle East regions equally divide the last 10 slots in the executive domain.

The highest ranking Tier 1 decision-maker was identified as a minister. The Tier 2 measure - senior executives - was typically occupied by a higher percentage of women than positions of minister. (Latin America/Caribbean was the exception to this trend.) In total among the 40 countries, there was less than a $2 \%$ difference between the percentage of ministers $(16.8 \%)$ and senior executives $(18.3 \%)$. The Tier 3 measurement - mayors of the 10 largest cities in each country - revealed an enormous gap in women's representation. If we set aside the special case of Liberia, women comprised $3.9 \%$ of the total number of mayors found in the 10 largest cities across the 40 countries mapped. Table $\mathbf{3 0}$ documents the straight percentage of women in the executive branch according to each tier level and averaged by region for the selected countries.

TABLE 30: Percent of Women in the Executive Branch by Tier and Region

\begin{tabular}{|l|c|c|c|c|c|c|c|} 
& $\begin{array}{c}\text { Eastern } \\
\text { Europe/ } \\
\text { Eurasia }\end{array}$ & $\begin{array}{c}\text { Latin } \\
\text { America/ } \\
\text { Caribbean }\end{array}$ & Asia & Africa & $\begin{array}{c}\text { Middle } \\
\text { East/ } \\
\text { N. Africa }\end{array}$ & Total & $\begin{array}{c}\text { Global } \\
\text { Average }\end{array}$ \\
\hline Tier 1 & 15.9 & 24.2 & 11.1 & 23.8 & 9.0 & 84.4 & 16.8 \\
\hline Tier 2 & 21.2 & 18.5 & 12.7 & 25.7 & 13.4 & 91.5 & 18.3 \\
\hline Tier 3 & 4.0 & 6.0 & 6.7 & 11.7 & 1.4 & 29.8 & 6.0 \\
\hline
\end{tabular}

500 Those countries with higher legislative domain scores included: Bangladesh, Cambodia, India, Indonesia, Mongolia, Nepal, Timor-Leste, Madagascar, Senegal, Iraq, Lebanon, and Ukraine. 
While percentages of women in each tier is important if we remain interested in tracking towards a critical mass or parity in these areas, we must also look at weighted scores established by the Diamond Index given the varying levels of authority accorded different tiers and decision-making positions. The 40-country executive Diamond Index score achieved an average of 3.8 out of a possible 25 points (with 25 representing all decision-making positions filled by women). Table 31 provides all 40 countries according to their weighted index executive score, ranked from highest to lowest.

TABLE 31: Executive Rankings: Diamond Index 2015

\begin{tabular}{|c|c|c|c|c|c|}
\hline \multirow{2}{*}{$\begin{array}{c}\text { ALL } \\
\text { COUNTRIES }\end{array}$} & \multicolumn{4}{|c|}{ WEIGHTED SCORES } & \multirow{2}{*}{$\begin{array}{l}\text { TOTAL } \\
\text { SCORE }\end{array}$} \\
\hline & EXECUTIVE & LEGISLATIVE & JUDICIAL & SECURITY & \\
\hline \multicolumn{6}{|c|}{ Global Executive Average Score $=3.8$} \\
\hline 1. South Africa & 9.5 & 7.6 & 6.0 & 7.0 & 30.1 \\
\hline 2. Rwanda & 9.5 & 7.8 & 9.2 & 1.4 & 27.9 \\
\hline 3. Liberia & 8.4 & 1.5 & 6.4 & - & 16.3 \\
\hline 4. Colombia & 6.8 & 4.3 & 4.8 & - & 15.9 \\
\hline 5. Kenya & 6.4 & 4.1 & 8.0 & 2.0 & 20.5 \\
\hline 6. Philippines & 6.2 & 5.1 & 6.3 & - & 17.6 \\
\hline 7. Albania & 6.2 & 4.4 & 5.9 & 2.0 & 18.5 \\
\hline 8. Ghana & 5.5 & 2.1 & 7.8 & - & 15.4 \\
\hline 9. Mozambique & 5.2 & 4.7 & 4.4 & - & 14.3 \\
\hline 10. Georgia & 5.0 & 2.5 & 8.4 & 1.5 & 17.4 \\
\hline 11. Nigeria & 5.0 & 1.7 & 6.7 & 1.5 & 14.9 \\
\hline 12. Guatemala & 4.8 & 4.0 & 6.4 & 1.8 & 17.0 \\
\hline 13. Benin & 4.6 & 2.1 & 7.2 & - & 13.9 \\
\hline 14. Brazil & 4.5 & 0.8 & 4.4 & 3.6 & 13.3 \\
\hline 15. Mexico & 4.4 & 3.5 & 4.5 & 1.5 & 13.9 \\
\hline 16. Tunisia & 4.4 & 3.4 & - & - & - \\
\hline 17. Madagascar & 4.3 & 4.6 & 5.9 & - & 14.8 \\
\hline 18. Haiti & 3.6 & 0.2 & 2.9 & 0.2 & 6.9 \\
\hline 19. Mongolia & 3.1 & 3.6 & 9.7 & - & 16.4 \\
\hline 20. Cote d'Ivoire & 3.1 & 3.1 & 6.9 & 2.2 & 15.3 \\
\hline 21. Indonesia & 3.1 & 3.7 & 2.0 & 1.7 & 10.5 \\
\hline 22. Timor-Leste & 3.0 & 4.0 & 8.9 & 1.8 & 17.7 \\
\hline 23. Senegal & 3.0 & 5.6 & 1.0 & - & 10.4 \\
\hline 24. Morocco & 3.0 & 2.6 & 3.8 & - & 9.4 \\
\hline
\end{tabular}




\begin{tabular}{|c|c|c|c|c|c|}
\hline \multirow{2}{*}{$\begin{array}{c}\text { ALL } \\
\text { COUNTRIES }\end{array}$} & \multicolumn{4}{|c|}{ WEIGHTED SCORES } & \multirow{2}{*}{$\begin{array}{l}\text { TOTAL } \\
\text { SCORE }\end{array}$} \\
\hline & EXECUTIVE & LEGISLATIVE & JUDICIAL & SECURITY & \\
\hline \multicolumn{6}{|c|}{ Global Executive Average Score $=3.8$} \\
\hline 25. Kyrgyzstan & 3.0 & 2.2 & - & - & - \\
\hline 26. Ukraine & 2.8 & 3.0 & 5.0 & - & 10.8 \\
\hline 27. Bosnia-Herz. & 2.6 & 2.5 & 11.6 & 1.1 & 17.8 \\
\hline 28. Burkina Faso & 2.6 & 2.5 & 10.4 & 1.7 & 17.2 \\
\hline 29. Mali & 2.5 & 2.5 & 6.6 & 1.1 & 12.7 \\
\hline 30. India & 2.4 & 6.2 & 1.9 & 1.1 & 11.5 \\
\hline 31. Algeria & 2.3 & 2.0 & 7.4 & - & 11.7 \\
\hline 32. Cambodia & 2.2 & 3.6 & 4.4 & - & 10.2 \\
\hline 33. Jordan & 2.2 & 1.9 & 1.6 & - & 5.7 \\
\hline 34. Yemen & 2.2 & 0.0 & 0.1 & - & 2.3 \\
\hline 35. Nepal & 1.9 & 3.6 & 1.3 & 0.3 & 7.1 \\
\hline 36. Bangladesh & 1.7 & 4.3 & 2.7 & 1.3 & 10.0 \\
\hline 37. Thailand & 1.1 & 0.7 & 1.4 & 0.4 & 3.6 \\
\hline 38. Lebanon & 0.9 & 1.2 & 1.5 & - & 3.6 \\
\hline 39. Iraq & 0.8 & 2.3 & 0.5 & - & 3.6 \\
\hline 40. Niger & - & 3.6 & - & 0.9 & - \\
\hline
\end{tabular}

- Unable to calculate score

\section{Regional Highlights}

Looking at all executive scores reinforces that while women are present in the executive branch, interesting differences appear when we examine the data across regions. Sample countries in the two regions of Africa and Latin America/Caribbean scored first and second, respectively, as seen in Table 30. Africa garners the highest average with 5.2 (again out of a total score of 25 with 12.5 approaching parity). This is achieved through the index's highest scores of South Africa, Rwanda, and Liberia. ${ }^{501}$ Kenya, with its 2010 constitution mandating one-third of all elected and appointed positions for women, is also among the higher-scoring countries at 6.4. The five lowest-scoring countries in this region are all from West Africa (Benin, Burkina Faso, Cote d'Ivoire, Mali, and Senegal).

The sample countries from the regions of Asia and Middle East/North Africa were ranked respectively fourth and fifth, with scores close to one another. Asia's

501 Calculating Liberia's score without Tier 3 Mayors, all appointed by the president, results in an executive score of 24.3 putting it in fourth place behind South Africa, Rwanda, and Kenya. 
executive score averaged 2.7 across nine countries while the Middle East/North Africa averaged 2.3 across seven countries. Despite India and Bangladesh having a history of women leaders at the highest executive level, both countries scored low in this domain.

Among the seven Middle East/North African countries, Morocco was the bright spot with a score of 3.0. This resulted from having the highest ministerial representation of women (15.8\%) and the sole woman mayor of a large urban center. Table 32 represents the Diamond Index scores across the 40 countries organized by region with the executive branch highlighted.

TABLE 32: Diamond Index 2015 - Weighted Executive Scores by Region

\begin{tabular}{|c|c|c|c|c|c|}
\hline \multirow{2}{*}{$\begin{array}{l}\text { REGION } \\
\text { COUNTRY }\end{array}$} & \multicolumn{4}{|c|}{ WEIGHTED SCORES } & \multirow{2}{*}{$\begin{array}{l}\text { TOTAL } \\
\text { SCORE }\end{array}$} \\
\hline & EXECUTIVE & LEGISLATIVE & JUDICIAL & SECURITY & \\
\hline \multicolumn{6}{|c|}{ Eastern Europe/Eurasia - 3.9 Average Score } \\
\hline Albania & 6.2 & 4.4 & 5.9 & 2.0 & 18.5 \\
\hline Georgia & 5.0 & 2.5 & 8.4 & 1.5 & 17.4 \\
\hline Kyrgyzstan & 3.0 & 2.2 & - & - & - \\
\hline Ukraine & 2.8 & 3.0 & 5.0 & - & 10.8 \\
\hline Bosnia-Herz. & 2.6 & 2.5 & 11.6 & 1.1 & 17.8 \\
\hline \multicolumn{6}{|c|}{ Latin America/Caribbean - 4.8 Average Score } \\
\hline Colombia & 6.8 & 4.3 & 4.8 & - & 15.9 \\
\hline Guatemala & 4.8 & 4.0 & 6.4 & 1.8 & 17.0 \\
\hline Brazil & 4.5 & 0.8 & 4.4 & 3.6 & 13.3 \\
\hline Mexico & 4.4 & 3.5 & 4.5 & 1.5 & 13.9 \\
\hline Haiti & 3.6 & 0.2 & 2.9 & 0.2 & 6.9 \\
\hline \multicolumn{6}{|c|}{ Asia - 2.7 Average Score } \\
\hline Philippines & 6.2 & 5.1 & 6.3 & - & 17.6 \\
\hline Mongolia & 3.1 & 3.6 & 9.7 & - & 16.4 \\
\hline Indonesia & 3.1 & 3.7 & 2.0 & 1.7 & 10.5 \\
\hline Timor-Leste & 3.0 & 4.0 & 8.9 & 1.8 & 17.7 \\
\hline India & 2.4 & 6.2 & 1.9 & 1.1 & 11.6 \\
\hline Cambodia & 2.2 & 3.6 & 4.4 & - & 10.2 \\
\hline Nepal & 1.9 & 3.6 & 1.3 & 0.3 & 7.1 \\
\hline Bangladesh & 1.7 & 4.3 & 2.7 & 1.3 & 10.0 \\
\hline Thailand & 1.1 & 0.7 & 1.4 & 0.4 & 3.6 \\
\hline
\end{tabular}




\begin{tabular}{|c|c|c|c|c|c|}
\hline \multirow{2}{*}{$\begin{array}{l}\text { REGION } \\
\text { COUNTRY }\end{array}$} & \multicolumn{4}{|c|}{ WEIGHTED SCORES } & \multirow{2}{*}{$\begin{array}{l}\text { TOTAL } \\
\text { SCORE }\end{array}$} \\
\hline & EXECUTIVE & LEGISLATIVE & JUDICIAL & SECURITY & \\
\hline \multicolumn{6}{|c|}{ Africa - 5.2 Average Score } \\
\hline South Africa & 9.5 & 7.6 & 6.0 & 7.0 & 30.1 \\
\hline Rwanda & 9.5 & 7.8 & 9.2 & 1.4 & 27.9 \\
\hline Liberia & 8.4 & 1.5 & 6.4 & - & 16.3 \\
\hline Kenya & 6.4 & 4.1 & 8.0 & 2.0 & 20.5 \\
\hline Ghana & 5.5 & 2.1 & 7.8 & - & 15.4 \\
\hline Mozambique & 5.2 & 4.7 & 4.4 & - & 14.3 \\
\hline Nigeria & 5.0 & 1.7 & 6.7 & 1.5 & 14.9 \\
\hline Benin & 4.6 & 2.1 & 7.2 & - & 13.9 \\
\hline Madagascar & 4.3 & 4.6 & 5.9 & - & 14.8 \\
\hline Cote d'Ivoire & 3.1 & 3.1 & 6.9 & 2.2 & 15.3 \\
\hline Senegal & 3.0 & 5.6 & 1.0 & - & 9.6 \\
\hline Burkina Faso & 2.6 & 2.5 & 10.4 & 1.7 & 17.2 \\
\hline Mali & 2.5 & 2.5 & 6.6 & 1.1 & 12.7 \\
\hline Niger & - & 3.6 & - & 0.9 & - \\
\hline \multicolumn{6}{|c|}{ Middle East/North Africa - 2.3 Average Score } \\
\hline Tunisia & 4.4 & 3.4 & - & - & - \\
\hline Morocco & 3.0 & 2.6 & 3.8 & - & 9.4 \\
\hline Algeria & 2.3 & 2.0 & 7.4 & - & 11.7 \\
\hline Jordan & 2.2 & 1.9 & 1.6 & - & 5.7 \\
\hline Yemen & 2.2 & 0.0 & 0.1 & - & 2.3 \\
\hline Lebanon & 0.9 & 1.2 & 1.5 & - & 3.6 \\
\hline Iraq & 0.8 & 2.3 & 0.5 & - & 3.6 \\
\hline \multicolumn{6}{|c|}{ Global Average Executive Score - 3.8} \\
\hline
\end{tabular}

- Unable to calculate score

\subsection{DIAMOND INDEX - LEGISLATIVE DOMAIN}

\section{Overview}

In the legislative domain, the 40-country average achieved a score of 3.0 on the Diamond Index (based on a maximum score of 25, with 12.5 approaching parity). Women appear in significant percentages at the Tier 2 Committee Chair level (18.2\%) as well as the Tier 3 Legislators (19.3\%). Tier 1 Political Party Leaders scored significantly lower, with an average of $6.0 \%$ female representation in this decision- 
making position. Women were strikingly absent from the Tier 1 position in all regions within the research sample, with Asia scoring the highest at $11.1 \%$ women in party leadership positions.

In examining the percentage of women holding Tier 2 committee leadership positions, it generally appears in proportion to the number of legislative seats held. So, as women are gaining legislative seats, they are also gaining access to committee leadership. What the Diamond Index does not attempt to measure, however, is which committee chairs women are gaining. Based on the analysis of ministerial appointments in 117 countries by Krook and O'Brien, ${ }^{502}$ one might assume that women are disproportionately assigned to "lower-prestige" committees. Currently, there exists insufficient data on legislative committee chairs to verify such claims.

The legislative branch composite measure averaged 3.0 (out of a maximum of 25), a score lower than the executive or judicial branches. Because the Diamond Index does not measure straight percentages of women, but rather weights specific positions, the overall percentage of females may be higher in the legislature than other parts of government but result in a relatively low score because women are under-represented as committee chairs or heads of parties. Table 33 documents the straight percentage of women in the legislative branch according to each tier level and averaged by region for the selected countries.

Table 33: Percent of Women in the Legislative Branch by Tier and Region

\begin{tabular}{|l|c|c|c|c|c|c|c|c} 
& $\begin{array}{c}\text { Eastern } \\
\text { Europe/ } \\
\text { Eurasia }\end{array}$ & $\begin{array}{c}\text { Latin } \\
\text { America/ }\end{array}$ & Caribbean & Asia & Africa & $\begin{array}{c}\text { Middle } \\
\text { East/ } \\
\text { N. Africa }\end{array}$ & $\begin{array}{c}\text { Total } \\
\text { Global } \\
\text { Average }\end{array}$ \\
\hline Tier 1 & 4.4 & 8.2 & 11.1 & 4.7 & 1.6 & 30.0 & 6.0 \\
\hline Tier 2 & 21.0 & 10.8 & 18.7 & 27.9 & 12.5 & 90.9 & 18.2 \\
\hline Tier 3 & 17.6 & 17.1 & 21.7 & 22.6 & 17.2 & 96.2 & 19.2 \\
\hline
\end{tabular}

The highest ranking (Tier 1) decision-maker was identified as a political party leader with party representation in the lower house. So, for example, in a country where 40,

\footnotetext{
502 Krook, Mona Lena, and Diana O'Brien. “All the President's Men? The Appointment of Female Cabinet Ministers Worldwide." Presented at the Midwest Political Science Association National Conference, Chicago, IL, 2011. http:// krook.wustl.edu/pdf/mpsa_krook_obrien_11.pdf.
} 
50 , or more parties are registered, only those obtaining seats in the legislature (lower house if a bi-cameral system) were counted. Women occupying party leadership positions averaged $6.0 \%$ across the 40 countries.

The Tier 3 measurement - percentage of women legislators - was also included, although weighted less than committee chairs and party leaders. The percent of women in the legislature has been the most common standard used to measure women's access to what other indexes term "political power" or women's "political empowerment." The data collected by the Inter-Parliamentary Union (IPU) is used in most gender indexes measuring the political space. It was also one of the indicators tracked for achievement of the UN Millennium Development Goals through 2015. Currently, the UN Sustainable Development Goals (SDGs) also use the proportion of seats held by women in national parliaments as a measure through $2030 .{ }^{503}$ Because the national-level parliamentary figures are continually updated as elections occur, and they cover almost every country in the world, this indicator is a valuable source for measuring and benchmarking progress by country of women in the legislature.

To understand how the Diamond Index might differ from the IPU's straight percentage measure of women in the lower legislature, I compared the Diamond Index countries to the IPU ranking of the same countries. The 40 countries were rank ordered from the highest to the lowest percentage of women - the typical IPU scoring method. In Table 34, the 40-country IPU list was then placed alongside the 40 countries of the Diamond Index, also ordered from highest score to lowest score. A "positive" match, highlighted in light grey, was considered when each of the two indexes located a country within five rankings of one another. A "negative" match, highlighted in dark grey, was noted when a country was separated by more than five rankings on each respective list.

Table 34: Comparison of 2015 Diamond Index to IPU Legislative Rankings

\begin{tabular}{l|c|l|c}
\multicolumn{1}{|c|}{ Country } & $\begin{array}{c}\text { Diamond Index } \\
\text { Legislative Score }\end{array}$ & \multicolumn{1}{|c}{ IPU Index } & $\begin{array}{c}\text { Percent } \\
\text { Parliamentarians }\end{array}$ \\
\hline 1. Rwanda & 7.8 & 1. Rwanda & 63.8 \\
\hline 2. South Africa & 7.6 & 2. Senegal & 42.7 \\
\hline 3. India & 6.2 & 3. South Africa & 41.9 \\
\hline 4. Senegal & 5.6 & 4. Mozambique & 39.6 \\
\hline
\end{tabular}

503 The official list of indicators used to track progress against the UN Sustainable Development Goals (SDGs) can be found at: https://unstats.un.org/sdgs/indicators/indicators-list/ 


\begin{tabular}{|c|c|c|c|}
\hline Country & $\begin{array}{l}\text { Diamond Index } \\
\text { Legislative Score }\end{array}$ & IPU Index & $\begin{array}{c}\text { Percent } \\
\text { Parliamentarians }\end{array}$ \\
\hline 5. Philippines & 5.1 & 5. Timor-Leste & 38.5 \\
\hline 6. Mozambique & 4.7 & 6. Mexico & 38.0 \\
\hline 7. Madagascar & 4.6 & 7. Algeria & 31.6 \\
\hline 8. Albania & 4.4 & 8. Tunisia & 31.3 \\
\hline 9. Bangladesh & 4.3 & 9. Nepal & 29.5 \\
\hline 10. Colombia & 4.3 & 10. Philippines & 27.2 \\
\hline 11. Kenya & 4.1 & 11. Iraq & 26.5 \\
\hline 12. Timor-Leste & 4.0 & 12. Kyrgyzstan & 23.3 \\
\hline 13. Guatemala & 4.0 & 13. Bosnia-Herzegovina & 21.4 \\
\hline 14. Indonesia & 3.7 & 14. Albania & 20.7 \\
\hline 15. Mongolia & 3.6 & 15. Madagascar & 20.5 \\
\hline 16. Cambodia & 3.6 & 16. Cambodia & 20.3 \\
\hline 17. Nepal & 3.6 & 17. Bangladesh & 20.0 \\
\hline 18. Niger & 3.6 & 18. Colombia & 19.9 \\
\hline 19. Mexico & 3.5 & 19. Kenya & 19.7 \\
\hline 20. Tunisia & 3.4 & 20. Indonesia & 17.1 \\
\hline 21. Cote d'Ivoire & 3.1 & 21. Morocco & 17.0 \\
\hline 22. Ukraine & 3.0 & 22. Mongolia & 14.9 \\
\hline 23. Morocco & 2.6 & 23. Burkina Faso & 13.3 \\
\hline 24. Mali & 2.5 & 24. Guatemala & 13.3 \\
\hline 25. Bosnia-Herz. & 2.5 & 25. Niger & 13.3 \\
\hline 26. Georgia & 2.5 & 26. India & 12.0 \\
\hline 27. Burkina Faso & 2.5 & 27. Jordan & 12.0 \\
\hline 28. Iraq & 2.3 & 28. Ukraine & 11.8 \\
\hline 29. Kyrgyzstan & 2.2 & 29. Georgia & 11.3 \\
\hline 30. Benin & 2.1 & 30. Liberia & 11.0 \\
\hline 31. Ghana & 2.1 & 31. Ghana & 10.9 \\
\hline 32. Algeria & 2.0 & 32. Brazil & 9.9 \\
\hline 33. Jordan & 1.9 & 33. Cote d'Ivoire & 9.2 \\
\hline 34. Nigeria & 1.7 & 34. Mali & 8.8 \\
\hline 35. Liberia & 1.5 & 35. Benin & 7.2 \\
\hline
\end{tabular}




\begin{tabular}{l|c|l|l}
\multicolumn{1}{|c|}{ Country } & $\begin{array}{c}\text { Diamond Index } \\
\text { Legislative Score }\end{array}$ & \multicolumn{1}{|c|}{$\begin{array}{c}\text { IPU Index } \\
\text { Percent } \\
\text { Parliamentarians }\end{array}$} \\
\hline 36. Lebanon & 1.2 & 36. Thailand & 6.1 \\
\hline 37. Brazil & 0.8 & 37. Nigeria & 4.2 \\
\hline 38. Thailand & 0.7 & 38. Lebanon & 3.1 \\
\hline 39. Haiti & 0.2 & 39. Haiti & 4.2 \\
\hline 40. Yemen & 0.0 & 40. Yemen & 0.0 \\
\hline
\end{tabular}

Countries ranked within 5 positions on the two indexes

Countries ranked more than 5 positions apart on the two indexes

The two indices align closely in the rankings of the top four countries and the bottom six countries. This is not unexpected. Because Tier 1 positions (party leadership) were among the most underrepresented in the Diamond Index, countries had to score strongly in Tier 2 and Tier 3 (overall percentage of women legislators) to place high in the index. This correlates with how the IPU - reliant on percentages of women scores its index. Likewise, the bottom six countries not only have scant representation in the legislature, but the lack of women is reflected throughout committees and party leadership. For purposes of the Diamond Index and IPU indexes, there are simply very few women present in any legislative capacity. Apart from the two extremes of the indices, however, there is wide variance in how countries are ranked. If we look at the remaining 30 countries, a total of 22 are considered a negative match while eight are considered a positive match.

Iraq and Guatemala are examples of the varying rankings, as presented in Graph $\mathbf{8}$. The IPU ranks Iraq $11^{\text {th }}$ (out of the 40 selected countries) based on a representational rate of $26.5 \%$ women in the legislature. The Diamond Index ranks Iraq much lower (28 out of 40) as there is limited committee leadership (15\%) and no women holding party leadership positions $(0 \%)$. Guatemala, for the opposite reasons, was ranked more than 11 places higher than its IPU rank of 24 . While the country lags behind in straight percentage of women legislators (13.3\%), it has a disproportionately high number of committee chairs (20\%) and party leadership (26.7\%). Because committee chairs and party leaders are defined as having greater decision-makers authority in the legislative, the Diamond Index recognizes and allocates greater weight to those positions as compared to those of rank-and-file members. 


\section{GRAPH 8: Diamond Index - Iraq and Guatemala}
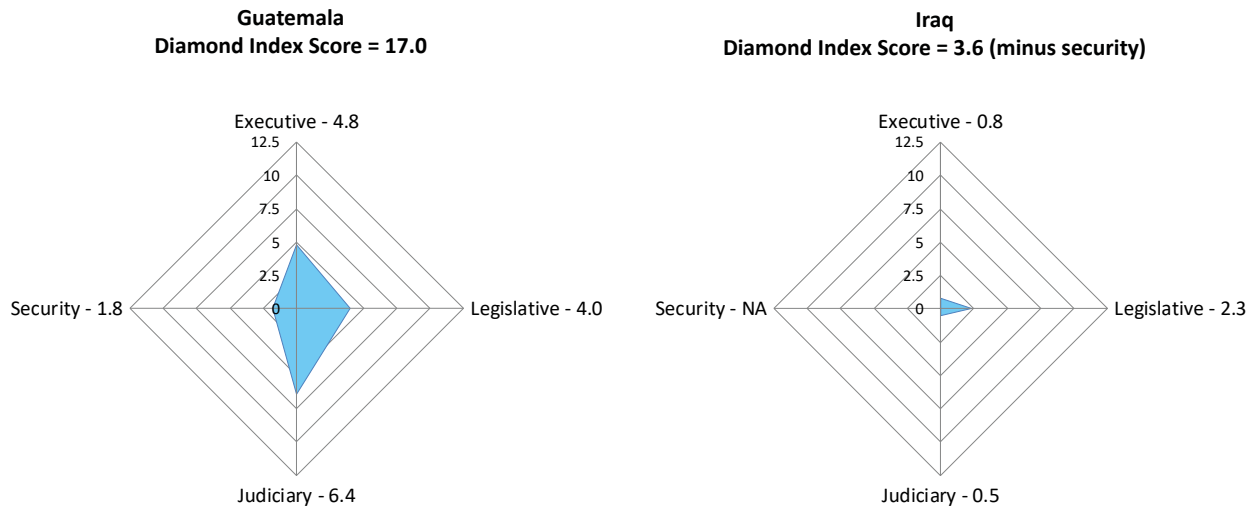

\section{Regional Highlights}

There were a number of regional differences worth noting in the legislative domain. In the Asian countries included in the regional sample, the average legislative score exceeds that of the executive branch; this is the only region where this occurs. Generally, the higher scores in Asia's legislative sector can be attributed to increased percentages of women encumbering the Tier 1 Political Party Leaders position. Of the nine Asian countries measured, six (Bangladesh, India, India, Indonesia, Mongolia, Philippines) had at least one woman party leader. This lends credence to research in this area around the approval of women stepping into party leadership positions, often assuming the role following the death of a close family member such as a husband or father; a phenomenon that D' Amico has described as "the widow's walk to power." ${ }^{504}$ This acceptance of the wife or daughter as a suitable replacement for the original male politician would seem to indicate a high level of tolerance for women as political leaders, whether she arrived at the position through her own accomplishments or in the wake of a male family member. ${ }^{505}$

High scores in the legislative domain do, however, seem to come at the expense of representation in other parts of government. The regional scores of the selected Asian countries in the executive and judicial domains are well below the 40-country

\footnotetext{
504 D’Amico, Francine, and Peter R. Beckman. Women in World Politics: An Introduction. Bergin \& Garvey Westport, Connecticut, 1995.

505 Paxton, Pamela, and Melanie M. Hughes. Women, Politics, and Power. Pine Forge Press, 2007.
} 
average and second only to the Middle East/North Africa average. In the security sector the two regions tie for last place. Within the sample of nine Asian countries selected, the Diamond Index points to women gaining significant representational ground in one sector of government - the legislature - but lagging behind global averages in the remaining.

Sample countries comprising the Africa region finished with the second-highest ranking behind Asia, with an average score of 3.8 as compared to Asia's 3.9. While close in score, for African countries selected (and other regions as well), the legislative score is the lowest among the three government branches. Kenya seems to typify this pattern, with relatively low levels of representation in the legislative branch $(19.7 \%)$ and higher scores in the judiciary and executive. In the case of Kenya, this may be due to 2010 constitutional quotas that now require a minimum of one-third women in all areas of government, either elected or appointed. While legislative numbers remain below the one-third mark for women, it would appear that other sectors relying on appointments are seeing greater gains.

Countries representing the Middle East/North Africa region, as consistently seen across the four domains, finished with the lowest regional score -1.9 out of a possible maximum of 25. Table 35 represents the Diamond Index scores across the 40 countries organized by region with the legislative branch highlighted.

TABLE 35: Diamond Index 2015 - Legislative Scores by Region

\begin{tabular}{|c|c|c|c|c|c|}
\hline \multirow{2}{*}{$\begin{array}{l}\text { REGION } \\
\text { COUNTRY }\end{array}$} & \multicolumn{4}{|c|}{ WEIGHTED SCORES } & \multirow{2}{*}{$\begin{array}{l}\text { TOTAL } \\
\text { SCORE }\end{array}$} \\
\hline & LEGISLATIVE & EXECUTIVE & JUDICIAL & SECURITY & \\
\hline \multicolumn{6}{|c|}{ Eastern Europe/Eurasia - 2.9 Average Score } \\
\hline Albania & 4.4 & 6.2 & 5.9 & 2.0 & 18.5 \\
\hline Ukraine & 3.0 & 2.8 & 5.0 & - & 10.8 \\
\hline Georgia & 2.5 & 5.0 & 8.4 & 1.5 & 17.4 \\
\hline Bosnia-Herz. & 2.5 & 2.6 & 11.6 & 1.1 & 17.8 \\
\hline Kyrgyzstan & 2.2 & 3.0 & - & - & - \\
\hline \multicolumn{6}{|c|}{ Latin America/Caribbean - 2.6 Average Score } \\
\hline Colombia & 4.3 & 6.8 & 4.8 & - & 15.9 \\
\hline Guatemala & 4.0 & 4.8 & 6.4 & 1.8 & 17.0 \\
\hline Mexico & 3.5 & 4.4 & 4.5 & 1.5 & 13.9 \\
\hline Brazil & 0.8 & 4.5 & 4.4 & 3.6 & 13.3 \\
\hline Haiti & 0.2 & 3.6 & 2.9 & 0.2 & 6.9 \\
\hline
\end{tabular}




\begin{tabular}{|c|c|c|c|c|c|}
\hline \multirow{2}{*}{$\begin{array}{l}\text { REGION } \\
\text { COUNTRY }\end{array}$} & \multicolumn{4}{|c|}{ WEIGHTED SCORES } & \multirow{2}{*}{$\begin{array}{l}\text { TOTAL } \\
\text { SCORE }\end{array}$} \\
\hline & LEGISLATIVE & EXECUTIVE & JUDICIAL & SECURITY & \\
\hline \multicolumn{6}{|c|}{ Asia - 3.9 Average Score } \\
\hline India & 6.2 & 2.4 & 1.9 & 1.1 & 11.6 \\
\hline Philippines & 5.1 & 6.2 & 6.3 & - & 17.6 \\
\hline Bangladesh & 4.3 & 1.7 & 2.7 & 1.3 & 10.0 \\
\hline Timor-Leste & 4.0 & 3.0 & 8.9 & 1.8 & 17.7 \\
\hline Indonesia & 3.7 & 3.1 & 2.0 & 1.7 & 10.5 \\
\hline Mongolia & 3.6 & 3.1 & 9.7 & - & 16.4 \\
\hline Cambodia & 3.6 & 2.2 & 4.4 & - & 10.2 \\
\hline Nepal & 3.6 & 1.9 & 1.3 & 0.3 & 7.1 \\
\hline Thailand & 0.7 & 1.1 & 1.4 & 0.4 & 3.6 \\
\hline \multicolumn{6}{|c|}{ Africa - 3.8 Average Score } \\
\hline Rwanda & 7.8 & 9.5 & 9.2 & 1.4 & 27.9 \\
\hline South Africa & 7.6 & 9.5 & 6.0 & 7.0 & 30.1 \\
\hline Senegal & 5.6 & 3.0 & 1.0 & - & 9.6 \\
\hline Mozambique & 4.7 & 5.2 & 4.4 & & 14.3 \\
\hline Madagascar & 4.6 & 4.3 & 5.9 & - & 14.8 \\
\hline Kenya & 4.1 & 6.4 & 8.0 & 2.0 & 20.5 \\
\hline Niger & 3.6 & - & - & 0.9 & - \\
\hline Cote d'Ivoire & 3.1 & 3.1 & 6.9 & 2.2 & 15.3 \\
\hline Burkina Faso & 2.5 & 2.6 & 10.4 & 1.7 & 17.2 \\
\hline Mali & 2.5 & 2.5 & 6.6 & 1.1 & 12.7 \\
\hline Ghana & 2.1 & 5.5 & 7.8 & - & 15.4 \\
\hline Benin & 2.1 & 4.6 & 7.2 & - & 13.9 \\
\hline Nigeria & 1.7 & 5.0 & 6.7 & 1.5 & 14.9 \\
\hline Liberia & 1.5 & 8.4 & 6.4 & - & 16.3 \\
\hline \multicolumn{6}{|c|}{ Middle East/North Africa - 1.9 Average Score } \\
\hline Tunisia & 3.4 & 4.4 & - & - & - \\
\hline Morocco & 2.6 & 3.0 & 3.8 & - & 9.4 \\
\hline Iraq & 2.3 & 0.8 & 0.5 & - & 3.6 \\
\hline Algeria & 2.0 & 2.3 & 7.4 & - & 11.7 \\
\hline Jordan & 1.9 & 2.2 & 1.6 & - & 5.7 \\
\hline Lebanon & 1.2 & 0.9 & 1.5 & - & 3.6 \\
\hline Yemen & 0.0 & 2.2 & 0.1 & - & 2.3 \\
\hline
\end{tabular}




\subsection{DIAMOND INDEX - JUDICIAL DOMAIN}

\section{Overview}

The judicial 40-country average was 5.1 (out of a possible maximum of 25). This component of the Diamond Index achieved the highest score, significantly above executive, legislative, and security. At the Tier 1 level, the constitutional court was considered the highest court unless in-country expertise or documentation explicitly identified it as a Tier 2 court (or, of course, there was no constitutional court as part of the judicial system). For 20 countries the constitutional court was considered the premier court and in 19 countries the supreme court was the highest court. TimorLeste was the sole country to have only two tiers of formal courts in its judicial system. In this instance, appellate courts were considered Tier 1 and district courts Tier 2. Table 36 documents the straight percentage of women in the judicial branch according to each tier level and averaged by region for the selected countries.

TABLE 36: Percent of Women in the Judicial Branch by Tier and Region

\begin{tabular}{l|c|c|c|c|c|c|c} 
& $\begin{array}{c}\text { Eastern } \\
\text { Europe/ } \\
\text { Eurasia }\end{array}$ & $\begin{array}{c}\text { Latin } \\
\text { America/ } \\
\text { Caribbean }\end{array}$ & Asia & Africa & $\begin{array}{c}\text { Middle East/ } \\
\text { N. Africa }\end{array}$ & Total & $\begin{array}{c}\text { Global } \\
\text { Average }\end{array}$ \\
\hline Tier 1 & 26.4 & 16.7 & 15.2 & 26.6 & 5.1 & 90.0 & 18.0 \\
\hline Tier 2 & 32.0 & 18.1 & 18.9 & 27.5 & 3.8 & 100.3 & 20.1 \\
\hline Tier 3 & 41.4 & 23.7 & 18.3 & 26.6 & 26.1 & 136.1 & 27.2 \\
\hline
\end{tabular}

In measuring straight percentages of women, the judiciary outscores the other sectors in numbers of women present in all three tiers. As expected, this translates into higher weighted scores in each tier and thus overall scores. Table 37 provides all 40 countries according to their weighted index judicial score, ranked from highest to lowest. 
TABLE 37: Diamond Index 2015 - Judicial Scores

\begin{tabular}{|c|c|c|c|c|c|}
\hline \multirow{2}{*}{$\begin{array}{c}\text { ALL } \\
\text { COUNTRIES }\end{array}$} & \multicolumn{4}{|c|}{ WEIGHTED SCORES } & \multirow{2}{*}{$\begin{array}{c}\text { TOTAL } \\
\text { SCORES }\end{array}$} \\
\hline & JUDICIAL & EXECUTIVE & LEGISLATIVE & SECURITY & \\
\hline \multicolumn{6}{|c|}{ Global Judicial Average Score $=5.1$} \\
\hline 1. Bosnia-Herz. & 11.6 & 2.6 & 2.5 & 1.1 & 17.8 \\
\hline 2. Burkina Faso & 10.4 & 2.6 & 2.5 & 1.7 & 17.2 \\
\hline 3. Mongolia & 9.7 & 3.1 & 3.6 & - & 16.4 \\
\hline 4. Rwanda & 9.2 & 9.5 & 7.8 & 1.4 & 27.9 \\
\hline 5. Timor-Leste & 8.9 & 3.0 & 4.0 & 1.8 & 17.7 \\
\hline 6. Georgia & 8.4 & 5.0 & 2.5 & 1.5 & 17.4 \\
\hline 7. Kenya & 8.0 & 6.4 & 4.1 & 2.0 & 20.5 \\
\hline 8. Ghana & 7.8 & 5.5 & 2.1 & - & 15.4 \\
\hline 9. Algeria & 7.4 & 2.3 & 2.0 & - & 11.7 \\
\hline 10. Benin & 7.2 & 4.6 & 2.1 & - & 13.9 \\
\hline 11. Cote d'Ivoire & 6.9 & 3.1 & 3.1 & 2.2 & 15.3 \\
\hline 12. Nigeria & 6.7 & 5.0 & 1.7 & 1.5 & 14.9 \\
\hline 13. Mali & 6.6 & 2.5 & 2.5 & 1.1 & 12.7 \\
\hline 14. Liberia & 6.4 & 8.4 & 1.5 & - & 16.3 \\
\hline 15. Guatemala & 6.4 & 4.8 & 4.0 & 1.8 & 17.0 \\
\hline 16. Philippines & 6.3 & 6.2 & 5.1 & - & 17.6 \\
\hline 17. South Africa & 6.0 & 9.5 & 7.6 & 7.0 & 30.1 \\
\hline 18. Albania & 5.9 & 6.2 & 4.4 & 2.0 & 18.5 \\
\hline 19. Madagascar & 5.9 & 4.3 & 4.6 & - & 14.8 \\
\hline 20. Colombia & 4.8 & 6.8 & 4.3 & - & 15.9 \\
\hline 21. Ukraine & 5.0 & 2.8 & 3.0 & & 10.8 \\
\hline 22. Mexico & 4.5 & 4.4 & 3.5 & 1.5 & 13.9 \\
\hline 23. Mozambique & 4.4 & 5.2 & 4.7 & - & 14.3 \\
\hline 24. Brazil & 4.4 & 4.5 & 0.8 & 3.6 & 13.3 \\
\hline 25. Cambodia & 4.4 & 2.2 & 3.6 & - & 10.2 \\
\hline 26. Morocco & 3.8 & 3.0 & 2.6 & - & 9.4 \\
\hline 27. Haiti & 2.9 & 3.6 & 0.2 & 0.2 & 6.9 \\
\hline 28. Bangladesh & 2.7 & 1.7 & 4.3 & 1.3 & 10.0 \\
\hline 29. Indonesia & 2.0 & 3.1 & 3.7 & 1.7 & 10.5 \\
\hline 30. India & 1.9 & 2.4 & 6.2 & 1.1 & 11.5 \\
\hline 31. Jordan & 1.6 & 2.2 & 1.9 & - & 5.7 \\
\hline 32. Lebanon & 1.5 & 0.9 & 1.2 & - & 3.6 \\
\hline 33. Thailand & 1.4 & 1.1 & 0.7 & 0.4 & 3.6 \\
\hline 34. Nepal & 1.3 & 1.9 & 3.6 & 0.3 & 7.1 \\
\hline
\end{tabular}




\begin{tabular}{|c|c|c|c|c|c|}
\hline \multirow{2}{*}{$\begin{array}{c}\text { ALL } \\
\text { COUNTRIES }\end{array}$} & \multicolumn{4}{|c|}{ WEIGHTED SCORES } & \multirow{2}{*}{$\begin{array}{c}\text { TOTAL } \\
\text { SCORES }\end{array}$} \\
\hline & JUDICIAL & EXECUTIVE & LEGISLATIVE & SECURITY & \\
\hline 35. Senegal & 1.0 & 3.0 & 5.6 & - & 9.6 \\
\hline 36. Iraq & 0.5 & 0.8 & 2.3 & - & 3.6 \\
\hline 37. Yemen & 0.1 & 2.2 & 0.0 & - & 2.3 \\
\hline 38. Tunisia & - & 4.4 & 3.4 & - & - \\
\hline 39. Kyrgyzstan & - & 3.0 & 2.2 & - & - \\
\hline 40. Niger & - & - & 3.6 & 0.9 & - \\
\hline
\end{tabular}

- Unable to calculate score

\section{Regional Highlights}

In examining regional differences among the selected sample countries, significant women's representation was found at all three tiers of the judiciary across all regions. In particular, high percentages of women emerged in the countries representing the Eastern Europe/Eurasia region. In this geographic area, the score totaled 7.7, more than twice the average score of 2.9 recorded in the legislative domain and well above the executive score of 3.9. In this region women are finding more space in the judiciary as compared to other domains measured.

We see the same trend in sample countries from Africa, with an average score of 6.7. Although not as dramatic as Eastern Europe/Eurasia, women are making greater headway in the judicial area when compared to the average scores in the executive (5.4), legislative (3.8), and security (2.2) sectors. Of the 14 African countries mapped, a total of 11 score above the Diamond Index 40-country average.

While the Middle East/North Africa countries again averaged the lowest scores, there are several states within this region that appear to be making headway. Algeria scored 7.4 and Morocco, while still below the 40-country average, registered a score of 3.8. The seven-country average from this region tempers these individual country gains, however, with Yemen (0.1) and Iraq (0.5) at the low end of all judicial spectrum scoring. Table 38 represents the Diamond Index scores across the 40 countries organized by region with the judicial branch highlighted. 
TABLE 38: Diamond Index 2015 - Judicial Scores by Region

\begin{tabular}{|c|c|c|c|c|c|}
\hline \multirow{2}{*}{$\begin{array}{l}\text { REGION } \\
\text { COUNTRY }\end{array}$} & \multicolumn{4}{|c|}{ WEIGHTED SCORES } & \multirow{2}{*}{$\begin{array}{l}\text { TOTAL } \\
\text { SCORE }\end{array}$} \\
\hline & JUDICIAL & EXECUTIVE & LEGISLATIVE & SECURITY & \\
\hline \multicolumn{6}{|c|}{ Eastern Europe/Eurasia - 7.7 Average Score } \\
\hline Bosnia-Herz. & 11.6 & 2.6 & 2.5 & 1.1 & 17.8 \\
\hline Georgia & 8.4 & 5.0 & 2.5 & 1.5 & 17.4 \\
\hline Albania & 5.9 & 6.2 & 4.4 & 2.0 & 18.5 \\
\hline Ukraine & 5.0 & 2.8 & 3.0 & - & 10.8 \\
\hline Kyrgyzstan & - & 3.0 & 2.2 & - & - \\
\hline \multicolumn{6}{|c|}{ Latin America/Caribbean - 4.6 Average Score } \\
\hline Guatemala & 6.4 & 4.8 & 4.0 & 1.8 & 17.0 \\
\hline Colombia & 4.8 & 6.8 & 4.3 & - & 15.9 \\
\hline Mexico & 4.5 & 4.4 & 3.5 & 1.5 & 13.9 \\
\hline Brazil & 4.4 & 4.5 & 0.8 & 3.6 & 13.3 \\
\hline Haiti & 2.9 & 3.6 & 0.2 & 0.2 & 6.9 \\
\hline \multicolumn{6}{|c|}{ Asia - 4.3 Average Score } \\
\hline Mongolia & 9.7 & 3.1 & 3.6 & - & 16.4 \\
\hline Timor-Leste & 8.9 & 3.0 & 4.0 & 1.8 & 17.7 \\
\hline Philippines & 6.3 & 6.2 & 5.1 & - & 17.6 \\
\hline Cambodia & 4.4 & 2.2 & 3.6 & - & 10.2 \\
\hline Bangladesh & 2.7 & 1.7 & 4.3 & 1.3 & 10.0 \\
\hline Indonesia & 2.0 & 3.1 & 3.7 & 1.7 & 10.5 \\
\hline India & 1.9 & 2.4 & 6.2 & 1.1 & 11.6 \\
\hline Thailand & 1.4 & 1.1 & 0.7 & 0.4 & 3.6 \\
\hline Nepal & 1.3 & 1.9 & 3.6 & 0.3 & 7.1 \\
\hline \multicolumn{6}{|c|}{ Africa - 6.6 Average Score } \\
\hline Burkina Faso & 10.4 & 2.6 & 2.5 & 1.7 & 17.2 \\
\hline Rwanda & 9.2 & 9.5 & 7.8 & 1.4 & 27.9 \\
\hline Kenya & 8.0 & 6.4 & 4.1 & 2.0 & 20.5 \\
\hline Ghana & 7.8 & 5.5 & 2.1 & - & 15.4 \\
\hline Benin & 7.2 & 4.6 & 2.1 & - & 13.9 \\
\hline Cote d'Ivoire & 6.9 & 3.1 & 3.1 & 2.2 & 15.3 \\
\hline Nigeria & 6.7 & 5.0 & 1.7 & 1.5 & 14.9 \\
\hline Mali & 6.6 & 2.5 & 2.5 & 1.1 & 12.7 \\
\hline Liberia & 6.4 & 8.4 & 1.5 & - & 16.3 \\
\hline South Africa & 6.0 & 9.5 & 7.6 & 7.0 & 30.1 \\
\hline Madagascar & 5.9 & 4.3 & 4.6 & - & 14.8 \\
\hline Mozambique & 4.4 & 5.2 & 4.7 & - & 14.3 \\
\hline
\end{tabular}




\begin{tabular}{|c|c|c|c|c|c|}
\hline \multirow{2}{*}{$\begin{array}{l}\text { REGION } \\
\text { COUNTRY }\end{array}$} & \multicolumn{4}{|c|}{ WEIGHTED SCORES } & \multirow{2}{*}{$\begin{array}{l}\text { TOTAL } \\
\text { SCORE }\end{array}$} \\
\hline & JUDICIAL & EXECUTIVE & LEGISLATIVE & SECURITY & \\
\hline Senegal & 1.0 & 3.0 & 5.6 & - & 9.6 \\
\hline Niger & - & - & 3.6 & 0.9 & - \\
\hline \multicolumn{6}{|c|}{ Middle East/North Africa - 2.5 Average Score } \\
\hline Algeria & 7.4 & 2.3 & 2.0 & - & 11.7 \\
\hline Morocco & 3.8 & 3.0 & 2.6 & - & 9.4 \\
\hline Jordan & 1.6 & 2.2 & 1.9 & - & 5.7 \\
\hline Lebanon & 1.5 & 0.9 & 1.2 & - & 3.6 \\
\hline Iraq & 0.5 & 0.8 & 2.3 & - & 3.6 \\
\hline Yemen & 0.1 & 2.2 & 0.0 & - & 2.3 \\
\hline Tunisia & - & 4.4 & 3.4 & - & - \\
\hline \multicolumn{6}{|c|}{ Global Average Score - 5.1} \\
\hline
\end{tabular}

- Unable to calculate score

\subsection{DIAMOND INDEX - SECURITY SECTOR DOMAIN}

\section{Overview}

The average security score for all regions was 1.7 (with a score of 25 representing only women in decision-making positions and 12.5 approaching parity). While some headway was made in opening this black box of data, there were shortfalls in collecting all three data points in the security domain. Table 39 documents the straight percentage of women in the security domain according to each tier level and averaged by region for the selected countries. 
Table 39: Percent of Women in the Security Sector by Tier and Region

\begin{tabular}{|l|c|c|c|c|c|cc} 
& $\begin{array}{c}\text { Eastern } \\
\text { Europe/ } \\
\text { Eurasia }\end{array}$ & $\begin{array}{c}\text { Latin } \\
\text { America/ } \\
\text { Caribbean }\end{array}$ & Asia & Africa & $\begin{array}{c}\text { Middle East/ } \\
\text { N. Africa }\end{array}$ & Total & $\begin{array}{c}\text { Global } \\
\text { Average }\end{array}$ \\
\hline Tier 1 & 3.7 & 4.9 & 2.8 & 7.7 & - & 19.1 & 4.8 \\
\hline Tier 2 & 8.5 & 8.6 & 5.0 & 8.3 & - & 30.4 & 7.6 \\
\hline Tier 3 & 8.9 & 9.4 & 7.5 & 10.8 & 4.8 & 41.4 & 8.3 \\
\hline
\end{tabular}

- Unable to calculate score

Of the 40 countries, full security sector data sets were collected for 21 countries $(52.5 \%) .{ }^{506}$ The percentage of women in all three tiers of security, and resulting overall country average, is low in comparison to other domains measured. As a result, scores appear not only low but also close to one another. For example, in the judicial sector more than 11 points separate the highest scoring (Bosnia-Herzegovina) from the lowest-scoring (Yemen). In the legislative domain there is almost an 8-point difference and close to a 10-point variation between the top and bottom countries in the executive. On the other hand, if we remove the outlier South Africa - the only country to have a robust security score - the difference between second place Brazil and last-place Haiti is 3.4 points. We see many more countries clustered around a few scores - for example, 12 countries scored between 1.8 and 1.1. This is the only domain of the four to have this type of closely clustered scoring among numerous countries. Table $\mathbf{4 0}$ provides all 40 countries according to their weighted index security score, ranked from highest to lowest.

TABLE 40: Diamond Index 2015 - Security Sector Scores

\begin{tabular}{|c|c|c|c|c|c|}
\hline \multirow{2}{*}{$\begin{array}{l}\text { COUNTRY AND } \\
\text { CATEGORY } \\
\text { RANKING }\end{array}$} & \multicolumn{4}{|c|}{ WEIGHTED SCORES } & \multirow{2}{*}{$\begin{array}{c}\text { TOTAL } \\
\text { SCORES }\end{array}$} \\
\hline & SECURITY & EXECUTIVE & LEGISLATIVE & JUDICIAL & \\
\hline \multicolumn{6}{|c|}{ Global Security Sector Average Score $=1.7$} \\
\hline 1. South Africa & 7.0 & 9.5 & 7.6 & 6.0 & 30.1 \\
\hline 2. Brazil & 3.6 & 4.5 & 0.8 & 4.4 & 13.3 \\
\hline 3. Cote d'Ivoire & 2.2 & 3.1 & 3.1 & 6.9 & 15.3 \\
\hline
\end{tabular}

${ }^{506}$ This includes Niger, for which data collection in the security sector was successful. Due to gaps in other sectors, however, an overall score for Niger could not be calculated. 


\begin{tabular}{|c|c|c|c|c|c|}
\hline \multirow{2}{*}{$\begin{array}{l}\text { COUNTRY AND } \\
\text { CATEGORY } \\
\text { RANKING }\end{array}$} & \multicolumn{4}{|c|}{ WEIGHTED SCORES } & \multirow{2}{*}{$\begin{array}{c}\text { TOTAL } \\
\text { SCORES }\end{array}$} \\
\hline & SECURITY & EXECUTIVE & LEGISLATIVE & JUDICIAL & \\
\hline 4. Kenya & 2.0 & 6.4 & 4.1 & 8.0 & 20.5 \\
\hline 5. Albania & 2.0 & 6.2 & 4.4 & 5.9 & 18.5 \\
\hline 6. Timor-Leste & 1.8 & 3.0 & 4.0 & 8.9 & 17.7 \\
\hline 7. Guatemala & 1.8 & 4.8 & 4.0 & 6.4 & 17.0 \\
\hline 8. Burkina Faso & 1.7 & 2.6 & 2.5 & 10.4 & 17.2 \\
\hline 9. Indonesia & 1.7 & 3.1 & 3.7 & 2.0 & 10.5 \\
\hline 10. Georgia & 1.5 & 5.0 & 2.5 & 8.4 & 17.4 \\
\hline 11. Nigeria & 1.5 & 5.0 & 1.7 & 6.7 & 14.9 \\
\hline 12. Mexico & 1.5 & 4.4 & 3.5 & 4.5 & 13.9 \\
\hline 13. Rwanda & 1.4 & 9.5 & 7.8 & 9.2 & 27.9 \\
\hline 14. Bangladesh & 1.3 & 1.7 & 4.3 & 2.7 & 10.0 \\
\hline 15. Bosnia-Herz. & 1.1 & 2.6 & 2.5 & 11.6 & 17.8 \\
\hline 16. Mali & 1.1 & 2.5 & 2.5 & 6.6 & 12.7 \\
\hline 17. India & 1.1 & 2.4 & 6.2 & 1.9 & 11.5 \\
\hline 18. Niger & 0.9 & - & 3.6 & - & - \\
\hline 19. Thailand & 0.4 & 1.1 & 0.7 & 1.4 & 3.6 \\
\hline 20. Nepal & 0.3 & 1.9 & 3.6 & 1.3 & 7.1 \\
\hline 21. Haiti & 0.2 & 3.6 & 0.2 & 2.9 & 6.9 \\
\hline
\end{tabular}

\section{Regional Highlights}

When looking at the different geographical zones, there are several points worth noting. Sample countries from Asia and Middle East/North Africa scored the lowest of the five regions. For the nine Asian countries selected, however, significant data was found. Out of a possible 27 data points, only seven were missing across three countries (Philippines, Cambodia, and Mongolia), allowing for the reasonable calculation of averages in the three tiers. Table $\mathbf{4 1}$ presents the security sector data collected for the selected Asian countries across all three tier levels. 
TABLE 41: Asia - Percent of Women by Security Tier and Weighted Security Score

\begin{tabular}{l|c|c|c|c}
\hline & $\begin{array}{c}\text { TIER 1 } \\
\text { Percent of } \\
\text { Women }\end{array}$ & $\begin{array}{c}\text { TIER 2 } \\
\text { Percent of } \\
\text { Women }\end{array}$ & $\begin{array}{c}\text { TIER 3 } \\
\text { Percent of } \\
\text { Women }\end{array}$ & $\begin{array}{c}\text { Weighted } \\
\text { Score }\end{array}$ \\
\hline Bangladesh & 4.0 & 3.2 & 12.5 & 1.3 \\
\hline Cambodia & - & - & 4.9 & - \\
\hline India & 4.2 & 3.7 & 5.9 & 1.1 \\
\hline Indonesia & 4.6 & 11.7 & 3.3 & 1.7 \\
\hline Mongolia & - & - & - & - \\
\hline Nepal & 0.4 & 0.3 & 5.8 & 0.3 \\
\hline Philippines & - & - & 7.7 & - \\
\hline Thailand & 0.0 & 1.7 & 5.8 & 0.4 \\
\hline Timor-Leste & 3.4 & 9.5 & 14.4 & 1.8 \\
\hline TOTALS & 16.6 & 30.1 & 60.3 & 6.6 \\
\hline AVERAGE & $\mathbf{2 . 8} \%$ & $5.0 \%$ & $7.5 \%$ & $\mathbf{1 . 1}$ \\
\hline
\end{tabular}

- Unable to calculate score

The data collection effort for countries representing the Middle East/North Africa region, however, yielded little information. Out of the 21 total possible indicators across seven countries, only four were collected and only in Tier 3. Governments were completely unwilling to share statistics, and little public information was available. Averaging together the four countries of Algeria, Jordan, Lebanon, and Yemen produced a Tier 3 average of $4.8 \%$. It is fairly certain, based on the pattern seen in other countries, that Tier 1 and Tier 2 percentages of higher-ranking women officers would be less than Tier 3 . This would most likely result in the lowest overall regional average. On a more positive note, women in Algeria and Jordan appear to be making some headway in entering the police force at the Tier 3 levels. Table 42 presents the security sector data collected for the selected Middle East/ North African countries across all three tier levels. 
TABLE 42: Middle East \& North Africa - Weighted Security Scores by Individual Tier

\begin{tabular}{l|c|c|c|c} 
& $\begin{array}{c}\text { TIER 1 } \\
\text { Percent of } \\
\text { Women }\end{array}$ & $\begin{array}{c}\text { TIER 2 } \\
\text { Percent of } \\
\text { Women }\end{array}$ & $\begin{array}{c}\text { TIER 3 } \\
\text { Percent of } \\
\text { Women }\end{array}$ & $\begin{array}{c}\text { Weighted } \\
\text { Score }\end{array}$ \\
\hline Algeria & - & - & 8.0 & - \\
\hline Iraq & - & - & - & - \\
\hline Jordan & - & - & 7.0 & - \\
\hline Lebanon & - & - & 2.4 & - \\
\hline Morocco & - & - & - & - \\
\hline Tunisia & - & - & 1.7 & - \\
\hline Yemen & - & - & 19.1 & - \\
\hline TOTALS & - & - & 4.8 & - \\
\hline AVERAGE & - & - & - & \\
\hline
\end{tabular}

- Unable to calculate score

Turning to Africa, South Africa stood out as the one exception among the 40 countries that recorded robust percentages in all three tiers of police decision-makers. While not on par with men, the final weighted score of 7 (out of a maximum of 25) demonstrated that women were present in all areas of the command structure. ${ }^{507}$ Brazil was also an interesting case in the security arena. While well behind South Africa, it recorded the second-highest score at 3.6. This score, in fact, far exceeded the country's weighted legislative score of 0.8 , which was much lower than the regional average and second only to Haiti. Table 43 represents the Diamond Index scores across the 40 countries organized by region with the security sector highlighted.

507 While not recorded for purposes of the Diamond Index, research collection also indicated that women in South Africa's military far outpaced all other African countries in terms of overall representation in army officer ranks. 
TABLE 43: Diamond Index 2015 - Security Scores by Region

\begin{tabular}{|c|c|c|c|c|c|}
\hline \multirow{2}{*}{$\begin{array}{l}\text { REGION } \\
\text { COUNTRY }\end{array}$} & \multicolumn{4}{|c|}{ WEIGHTED SCORES } & \multirow{2}{*}{$\begin{array}{l}\text { TOTAL } \\
\text { SCORE }\end{array}$} \\
\hline & SECURITY & EXECUTIVE & LEGISLATIVE & JUDICIAL & \\
\hline \multicolumn{6}{|c|}{ Eastern Europe/Eurasia - 1.5 Average Score } \\
\hline Albania & 2.0 & 6.2 & 4.4 & 5.9 & 18.5 \\
\hline Georgia & 1.5 & 5.0 & 2.5 & 8.4 & 17.4 \\
\hline Ukraine & - & 2.8 & 3.0 & 5.0 & 10.8 \\
\hline Bosnia-Herz. & 1.1 & 2.6 & 2.5 & 11.6 & 17.8 \\
\hline Kyrgyzstan & - & 3.0 & 2.2 & - & - \\
\hline \multicolumn{6}{|c|}{ Latin America/Caribbean - 1.8 Average Score } \\
\hline Brazil & 3.6 & 4.5 & 0.8 & 4.4 & 13.3 \\
\hline Guatemala & 1.8 & 4.8 & 4.0 & 6.4 & 17.0 \\
\hline Colombia & - & 6.8 & 4.3 & 4.8 & 15.9 \\
\hline Mexico & 1.5 & 4.4 & 3.5 & 4.5 & 13.9 \\
\hline Haiti & 0.2 & 3.6 & 0.2 & 2.9 & 6.9 \\
\hline \multicolumn{6}{|c|}{ Asia - 1.1 Average Score } \\
\hline Timor-Leste & 1.8 & 3.0 & 4.0 & 8.9 & 17.7 \\
\hline Indonesia & 1.7 & 3.1 & 3.7 & 2.0 & 10.5 \\
\hline Bangladesh & 1.3 & 1.7 & 4.3 & 2.7 & 10.0 \\
\hline Philippines & - & 6.2 & 5.1 & 6.3 & 17.6 \\
\hline Mongolia & - & 3.1 & 3.6 & 9.7 & 16.4 \\
\hline India & 1.1 & 2.4 & 6.2 & 1.9 & 11.6 \\
\hline Cambodia & - & 2.2 & 3.6 & 4.4 & 10.2 \\
\hline Thailand & 0.4 & 1.1 & 0.7 & 1.4 & 3.6 \\
\hline Nepal & 0.3 & 1.6 & 3.6 & 1.3 & 6.8 \\
\hline \multicolumn{6}{|c|}{ Africa - 2.2 Average Score } \\
\hline South Africa & 7.0 & 9.5 & 7.6 & 6.0 & 30.1 \\
\hline Ghana & - & 5.5 & 2.1 & 7.8 & 15.4 \\
\hline Madagascar & - & 4.3 & 4.6 & 5.9 & 14.8 \\
\hline Cote d'Ivoire & 2.2 & 3.1 & 3.1 & 6.9 & 15.3 \\
\hline Mozambique & - & 5.2 & 4.7 & 4.4 & 14.3 \\
\hline Kenya & 2.0 & 6.4 & 4.1 & 8.0 & 20.5 \\
\hline Benin & - & 4.6 & 2.1 & 7.2 & 13.9 \\
\hline Senegal & - & 3.0 & 5.6 & 1.0 & 9.6 \\
\hline Liberia & - & 8.4 & 1.5 & 6.4 & 16.3 \\
\hline Burkina Faso & 1.7 & 2.6 & 2.5 & 10.4 & 17.2 \\
\hline Nigeria & 1.5 & 5.0 & 1.7 & 6.7 & 14.9 \\
\hline Rwanda & 1.4 & 9.5 & 7.8 & 9.2 & 27.9 \\
\hline
\end{tabular}




\begin{tabular}{|c|c|c|c|c|c|}
\hline \multirow{2}{*}{$\begin{array}{l}\text { REGION } \\
\text { COUNTRY }\end{array}$} & \multicolumn{4}{|c|}{ WEIGHTED SCORES } & \multirow{2}{*}{$\begin{array}{l}\text { TOTAL } \\
\text { SCORE }\end{array}$} \\
\hline & SECURITY & EXECUTIVE & LEGISLATIVE & JUDICIAL & \\
\hline Mali & 1.1 & 2.5 & 2.5 & 6.6 & 12.7 \\
\hline Niger & 0.9 & - & 3.6 & - & - \\
\hline \multicolumn{6}{|c|}{ Middle East/North Africa - NA Average Score } \\
\hline Algeria & - & 2.3 & 2.0 & 7.4 & 11.7 \\
\hline Morocco & - & 3.0 & 2.6 & 3.8 & 9.4 \\
\hline Jordan & - & 2.2 & 1.9 & 1.6 & 5.7 \\
\hline Lebanon & - & 0.9 & 1.2 & 1.5 & 3.6 \\
\hline Iraq & - & 0.8 & 2.3 & 0.5 & 3.6 \\
\hline Yemen & - & 2.2 & 0.0 & 0.1 & 2.3 \\
\hline Algeria & - & 2.3 & 2.0 & 7.4 & 11.7 \\
\hline Tunisia & - & 4.4 & 3.4 & - & - \\
\hline
\end{tabular}

- Unable to calculate score

\subsection{GLASS WALLS: HORIZONTAL REPRESENTATION AMONG DECISION-MAKERS}

There are numerous impediments that hinder women's entrance into decisionmaking positions across formal government. From strong cultural preferences for male candidates to inherently structural gender biases built into institutions, the challenges that women must overcome to climb the professional scale are daunting. Rule describes these obstacles as "narrow gender roles, restrictive religious doctrines, unequal laws and education, discriminatory socioeconomic conditions, male-biased party leaders or other political elites and some voters, and 'women unfriendly' election systems. ${ }^{508}$ While earlier attempts to quantify the glass ceiling focused on the labor market, ${ }^{509}$ this same concept and language were also adopted early by academics to describe women's lack of advancement in the political arena. ${ }^{510}$

The following tables highlight the horizontal distribution of women across the four sectors: executive, legislative, judicial, and security. A line has been drawn at the

\footnotetext{
508 Rule, Wilma. "Parliaments of, by, and for the People: Except for Women?" Contributions in Political Science 338 (1994): 15-15.

509 Cotter, David A., Joan M. Hermsen, Seth Ovadia, and Reeve Vanneman. "The Glass Ceiling Effect." Social Forces 80, no. 2 (2001): 655-681.

510 Borrelli, MaryAnne, and Janet M. Martin. The Other Elites: Women, Politics, and Power in the Executive Branch. Boulder, Colorado: Lynne Rienner Publishers, 1997. Reynolds, Andrew. "Women in the Legislatures and Executives of the World: Knocking at the Highest Glass Ceiling." World Politics 51, no. 4 (July 1, 1999): 547-72.
} 
$31 \%-35 \%$ mark to indicate the achievement of a critical mass of decision-makers in any one sector. This is not to assume that $30 \%$ or $35 \%$ of women is sufficient, but rather to demonstrate how women are faring against the typical global benchmark of women's representation.

\section{Eastern Europe/Eurasia}

For the sample countries selected within this region, Tier 2 and Tier 3 in the judiciary were the only two tiers - out of all 60 measured across the varied geographic zones to achieve this threshold. Tier 3 in the judiciary for the five Eastern Europe/Eurasia countries was the single area to surpass the $35 \%$ measure. The trend emerging is robust women's representation in the judiciary. While women have strong access to the judicial sector, and moderate access to the executive and legislative, the decisionmaking positions of: 1) mayor, 2) political party leader, and 3) senior-level security officers remain almost completely closed, with scores that only surpass those found in the Middle East/North Africa. Table 44 highlights the average percentage of women by domain and tier level in the sample countries selected for Eastern Europe/Eurasia.

\section{TABLE 44: Eastern Europe/Eurasia - Horizontal Distribution}

\begin{tabular}{|c|c|c|c|c|c|c|c|c|c|c|c|c|}
\hline \multirow{2}{*}{$\begin{array}{l}\text { Percentage } \\
\text { Of Women }\end{array}$} & \multicolumn{3}{|c|}{ Executive } & \multicolumn{3}{|c|}{ Legislative } & \multicolumn{3}{|c|}{ Judiciary } & \multicolumn{3}{|c|}{ Security } \\
\hline & Tier 1 & Tier 2 & Tier 3 & Tier 1 & Tier 2 & Tier 3 & Tier 1 & Tier 2 & Tier 3 & Tier 1 & Tier 2 & Tier 3 \\
\hline $0-5$ & & & $x$ & $x$ & & & & & & $x$ & & \\
\hline $5-10$ & & & & & & & & & & & $X$ & $x$ \\
\hline \multicolumn{13}{|l|}{$11-15$} \\
\hline $16-20$ & $x$ & & & & & $x$ & & & & & & \\
\hline 21-25 & & $x$ & & & $x$ & & & & & & & \\
\hline $26-30$ & & & & & & & $x$ & & & & & \\
\hline $31-35$ & & & & & & & & $x$ & & & & \\
\hline \multicolumn{13}{|l|}{$36-40$} \\
\hline $41-45$ & & & & & & & & & $x$ & & & \\
\hline \multicolumn{13}{|l|}{$46-50$} \\
\hline \multicolumn{13}{|l|}{$51+$} \\
\hline AVERAGE & 15.9 & 21.2 & 4.0 & 4.4 & 21.0 & 17.6 & 26.4 & 32.0 & 41.4 & 3.7 & 8.5 & 8.9 \\
\hline
\end{tabular}




\section{Latin America/Caribbean}

While no domain approaches the 30\% mark, there are also few tiers where women have little representation ( $0 \%$ to $5 \%$ range). The Latin American/Caribbean sample countries appear to be making some progress across all four sectors. This includes modest gains in one of the most difficult measures: political party leadership (legislative, Tier 1). In this measure the regional average is second only to Asia. Also worth noting is the low intake of women in the judiciary lower courts (Tier 3 ). The percentage of women $(23.7 \%)$ is approximately $4 \%$ lower than the 40 -country average and all regions except Asia. So while overall women seem to be making the greatest gains in the judicial sector, smaller-than-average percentages of women in the lowest courts may dampen future levels of representation in higher courts. Table 45 highlights the average percentage of women by domain and tier level in the sample countries selected for Latin America/Caribbean.

TABLE 45: Latin America/Caribbean - Horizontal Distribution

\begin{tabular}{|c|c|c|c|c|c|c|c|c|c|c|c|c|}
\hline \multirow{2}{*}{$\begin{array}{l}\text { Percentage } \\
\text { of Women }\end{array}$} & \multicolumn{3}{|c|}{ Executive } & \multicolumn{3}{|c|}{ Legislative } & \multicolumn{3}{|c|}{ Judiciary } & \multicolumn{3}{|c|}{ Security } \\
\hline & Tier 1 & Tier 2 & Tier 3 & Tier 1 & Tier 2 & Tier 3 & Tier 1 & Tier 2 & Tier 3 & Tier 1 & Tier 2 & Tier 3 \\
\hline $0-5$ & & & & & & & & & & $X$ & & \\
\hline $6-10$ & & & $X$ & $X$ & $X$ & & & & & & $X$ & $X$ \\
\hline \multicolumn{13}{|l|}{$11-15$} \\
\hline $16-20$ & & $X$ & & & & $X$ & $x$ & $X$ & & & & \\
\hline $21-25$ & $X$ & & & & & & & & $X$ & & & \\
\hline \multicolumn{13}{|l|}{$26-30$} \\
\hline \multicolumn{13}{|l|}{$31-35$} \\
\hline \multicolumn{13}{|l|}{$36-40$} \\
\hline \multicolumn{13}{|l|}{$41-45$} \\
\hline \multicolumn{13}{|l|}{$46-50$} \\
\hline \multicolumn{13}{|l|}{$51+$} \\
\hline AVERAGE & 24.2 & 18.5 & 6.0 & 8.2 & 10.8 & 17.1 & 16.7 & 18.1 & 23.7 & 4.9 & 8.6 & 9.4 \\
\hline
\end{tabular}




\section{Asia}

While women are making representational headway within the legislative and judicial branches, the percentage of women gaining access to the judicial, Tier $3(18.3 \%)$ is significantly below all other regions as well as below the 40 -country average of $27.9 \%$. The result is a flat line, with representation more or less equal across all levels of the judicial system. Women seem to be faring well in the legislative branch, with strong scores in all three tiers. The use of quotas may help explain robust representation in this sector. ${ }^{511}$ As with the other regions examined, women are significantly underrepresented in security across all tiers and are rarely present in the chain of police command. Glass walls would seem to be firmly in place around the security sector in this region where Asia's scores are among the lowest, rivaled only by countries in the Middle East/North Africa. Table 46 highlights the average percentage of women by domain and tier level in the sample countries selected for Asia.

\section{TABLE 46: Asia - Horizontal Distribution}

\begin{tabular}{|c|c|c|c|c|c|c|c|c|c|c|c|c|}
\hline \multirow{2}{*}{$\begin{array}{l}\text { Percentage } \\
\text { of Women }\end{array}$} & \multicolumn{3}{|c|}{ Executive } & \multicolumn{3}{|c|}{ Legislative } & \multicolumn{3}{|c|}{ Judiciary } & \multicolumn{3}{|c|}{ Security } \\
\hline & Tier 1 & Tier 2 & Tier 3 & Tier 1 & Tier 2 & Tier 3 & Tier 1 & Tier 2 & Tier 3 & Tier 1 & Tier 2 & Tier 3 \\
\hline $0-5$ & & & & & & & & & & $x$ & $x$ & \\
\hline $6-10$ & & & $x$ & & & & & & & & & $x$ \\
\hline $11-15$ & $x$ & $X$ & & $x$ & & & & & & & & \\
\hline $16-20$ & & & & & $X$ & & $X$ & $x$ & $X$ & & & \\
\hline 21-25 & & & & & & $x$ & & & & & & \\
\hline \multicolumn{13}{|l|}{$26-30$} \\
\hline \multicolumn{13}{|l|}{ 31-35 } \\
\hline \multicolumn{13}{|l|}{$36-40$} \\
\hline \multicolumn{13}{|l|}{ 41-45 } \\
\hline \multicolumn{13}{|l|}{$46-50$} \\
\hline \multicolumn{13}{|l|}{$51+$} \\
\hline AVERAGE & 11.1 & 12.7 & 6.7 & 11.1 & 18.7 & 21.7 & 15.2 & 18.9 & 18.3 & 2.8 & 5.0 & 7.5 \\
\hline
\end{tabular}

511 Bangladesh reserved seats - Indonesia and Nepal legislated candidate quotas - Mongolia legislated quotas - Philippines and Thailand voluntary political party quotas - India has no national quotas - Cambodia and TimorLeste have no information available. 


\section{Africa}

No sector in Africa achieved a critical mass of decision-makers. The judiciary is close, exhibiting high percentages of women across all three tiers. This appears as the sector where women are making the most progress. Looking at the executive and legislative branches, significant numbers of decision-makers are appearing, although not at the same level as the judiciary. Even at the Tier 2 level, however, committee chairs (legislative) and senior executives (executive) are well represented and close to the $30 \%$ benchmark.

Whether a result of political will or legal mandate, the sample of African countries were the only regional grouping to have all three security tiers exceed the 5\% benchmark. This was due in large part to the higher-than-average scores witnessed across South African officer ranks. In summary, women seem to be making strong gains in the judicial sector and steady gains in the executive and legislative branch. Even in the difficult security sector, a number of African countries seem to be showing flexibility towards accommodating women decision-makers. Table 47 highlights the average percentage of women by domain and tier level in the sample countries selected for Africa.

\section{TABLE 47: Africa - Horizontal Distribution}

\begin{tabular}{|c|c|c|c|c|c|c|c|c|c|c|c|c|}
\hline \multirow{2}{*}{$\begin{array}{l}\text { Percentage } \\
\text { of Women }\end{array}$} & \multicolumn{3}{|c|}{ Executive } & \multicolumn{3}{|c|}{ Legislative } & \multicolumn{3}{|c|}{ Judiciary } & \multicolumn{3}{|c|}{ Security } \\
\hline & Tier 1 & Tier 2 & Tier 3 & Tier 1 & Tier 2 & Tier 3 & Tier 1 & Tier 2 & Tier 3 & Tier 1 & Tier 2 & Tier 3 \\
\hline $0-5$ & & & & $X$ & & & & & & & & \\
\hline $6-10$ & & & & & & & & & & $X$ & $X$ & $X$ \\
\hline $11-15$ & & & $X$ & & & & & & & & & \\
\hline \multicolumn{13}{|l|}{$16-20$} \\
\hline $21-25$ & $X$ & $X$ & & & & $X$ & & & & & & \\
\hline $26-30$ & & & & & $x$ & & $X$ & $X$ & $x$ & & & \\
\hline \multicolumn{13}{|l|}{$31-35$} \\
\hline \multicolumn{13}{|l|}{$36-40$} \\
\hline \multicolumn{13}{|l|}{ 41-45 } \\
\hline \multicolumn{13}{|l|}{$46-50$} \\
\hline \multicolumn{13}{|l|}{$51+$} \\
\hline AVERAGE & 23.8 & 25.7 & 11.7 & 4.7 & 27.9 & 22.6 & 26.6 & 27.5 & 26.6 & 7.7 & 8.3 & 10.8 \\
\hline
\end{tabular}




\section{Middle East/North Africa}

The judiciary emerges as the one sector where women are making solid gains in the Middle East/North Africa countries selected, although their presence is focused almost exclusively in the lowest (Tier 3) level, typically courts of appeal or courts of first instance. Women are, however, also present in the executive and legislative domains. Thus, the perception that women in the Middle East/North Africa are absent from formal government is not true for the countries selected, while recognizing that gains are modest. In the security sector, however, women were strikingly absent. Whether their lack of presence is due to societal barriers or missing data is hard to determine. Despite all efforts - including sending a research team to Jordan and country expert to Tunisia - no data on the command structure of any police force was made available in any of the seven countries mapped in this region. In summary, women in the seven countries selected for the Middle East/ North Africa region showed some noteworthy gains in the judicial sector and more modest gains in legislative representation. The security sector appears barred to women, although the lack of data makes it difficult to draw conclusions. Table 48 highlights the average percentage of women by domain and tier level in the sample countries selected for the Middle East/North Africa.

TABLE 48: Middle East/North Africa - Horizontal Distribution

\begin{tabular}{|c|c|c|c|c|c|c|c|c|c|c|c|c|}
\hline \multirow{2}{*}{$\begin{array}{l}\text { Percentage } \\
\text { of Women }\end{array}$} & \multicolumn{3}{|c|}{ Executive } & \multicolumn{3}{|c|}{ Legislative } & \multicolumn{3}{|c|}{ Judiciary } & \multicolumn{3}{|c|}{ Security } \\
\hline & Tier 1 & Tier 2 & Tier 3 & Tier 1 & Tier 2 & Tier 3 & Tier 1 & Tier 2 & Tier 3 & Tier 1 & Tier 2 & Tier 3 \\
\hline $0-5$ & & & $x$ & $x$ & & & & $x$ & & NA & NA & $x$ \\
\hline $5-10$ & $x$ & & & & & & $x$ & & & & & \\
\hline $11-15$ & & $x$ & & & $x$ & & & & & & & \\
\hline $16-20$ & & & & & & $x$ & & & & & & \\
\hline \multicolumn{13}{|l|}{ 21-25 } \\
\hline $26-30$ & & & & & & & & & $x$ & & & \\
\hline \multicolumn{13}{|l|}{ 31-35 } \\
\hline \multicolumn{13}{|l|}{$36-40$} \\
\hline \multicolumn{13}{|l|}{ 41-45 } \\
\hline \multicolumn{13}{|l|}{$46-50$} \\
\hline AVERAGE & 9.0 & 13.4 & 1.4 & 1.6 & 12.5 & 17.2 & 5.1 & 3.8 & 26.1 & NA & NA & 4.8 \\
\hline
\end{tabular}




\subsection{GLASS CEILINGS: VERTICAL REPRESENTATION AMONG DECISION-MAKERS}

The Diamond Index also examines women's access to decision-making positions vertically, offering an opportunity to compare women's positional progress across a range of increasingly senior levels of government. Because Tier 1 positions are defined as senior to Tier 2 which, in turn, are defined as senior to Tier 3, data collected over time would allow for the measurement of women's representation through ascending levels of decision-makers across different sectors. Were a glass ceiling to exist, one would expect to find decreasing percentages of women from Tier 3 to Tier 2 , and again from Tier 2 to Tier 1 .

\section{Eastern Europe/Eurasia}

Most notable among the countries selected from this region is the high judiciary percentages consistent across countries. The average percentage of women's representation in this sector exceeds all other regions. Within the legislative branch we also see the percentage of women chairing committees $(21.0 \%)$ exceeding the percentage of women holding seats $(17.6 \%)$. So women are not only being elected into legislatures, but also moving into committee leadership positions beyond their elected percentages. Within the executive branch the outlier remains the number of women mayors of the 10 largest cities in the country. Women are virtually absent from this tier of local government. Table 49 highlights the average percentage of women across the three tiers in the sample countries selected for Eastern Europe/ Eurasia.

TABLE 49: Eastern Europe/Eurasia - Vertical Distribution

\begin{tabular}{|c|c|c|c|c|c|c|c|c|c|c|c|}
\hline 12 Data Points & $0-5$ & $6-10$ & 11-15 & $16-20$ & $21-25$ & $26-30$ & $31-35$ & $36-40$ & $41-45$ & $46-50$ & $51+$ \\
\hline \multicolumn{12}{|l|}{ Executive } \\
\hline \multicolumn{12}{|l|}{ Ministers } \\
\hline Senior Executives & & & & & $X$ & & & & & & \\
\hline Top 10 Mayors & $X$ & & & & & & & & & & \\
\hline \multicolumn{12}{|l|}{ Legislative } \\
\hline \multicolumn{12}{|l|}{ Party Leaders } \\
\hline Committee Chairs & & & & & $X$ & & & & & & \\
\hline Legislators & & & & $X$ & & & & & & & \\
\hline
\end{tabular}




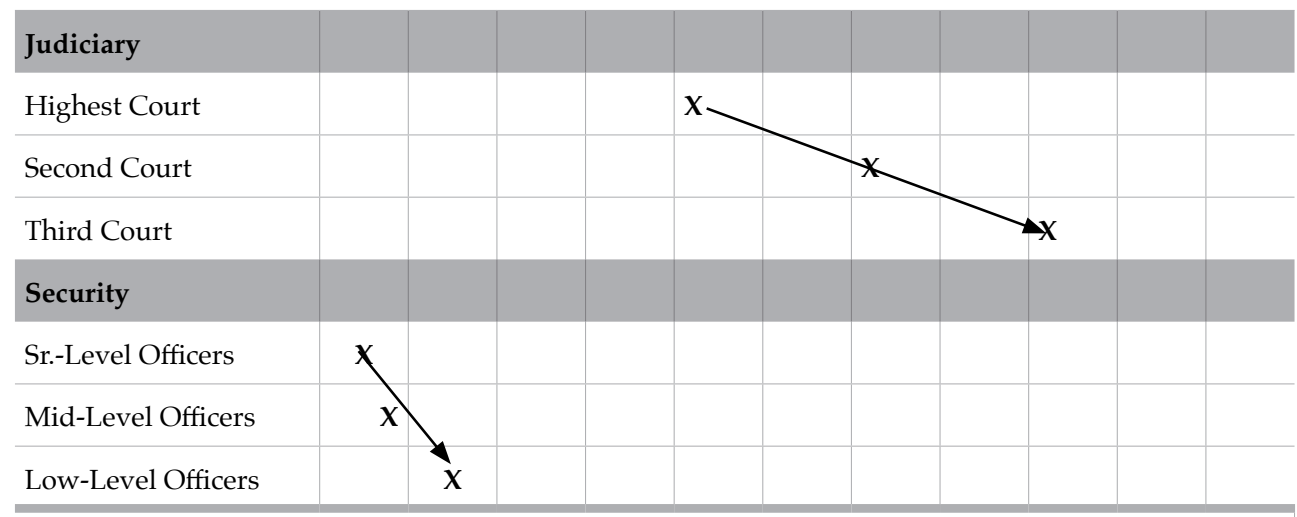

Executive: 15.9-21.2-4.0 Legislative: 4.4-21.0.-17.6 Judiciary: 26.4-32.0-41.4 Security: 3.7-8.5-8.9

\section{Latin America/Caribbean}

Like other regional patterns seen, Latin America/Caribbean had few women represented in the mayoral arena (3 out of 50). Unlike other regions, however, the percentage of women in executive ministerial positions exceeded Tier 2 senior executives. Although the sample of countries was among the smallest by region (5 countries), in every instance the percentage of ministers exceeded the percentage of senior executives. While ministerial representation was among the highest, legislative representation was among the lowest. Women are moving into party leadership positions to some extent, but their representation as committee chairs is significantly lower in relation to the percentage of women parliamentary members. For example, while women hold an average of $17.1 \%$ of the lower house seats, they head only $10.8 \%$ of the committees. This is the largest gap between legislative Tier 2 and Tier 3 percentages in all regions. As women are gaining access to legislative bodies, it would appear that they are not making equal progress in accessing committee leadership in equal proportion. Consistently low percentages of women in political party leadership, committee chairs, and percentages of parliamentarians resulted in the Latin America/Caribbean country average outscoring only the Middle East/North Africa in the legislative arena. In the security sector, excellent access to data provided insights into what is happening with women's representation at the highest levels of the police, including figures that point to a potentially strong glass ceiling in place at the senior officer level. ${ }^{512}$ Table 50 highlights the average

\footnotetext{
512 The Latin American Network of Security and Defence (RESDAL) has produced the definitive book on the military for Latin America and the Caribbean. While it does not include a breakdown of police statistics, the organization was able to easily collect the needed police data given their contacts in the security domain. For an insightful look into the gender aspects of women and the military, refer to their excellent publication: "A Comparative Atlas of Defence in Latin America and Caribbean." Latin American Network of Security and Defence, 2014.
} 
percentage of women across the three tiers in the sample countries selected for Latin America/Caribbean.

TABLE 50: Latin America/Caribbean - Vertical Distribution

\begin{tabular}{|c|c|c|c|c|c|c|c|c|c|c|c|}
\hline 12 Data Points & $0-5$ & $6-10$ & 11-15 & $16-20$ & 21-25 & $26-30$ & $31-35$ & $36-40$ & $41-45$ & $46-50$ & $51+$ \\
\hline \multicolumn{12}{|l|}{ Executive } \\
\hline \multicolumn{12}{|l|}{ Ministers } \\
\hline \multicolumn{12}{|l|}{ Senior Executives } \\
\hline \multicolumn{12}{|l|}{ Top 10 Mayors } \\
\hline \multicolumn{12}{|l|}{ Legislative } \\
\hline \multicolumn{12}{|l|}{ Party Leaders } \\
\hline \multicolumn{12}{|l|}{ Committee Chairs } \\
\hline \multicolumn{12}{|l|}{ Legislators } \\
\hline \multicolumn{12}{|l|}{ Judiciary } \\
\hline \multicolumn{12}{|l|}{ Highest Court } \\
\hline \multicolumn{12}{|l|}{ Second Court } \\
\hline \multicolumn{12}{|l|}{ Third Court } \\
\hline \multicolumn{12}{|l|}{ Security } \\
\hline \multicolumn{12}{|l|}{ Sr.-Level officers } \\
\hline \multicolumn{12}{|l|}{ Mid-Level officers } \\
\hline Low-Level officers & & $4_{x}$ & & & & & & & & & \\
\hline
\end{tabular}

Executive: $24.2-18.5-6.0$ Legislative: 8.2-10.8-17.1 Judiciary: 16.7-18.1-23.7 Security: 4.9-8.6-9.4

\section{Asia}

On average, with the exception of the legislative branch, scores were low in the Asia countries selected from the region. Here we see women leading political parties at higher percentages than other regions. The number of women parliamentarians is also $2.4 \%$ above the 40 -country average. While a glass ceiling may appear to exist in the countries measured, it is not as apparent as in the other four geographical regions. The differences in the percent of women serving in a Tier 1 verses a Tier 
2 or a Tier 3 are not as wide, thus women are more evenly distributed among the varying three tiers. Overall, however, lower percentages of women are entering the executive, judiciary, and security sectors at the Tier 3 level in relation to other regions measured. The Asia model reflects fewer numbers of women more evenly distributed across decision-making positions, as compared to the other regions where the selected countries exhibited distinctive bulges of women clustered in the bottom Tier 3. Table 51 highlights the average percentage of women across all three tiers in the sample countries selected for Asia.

TABLE 51: Asia - Vertical Distribution

\begin{tabular}{|c|c|c|c|c|c|c|c|c|c|c|c|}
\hline 12 Data Points & $0-5$ & $6-10$ & 11-15 & $16-20$ & 21-25 & 26-30 & 31-35 & $36-40$ & $41-45$ & $46-50$ & $51+$ \\
\hline \multicolumn{12}{|l|}{ Executive } \\
\hline \multicolumn{12}{|l|}{ Ministers } \\
\hline \multicolumn{12}{|l|}{ Senior Executives } \\
\hline Top 10 Mayors & & $x$ & & & & & & & & & \\
\hline \multicolumn{12}{|l|}{ Legislative } \\
\hline \multicolumn{12}{|l|}{ Party Leaders } \\
\hline \multicolumn{12}{|l|}{ Committee Chairs } \\
\hline Legislators & & & & & $x$ & & & & & & \\
\hline \multicolumn{12}{|l|}{ Judiciary } \\
\hline \multicolumn{12}{|l|}{ Highest Court } \\
\hline \multicolumn{12}{|l|}{ Second Court } \\
\hline Third Court & & & & $x$ & & & & & & & \\
\hline \multicolumn{12}{|l|}{ Security } \\
\hline \multicolumn{12}{|l|}{ Sr.-Level Officers } \\
\hline \multicolumn{12}{|l|}{ Mid-Level Officers } \\
\hline Low-Level Officers & & $x$ & & & & & & & & & \\
\hline
\end{tabular}

Executive: 11.1-12.7-6.7 Legislative: 11.1-18.7-21.7 Judiciary: 15.2-18.9-18.3 Security: 2.8-5.0-7.5 


\section{Africa}

Africa appears as the success story in terms of higher percentages of women across the political spectrum as well as scoring in the Diamond Index. This is due, in part, to the cross-cutting high scores of South Africa and, with the exception of the security sector, Rwanda. Yet many other countries across the continent are seeing significant jumps in women's representation as well - Kenya, Mozambique, Ghana, and Liberia all scored well. Despite significant percentages of women across all sectors, we see in Table 50 a possible glass ceiling effect, especially in the legislative arena. In this sector we can see a $23.2 \%$ drop between Tier 1 and Tier 2 . While there are few women political party leaders, it would appear that women are being given opportunities through appointments in the executive and judiciary. Within the judiciary women are also making steady gains at all levels. There is only a $2.5 \%$ separation in women's representation between Tier 1 and Tier 3 courts. Higher-than-average levels of representation were consistently seen in high-prestige positions on constitutional, supreme, and high courts across the selection of countries from the African region. Women are also making more headway in the security sector, with no tier level at less than $7 \%$ representation. Table 52 highlights the average percentage of women across the three tiers in the sample countries selected for Africa.

TABLE 52: Africa - Vertical Distribution

\begin{tabular}{|c|c|c|c|c|c|c|c|c|c|c|c|}
\hline 12 Data Points & $0-5$ & $6-10$ & 11-15 & $16-20$ & 21-25 & $26-30$ & 31-35 & $36-40$ & $41-45$ & $46-50$ & $51+$ \\
\hline \multicolumn{12}{|l|}{ Executive } \\
\hline \multicolumn{12}{|l|}{ Ministers } \\
\hline Senior Executives & & & & & $X$ & & & & & & \\
\hline Top 10 Mayors & & & $x$ & & & & & & & & \\
\hline \multicolumn{12}{|l|}{ Legislative } \\
\hline \multicolumn{12}{|l|}{ Party Leaders } \\
\hline \multicolumn{12}{|l|}{ Committee Chairs } \\
\hline \multicolumn{12}{|l|}{ Legislators } \\
\hline \multicolumn{12}{|l|}{ Judiciary } \\
\hline Highest Court & & & & & & $x$ & & & & & \\
\hline Second Court & & & & & & $X$ & & & & & \\
\hline Third Courts & & & & & & $x$ & & & & & \\
\hline
\end{tabular}




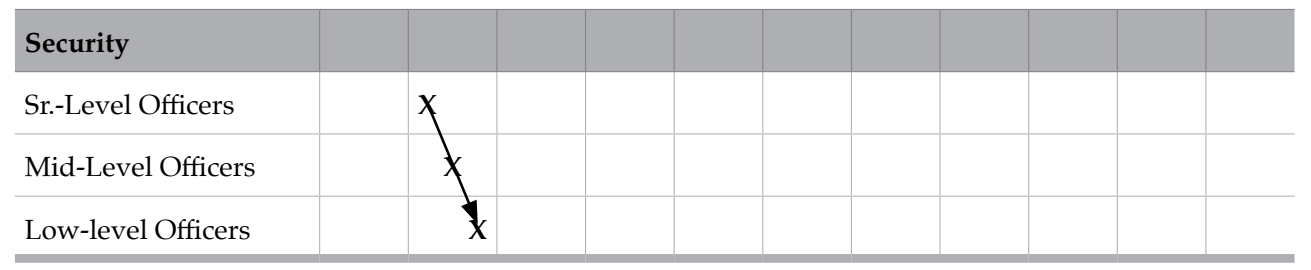

Executive: 23.8-25.7-11.7 Legislative: 4.7-27.9-22.6 Judiciary: 26.6-27.5-26.6 Security: 7.7-8.3-10.8

\section{Middle East/North Africa}

If Sub-Saharan Africa is the success story, countries from Northern Africa and the Middle East present the greatest set of challenges, both in terms of women entering into decision-making positions as well as access to information. Political turmoil in the Middle East limited access to in-country travel as well as expertise normally available. Of the seven countries selected, sufficient data was collected on six. The status of women in the security sector remains almost completely unknown across the region. Governments are unwilling to share the information and the team could find no experts or non-governmental organizations tracking data in this area. Along with little progress in the security sector, the legislative branch also appears to exhibit a glass ceiling, with a $15.6 \%$ drop in the percent of political-party leaders who are women to the percent of female rank-and-file members. There are a several noteworthy areas in this region to report, however. We see some progress in the upper echelons of the executive, with a number of women appointed to the position of senior executive $(13.4 \%)$. We can also see significant numbers of women in the lower courts of the judicial arena. While few women serve on the higher courts, percentages in the lower courts (Tier 3) surpass those of countries sampled in Asia and Latin America. Again, while Asia has fewer women more evenly distributed across varying levels of the judiciary, the Middle East/North Africa region distribution clusters women in the lower ranks, a pattern more reflective of the 40-country trend. Table 53 highlights the average percentage of women across the three tiers in the sample countries selected for the Middle East/North Africa. 
TABLE 53: Middle East/North Africa - Vertical Distribution

\begin{tabular}{|c|c|c|c|c|c|c|c|c|c|c|c|}
\hline 12 Data Points & $0-5$ & $6-10$ & 11-15 & $16-20$ & $21-25$ & $26-30$ & $31-35$ & $36-40$ & $41-45$ & $46-50$ & $51+$ \\
\hline \multicolumn{12}{|l|}{ Executive } \\
\hline \multicolumn{12}{|l|}{ Ministers } \\
\hline \multicolumn{12}{|l|}{ Senior Executives } \\
\hline Top 10 mayors & $X$ & & & & & & & & & & \\
\hline \multicolumn{12}{|l|}{ Legislative } \\
\hline \multicolumn{12}{|l|}{ Party Leaders } \\
\hline \multicolumn{12}{|l|}{ Committee Chairs } \\
\hline \multicolumn{12}{|l|}{ Legislators } \\
\hline \multicolumn{12}{|l|}{ Judiciary } \\
\hline Highest Court & & $X$ & & & & & & & & & \\
\hline \multicolumn{12}{|l|}{ Second Court } \\
\hline \multicolumn{12}{|l|}{ Third Court } \\
\hline \multicolumn{12}{|l|}{ Security } \\
\hline Sr.-Level Officers & NA & & & & & & & & & & \\
\hline Mid-Level Officers & NA & & & & & & & & & & \\
\hline Low-level Officers & $X$ & & & & & & & & & & \\
\hline
\end{tabular}

Executive: 9.0-13.4-1.4 Legislative: 1.6-12.5-17.2 Judiciary: 5.1-3.8-26.1 Security: NA-NA-4.8

\subsection{CONCLUSION}

The global average score of 13.6 - out of a possible maximum of 100 points - indicates that women's representation in decision-making positions is less than one-sixth of men's, resulting in restricted political access. That is not to say that women are not making gains in specific government sectors or positions of decision-making authority. In returning to the two sub-questions posed at the beginning of this chapter, some interesting highlights emerge.

1) To what degree are women accessing decision-making positions horizontally across formal government and the security sector? 
In regard to horizontal or sectoral representation (glass walls), women seem to be making the most gains in the judicial sector. Out of a maximum of 25 possible points, indicating only women in judicial decision-making positions, the 40-country average score was 5.1. Across all regions, including the Middle East/North Africa, women are gaining access to magisterial and judicial positions from lower courts to higher courts.

The second-highest sector for women's representation was the executive branch. Here the Diamond Index overall average score was 3.8 (out of a possible maximum of 25). While sample countries from Africa and Latin America/Caribbean scored well in this regard, achievements were tempered by the lack of representation in the countries selected from Asia and the Middle East/North Africa.

The third-ranked sector among the four was the legislative branch with a 40-country average of 3.0 (out of a possible maximum of 25). Countries representing Asia (3.9) and Africa (3.8) recorded the highest Diamond Index scores in this domain. The significant representation of Asian women as heads of political parties resulted in its first-place showing. Eastern Europe/Eurasia (2.9) along with Latin America/ Caribbean (2.6) scored close to one another in the mid-range. The Middle East/ North Africa region scored lowest at 1.9.

2) To what degree are women accessing decision-making positions vertically across formal government and the security sector?

Looking at the judiciary from a vertical perspective (glass ceilings), steady gains are being made in the overall percentage of women occupying Tier $1(17.1 \%)$ and Tier $2(19.9 \%)$. The majority of positions measured, however, remain clustered in Tier 3 (27.9\%) decision-making positions. In the seven countries representing the Middle East/North Africa region, significant numbers of women are entering the judiciary at the lower-court level.

Within the executive sector, the lack of women mayors across all geographic zones was most striking. While the average percentage of ministers $(16.8 \%)$ and senior executives $(18.3 \%)$ was significant, the absence of women leaders among large urban centers $(6 \%)$ was in direct contrast to gains made in the upper tiers of the executive.

In the legislative sector, women are making headway in gaining seats with a 40-country average of $19.2 \%$. If women can access parliamentary seats, they also seem able to access committee chairs. Female chairwomen seats, at $18.2 \%$, reflected the general percentage of women members of parliament. Women as political party 
leaders appeared as a significant gap. On average, women encumber $6 \%$ of the top party positions. Asia is the only region with significantly higher scores in this category.

While representation of women across all three government branches lags significantly behind men, typically two out of the three tiers in each domain find women's representation close to $20 \%$. The exceptions to this were women mayors, political party leaders, and all tiers of the security sector. The sole exception to the security sector trend was South Africa, with a Diamond Index score of 7 (out of a possible maximum of 25) - approximately double the score of any other country. At each tier level women were well represented. This moved the average score for Africa's 14 countries to 2.2. All other regions scored below 2, with Asia scoring just above 1 point and no average score for the Middle East/North Africa countries due to a lack of data. The 40 -country average score of 1.7 points to thick glass walls and a glass ceiling surrounding the security sector.

From the methodology of the Diamond Index we can begin to see in more detail where women are represented in the political space horizontally across government as well as vertically within institutions. This information, especially if collected over time, can provide greater nuance and understanding surrounding women's descriptive representation in the political space and where they are accessing, or excluded from, decision-making positions. 


\title{
Chapter 7 \\ Diamond Index Findings and Limitations
}

\author{
We can track their numbers, and the reversals. \\ Simply by counting women, we can learn a great deal. ${ }^{513}$
}

\subsection{INTRODUCTION}

In attempting to construct a new gender composite indicator in the political domain, it quickly becomes clear that such an effort is a careful balancing act. Global indicators need national data that can be captured by all governments and reported annually. This is a difficult bar to meet in the political sector, and has traditionally been seen as a fairly limited exercise. Regional indexes are more robust in what they aim to collect, moving beyond the percentage of women legislators and ministers to other sectors and often to the sub-national level. For some regions, such as the European Union, more detailed data may be readily available. In much of the Middle East, Asia, and Africa, however, gathering extensive data on the status of women's descriptive representation in the political space may require on-the-ground analysis or in-country experts. This more robust data collection effort can quickly escalate costs, require longer collection timeframes, reduce geographic reach, and limit the ability to publish results annually.

The Diamond Index attempts to strike a middle ground. It ambitiously strives to capture more varied political data, yet is realistic enough to understand the limitations of individual countries to collect this information on an annual basis. The Diamond Index begins by identifying 12 positions across government (executive, legislative, judicial, and security) and then weighting each according to their perceived decision-making authority. These individuals, by virtue of their elected or appointed position within the formal system of government, have varying levels of authority and agency.

Current gender equality indexes typically benchmark women's progress against men's in the domains of health, education, labor, and power. The intent in

513 Kenney, Sally Jane. Gender and Justice: Why Women in the Judiciary Really Matter. Routledge, 2013. 
developing the Diamond Index was to propose a more nuanced model for measuring women's political access only. Once the index was developed, the research then tested whether the data could be collected on a global scale while maintaining a focus on the quality of information gathered.

The first part of this chapter focuses on the quality of the data, and a determination as to whether it can be collected sufficiently on a global scale. This includes a reexamination of the quality data framework upon which the Diamond Index was designed. ${ }^{514}$ The framework's eight quality data criteria are applied across the information gathered in the 40 selected countries.

The remainder of the chapter is devoted to the findings emerging from the data in the 40 pilot countries. In discussing the strengths of the Diamond Index, the depth and breadth of data holds the potential for identifying different trends and patterns that have not been fully explored through current gender indexes in use. Some areas of interest include a closer examination of appointed versus elected positions across government; the location of women in relation to decision-making positions assigned increasing levels of authority; and the ability to compare one specific branch of government (or a mix of branches) across countries, regions, and the world. This section is followed by a final discussion of the research value as well as limitations associated with the Diamond Index.

\subsection{EVALUATING THE QUALITY DATA FRAMEWORK}

In Chapter 3 - For Good Measure, the Diamond Index Quality Data Framework was developed. This framework contains eight criteria against which the quality of the data collected is judged: 1) relevance, 2) completeness, 3) comparability, 4) accuracy, 5) timeliness, 6) cost effectiveness, 7) accessibility, and 8) granularity. Data perceived to be of high quality is marked with the symbol +, medium-quality data \pm , and lowquality data by the - symbol. In the following section, the data gathered across the 12 decision-making positions is evaluated against each of the eight criteria and then categorized as being of high, medium, or low quality.

\footnotetext{
514 See Chapter 3: For Good Measure for further explanation of the Diamond Index Quality Data Framework and the selection of its eight criteria.
} 


\subsubsection{Relevance}

Relevance examines whether the data adequately captures the theoretical concept or ideas that it claims to be measuring. In short, do the indicators selected measure what they say they are measuring? Meeting this criteria can be challenging with a composite indicator, given attempts to often measure different domains or even concepts using the same instrument. ${ }^{515}$ In order to minimize this risk, I selected an equal number of horizontal and vertical measures of perceived equality - to the greatest extent possible on a global scale - in order to ensure consistency across each domain. As a result, the index relies on the same type of indicator (a position) across all four domains, the same number of positions selected per domain (three), each chosen at approximately the same level of authority (ranked according to three tiers), and each weighted in the same manner (based on percentages of women). ${ }^{516}$ While not perfect, this focus on consistency in horizontal and vertical approach reinforces relevancy across all measures.

Executive: Across tier 1 and tier 2, variations occur as to whether the official in a particular position focuses on developing policy, implementing policy, or a combination of both. Within the tier 2 level there will also be differentiation in how individuals arrived at their position. While ministers are appointed, senior executives will be a mix of political appointees and career civil servants. Others may be perceived as apolitical, appointed for their technical or managerial strengths irrespective of political affiliation. The commonality in these two cadres is their collective responsibility for ensuring executive branch policy is set and carried out, emanating from the highest positional levels of the ministerial structure. Within the executive branch, data collected for Tier 1 -Ministers and Tier 2 - Senior Executives is perceived as highly relevant.

Relevancy concerns emerge around the data collected for Tier 3 -Mayor. Ideally, this measure would have focused on women leaders at the first sub-national tier below the national level. This would include more typically, for example, a state governor, regional commissioner, provincial leader, or district official. This lack of available information, when paired with the inconsistency in measurement units, made it difficult to collect this level as a viable data point. As a result, the commonality of mayoral positions at the sub-national level, and collectability of data among the largest urban centers, equated to mayoral positions being a reliable "second-best" - while still deemed a relevant measure - of women's access to decision-making

515 Nardo, Michela, Michaela Saisana, Andrea Saltelli, Anders Hoffman, and Enrico Giovannini. "Handbook on Constructing Composite Indicators: Methodology and User Guide." OECD publishing, 2005.

516 A more in-depth narrative as to why the 12 positions were selected, including each indicator's relevancy as a measure, is discussed in Chapter 4 -Developing the Diamond Index. 
positions at the sub-national level. For these reasons, the tier 3 data was given a rank of medium quality.

Legislative: The relevancy of the Tier 1 - Political Party Leader data links to the role leadership can play as a determinant of party priorities. Equally important, leadership can also take on a gatekeeper role that facilitates or blocks access to a variety of formal political positions. ${ }^{517}$ Tier 2 - Committee Chairs was also deemed a relevant measure given the increasing role parliamentary committees play as the organizing structure responsible for legislating and conducting government oversight. ${ }^{518}$ Given the decision-making authority inherent in each of these positions to determine party representation and policy direction, both tier 1 and tier 2 data was given a rank of high quality,

The intent of the Tier 3 -Legislative Members measure was to capture data at the subnational level. Efforts to create a consistent definition of sub-national representation have not been successful to date, and there is currently no standardized collection of global data below the national level. Given definitional inconsistencies and the lack of available data to gather, the first-choice of information collection at the subnational level was not considered realistic. Unable to gather the most relevant measure, in keeping with the logical construction of the index, the decision was made to focus on members of parliament who do represent local constituencies at the sub-national level. Legislative member data is consistently used as a valid indicator across global gender indexes, even as claims to what it actually measures - women's empowerment, political power, voice, agency - remain open to debate. Given the role of legislators as representatives of sub-national constituencies, and wide academic acceptance of members of parliament as a measure of women in the political space, the Tier 3 - Legislative measure was considered relevant. The preference for this tier, however, was data directly tied to a sub-national official. For these reasons, a ranking of medium-data quality was given for tier 3 .

Judicial: There is little discussion in current global gender indexes, nor the literature underpinning the development of those tools, about women's presence in the judiciary. In attempting to capture women's descriptive representation in formal government, however, it was important from a relevancy perspective that data from all three branches of government be collected. Selecting judges from the most powerful courts was viewed as an accurate representation of women's access to decision-making authority in the judicial branch. While clerks and administrative

517 Norris, Pippa, and Joni Lovenduski. Gender and Party Politics. Sage Publications, 1993. Rahat, Gideon. "Candidate Selection: The Choice before the Choice." Journal of Democracy 18, no. 1 (2007): 157-170.

518 The rationale underpinning the selection for each of the 12 positions is detailed in Chapter 4 -Developing the Diamond Index. 
staff may admittedly serve as gate-keepers, it is the judges themselves who have the formal authority to rule on cases. The quality of the data measuring judges selected from the top three tiers of each country's respective judicial structure was given a ranking of highly relevant.

Security: The police sector is one piece of state security. By focusing on this branch, the Diamond Index can only capture a single aspect of formal representation in the security domain. Also, because collection efforts highlighted that police units appear more open to the presence of women than other security organizations, such as the military, the Diamond Index measure may be overvaluing women's presence in this domain. Given current data limitations, however, there is no simple solution for fully capturing women's presence in the security arena. As a result, in choosing to measure women in the police we are directed to where the most data is available. While data within the command structure of the national police force is considered adequate to capture the intent of measuring women leaders in the security sector, it does not comprise the full picture of women's representation. Based on the definitional narrowness of what constitutes women's formal decision-making in the security domain, relevancy was scored as medium quality. Table $\mathbf{5 4}$ presents the final scoring for the 12 positions against the "relevance" quality data criteria.

\section{TABLE 54: Relevance Quality Data Criteria}

\begin{tabular}{|c|c|c|c|c|c|c|c|c|c|c|c|c|c|}
\hline & \multicolumn{4}{|c}{ EXECUTIVE } & \multicolumn{3}{c|}{ LEGISLATIVE } & \multicolumn{3}{c|}{ JUDICIAL } & \multicolumn{3}{c}{ SECURITY } \\
\hline QUALITY & Tier & Tier & Tier & Tier & Tier & Tier & Tier & Tier & Tier & Tier & Tier & Tier \\
DATA CRITERIA & $\mathbf{1}$ & $\mathbf{2}$ & $\mathbf{3}$ & $\mathbf{1}$ & $\mathbf{2}$ & $\mathbf{3}$ & $\mathbf{1}$ & $\mathbf{2}$ & $\mathbf{3}$ & $\mathbf{1}$ & $\mathbf{2}$ & $\mathbf{3}$ \\
\hline RELEVANCE & + & + & \pm & + & + & + & + & + & + & \pm & \pm & \pm \\
\hline
\end{tabular}

\subsubsection{Completeness}

This criteria examines whether the data selected provides sufficient breadth and depth of information. The difficulty is compounded when attempting to do this for every country across the globe. Do the indicators selected apply to the majority of countries? Do the countries collect this type of data? Often the data sought by researchers can not be found on a consistent basis, leading to the use of proxy indicators. This in itself should not be deemed negative. Concerns emerge, however, when "choices of convenience" are made: using the data at hand rather than the data 
required. ${ }^{519}$ The Diamond Index is not immune to this tension. It attempts to alleviate issues of completeness by carefully selecting a wider breadth and depth of measures across government, thereby spreading the risk that final results are over-reliant on a few proxy measures that may more strongly reflect availability (completeness) rather than relevance.

The majority of the 40 countries selected for my research were low- or lower-middle income. ${ }^{520}$ No country was selected from the middle- or high-income range. Most countries were considered partly free, with only $17.5 \%$ of the countries rated as free..$^{521}$ A number of those selected, in particular low-income countries, were perceived as data-scarce, with limited in-country expertise and resources available to state institutions responsible for data collection. The premise was to test the viability of data collection in difficult pilot countries, with the expectation that if information could be gathered under these constrained economic and political conditions it would be feasible to gather the same information in more advanced economies and liberal democracies. ${ }^{522}$

Executive: The ability to collect data using publically available information was consistently high, with tier 1 recording the collection of all indicators at 100\%, tier 2 at $87.5 \%$, and tier 3 at $97.5 \%$. The selected positions were considered highly complete.

Legislative: The ability to collect data using publically available information was the highest in this domain, with tier 1 and tier 3 gathering $100 \%$ of all indicators. Tier 2 was able to collect $95.0 \%$ of the data points. The selected positions were considered highly complete.

Judicial: The ability to collect data using publically available data was consistently high, with tier 1 recording the collection of indicators at $95.0 \%$ and tier 2 and tier 3 collecting $87.5 \%$ of the data. The selected positions were considered highly complete.

Security: The security sector consistently experienced data collection problems across all three tiers. While the national police appeared in most countries to have more information available than other elements of the security sector, it was by no means robust. Public resources available produced results in less than half of the 40 countries selected. To attempt to reach higher percentages of data collection,

\footnotetext{
519 Hawken, Angela, and Gerardo L. Munck. "Cross-National Indices with Gender-Differentiated Data: What Do They Measure? How Valid Are They?" Social Indicators Research, 2013, 1-38.

520 World Bank 2013 (http://data.worldbank.org/country).

521 Freedom House 2013 (http://freedomhouse.org/report/freedom-world/freedom-world-2013).

522 Chapter 5 - Gathering Data for the Diamond Index provides a more complete narrative describing and documenting all data collection efforts.
} 
in-country experts were called upon with mixed success. In a number of instances, countries admitted to having the data yet were unwilling to share it with researchers. Even with the help of local experts, the ability to collect complete data sets in the security area was limited to the following: tier 1 at $55.0 \%$, tier 2 at $52.5 \%$, and tier 3 at $82.5 \%$. Overall, the completeness criteria in the security sector was given a ranking of low data quality. Table 55 presents the final scoring for the 12 positions against the "completeness" quality data criteria.

\section{TABLE 55: Completeness Quality Data Criteria}

\begin{tabular}{|c|c|c|c|c|c|c|c|c|c|c|c|c|c|}
\hline & \multicolumn{4}{|c}{ EXECUTIVE } & \multicolumn{3}{c|}{ LEGISLATIVE } & \multicolumn{3}{c|}{ JUDICIAL } & \multicolumn{3}{c|}{ SECURITY } \\
\hline $\begin{array}{c}\text { QUALITY DATA } \\
\text { CRITERIA }\end{array}$ & Tier & Tier & Tier & Tier & Tier & Tier & Tier & Tier & Tier & Tier & Tier & Tier \\
\hline COMPLETENESS & + & + & + & $\mathbf{1}$ & $\mathbf{2}$ & $\mathbf{3}$ & $\mathbf{1}$ & $\mathbf{2}$ & $\mathbf{3}$ & $\mathbf{1}$ & $\mathbf{2}$ & $\mathbf{3}$ \\
\hline
\end{tabular}

\subsubsection{Comparability}

This criteria ensures that data definitions and concepts are consistent across countries and over time. While comparability is always a concern, it assumes significant importance for those composite indicators attempting to measure on a global basis. There are few political consistencies to be found across the world's nearly 200 countries. For example, in identifying decision-makers, I selected identifiable positions common to the vast majority of countries. Yet carefully examining any one of the 12 positions across a range of countries highlights that decision-making and responsibilities will vary according to the type of political system, constitutional framework, body of laws, and cultural context. So while the names of the positions may be consistent, we must acknowledge that inherent differences in roles - despite similarity in titles - will differ from country to country.

Executive: In several global gender indexes, data collected for Diamond Index Tier 1 - Ministers and Tier 2 -Senior Executives has been combined into one indicator that is commonly accepted as a viable measure of women's presence in the executive branch of government. ${ }^{523}$ Although the literature underpinning the development of these global indexes differs as to what this presence stands for, it is recognized that across countries these positions are comparable units. The Diamond Index separates

\footnotetext{
523 For example, this indicator is used by the World Economic Form's Global Gender Gap Index and Social Watch's Gender Equity Index. It is produced annually by UN Women and the Inter-Parliamentary Union.
} 
the ministerial positions from those executive positions directly under ministerial supervision to create two separate tiers of data. Given the consistent use of this descriptive representational measure in established global indexes and by the United Nations, the data is considered highly comparable.

One concern in the executive branch surrounding comparability involves the Tier 3 Mayor data. While there are many commonalities in the position - for example, each mayor is responsible for the day-to-day functioning of a defined, generally legally recognized, geographic area ${ }^{524}$ - there are also many differences. Mayors may be elected by local citizens, a council, or appointed by the central government. They may wield enormous autonomy, including over resources, or they may have extremely limited decision-making powers. In collecting data, it became clear that even when limiting mayoral selection to the 10 largest urban areas, the difference between cities remains significant. In some instances cities outstripped the population and resources levels of entire countries. The decision-making and authority of a mayor in these instances may be more akin to a national-level actor. In less developed and smaller countries, the mayoral position presided over a municipal area that resembled a rural town. These differences challenge the comparability of mayors across all spectrums of countries, thereby leading to a medium-quality data ranking.

Legislative: Working backwards in the legislative branch, Tier 3 - Legislator is the most commonly used indicator in gender indexes to measure women's descriptive representation in the political space. This data has now been collected for several decades by the Inter-Parliamentary Union $^{525}$ and is considered a comparable measure across legislative branches, acknowledging that parliaments themselves vary in their authorities. Tier 3 data is considered highly comparable.

Regarding data for Tier 2-Committee Chair, there is currently no systematic collection of this information in the legislative branch. The literature, however, attests to the increasing importance of committees in addressing party conflict and achieving policy resolution. ${ }^{526}$ The head of the committee is recognized as having enhanced status and greater access to resources in their role. ${ }^{527}$ While committees will vary in their authorities across different political systems - and prestige of committees will themselves vary within the each legislative institution - the role of committee chairperson is considered highly comparable across political systems.

\footnotetext{
524 Teune, Henry. "Local Government and Democratic Political Development." The Annals of the American Academy of Political and Social Science 540, no. 1 (1995): 11-23.

525 Inter-Parliamentary Union. "Parliaments at a Glance," 2017.

526 Lawrence Longley, and Roger H. Davidson. "Parliamentary Committees: Changing Perspectives on Changing Institutions," n.d. Accessed April 28, 2018.

527 Kathlene, Lyn. "Position Power Versus Gender Power: Who Holds the Floor?" Gender Power, Leadership, and Governance, 1995, 167-94.
} 
Within the legislative branch the Tier 1-Political Party Leader is open to comparability concerns. Namely, all political parties with lower-house representation are considered viable for measurement. So, for example, the Alliance for Transparency and Change party, with one leader in Tanzania's national assembly, is given the same weight as the leader of the Party of the Revolution with approximately 270 seats. ${ }^{528}$ While their duties as party leaders may be similar, their influence in the national assembly can not be considered fully comparable. For this reason, a ranking of medium-quality data was given.

Judicial: Judicial systems are varied across the globe in a number of ways. While some follow the common law tradition, others are based on civil law. Making comparisons more difficult, however, is how different countries physically structure their court systems and the attendant level of authority at each level. This becomes especially problematic at the tier 3 level in the judicial branch. In some countries this may still be a national level court while in others this tier is devolved to the subnational level. So a third tier may include a small number of elite judicial decisionmakers on the national stage; in other instances this level could comprise dozens or hundreds of lower-level magistrates. There is no easy fix to the comparability of judicial systems at this level. The comparability and consistency is in its location at the third tier of court within each country's judicial framework. These comparability concerns resulted in a judicial tier 3 medium-quality data ranking.

Security: Data included the police force with national jurisdiction. For smaller and developing countries, this was typically clear as the state relied on one national police force. In larger, more populated and diverse countries, this narrow criteria was at times problematic, considering the number of overlapping responsibilities between different types of security forces. Within any respective national police force, however, the ability to compare officer rankings within that selected structure was surprisingly similar. While some forces may have several additional classifications of officer, for most of the 40 countries the police hierarchy of command varies little. So while the positions themselves were highly comparable, the nature of the differing forces resulted in an overall medium-quality data ranking. Table 56 presents the final scoring for the 12 positions against the "comparability" quality data criteria.

528 www.parliament.go.tz/mps-list 
TABLE 56: Comparability Quality Data Criteria

\begin{tabular}{|c|c|c|c|c|c|c|c|c|c|c|c|c|c|} 
& & \multicolumn{4}{|c}{ EXECUTIVE } & \multicolumn{3}{c|}{ LEGISLATIVE } & \multicolumn{3}{c|}{ JUDICIAL } & \multicolumn{3}{c|}{ SECURITY } \\
\hline $\begin{array}{c}\text { QUALITY DATA } \\
\text { CRITERIA }\end{array}$ & Tier & Tier & Tier & Tier & Tier & Tier & Tier & Tier & Tier & Tier & Tier & Tier \\
\hline COMPARABILITY & + & + & $\mathbf{2}$ & $\mathbf{1}$ & $\mathbf{2}$ & $\mathbf{3}$ & $\mathbf{1}$ & $\mathbf{2}$ & $\mathbf{3}$ & $\mathbf{1}$ & $\mathbf{2}$ & $\mathbf{3}$ \\
\hline
\end{tabular}

\subsubsection{Accuracy}

The criteria of accuracy partners closely with completeness. While noteworthy that data can be gathered successfully and completely, it is also necessary to determine if the information was accurate, limited in its bias, and if any data gaps were identified. In terms of bias, because the Diamond Index is measuring descriptive representation in specific positions, the introduction of bias is limited. Either a man or women (as selfidentified) holds the position; it is a simple binary choice. Therefore, across the four domains, bias was not perceived as problematic. Concerns about inaccuracies and data gaps were more closely examined given that composite indicators, in particular, rely on the generation of data from a variety of entities, including under-resourced national statistical offices. Part of the intention behind the Diamond Index was to test to what extent useful data could be collected without relying or requesting formal government participation. This was done, in particular, with a focus on countries where governments were unable or uninterested in gathering and sharing more expansive gender data in the political space.

Executive: For tier 1 and tier 2, public information was available. This included data from official government websites and multi-lateral agencies. The data gathered for tier 3 (mayors) relied on a broader array of public sources. Information for larger urban centers was easily gathered. More remote and smaller cities did require the use of local media and Internet searches. Once cities and mayors were identified, however, it was perceived as relatively easy to fact-check the information through insider knowledge and media reporting. The data for the three selected positions within the executive domain was considered highly accurate.

Legislative: Tier 1 and tier 3 data is provided through a combination of official government, multi-lateral, political party, and United States government websites. The ability to fact-check against multiple sources lends a high degree of confidence to the accuracy of the information. The one area of concern in the legislative branch was tier 2 (committee chairs). While data is publically available in most countries 
on parliamentary committees and leadership, it is not always clear if the committees being cited are permanent or ad hoc in nature. The goal of the Diamond Index was to include only permanent committees. It is possible, however, that in some instances ad hoc committees were included. There was no easily discernable way to distinguish ad hoc from permanent committees if the legislative branch itself did not make that distinction. For this reason legislative tier 2 received a medium-quality data ranking in accuracy.

Judicial: Data for the tier 1 and tier 2 judicial levels was most often found through official government websites. These judges are typically few in number and maintain a high public profile. Concerns around accuracy emerge with the judicial tier 3 positions, especially when these courts are located at the sub-national level. This level of regional or district judge or magistrate is typically not included on public government websites, and it can be difficult to verify the accuracy of data produced. While the information was often found, it relied on older reports, grey literature, assessments of the judiciary, or government reports. In some instances, simply a long list of names was provided. Using this mixture of information, it was difficult to confirm in any meaningful way the accuracy and currency of the data being provided - short of in-country expertise, confirmation from the judicial branch, or verification by an appropriate ministry. For the variability in data provided at the tier 3 level - in particular for sub-national courts - a medium-quality data ranking was conferred for accuracy.

Security: The data collected in the security sector was considered accurate when researchers were able to access the information. Wider concerns around accuracy emerge, however, given the large data gaps. In particular, approximately half of the countries were unable or unwilling to provide data detailing officers occupying the top and middle command structures of their national police force. Given these significant data gaps, tier 1 and tier 2 were ranked low-quality data while tier 3 (reporting in $82.5 \%$ of the countries) was allocated a medium-quality data score for accuracy. Table 57 presents the final scoring of the 12 positions against the "accuracy" quality data criteria. 
TABLE 57: Accuracy Quality Data Criteria

\begin{tabular}{|c|c|c|c|c|c|c|c|c|c|c|c|c|c|}
\hline & \multicolumn{3}{|c}{ EXECUTIVE } & \multicolumn{3}{c|}{ LEGISLATIVE } & \multicolumn{3}{c}{ JUDICIAL } & \multicolumn{3}{c}{ SECURITY } \\
\hline $\begin{array}{c}\text { QUALITY DATA } \\
\text { CRITERIA }\end{array}$ & Tier & Tier & Tier & Tier & Tier & Tier & Tier & Tier & Tier & Tier & Tier & Tier \\
\hline ACCURACY & + & + & $\mathbf{3}$ & $\mathbf{1}$ & $\mathbf{2}$ & $\mathbf{3}$ & $\mathbf{1}$ & $\mathbf{2}$ & $\mathbf{3}$ & $\mathbf{1}$ & $\mathbf{2}$ & $\mathbf{3}$ \\
\hline
\end{tabular}

\subsubsection{Timeliness}

In order to construct the Diamond Index on a consistent annual basis, this criteria of the data quality framework is focused on the ability to collect information across a single-year timeframe. One attribute of a typical composite indicator is its reliance on a multitude of sources for data. This may leave the researcher dependent on a variety of publication dates that lack coherence when aggregated. For example, one domain may use current data while a different domain relies on much older data. If examining formal government, this can be problematic when new elections or incidents result in a dramatic reordering of the political space. Having to wait another year or two to reflect these changes may not be optimal.

Executive: The public sources used to collect the data were consistently updated and reflected the reality of current positions. One concern for the Diamond Index would be, however, attempting to collect this data in the immediate days or weeks following an election, in particular where there was significant change due to the reordering of political parties in power. Time would be required for the new regime to take its position, conclude appointments, and update information for the public. With the caveat of this short timeframe immediately following national or mayoral elections, the selected positions were considered highly timely.

Legislative: Official parliamentary websites, multi-lateral agencies, and United States government data bases provide timely data for all three tiers of the legislative branch. Although the data is not always collected systematically in one place, multiple sources allow adequate information to be gathered in a timely manner. As noted with the executive, gathering data immediately following parliamentary elections would be problematic. A period of recalibration would be required to allow for parties to seat members and possibly reallocate committee leadership positions. With the caveat of this short timeframe immediately following parliamentary elections, the selected positions were considered highly timely. 
Judicial: Ingeneral, judges selected for tier 1 positions tend to have long appointments and are less subject to the vagaries of political elections. Data at this level was consistently available and updated in official judicial websites and verifiable through multiple sources. Tier 1 data was ranked as high quality. Timeliness issues emerge in the tier 2 category depending on the type of court. For some countries, this court remains prominent at the national level and public information is available and updated regularly. In other instances, this court may not have the national profile as the top-tier court, thus making information harder to find and verify its currency. This same situation is exacerbated at the tier 3 level; information is pulled from a variety of sources wherever it can be found. Reports may be out of date. New appointments are not consistently updated into a central registry. At this level it becomes difficult to confirm the timing of the information provided, including when it was last updated to reflect on-the-ground realities. Given these challenges, tier 2 was ranked medium-quality data and tier 3 was ranked low-quality data.

Security: When information is provided, it is typically of high quality, including timeliness. Weaknesses occur when researchers must dig for information from a range of sources. As noted with the judiciary tier 3, reports may be old or the sources unclear about when the data being presented was collected. This makes it difficult to ascertain the timeliness of the data and whether it reflects reality. Given the large numbers present in the lower ranks of officers, and certain movement in and out of these positions, it is fairly certain that unless the ministry or police itself are providing the information, changes will have occurred. These challenges result in all tiers within the security sector receiving a low-quality data ranking for timeliness. Table 58 presents the final scoring for the 12 positions against the "timeliness" quality data criteria.

\section{TABLE 58: Timeliness Quality Data Criteria}

\begin{tabular}{|c|c|c|c|c|c|c|c|c|c|c|c|c|c|} 
& & \multicolumn{4}{|c}{ EXECUTIVE } & \multicolumn{3}{c|}{ LEGISLATIVE } & \multicolumn{3}{c|}{ JUDICIAL } & \multicolumn{3}{c|}{ SECURITY } \\
$\begin{array}{c}\text { QUALITY DATA } \\
\text { CRITERIA }\end{array}$ & Tier & Tier & Tier & Tier & Tier & Tier & Tier & Tier & Tier & Tier & Tier & Tier \\
\hline TIMELINESS & + & + & $\mathbf{3}$ & $\mathbf{1}$ & $\mathbf{2}$ & $\mathbf{3}$ & $\mathbf{1}$ & $\mathbf{2}$ & $\mathbf{3}$ & $\mathbf{1}$ & $\mathbf{2}$ & $\mathbf{3}$ \\
\hline
\end{tabular}




\subsubsection{Cost Effectiveness}

Cost effectiveness will have different connotations if you are the Bill and Melinda Gates Foundation verses an individual student researcher. What may be cost effective to one may be a "blue sky" exercise for another. This criteria is meant to focus more attention on how data can be collected in a cost-effective manner without the deep pockets of a foundation or international organization - that is sustainable and replicable on a regular basis. For my purposes the intent was to create a measure that could realistically be collected by in-country stakeholders whether a low-income or high-income country - by a government office, local nongovernmental organization, or small group of researchers.

Executive: Publicly available data provides affordable access to tier 1 and tier 2 information. Data from both levels was ranked as highly cost effective. There is also a range of information on the largest cities in most countries. Mayors and statistics are typically found in official government websites or through the media. Problems arise, however, with the lack of data on women in government beyond the prominent urban centers, particularly in lower-income countries. Specific language skills, the triangulation of multiple data sources, and even in-country expertise may be required beyond the regional capitals. This can quickly lead to significant human resource hours needed to chase down data on smaller cities in highly rural countries. Because of the mixed nature of mayoral data availability at the tier 3 level, a medium-quality data ranking was given for cost effectiveness.

Legislative: Public data exists for all three tiers of the legislative branch, in particular for tier 1 and tier 3. Tier 2 data (committee chairs) also exists to a great extent on official websites. It is not, however, collected in any single format. More time, therefore, is required to systematically collect and verify the data, but it can be achieved using only public data with no additional costs incurred beyond research hours. The selected positions were considered highly cost effective.

Judicial: Given the difficulties previously outlined in collecting quality data at the tier 3 level, it correlates that more human resources may be required to adequately gather information. This remains, however, very country specific depending on where this court level sits. If it remains at the national level, public information is more readily available at low cost. Once this tier of court moves to the sub-national level, however, the number of judges increases substantially while at the same time the amount of public information decrease substantially. In this case, triangulation, in-country verification, language skills, etc., may be all be required, increasing the 
associated cost. Because some countries require a greater resource investment, but not all, the judiciary tier 3 was ranked as medium-quality data.

Security: It quickly became apparent that the entire project budget for this research could be quickly consumed trying to track down security data. Strategic choices were then made as to where the best opportunity for gathering information could realistically materialize. An intensive effort was then made in those countries. Even allocating greater resources had a minimal return on the investment given the lack of public information, the low political will to share any information, and the mistrust by the security sector of "outsiders." It was soon apparent to the research team why so little information detailing women military and police officers exists for public consumption. The ability to adequately gather information in this arena was beyond the resource scope - both financial and human - of this research effort. The overall security score was ranked low quality data for cost effectiveness. Table 59 presents the final scoring of the 12 positions against the "cost effectiveness" quality data criteria.

\section{TABLE 59: Cost Effectiveness Quality Data Criteria}

\begin{tabular}{|l|c|c|c|c|c|c|c|c|c|c|c|c|c|} 
& \multicolumn{3}{|c}{ EXECUTIVE } & \multicolumn{3}{c|}{ LEGISLATIVE } & \multicolumn{3}{c|}{ JUDICIAL } & \multicolumn{3}{c|}{ SECURITY } \\
$\begin{array}{l}\text { QUALITY DATA } \\
\begin{array}{l}\text { CRITERIA } \\
\text { Cier }\end{array}\end{array}$ & $\mathbf{1}$ & $\mathbf{2}$ & $\mathbf{3}$ & $\mathbf{1}$ & $\mathbf{2}$ & $\mathbf{3}$ & $\mathbf{1}$ & $\mathbf{2}$ & $\mathbf{3}$ & $\mathbf{1}$ & $\mathbf{2}$ & $\mathbf{3}$ \\
\hline $\begin{array}{l}\text { COST } \\
\text { EFFECTIVENESS }\end{array}$ & + & + & \pm & + & + & + & + & + & \pm & - & - & - \\
\hline
\end{tabular}

\subsubsection{Accessibility}

The Diamond Index was designed with access to public information and ease of use as foundational principles. The ability to present data in a format that is simple to understand, access, and replicate by the general public, governments, or other interested stakeholders was foundational. With a template created, the desire is to see others replicate the index according to their individual country needs and time frame. For this reason, simple mathematical formulas and logical construction were designed with replicability in mind.

Executive: Tier 1 and Tier 2 data was ranked of high quality given its public nature and ease of access. The goal of replicability, however, fell short in tier 3. For an 
expert sitting in the country, the data is typically available. On several occasions a quick call to the city council office from a citizen could confirm the name and sex of the mayor. For those sitting outside the problematic country, however, this information is not always easy to find in data-scarce, conflict, or insecure states. While trying to replicate the information on an individual country-to-country basis is feasible, researchers attempting to consolidate the data on a regional or global scale will find challenges in a number of data-scarce countries. As a result, tier 3 was ranked medium quality data.

Legislative: As noted earlier, public data exists for all three tiers of the legislative branch, in particular, specific data bases for tier 1 and tier 3 indicators. Tier 2 data (committee chairs), however, does not have the same ease of access where information can be found in one location aggregated by an international organization or government. A greater level of effort is required to systematically gather the data. But, this can be achieved using only public data with a reasonable amount of time and effort. Given the replicability and ease of understanding the information presented in the legislative branch, all three tiers were considered highly accessible.

Judicial: While the tier 3 data may be simple to understand (magistrates at the third court level), accessibility and replicability vary widely. As noted earlier, much of this depends on at which level - national or sub-national - the court is located. If the court is situated nationally, data will typically be accessible and easy to replicate. For courts sitting at the sub-national level, in-country assistance or country expertise may be required to affirm the reliability of data. This might include, for example, local language skills to read government documents or cultural expertise to determine the sex of individuals. Based on these types of access and replicability constraints encountered in some countries, tier 3 was ranked medium quality data.

Security: In keeping with the woes of security data, accessibility remains problematic across all three tiers. Without in-country expertise or a trusted intermediary, security officials are often unwilling to share statistics on officer positions. While information was obtained when the right mix of official and expert were paired, this approach can not be considered the appropriate level of accessibility for the Diamond Index purposes. For these reasons, all three tiers of the security sector data were ranked of low quality. Table 60 presents the final scoring of the 12 positions against the "accessibility" quality data criteria. 
TABLE 60: Accessibility Quality Data Criteria

\begin{tabular}{|c|c|c|c|c|c|c|c|c|c|c|c|c|c|}
\hline & \multicolumn{4}{|c}{ EXECUTIVE } & \multicolumn{3}{c|}{ LEGISLATIVE } & \multicolumn{3}{c|}{ JUDICIAL } & \multicolumn{3}{c}{ SECURITY } \\
QUALITY DATA & Tier & Tier & Tier & Tier & Tier & Tier & Tier & Tier & Tier & Tier & Tier & Tier \\
CRITERIA & Tier & $\mathbf{2}$ & $\mathbf{3}$ & $\mathbf{1}$ & $\mathbf{2}$ & $\mathbf{3}$ & $\mathbf{1}$ & $\mathbf{2}$ & $\mathbf{3}$ & $\mathbf{1}$ & $\mathbf{2}$ & $\mathbf{3}$ \\
\hline ACCESSIBILITY & + & + & \pm & + & + & + & + & + & \pm & - & - & - \\
\hline
\end{tabular}

\subsubsection{Granularity}

The ability to disaggregate data into smaller units is considered an indispensable quality data criteria. The purpose of the Diamond Index construction is to look at women's descriptive representation among key decision-making positions in government. Fundamental to the selection of indicators was the ability to disaggregate the data into smaller information units including, at a minimum, by sex. Therefore, no position was selected, nor data collected, if the position was not able to be - at a minimum - disaggregated by male / female.

That is not to say that the data could not be disaggregated in other ways: by age, religion, tribe, persons with disabilities, etc. This was simply not my area of research focus. My concern was only granularity according to sex and all indicators selected for their ability to do so. Therefore, all positions were ranked of high quality. Table 61 presents the final scoring of the 12 positions against the "granularity" quality data criteria.

\section{TABLE 61: Granularity Quality Data Criteria}

\begin{tabular}{|c|c|c|c|c|c|c|c|c|c|c|c|c|c|}
\hline & \multicolumn{4}{|c}{ EXECUTIVE } & \multicolumn{4}{c|}{ LEGISLATIVE } & \multicolumn{3}{c|}{ JUDICIAL } & \multicolumn{3}{c}{ SECURITY } \\
$\begin{array}{c}\text { QUALITY DATA } \\
\text { CRITERIA }\end{array}$ & Tier & Tier & Tier & Tier & Tier & Tier & Tier & Tier & Tier & Tier & Tier & Tier \\
\hline GRANULARITY & + & $\mathbf{1}$ & $\mathbf{3}$ & $\mathbf{1}$ & $\mathbf{2}$ & $\mathbf{3}$ & $\mathbf{1}$ & $\mathbf{2}$ & $\mathbf{3}$ & $\mathbf{1}$ & $\mathbf{2}$ & $\mathbf{3}$ \\
\hline
\end{tabular}

Table 62 combines the quantity (percentage) of the data collected with the eight quality data criteria rankings for each of the 12 positions. For ease of reference, high quality data has been color coded as green, medium quality data as yellow, 
and low quality data as red. So, for example, 40 indicators out of a possible 40 were collected for Executive Tier 1 - Ministers. This is indicated by 100\%. All data points were ranked as high quality, reflected in a green score for each of the eight criteria. At the opposite extreme, only $52.5 \%$ of the indicators were collected for the Security Tier 2 -Mid-Level Officers. Of the eight quality data criteria, one received a ranking of high quality, two of medium quality, and five of low quality. Based on this approach, both high quantity and quality data for the ministerial position can be collected on a global scale while data for mid-level security officers is unlikely to achieve either the quantity or quality envisioned for the Diamond Index. 


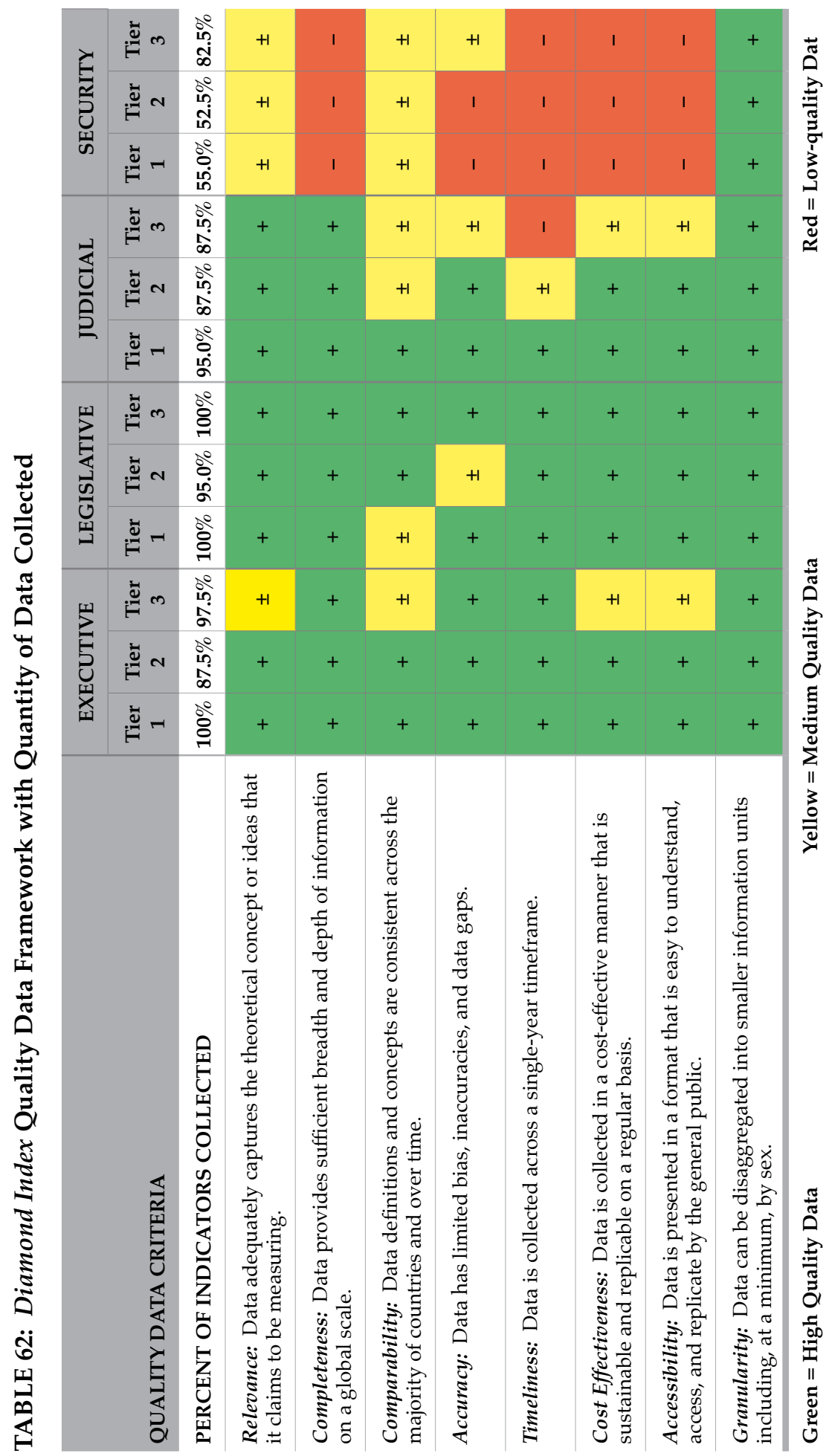


With a better understand of quality data concerns across the 12 measures, we return to the purpose of this research. Specifically, the design and piloting of the Diamond Index attempts to answer the following research question:

\section{Can quality data measuring women's positions \\ of formal political decision-making \\ be collected on a global scale?}

The overall quality of the data gathered across 12 indicators in 40 less-developed countries presents mixed findings. Looking only at the positions selected for the executive, legislative, and tier 1 and 2 of the judiciary, the picture is positive. Of the 64 rankings possible ( 8 positions $\times 8$ criteria), a total of $56(87.5 \%)$ were judged to be of high quality and $8(12.5 \%)$ of medium quality. None were ranked of low quality. Across these 8 positions an average of $95.3 \%$ of all indicators were collected. Based on this 40-country pilot, there is a strong argument to be made that both the quality and quantity of information available for 8 of the 12 indicators is excellent and quality data can be collected on a global scale.

The picture is not as rosy for the remaining 4 indicators: the third tier in the judiciary and the security sector. While the quantity of indicators remains high in the judiciary $(87.5 \%)$, the quality of the data is more open to criticism given that four quality criteria received medium rankings and one received a low quality ranking. While the information may be there for collection, it lacks the quality rigor seen across the other indicators.

The security sector, however, is the weakest point in the Diamond Index. It is here that the lowest quantity of indicators was collected $(63 \%$ on average across all three tiers) and the greatest number of quality concerns emerge. Of the 24 rankings, only the granularity criteria - the ability to differentiate by sex - was considered of high quality. The remaining 21 rankings received either medium quality (7 total) or low quality (14 total). This rather sobering look at women's leadership in the security sector should not discourage us from using it or attempting to collect more of this information type, but rather should urge caution in how it is used, understanding that it lacks the same quality and quantity standards as the majority of the data contained in the Diamond Index. 


\subsection{DIAMOND INDEX FINDINGS AND AREAS OF INTEREST}

Given the amount of information collected, there were a number of interesting findings that emerged once the data was organized, graphed, and mapped into the Diamond Index. This section will highlight three areas of interest stemming from the research.

\subsubsection{Appointment Advantage}

Results of the Diamond Index consistently point to women gaining greater access to positions reliant on appointment as compared to positions achieved through an electoral process. The constraints associated with women being elected into formal office have been well documented. In the political arena, for example, parliamentary systems typically advantage women candidates over single-member districts or winner-take-all formats. ${ }^{529}$ Cultural biases can often limit women's viability to the general public as a candidate. ${ }^{530}$ Lack of access to financial resources and negative media coverage can be restrictive factors. ${ }^{531}$ Political party gate-keepers may be a strong deterrent to a potentially successful candidacy. ${ }^{532}$ In short, the obstacles women face in gaining elected decision-making positions are daunting, even among long-standing democracies.

As women continue to face difficulties surmounting ballot-box constraints, the use of government appointment appears as a viable way to place more women in decision-making positions. While global tracking of disaggregated, decision-making positions is limited, the appointment of women as ministers is one indicator where longitudinal data exists. Since 2005 the International Parliamentary Union and UN Women have been collecting and publishing data on the percentages of women ministers and their area of appointment. During the past decade, women's share of ministerial appointments has risen from approximately $14.2 \%$ to $17.7 \% .533$ This increase has occurred largely on a voluntary basis without the use of quotas. Global

529 Kenworthy, Lane, and Melissa Malami. "Gender Inequality in Political Representation: A Worldwide Comparative Analysis." Social Forces 78, no. 1 (1999): 235-68. Matland, Richard E., and Donley T. Studlar. "The Contagion of Women Candidates in Single-Member District and Proportional Representation Electoral Systems: Canada and Norway." The Journal of Politics 58, no. 03 (1996): 707-33.

530 Norris, Pippa, and Ronald Inglehart. "Cultural Obstacles to Equal Representation." Journal of Democracy 12, no. 3 (July 2001): 126-40. Charles, Maria. "Deciphering Sex Segregation Vertical and Horizontal Inequalities in Ten National Labor Markets." Acta Sociologica 46, no. 4 (2003): 267-87.

531 Lianos, Beatriz, and Kristen Sample. "30 Years of Democracy: Riding the Wave?," 2009. Hunt, Swanee. "Let Women Rule." Foreign Affairs, June 2007.

532 Norris, Pippa, and Joni Lovenduski. Gender and Party Politics. Sage Publications, 1993. Dahlerup, Drude, and Lenita Freidenvall. "Quotas as a 'Fast Track' to Equal Representation for Women: Why Scandinavia Is No Longer the Model." International Feminist Journal of Politics 7, no. 1 (2005): 26-48. Kenney, Sally Jane. Gender and Justice: Why Women in the Judiciary Really Matter. Routledge, 2013.

533 "Women in Politics: 2005." Inter-Parliamentary Union, 2005. "Women in Politics: 2015." Inter-Parliamentary Union, 2015. "The Full Participation Report: No Ceilings." Clinton Foundation, Gates Foundation, The Economist 
data does not exist for other appointed positions. Table 63, based on my 40-country sample, highlights the percentage of women within the executive, legislative, and judicial sectors organized by tier and determination as to whether the position is, in general, elected or appointed.

TABLE 63: Average Percentage of Women by Elected or Appointed Position

\begin{tabular}{|c|c|c|}
\hline Decision-Making Position & Percent Women & Typical Selection Method \\
\hline \multicolumn{3}{|l|}{ TIER 1} \\
\hline Judicial - Highest-Level Court Judges & $18.0 \%$ & Appointed \\
\hline Executive - Ministers & $16.8 \%$ & Appointed \\
\hline Legislative - Political Party Leaders & $6.0 \%$ & Elected \\
\hline \multicolumn{3}{|l|}{ TIER 2} \\
\hline Judicial - Second-Level Court Judges & $20.1 \%$ & Appointed \\
\hline Executive - Sub-Ministerial & $18.3 \%$ & Appointed \\
\hline Legislative - Committee Chairs & $18.2 \%$ & Elected \\
\hline \multicolumn{3}{|l|}{ TIER 3} \\
\hline Judicial - Third-Level Court Judges & $27.2 \%$ & Appointed \\
\hline Legislative - Legislators & $19.2 \%$ & Elected \\
\hline Executive - Mayors 10 Largest Cities & $6.0 \%$ & Elected \\
\hline
\end{tabular}

It is important to acknowledge that positions reliant on appointment or an election will vary across countries and political systems: not every mayor is elected nor every judge appointed. For the majority of high-level courts across the Diamond Index sample, however, judicial appointment is favored. Likewise, while the type of election will vary for mayors - with some directly elected by the population while others are elected through a local body, such as a council - most mayors in the 40 countries selected do not arrive at their position through appointment.

Where we see delineation between elected and appointed begin to blur is around the use of legislative quotas (Tier 3 -Legislators). In a number of the 40 countries examined in the sample, women gain their seats through a political party appointment process. In these instances, women may be directly "elected" by the party, irrespective of the popular vote. Given the variety of ways women might come to encumber a legislative

Intelligence Unit, World Policy Analysis Center, Maternal and Child Health Equity Research Program, March 2015. http://noceilings.org/report/report.pdf. 
seat - especially those deemed as "reserved" for women - it is acknowledged that classifying Tier 3 decision-makers as an "elected" official lacks nuance into how quotas might lead to women encumbering these positons.

In the Diamond Index 40-country sample, higher percentages of women were consistently appointed rather than elected across all three levels measured. This is occurring even as the majority of focus on women's political descriptive representation has been focused on decision-makers and advocacy for quota adoption to bolster women's numbers in legislative bodies around the world. ${ }^{534}$ Given the amount of attention the legislative branch has received, one might expect to see higher scores in this area than those found in other parts of government. The Diamond Index, however, scored the legislative domain third, behind the judicial and executive domains but above the security sector. Of the 37 countries registering judicial scores, only 9 countries (25\%) tallied higher legislative scores. Of the 39 countries registering executive scores, only 12 countries (31\%) had higher legislative scores. In the majority of instances, the legislative branch (accessed through elected positions) finished behind those branches more reliant on women gaining decisionmaking positions through appointment. Table 64 highlights the 10 lowest-scoring countries in the legislative sector and their respective Diamond Index scores in the other three domains measured.

\section{TABLE 64: Lowest Diamond Index Scores in the Legislative Domain}

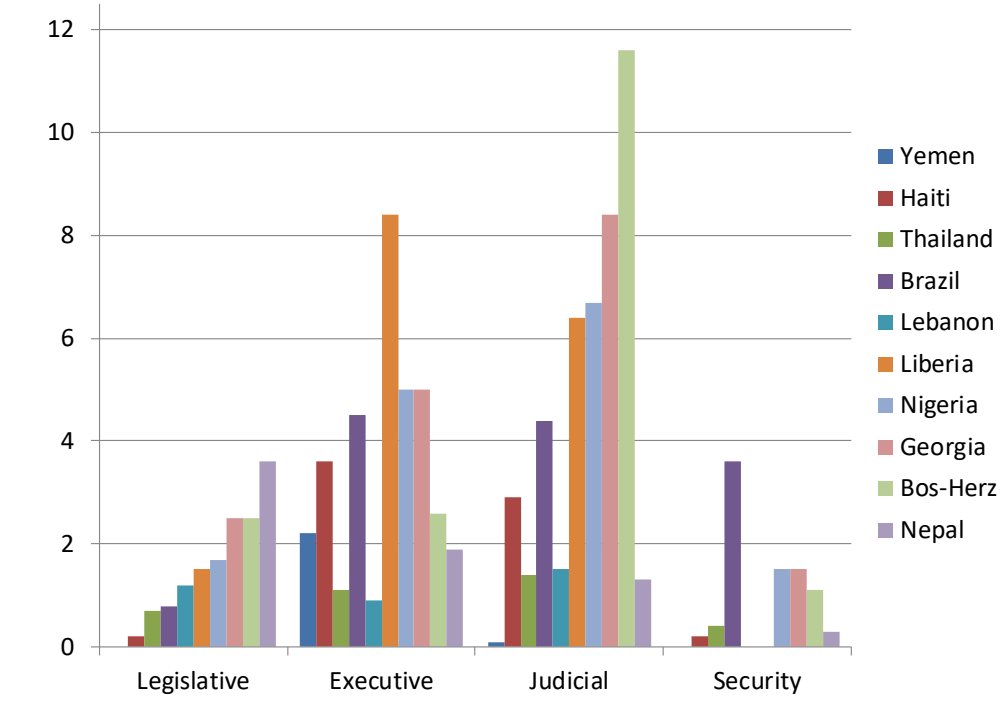

534 Inter-Parliamentary Union. "Parliaments at a Glance," 2017. Krook, Mona Lena. Quotas for Women in Politics: Gender and Candidate Selection Reform Worldwide. Oxford University Press, 2010. 
On average, the data from this small sample points to women's high exclusion from the legislative domain. This does not, however, seem to preclude women from the political space given consistently higher rates of access to appointed executive and judicial decision-making positions. If we examine the African countries, for example, women in Nigeria and Liberia appear to be making significant inroads into appointed sectors, even as they fail to gain seats in the legislature. It is also interesting to note the higher level of Brazilian women represented in the security sector, especially in light of a legislative score that is well below regional and overall averages. At first glance it would appear that Brazilian women find the barriers to military leadership lower than that of an elected position in the legislature. It seems clear from the examples of Georgia and Bosnia-Herzegovina that women are accessing, in particular, the judicial branch of government as barriers appear in the legislative space. From this research, based on the decision-making positions selected in the 40-country sample, it appears that women are able to access appointed positions in greater numbers than elected positions. Even in countries where women are highly excluded from the legislative branch, this does not preclude them from participation in other sectors of government.

\subsubsection{Gaining Ground in the Judiciary}

As measured by the Diamond Index sample, women seem to be making the largest gains in the judicial arena, with women appearing in significant percentages at all three levels measured, as seen in Table 65. The 40-country average score was 3.8 on the Diamond Index (based on a maximum score of 25, with 12.5 approaching parity). In an effort to target decision-makers, the Diamond Index purposely included only the top three tiers of courts. In most countries, courts of first instance - where one might expect to find the bulk of women - were excluded from the measurement.

Of the 37 countries for which a score was calculated, 22 countries (59.4\%) ranked the judicial score highest, outperforming the executive, legislative, and security sectors. While past research in advanced industrialized countries has supported the notion that a tradition of women's participation will more likely see women serving in courts, ${ }^{535}$ the Diamond Index indicates that women in less developed economies are also making significant inroads from the lowest to the highest courts, even in countries where women's participation in political life has been limited. This includes the Middle East/North Africa region, where women are making noticeable judicial gains, although predominately in the lower courts.

535 Thames, Frank C., and Margaret S. Williams. Contagious Representation: Women's Political Representation in Democracies Around the World. NYU Press, 2012. 
TABLE 65: Average Percentage of Women in the Diamond Index 40 Countries

\begin{tabular}{l|c}
\multicolumn{1}{c|}{ Decision-Making Position } & Percent Women \\
\hline JUDICIAL & \\
\hline Tier 1 - Highest-Level Court Judges & 18.0 \\
\hline Tier 2 - Second-Level Court Judges & 20.1 \\
\hline Tier 3 - Third-Level Court Judges & 27.2 \\
\hline EXECUTIVE & \\
\hline Tier 1 - Ministers & 16.8 \\
\hline Tier 2 - Sub-Ministers & 18.3 \\
\hline Tier 3 - Mayors & 6.0 \\
\hline LEGISLATIVE & \\
\hline Tier 1 - Party Leaders & 6.0 \\
\hline Tier 2 - Committee Chairs & 18.2 \\
\hline Tier 3 - Legislative Members & 19.2 \\
\hline SECURITY & \\
\hline Tier 1 - Top-Level Commanders & 4.8 \\
\hline Tier 2 - Mid-Level Commanders & 7.6 \\
\hline Tier 3 - Lower-Level Commanders & 8.3 \\
\hline
\end{tabular}

In particular, high levels of inclusion were seen within the countries selected for the Eastern European/Eurasia region, followed by Africa. In an interview with a Kenyan High Court judge she responded, when discussing the robust numbers of women in her country's judiciary: Many women prefer the regular hours, paycheck, and reliability of the work as a judge, especially if you are a woman with small children. ${ }^{536}$ Conversely, stories were also related about the difficulty women find when trying to enter into private legal practice. Interviewees articulated how cultural beliefs reinforce the notion that men are more suited to legal representation as women are not aggressive enough, thus unable to represent positions adequately in negotiations or the courtroom. ${ }^{537}$ Also important, in the Kenyan context, the 2010 constitution mandated compositional changes to the judiciary at the highest levels. ${ }^{538}$ So, for

\footnotetext{
536 Interview conducted by the author with a Kenyan Appellate Court Judge in Nairobi, Kenya, June 2012.

537 Interview conducted by the author in Nairobi, Kenya, May 2014.

538 Chapter 4, Part II, 27(8): “In addition to the measures contemplated in clause (6), the Right to life. Equality and freedom from discrimination. The State shall take legislative and other measures to implement the principle that not more than two-thirds of the members of elective or appointive bodies shall be of the same gender."
} 
example, in this particular African country, one might argue that a combination of legal changes, cultural norms, and a more family-friendly environment are moving larger numbers of women into the judiciary.

The level of institutional prestige could also come into play when denying or allowing women's entrance. ${ }^{539}$ This may be the case in Mongolia. While women dominate the judicial sector, critics point out that this high percentage of representation is indicative of the profession's low prestige. ${ }^{540}$ Along with Mongolia, Eastern European countries selected for the sample scored well in the judiciary. Under communism ideology women were to be treated as equals to men, allowing for significant representation across the political spectrum. ${ }^{541}$ As a result, there may be a historical openness to seeing women occupy judicial roles in former communist countries. A second narrative might argue that women never actually held real power in the Soviet Union, and following the fall of communism they were readily excluded from accessing powerful positions and moved into less benign roles, including the judiciary. ${ }^{542}$ There also exist perceptions in some cultures that women are less corrupt then men and, therefore, perhaps better suited to the courtroom demands of impartiality. ${ }^{543}$

The reasons for women's above-average representation in the judicial domain are varied and overlapping. What remains noteworthy, however, is that women are appearing across all regions. While some advocates have called for judicial quotas, similar to what we see in the legislative area, ${ }^{544}$ a snapshot of the 40 countries featured in the Diamond Index indicates that women are making greater headway in this branch of government than others, despite strong advocacy for, and virtual absence of, the use of quotas. Why these gains are being made, however, deserves more attention.

\subsubsection{The Security Sector Blind Spot}

There is currently no systematic, global effort to benchmark women's progress in the security sector, and the number of organizations working in this space remains

\footnotetext{
539 Williams, Margaret S., and Frank C. Thames. "Women's Representation on High Courts in Advanced Industrialized Countries." Politics \& Gender 4, no. 03 (2008): 451-71. Yoder, Janice D. "Rethinking Tokenism: Looking beyond Numbers." Gender \& Society 5, no. 2 (1991): 178-92.

540 "The Long Winding Road: Judicial Sector Reform in Mongolia." International Judicial Monitor 2, no. 1 (February 2007).

541 Paxton, Pamela, and Melanie M. Hughes. Women, Politics, and Power. Pine Forge Press, 2007.

542 lbid.

543 Goetz, Anne Marie. "Political Cleaners: Women as the New Anti-Corruption Force?" Development and Change 38, no. 1 (2007): 87-105.

544 Kenney, Sally J. “Critical Perspectives on Gender and Judging." Politics \& Gender 6 (2010): 433-41.
} 
limited. ${ }^{545}$ The UN does collect general statistics around women peacekeepers and negotiators, in line with Resolution 1325. This snapshot of peacekeeper percentages, however, provides a limited understanding of internal state dynamics and how women are represented in their individual countries across the police, military, and internal security services. ${ }^{546}$

UN gender experts have identified the security sector data as a missing gap, while also noting that some progress is being made. For example, "indicators on police and judges are conceptually clear, with an agreed international definition, but not yet regularly produced by countries." ${ }^{547}$ The United Nations office of Drugs and Crime (UNODC) has been working on better data collection on police and judges. Currently, the country-level data identified for collection and reporting to the United Nations includes: Tier II, indicator \#46 - "Share of female police officers" and Tier II, indicator \#47 - "Share of female judges." ${ }^{458}$

As measured by the Diamond Index sample, women seem to be making the least gains in the security arena. The 40-country average score was 1.7 (based on a maximum score of 25 , with 12.5 approaching parity). The lowest percentage of women was seen in tier 1 Top-Level Officers (4.8\%). Of the 18 countries with scores captured across all four sectors, there were 2 instances $(11.1 \%)$ in which the security score was able to outperform another sector. ${ }^{549}$ In most countries there are so few women within the command structure that the measure did not make a significant difference when all scores were compiled and aggregated.

Repeated anecdotal evidence among women highlighted the negative environment in which women officers are often asked to perform. Verbal harassment, for example, was cited as a daily encounter for two of Kenya's highest-ranking female police

\footnotetext{
545 Globally, there are few organizations working at the intersection of gender and the security sector in a substantive way beyond individual country activities. The first is the Geneva Centre for the Democratic Control of Armed Forces (DCAF). Phone calls and a meeting in Washington D.C. (November 2014) were held to understand the extent of DCAF's work and available data. A number of DCAF reports provided interesting insights and data on some of the selected countries. The second organization is the Latin American Security and Defence Network (RESDAL) based out of Brazil. This NGO publishes the Comparative Atlas of Defence in Latin America and Caribbean, a regional source of data that is considered by experts to be the best source of public information on the military. The United States Agency for International Development, through Management Systems International, provided a small grant to RESDAL in 2014 to use its extensive network to collect data on three countries - Mexico, Brazil, and Guatemala. While other international organizations and governments have expressed interest in replicating the atlas in different regions, to date, due to lack of resources and personnel, REDSAL has limited its publication to only one region.

546 “United Nations Women in Peacekeeping." United Nations, 2017.

547 Presentation by UN Women Policy Advisor Julie Ballington at the USAID workshop “Women's Leadership and Political Empowerment: Progress Review and Ways Forward, November 3-4, 2014, Washington D.C.

548 "UN Gender Statistics." New York, N.Y.: United Nations, 2016.

549 South Africa's security sector outperformed its judicial score (7.0 as compared to 6.0); Brazil's security sector outperformed its legislative sector (3.6 as compared to 0.8 ).
} 
officers. ${ }^{50}$ The lack of women in the security arena might also be due to women's later arrival in this sector. Promotion up the chain of command is often tied to years of service. Whether a hostile work environment, women's late arrival to this sector generally, or other constraints not yet understood, the Diamond Index points to strong "glass walls" erected around accessing security sector decision-making positions.

The Diamond Index also points to an interesting relationship between countries exhibiting the lowest percentages of women in decision-making positions and their concurrent high levels of insecurity. While the Diamond Index did not attempt to examine women's descriptive representation in relation to conflict, as the scores were calculated it became apparent that the lowest ranked countries in each region were tending towards those with ongoing or recent conflicts. TABLE 66 lists the lowest-scoring country for each of the five regions.

\section{TABLE 66: Lowest-Scoring Country by Region}

\begin{tabular}{l|c|c|c}
\hline REGION & COUNTRY & $\begin{array}{c}\text { COUNTRY } \\
\text { SCORE }\end{array}$ & $\begin{array}{c}\text { REGIONAL } \\
\text { AVERGE }\end{array}$ \\
\hline Middle East/North Africa & Yemen & 2.3 & 6.7 \\
\hline Asia & Thailand & 3.6 & 12.0 \\
\hline Latin America/Caribbean & Haiti & 6.9 & 13.9 \\
\hline Africa & Senegal & 10.4 & 18.1 \\
\hline Eastern Europe/Eurasia & Ukraine & 10.8 & 16.0 \\
\hline
\end{tabular}

At the time of writing, Yemen and Ukraine had active conflicts within their borders, Haiti was occupied by an international peace-keeping force as the country continued its struggle to form a fully functioning government, and Thailand was ruled by a military junta that seized power from a civilian government in May 2014. Senegal appears to be the exception to the trend, although the second-lowest score in Africa, Mali, more closely fits the profile given persistence levels of tension and violence, despite the signed 2015 Peace Accord, and unresolved tribal conflict in the northern part of the country. ${ }^{551}$

\footnotetext{
550 Interviews conducted by the author with Kenya's former highest-ranking woman police officer and current second-highest ranked officer in Nairobi, Kenya, during June 2012.

551 Many of the African countries experiencing conflict at the time of data collection - Somalia, South Sudan, Democratic Republic of Congo, Burundi, etc. - were purposely excluded from the index. Reasons included one or more of the following: 1) ongoing instability and security risks, 2) political unrest that was quickly changing the governmental landscape, and 3) uncertainty about USAID's continued programming or presence in the country,
} 
What insights we can draw from this confluence of low-scoring Diamond Index countries and conflict is tenuous. The perception that women are negotiators, peacemakers, and more conflict adverse ${ }^{552}$ then men might be a significant factor. Perhaps women act as a moderating force to more aggressive reactionary tendencies. Their absence throughout the political system, therefore, allows for no dissenting voice or moderation. Or, perhaps the lack of women as decision-makers is a proxy for wider societal exclusion of all populations from formal government, save the ruling elite, which meets challenges to its authority with suppression. While it is impossible to draw conclusions, the neat alignment of low Diamond Index scores and predominance of conflict-ridden countries supports the existing literature that there is a positive relationship between higher levels of domestic gender equality and lower levels of intrastate armed conflicts. ${ }^{553}$

Although concerns remain around the quality of the data gathered for the security domain in the Diamond Index sample, given the lacuna of information available in this area the data collected can still provide interesting insights. Going forward, more detailed information about which positions women hold in the chain of command, whether they are commissioned or non-commissioned officers, predominant in logistical support, directing traffic, or leading combat troops can collectively groundtruth reality and dispel perceptions about women's relationship to the security sector domain. As more police and militaries open their doors to women's participation, it becomes increasingly important to understand the roles they are filling and how they are advancing through, or stagnating within, the wider system. Commitments to increase women's participation, codified in such international documents as the Beijing Platform for Action and Resolution 1325, require that better information be made available on a country, regional, and international basis.

\footnotetext{
thus ability to use findings from the Diamond Index. More information about how countries were selected can be found in Chapter 5: Gathering Data for the Diamond Index.

552 Childs, Sarah. "A Feminised Style of Politics? Women MPs in the House of Commons." The British Journal of Politics \& International Relations 6, no. 1 (2004): 3-19. Borrelli, MaryAnne, and Janet M. Martin. The Other Elites: Women, Politics, and Power in the Executive Branch. Boulder, Colorado: Lynne Rienner Publishers, 1997.

553 Caprioli, Mary. "Gendered Conflict." Journal of Peace Research 37, no. 1 (2000): 51-68. Caprioli, Mary. "Primed for Violence: The Role of Gender Inequality in Predicting Internal Conflict." International Studies Quarterly 49, no. 2 (2005): 161-178. Caprioli, Mary, and Mark A. Boyer. "Gender, Violence, and International Crisis." Journal of Conflict Resolution 45, no. 4 (2001): 503-518. Melander, Erik. "Gender Equality and Intrastate Armed Conflict." International Studies Quarterly 49, no. 4 (2005): 695-714. Regan, Patrick M., and Aida Paskeviciute. "Women's Access to Politics and Peaceful States." Journal of Peace Research 40, no. 3 (2003): 287-302.
} 


\subsection{VALUE OF THE DIAMOND INDEX AND AREAS OF FUTURE RESEARCH}

There are a variety of gender indexes in use that offer a holistic picture of women's status in relation to men's. Most of these include a much broader range of variables examining health, education, labor, etc. My research is interested specifically in a descriptive representational approach towards measuring women's access to decision-making positions in formal government. My goal was to create a more nuanced measure focused solely on the political space - by identifying a cluster of senior decisionmaking positions across government while recognizing, through a weighting process, that some positions have greater decision-making authority than others.

For researchers or practitioners interested in gauging women's progress against a range of aspects affecting day-to-day life - health, education, leisure time, labor, etc. - the Diamond Index offers less value given its more narrow focus on the political space. I specifically chose to concentrate on the political arena, however, given that this is the domain where women are the least represented. While not attempting to intuit if more women leads to greater gender equality, the starting point of this research is to better understand the extent of women's presence.

In that respect, the Diamond Index's greater breadth and depth of information collected can increase our understanding of women's political presence. The data can, for example, be combined in different ways to spot patterns, trends, and interesting dynamics that more streamlined indexes are not capturing. Because of the vertical and horizontal design of the composite indicator, patterns emerge in different places than other tools.

\subsubsection{Focus on Horizontal Distribution of Women across Formal Government}

The breadth of information the Diamond Index sample provides can be useful to examine the issue of horizontal walls in the political and security space. For example, while women in Rwanda are making strong progress in the legislative branch of government, their almost complete exclusion from the security sector stands in striking contrast. Conversely, across the 40 countries, Brazil exhibited the secondhighest security sector score while garnering the fourth-lowest legislative score. While this data can not answer why women appear underrepresented or shunted out of particular domains, it does allow for new patters to emerge and questions to be raised.

Horizontal comparisons can also be conducted from a regional perspective. For example, the Diamond Index points to strong horizontal differentiation by region. In Asia, we see a clear pattern of legislative inclusion - even at the highest levels - 
while judicial, executive, and security sectors exhibit strong exclusion. In the Eastern Europe/Eurasia region, the judicial sector representation far outpaces all others, with scores approximately double any other domain. In Latin America/Caribbean countries, the executive branch consistently demonstrated the highest scores.

Why women appear to dominate one branch is open to interpretation. Perhaps the perception that women are well represented in one area - essentially achieving their "fair share" - reduces pressure to appoint or elect women into another branch. Or conversely, if women's "fair share" of elected positions remains below international norms, does this exert societal or political pressure to appoint greater numbers of women to other decision-making positions when the election route fails to produce significant representation?

This becomes a topic of special interest in those legislatures that seem impervious or exceedingly slow to change through traditional electoral processes. While our understanding of women's constraints to elected positions has been well documented, less understood is whether the political system makes allowances for women's presence in other ways. For example, if women find the legislative door firmly shut, are other doors opened, which ones, and under what conditions?

Why women dominate in one particular domain across a region is not something the index can answer. But, it can bring to light new patterns for future consideration.

\subsubsection{Focus on Vertical Distribution of Women across Formal Government}

Along with tracking women's horizontal movements across formal government, the Diamond Index also collects women's vertical positions. This approach builds on the premise that different positions within government wield varying levels of access to decision-making authority. Current literature points to the existence of a glass ceiling in the political arena. As women attempt to encumber positions that hold greater authority, sometimes identified as greater power, constraints come into play, including both cultural and institutional. ${ }^{554}$ In recognizing that some government positions wield greater access to decision-making authority than others, it becomes important to identify which seats women occupy. For example, would having smaller numbers of women in powerful positions, such as chairwomen of influential committees, be more desirable than having an overall larger percentage of women in the legislative body? Is there any relation between the percentage of women leading political parties and societal measures of gender equality?

554 Borrelli, MaryAnne, and Janet M. Martin. The Other Elites: Women, Politics, and Power in the Executive Branch. Boulder, Colorado: Lynne Rienner Publishers, 1997. 
There seems an inherent assumption that having women in lower levels of decisionmaking positions is a positive, as over time they will ascend upwards to more senior positions wielding greater access to decision-making authority. The Diamond Index countries exhibit significant "bulges" of women in tier 3, the lowest-level of measurement, in most regions. Asia presents a slightly different picture, however, with overall numbers of women in formal government and security sectors on average quite low, yet having smaller percentage differences between the number of senior-, mid-, and lower-level decision-makers. So while the overall result may be fewer women, those women in formal government seem to occupy positions at all levels rather than clustered into the lower tier.

This raises an interesting question as to the model of descriptive representation that might prove most favorable to positive gender change. Is the preference to have lower numbers of women distributed more evenly throughout all ascending levels of leadership, such as appears in the Asia region, or are we more interested in having larger percentages of women in less prestigious positions on the assumption that they will ascend upwards given more time?

The Diamond Index supports the research on the existence of a glass political ceiling. There appears a clear trend of fewer women at each progressively senior tier, with tier 1 defined as having greater decision-making authority than tier 2, and tier 2 as having greater decision-making authority than tier 3 . Because the index presents only one snapshot in time, however, it is difficult to draw conclusions.

Over time, data collected consistently could demonstrate whether women are encountering glass ceilings in particular sectors and decision-making tiers of authority.

\subsubsection{Delineate Appointed and Elected Positions across Formal Government}

The decision-making positions selected in the Diamond Index sample are a mix of both elected and appointed positions. The Diamond Index data indicates that women are making greater headway in appointed as compared to elected seats, with generally higher scores in the executive and judicial appointed domains as compared to the elected legislative arena. The premise of indexes heavily dependent on parliamentary percentages posits that without significant legislative branch representation, women will have limited political voice in the formal arena. Is it possible, however, that more robust representation of women is shifting to other decision-making positions that are less measured? Perhaps as women find the elected legislative door difficult to open, a doorway into politics through appointment is being opened. Much of 
the literature to date has focused on the legislative branch as a way to increase percentages of women in political positions.

The Diamond Index data holds the possibility for better delineation, across a wider range of positions, between women accessing elected verses appointed positions.

\subsubsection{Expand Information in Less-Developed Regions and Countries}

One unexpected outcome of the Diamond Index was how well countries selected in the Sub-Saharan Africa region fared, outperforming the other four regions. By sector, Africa was the top finisher in the executive (scoring 5.4) and security (2.2). ${ }^{555}$ Africa finished second in the legislative arena (3.8, slightly behind Asia's score of 3.9) and second in the judiciary (6.6, behind Eastern Europe/Eurasia's total of 7.7). So, while Asia and Eastern Europe/Eurasia were able to outperform Africa in one domain, Africa's more consistent performance across all four domains resulted in a higher overall regional average. The top three Diamond Index finishers were all African countries: South Africa, Rwanda, and Kenya.

Across the sample of African countries, women are making greater gains in appointed positions within the executive and judicial sectors, although substantial numbers were also seen in the legislative area. These leading scores are not to insinuate that all decision-making positions have made marked gains. Like other countries measured, African women remained woefully underrepresented as heads of political parties, urban mayors, and police commanders. Yet, in comparison to the other regions, the Diamond Index sample shows significant numbers of women across a broader array of positions. The continent's performance, based on the 14 countries selected, raises a number of interesting questions examining the conditions present in Africa that might lead to broad-based growth in women's political access.

To date, African countries - especially more data-scarce states such as Mali, Madagascar, Liberia, Benin, Burkina Faso, etc. - have not received the same level of academic attention as countries in Western Europe, Scandinavia, and North America. The same argument might plausibly be made for a number of Asian and Middle Eastern countries. This is understandable given language, security, access, and financial barriers that often emerge to constrain research efforts in a range of less-developed countries.

\footnotetext{
555 Although Africa finished as the top performer, the paucity of women in the security command structure leaves little room for differentiation between countries. Africa topped the list with a score of 2.2; the lowest scoring regions achieved 1.2.
} 
The Diamond Index can help fill in some of the gaps regarding women's descriptive representation in less-researched countries which may, in turn, provide for increased inclusion in global or regional comparisons and future research opportunities.

\subsubsection{Ability to Mix and Match Data in Different Combinations}

The data - collected across four domains and three vertical tiers - allows for a wider variety of mixing, matching, and comparing in the political space. Interested parties can compare all four domains, any three domains, two, or only one. For example, examining women's judicial representation across the globe or in one specific region. It is also possible to compare one, two, or three different tiers. A researcher interested in sub-national representation, for example, may pull out data limited to tier 3 positions across countries.

In examining the underrepresented security sector, what types of data patterns can we see emerge around the few counties making gains in this sector? Of the six Diamond Index countries identified as "Not Free" according to Freedom House rankings, ${ }^{556}$ women performed below the 40 -country average in five of the six. Three of these five registered among the 10 lowest-scoring countries overall. While it was not the intent of this research to look at women's representation in relation to democratic rankings, the index allows for this type of examination. Do specific types of government (liberal, free, not-free, high-income, low-income, parliamentary, presidential, etc.) have higher or lower representation? What does that representation look like across domains?

The ability to use the data to create a more nuanced picture of women's political representation is one of the strongest attributes of the Diamond Index. While in itself it can not explain differences across countries, it can help emerge more targeted questions about women's senior-level descriptive representation in the political realm for future research efforts.

\subsubsection{Use as an Advocacy and Benchmarking Tool}

One explicit goal of the Diamond Index was to simplify the process of gathering, weighting, and aggregating individual country information in a way that could be easily understood by development practitioners, government officials, nongovernmental organizations, and advocates. Using publicly available data to the largest extent possible, the index attempts to strike a balance between academic rigor, data accessibility, and practical application. For lay persons or government officials

556 Freedom House. "Freedom in the World," 2015. 
committed to gender empowerment, it is intuitive to understand the purpose of the model, its weighting system, and what it is trying to capture.

The intent was also to ensure that the index could be developed at any time, according to the user's needs, and updated accordingly. This allows for any user to gather the information for benchmarking, advocacy, or policy on a time schedule that fits the intended purpose, rather than work around the publication dates of the international or multilateral organizations currently producing gender indexes.

Out of a possible 480 total data points (12 per country X 40 countries), the index was able to collect $416(86.7 \%)$. The majority of data gaps were in the security sector where 76 out of 120 data points were collected $(63.3 \%)$. Excluding the security domain, and looking only at the executive, legislative, and judicial, a total of 340 data points were collected out of a possible 360 (94.4\%). As noted in the quality data criteria of "accessibility" discussed earlier in this chapter, 7 out of 12 indicators were considered highly accessible with data readily available to the general public. Of the remaining five indicators, one was ranked of medium quality in terms of accessibility with the remaining four indicators (one judiciary and three security) considered as having low accessibility. As a result, in particular given the current inaccessibility of security data, it does remain difficult for all parties to easily replicate the Diamond Index across all four domains. While government staff would likely have access to information required, non-governmental organizations, donors, and advocates may find it difficult to collect security information - given the lack of public data access in their capacity as outsiders.

Leaving the security sector aside, however, there remains a breadth of data across the executive, legislative, and judiciary sectors that are easily collected by those outside government. ${ }^{557}$ While acknowledging that collecting this information on a global scale, across almost 200 countries, would require significant resources, the ability to gather country-specific data, or comparative data across a smaller regional grouping of countries, remains highly feasible using publicly available resources. This approach allows development practitioners and advocates to apply the Diamond Index in a country or region of interest as part of a broader assessment, as a more narrow analysis of women's political participation, or adopt it in different ways to better align with a specific country context.

\footnotetext{
557 As a practical example, in August 2018 the USAID Tanzania Mission undertook the Diamond Index exercise to map the country. A college intern was able to collect the required information within a one-week period using only public data and several hours of assistance from a Tanzanian national who helped differentiate names by sex and verify the identify of three mayors. At the end of the one-week period, a $100 \%$ success rate had been achieved for 8 of the 12 indicators. More senior experts were then called in to tackle the security sector data.
} 
Data collected through the Diamond Index, especially if collected consistently over time, could be used to benchmark progress in a country or region, applied as an advocacy tool for greater gender inclusion, or introduced as a planning instrument to help inform and develop future programming opportunities.

The data gathered for this research represents the most recent figures available at the time of collection. Despite the wide range of information captured across the 40 -country sample, it does represent only a single point in time, thus limiting its utility as an analytical or predictive tool. Were the data collection effort to continue on a regular basis in the same countries, or be extended globally, the index holds the promise of providing a greater wealth of information as researchers continue efforts to build a more robust body of literature around the dynamic of women in the political public sphere.

\subsection{LIMITATIONS OF THE DIAMOND INDEX}

The Diamond Index was created in an effort to expand beyond the measurement efforts of current gender composite indicators. These gender indicators, primarily using percentages of women in government institutions, make claims to measure women's political power or empowerment. ${ }^{558}$ Because of the limitations surrounding such polysemic terms as empowerment and power, ${ }^{559}$ attempting to equate women's numbers with such contested terms as power and empowerment is not without its detractors. ${ }^{560}$

Limitations also exist around the validity of using one composite indicator as a global measure. In short, can one measurement tool be all things to all countries? Two well-known regional indexes were created, in fact, to counter what was seen as failings by established global indexes to provide relevant measures indicative of their challenges and status. The EU Gender Equality Index, for example, was formulated to better capture the challenges faced by the majority of high-income EU member states. ${ }^{561}$ At the opposite extreme, the UN African Gender and Development Index was

\footnotetext{
558 UNDP Gender Inequality Index (empowerment), World Economic Forum Global Gender Gap Index (empowerment), Social Watch Gender Equity Index (empowerment), European Institute of Gender Equality Gender Equality Index (power), UN African Gender and Development Index (power).

559 Lukes, Steven. Power: A Radical View-The Original Text with Two Major New Chapters. New York: Palgrave Macmillan, 2005.

560 This topic is discussed in greater detail in Chapter 2 - Measuring Women in the Political Domain: A Critical Appraisal.

561 European Institute for Gender Equality. "Gender Equality Index." 2012. Plantenga, Janneke, Chantal Remery, Hugo Figueiredo, and Mark Smith. "Towards a European Union Gender Equality Index." Journal of European Social Policy 19, no. 1 (2009): 19-33.
} 
constructed as a benchmarking tool for African countries that, due to a lack of data, were consistently being left out of global indexes. ${ }^{562}$

Like other gender composite indicators, my work in the political space also focuses on numbers according to sex: where women sit vis-à-vis men. Percentages of women and specific positions held by women are tangible measures that are easy to target and trace. Simple numbers, however, sideline the complex gender underpinnings of women's role and place in society, and how that impacts substantive representation within the political system. Generating data segregated by sex should not be the goal in itself, notes Meier and Celis, but rather how might that collected data be used in the future to create a more egalitarian society. ${ }^{563}$ As the academic credibility of a critical mass of women leading to substantive outcomes is called further into question, we should be wary of what story a headcount of women tells us. Yet counting numbers of women remains an important starting point. It is through the lens of representational percentages that we can see gains, losses, and view how women are holistically faring in the political system.

The Diamond Index, like other indexes, remains tempered by the information available, even as it attempts to expand the data set. While the index can provide more data on women's descriptive representation in the political arena, as a measurement tool it also has a number of limitations.

\subsubsection{Variations across Differing Political System}

The Diamond Index attempts to provide a useful measurement tool for all countries. In doing so, however, its application to diverse political systems may result in different interpretations. For example, should high numbers of women in a tightly controlled authoritarian system be viewed in the same light as high numbers of women in a liberal democracy? Even within liberal democracies the variations between parliamentary and presidential systems can vary extensively, including where decision-making authority is situated. ${ }^{564}$ Whether authoritarian or liberal, the Diamond Index does not make allowances for different political contexts.

Of the 40 countries chosen for the index, Freedom House rates six as "Not Free," seven as "Free," and the remaining 27 as "Partly Free." If we examine our two top finishers - South Africa (30.1) and Rwanda (27.9) - there are wide differences in

\footnotetext{
562 United Nations Economic Commission for Africa. "The African Gender and Development Index," 2011.

563 Meier, Petra, and Karen Celis. "Sowing the Seeds of Its Own Failure: Implementing the Concept of Gender Mainstreaming." Social Politics 18, no. 4 (2011): 469-89.

564 Lijphart, Arend. Patterns of Democracy: Government Forms and Performance in Thirty-Six Countries. Yale University Press, 2012.
} 
their political rankings with South Africa being judged "Free" and Rwanda at the opposite end of the spectrum with a "Not Free" classification. ${ }^{565}$ The 2015 Freedom in the World report further highlights Rwanda's declining score in civil liberties "due to the narrowing space for expression and discussion of views that are critical of the government...." So in the case of Rwanda, we have large percentages of women being appointed by one dominate party that is increasingly intolerant of dissent. Does an environment intolerant of dissent place a "double gag" on women in the public arena? First, women may be hesitant to champion gender causes not supported by the male elite and second, they may be hesitant to speak out unless the party leadership sanctions their view. In a "Not Free" environment should our expectations for women's representation be the same? While the questions around different polities are relevant, the Diamond Index does not make any distinction between parliamentarian or presidential, free or not free. The comparability of different political systems, using the limited data set currently available, remains a constraint and limitation for all gender composite indicators in use, including the Diamond Index.

\subsubsection{Variations in Status of Selected Decision-Makers}

The Diamond Index attempts to measure only senior decision-making positions that are comparable across all countries. While these positions may be similar in name, the variations in their respective roles and responsibilities will differ not only according to the political system and where decision-making authority lies, but also according to the varied societal and cultural contexts. For example, the high percentages of women we find in judicial courts in a number of countries may reflect lower levels of authority and economic remuneration associated with those positions. Rather than making significant strides in gender equality among male judicial peers, it may be that women are filling less desirable jobs. As described in the case of Mongolia, which garnered one of the highest-ranking judicial scores, the position of a Mongolian judge is perceived as having low social status and equivalent salary. ${ }^{566}$ Yet countries such as Mongolia are ranked directly against more respected judiciaries, such as South Africa's. The index does not factor in differences in decision-making positions that may be affected by cultural attitudes, economic status, or societal value accorded the decision-maker. While all of these factors are acknowledged as important, they are not used to weight the value of any decisionmaker in any sector.

565 Ibid.

566 Author interview with International Republican Institute Mongolia Country Representative, Ulaanbaatar, 2016. 


\subsubsection{Election or Appointed Distinctions}

The Diamond Index also makes no distinction or judgment as to how women obtain a decision-making position. If we use our two top finishers as examples again, Rwanda has 80 seats in its lower house, of which 30\% (24 seats) are reserved for women. To reach their record-high percentage of $63.8 \%$ women in the lower house, a total of 27 women were elected in their own right. In South Africa the dominant party, the African National Congress, adopted a voluntary 50\% quota for national elections in 2009. Of the 400 seats in Parliament, all are directly elected. The party, rather than the constitution or electoral law, ensures that women are elected. So in the case of Rwanda we have 27 directly elected women and 24 quota seats, while in South Africa we see 166 directly elected women. Does this matter? If women are directly elected by their own constituency does that accord them more legitimacy and authority? We see the same situation with mayors, with some women directly elected by the citizens while others are appointed from the central level. The Diamond Index does not differentiate between an appointed, reserved, legislated, constitutional, or elected position and the value attached to that seat. How a woman reaches a decision-making position is not factored into the score, only the fact that she holds it.

\subsubsection{As a Measurement Tool}

Underpinning the Diamond Index measurement tool is an inherent assumption that when sufficient numbers of women occupy decision-making positions it will produce some type of positive gender change. The empirical grounds underpinning this assumption remain mixed to date. This index remains a measure of women's political descriptive representation, albeit more refined than what has been used to date. Because it is only one point in time it can not be used to demonstrate progress or regression. Finally, it remains unable to measure how women will choose to use their political access: whether they will act on behalf of other women or that genderfriendly policies, rules, and procedures will emerge from increased numbers. In short, it cannot predict or measure substantive representation.

\subsection{CONCLUSION}

The Diamond Index attempts to demonstrate how a new measurement tool can better capture women's access to decision-making positions in the formal political space. The design of the index, however, was only half of the solution when trying to improve understanding around women's descriptive representation in 
the political realm. The best-designed efforts have little value if they are unable to gather the information required to create a compelling narrative. The goal in mapping the Diamond Index in 40 different countries was to test the premise that not only could a more nuanced descriptive representational index be developed, but interested stakeholders, non-governmental organizations, advocates, and interested government could gather quality data reliably for their respective country. The challenge was, therefore, to not only broaden and deepen the selection of indicators, but to also ensure that the quality of the data was sufficient.

The Diamond Index proved that its collection approach was viable in three of the four selected domains. Excluding the security domain, where the majority of gaps existed, $94.4 \%$ of the data points were collected. ${ }^{567}$ Much of this data -9 of the 12 indicators - was information not previously collected in a systematic way at the level of detail offered in the Diamond Index. Equally important, the information was culled from a wide variety of countries, with 32 of the selected 40 countries classified as low income or lower-middle income, with many considered data-scarce.

An analysis was then undertaken regarding the quality of the data collected, acknowledging that it was not enough to simply find numbers of women. All 12 indicators were examined against the Diamond Index Data Quality Framework comprised of eight distinct criteria: (1) relevance, (2) completeness, (3) comparability, (4) accuracy, (5) timeliness, (6) cost effectiveness, (7) accessibility, and (8) granularity. For each position, a data quality ranking was given: high, medium, or low. This resulted in 96 distinct rankings. For 8 of the 12 positions the data was, on average, ranked as high quality. Judges occupying the third tier of courts in the judiciary was considered of medium quality, with criteria rankings mixed between high (3), medium (3), and low (2).

The most problematic area for data collection and quality was seen in the security domain. Of the 24 rankings across this sector ( 3 tiers $X 8$ criteria), a total of 3 were ranked high quality, 7 medium quality, and 14 low quality. The lack of public data in the security domain, combined with the lack of political will among many governments to share this information, made it extremely difficult to accurately capture the status of women's descriptive representation in any iteration of the security sector, be it military or police. In conclusion, the Diamond Index offers the opportunity for accessing a greater breadth and depth of information on women's political descriptive representation, yet falls short in providing the full picture

567 As detailed in Chapter 4, the initial data collection efforts, using only publicly accessible data, achieved 9 out of 9 indicators in the executive, legislative, and judicial branch for 25 out of 40 countries and 8 out of 9 indicators for 30 of the 40 countries. By using in-country experts, I was able to gather 9 out of 9 indicators in 29 countries and 8 out of 9 indicators in 35 countries. 
envisioned given the lack and quality of data publically available in the security domain.

The second half of this chapter focused on three areas: the findings emerging from the information collected across the 40 pilot countries; the value of this data, including possible areas for future research; and the limitations associated with the Diamond Index.

The arrangement of the data - examined through both a horizontal and vertical lens - is perhaps the most valuable contribution of the index as it allows for merging information in different ways than previously seen. If collected over time, and in combination with other research available, it allows for the further investigation of such important issues as, for example: (1) elected verses appointed positions, (2) women's representation throughout the judiciary, and (3) links between insecurity and women's political representation.

As with other gender measurement tools, the Diamond Index also exhibits a number of limitations in what it can accomplish. It can not differentiate between political systems or the varied authorities held by decision-makers across regime types. The fact that more women encumber a specific position may not always signify gender gains but rather cultural constraints or acceptance. While acknowledging that variations in authority and prestige exist among decision-makers, the Diamond Index makes no distinction. Finally, because the data represents only a single point in time, it is impossible to conjuncture beyond the figures presented, thus limiting the index's utility as an analytical tool given the absence of longitudinal data.

In striving to collect quality data across a range of indicators, the Diamond Index attempts to facilitate greater deliberation around women's presence in the formal political space. More complete information about where women are both present and lacking is a valuable contribution to our understanding of descriptive representation. Given the lack of data in the political area to date, we should begin by collecting what is possible, while not perfect, in order to continue expanding collective knowledge in this field. 



\title{
CHAPTER 8 \\ Conclusion
}

\section{Every country deserves to have the best possible leader and that means that women have to be given a chance to compete. If they're never allowed to compete...then the countries are robbing themselves of a great deal of talent. ${ }^{568}$}

\begin{abstract}
A burning passion, driving dedication, and a strong stomach for the unsavory are often required in elected politics across much of the world. I had seen numerous instances of women harassed, threatened, beaten, and raped for daring to run for office. And, in some instances, of women doing the beating themselves as they strive to survive in a toxic political environment. Given the cultural and political barriers that often face women in the elected space, I wondered to what degree women were seeking other avenues for representation. Were women finding more welcoming spaces in other institutions and, if so, at what level? Where would one look for such data and would it be available, especially in less-developed countries? And, if data were to be found and collected systematically, would it be considered of adequate quality to be taken seriously?
\end{abstract}

The construction of the Diamond Index is my attempt to answer these questions. Fundamental to the creation of the index was the principle that it had to be easily understood, user-friendly, and replicable in any given country by interested stakeholders. It seemed that a local non-governmental organization, or a small government office, shouldn't be dependent on an index created by an international body to better understand how women in their own country were faring in the political space.

While challenges emerged, the final version of the Diamond Index produced a more nuanced descriptive representational measure of women's access to positions of

\footnotetext{
568 Spoken by Madeleine K. Albright, the first woman to serve as the United States Secretary of State (January 1997 to January 2001).
} 
decision-making authority across formal government in the 40 countries measured. Ultimately, over time, the Diamond Index could create a clearer picture of where women are falling behind, or failing to make inroads, horizontally across a wider band of the political spectrum and vertically within government institutions. With more detailed information on women's presence it then becomes clearer for governments, donors, advocates, and stakeholders to determine if women are being excluded - either intentionally or unintentionally - from elected and appointed positions.

\subsection{SUMMARY OF RESULTS}

I began with a review of the literature on gender measurement in the political space. This included an in-depth analysis of the existing global and regional gender indexes in use today, and the literature underpinning their development. Using the existing literature and gender measurement indexes as a guide, I then selected a total of 12 positions with senior decision-making authority consistently found across government typologies. Next, I developed a Data Quality Framework, against which data collected could be compared, followed by the Diamond Index tool itself. Forty selected countries were then mapped across five regions to determine women's descriptive representation in those positions. The majority of countries were ranked as "lower income" or "lower-middle income."569 Of the 40 countries, 6 were categorized as "not free," 27 as "partly free," and 7 designated as "free." 570 Because countries were not selected in a randomized fashion, it remains difficult to draw global conclusions given the lack of representation by developed democracies and economies.

Data was collected for $86.7 \%$ of the indicators (416 out of a possible 480 ). The legislative branch provided the highest success rate of indicator collection at $98.3 \%$ (118 out of a possible 120). The executive branch was second-highest at $95.0 \%$ (114 out of a possible 120). The judicial domain was third in ease of collection, with $90.0 \%$ of all indicators collected (108 out of a possible 120). The security sector proved a difficult arena in which to find information, with $63.3 \%$ of the indicators collected (76 out of a possible 120). The high percentage of indicators collected for the Diamond Index provides evidence that it is a viable tool for gathering additional data on women's access to formal government decision-making positions.

569 Freedom House. "Freedom in the World," 2013.

570 World Bank Group. World Development Indicators 2014. World Bank Publications, 2014. 
In looking at the quality of the data collected across the 12 positions, variations occurred. Eight indicators received a "high-quality" data ranking, one indicator "medium-quality," and three indicators "low-quality." Tier 3 in the judicial domain was the one indicator garnering a medium-quality data ranking. Unlike the higherlevel courts, this stratum of legal professional does not figure prominently in academic research, index rankings, government websites, publications, or media. Depending on the country, judges may range from a few dozen to hundreds at the Tier 3 level. In general, there seemed no perceived intent to hide this type of data. Problems with data collection more often appeared to be caused by the lack of information assembled in one place in a format available for public consumption.

Topping the low-quality list were all three security sector indicators. It proved to be the toughest domain for gathering information. While face-to-face interviews conducted with officials in five case-study countries seemed to indicate that data was available, it was not readily shared. This proved especially true for military data. ${ }^{571}$ Governments were more forthcoming with police statistics and, in general, better police information was available through public documents. For example, of the 40 countries, full data sets on the police were collected for 20 countries $(50 \%)$ in comparison to nine countries (23\%) for the military. There was no clear and consistent explanation given for government reluctance to share the percentage of women commanders in either the police or military. Lack of trust towards "outsiders" - and concerns over how that information might be used - was described by the leading non-governmental organization in this field as a predominant rationale for nondisclosure. ${ }^{572}$ The lack of women in the security sector, especially at the Tier 1 and Tier 2 levels, may also reinforce a government's desire to maintain a close hold on information given that statistics glaringly reinforce perceptions that women have a nominal role to play in this field. Finally, it may simply be that minimal public pressure exists to make this information available and, therefore, it is not available.

The Diamond Index provides evidence that greater amounts of quality data on women's representation exists across the executive, legislative, and judicial domains of formal government, and this information is available to the general public. This is not true of the security sector. While the Diamond Index was able to paint a basic picture of women officers in the police, much more information must be

\footnotetext{
571 In the initial data-collection sweep undertaken in the early days of the research project, data on military branches was also collected. A full discussion of the security domain and gathering information in this sector is discussed in Chapter 5.

572 The most advanced work in this area has been undertaken by the Latin American Security and Defense Network (Red de Seguridad y Defensa de América Latina - RESDAL) led by Marcela Donadio, RESDAL Executive Secretary, and Paz Tibiletti, President of the Executive Secretariat. The process of how RESDAL collects its data was discussed in a meeting between the author, Donadio, and Tibiletti at USAID in Washington D.C., June 2014.
} 
made available by governments to unpack this under-documented area of women's representation.

\subsection{LIMITATIONS OF THE RESEARCH}

The Diamond Index makes no attempt to examine differences among women in relation to religion, race, sexuality, economic status, age, etc. While acknowledging that the intersection of these identities can further marginalize or privilege individuals, as well as generate more refined results, ${ }^{573}$ an examination beyond the sex of the individual in each decision-making position was not undertaken. The Diamond Index model does, however, allow for reflecting differing levels of granularity based on other characterizations that may be of interest to the researcher.

In addition, the index makes no attempt to account for cultural disparities within societies. For example, the high percentages of women we find in some decisionmaking roles may be attributed to society holding those positions in lower esteem and, therefore, allocated more often to women. While cultural, political, and social differences are all recognized as factors that may influence attainment of specific positions, they were not considered in the design of the Diamond Index when weighting the value of any position in any domain. The tool also makes no distinction as to how a woman obtains a position: whether she was elected in her own right, appointed, or achieved her place based on merit. How a woman reaches a decision-making position is not factored into the score, only the fact that she holds it.

While the intent of the Diamond Index is to be used as a global measurement tool, the research effort included only 40 countries in total. And, of those countries sampled, the majority are skewed towards less democratic and less developed nations, with approximately half classified by Freedom House as "partly free." The selection of countries was not randomized due to project constraints that dictated a minimum sub-set of countries be included in the research project and the desire to focus on more data-scarce environments. Therefore, it is difficult to extrapolate regional or global generalizations based on the selection process and limited number of countries. Researchers attempting to collect and consolidate data on a global scale will find challenges based on the sheer number of countries to be included as well as a sub-set of data-scarce countries that may require more localized attention.

573 Celis, Karen, and Liza M. Mügge. “Whose Equality? Measuring Group Representation.” Politics 38, no. 2 (2018): 197-213. 
Finally, the Diamond Index is a measure of women's political descriptive representation. It is unable to measure how any individual or collective group of women will choose to use that political access and whether they will act on behalf of other women. Without longitudinal data, the index can not be used as a predictive measure of how women are advancing or declining in their access to the political space. It is, as currently researched and presented, simply a snapshot in time of women's state-of-play in the political space. While other indexes draw correlations between increasing numbers linked to greater political power or empowerment, I have not attempted to do so.

\subsection{ADDED VALUE OF THE RESEARCH}

In turning to the value of this research, one of its strongest contributions lies in the design of the index and its stretch across government branches to better identify where women are represented. While acknowledging that higher percentages of women are important, the Diamond Index takes the additional step of recognizing that some positions wield greater decision-making authority than others and adjusting for that differentiation through a weighting system. In this manner, the index can more precisely measure women's location in relation to low-, medium-, and high-level decision-making positions horizontally across government as well as vertically within specific formal government institutions. This arrangement of data - examined through both a horizontal and vertical lens - holds the potential for combining information in different ways to identify trends and patterns that have not been fully explored through current gender indexes.

Second, the index offers a clearer alignment of descriptive representation along appointed and elected access lines. This information collected over time - when combined with data on horizontal walls and vertical ceilings - begins to weave a much richer narrative. With this information we can begin to delineate how women are accessing elected verses appointed positions, what level of position, in what types of regime, and under what conditions.

The Diamond Index also made significant headway in collecting a broader array of data in a range of low-income and least-developed countries, several of which are excluded from global indexes. ${ }^{574}$ The inclusion of data across less-researched countries can lead to a more thorough understanding of women's representational

\footnotetext{
574 For example, a number of Diamond Index countries were exluded from the most recent survies of the Global Gender Gap Index (Niger and Iraq), Gender Equity Index (Timor-Leste), and the Africa Gender and Development Index (Liberia, Niger, Nigeria, and Rwanda).
} 
gains. Authoritarianism and persistent one-party rule, ongoing insecurity, and tribal violence are all factors less accounted for in the current academic literature surrounding women's descriptive representation. Expanding our views to account for the many ways women are moving into the political arena is needed to not only challenge Western assumptions, but to ensure a more accurate picture of what is happening globally.

Finally, one explicit goal of the Diamond Index was to create a tool that that could be replicated by any interested stakeholder or organization, be it a government, civil society organization, development practitioner, or even knowledgeable individual. Using publically available data to the greatest extent possible, the methodology for collecting, weighting, calculating, and aggregating the data is logical and straightforward in its application. In essence, the Diamond Index attempts to strike a balance between academic rigor, data accessibility, and practical application.

\subsection{FUTURE AREAS OF RESEARCH AND PRACTITIONER USE}

Numerous themes emerged from this research effort that beg additional attention. Faced with a limit to my personal stamina and financial resources, for now I have drawn a line under this academic undertaking. Going forward, however, there are a number of areas that seem fruitful for future exploration. With longitudinal data, for example, the Diamond Index could allow for greater vertical and horizontal observation detailing the movement of women across and within government sectors or, conversely, the lack of women's movement. In particular, because positions are weighted vertically within distinct branches of government, data over a sustained period of time would more clearly track women's movement from positions of lower to higher decision-making authority. While the Diamond Index can not account for why women are moving, it is a tool that can be used to better identify where glass walls and glass ceilings are appearing.

A second area of research concerns further work on differentiating elected and appointed representation of women. The Diamond Index 40-country sample points to stronger gains being made in appointed positions, especially when barriers to elected positions seem particularly resilient. As discussed previously, this supports the existing literature linked to the numerous hurdles associated with women gaining access to elected positions. A useful addition to the literature and measurement effort would include a better delineation between elected and appointed positions, the levels at which women are accessing these positions, and under what conditions. For example, if one door is firmly shut for women, are others opened as a response? 
Women's representation in appointed and elected positions across time, regions, and types of government holds the possibility of bolstering an understudied area of research.

As noted throughout this research, data gaps are replete across the security sector and multiple challenges exist for collecting this information. This is especially true for women's presence within military branches and, in particular, within the chain of command. With the information available, the Diamond Index 40-country sample highlighted a consistent pattern of low index scores being linked to those countries exhibiting the highest levels of insecurity. ${ }^{575}$ It seems likely - based on consistent terrorism threats, predicted upheaval from future climate change, and ongoing conflicts across multiple regions - that the issue of security will continue to assume primary importance in the day-to-day lives of millions. This research highlighted the ongoing challenges of finding and tracking data on women's leadership in the security sector. How women are represented in decision-making roles, as these ongoing security concerns are tackled, appears as a gap in the global data and literature. It remains, for all intents and purposes, a closed door to the general public. Better data at all levels of the security domain are needed to map consistent patterns and draw more definitive conclusions.

Finally, one of the fundamental principles in designing the index was to create a tool that could realistically be replicated in a country lacking robust resources, data, or both. This has the double benefit of individual countries taking ownership of their data while increasing information from less-accessible and researched countries. While Europe may have claimed all top 10 rankings for the percentage of women in parliament during the mid-1990s, today Sub-Saharan Africa holds four of those spots. ${ }^{576}$ In looking at the six commonly used gender indexes examined for this research, three have the principal author or organization based in Europe with a fourth headquartered in the United States. ${ }^{577}$ While the predominance of Westernbased indexes does not necessarily equate to other parts of the globe receiving less attention, we should be cognizant that much of the research to date in this field has focused on those countries with greater data accessibility. This has the potential to result in Western bias towards other parts of the world, where violent conflict, political upheaval, newly written constitutions, and fast-track quotas have

\footnotetext{
575 Caprioli, Mary. “Gendered Conflict.” Journal of Peace Research 37, no. 1 (2000): 51-68. Melander, Erik. “Gender Equality and Intrastate Armed Conflict." International Studies Quarterly 49, no. 4 (2005): 695-714. Regan, Patrick M., and Aida Paskeviciute. "Women's Access to Politics and Peaceful States." Journal of Peace Research 40, no. 3 (2003): 287-302.

576 “The Millennium Development Goals Report 2015." New York, N.Y.: United Nations, 2015.

577 The United Nations Economic Commission for Africa, author of the African Gender and Development Index, is based in Ethiopia and intended to be a measure only for African countries. Social Watch's Gender Equity Index, with a secretariat located in Uruguay, is the one global index headquartered outside of Europe or the USA.
} 
all upended the status quo on women's political representation in an extremely condensed timeframe not seen in Western Europe, Scandinavian countries, or North America. While the predominance of Western-based global indexes, research, and donor-based programming has helped us better understand how women are faring in the political space, adding more data from less-studied countries can present a more holistic picture of how women are gaining access to political power in varied ways across different regions.

\subsubsection{Practitioner's Tool}

Although this research effort was focused on adding value to the academic literature on women's political descriptive representation, it does offer potential value from a practical application standpoint. Rather than await the annual publication of gender indexes that focus on a few global measures, stakeholders are empowered to replicate the Diamond Index in their own countries as part of a wider gender or political-economy analysis - or simply to better measure and track women's representational progress.

The Diamond Index also adds value as an advocacy and benchmarking tool with which to hold government accountable. Its detailed presentation of women's descriptive representation allows for more targeted advocacy around specific branches of government or within institutions themselves. For example, in one country we may see large numbers of women parliamentarians elected but a small percentage of women holding committee leadership positions. Rather than arguing for more elected women, the point of advocacy may be to narrow the disparity in women committee chairs. In instances where commitments are not being met, the index is an easily understood visualization of where the country is falling behind. In instances where a country is exceeding expectations, the tool can be used to leverage greater awareness of gains being made to the local population or a wider global audience.

My interest in developing the Diamond Index was to measure women's political representation. Others may find value, however, in redefining the tool as a measurement for an array of categories. To better understand, for example, the representation of tribes, religions, persons with disabilities, or youth in decisionmaking positions across government. The index is easily adaptable for other purposes, although likely to continue presenting limitations for robust data collection throughout the security sector, irrespective of the themes being explored. 


\subsection{FINAL NOTE}

In striving to collect quality data across a range of indicators, the Diamond Index attempts to facilitate greater deliberation around women's presence in the formal political space. It is in this space where determinations of government resource allocation and policy prioritization are debated and determined. These decisions on budget and policy impact the lives of every citizen in numerous ways: health, education, security, employment, etc. While there is no guarantee that women will effectively represent women's interests if elected or appointed to office, ${ }^{578}$ the fact remains that gender gaps and inequalities affecting women exist in all countries - without exception. This seems to indicate that male representation of women's interests is currently inadequate.

When developing a descriptive representational tool the inclination is to allow findings to bleed into the realm of substantive representation. Putting women into office must, logic dictates, make some sort of difference that can be measured. Yet we should not lose sight of the fact that understanding where women are present remains, in and of itself, a valuable source of information. Numbers can be used to identify the progress of women's inclusion at the individual country level and facilitate cross-country, regional, and global comparisons. Numbers can measure progress and play a vital role in signaling policy shifts. ${ }^{579}$ Quantitative analysis using sex as a variable can also reveal discrimination and identify patterns of exclusion, including double standards and so-called neutral standards that disproportionately exclude women. ${ }^{580}$ Armed with this data, well-intentioned governments can use descriptive representational information to ensure that women are not excluded from elected and appointed roles, including influential decision-making positions.

More than 35 years after the signing of CEDAW, and more than 20 years after Beijing, increasing women's political presence remains stubbornly resistant to change. Efforts to close the gap in the political domain, and "catch up" to men, have been slow to shift. The data being used in the political space to measure women's representation has also been slow to coalesce around globally accepted measures. A small handful is deemed appropriate for collection across all countries and regions. Perhaps we

\footnotetext{
578 Lindberg, Staffan I. "Women's Empowerment and Democratization: The Effects of Electoral Systems, Participation, and Experience in Africa." Studies in Comparative International Development 39, no. 1 (2004): 28-53. Tremblay, Manon. "The Substantive Representation of Women and PR: Some Reflections on the Role of Surrogate Representation and Critical Mass." Politics \& Gender 2, no. 4 (2006): 502-11. Childs, Sarah. "The Complicated Relationship between Sex, Gender and the Substantive Representation of Women." European Journal of Women's Studies 13, no. 1 (2006): 7-21.

579 Plantenga, Janneke, Chantal Remery, Hugo Figueiredo, and Mark Smith. "Towards a European Union Gender Equality Index." Journal of European Social Policy 19, no. 1 (2009): 19-33.

580 Kenney, Sally Jane. Gender and Justice: Why Women in the Judiciary Really Matter. Routledge, 2013.
} 
could be more complacent with this diminished set of global indicators if greater progress on political parity was being made. Attempts to reach parity, however, lag so far behind in progress that the phrase "not in my lifetime" - at current rates of change - could also be applied to my young daughters.

The slow uptick in percentages of women begs the question: Are we looking at the right things? Maybe parliamentarians and ministers are sufficient measures for capturing the full picture of what is happening with women in politics. Or, perhaps a greater breadth and depth of indicators in the political domain would paint a different picture. For example, could women be making headway in places where we simply aren't looking? Or conversely, if we cast a wider net across an array of high-level, decision-making positions will we see stagnation at every turn? At the very least, a greater array of indicators focused on political access may help us better untangle women's difficulty in significantly shifting the representational gap in this arena.

The Diamond Index, while far from perfect, is an attempt to bolster the quality and quantity of information available. There are, unquestionably, gaps in the data collected and issues of quality, especially across the security sector. That should not, however, discourage attempts to improve current measures or allow for complacency with the status quo. "There were, are, and always will be shortcomings and limitations in datasets, and the costs of poor data must be traded-off against the opportunity costs of the effort required to improve the data." ${ }^{581}$ While measurement findings are always open to interpretation - including those highlighted in the Diamond Index - the goal behind this effort is to better document the changes that are occurring around women's political presence. This, in turn, will constructively advance the debate. That is not to say that women - if given full access to political decision-making positions - would create a new political order. But, given that nowhere in the world have we seen women offered this opportunity, today we can only speculate about the changes that might occur.

581 Herrera, Yoshiko M., and Devesh Kapur. "Improving Data Quality: Actors, Incentives, and Capabilities." Political Analysis 15, no. 4 (2007): 365-386. 



\section{ANNEXES}

\section{Annex A}

\section{DIAMOND INDEX COUNTRY MAPS}

Eastern Europe and Eurasia

Albania

Bosnia-Herzegovina

Georgia

Kyrgyzstan

Ukraine

Regional Average

Latin America and Caribbean

Brazil

Columbia

Guatemala

Haiti

Mexico

Regional Average

Asia

Bangladesh

Cambodia

India

Indonesia

Mongolia

Nepal

Philippines

Thailand

Timor-Leste

Regional Average
Africa

Benin

Burkina Faso

Cote d'Ivoire

Ghana

Kenya

Liberia

Madagascar

Mali

Mozambique

Niger

Nigeria

Rwanda

Senegal

South Africa

Regional Average

Middle East/North Africa

Algeria

Iraq

Jordan

Lebanon

Morocco

Tunisia

Yemen

Regional Average 


\section{Albania \\ Diamond Index Score $=18.5$}

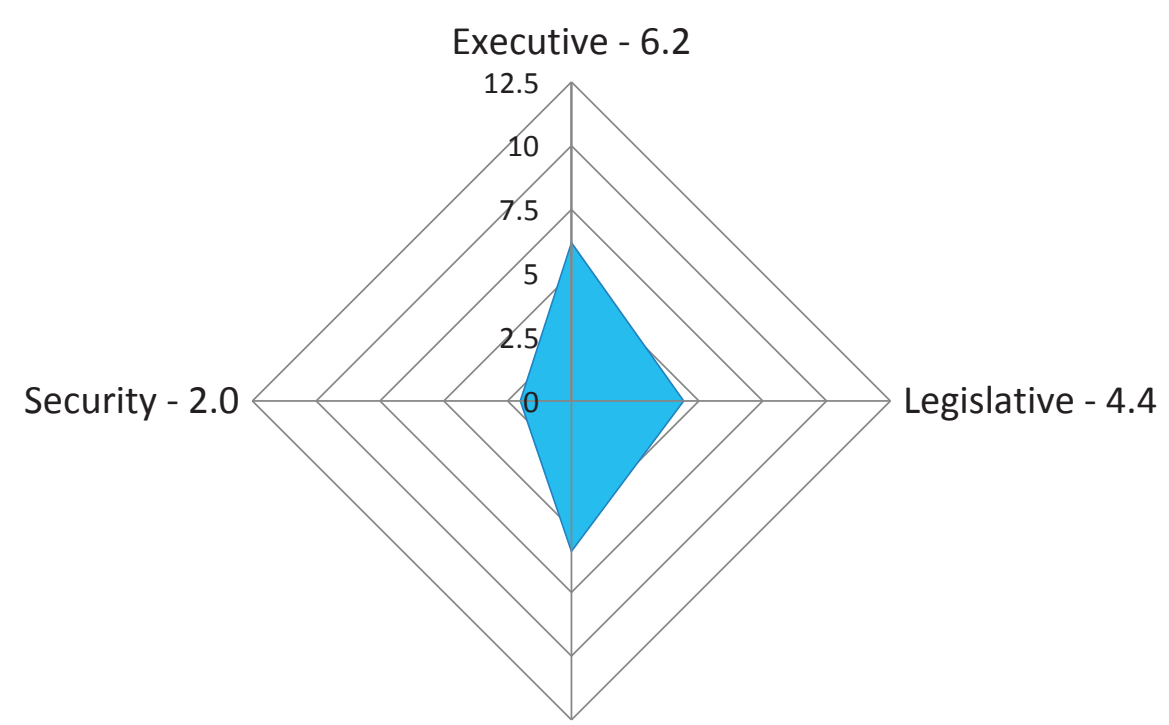

Judiciary - 5.9 


\section{Bosnia-Herzegovina Diamond Index Score $=17.8$}

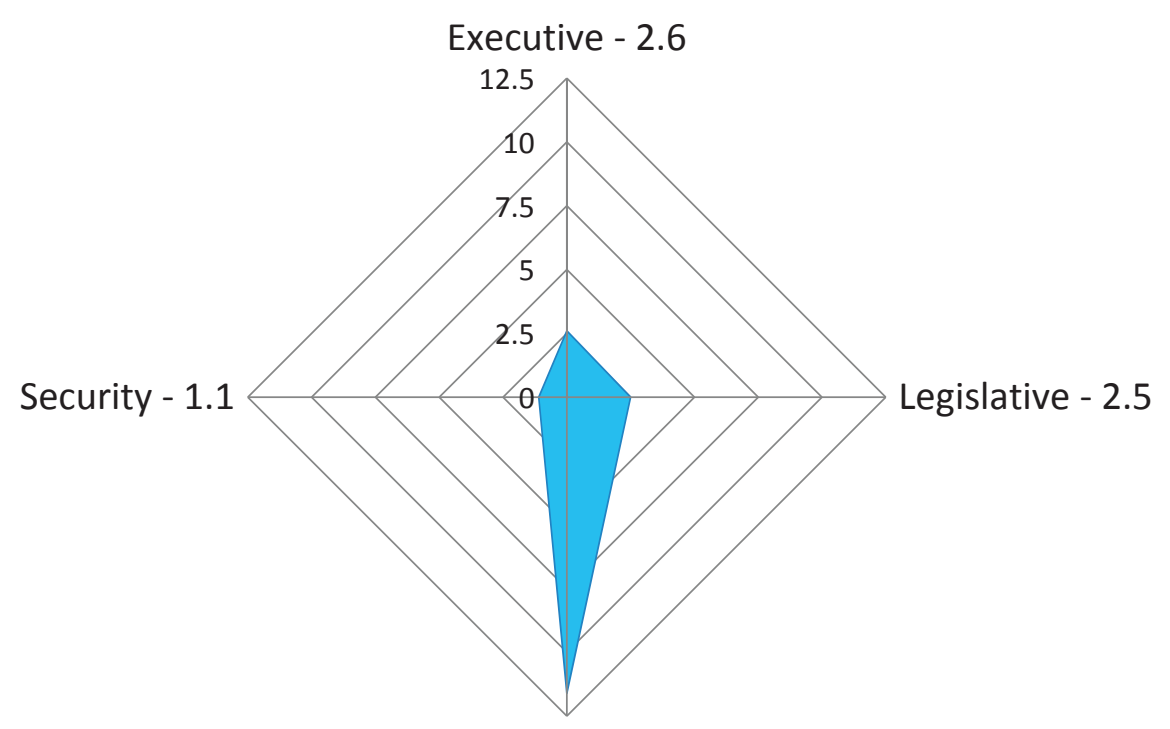

Judiciary - 11.6 


\section{Georgia \\ Diamond Index Score $=17.4$}

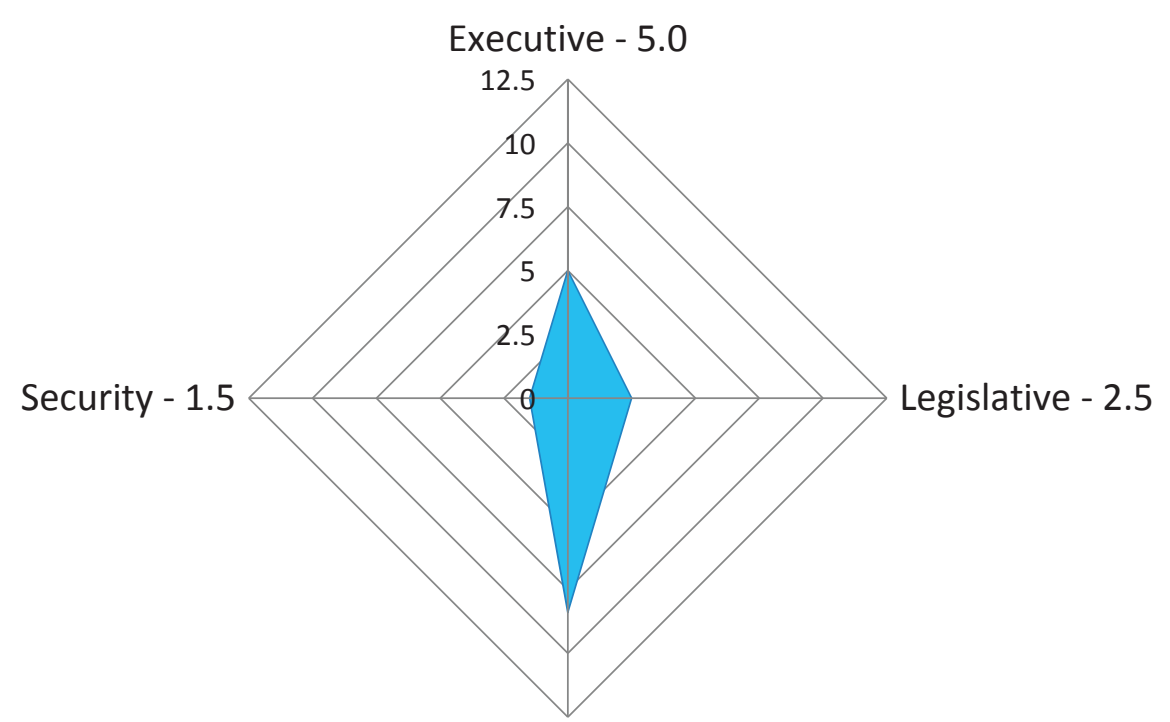

Judiciary - 8.4 


\section{Kyrgyzstan \\ Diamond Index Score = NA}

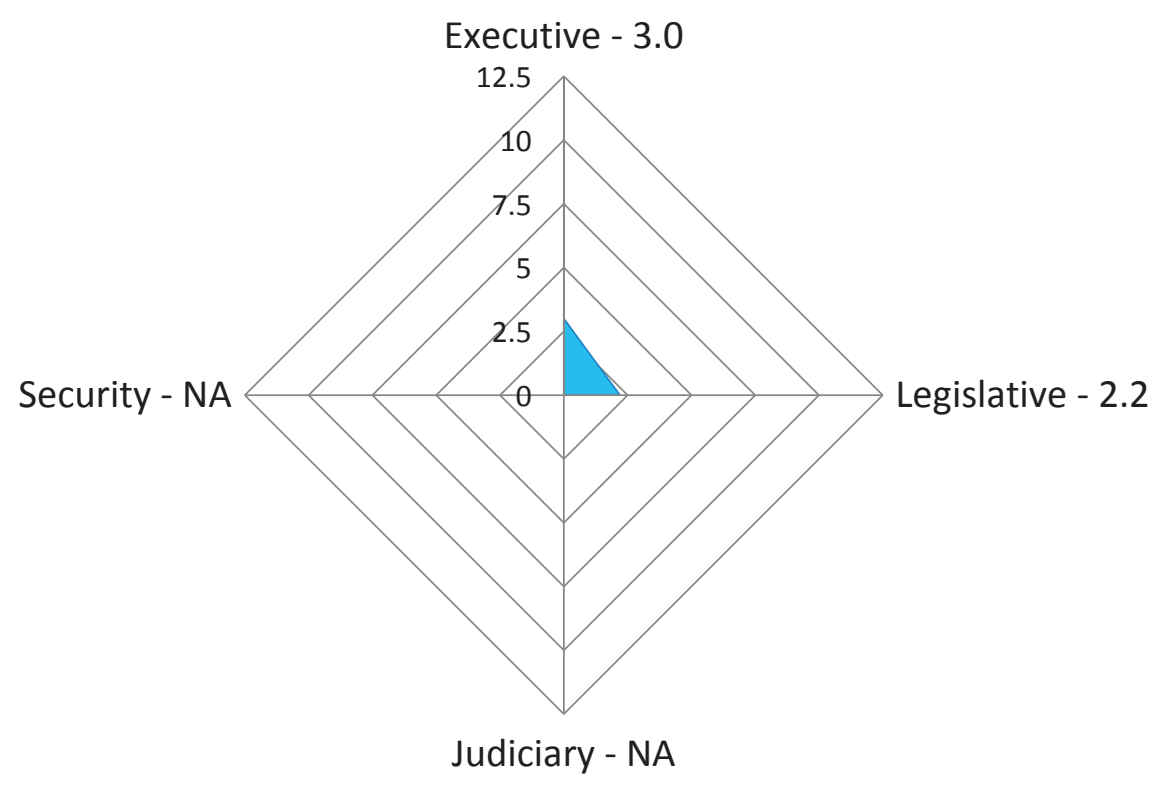




\section{Ukraine \\ Diamond Index Score = NA (10.8 Minus Security)}

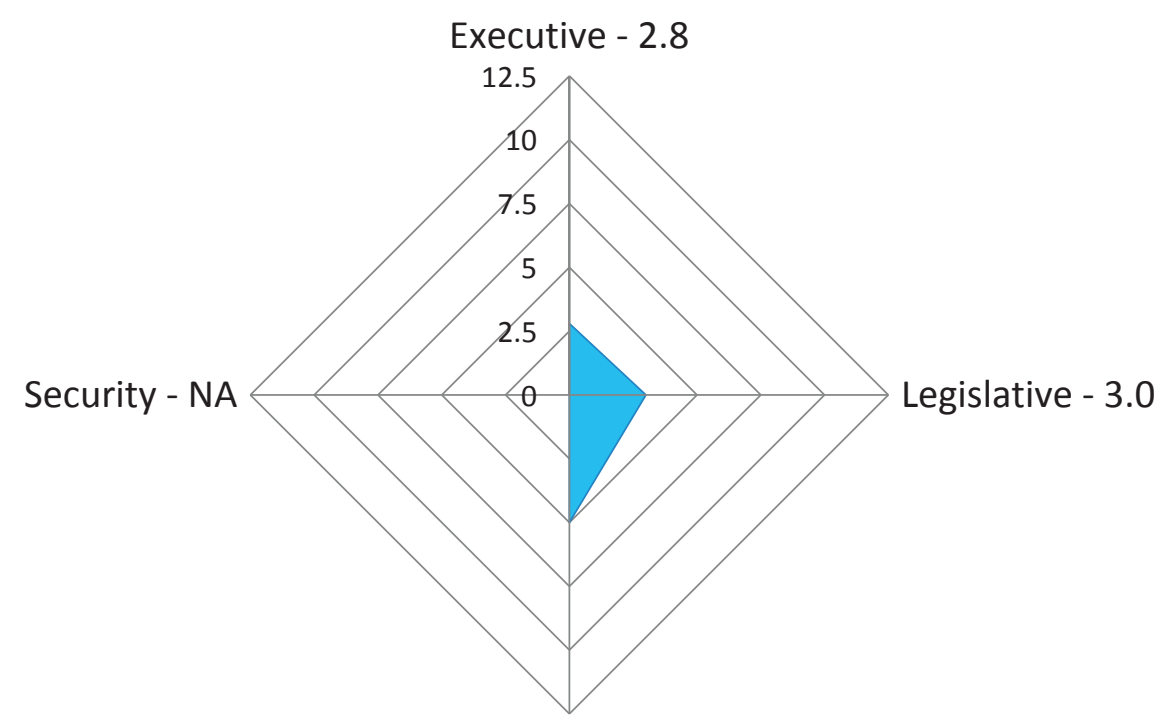

Judiciary - 5.0 


\section{Eastern Europe/Eurasia Diamond Index Regional Average $=\mathbf{1 6 . 0}$}

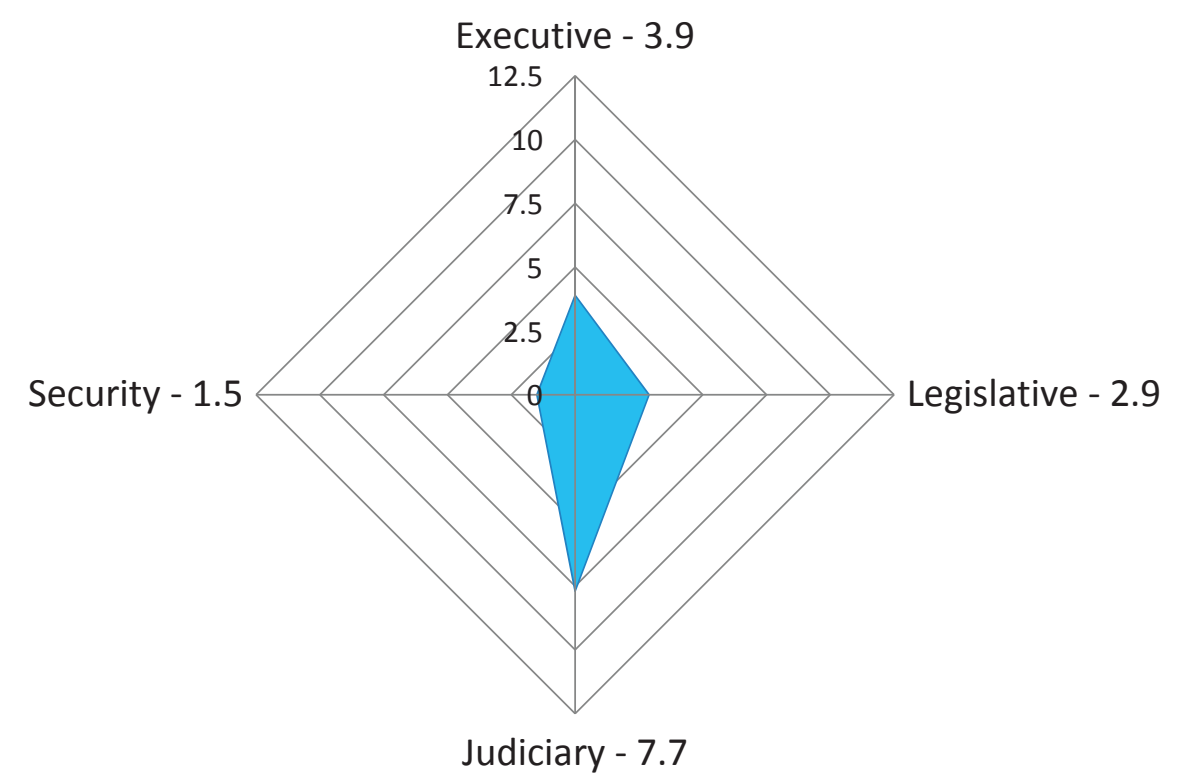




\section{Brazil \\ Diamond Index Score $=13.3$}

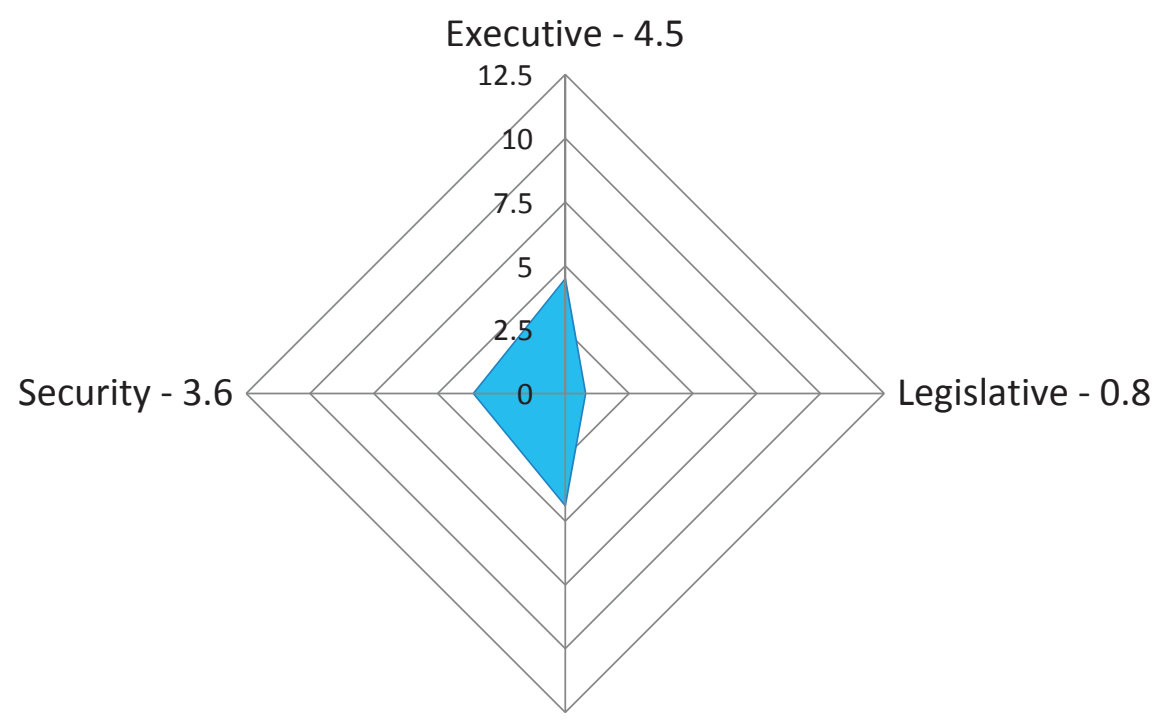

Judiciary - 4.4 


\section{Columbia}

\section{Diamond Index Score = NA (15.9 Minus Security)}

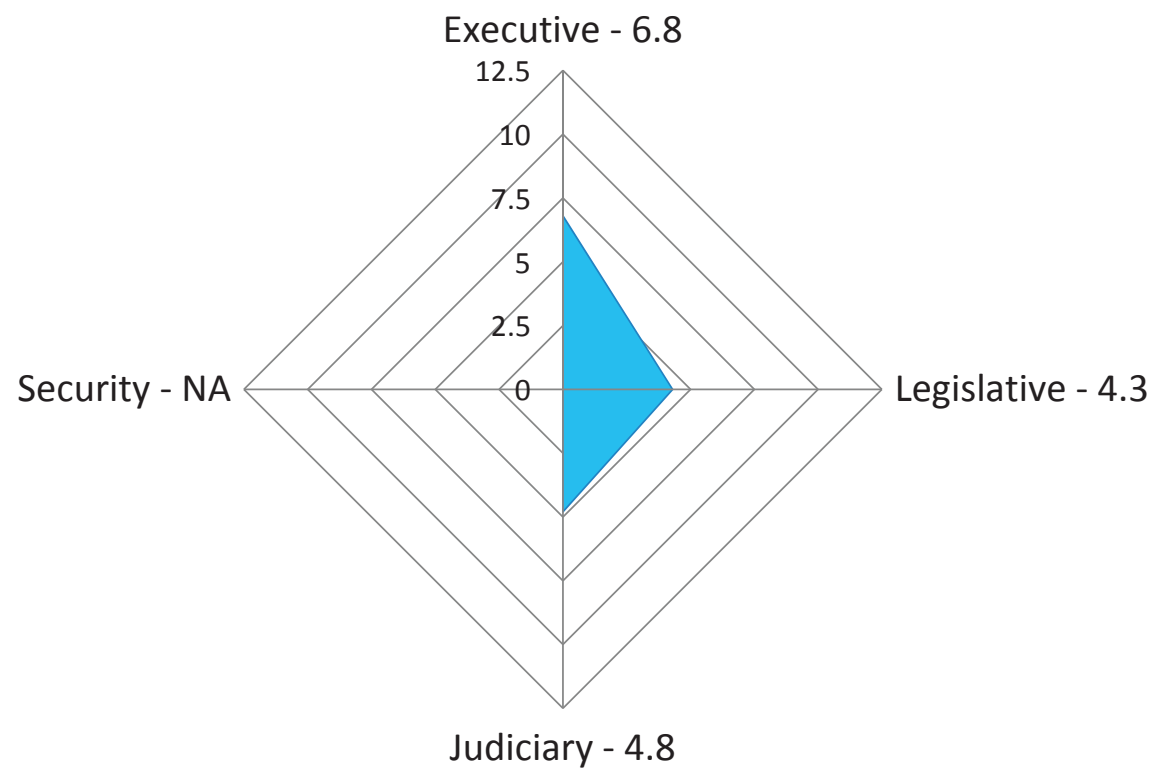




\section{Guatemala Diamond Index Score $=\mathbf{1 7 . 0}$}

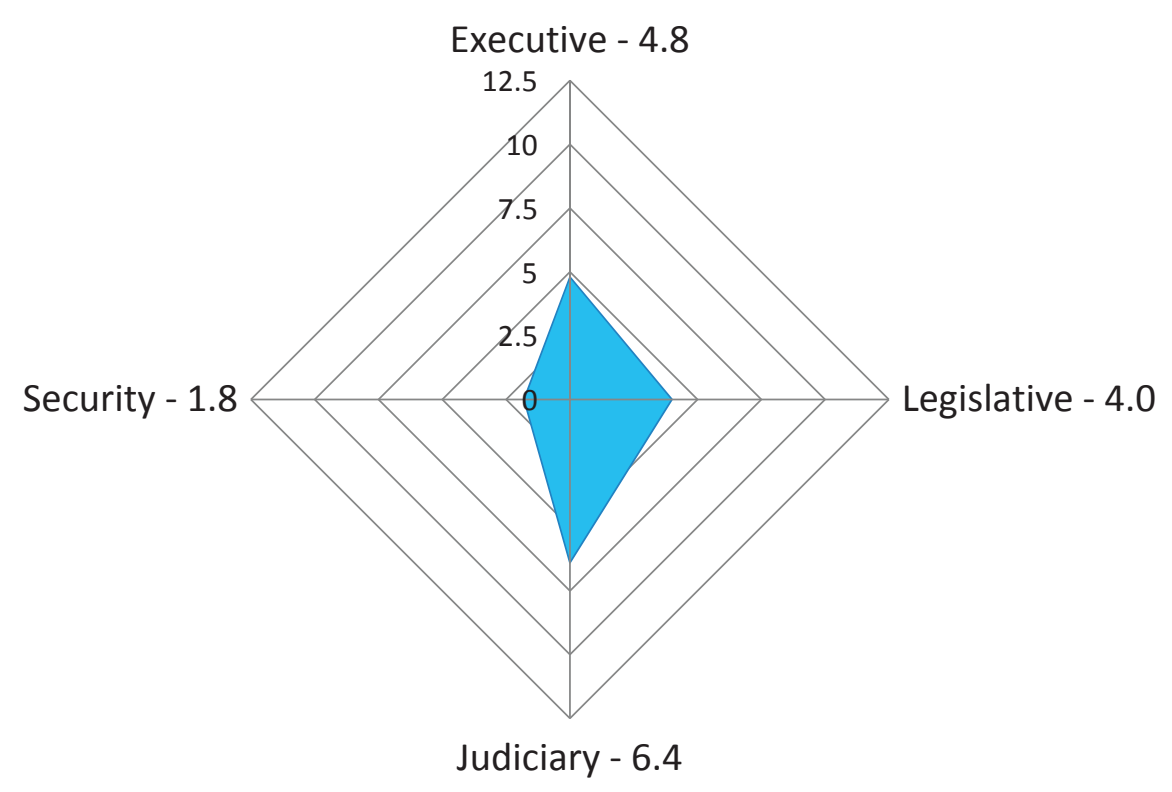




\section{Haiti \\ Diamond Index Score $=6.9$}

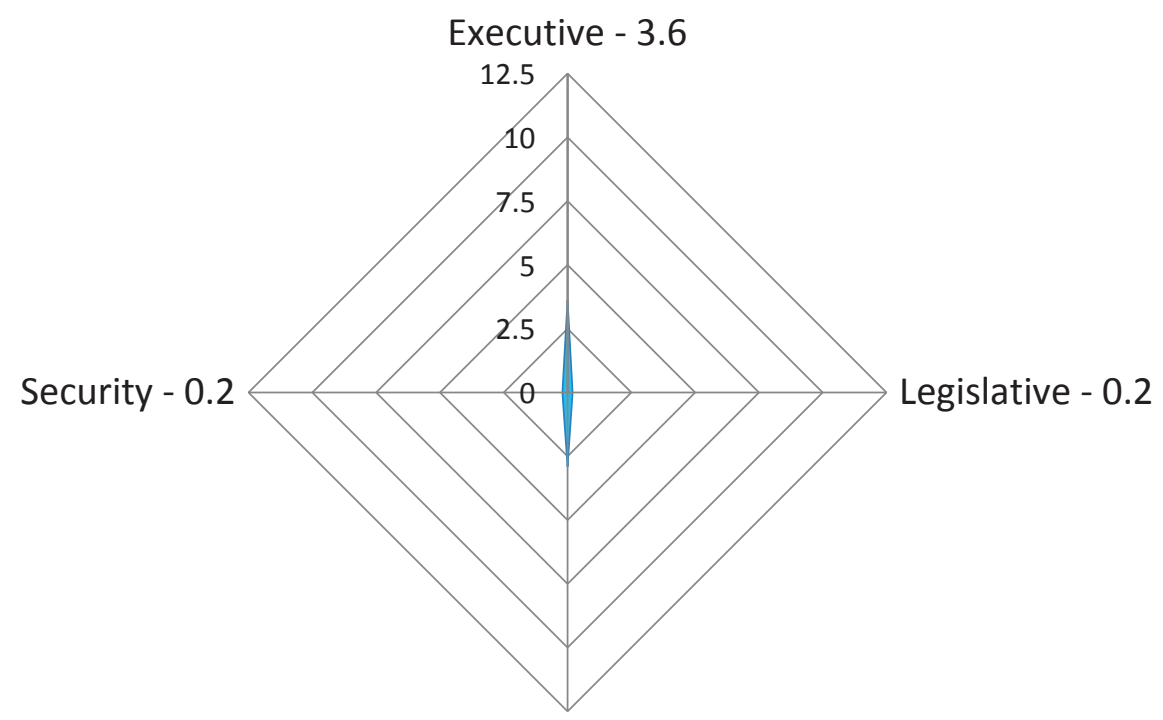

Judiciary - 2.9 


\section{Mexico \\ Diamond Index Score = 13.9}

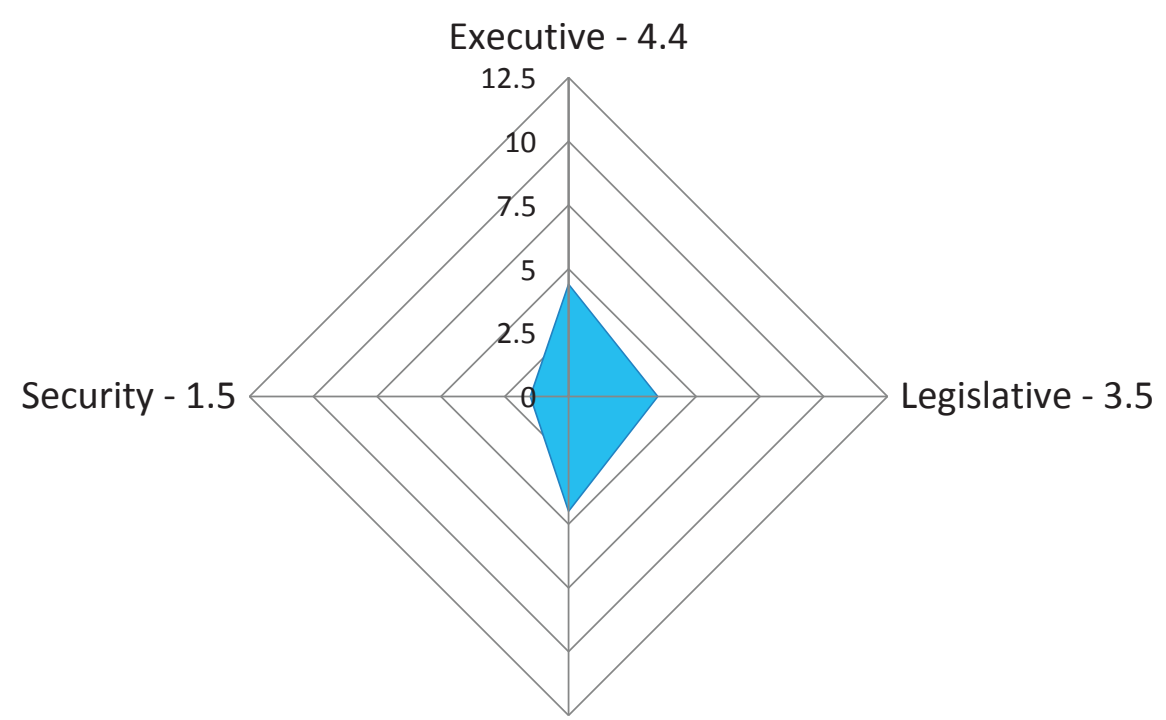

Judiciary - 4.5 


\section{Latin America/Caribbean Diamond Index Regional Average $=13.8$}

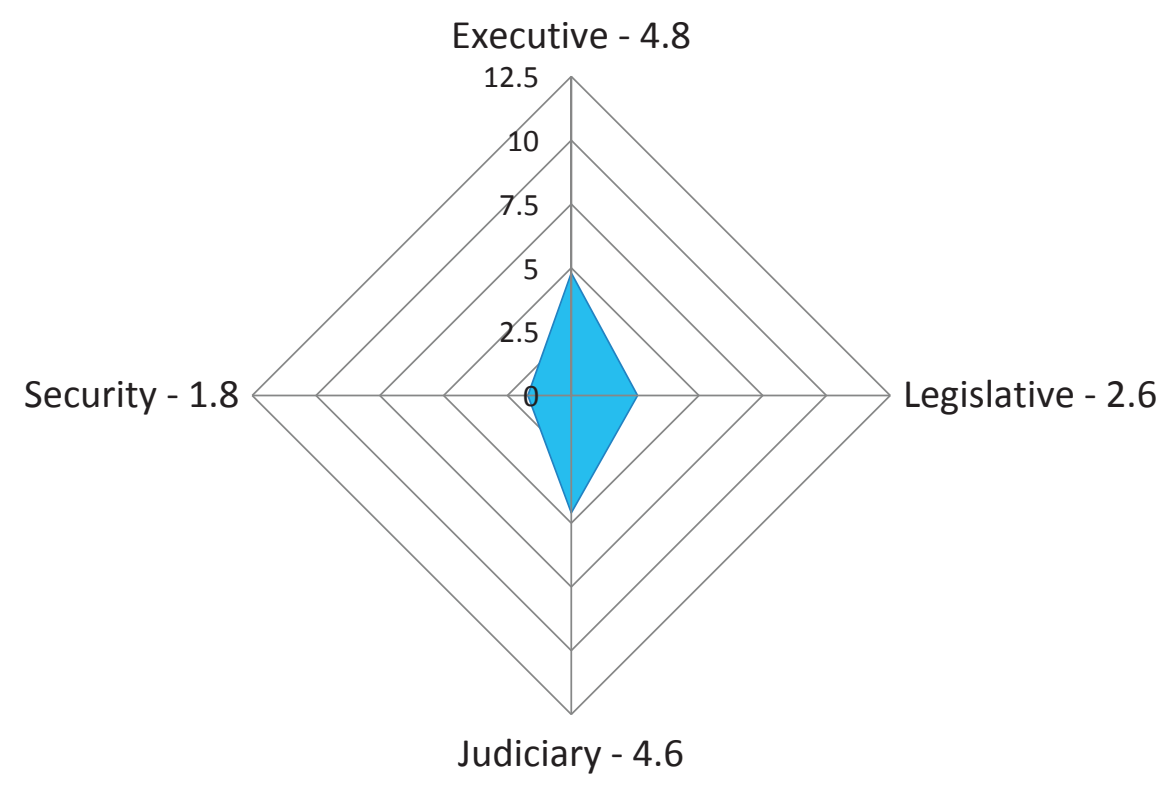




\section{Bangladesh \\ Diamond Index Score $=\mathbf{1 0 . 0}$}

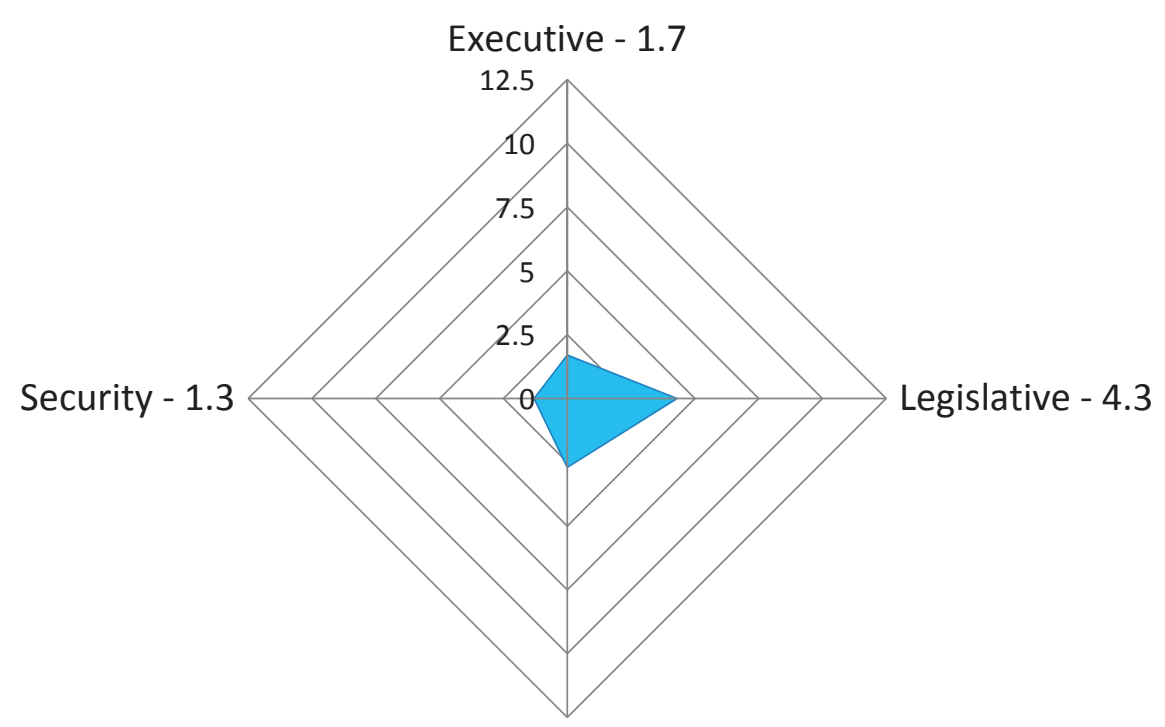

Judiciary - 2.7 


\section{Cambodia \\ Diamond Index Score = NA (10.2 Minus Security)}

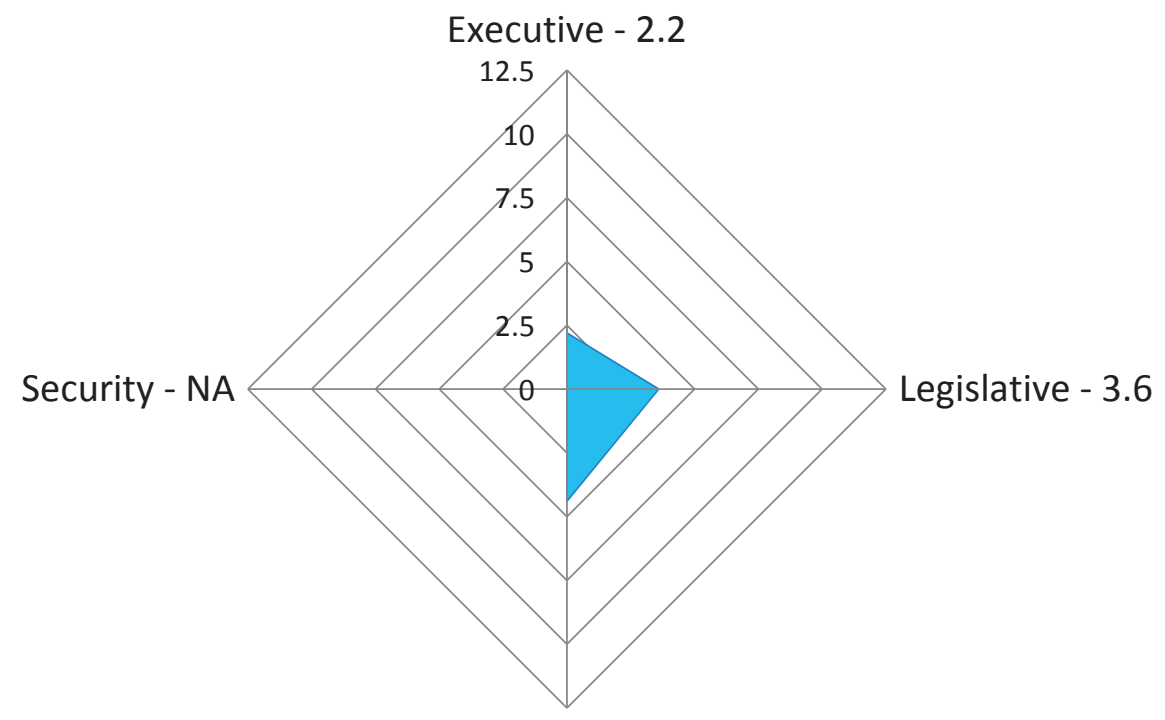

Judiciary - 4.4 


\section{India \\ Diamond Index Score $=11.6$}

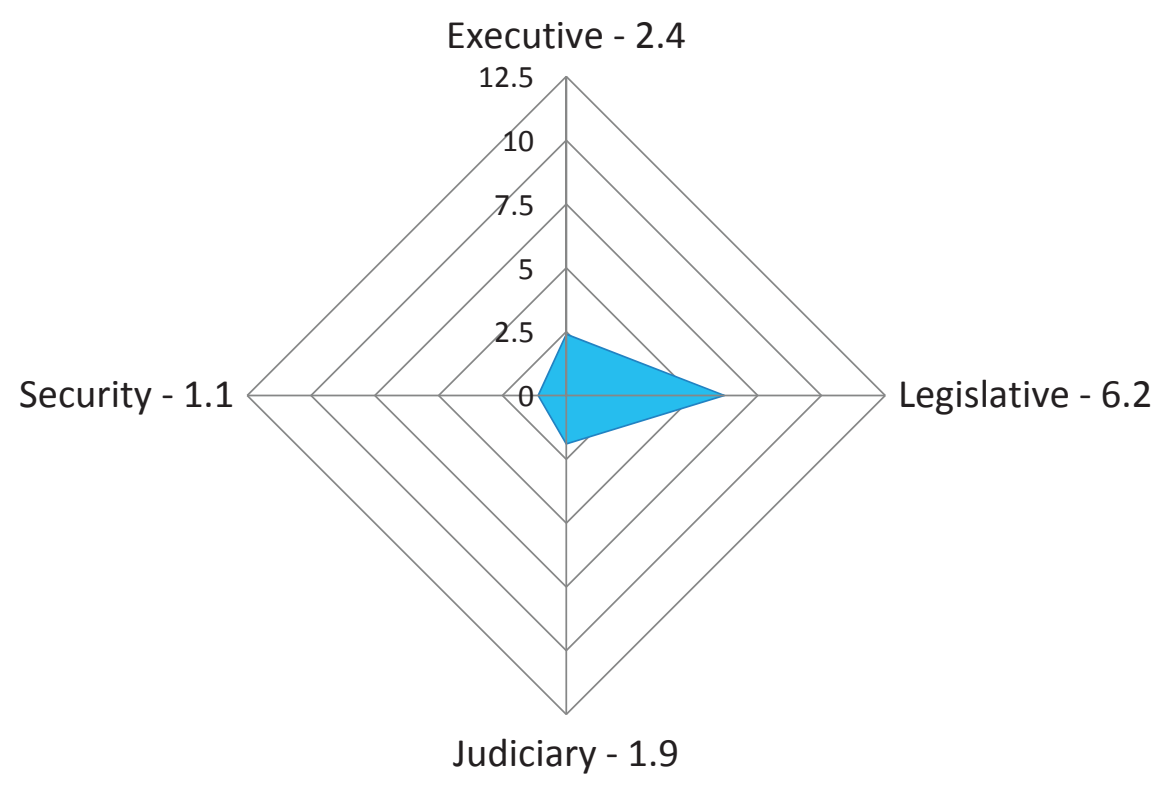




\section{Indonesia \\ Diamond Index Score = 10.5}

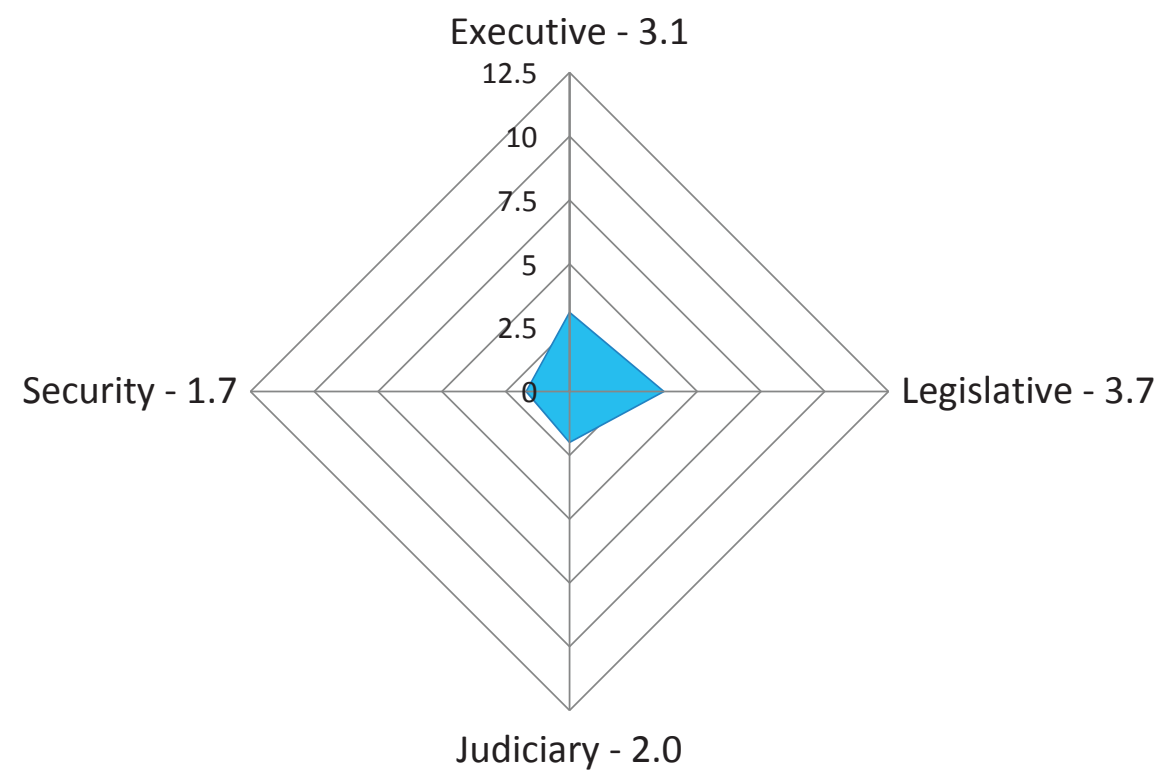




\section{Mongolia \\ Diamond Index Score = NA (16.4 Minus Security)}

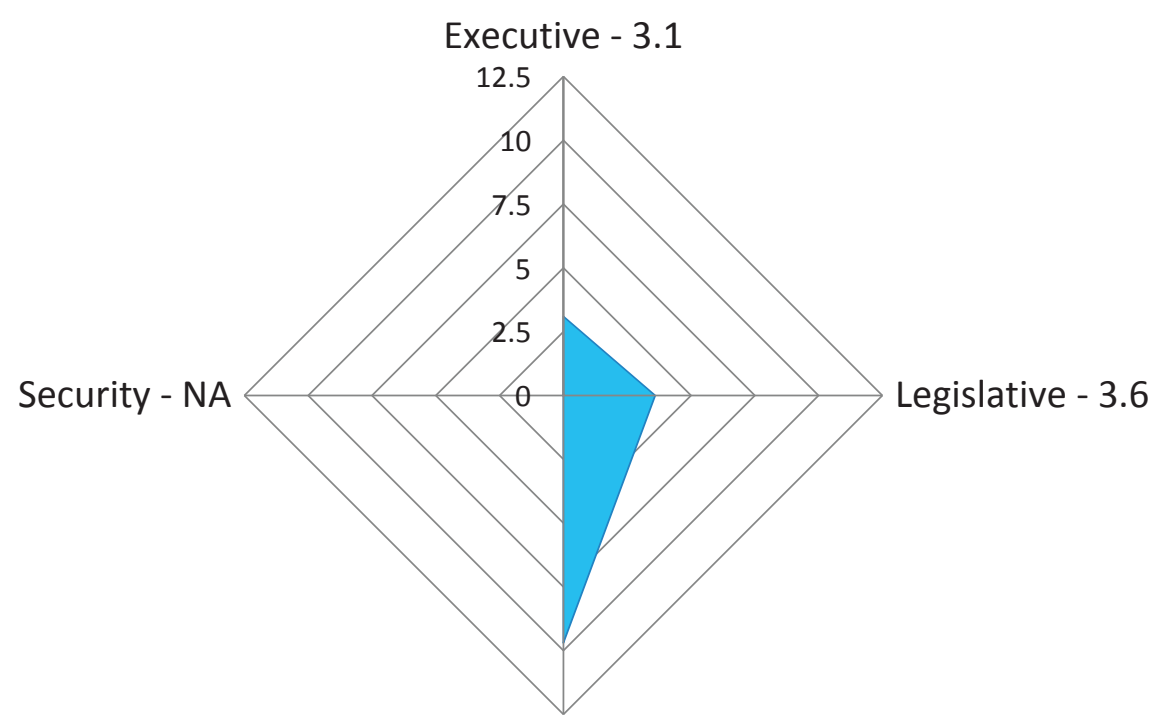

Judiciary - 9.7 


\section{Nepal \\ Diamond Index Score = 7.1}

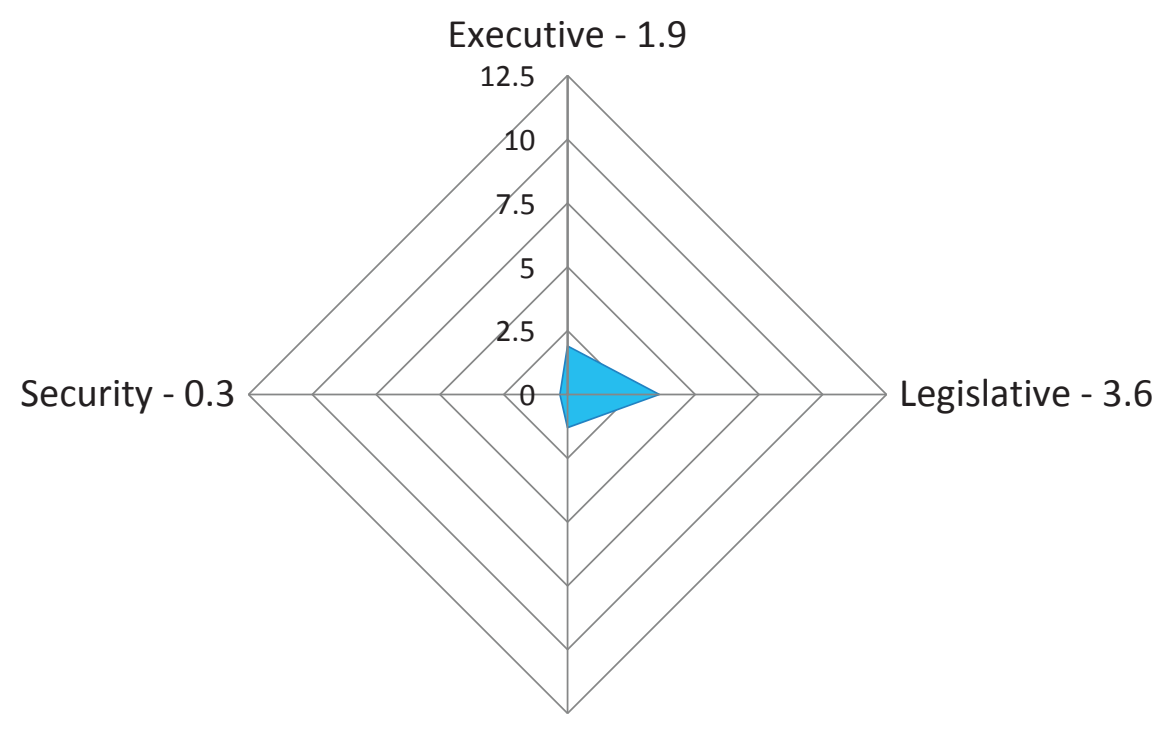

Judiciary - 1.3 


\section{Philippines \\ Diamond Index Score = NA (17.6 Minus Security)}

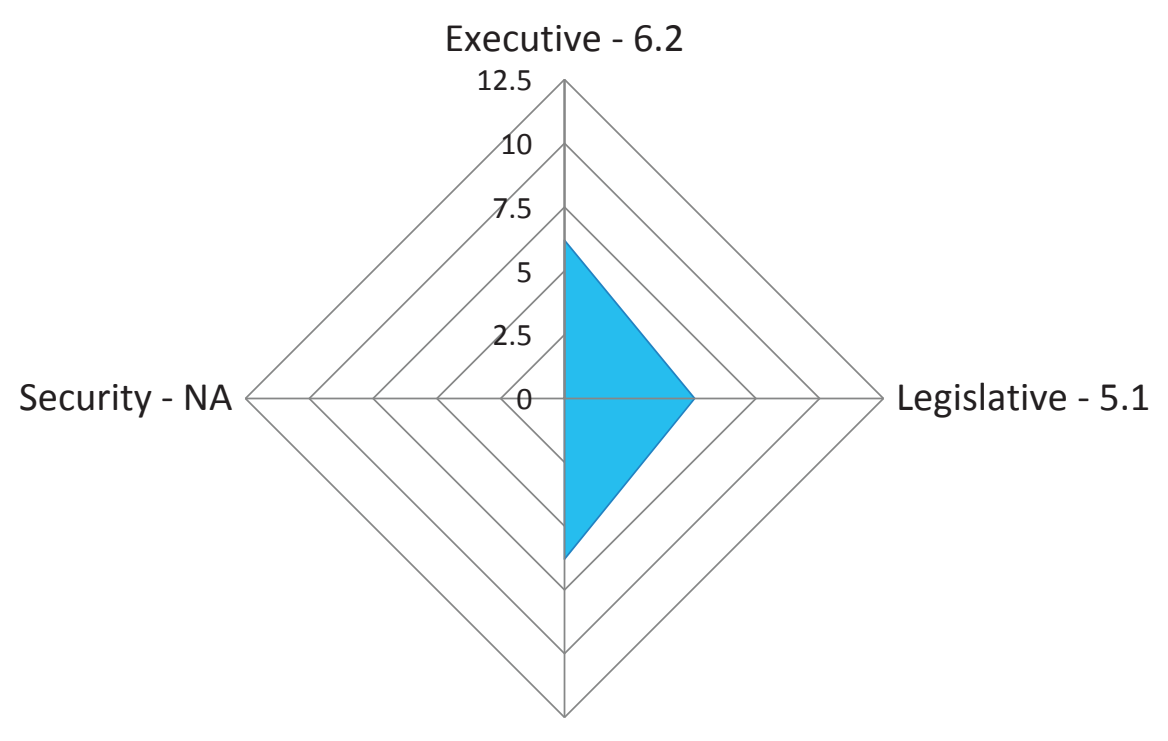

Judiciary - 6.3 


\section{Thailand \\ Diamond Index Score = 3.6}

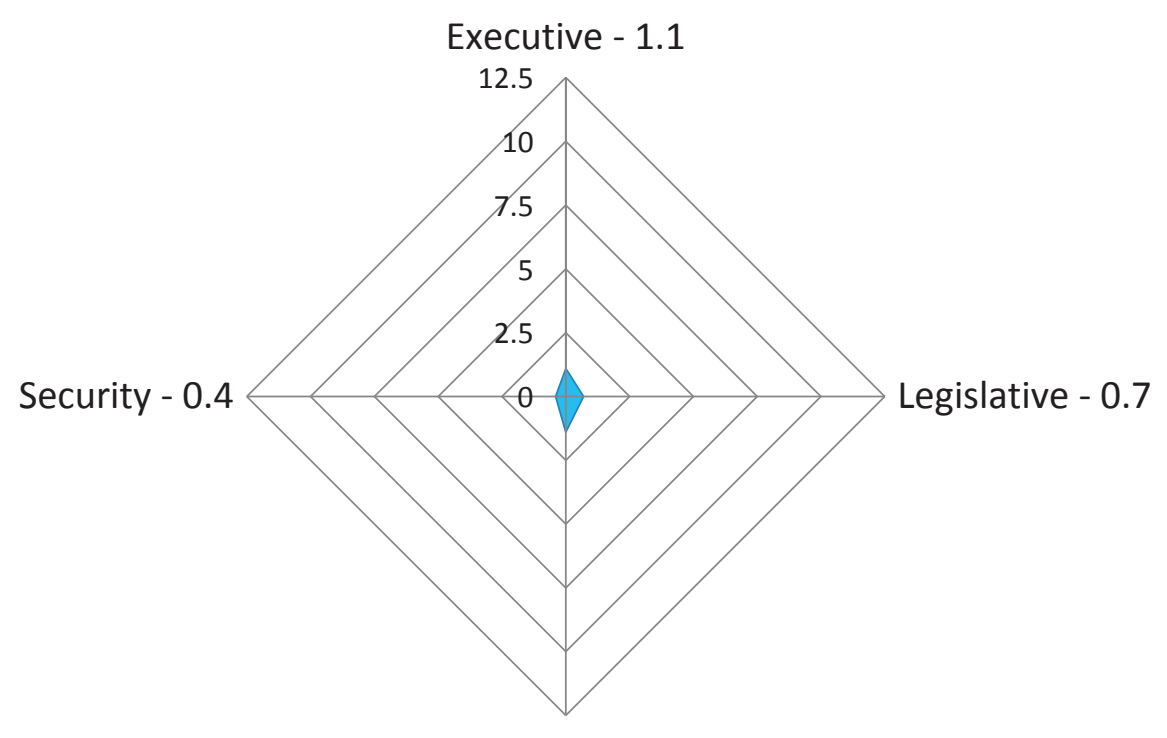

Judiciary - 1.4 


\section{Timor-Liste Diamond Index Score $=17.7$}

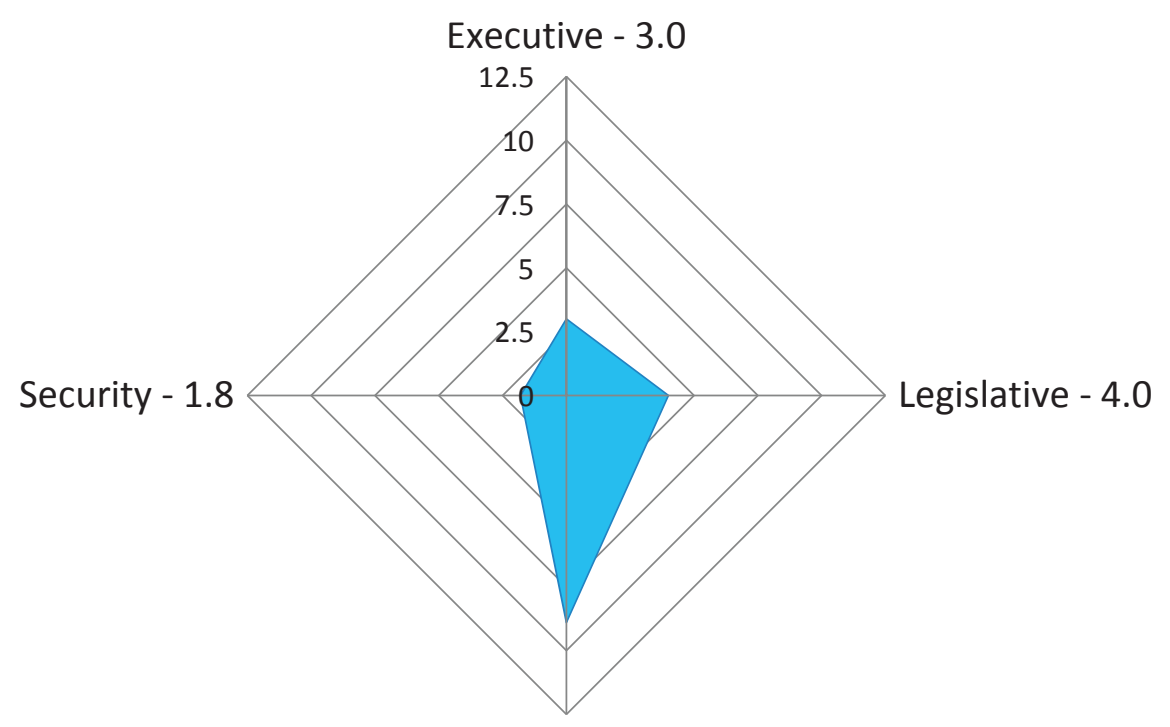

Judiciary - 8.9 


\section{Asia \\ Diamond Index Regional Average $=\mathbf{1 2 . 0}$}

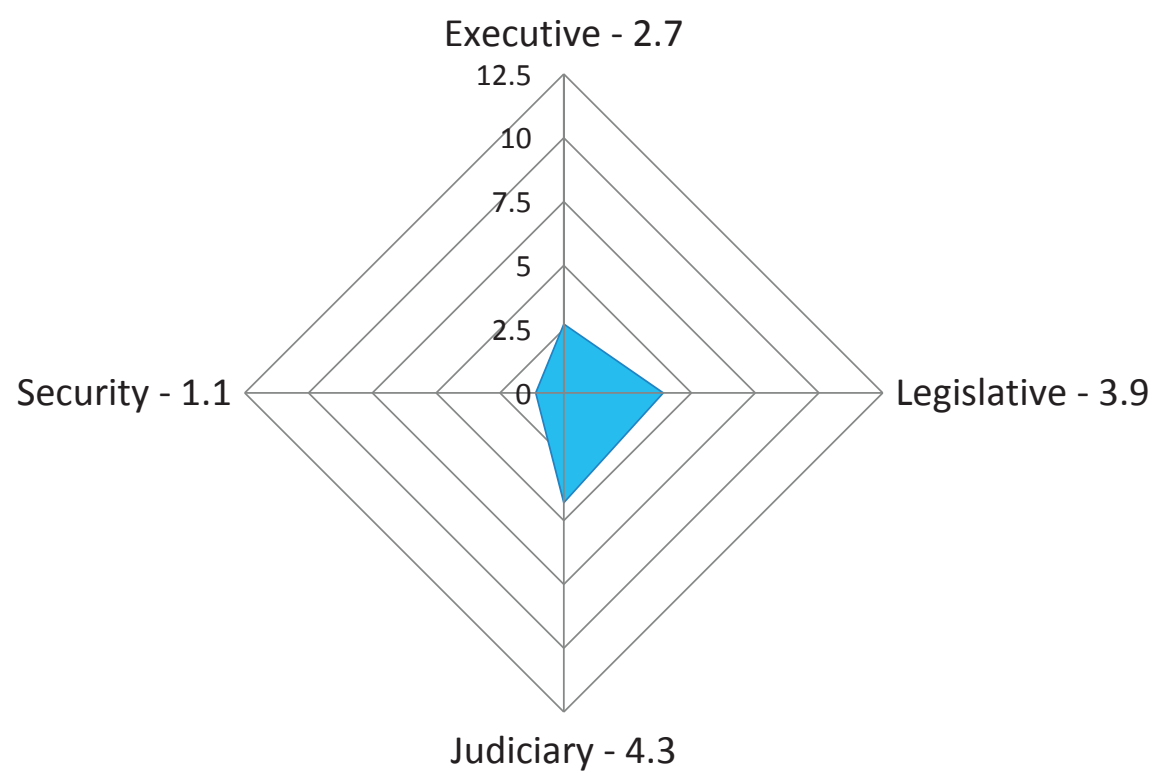




\section{Benin \\ Diamond Index Score = NA (13.9 Minus Security)}

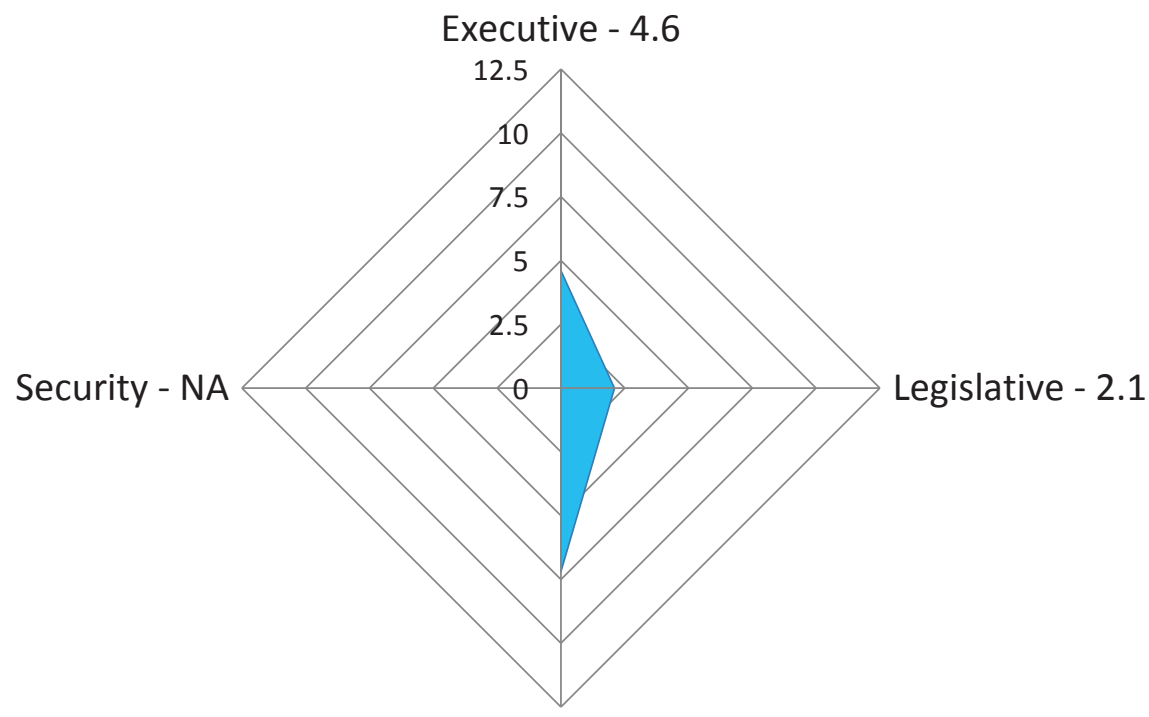

Judiciary -7.2 


\section{Burkina Faso \\ Diamond Index Score $=17.2$}

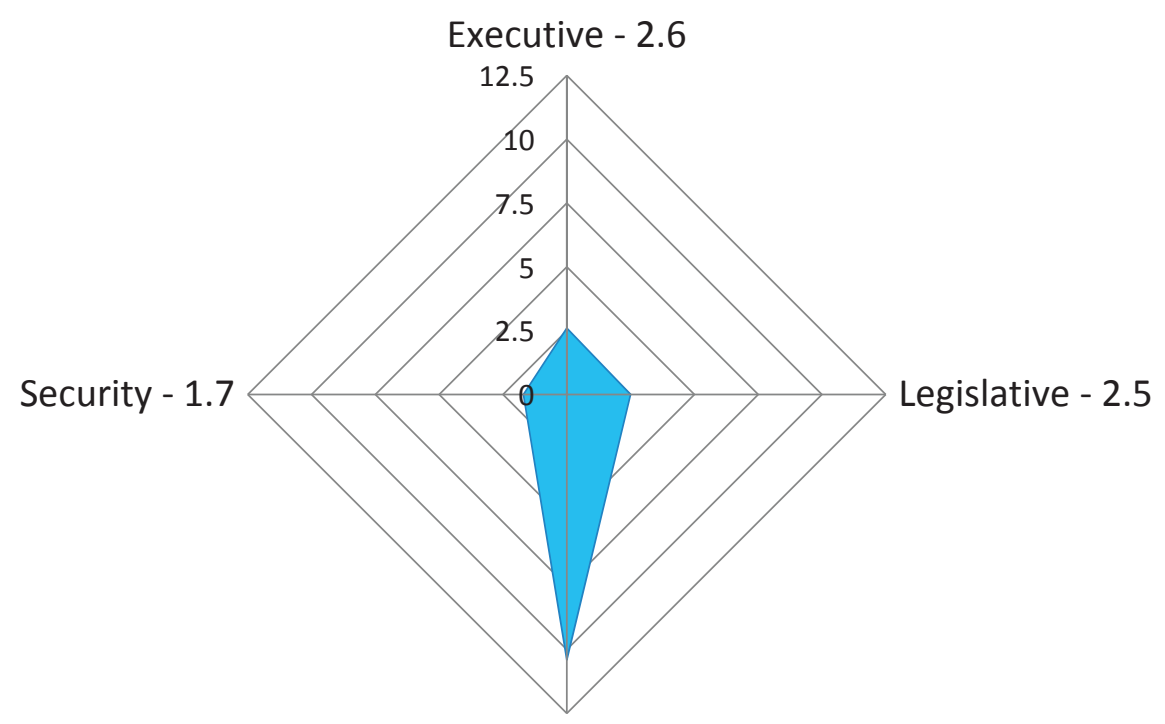

Judiciary - 10.4 


\section{Cote d'Ivoire Diamond Index Score $=15.3$}

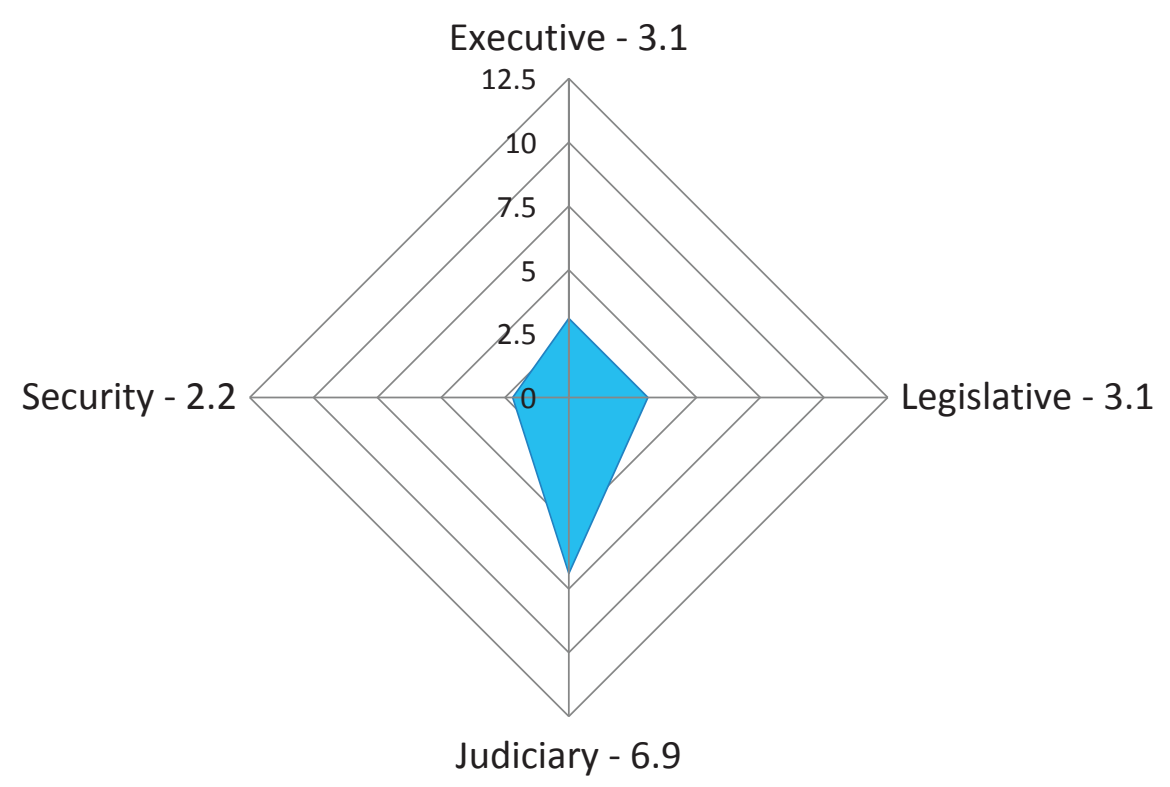


Ghana

\section{Diamond Index Score = NA (15.4 Minus Security)}

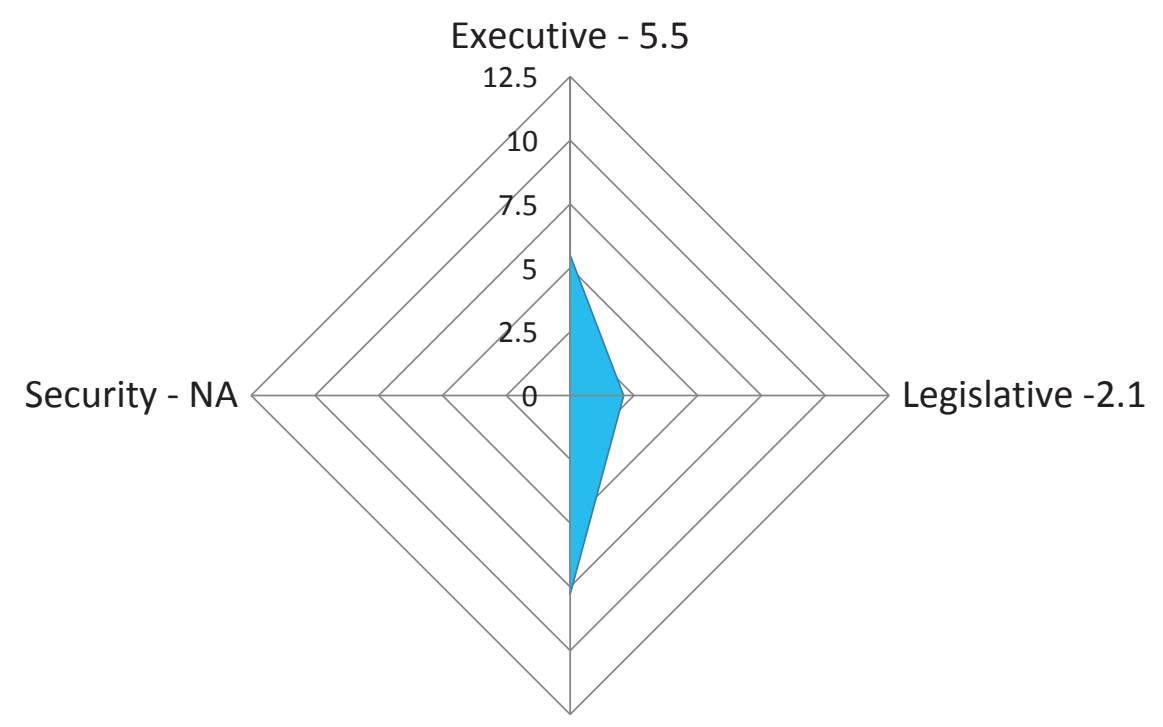

Judiciary - 7.8 


\section{Kenya \\ Diamond Index Score $=\mathbf{2 0 . 5}$}

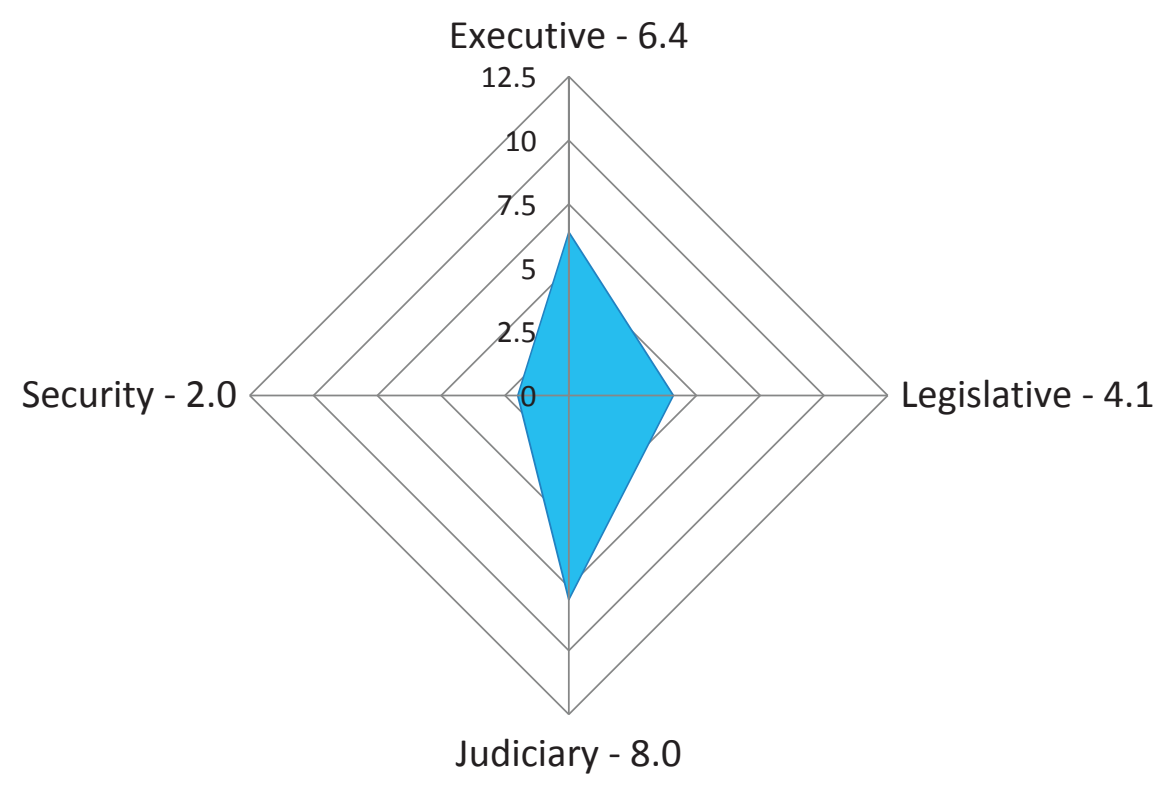


Liberia

\section{Diamond Index Score = NA (16.3 Minus Security)}

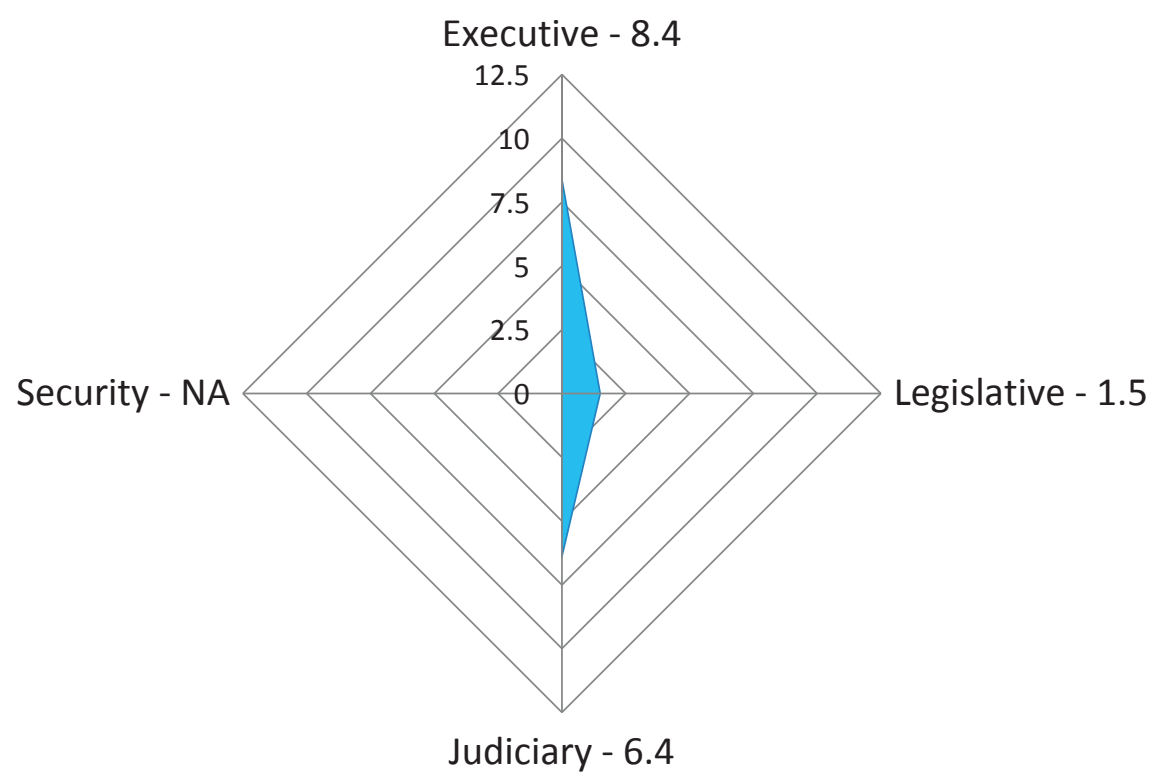




\section{Madagascar \\ Diamond Index Score = NA (14.8 Minus Security)}

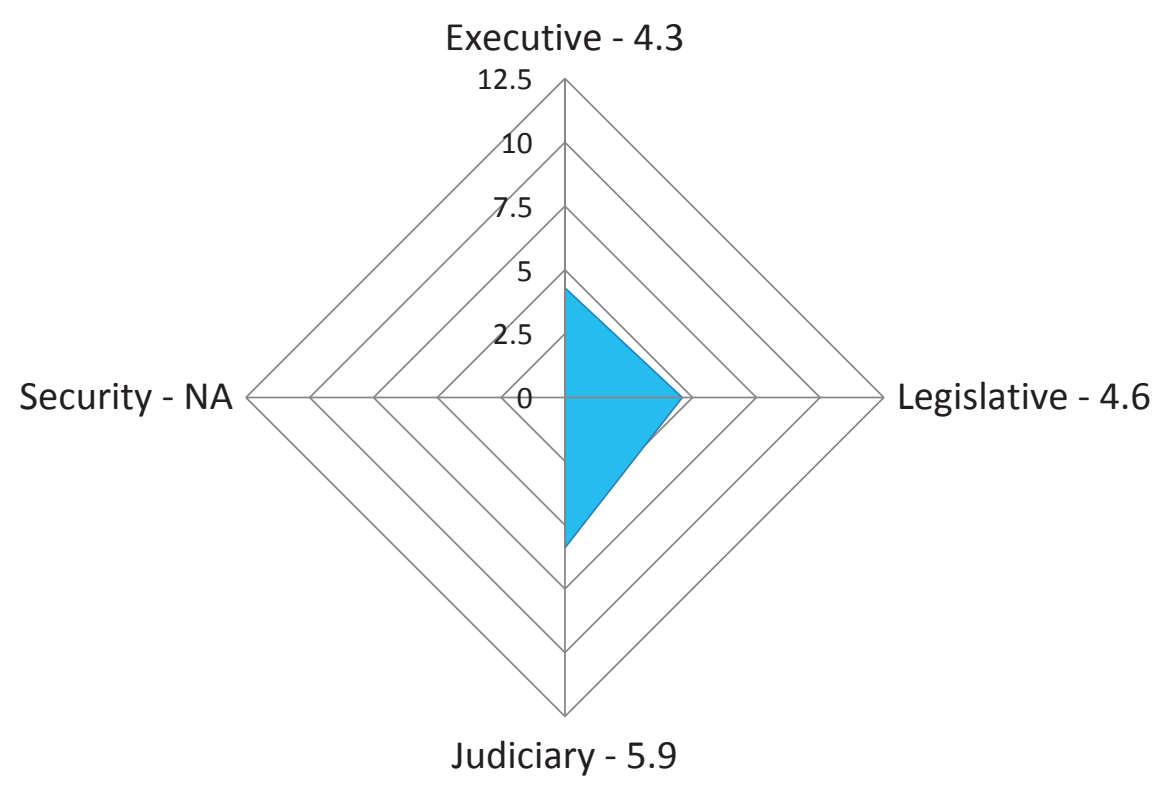




\section{Mali \\ Diamond Index Score $=12.7$}

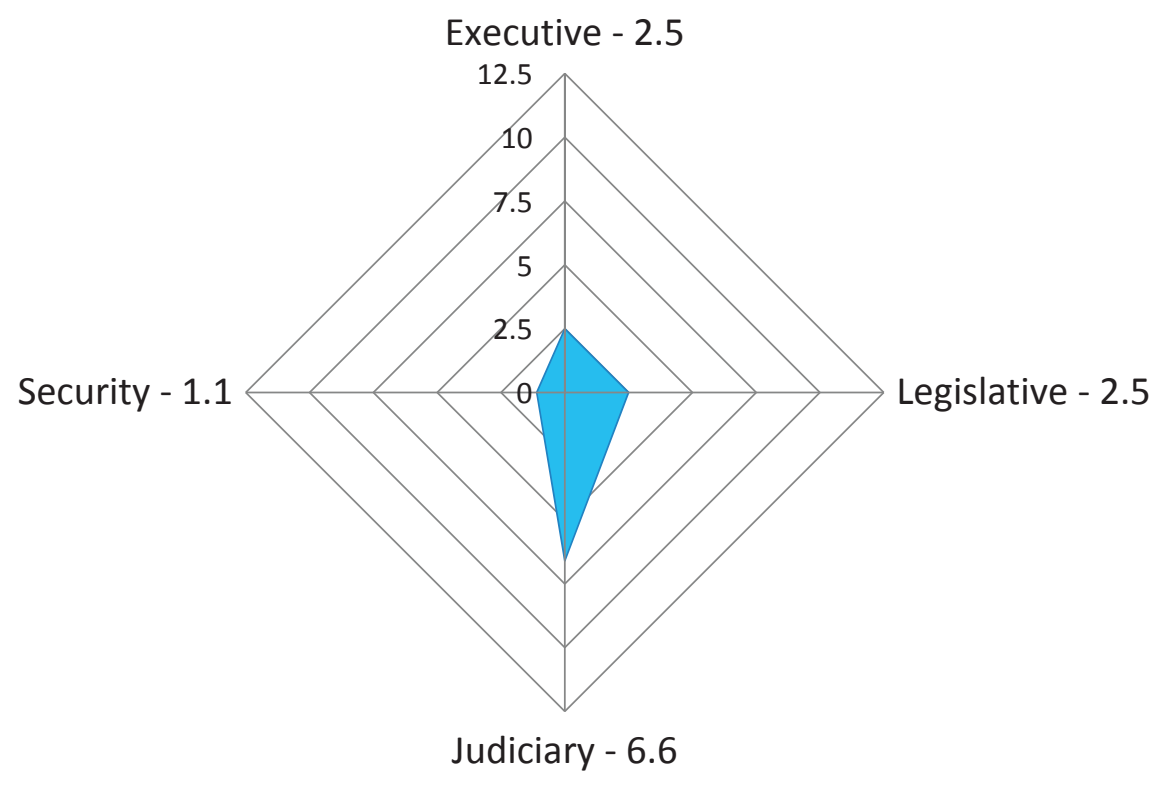




\section{Mozambique \\ Diamond Index Score = NA (14.3 Minus Security)}

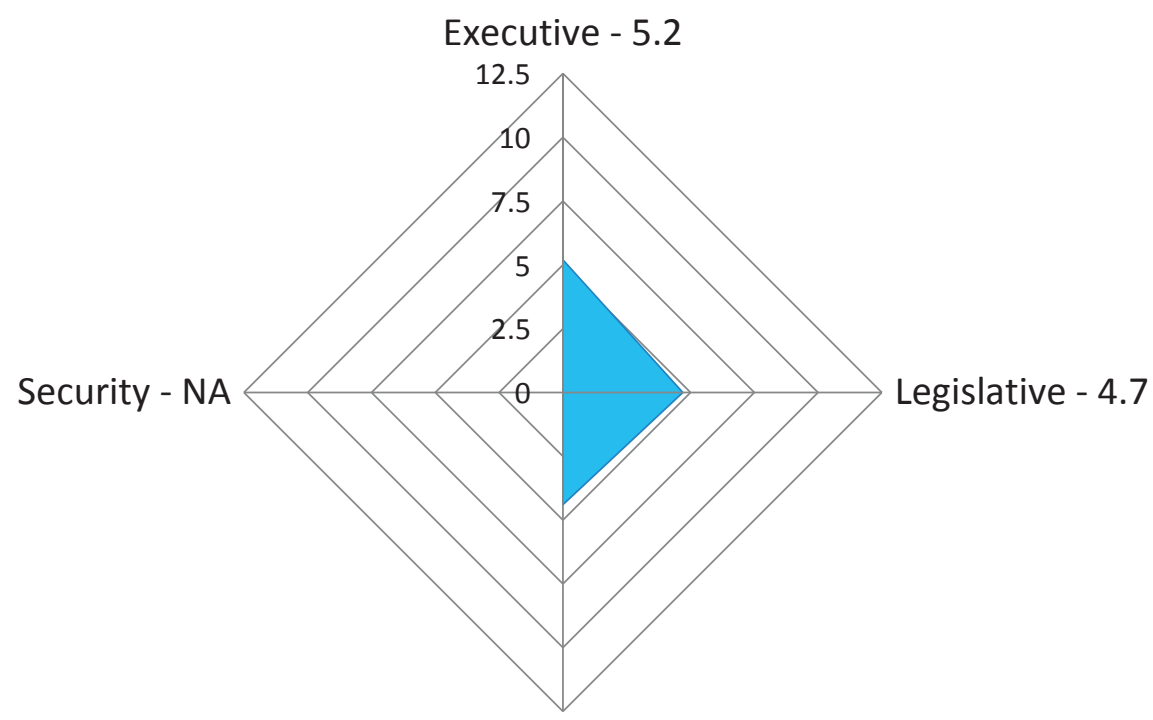

Judiciary - 4.4 


\section{Niger \\ Diamond Index Score $=$ NA}

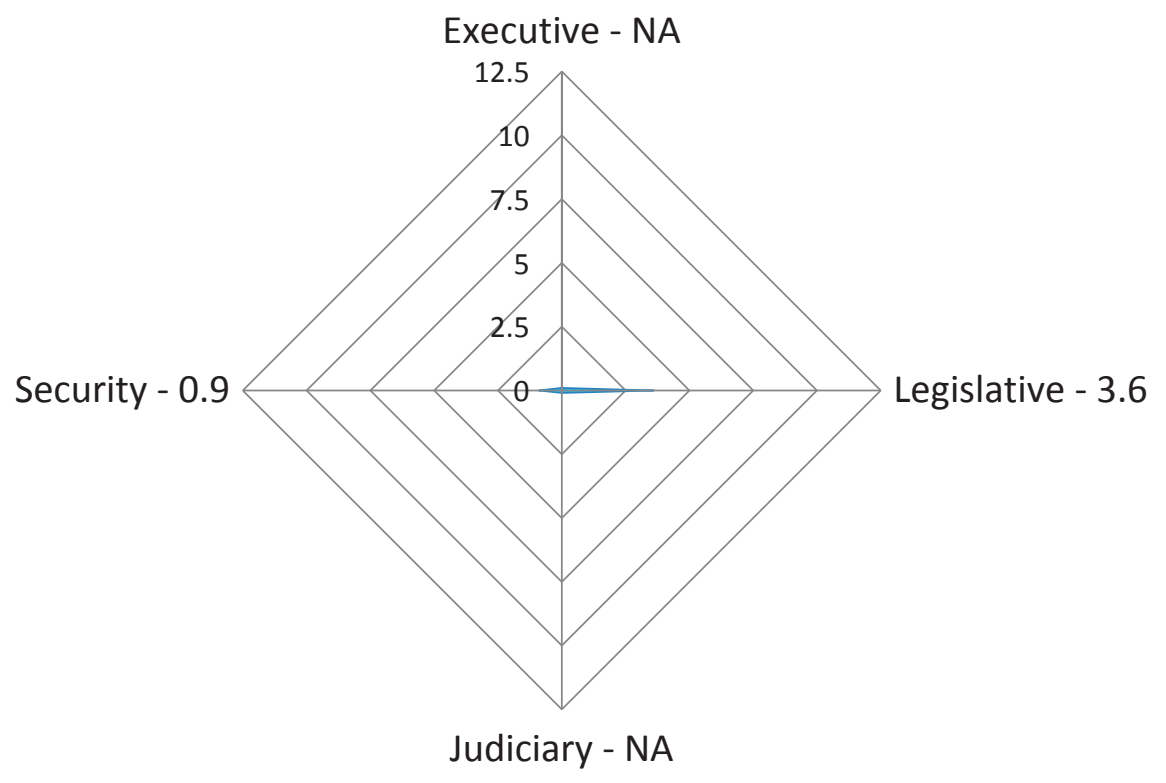




\section{Nigeria \\ Diamond Index Score $=14.9$}

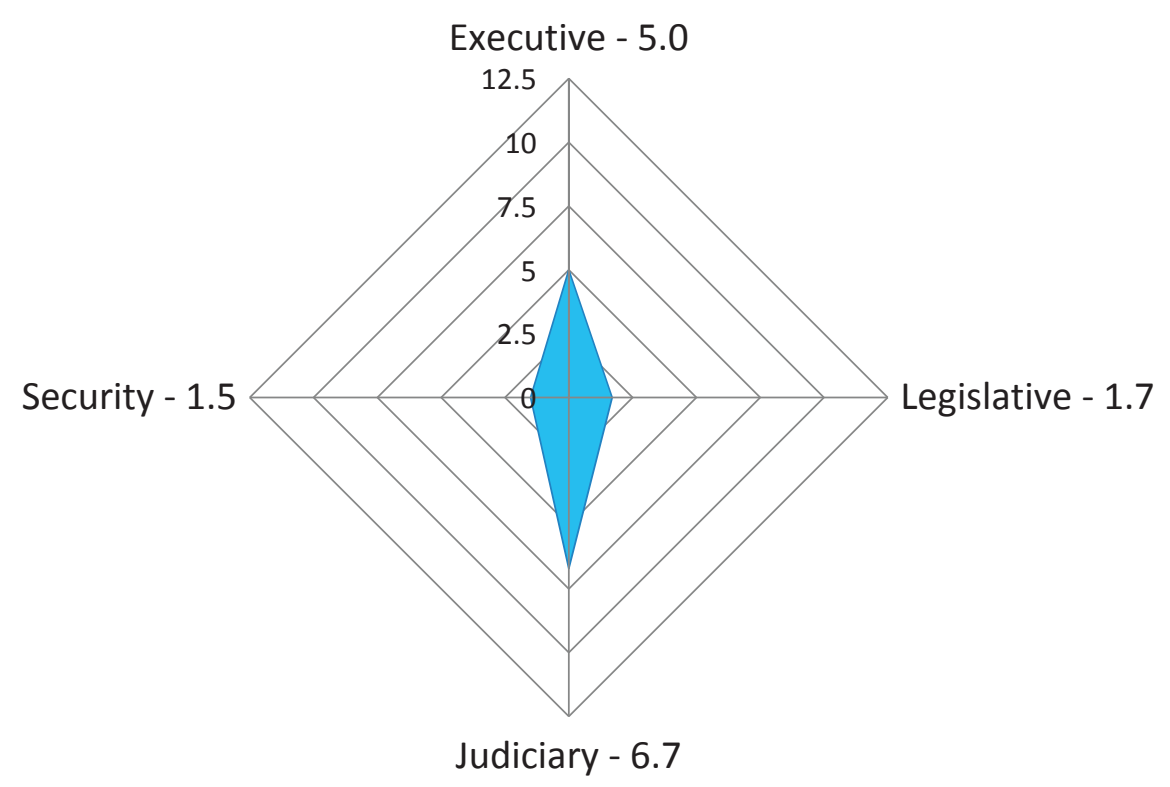




\section{Rwanda Diamond Index Score $=\mathbf{2 7 . 9}$}

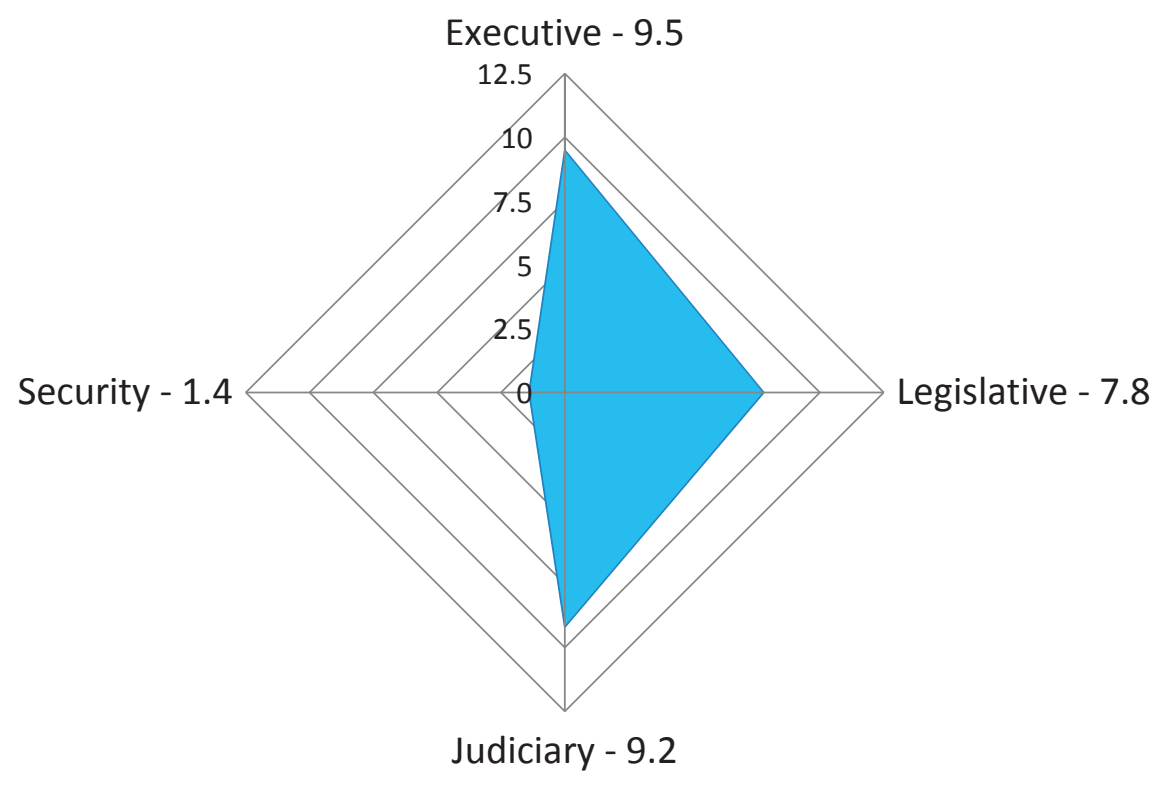




\section{Senegal \\ Diamond Index Score = NA (9.6 Minus Security)}

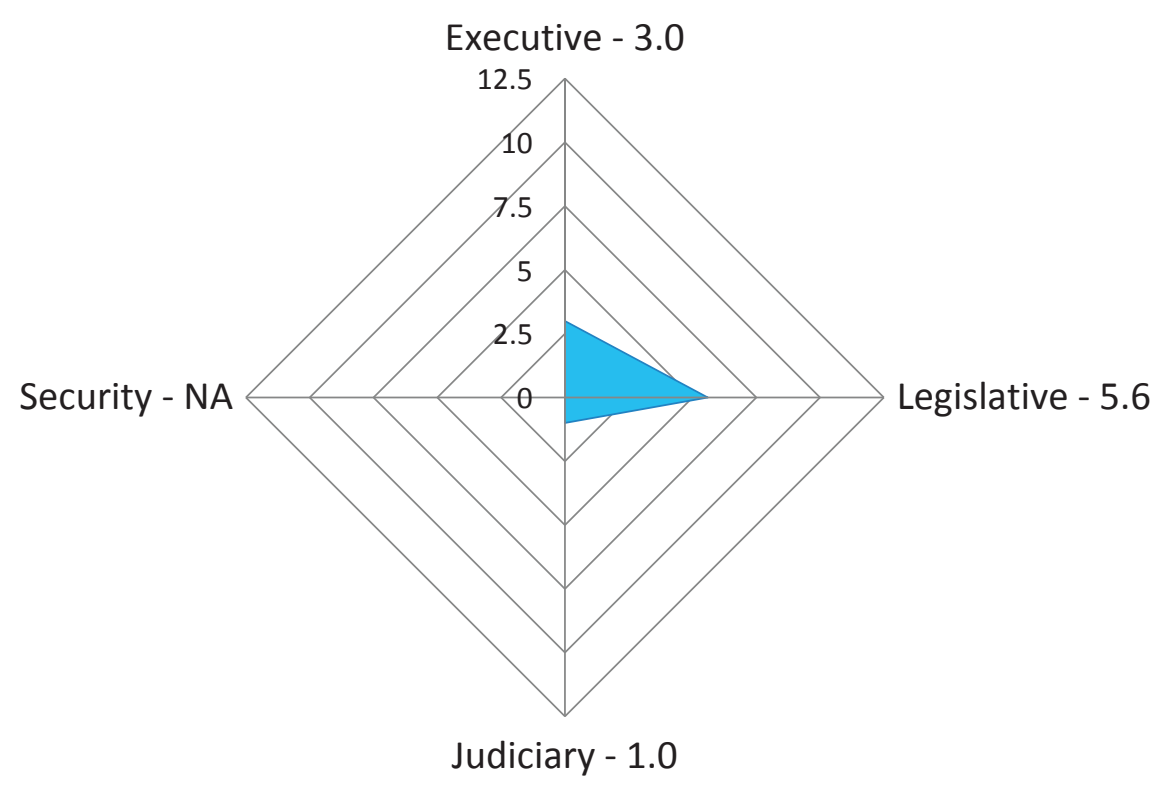




\section{South Africa \\ Diamond Index Score $=\mathbf{3 0 . 1}$}

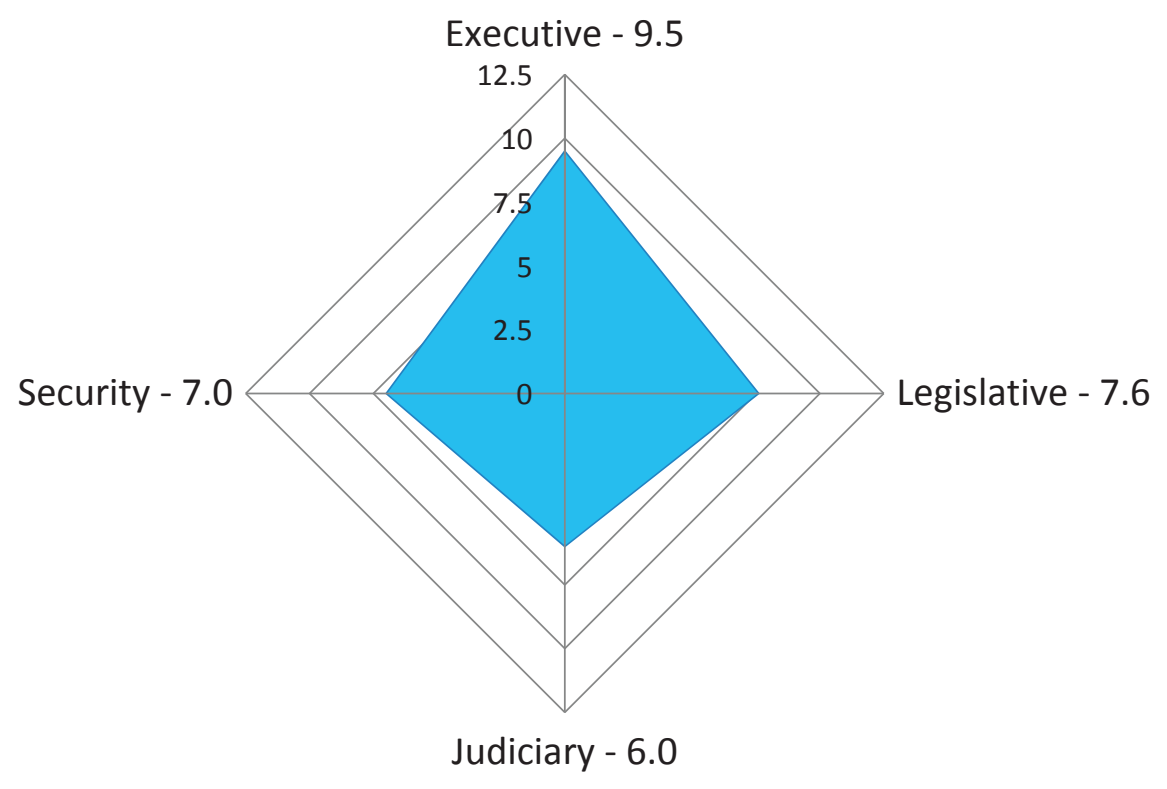




\section{Africa \\ Diamond Index Regional Average $=18.1$}

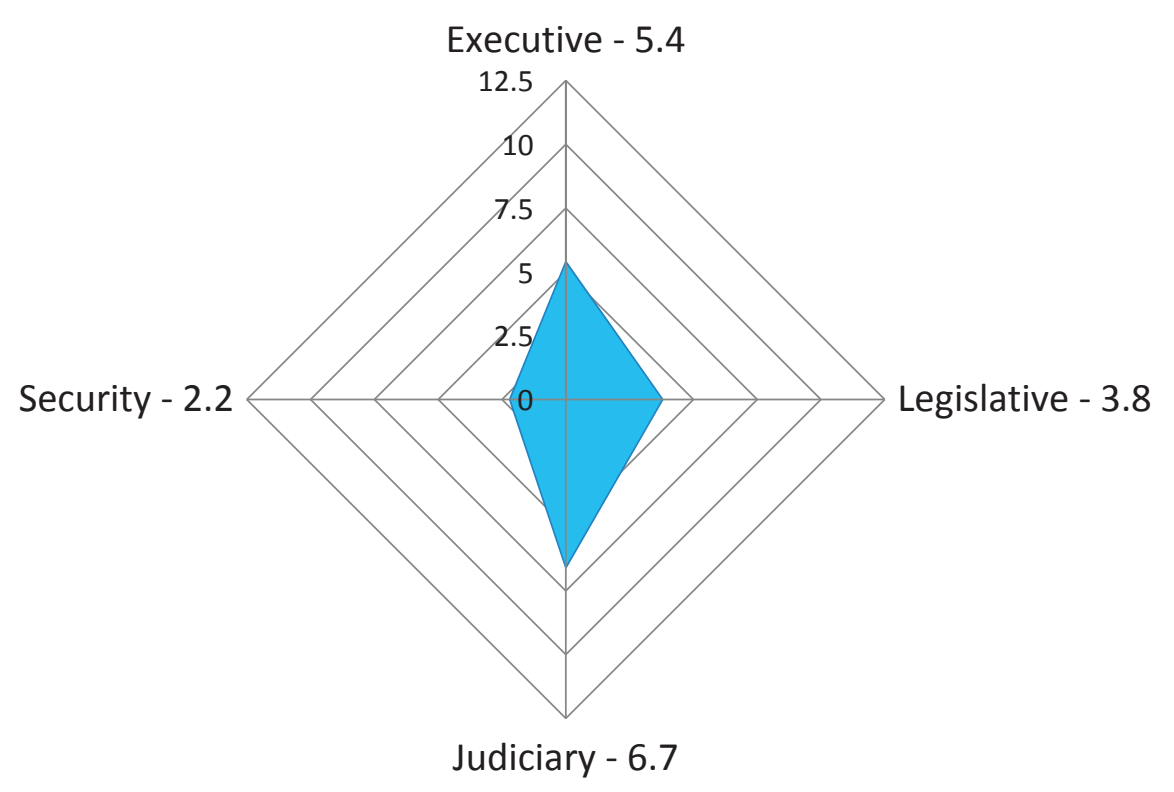




\section{Algeria \\ Diamond Index Score = NA (11.7 Minus Security)}

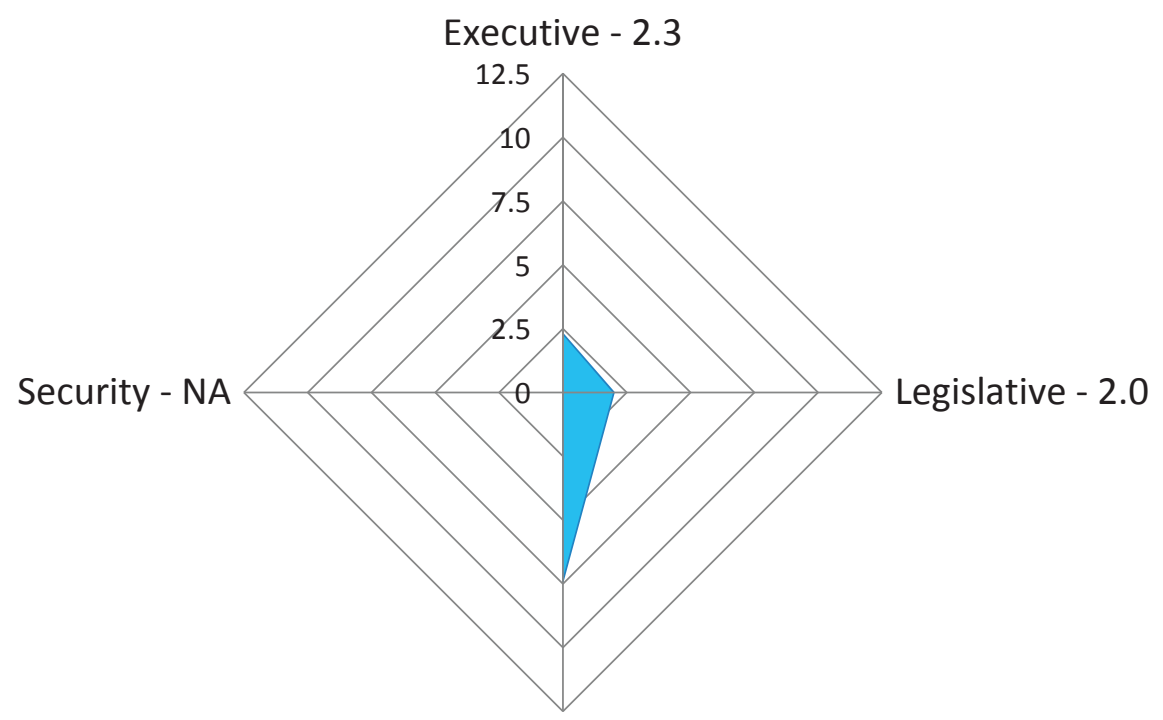

Judiciary -7.4 


\section{Iraq \\ Diamond Index Score = NA (3.6 Minus Security)}

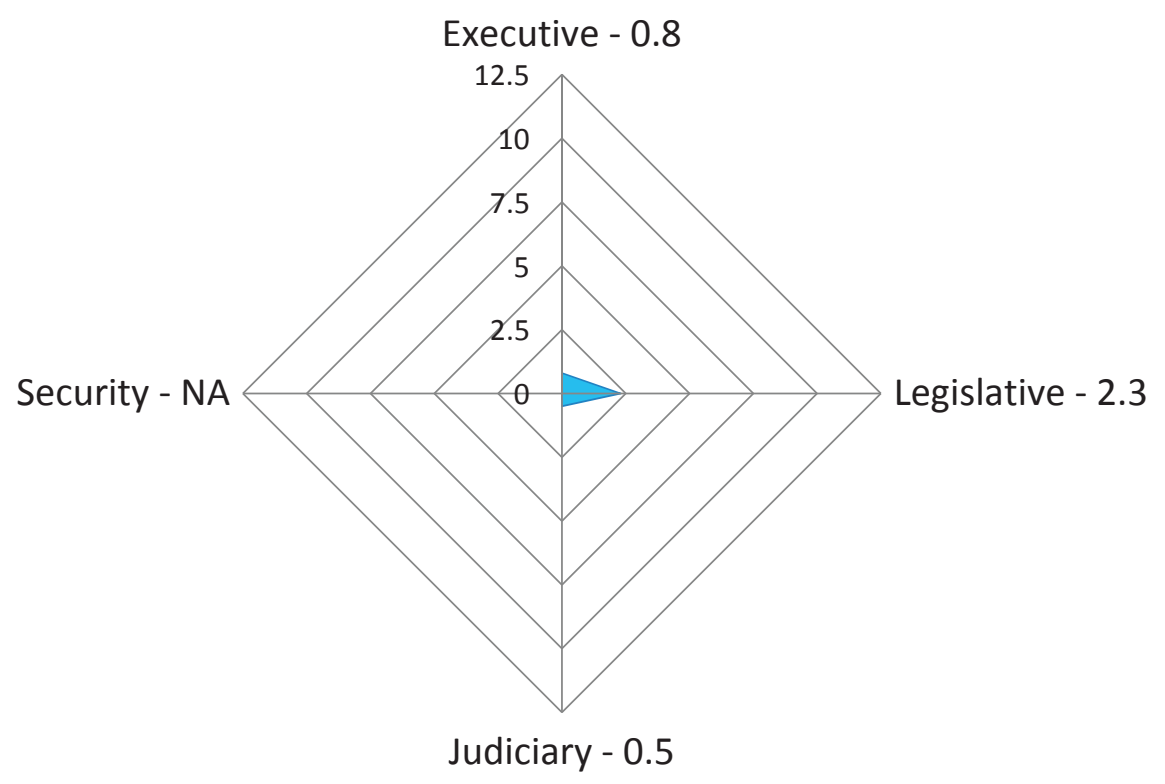




\section{Jordan \\ Diamond Index Score = NA (5.7 Minus Security)}

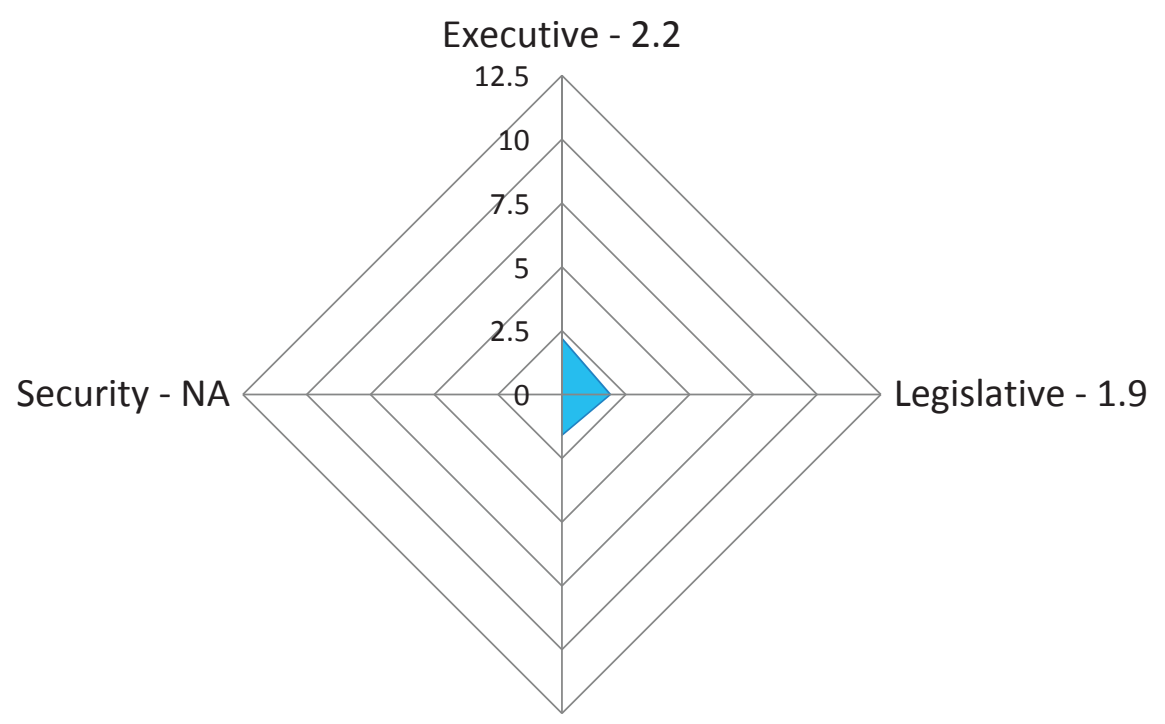

Judiciary - 1.6 


\section{Lebanon \\ Diamond Index Score = NA (3.6 Minus Security)}

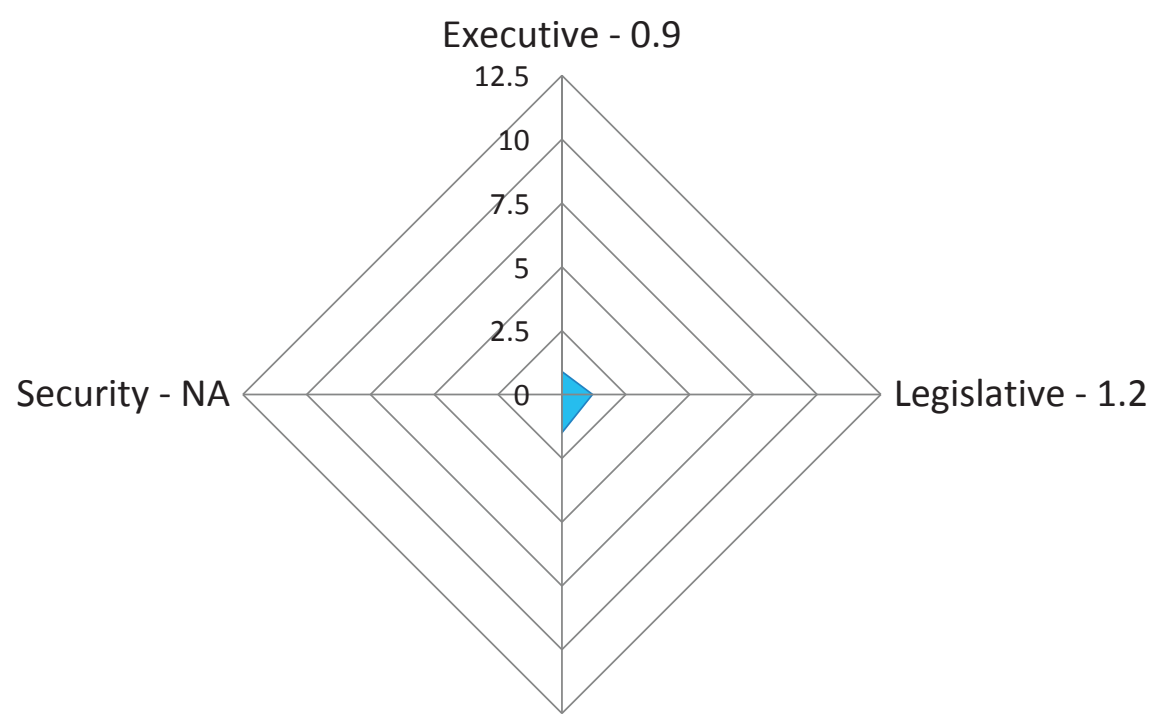

Judiciary - 1.5 


\section{Morocco \\ Diamond Index Score = NA (9.4 Minus Security)}

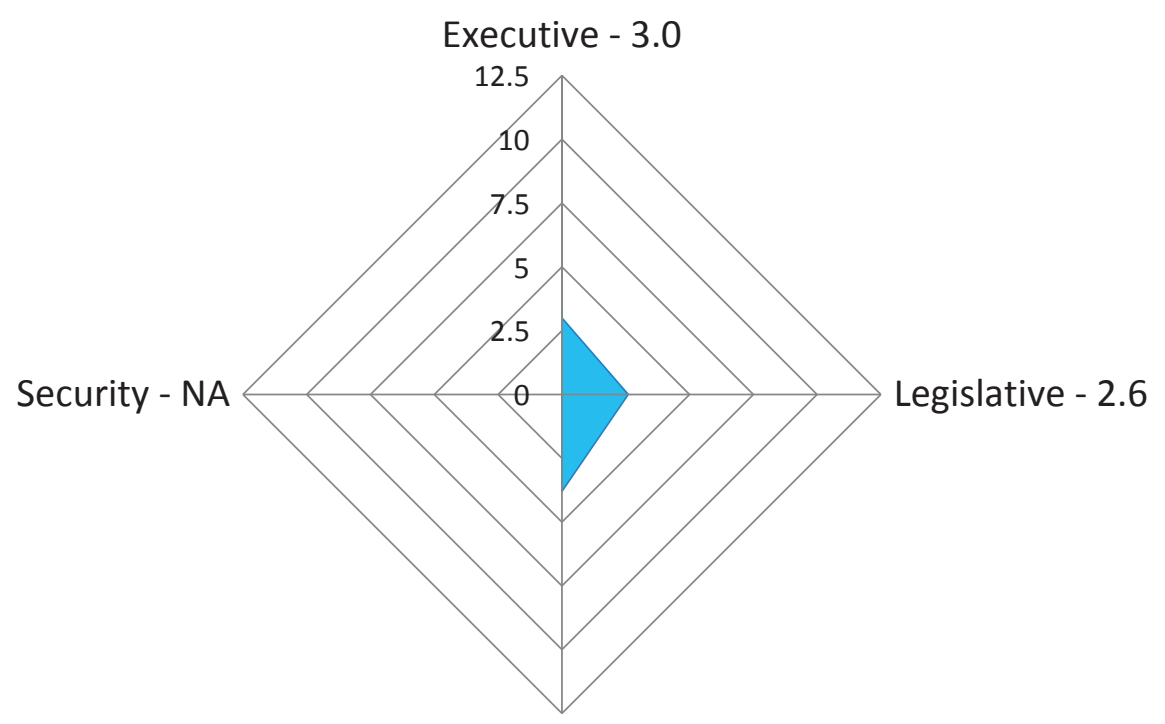

Judiciary - 3.8 


\section{Tunisia \\ Diamond Index Score $=$ NA}

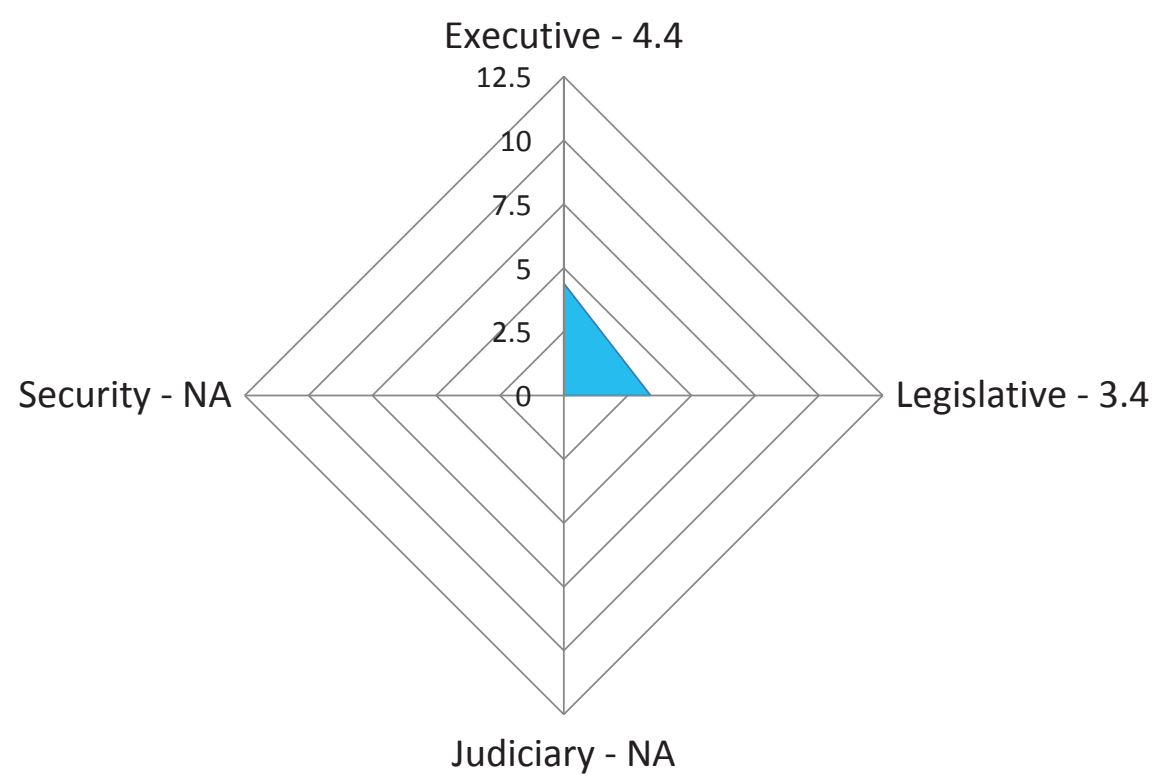




\section{Yemen \\ Diamond Index Score = NA (2.3 Minus Security)}

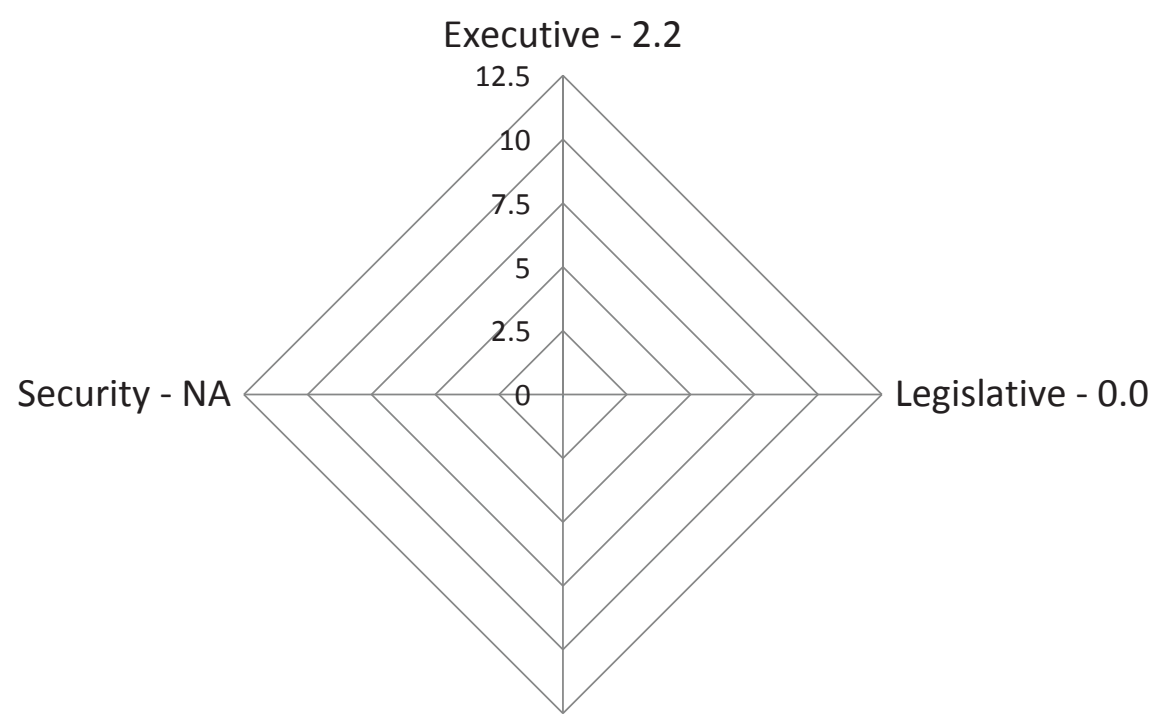

Judiciary - 0.1 


\section{Middle East/North Africa \\ Diamond Index Regional Average $=6.7$ (Minus Security)}

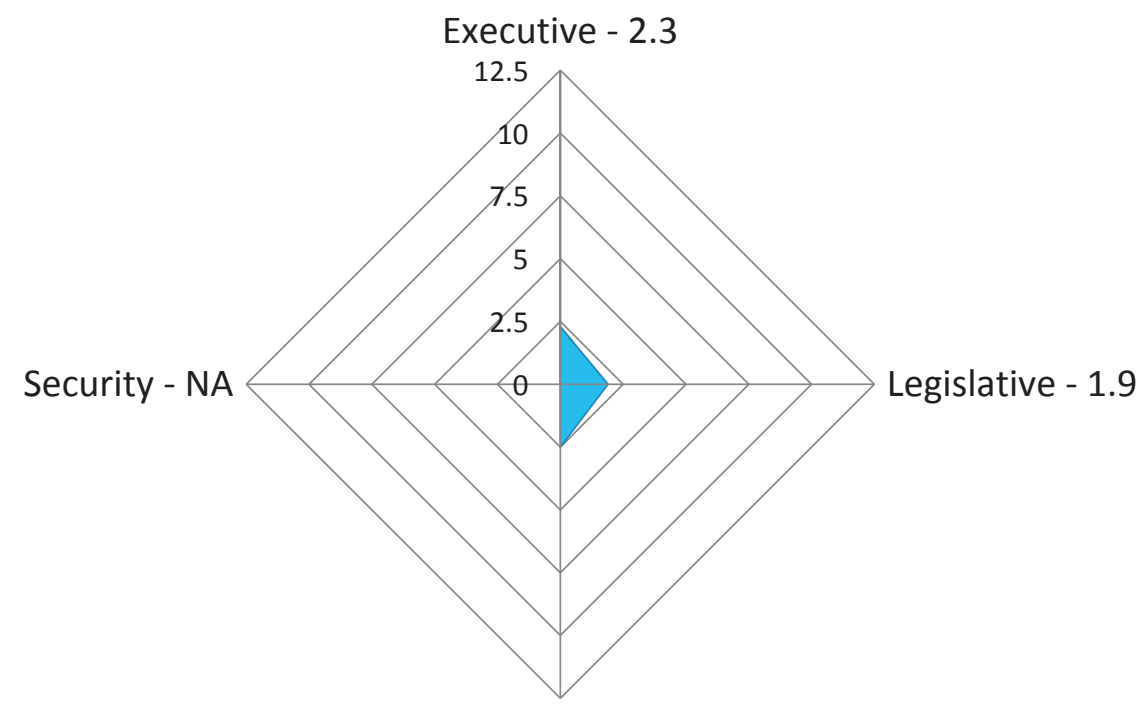

Judiciary - 2.5 


\section{Global Average Diamond Index Score = 13.6}

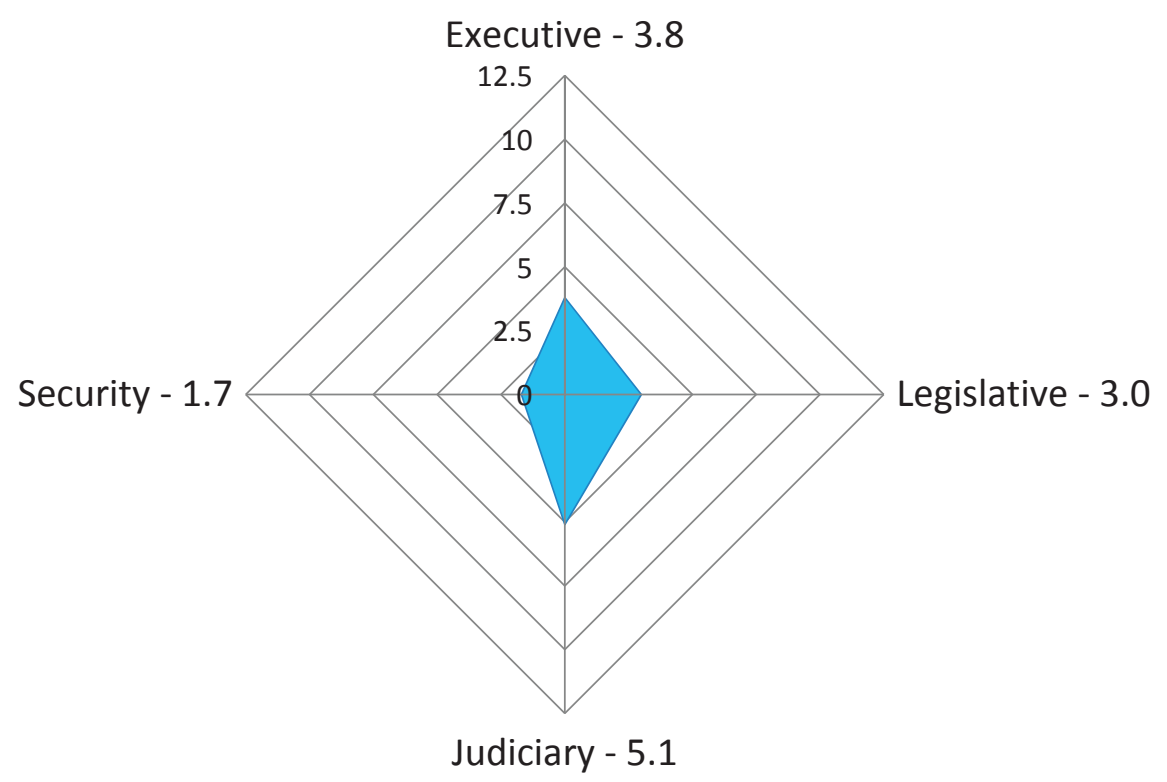





\section{Annex B}

DIAMOND INDEX SCORECARDS

Eastern Europe and Eurasia

Albania

Bosnia-Herzegovina

Georgia

Kyrgyzstan

Ukraine

Regional Average

Latin America and Caribbean

Brazil

Columbia

Guatemala

Haiti

Mexico

Regional Average

Asia

Bangladesh

Cambodia

India

Indonesia

Mongolia

Nepal

Philippines

Thailand

Timor-Leste

Regional Average
Africa

Benin

Burkina Faso

Cote d'Ivoire

Ghana

Kenya

Liberia

Madagascar

Mali

Mozambique

Niger

Nigeria

Rwanda

Senegal

South Africa

Regional Average

Middle East/North Africa

Algeria

Iraq

Jordan

Lebanon

Morocco

Tunisia

Yemen

Regional Average 


\section{ALBANIA $=18.5$}

Executive weighted score $=6.2$

\begin{tabular}{l|l|l} 
TIER 1 & Ministers & $30 \%$ women \\
\hline TIER 2 & Top Technocrats & $29 \%$ women \\
\hline TIER 3 & Mayors of 10 largest cities & $0.0 \%$ women \\
\hline
\end{tabular}

TOTAL: $(3 \times .30)+(2 \times .29)+(1 \times .000) \div 6=.246 \times 100=24.6 \div 4=6.2$

\section{Legislative weighted score 4.4}

\begin{tabular}{l|l|l}
\hline TIER 1 & Political Party Leaders & $0.0 \%$ women \\
\hline TIER 2 & Committee Chairs & $43.0 \%$ women \\
\hline TIER 3 & Legislators & $20.0 \%$ women
\end{tabular}

TOTAL: $(3 \times .0)+(2 \times .43)+(1 \times .2) \div 6=.176 \times 100=17.6 \div 4=4.4$

\begin{tabular}{l|l|l}
\hline Judicial weighted score $=\mathbf{5 . 9}$ & \\
\hline TIER 1 & Constitutional Court & $22.2 \%$ women \\
\hline TIER 2 & Supreme Court & $23.5 \%$ women \\
\hline TIER 3 & Appellate Court & $27.1 \%$ women
\end{tabular}

TOTAL: $(3 \times .222)+(2 \times .235)+(1 \times .271) \div 6=.235 \times 100=23.5 \div 4=5.9$

\begin{tabular}{l|l|l}
\multicolumn{2}{l|}{ Security weighted score $=\mathbf{2 . 0}$} & \\
\hline TIER 1 & Top-Level Officers & $7.0 \%$ women \\
\hline TIER 2 & Mid-Level Officers & $11.0 \%$ women \\
\hline TIER 3 & Lower-Level Officers & $6.0 \%$ women
\end{tabular}

TOTAL: $(3 \times .07)+(2 \times .11)+(1 \times .06) \div 6=.081 \times 100=8.1 \div 4=2.0$

\section{$6.2($ Executive $)+4.4($ Legislative $)+5.9($ Judicial $)+2.0($ Security $)=18.5$}


BOSNIA \& HERZEGOVINA $=\mathbf{1 7 . 8}$

\begin{tabular}{|c|c|c|}
\hline \multicolumn{3}{|c|}{ Executive weighted score $=2.6$} \\
\hline TIER 1 & Ministers & $6.7 \%$ women \\
\hline TIER 2 & Top Technocrats & $21.4 \%$ women \\
\hline TIER 3 & Mayors of 10 largest cities & $0.0 \%$ women \\
\hline
\end{tabular}

TOTAL: $(3 \times .067)+(2 \times .214)+(1 \times .0) \div 6=.105 \times 100=10.5 \div 4=2.6$

Legislative weighted score $=2.5$

\begin{tabular}{l|l|l}
\hline TIER 1 & Political Party Leaders & $0.0 \%$ women \\
\hline TIER 2 & Committee Chairs & $19.0 \%$ women \\
\hline TIER 3 & Legislators & $21.4 \%$ women
\end{tabular}

TOTAL: $(3 \times .0)+(2 \times .190)+(1 \times .214) \div 6=.099 \times 100=9.9 \div 4=2.5$

\begin{tabular}{l|l|l} 
Judicial weighted & score $=\mathbf{1 1 . 6}$ & \\
\hline TIER 1 & Constitutional Court & $44.4 \%$ women \\
\hline TIER 2 & Supreme Court & $46.2 \%$ women \\
\hline TIER 3 & Appellate Court & $51.5 \%$ women \\
\hline
\end{tabular}

TOTAL: $(3 \times .444)+(2 \times .462)+(1 \times .515) \div 6=.462 \times 100=46.2 \div 4=11.6$

Security weighted score $=\mathbf{1 . 1}$

\begin{tabular}{l|l|l}
\hline TIER 1 & Top-Level Officers & $0.0 \%$ women \\
\hline TIER 2 & Mid-Level Officers & $9.2 \%$ women \\
\hline TIER 3 & Lower-Level Officers & $8.0 \%$ women
\end{tabular}

TOTAL: $(3 \times .0)+(2 \times .092)+(1 \times .08) \div 6=.044 \times 100=4.4 \div 4=1.1$

$2.6($ Executive $)+2.5($ Legislative $)+11.6($ Judicial $)+1.1($ Security $)=17.8$ 


\section{GEORGIA $=17.4$}

\begin{tabular}{l|l|l}
\multicolumn{2}{l}{ Executive weighted score $=\mathbf{5 . 0}$} & \\
\hline TIER 1 & Ministers & $21.1 \%$ women \\
\hline TIER 2 & Top Technocrats & $23.0 \%$ women \\
\hline TIER 3 & Mayors of 10 largest cities & $10.0 \%$ women \\
\hline
\end{tabular}

TOTAL: $(3 \times .211)+(2 \times .230)+(1 \times .100) \div 6=.199 \times 100=19.9 \div 4=5.0$

Legislative weighted score $=2.5$

\begin{tabular}{l|l|l}
\hline TIER 1 & Political Party Leaders & $11.1 \%$ women \\
\hline TIER 2 & Committee Chairs & $6.7 \%$ women \\
\hline TIER 3 & Legislators & $12.0 \%$ women
\end{tabular}

TOTAL: $(3 \times .111)+(2 \times .067)+(1 \times .120) \div 6=.098 \times 100=9.8 \div 4=2.5$

\begin{tabular}{l|l|l}
\hline Judicial weighted & score $=\mathbf{8 . 4}$ & \\
\hline TIER 1 & Constitutional Court & $33.3 \%$ women \\
\hline TIER 2 & Supreme Court & $30.0 \%$ women \\
\hline TIER 3 & Appellate Court & $41.8 \%$ women
\end{tabular}

TOTAL: $(3 \times .333)+(2 \times .300)+(1 \times .418) \div 6=.336 \times 100=33.6 \div 4=8.4$

\begin{tabular}{l|l|l} 
Security weighted score $=\mathbf{1 . 5}$ & \\
\hline TIER 1 & Top-Level Officers & $4.1 \%$ women \\
\hline TIER 2 & Mid-Level Officers & $5.4 \%$ women \\
\hline TIER & Lower-Level Officers & $12.7 \%$ women
\end{tabular}

TOTAL: $(3 \times .041)+(2 \times .054)+(1 \times .127) \div 6=.597 \times 100=5.97 \div 4=1.5$

$5.0($ Executive $)+2.5($ Legislative $)+8.4($ Judicial $)+1.5($ Security $)=17.4$ 


\section{KYRGYZSTAN $=$ NA}

\begin{tabular}{l|l|l}
\multicolumn{2}{l}{ Executive weighted score $=\mathbf{3 . 0}$} & \\
\hline TIER 1 & Ministers & $15.8 \%$ women \\
\hline TIER 2 & Top Technocrats & $12.5 \%$ women \\
\hline TIER 3 & Mayors of 10 largest cities & $0.0 \%$ women
\end{tabular}

TOTAL: $(3 \times .158)+(2 \times .125)+(1 \times .000) \div 6=.121 \times 100=12.1 \div 4=3.0$

Legislative weighted score $=2.2$

\begin{tabular}{l|l|l} 
TIER 1 & Political Party Leaders & $0.0 \%$ women \\
\hline TIER 2 & Committee Chairs & $14.3 \%$ women \\
\hline TIER 3 & Legislators & $23.0 \%$ women
\end{tabular}

TOTAL: $(3 \times .000)+(2 \times .143)+(1 \times .230) \div 6=.086 \times 100=8.6 \div 4=2.2$

\begin{tabular}{l|l|l|}
\hline \multicolumn{2}{l}{ Judicial weighted score $=$ NA } & \\
\hline TIER 1 & Constitutional Court (9 judges) & NA\% women \\
\hline TIER 2 & Supreme Court (25 judges) & NA\% women \\
\hline TIER 3 & Higher Court of Arbitration & NA\% women \\
\hline
\end{tabular}

TOTAL: NA

Security weighted score $=$ NA

\begin{tabular}{|l|l|l|} 
TIER 1 & Top-Level Officers & NA\% women \\
\hline TIER 2 & Mid-Level Officers & NA\% women \\
\hline TIER 3 & Lower-Level Officers & NA\% women \\
\hline
\end{tabular}

TOTAL: NA

$3.0($ Executive $)+2.2($ Legislative $)+$ NA $($ Judicial $)+$ NA $($ Security $)=$ NA 


\section{UKRAINE = NA (10.8 Minus Security)}

\begin{tabular}{l|l|l}
\multicolumn{2}{l}{ Executive weighted score $=\mathbf{2 . 8}$} & \\
\hline TIER 1 & Ministers & $5.9 \%$ women \\
\hline TIER 2 & Top Technocrats (3 out of 15) & $20.0 \%$ women \\
\hline TIER 3 & Mayors of 10 largest cities & $10.0 \%$ women \\
\hline
\end{tabular}

TOTAL: $(3 \times .059)+(2 \times .200)+(1 \times .100) \div 6=.113 \times 100=11.3 \div 4=2.8$

Legislative weighted score $=3.0$

\begin{tabular}{l|l|l}
\hline TIER 1 & Political Party Leaders & $11.1 \%$ women \\
\hline TIER 2 & Committee Chairs & $22.2 \%$ women \\
\hline TIER 3 & Legislators & $11.8 \%$ women
\end{tabular}

TOTAL: $(3 \times .111)+(2 \times .138)+(1 \times .118) \div 6=.121 \times 100=12.1 \div 4=3.0$

\begin{tabular}{l|l|l}
\hline Judicial weighted & score $=\mathbf{5 . 0}$ & \\
\hline TIER 1 & Constitutional Court & $5.6 \%$ women \\
\hline TIER 2 & Supreme Court & $28.4 \%$ women \\
\hline TIER 3 & High Courts & $45.0 \%$ women
\end{tabular}

TOTAL: $(3 \times .056)+(2 \times .284)+(1 \times .450) \div 6=.198 \times 10019.8 \div 4=5.0$

\begin{tabular}{l|l|l|}
\multicolumn{2}{l}{ Security weighted score $=$ NA } & \\
\hline TIER 1 & Top-Level Officers & NA\% women \\
\hline TIER 2 & Mid-Level Officers & NA\% women \\
\hline TIER 3 & Lower-Level Officers & NA\% women \\
\hline
\end{tabular}

TOTAL: NA

$2.8($ Executive $)+3.0($ Legislative $)+5.0($ Judicial $)+$ NA $($ Security $)=$ NA 
Eastern Europe and Eurasia - Weighted Scores Averaged

\begin{tabular}{l|c|c|c|c} 
& EXECUTIVE & LEGISLATIVE & JUDICIAL & SECURITY \\
\hline Albania & 6.2 & 4.4 & 5.9 & 2.0 \\
\hline Bosnia-Herzegovina & 2.6 & 2.5 & 11.6 & 1.1 \\
\hline Georgia & 5.0 & 2.5 & 8.4 & 1.5 \\
\hline Kyrgyzstan & 3.0 & 2.2 & - & - \\
\hline Ukraine & 2.8 & 3.0 & 5.0 & $\mathbf{4 . 6}$
\end{tabular}


BRAZIL $=13.3$

Executive weighted score $=4.5$

\begin{tabular}{l|l|l} 
TIER 1 & Ministers & $25.6 \%$ women \\
\hline TIER 2 & Top Technocrats & $15.7 \%$ women \\
\hline TIER 3 & Mayors of 10 largest cities & $0.0 \%$ women \\
\hline
\end{tabular}

TOTAL: $(3 \times .256)+(2 \times .157)+(1 \times .000) \div 6=.180 \times 100=18.0 \div 4=4.5$

Legislative weighted score $=0.8$

\begin{tabular}{l|l|l} 
TIER 1 & Political Party Leaders & $0.0 \%$ women \\
\hline TIER 2 & Committee Chairs & $5.0 \%$ women \\
\hline TIER 3 & Legislators & $9.0 \%$ women \\
\hline
\end{tabular}

TOTAL: $(3 \times .0)+(2 \times .05)+(1 \times .090) \div 6=.032 \times 100=3.2 \div 4=0.8$

Judicial weighted score $=4.4$

\begin{tabular}{l|l|l} 
TIER 1 & Supreme Federal Court & $18.2 \%$ women \\
\hline TIER 2 & Superior Court & $16.1 \%$ women \\
\hline TIER 3 & Federal District Court & $18.6 \%$ women \\
\hline
\end{tabular}

TOTAL: $(3 \times .182)+(2 \times .161)+(1 \times .186) \div 6=.176 \times 100=17.6 \div 4=4.4$

Security weighted score $=3.6$

\begin{tabular}{l|l|l} 
TIER 1 & Top-Level Officers & $7.6 \%$ women \\
\hline TIER 2 & Mid-Level Officers & $23.7 \%$ women \\
\hline TIER 3 & Lower-Level Officers & $15.2 \%$ women \\
\hline
\end{tabular}

TOTAL: $(3 \times .076)+(2 \times .237)+(1 \times .152) \div 6=.142 \times 100=14.2 \div 4=3.6$

$4.5($ Executive $)+0.8($ Legislative $)+4.4($ Judicial $)+3.6($ Security $)=13.3$ 


\section{COLUMBIA = NA (15.9 Minus Security)}

\begin{tabular}{l|l|l}
\multicolumn{2}{l}{ Executive weighted score $=\mathbf{6 . 8}$} & \\
\hline TIER 1 & Ministers & $31.3 \%$ women \\
\hline TIER 2 & Top Technocrats & $30.0 \%$ women \\
\hline TIER 3 & Mayors of 10 largest cities & $10.0 \%$ women
\end{tabular}

TOTAL: $(3 \times .313)+(2 \times .300)+(1 \times .100) \div 6=.273 \times 100=27.3 \div 4=6.8$

Legislative weighted score $=4.3$

\begin{tabular}{l|l|l}
\hline TIER 1 & Political Party Leaders & $14.3 \%$ women \\
\hline TIER 2 & Committee Chairs & $20.0 \%$ women \\
\hline TIER 3 & Legislators & $19.9 \%$ women
\end{tabular}

Total: $(3 \times .143)+(2 \times .200)+(1 \times .199) \div 6=.171 \times 100=17.1 \div 4=4.3$

Judicial weighted score $=4.8$

\begin{tabular}{l|l|l}
\hline TIER 1 & Constitutional Court & $11.1 \%$ women \\
\hline TIER 2 & Supreme Court of Justice & $26.1 \%$ women \\
\hline TIER 3 & Appellate Court & $29.0 \%$ women
\end{tabular}

Total: $(3 \times .111)+(2 \times .261)+(1 \times .290) \div 6=.191 \times 100=19.1 \div 4=4.8$

\begin{tabular}{l|l|l|}
\multicolumn{2}{l}{ Security weighted score $=$ NA } & \\
\hline TIER 1 & Top-Level Officers & NA\% women \\
\hline TIER 2 & Mid-Level Officers & NA\% women \\
\hline TIER 3* & Lower-Level Officers & $7.0 \%$ women
\end{tabular}

TOTAL: NA

$6.8($ Executive $)+4.3($ Legislative $)+4.8($ Judicial $)+$ NA $($ Security $)=$ NA

* Tier 3 is the total percent of women in the police force 
GUATEMALA $=\mathbf{1 7 . 0}$

\begin{tabular}{l|l|l} 
Executive weighted score $=\mathbf{4 . 8}$ & \\
\hline TIER 1 & Ministers & $26.7 \%$ women \\
\hline TIER 2 & Top Technocrats & $17.4 \%$ women \\
\hline TIER 3 & Mayors of 10 largest cities & $0.0 \%$ women
\end{tabular}

TOTAL: $(3 \times .267)+(2 \times .174)+(1 \times .000) \div 6=.192 \times 100=19.2 \div 4=4.8$

Legislative weighted score $=4.0$

\begin{tabular}{l|l|l} 
TIER 1 & Political Party Leaders & $26.7 \%$ women \\
\hline TIER 2 & Committee Chairs & $6.0 \%$ women \\
\hline TIER 3 & Legislators & $13.3 \%$ women \\
\hline
\end{tabular}

TOTAL: $(3 \times .235)+(2 \times .06)+(1 \times .133) \div 6=.160 \times 100=16.0 \div 4=4.0$

Judicial weighted score $=6.4$

\begin{tabular}{l|l|l} 
TIER 1 & Constitutional Court & $30.0 \%$ women \\
\hline TIER 2 & Supreme Court & $15.4 \%$ women \\
\hline TIER 3 & Appellate Courts & $33.3 \%$ women \\
\hline
\end{tabular}

Total: $(3 \times .300)+(2 \times .154)+(1 \times .333) \div 6=.257 \times 100=25.7 \div 4=6.4$

Security weighted score $=\mathbf{1 . 8}$

\begin{tabular}{l|l|l}
\hline TIER 1 & Top-Level Officers & $5.9 \%$ women \\
\hline TIER 2 & Mid-Level Officers & $5.4 \%$ women \\
\hline TIER 3 & Lower-Level Officers & $13.5 \%$ women \\
\hline
\end{tabular}

TOTAL: $(3 \times .059)+(2 \times .054)+(1 \times .135) \div 6=.070 \times 100=7.0 \div 4=1.8$

$4.8($ Executive $)+4.0($ Legislative $)+6.4($ Judicial $)+1.8($ Security $)=17.0$ 


\section{HAITI $=6.9$}

Executive weighted score $=3.6$

\begin{tabular}{l|l|l} 
TIER 1 & Ministers & $20.0 \%$ women \\
\hline TIER 2 & Top Technocrats & $13.3 \%$ women \\
\hline TIER 3 & Mayors of 10 largest cities & $0.0 \%$ women \\
\hline
\end{tabular}

TOTAL: $(3 \times .200)+(2 \times .133)+(1 \times .000) \div 6=.144 \times 100=14.4 \div 4=3.6$

Legislative weighted score $=0.2$

\begin{tabular}{l|l|l} 
TIER 1 & Political Party Leaders & $0.0 \%$ women \\
\hline TIER 2 & Committee Chairs & $0.0 \%$ women \\
\hline TIER 3 & Legislators & $5.3 \%$ women \\
\hline
\end{tabular}

TOTAL: $(3 \times .000)+(2 \times .000)+(1 \times .053) \div 6=.009 \times 100=.9 \div 4=0.2$

Judicial weighted score $=2.9$

\begin{tabular}{l|l|l} 
TIER 1 & Supreme Court & $5.9 \%$ women \\
\hline TIER 2 & Courts of Appeal & $18.8 \%$ women \\
\hline TIER 3 & Courts of First Instance & $13.5 \%$ women
\end{tabular}

Total: $(3 \times .059)+(2 \times .188)+(1 \times .135) \div 6=.115 \times 100=11.5 \div 4=2.9$

Security weighted score $=0.2$

\begin{tabular}{l|l|l}
\hline TIER 1 & Top-Level Officers & $0.5 \%$ women \\
\hline TIER 2 & Mid-Level Officers & $0.9 \%$ women \\
\hline TIER 3 & Lower-Level Officers & $0.9 \%$ women \\
\hline
\end{tabular}

TOTAL: $(3 \times .005)+(2 \times .009)+(1 \times .009) \div 6=.007 \times 100=0.7 \div 4=0.2$

$3.6($ Executive $)+0.2($ Legislative $)+2.9($ Judicial $)+0.2($ Security $)=6.9$ 


\section{MEXICO $=13.9$}

\begin{tabular}{l|l|l}
\multicolumn{2}{l}{ Executive weighted score $=\mathbf{4 . 4}$} & \\
\hline TIER 1 & Ministers & $17.6 \%$ women \\
\hline TIER 2 & Top Technocrats & $16.3 \%$ women \\
\hline TIER 3 & Mayors of 10 largest cities & $20.0 \%$ women
\end{tabular}

TOTAL: $(3 \times .176)+(2 \times .163)+(1 \times .200) \div 6=.176 \times 100=17.6 \div 4=4.4$

Legislative weighted score $=3.5$

\begin{tabular}{l|l|l} 
TIER 1 & Political Party Leaders & $0.0 \%$ women \\
\hline TIER 2 & Committee Chairs & $23.2 \%$ women \\
\hline TIER 3 & Legislators & $38.0 \%$ women \\
\hline
\end{tabular}

TOTAL: $(3 \times .000)+(2 \times .232)+(1 \times .380) \div 6=.141 \times 100=14.1 \div 4=3.5$

Judicial weighted score $=4.5$

\begin{tabular}{l|l|l} 
TIER 1 & Supreme Court & $18.2 \%$ women \\
\hline TIER 2 & Federal Electoral Tribunal & $14.3 \%$ women \\
\hline TIER 3 & Superior Courts & $24.1 \%$ women \\
\hline
\end{tabular}

TOTAL: $(3 \times .182)+(2 \times .143)+(1 \times 241) \div 6=.179 \times 100=17.9 \div 4=4.5$

Security weighted score $=1.5$

\begin{tabular}{l|l|l}
\hline TIER 1 & Top-Level Officers & $5.6 \%$ women \\
\hline TIER 2 & Mid-Level Officers & $4.2 \%$ women \\
\hline TIER 3 & Lower-Level Officers & $10.4 \%$ women \\
\hline
\end{tabular}

TOTAL: $(3 \times .056)+(2 \times .042)+(1 \times .104) \div 6=.059 \times 100=5.9 \div 4=1.5$

$4.4($ Executive $)+3.5($ Legislative $)+4.5($ Judicial $)+1.5($ Security $)=13.9$ 


\begin{tabular}{l|c|c|c|c}
\hline \multicolumn{2}{|c}{ Latin America and the Caribbean - Weighted Scores Averaged } & \\
\hline & EXECUTIVE & LEGISLATIVE & JUDICIAL & SECURITY \\
\hline Brazil & 4.5 & 0.8 & 4.4 & 3.6 \\
\hline Columbia & 6.8 & 4.3 & 4.8 & - \\
\hline Guatemala & 4.8 & 4.0 & 6.4 & 1.8 \\
\hline Haiti & 3.6 & 0.2 & 2.9 & 0.2 \\
\hline Mexico & 4.4 & 3.5 & 4.5 & 1.5 \\
\hline TOTALS & $\mathbf{2 4 . 1}$ & $\mathbf{1 2 . 8}$ & $\mathbf{2 3 . 0}$ & $\mathbf{7 . 1}$ \\
\hline AVERAGE & $\mathbf{4 . 8}$ & $\mathbf{2 . 6}$ & $\mathbf{4 . 6}$ & $\mathbf{1 . 8}$
\end{tabular}




\section{BANGLADESH $=\mathbf{1 0 . 0}$}

\begin{tabular}{l|l|l} 
Executive weighted score $=\mathbf{1 . 7}$ & \multicolumn{2}{l}{} \\
\hline TIER 1 & Ministers & $6.7 \%$ women \\
\hline TIER 2 & Top Technocrats & $10.5 \%$ women \\
\hline TIER 3 & Mayors of 10 largest cities & $0.0 \%$ women
\end{tabular}

TOTAL: $(3 \times .067)+(2 \times .105)+(1 \times .000) \div 6=.069 \times 100=6.9 \div 4=1.7$

Legislative weighted score $=4.3$

\begin{tabular}{l|l|l} 
TIER 1 & Political Party Leaders & $20.0 \%$ women \\
\hline TIER 2 & Committee Chairs & $12.0 \%$ women \\
\hline TIER 3 & Legislators & $20.0 \%$ women
\end{tabular}

Total: $(3 \times .200)+(2 \times .120)+(1 \times .200) \div 6=.173 \times 100=17.3 \div 4=4.3$

Judicial weighted score $=2.7$

\begin{tabular}{l|l|l} 
TIER 1 & Constitutional Court & $13 \%$ women \\
\hline TIER 2 & Supreme Court & $7.0 \%$ women \\
\hline TIER 3 & Appellate Court & $11.0 \%$ women \\
\hline
\end{tabular}

Total: $(3 \times .130)+(2 \times .070)+(1 \times .110) \div 6=.107 \times 10.7=10.7 \div 4=2.7$

Security weighted score $=1.3$

\begin{tabular}{l|l|l}
\hline TIER 1 & Top-Level Officers & $4.0 \%$ women \\
\hline TIER 2 & Mid-Level Officers & $3.2 \%$ women \\
\hline TIER 3 & Lower-Level Officers & $12.5 \%$ women \\
\hline
\end{tabular}

TOTAL $(3 \times .040)+(2 \times .032)+(1 \times .125) \div 6=.052 \times 100=5.2 \div 4=1.3$

$1.7($ Executive $)+4.3($ Legislative $)+2.7($ Judicial $)+1.3($ Security $)=10.0$ 


\section{CAMBODIA = NA (10.2 Minus Security)}

\begin{tabular}{l|l|l} 
Executive weighted score $=\mathbf{2 . 2}$ & \\
\hline TIER 1 & Ministers & $4.7 \%$ women \\
\hline TIER 2 & Top Technocrats & $18.7 \%$ women \\
\hline TIER 3 & Mayors of 10 largest cities & $0.0 \%$ women
\end{tabular}

TOTAL: $(3 \times .047)+(2 \times .187)+(1 \times .000) \div 6=.086 \times 100=8.6 \div 4=2.2$

\begin{tabular}{l|l|l}
\multicolumn{2}{l}{ Legislative weighted score $=\mathbf{3 . 6}$} & \\
\hline TIER 1 & Political Party Leaders & $0.0 \%$ women \\
\hline TIER 2 & Committee Chairs & $33.3 \%$ women \\
\hline TIER 3 & Legislators & $20.0 \%$ women
\end{tabular}

TOTAL: $(3 \times .000)+(2 \times .333)+(1 \times .200) \div 6=.144 \times 100=14.4 \div 4=3.6$

\begin{tabular}{l|l|l} 
Judicial weighted score $=\mathbf{4 . 4}$ & \\
\hline TIER 1 & Constitutional Court & $22.2 \%$ women \\
\hline TIER 2 & Supreme Court & $13.3 \%$ women \\
\hline TIER 3 & Appellate Court & $11.1 \%$ women
\end{tabular}

TOTAL: $(3 \times .222)+(2 \times .133)+(1 \times .111) \div 6=.174 \times 100=17.4 \div 4=4.4$

\begin{tabular}{l|l|l|}
\multicolumn{2}{l}{ Security weighted score $=$ NA } & \\
\hline TIER 1 & Top-Level Officers & NA\% women \\
\hline TIER 2 & Mid-Level Officers & NA\% women \\
\hline TIER 3* & Lower-Level Officers & $4.9 \%$ women \\
\hline
\end{tabular}

TOTAL: NA

$2.2($ Executive $)+3.6($ Legislative $)+4.4($ Judicial $)+$ NA $($ Security $)=$ NA

* Tier 3 is the total percent of women in the police force 
INDIA $=\mathbf{1 1 . 6}$

Executive weighted score $=2.4$

\begin{tabular}{l|l|l} 
TIER 1 & Ministers & $9.3 \%$ women \\
\hline TIER 2 & Top Technocrats & $4.5 \%$ women \\
\hline TIER 3 & Mayors of 10 largest cities & $20.0 \%$ women \\
\hline
\end{tabular}

TOTAL: $(3 \times .093)+(2 \times .045)+(1 \times .200) \div 6=.095 \times 100=9.5 \div 4=2.4$

Legislative weighted score $=6.2$

\begin{tabular}{l|l|l} 
TIER 1 & Political Party Leaders & $33.3 \%$ women \\
\hline TIER 2 & Committee Chairs & $18.0 \%$ women \\
\hline TIER 3 & Legislators & $11.4 \%$ women \\
\hline
\end{tabular}

TOTAL: $(3 \times .333)+(2 \times .180)+(1 \times .114) \div 6=.246 \times 100=24.6 \div 4=6.2$

Judicial weighted score $=1.9^{*}$

\begin{tabular}{l|l|l} 
TIER 1 & Supreme Court & $7.7 \%$ women \\
\hline TIER 2 & High Court & $7.3 \%$ women \\
\hline TIER 3 & Trial Court & NA \% of women \\
\hline
\end{tabular}

TOTAL: $(3 \times .077)+(2 \times .073) \div 5=.075 \times 100=7.5 \div 4=1.9$

Security weighted score $=\mathbf{1 . 1}$

\begin{tabular}{l|l|l}
\hline TIER 1 & Top-Level Officers & $4.2 \%$ women \\
\hline TIER 2 & Mid-Level Officers & $3.7 \%$ women \\
\hline TIER 3 & Lower-Level Officers & $5.9 \%$ women \\
\hline
\end{tabular}

TOTAL: $(3 \times .042)+(2 \times .037)+(1 \times .059) \div 6=.043 \times 100=4.3 \div 4=1.1$

$2.4($ Executive $)+6.2($ Legislative $)+1.9^{*}($ Judicial $)+1.1($ Security $)=11.6$

${ }^{*}$ Weighted Tier $1+$ Tier 2 only 
INDONESIA $=10.5$

\begin{tabular}{l|l|l}
\multicolumn{2}{l}{ Executive weighted score $=\mathbf{3 . 1}$} & \\
\hline TIER 1 & Ministers & $11.8 \%$ women \\
\hline TIER 2 & Top Technocrats & $9.0 \%$ women \\
\hline TIER 3 & Mayors of 10 largest cities & $20.0 \%$ women
\end{tabular}

TOTAL: $(3 \times .118)+(2 \times .090)+(1 \times .200) \div 6=.122 \times 100=12.2 \div 4=3.1$

Legislative weighted score $=3.7$

\begin{tabular}{l|l|l} 
TIER 1 & Political Party Leaders & $11.0 \%$ women \\
\hline TIER 2 & Committee Chairs & $18.0 \%$ women \\
\hline TIER 3 & Legislators & $18.6 \%$ women \\
\hline
\end{tabular}

TOTAL: $(3 \times .110)+(2 \times .180)+(1 \times .186) \div 6=.146 \times 100=14.6 \div 4=3.7$

Judicial weighted score $=2.0$

\begin{tabular}{l|l|l}
\hline TIER 1 & Constitutional Court & $11.1 \%$ women \\
\hline TIER 2 & Supreme Court & $0.0 \%$ women \\
\hline TIER 3 & Appellate Court & $15.4 \%$ women \\
\hline
\end{tabular}

TOTAL: $(3 \times .111)+(2 \times .000)+(1 \times .154) \div 6=.812 \times 100=8.1 \div 4=2.0$

Security weighted score $=1.7$

\begin{tabular}{l|l|l}
\hline TIER 1 & Top-Level Officers & $4.6 \%$ women \\
\hline TIER 2 & Mid-Level Officers & $11.7 \%$ women \\
\hline TIER 3 & Lower-Level Officers & $3.3 \%$ women \\
\hline
\end{tabular}

TOTAL: $(3 \times .046)+(2 \times .117)+(1 \times .033) \div 6=.068 \times 100=6.8 \div 4=1.7$

$3.1($ Executive $)+3.7($ Legislative $)+2.0($ Judicial $)+1.7($ Security $)=10.5$ 


\section{MONGOLIA $=$ NA (16.4 Minus Security)}

\begin{tabular}{l|l|l}
\multicolumn{2}{l}{ Executive weighted score $=\mathbf{3 . 1}^{*}$} & \\
\hline TIER 1 & Ministers & $16.7 \%$ women \\
\hline TIER 2 & Top Technocrats & NA\% women \\
\hline TIER 3 & Mayors of 10 largest cities & $0.0 \%$ women \\
\hline
\end{tabular}

TOTAL: $(3 \times .167)+(2 \times$ NA $)+(1 \times .000) \div 4=.125 \times 100=12.5 \div 4=3.1$

\begin{tabular}{l|l|l}
\multicolumn{2}{l}{ Legislative weighted score $=\mathbf{3 . 6}$} & \multicolumn{2}{l}{} \\
\hline TIER 1 & Political Party Leaders & $20.0 \%$ women \\
\hline TIER 2 & Committee Chairs & $5.9 \%$ women \\
\hline TIER 3 & Legislators & $14.9 \%$ women
\end{tabular}

TOTAL: $(3 \times .200)+(2 \times .059)+(1 \times .149) \div 6=.145 \times 100=14.5 \div 4=3.6$

\begin{tabular}{l|l|l} 
Judiciary weighted score $=9.7$ & \\
\hline TIER 1 & Constitutional Court & $22.2 \%$ women \\
\hline TIER 2 & High Court & $48.0 \%$ women \\
\hline TIER 3 & Appellate Court & $69.0 \%$ women
\end{tabular}

TOTAL: $(3 \times .222)+(2 \times .480)+(1 \times .690) \div 6=.387 \times 100=38.6 \div 4=9.7$

\begin{tabular}{l|l|l}
\multicolumn{2}{l}{ Security weighted score $=$ NA } & \\
\hline TIER 1 & Top-Level Officers & NA\% women \\
\hline TIER 2 & Mid-Level Officers & NA\% women \\
\hline TIER 3 & Lower-Level Officers & NA\% women
\end{tabular}

TOTAL: NA

$3.1^{*}($ Executive $)+3.6($ Legislative $)+9.7($ Judiciary $)+$ NA $($ Security $)=$ NA

${ }^{*}$ Weighted Tier $1+$ Tier 3 


\section{$\mathrm{NEPAL}=7.1$}

Executive weighted score $=1.9$

\begin{tabular}{l|l|l} 
TIER 1 & Ministers & $15.0 \%$ women \\
\hline TIER 2 & Top Technocrats & $0.0 \%$ women \\
\hline TIER 3 & Mayors of 10 largest cities & $0.0 \%$ women \\
\hline
\end{tabular}

TOTAL: $(3 \times .150)+(2 \times .000)+(1 \times .000) \div 6=.075 \times 100=7.5 \div 4=1.9$

Legislative weighted score $=3.6$

\begin{tabular}{l|l|l} 
TIER 1 & Political Party Leaders & $3.3 \%$ women \\
\hline TIER 2 & Committee Chairs & $23.5 \%$ women \\
\hline TIER 3 & Legislators & $29.5 \%$ women \\
\hline
\end{tabular}

TOTAL: $(3 \times .033)+(2 \times .235)+(1 \times .295) \div 6=.144 \times 100=14.4 \div 4=3.6$

Judicial weighted score $=\mathbf{1 . 3}$

\begin{tabular}{l|l|l} 
TIER 1 & Supreme Court & $7.7 \%$ women \\
\hline TIER 2 & Appellate Court & $4.1 \%$ women \\
\hline TIER 3 & District Court & $0.0 \%$ women \\
\hline
\end{tabular}

TOTAL: $(3 \times .077)+(2 \times .041)+(1 \times .000) \div 6=.052 \times 100=5.2 \div 4=1.3$

Security weighted score $=0.3$

\begin{tabular}{l|l|l}
\hline TIER 1 & Top-Level Officers & $0.4 \%$ women \\
\hline TIER 2 & Mid-Level Officers & $0.3 \%$ women \\
\hline TIER 3 & Lower-Level Officers & $5.8 \%$ women \\
\hline
\end{tabular}

TOTAL: $(3 \times .004)+(2 \times .003)+(1 \times .058) \div 6=.013 \times 100=1.3 \div 4=0.3$

$1.9($ Executive $)+3.6($ Legislative $)+1.3($ Judicial $)+0.3($ Security $)=7.1$ 


\section{PHILIPPINES $=$ NA (17.6 Minus Security)}

\begin{tabular}{l|l|l}
\multicolumn{2}{l}{ Executive weighted score $=\mathbf{6 . 2}$} & \\
\hline TIER 1 & Ministers & $16.0 \%$ women \\
\hline TIER 2 & Top Technocrats & $40.7 \%$ women \\
\hline TIER 3 & Mayors of 10 largest cities & $20.0 \%$ women
\end{tabular}

TOTAL: $(3 \times .160)+(2 \times .407)+(1 \times .200) \div 6=.249 \times 100=24.9 \div 4=6.2$

Legislative weighted score $=5.1$

\begin{tabular}{l|l|l} 
TIER 1 & Political Party Leaders & $12.5 \%$ women \\
\hline TIER 2 & Committee Chairs & $28.6 \%$ women \\
\hline TIER 3 & Legislators & $27.0 \%$ women \\
\hline
\end{tabular}

TOTAL: $(3 \times .125)+(2 \times .286)+(1 \times .270) \div 6=.203 \times 100=20.3 \div 4=5.1$

\begin{tabular}{l|l|l}
\hline Judicial weighted score $=\mathbf{6 . 3}$ & \\
\hline TIER 1 & Supreme Court & $20.0 \%$ women \\
\hline TIER 2 & Court of Appeals & $34.8 \%$ women \\
\hline TIER 3 & Graft and Corruption Court & $21.4 \%$ women
\end{tabular}

TOTAL: $(3 \times .200)+(2 \times .348)+(1 \times .214) \div 6=.252 \times 100=25.2 \div 4=6.3$

\begin{tabular}{l|l|l|}
\multicolumn{2}{l}{ Security weighted score $=$ NA } & \\
\hline TIER 1 & Top-Level Officers & NA\% women \\
\hline TIER 2 & Mid-Level Officers & NA\% women \\
\hline TIER 3* & Lower-Level Officers & $7.7 \%$ women \\
\hline
\end{tabular}

TOTAL: NA

$$
6.2(\text { Executive })+5.1(\text { Legislative })+6.3(\text { Judicial })+\text { NA }(\text { Security })=\text { NA }
$$

* Tier 3 is the total percent of women in the police force 
THAILAND $=3.6$

\begin{tabular}{l|l|l}
\multicolumn{2}{l}{ Executive weighted score $=\mathbf{1 . 1}$} & \\
\hline TIER 1 & Ministers & $8.3 \%$ women \\
\hline TIER 2 & Top Technocrats & $0.0 \%$ women \\
\hline TIER 3 & Mayors of 10 largest cities & $0.0 \%$ women
\end{tabular}

TOTAL: $(3 \times .083)+(2 \times .000)+(1 \times .000) \div 6=.042 \times 100=4.2 \div 4=1.1$

Legislative weighted score $=0.7$

\begin{tabular}{l|l|l} 
TIER 1 & Political Party Leaders & $0.0 \%$ women \\
\hline TIER 2 & Committee Chairs & $0.0 \%$ women \\
\hline TIER 3 & Legislators & $15.8 \%$ women \\
\hline
\end{tabular}

TOTAL: $(3 \times .000)+(2 \times .000)+(1 \times .158) \div 6=.026 \times 100=2.6 \div 4=0.7$

Judicial weighted score $=\mathbf{1 . 4}$

\begin{tabular}{l|l|l} 
TIER 1 & Constitutional Court & $0.0 \%$ women \\
\hline TIER 2 & Supreme Court of Justice & $16.7 \%$ women \\
\hline TIER 3 & Supreme Administrative Court & $0.0 \%$ women \\
\hline
\end{tabular}

TOTAL: $(3 \times .000)+(2 \times .167)+(1 \times .000) \div 6=.056 \times 100=5.6 \div 4=1.4$

Security weighted score $=0.4$

\begin{tabular}{l|l|l}
\hline TIER 1 & Top-Level Officers & $0.0 \%$ women \\
\hline TIER 2 & Mid-Level Officers & $1.7 \%$ women \\
\hline TIER 3 & Lower-Level Officers & $5.8 \%$ women \\
\hline
\end{tabular}

TOTAL: $(3 \times .000)+(2 \times .017)+(1 \times .058) \div 6=.015 \times 100=1.5 \div 4=0.4$

$1.1($ Executive $)+0.7($ Legislative $)+1.4($ Judicial $)+0.4($ Security $)=3.6$ 


\section{TIMOR-LISTE $=\mathbf{1 7 . 7}$}

\begin{tabular}{l|l|l}
\multicolumn{2}{l}{ Executive weighted score $=\mathbf{3 . 0}$} & \\
\hline TIER 1 & Ministers & $11.8 \%$ women \\
\hline TIER 2 & Top Technocrats & $18.4 \%$ women \\
\hline TIER 3 & Mayors of 10 largest cities & $0.0 \%$ women \\
\hline
\end{tabular}

TOTAL: $(3 \times .118)+(2 \times .184)+(1 \times .000) \div 6=.120 \times 100=12.0 \div 4=3.00$

\begin{tabular}{l|l|l}
\multicolumn{2}{l}{ Legislative weighted score $=\mathbf{4 . 0}$} & \\
\hline TIER 1 & Political Party Leaders & $0.0 \%$ women \\
\hline TIER 2 & Committee Chairs & $28.6 \%$ women \\
\hline TIER 3 & Legislators & $38.5 \%$ women \\
\hline
\end{tabular}

TOTAL: $(3 \times .000)+(2 \times .286)+(1 \times .385) \div 6=.160 \times 100=16.0 \div 4=4.00$

\begin{tabular}{l|l|l}
\hline Judicial weighted score $=\mathbf{8 . 9}$ & \\
\hline TIER 1 & Court of Appeal & $33.3 \%$ women \\
\hline TIER 2 & District Courts & $38.7 \%$ women \\
\hline TIER 3* & (No third tier of formal court) & NA\% women
\end{tabular}

TOTAL: $(3 \times .333)+(2 \times .387)+(1 \times \mathrm{NA}) \div 5=.355 \times 100=35.5 \div 4=8.88$

\begin{tabular}{l|l|l} 
Security weighted score $=\mathbf{1 . 8}$ & \\
\hline TIER 1 & Top-Level Officers & $3.4 \%$ women \\
\hline TIER 2 & Mid-Level Officers & $9.5 \%$ women \\
\hline TIER 3 & Lower-Level Officers & $14.4 \%$ women \\
\hline
\end{tabular}

TOTAL: $(3 \times .034)+(2 \times .095)+(1 \times .144) \div 6=.073 \times 100=7.3 \div 4=1.83$

$$
3.0(\text { Executive })+4.0(\text { Legislative })+8.9^{*}(\text { Judicial })+1.8(\text { Security })=17.7
$$

*Weighted Tier $1+$ Tier 2 only as there is no formal third tier of courts in the country 


\begin{tabular}{l|c|c|c|c}
\hline Asia - Weighted Scores Averaged & EXECUTIVE & LEGISLATIVE & JUDICIARY & SECURITY \\
\hline Bangladesh & 1.7 & 4.3 & 2.7 & 1.3 \\
\hline Cambodia & 2.2 & 3.6 & 4.4 & - \\
\hline India & 2.4 & 6.2 & 1.9 & 1.1 \\
\hline Indonesia & 3.1 & 3.7 & 2.0 & 1.7 \\
\hline Mongolia & 3.1 & 3.6 & 9.7 & - \\
\hline Nepal & 1.9 & 3.6 & 1.3 & 0.3 \\
\hline Philippines & 6.2 & 5.1 & 6.3 & - \\
\hline Thailand & 1.1 & 0.7 & 1.4 & 0.4 \\
\hline Timor-Leste & 3.0 & 4.0 & 8.9 & 1.8 \\
\hline TOTALS & $\mathbf{2 4 . 7}$ & $\mathbf{3 4 . 8}$ & $\mathbf{3 8 . 6}$ & $\mathbf{6 . 6}$ \\
\hline AVERAGE & $\mathbf{2 . 7}$ & 3.9 & $\mathbf{4 . 3}$ & $\mathbf{1 . 1}$ \\
\hline
\end{tabular}




\section{BENIN = NA (13.9 Minus Security)}

\begin{tabular}{l|l|l}
\multicolumn{2}{l}{ Executive weighted score $=\mathbf{4 . 6}$} & \\
\hline TIER 1 & Ministers & $22.2 \%$ women \\
\hline TIER 2 & Top Technocrats & $22.0 \%$ women \\
\hline TIER 3 & Mayors of 10 largest cities & $0.0 \%$ women
\end{tabular}

TOTAL: $(3 \times .222)+(2 \times .220)+(1 \times .000) \div 6=.184 \times 100=18.4 \div 4=4.6$

Legislative weighted score $=2.1^{*}$

\begin{tabular}{l|l|l} 
TIER 1 & Political Party Leaders & $0.0 \%$ women \\
\hline TIER 2 & Committee Chairs & NA\% women \\
\hline TIER 3 & Legislators & $8.4 \%$ women \\
\hline
\end{tabular}

TOTAL: $(3 \times .000)+(2 \times$ NA $)+(1 \times .084) \div 4=.084 \times 100=8.4 \div 4=2.1$

Judiciary weighted score $=7.2$

\begin{tabular}{l|l|l}
\hline TIER 1 & Supreme Court & $28.6 \%$ women \\
\hline TIER 2 & Constitutional Court & $22.2 \%$ women \\
\hline TIER 3 & High Court & $42.9 \%$ women \\
\hline
\end{tabular}

TOTAL: $(3 \times .286)+(2 \times .222)+(1 \times .429) \div 6=.289 \times 100=28.9 \div 4=7.2$

\begin{tabular}{l|l|l|}
\multicolumn{2}{l}{ Security weighted score $=$ NA } & \\
\hline TIER 1 & Top-Level Officers & NA\% women \\
\hline TIER 2 & Mid-Level Officers & NA\% women \\
\hline TIER $3^{* *}$ & Lower-Level Officers & $6.5 \%$ women
\end{tabular}

TOTAL: NA

4.6 (Executive) $+2.1^{*}$ (Legislative) $+7.2($ Judiciary $)+$ NA $($ Security $)=$ NA

* Weighted score of Tier $1+$ Tier 3

** Tier 3 is the total percent of women in the police force 


\section{BURKINA FASO $=\mathbf{1 7 . 2}$}

\begin{tabular}{l|l|l}
\multicolumn{2}{l}{ Executive weighted score $=\mathbf{2 . 6}^{*}$} & \\
\hline TIER 1 & Ministers & $\mathbf{1 3 . 8 \% \text { women }}$ \\
\hline TIER 2 & Top Technocrats & NA\% women \\
\hline TIER 3 & Mayors of 10 largest cities & $0.0 \%$ women
\end{tabular}

TOTAL: $(3 \times .138)+(2 \times$ NA $)+(1 \times .000) \div 4=.104 \times 100=10.4 \div 4=2.6$

Legislative weighted score $=2.5$

\begin{tabular}{l|l|l}
\hline TIER 1 & Political Party Leaders & $0.0 \%$ women \\
\hline TIER 2 & Committee Chairs & $20.0 \%$ women \\
\hline TIER 3 & Legislators & $18.9 \%$ women
\end{tabular}

TOTAL: $(3 \times .000)+(2 \times .200)+(1 \times .189) \div 6=.098 \times 100=9.8 \div 4=2.5$

Judicial weighted score $=\mathbf{1 0 . 4}$

\begin{tabular}{l|l|l} 
TIER 1 & Supreme Court & $45.5 \%$ women \\
\hline TIER 2 & Constitutional Council & $42.9 \%$ women \\
\hline TIER 3 & Court of Appeals & $27.8 \%$ women \\
\hline
\end{tabular}

TOTAL: $(3 \times .455)+(2 \times .429)+(1 \times .278) \div 6=.417 \times 100=41.7 \div 4=10.4$

Security weighted score $=\mathbf{1 . 7}$

\begin{tabular}{l|l|l}
\hline TIER 1 & Top-Level Officers & $8.9 \%$ women \\
\hline TIER 2 & Mid-Level Officers & $3.8 \%$ women \\
\hline TIER 3 & Lower-Level Officers & $5.0 \%$ women \\
\hline
\end{tabular}

TOTAL: $(3 \times .089)+(2 \times .038)+(1 \times .050) \div 6=.066 \times 100=6.6 \div 4=1.7$

$2.6^{*}($ Executive $)+2.5($ Legislative $)+10.4($ Judicial $)+1.7($ Security $)=17.2$

* Weighted score of Tier $1+$ Tier 3 


\section{COTE D'IVOIRE $=\mathbf{1 5 . 3}$}

\begin{tabular}{l|l|l}
\multicolumn{2}{l}{ Executive weighted score $=\mathbf{3 . 1}$} & \\
\hline TIER 1 & Ministers & $15.6 \%$ women \\
\hline TIER 2 & Top Technocrats & $13.6 \%$ women \\
\hline TIER 3 & Mayors of 10 largest cities & $0.0 \%$ women
\end{tabular}

TOTAL: $(3 \times .156)+(2 \times .136)+(1 \times .000) \div 6=.123 \times 100=12.3 \div 4=3.1$

Legislative weighted score $=3.1$

\begin{tabular}{l|l|l} 
TIER 1 & Political Party Leaders & $0.0 \%$ women \\
\hline TIER 2 & Committee Chairs & $33.0 \%$ women \\
\hline TIER 3 & Legislators & $9.2 \%$ women \\
\hline
\end{tabular}

TOTAL: $(3 \times .000)+(2 \times .330)+(1 \times .092) \div 6=.125 \times 100=12.5 \div 4=3.1$

Judicial weighted score $=6.9$

\begin{tabular}{l|l|l} 
TIER 1 & Supreme Court & $28.6 \%$ women \\
\hline TIER 2 & Constitutional Court & $28.6 \%$ women \\
\hline TIER 3* & Court of Appeals & $23.4 \%$ women \\
\hline
\end{tabular}

TOTAL: $(3 \times .286)+(2 \times .286)+(1 \times .234) \div 6=.277 \times 100=27.7 \div 4=6.9$

Security weighted score $=\mathbf{2 . 2}$

\begin{tabular}{l|l|l}
\hline TIER 1 & Top-Level Officers & $6.0 \%$ women \\
\hline TIER 2 & Mid-Level Officers & $11.6 \%$ women \\
\hline TIER 3 & Lower-Level Officers & $11.1 \%$ women ** \\
\hline
\end{tabular}

TOTAL: $(3 \times .060)+(2 \times .116)+(1 \times .111) \div 6=.088 \times 100=8.8 \div 4=2.2$

$3.1($ Executive $)+3.1($ Legislative $)+6.9^{*}($ Judicial $)+2.2($ Security $)=15.3$

*Tier 3 is the total percent of women in the Judiciary 


\section{GHANA = NA (15.4 Minus Security)}

\begin{tabular}{l|l|l} 
Executive weighted score $=\mathbf{5 . 5}$ & \multicolumn{2}{l}{} \\
\hline TIER 1 & Ministers & $22.5 \%$ women \\
\hline TIER 2 & Top Technocrats & $22.0 \%$ women \\
\hline TIER 3 & Mayors of 5 largest cities* & $20.0 \%$ women
\end{tabular}

TOTAL: $(3 \times .225)+(2 \times .220)+(1 \times .200) \div 6=.219 \times 100=21.9 \div 4=5.5$

Legislative weighted score $=\mathbf{2 . 1}$

\begin{tabular}{l|l|l} 
TIER 1 & Political Party Leaders & $8.7 \%$ women \\
\hline TIER 2 & Committee Chairs & $6.7 \%$ women \\
\hline TIER 3 & Legislators & $10.9 \%$ women
\end{tabular}

TOTAL: $(3 \times .087)+(2 \times .067)+(1 \times .109) \div 6=.084 \times 100=8.4 \div 4=2.1$

Judicial weighted score $=7.8$

\begin{tabular}{l|l|l} 
TIER 1 & Supreme Court & $33.3 \%$ women \\
\hline TIER 2 & Court of Appeal & $32.0 \%$ women \\
\hline TIER 3 & High Court & $25.0 \%$ women \\
\hline
\end{tabular}

TOTAL: $(3 \times .333)+(2 \times .320)+(1 \times .250) \div 6=.312 \times 100=31.2 \div 4=7.8$

\begin{tabular}{|c|c|c|}
\hline TIER 1 & Top-Level Officers & NA $\%$ women \\
\hline TIER 2 & Mid-Level Officers & NA $\%$ women \\
\hline TIER $3^{*}$ & Lower-Level Officers & $13.8 \%$ women \\
\hline
\end{tabular}

\section{TOTAL: NA}

$$
5.5^{*}(\text { Executive })+2.1(\text { Legislative })+7.8(\text { Judicial })+\text { NA }(\text { Security })=\text { NA }
$$

*Data available for top five cities only

** Tier 3 is the total percent of women in the police force 


\section{KENYA $=\mathbf{2 0 . 5}$}

\begin{tabular}{l|l|l}
\multicolumn{2}{l}{ Executive weighted score $=\mathbf{6 . 4}$} & \\
\hline TIER 1 & Ministers & $33.3 \%$ women \\
\hline TIER 2 & Top Technocrats & $26.9 \%$ women \\
\hline TIER 3 & Mayors of 10 largest cities & $0.0 \%$ women
\end{tabular}

TOTAL: $(3 \times .333)+(2 \times .269)+(1 \times .000) \div 6=.256 \times 100=25.6 \div 4=6.4$

Legislative weighted score $=4.1$

\begin{tabular}{l|l|l} 
TIER 1 & Political Party Leaders & $9.1 \%$ women \\
\hline TIER 2 & Committee Chairs & $25.9 \%$ women \\
\hline TIER 3 & Legislators & $19.7 \%$ women
\end{tabular}

TOTAL: $(3 \times .091)+(2 \times .259)+(1 \times .197) \div 6=.165 \times 100=16.5 \div 4=4.1$

Judicial weighted score $=8.0$

\begin{tabular}{l|l|l} 
TIER 1 & Supreme Court & $28.6 \%$ women \\
\hline TIER 2 & Court of Appeal & $30.8 \%$ women \\
\hline TIER 3 & High Court & $43.5 \%$ women \\
\hline
\end{tabular}

TOTAL: $(3 \times .286)+(2 \times .308)+(1 \times .435) \div 6=.318 \times 100=31.8 \div 4=8.0$

Security weighted score $=\mathbf{2} .0$

\begin{tabular}{l|l|l} 
TIER 1 & Top-Level Officers & $6.5 \%$ women \\
\hline TIER 2 & Mid-Level Officers & $8.5 \%$ women \\
\hline TIER 3 & Lower-Level Officers & $11.7 \%$ women \\
\hline
\end{tabular}

TOTAL: $(3 \times .065)+(2 \times .085)+(1 \times .117) \div 6=.080 \times 100=8.0 \div 4=2.00$

$6.4($ Executive $)+4.1($ Legislative $)+8.0($ Judicial $)+2.0($ Security $)=20.5$ 


\section{LIBERIA = NA (16.3 Minus Security)}

\begin{tabular}{l|l|l}
\multicolumn{2}{l}{ Executive weighted score $=\mathbf{8 . 4}$} & \\
\hline TIER 1 & Ministers & $21.1 \%$ women \\
\hline TIER 2 & Top Technocrats & $29.0 \%$ women \\
\hline TIER 3 & Mayors & $80.0 \%$ women
\end{tabular}

TOTAL: $(3 \times .211)+(2 \times .290)+(1 \times .800) \div 6=.336 \times 100=33.6 \div 4=8.4$

Legislative weighted score $=1.5$

\begin{tabular}{l|l|l} 
TIER 1 & Political Party Leaders & $0.0 \%$ women \\
\hline TIER 2 & Committee Chairs & $12.0 \%$ women \\
\hline TIER 3 & Legislators & $11.0 \%$ women
\end{tabular}

TOTAL: $(3 \times .000)+(2 \times .120)+(1 \times .110) \div 6=.058 \times 100=5.8 \div 4=1.5$

Judiciary weighted score $=6.4$

\begin{tabular}{l|l|l} 
TIER 1 & Supreme Court & $40.0 \%$ women \\
\hline TIER 2 & Circuit Courts & $14.3 \%$ women \\
\hline TIER 3 & Specialized Courts & $5.3 \%$ women \\
\hline
\end{tabular}

TOTAL: $(3 \times .400)+(2 \times .143)+(1 \times .053) \div 6=.257 \times 100=25.7 \div 4=6.4$

Security weighted score $=$ NA

\begin{tabular}{|l|l|l|}
\hline TIER 1 & Top-Level Officers & $4.3 \%$ women \\
\hline TIER 2 & Mid-Level Officers & NA\% women \\
\hline TIER 3 & Lower-Level Officers & NA\% women \\
\hline
\end{tabular}

TOTAL: NA

8.4 (Executive $)+1.5$ (Legislative) $+6.4($ Judiciary $)+$ NA $($ Security Sector $)=$ NA 


\section{MADAGASCAR = NA (14.8 Minus Security)}

\begin{tabular}{l|l|l}
\multicolumn{2}{l}{ Executive weighted score $=\mathbf{4 . 3}$} & \\
\hline TIER 1 & Ministers & $19.4 \%$ women \\
\hline TIER 2 & Top Technocrats & $17.9 \%$ women \\
\hline TIER 3 & Mayors of 10 largest cities & $10.0 \%$ women \\
\hline
\end{tabular}

TOTAL: $(3 \times .194)+(2 \times .179)+(1 \times .100) \div 6=.173 \times 100=17.3 \div 4=4.3$

\begin{tabular}{l|l|l}
\multicolumn{2}{l}{ Legislative weighted score $=\mathbf{4 . 6}$} & \\
\hline TIER 1 & Political Party Leaders & $8.3 \%$ women \\
\hline TIER 2 & Committee Chairs & $32.3 \%$ women \\
\hline TIER 3 & Legislators & $20.5 \%$ women
\end{tabular}

TOTAL: $(3 \times .083)+(2 \times .323)+(1 \times .205) \div 6=.183 \times 100=18.3 \div 4=4.6$

\begin{tabular}{l|l|l}
\hline Judicial weighted score $=\mathbf{5 . 9 ^ { * }}$ & \\
\hline TIER 1 & Constitutional High Court & $33.3 \%$ women \\
\hline TIER 2 & Supreme Court & $9.1 \%$ women \\
\hline TIER 3 & Courts of Appeal & NA\% women \\
\hline
\end{tabular}

TOTAL: $(3 \times .333)+(2 \times .091)+(1 \times$. NA $) \div 5=.236 \times 100=23.6 \div 4=5.9$

\begin{tabular}{l|l|l|}
\multicolumn{2}{l}{ Security weighted score $=$ NA } & \\
\hline TIER 1 & Top-Level Officers & NA\% women \\
\hline TIER 2 & Mid-Level Officers & NA\% women \\
\hline TIER 3* & Lower-Level Officers & $12.0 \%$ women \\
\hline
\end{tabular}

TOTAL: NA

$4.3($ Executive $)+4.6($ Legislative $)+5.9^{*}($ Judicial $)+$ NA $($ Security $)=$ NA

* Weighted Tier $1+$ Tier 2

** Tier 3 is the total percent of women in the police force 
MALI $=\mathbf{1 2 . 7}$

Executive weighted score $=3.1$

\begin{tabular}{l|l|l} 
TIER 1 & Ministers & $16.1 \%$ women \\
\hline TIER 2* & Top Technocrats & $13.3 \%$ women \\
\hline TIER 3 & Mayors of 10 largest cities & $0.0 \%$ women \\
\hline
\end{tabular}

TOTAL: $(3 \times .161)+(2 \times .133)+(1 \times .000) \div 6=.125 \times 100=12.5 \div 4=3.1$

Legislative weighted score $=2.5$

\begin{tabular}{l|l|l} 
TIER 1 & Political Party Leaders & $0.0 \%$ women \\
\hline TIER 2 & Committee Chairs & $25.0 \%$ women \\
\hline TIER 3 & Legislators & $9.5 \%$ women \\
\hline
\end{tabular}

TOTAL: $(3 \times .000)+(2 \times .250)+(1 \times .095) \div 6=.099 \times 100=9.9 \div 4=2.5$

Judicial weighted score $=6.6$

\begin{tabular}{l|l|l} 
TIER 1 & Supreme Court & $17.1 \%$ women \\
\hline TIER 2 & Constitutional Court & $50.0 \%$ women \\
\hline TIER 3 & Appellate Courts & $7.5 \%$ women \\
\hline
\end{tabular}

TOTAL: $(3 \times .171)+(2 \times .500)+(1 \times .075) \div 6=.265 \times 100=26.5 \div 4=6.6$

Security weighted score $=\mathbf{1 . 1}$

\begin{tabular}{l|l|l}
\hline TIER 1 & Top-Level Officers & $0.2 \%$ women \\
\hline TIER 2 & Mid-Level Officers & $8.2 \%$ women \\
\hline TIER 3 & Lower-Level Officers & $9.7 \%$ women \\
\hline
\end{tabular}

TOTAL: $(3 \times .002)+(2 \times .082)+(1 \times .097) \div 6=.045 \times 100=4.5 \div 4=1.1$

$3.1^{*}($ Executive $)+2.5($ Legislative $)+6.6($ Judicial $)+1.1($ Security $)=12.7$

*Tier 2 is the percent of women working in ministries that are not ministers 


\section{MOZAMBIQUE $=$ NA (14.3 Minus Security)}

\begin{tabular}{l|l|l}
\multicolumn{2}{l}{ Executive weighted score $=\mathbf{5 . 2}$} & \\
\hline TIER 1 & Ministers & $28.6 \%$ women \\
\hline TIER 2 & Top Technocrats (see notes below) & $19.2 \%$ women \\
\hline TIER 3 & Mayors of 10 largest cities & $0.0 \%$ women \\
\hline
\end{tabular}

TOTAL: $(3 \times .286)+(2 \times .192)+(1 \times .000) \div 6=.207 \times 100=20.7 \div 4=5.2$

Legislative weighted score $=4.7$

\begin{tabular}{l|l|l} 
TIER 1 & Political Party Leaders & $0.0 \%$ women \\
\hline TIER 2 & Committee Chairs & $36.4 \%$ women \\
\hline TIER 3 & Legislators & $39.6 \%$ women \\
\hline
\end{tabular}

TOTAL: $(3 \times .000)+(2 \times .364)+(1 \times .396) \div 6=.187 \times 100=18.7 \div 4=4.7$

Judicial weighted score $=4.4^{*}$

\begin{tabular}{l|l|l} 
TIER 1 & Constitutional Council & $16.7 \%$ women \\
\hline TIER 2 & Supreme Court & $18.8 \%$ women \\
\hline TIER 3 & Provincial Courts & NA women \\
\hline
\end{tabular}

TOTAL: $(3 \times .167)+(2 \times .188)+(1 \times$. NA $) \div 5=.175 \times 100=17.5 \div 4=4.4$

\begin{tabular}{l|l|l}
\multicolumn{2}{l}{ Security weighted score $=$ NA } & \\
\hline TIER 1 & Top-Level Officers & NA\% women \\
\hline TIER 2 & Mid-Level Officers & NA\% women \\
\hline TIER 3 & Lower-Level Officers & $10.0 \%$ women \\
\hline
\end{tabular}

TOTAL: NA

$5.2($ Executive $)+4.7($ Legislative $)+4.4^{*}($ Judicial $)+\mathrm{NA}($ Security $)=\mathrm{NA}$

${ }^{*}$ Weighted score of Tier $1+$ Tier 2

** Tier 3 is the total percent of women in the police force 


\section{NIGER $=$ NA}

\begin{tabular}{l|l|l|}
\multicolumn{2}{|l}{ Executive weighted score $=$ NA } & \\
\hline TIER 1 & Ministers & $22.2 \%$ women \\
\hline TIER 2 & Top Technocrats & NA\% women \\
\hline TIER 3 & Mayors of 10 largest cities & NA\% women \\
\hline
\end{tabular}

TOTAL: NA

Legislative weighted score $=3.6$

\begin{tabular}{l|l|l} 
TIER 1 & Political Party Leaders & $0.0 \%$ women \\
\hline TIER 2 & Committee Chairs & $36.4 \%$ women \\
\hline TIER 3 & Legislators & $13.3 \%$ women
\end{tabular}

TOTAL: $(3 \times .000)+(2 \times .364)+(1 \times .133) \div 6=.144 \times 100=14.4 \div 4=3.6$

Judicial weighted score $=$ NA

\begin{tabular}{|l|l|l|}
\hline TIER 1 & Constitutional Council & $14.3 \%$ women \\
\hline TIER 2 & High Court of Justice & NA\% women \\
\hline TIER 3 & Court of Cassation & NA\% women \\
\hline
\end{tabular}

TOTAL: NA

Security weighted score $=0.9$

\begin{tabular}{l|l|l} 
TIER 1 & Top-Level Officers & $5.0 \%$ women \\
\hline TIER 2 & Mid-Level Officers & $0.8 \%$ women \\
\hline TIER 3 & Lower-Level Officers & $3.7 \%$ women \\
\hline
\end{tabular}

TOTAL: $(3 \times .050)+(2 \times .008)+(1 \times .037) \div 6=.034 \times 100=3.4 \div 4=0.9$

NA $($ Executive $)+3.6($ Legislative $)+\mathrm{NA}($ Judicial $)+0.9($ Security $)=\mathrm{NA}$ 
NIGERIA $=14.9$

\begin{tabular}{l|l|l}
\multicolumn{2}{l}{ Executive weighted score $=\mathbf{5 . 0}$} & \multicolumn{2}{l}{} \\
\hline TIER 1 & Ministers & $25.0 \%$ women \\
\hline TIER 2 & Top Technocrats & $22.6 \%$ women \\
\hline TIER 3 & Mayors of 10 largest cities & $0.0 \%$ women
\end{tabular}

TOTAL: $(3 \times .250)+(2 \times .226)+(1 \times .000) \div 6=.200 \times 100=20.0 \div 4=5.0$

Legislative weighted score $=1.7$

\begin{tabular}{l|l|l} 
TIER 1 & Political Party Leaders & $3.7 \%$ women \\
\hline TIER 2 & Committee Chairs & $11.1 \%$ women \\
\hline TIER 3 & Legislators & $6.7 \%$ women \\
\hline
\end{tabular}

TOTAL: $(3 \times .037)+(2 \times .111)+(1 \times .067) \div 6=.067 \times 100=6.7 \div 4=1.7$

Judicial weighted score $=6.7$

\begin{tabular}{l|l|l} 
TIER 1 & Supreme Court & $25.0 \%$ women \\
\hline TIER 2 & Court of Appeals & $26.1 \%$ women \\
\hline TIER 3 & Federal High Courts & $33.9 \%$ women \\
\hline
\end{tabular}

TOTAL: $(3 \times .250)+(2 \times .261)+(1 \times .339) \div 6=.269 \times 100=26.9 \div 4=6.7$

Security weighted score $=1.5$

\begin{tabular}{l|l|l}
\hline TIER 1 & Top-Level Officers & $4.0 \%$ women \\
\hline TIER 2 & Mid-Level Officers & $5.0 \%$ women \\
\hline TIER 3 & Lower-Level Officers & $12.9 \%$ women \\
\hline
\end{tabular}

TOTAL: $(3 \times .040)+(2 \times .050)+(1 \times .129) \div 6=.058 \times 100=5.8 \div 4=1.5$

$5.0($ Executive $)+1.7($ Legislative $)+6.7($ Judicial $)+1.5($ Security $)=14.9$ 
RWANDA $=27.9$

Executive weighted score $=9.5$

\begin{tabular}{l|l|l} 
TIER 1 & Ministers & $40.0 \%$ women \\
\hline TIER 2 & Top Technocrats & $47.4 \%$ women \\
\hline TIER 3 & Mayors of 10 largest cities & $10.0 \%$ women \\
\hline
\end{tabular}

TOTAL: $(3 \times .400)+(2 \times .474)+(1 \times .100) \div 6=. \times 100=38.1 \div 4=9.5$

Legislative weighted score $=7.8$

\begin{tabular}{l|l|l} 
TIER 1 & Political Party Leaders & $14.3 \%$ women \\
\hline TIER 2 & Committee Chairs & $40.0 \%$ women \\
\hline TIER 3 & Legislators & $63.8 \%$ women
\end{tabular}

TOTAL: $(3 \times .143)+(2 \times .400)+(1 \times .638) \div 6=.311 \times 100=31.1 \div 4=7.8$

Judicial weighted score $=9.2$

\begin{tabular}{l|l|l} 
TIER 1 & Supreme Court & $43.8 \%$ women \\
\hline TIER 2 & High Courts & $25.0 \%$ women \\
\hline TIER 3 & Intermediate Courts & $39.4 \%$ women \\
\hline
\end{tabular}

TOTAL: $(3 \times .438)+(2 \times .250)+(1 \times .394) \div 6=.368 \times 100=36.8 \div 4=9.2$

Security weighted score $=\mathbf{1 . 4}$

\begin{tabular}{l|l|l}
\hline TIER 1 & Top-Level Officers & $8.0 \%$ women \\
\hline TIER 2 & Mid-Level Officers & $0.6 \%$ women \\
\hline TIER 3 & Lower-Level Officers & $8.7 \%$ women \\
\hline
\end{tabular}

TOTAL: $(3 \times .080)+(2 \times .006)+(1 \times .087) \div 6=.057 \times 100=5.7 \div 4=1.4$

$9.5($ Executive $)+7.8($ Legislative $)+9.2($ Judicial $)+1.4($ Security $)=27.9$ 


\section{SENEGAL $=$ NA (9.6 Minus Security)}

\begin{tabular}{l|l|l}
\multicolumn{2}{l}{ Executive weighted score $=\mathbf{3 . 0}$} & \\
\hline TIER 1 & Ministers & $16.1 \%$ women \\
\hline TIER 2 & Top Technocrats & NA\% women \\
\hline TIER 3 & Mayors of 10 largest cities & $0.0 \%$ women \\
\hline
\end{tabular}

TOTAL: $(3 \times .161)+(2 \times$ NA $)+(1 \times .000) \div 4=.121 \times 100=12.1 \div 4=3.0$

Legislative weighted score $=\mathbf{5 . 6}$

\begin{tabular}{l|l|l} 
TIER 1 & Political Party Leaders & $0.0 \%$ women \\
\hline TIER 2 & Committee Chairs & $45.5 \%$ women \\
\hline TIER 3 & Legislators & $42.7 \%$ women \\
\hline
\end{tabular}

TOTAL: $(3 \times .000)+(2 \times .455)+(1 \times .427) \div 6=.223 \times 100=22.3 \div 4=5.6$

Judicial weighted score $=1.0^{* *}$

\begin{tabular}{l|l|l|}
\hline TIER 1 & Constitutional Council & $0 \%$ women \\
\hline TIER 2 & Highest Court of Appeals & NA\% women \\
\hline TIER 3 & High Courts & $15 \%$ women \\
\hline
\end{tabular}

TOTAL: $(3 \times .000)+(2 \times \mathrm{NA})+(1 \times .150) \div 4=.038 \times 100=3.8 \div 4=1.0$

\begin{tabular}{|c|c|c|}
\hline \multicolumn{3}{|c|}{ Security weighted score $=$ NA } \\
\hline TIER 1 & Top-Level Officers & NA\% women \\
\hline TIER 2 & Mid-Level Officers & NA\% women \\
\hline TIER 3 & Lower-Level Officers & $5.0 \%$ women \\
\hline
\end{tabular}

TOTAL: NA

$3.0^{*}($ Executive $)+5.6($ Legislative $)+1.0^{* *}($ Judicial $)+$ NA $($ Security $)=$ NA

* Weighted average of Tier $1+$ Tier 3

** Weighted average of Tier $1+$ Tier 3 (Tier 3 is the total percentage of women judges)

$* * *$ Tier 3 is the total percent of women in the police force 


\section{SOUTH AFRICA $=30.1$}

\begin{tabular}{l|l|l} 
Executive weighted score $=\mathbf{9 . 5}$ & \multicolumn{2}{l}{} \\
\hline TIER 1 & Ministers & $37.1 \%$ women \\
\hline TIER 2 & Top Technocrats & $48.5 \%$ women \\
\hline TIER 3 & Mayors of 10 largest cities & $20.0 \%$ women
\end{tabular}

TOTAL: $(3 \times .371)+(2 \times .485)+(1 \times .200) \div 6=.381 \times 100=38.1 \div 4=9.5$

Legislative weighted score $=7.6$

\begin{tabular}{l|l|l} 
TIER 1 & Political Party Leaders & $21.4 \%$ women \\
\hline TIER 2 & Committee Chairs & $37.8 \%$ women \\
\hline TIER 3 & Legislators & $41.5 \%$ women
\end{tabular}

TOTAL: $(3 \times .214)+(2 \times .378)+(1 \times .415) \div 6=.302 \times 100=30.2 \div 4=7.6$

Judicial weighted score $=6.0$

\begin{tabular}{l|l|l} 
TIER 1 & Constitutional Court & $18.2 \%$ women \\
\hline TIER 2 & Supreme Court of Appeals & $30.4 \%$ women \\
\hline TIER 3 & High Courts & $28.8 \%$ women \\
\hline
\end{tabular}

TOTAL: $(3 \times .182)+(2 \times .304)+(1 \times .288) \div 6=.240 \times 100=24.0 \div 4=6.0$

Security weighted score $=7.0$

\begin{tabular}{l|l|l}
\hline TIER 1 & Top-Level Officers & $26.6 \%$ women \\
\hline TIER 2 & Mid-Level Officers & $28.2 \%$ women \\
\hline TIER 3 & Lower-Level Officers & $30.3 \%$ women
\end{tabular}

TOTAL: $(3 \times .266)+(2 \times .282)+(1 \times .303) \div 6=.278 \times 100=27.8 \div 4=7.0$

$9.5($ Executive $)+7.6($ Legislative $)+6.0($ Judicial $)+7.0($ Security $)=30.1$ 


\begin{tabular}{l|l|l|l|l}
\hline Africa - Weighted Scores & Averaged & & \\
& EXECUTIVE & LEGISLATIVE & JUDICIAL & SECURITY \\
\hline Benin & 4.6 & 2.1 & 7.2 & - \\
\hline Burkina Faso & 2.6 & 2.5 & 10.4 & 1.7 \\
\hline Cote d'Ivoire & 3.1 & 3.1 & 6.9 & 2.2 \\
\hline Ghana & 5.5 & 2.1 & 7.8 & - \\
\hline Kenya & 6.4 & 4.1 & 8.0 & 2.0 \\
\hline Liberia & 8.4 & 1.5 & 6.4 & - \\
\hline Madagascar & 4.3 & 4.6 & 5.9 & - \\
\hline Mali & 3.1 & 2.5 & 6.6 & 1.1 \\
\hline Mozambique & 5.2 & 4.7 & 4.4 & - \\
\hline Niger & - & 3.6 & - & 0.9 \\
\hline Nigeria & 5.0 & 1.7 & 6.7 & 1.5 \\
\hline Rwanda & 9.5 & 7.8 & 9.2 & 1.4 \\
\hline Senegal & 3.0 & 5.6 & 1.0 & - \\
\hline South Africa & 9.5 & 7.6 & 6.0 & 7.0 \\
\hline TOTALS & 70.2 & 53.5 & 86.5 & 17.8 \\
\hline AVERAGES & 5.4 & 3.8 & 6.7 & 2.2 \\
\hline & & & & \\
\hline
\end{tabular}




\section{ALGERIA = NA (11.7 Minus Security)}

\begin{tabular}{l|l|l}
\multicolumn{2}{l}{ Executive weighted score $=\mathbf{2 . 3}^{*}$} & \\
\hline TIER 1 & Ministers & $12.1 \%$ women \\
\hline TIER 2 & Top Technocrats & NA \% women \\
\hline TIER 3 & Mayors of 10 largest cities & $0.0 \%$ women \\
\hline
\end{tabular}

TOTAL: $(3 \times .120)+(2 \times$ NA $)+(1 \times .000) \div 4=.091 \times 100=9.1 \div 4=2.3$

Legislative weighted score $=2.0^{*}$

\begin{tabular}{l|l|l}
\hline TIER 1 & Political Party Leaders & $0.0 \%$ women \\
\hline TIER 2 & Committee Chairs & NA\% women \\
\hline TIER 3 & Legislators & $31.6 \%$ women \\
\hline
\end{tabular}

TOTAL: $(3 \times .000)+(2 \times \mathrm{NA})+(1 \times .316) \div 4=.079 \times 100=7.9 \div 4=2.0$

Judicial weighted score $=7.4^{* *}$

\begin{tabular}{l|l|l|}
\hline TIER 1 & Constitutional Council & $22.2 \%$ women \\
\hline TIER 2 & Supreme Court (150 judges total) & NA\% women \\
\hline TIER 3 & Appellate Courts (Wilaya) & $51.5 \%$ \\
\hline
\end{tabular}

TOTAL: $(3 \times .222)+(2 \times \mathrm{NA})+(1 \times .51 .5) \div 4=.295 \times 100=29.5 \div 4=7.4$

\begin{tabular}{l|l|l|}
\multicolumn{2}{l}{ Security weighted score $=$ NA } & \\
\hline TIER 1 & Top-Level Officers & NA\% women \\
\hline TIER 2 & Mid-Level Officers & NA\% women \\
\hline TIER 3 & Lower-Level Officers & $8.0 \%$ women \\
\hline
\end{tabular}

TOTAL: NA

${ }^{*} 2.3$ (Executive) $+{ }^{*} 2.0$ (Legislative) $+{ }^{* *} 7.4$ (Judicial) + NA $($ Security $)=$ NA

${ }^{*}$ Weighted Tier $1+$ Tier 3

${ }^{* *}$ Weighted Tier $1+$ Tier 3 is the overall percentage of women in the judiciary 


\section{IRAQ = NA (3.6 Minus Security)}

\begin{tabular}{l|l|l}
\multicolumn{2}{l|}{ Executive weighted score $=\mathbf{0 . 8}$} & \\
\hline TIER 1 & Ministers & $3.7 \%$ women \\
\hline TIER 2 & Top Technocrats & $3.7 \%$ women \\
\hline TIER 3 & Mayors of 10 largest cities & $0.0 \%$ women \\
\hline
\end{tabular}

TOTAL: $(3 \times .037)+(2 \times .037)+(1 \times .000) \div 6=.031 \times 100=3.1 \div 4=0.8$

Legislative weighted score $=2.3$

\begin{tabular}{l|l|l}
\hline TIER 1 & Political Party Leaders & $0.0 \%$ women \\
\hline TIER 2 & Committee Chairs & $15.0 \%$ women \\
\hline TIER 3 & Legislators & $25.3 \%$ women \\
\hline
\end{tabular}

TOTAL: $(3 \times .000)+(2 \times .150)+(1 \times .253) \div 6=.092 \times 100=9.2 \div 4=2.3$

Judicial weighted score $=0.5$

\begin{tabular}{l|l|l} 
TIER 1 & Federal Supreme Court & $0.0 \%$ women \\
\hline TIER 2 & Court of Cassation & $0.0 \%$ women \\
\hline TIER 2 & Courts of Appeal & $11.1 \%$ women \\
\hline
\end{tabular}

TOTAL: $(3 \times .000)+(2 \times .000)+(1 \times .111) \div 6=.018 \times 100=1.8 \div 4=.5$

\section{Security weighted score $=$ NA}

\begin{tabular}{l|l|l} 
TIER 1 & Top-Level Officers & NA\% women \\
\hline TIER 2 & Mid-Level Officers & NA\% women \\
\hline TIER 3 & Lower-Level Officers & NA\% women \\
\hline
\end{tabular}

TOTAL: NA

$0.8($ Executive $)+2.3($ Legislative $)+0.5($ Judicial $)+$ NA $($ Security $)=$ NA 


\section{JORDAN = NA (5.7 Minus Security)}

\begin{tabular}{l|l|l}
\multicolumn{2}{l}{ Executive weighted score $=\mathbf{2 . 2}$} & \\
\hline TIER 1 & Ministers & $11.1 \%$ women \\
\hline TIER 2 & Top Technocrats & $10.0 \%$ women \\
\hline TIER 3 & Mayors of 10 largest cities & $0.0 \%$ women \\
\hline
\end{tabular}

TOTAL: $(3 \times .111)+(2 \times .100)+(1 \times .000) \div 6=.089 \times 100=8.9 \div 4=2.2$

Legislative weighted score $=1.9$

\begin{tabular}{l|l|l}
\hline TIER 1 & Political Party Leaders & $4.6 \%$ women \\
\hline TIER 2 & Committee Chairs & $10.0 \%$ women \\
\hline TIER 3 & Legislators & $12.0 \%$ women \\
\hline
\end{tabular}

TOTAL: $(3 \times .046)+(2 \times .100)+(1 \times .120) \div 6=.076 \times 100=7.6 \div 4=1.9$

Judicial weighted score $=1.6$

\begin{tabular}{l|l|l}
\hline TIER 1 & Supreme Court (Cassation) & $0.0 \%$ women \\
\hline TIER 2 & Courts of Appeal & $3.0 \%$ women \\
\hline TIER 3 & Court of First Instance & $32.0 \%$ women \\
\hline
\end{tabular}

TOTAL: $(3 \times .000)+(2 \times .030)+(1 \times .320) \div 6=.063 \times 100=6.3 \div 4=1.6$

\begin{tabular}{|c|c|c|}
\hline \multicolumn{3}{|c|}{ Security weighted score $=$ NA } \\
\hline TIER 1 & Top-Level Officers & NA\% women \\
\hline TIER 2 & Mid-Level Officers & NA $\%$ women \\
\hline TIER $3^{*}$ & Lower-Level Officers & $7.0 \%$ women \\
\hline
\end{tabular}

TOTAL: NA

$2.2($ Executive $)+1.9($ Legislative $)+1.6($ Judicial $)+$ NA $($ Security $)=$ NA

* Tier 3 is the total percentage of women in the police force 


\section{LEBANON = NA (3.6 Minus Security)}

\begin{tabular}{l|l|l}
\multicolumn{2}{l}{ Executive weighted score $=\mathbf{0 . 9}$} & \\
\hline TIER 1 & Ministers & $0.0 \%$ women \\
\hline TIER 2 & Top Technocrats & $10.1 \%$ women \\
\hline TIER 3 & Mayors of 10 largest cities & $0.0 \%$ women
\end{tabular}

TOTAL: $(3 \times .000)+(2 \times .101)+(1 \times .000) \div 6=.034 \times 100=3.4 \div 4=0.9$

Legislative weighted score $=\mathbf{1 . 2}$

\begin{tabular}{l|l|l} 
TIER 1 & Political Party Leaders & $0.0 \%$ women \\
\hline TIER 2 & Committee Chairs & $12.5 \%$ women \\
\hline TIER 3 & Legislators & $3.1 \%$ women \\
\hline
\end{tabular}

TOTAL: $(3 \times .000)+(2 \times .125)+(1 \times .031) \div 6=.047 \times 100=4.7 \div 4=1.2$

Judicial weighted score $=\mathbf{1 . 5}$

\begin{tabular}{l|l|l}
\hline TIER 1 & Supreme Court (Cassation) & $0.0 \%$ women \\
\hline TIER 2 & Constitutional Council & $0.0 \%$ women \\
\hline TIER 3 & Civil - Criminal - Commercial Courts & $36.5 \%$ women \\
\hline
\end{tabular}

TOTAL: $(3 \times .000)+(2 \times .000)+(1 \times .365) \div 6=.061 \times 100=6.1 \div 4=1.5$

\begin{tabular}{l|l|l|}
\multicolumn{2}{l}{ Security weighted score $=$ NA } & \\
\hline TIER 1 & Top-Level Officers & NA\% women \\
\hline TIER 2 & Mid-Level Officers & NA\% women \\
\hline TIER 3* & Lower-Level Officers & $2.4 \%$ women \\
\hline
\end{tabular}

TOTAL: NA

$$
0.9(\text { Executive })+1.2(\text { Legislative })+1.5(\text { Judicial })+\text { NA }(\text { Security })=4.8
$$

* Tier 3 is the total percentage of women in the police force 


\section{MOROCCO = NA (9.4 Minus Security)}

\begin{tabular}{l|l|l}
\multicolumn{2}{l}{ Executive weighted score $=\mathbf{3 . 0}$} & \\
\hline TIER 1 & Ministers & $15.8 \%$ women \\
\hline TIER 2 & Top Technocrats & $7.4 \%$ women \\
\hline TIER 3 & Mayors of 10 largest cities & $10.0 \%$ women
\end{tabular}

TOTAL: $(3 \times .158)+(2 \times .074)+(1 \times .100) \div 6=.120 \times 100=12.0 \div 4=3.0$

Legislative weighted score $=\mathbf{2 . 6}$

\begin{tabular}{l|l|l} 
TIER 1 & Political Party Leaders & $6.3 \%$ women \\
\hline TIER 2 & Committee Chairs & $12.5 \%$ women \\
\hline TIER 3 & Legislators & $17.0 \%$ women
\end{tabular}

TOTAL: $(3 \times .063)+(2 \times .125)+(1 \times .170) \div 6=.102 \times 100=10.2 \div 4=2.6$

\begin{tabular}{l|l|l} 
Judicial weighted score $=\mathbf{3 . 8}^{*}$ & \\
\hline TIER 1 & Constitutional Court & $8.3 \%$ women \\
\hline TIER 2 & Supreme Court & $16.0 \%$ women \\
\hline TIER 3* & Courts of Appeal & $22.1 \%$ women
\end{tabular}

TOTAL: $(3 \times .083)+(2 \times .160)+(1 \times .221) \div 6=.152 \times 100=15.2 \div 4=3.8$

\begin{tabular}{l|l|l}
\multicolumn{2}{l}{ Security weighted score $=$ NA } & \\
\hline TIER 1 & Top-Level Officers & NA\% women \\
\hline TIER 2 & Mid-Level Officers & NA\% women \\
\hline TIER 3 & Lower-Level Officers & NA\% women
\end{tabular}

TOTAL: NA

$3.0($ Executive $)+2.6($ Legislative $)+3.8^{*}($ Judicial $)+$ NA $($ Security $)=$ NA

*The Tier 3 Judicial score is based on the overall percentage of women judges 
TUNISIA $=$ NA

\begin{tabular}{l|l|l}
\multicolumn{2}{l}{ Executive weighted score $\mathbf{4 . 4}$} & \\
\hline TIER 1 & Ministers & $11.5 \%$ women \\
\hline TIER 2 & Top Technocrats & $35.7 \%$ women \\
\hline TIER 3 & Mayors of 10 largest cities & $0.0 \%$ women
\end{tabular}

TOTAL: $(3 \times .115)+(2 \times .357)+(1 \times .000) \div 6=.177 \times 100=17.7 \div 4=4.4$

Legislative weighted score $=3.4$

\begin{tabular}{l|l|l} 
TIER 1 & Political Party Leaders & $0.0 \%$ women \\
\hline TIER 2 & Committee Chairs & $25.0 \%$ women \\
\hline TIER 3 & Legislators & $31.3 \%$ women \\
\hline
\end{tabular}

TOTAL: $(3 \times .000)+(2 \times .250)+(1 \times .313) \div 6=.136 \times 100=13.6 \div 4=3.4$

\begin{tabular}{l|l|l}
\hline Judicial weighted score $=$ NA & \\
\hline TIER 1 & Supreme Court (Cassation) & NA\% women \\
\hline TIER 2 & Appeals Courts & NA\% women \\
\hline TIER 3 & Courts of First Instance & $27.7 \%$ women*
\end{tabular}

TOTAL: Total percentage of women judges in all courts with no distinction made

\begin{tabular}{l|l|l|}
\multicolumn{2}{l}{ Security weighted score $=$ NA } & \\
\hline TIER 1 & Top-Level Officers & NA\% women \\
\hline TIER 2 & Mid-Level Officers & NA\% women \\
\hline TIER 3 & Lower-Level Officers & NA\% women \\
\hline
\end{tabular}

TOTAL: NA

$4.4($ Executive $)+3.4$ (Legislative) + NA $($ Judicial $)+$ NA $($ Security $)=$ NA 
YEMEN = NA (2.3 Minus Security)

\begin{tabular}{l|l|l}
\multicolumn{2}{l}{ Executive weighted score $=\mathbf{2 . 2}$} & \\
\hline TIER 1 & Ministers & $8.8 \%$ women \\
\hline TIER 2 & Top Technocrats & $13.3 \%$ women \\
\hline TIER 3 & Mayors of 10 largest cities & $0.0 \%$ women
\end{tabular}

TOTAL: $(3 \times .088)+(2 \times .133)+(1 \times .000) \div 6=.088 \times 100=8.8 \div 4=2.2$

Legislative weighted score $=0.0$

\begin{tabular}{l|l|l} 
TIER 1 & Political Party Leaders & $0.0 \%$ women \\
\hline TIER 2 & Committee Chairs & $0.0 \%$ women \\
\hline TIER 3 & Legislators & $0.3 \%$ women
\end{tabular}

TOTAL: $(3 \times .000)+(2 \times .000)+(1 \times .003) \div 6=.001 \times 100=0.1 \div 4=0.0$

Judicial weighted score $=0.1$

\begin{tabular}{l|l|l} 
TIER 1 & Supreme Court & $0.0 \%$ women \\
\hline TIER 2 & Appeals Court & $0.0 \%$ women \\
\hline TIER 3 & District Courts & $2.1 \%$ women \\
\hline
\end{tabular}

TOTAL: $(3 \times .000)+(2 \times .000)+(1 \times .021) \div 6=.004 \times 100=0.4 \div 4=0.1$

\begin{tabular}{l|l|l|}
\multicolumn{2}{l}{ Security weighted score $=$ NA } & \\
\hline TIER 1 & Top-Level Officers & NA\% women \\
\hline TIER 2 & Mid-Level Officers & NA\% women \\
\hline TIER 3 & Lower-Level Officers & $1.7 \%$ women \\
\hline
\end{tabular}

TOTAL: NA

$2.2($ Executive $)+0.0($ Legislative $)+0.1($ Judicial $)+\mathrm{NA}($ Security $)=\mathrm{NA}$

* Tier 3 is the total percentage of women in the police force 


\begin{tabular}{l|c|c|c|c}
\multicolumn{5}{c}{ Middle East \& North Africa - Weighted Scores Averaged } \\
\hline & EXECUTIVE & LEGISLATIVE & JUDICIAL & SECURITY \\
\hline Algeria & 2.3 & 2.0 & 7.4 & - \\
\hline Iraq & 0.8 & 2.3 & 0.5 & - \\
\hline Jordan & 2.2 & 1.9 & 1.6 & - \\
\hline Lebanon & 0.9 & 1.2 & 1.5 & - \\
\hline Morocco & 3.0 & 2.6 & 3.8 & - \\
\hline Tunisia & 4.4 & 3.4 & - & - \\
\hline Yemen & 2.2 & 0.0 & 0.1 & - \\
\hline TOTALS & $\mathbf{1 5 . 8}$ & $\mathbf{1 3 . 4}$ & $\mathbf{1 4 . 9}$ & - \\
\hline AVERAGES & $\mathbf{2 . 3}$ & $\mathbf{1 . 9}$ & $\mathbf{2 . 5}$ & - \\
\hline
\end{tabular}




\begin{tabular}{l|c|c|c|c}
\hline \multicolumn{2}{|l|}{ GLOBAL - Weighted Scores Averaged } & & \\
& EXECUTIVE & LEGISLATIVE & JUDICIAL & SECURITY \\
\hline Eastern Europe \& Eurasia & 3.9 & 2.9 & 7.7 & 1.5 \\
\hline Latin America \& Caribbean & 4.8 & 2.6 & 4.6 & 1.8 \\
\hline Asia & 2.7 & 3.9 & 4.3 & 1.1 \\
\hline Africa & 5.2 & 3.8 & 6.6 & 2.2 \\
\hline Middle East \& North Africa & 2.3 & 1.9 & 2.5 & - \\
\hline TOTALS & $\mathbf{1 8 . 9}$ & $\mathbf{1 5 . 1}$ & $\mathbf{2 5 . 7}$ & $\mathbf{6 . 6}$ \\
\hline AVERAGES & $\mathbf{3 . 8}$ & $\mathbf{3 . 0}$ & $\mathbf{5 . 1}$ & $\mathbf{1 . 7}$ \\
\hline
\end{tabular}





\section{BIBLIOGRAPHY}

Allen, Amy. "Rethinking Power." Hypatia 13, no. 1 (1998): 21-40.

. The Power of Feminist Theory: Domination, Resistance, Solidarity. Westview

Press, 1999.

American Society of International Law and the International Judicial Academy. "The

Long Winding Road: Judicial Sector Reform in Mongolia." International Judicial

Monitor 2, no. 1 (January / February 2007).

Arendt, Hannah. On Violence. Houghton Mifflin Harcourt, 1970.

Baden, Sally, and Hazel Reeves. Gender and Development: Concepts and Definitions.

Brighton, United Kingdom: Institute of Development Studies, University of Sussex, 2000.

Ballington, Julie, and Azza M. Karam. Women in Parliament: Beyond Numbers. Vol. 2. International IDEA, 2005.

Bandura, Romina. "A Survey of Composite Indices Measuring Country Performance:

2008 Update." Office of Development Studies, New York: United Nations Development Program, 2008.

Bardhan, Kalpana, and Stephan Klasen. “UNDP's Gender-Related Indices: A Critical

Review." World Development 27, no. 6 (1999): 985-1010.

Barnes, Tiffany D., and Stephanie Burchard. "The Impact of Descriptive

Representation on Women's Political Participation in Sub-Saharan Africa." (2010). APSA 2010 Annual Meeting Paper.

Basedau, Matthias, Gero Erdmann, and Andreas Mehler. Votes, Money and Violence:

Political Parties and Elections in Sub-Saharan Africa. South Africa: Nordiska Afrikainstitutet; Kwazulu-Natal Press, 2007.

Batliwala, Srilatha. "The Meaning of Women's Empowerment: New Concepts from Action.," 1994.

Batliwala, Srilatha. "Taking the Power out of Empowerment - an Experiential Account." Development in Practice 17, no. 4-5 (2007): 557-65.

Beaman, Lori, Raghabendra Chattopadhyay, Esther Duflo, Rohini Pande, and Petia Topalova. "Powerful Women: Does Exposure Reduce Bias?" The Quarterly Journal of Economics, November 2009, 1497-1540.

Beckman, Peter R., and Francine D'Amico. Women, Gender, and World Politics: Perspectives, Policies, and Prospects. ABC-CLIO, 1994.

“Beijing Declaration Platform for Action." Fourth World Conference on Women, 1995.

Bensahel, Nora, David Barno, Katherine Kidder, and Kelley Sayler. "Battlefields and Boardrooms: Women's Leadership in the Military and the Private Sector." Washington DC: Center for a New American Security, 2015. 
Bericat, Eduardo. "The European Gender Equality Index: Conceptual and Analytical Issues." Social Indicators Research 108, no. 1 (2012): 1-28.

Bhagwati, Anu. "Ending Sexual Assault in the Military." The Washington Post. May 26, 2013, section B.

Borrelli, MaryAnne, and Janet M. Martin. The Other Elites: Women, Politics, and Power in the Executive Branch. Boulder, Colorado: Lynne Rienner Publishers, 1997.

Bowers-Krishnan, Nathan. "Do Legislatures Matter? Strengthening Governance in Africa." North-South Institute, January 22, 2013.

Bowler, Shaun, and Jeffrey A. Karp. "Politicians, Scandals, and Trust in Government." Political Behavior 26, no. 3 (2004): 271-87.

Branisa, Boris, Stephan Klasen, and Maria Ziegler. "The Construction of the Social Institutions and Gender Index (SIGI)." Discussion papers, Ibero America Institute for Economic Research, 2009.

Burgess, Michael. Comparative Federalism: Theory and Practice. Routledge, 2006.

Buvinic, Mayra, Gayatri Koolwal, and Rebecca Furst-Nichols. "Data 2X: Mapping Gender Data Gaps DRAFT.” UN Foundation, April 2013.

Caprioli, Mary. Gender Equality and Civil Wars. Conflict Prevention and Reconstruction Unit, Social Development Department, Environmentally and Socially Sustainable Development Network, World Bank, 2003.

. "Gendered Conflict." Journal of Peace Research 37, no. 1 (2000): 51-68.

. "Primed for Violence: The Role of Gender Inequality in Predicting Internal Conflict." International Studies Quarterly 49, no. 2 (2005): 161-178.

Caprioli, Mary, and Mark A. Boyer. "Gender, Violence, and International Crisis." Journal of Conflict Resolution 45, no. 4 (2001): 503-518.

Caprioli, Mary, Valerie M. Hudson, Rose McDermott, Bonnie Ballif-Spanvill, Chad F. Emmett, and S. Matthew Stearmer. "The Womanstats Project Database: Advancing an Empirical Research Agenda." Journal of Peace Research 46, no. 6 (2009): 839-51.

Cawkill, Paul, Alison Rogers, Sarah Knight, and Laura Spear. "Women in Ground Close Combat Roles: The Experiences of Other Nations and a Review of the Academic Literature." United Kingdom: DSTL, Ministry of Defence, 2010.

Celis, Karen. "Studying Women's Substantive Representation in Legislatures: When Representative Acts, Contexts and Women's Interests Become Important." Representation 44, no. 2 (2008): 111-23.

. "Substantive Representation of Women: The Representation of Women's Interests and the Impact of Descriptive Representation in the Belgian Parliament (1900-1979)." Journal of Women, Politics E Policy 28, no. 2 (2007): 85-114.

Celis, Karen and Sarah Childs. "The Substantive Representation of Women: What to Do with Conservative Claims?" Political Studies 60 (2012): 213-225. 
Celis, Karen, and Joni Lovenduski. "Power Struggles: Gender Equality in Political Representation." European Journal of Politics and Gender 1, no. 1-2 (2018): 149-166.

Celis, Karen, and Liza M. Mügge. "Whose Equality? Measuring Group Representation." Politics 38, no. 2 (2018): 197-213.

Centre for Social Development, Humanitarian Affairs (United Nations), UNICEF, United Nations Population Fund, United Nations Development Fund for Women, United Nations Statistical Division, United Nations Office for Project Services, World Food Program, Inter-parliamentary Union, and World Health Organization. The World's Women: Trends and Statistics. New York: United Nations, 2010.

Center for Women in Government and Civil Service; Rockefeller College of Public Affairs and Policy, University at Albany; Nkumba University, Uganda. "Mapping the Substantive Representation of Women in the Ugandan Parliament," 2014.

Cerise, Somali, Gaelle Ferrant, and Jason Gagnon. "2012 Social Institutions and Gender Index: A Methodological and Technical Background Paper." Paris: Organization for Economic Co-operation and Development, 2012.

Charles, Maria. "Deciphering Sex Segregation Vertical and Horizontal Inequalities in Ten National Labor Markets." Acta Sociologica 46 , no. 4 (2003): 267-87.

Childs, Sarah. "A Feminised Style of Politics? Women MPs in the House of Commons." The British Journal of Politics \& International Relations 6, no. 1 (2004): 3-19.

. "The Complicated Relationship between Sex, Gender and the Substantive Representation of Women." European Journal of Women's Studies 13, no. 1 (2006): $7-21$.

Childs, Sarah, and Mona Lena Krook. "Should Feminists Give up on Critical Mass? A Contingent Yes." Politics \& Gender 2, no. 04 (2006): 522-530.

. "Analysing Women's Substantive Representation: From Critical Mass to Critical Actors." Government and Opposition 44, no. 2 (2009): 125-45.

. "The Substantive Representation of Women: Rethinking the 'Critical Mass' Debate." Annual Meeting of the American Political Science Association, Washington DC, 2005.

Childs, Sarah, Paul Webb, and Sally Marthaler. "Constituting and Substantively Representing Women: Applying New Approaches to a UK Case Study." Politics E Gender 6, no. 02 (2010): 199-223.

Cingranelli, David, and David Richards. "Cingranelli-Richards Human Rights Dataset," 2009.

Clinton Foundation, Gates Foundation, The Economist Intelligence Unit, World Policy Analysis Center, Maternal and Child Health Equity Research Program. “No Ceilings: The Full Participation Report,” 2015. 
Cooley, Alexander. "Countering Democratic Norms." Journal of Democracy 26, no. 3 (2015): 49-63.

Corner, Lorraine. "Gender-Sensitive and Pro-Poor Indicators of Good Governance." New York: United Nations Development Program, 2005.

Costa Lobo, Marina. "Parties and Leader Effects: Impact of Leaders in the Vote for Different Types of Parties." Party Politics 14, no. 3 (2008): 281-298.

Cotter, David A., Joan M. Hermsen, Seth Ovadia, and Reeve Vanneman. "The Glass Ceiling Effect." Social Forces 80, no. 2 (2001): 655-81.

Cueva Beteta, Hanny. "What Is Missing in Measures of Women's Empowerment?" Journal of Human Development 7, no. 2 (2006): 221-41.

Dahl, Robert Alan. Who Governs?: Democracy and Power in an American City. Yale University Press, 2005.

Dahlerup, Drude. "From a Small to a Large Minority: Women in Scandinavian Politics." Scandinavian Political Studies 11, no. 4 (1988): 275-298.

. "The Story of the Theory of Critical Mass." Politics \& Gender 2, no. 4 (2006): 522-30.

Dahlerup, Drude, and Lenita Freidenvall. "Quotas as a 'Fast Track' to Equal Representation for Women: Why Scandinavia Is No Longer the Model." International Feminist Journal of Politics 7, no. 1 (2005): 26-48.

Desai, Manisha A. "Hope in Hard Times: Women's Empowerment and Human Development." UNDP, 2010.

Devlin, Claire, and Robert Elgie. "The Effect of Increased Women's Representation in Parliament: The Case of Rwanda." Parliamentary Affairs 61, no. 2 (2008): 237-54.

DiNoia, Jennifer. "Indicators of Gender Equality for American States and Regions: An Update." Social Indicators Research 59, no. 1 (2002): 35-77.

Dijkstra, Geske A. "Towards a Fresh Start in Measuring Gender Equality: A Contribution to the Debate." Journal of Human Development 7, no. 2 (2006): 275-83.

Dijkstra, A. Geske. "Revisiting UNDP's GDI and GEM: Towards an Alternative." Social Indicators Research 57, no. 3 (2002): 301-38.

Doherty, Joshua. “Women's Representation in Judiciaries Worldwide,” 2012.

Domhoff, G. William. Who Really Rules?: New Haven and Community Power Reexamined. New Brunswick: Transaction Publishers, 1978.

Donadio, Marcela, and Maria de la Paz Tiblietti. A Comparative Atlas of Defence in Latin America and Caribbean. Red de Seguridad y Defensa de America (RESDAL), 2010.

Dovi, Suzanne. "Preferable Descriptive Representatives: Will Just Any Woman, Black, or Latino Do?" American Political Science Review 96, no. 4 (2002): 729-43.

Ellison, Sheila EDITOR. If Women Ruled the World. Maui, Hawaii: Inner Ocean Publishing, 2004.

Elson, Diame, and Hande Keklik. "Progress of the World's Women 2002: Volume 2." New York: UNIFEM, 2002. 
European Institute for Gender Equality. "Gender Equality Index," 2012.

Fallon, Kathleen M., Liam Swiss, and Jocelyn Viterna. "Resolving the Democracy Paradox: Democratization and Women's Legislative Representation in Developing Nations, 1975 to 2009." American Sociological Review 77, no. 3 (2012): 380-408.

Federation of Women Lawyers Kenya. "Key Gains and Challenges: A Gender Audit of Kenya's 2013 Election Process." Nairobi, Kenya: FIDA, 2013.

Fish, M. Steven, and Matthew Kroenig. The Handbook of National Legislatures: A Global Survey. Cambridge University Press, 2009.

Fox, Richard L., and Jennifer L. Lawless. "Entering the Arena? Gender and the Decision to Run for Office." American Journal of Political Science 48, no. 2 (2004): 264-80.

Franceschet, Susan, and Jennifer M. Piscopo. "Equality, Democracy, and the Broadening and Deepening of Gender Quotas." Politics \& Gender 9, no. 3 (2013): 310-316.

Fraser, Nancy. "After the Family Wage: A Postindustrial Thought Experiment." Gender and Citizenship in Transition (2000): 1-32.

Freedom House. "Freedom in the World," 2013.

. "Freedom in the World," 2017.

Geraghty, Terese. "Gender and State-Building: The Case for Timor-Leste." Volume II, 2014, 121.

Goetz, Anne Marie. "Political Cleaners: Women as the New Anti-Corruption Force?" Development and Change 38, no. 1 (2007): 87-105.

Goetz, Anne-Marie, and Shireen Hassim. No Shortcuts to Power: African Women in Politics and Policy Making. Vol. 3. Zed Books, 2003.

Goetz, Anne-Marie, and Celestine Nyamu. "Voice and Women's Empowerment: Mapping a Research Agenda." (2008).

Gonzalez, Keila, and Kristen Sample. One Size Does Not Fit All: Lessons Learned from Legislative Gender Commissions and Caucuses. National Democratic Institute, International Institute for Democracy and Electoral Assistance, 2010.

Green, Joanne Helen. “Measuring Women's Empowerment: Development of a Model." International Journal of Media \& Cultural Politics 4, no. 3 (2008): 369-89.

Grey, Sandra. "Numbers and Beyond: The Relevance of Critical Mass in Gender Research." Politics \& Gender 2, no. 4 (2006): 492-502.

Gunther, Richard, and Larry Diamond. "Species of Political Parties: A New Typology." Party Politics 9, no. 2 (2003): 167-199.

Habitat, U. N. State of the World's Cities 2012/2013: Prosperity of Cities. Routledge, 2013. Hague, Rod, and Martin Harrop. Political Science: A Comparative Introduction. Sixth Edition. St. Martin's Press, 2010. 
Haq, Mahbubul. Reflections on Human Development. New York: Oxford University Press, 1995.

Hawken, Angela, and Gerardo L. Munck. "Cross-National Indices with GenderDifferentiated Data: What Do They Measure? How Valid Are They?" Social Indicators Research, 2013, 1-38.

Henisz, Witold, and Bennet Zelner. "Political Constraint Index," 2007.

Heritage Foundation. "Index of Economic Freedom," 2012.

Herrera, Yoshiko M., and Devesh Kapur. "Improving Data Quality: Actors, Incentives, and Capabilities." Political Analysis 15, no. 4 (2007): 365-386.

Hills, Alice. "Police Commissioners, Presidents and the Governance of Security." Journal of Modern African Studies 45, no. 3 (2007): 403-23.

Hoekstra, Valerie. "Increasing the Gender Diversity of High Courts: A Comparative View." Politics \& Gender 6, no. 3 (2010): 474-82.

Horowitz, Donald L. "Constitutional Courts: A Primer for Decision Makers." Journal of Democracy 17, no. 4 (2006): 125-137.

Horowitz, Donald L. "Constitutional Courts: Opportunities and Pitfalls." Towards a New Constitution for Afghanistan, 2003.

Hughes, Melanie M. "Armed Conflict, International Linkages, and Women's Parliamentary Representation in Developing Nations." Social Problems 56, no. 1 (2009): 174-204.

. "Women's Leadership as a Route to Greater Empowerment: Report on the Diamond Leadership Model." Washington DC: USAID, 2014.

Hughes, Melanie M., and Pamela Paxton. “Continuous Change, Episodes, and Critical Periods: A Framework for Understanding Women's Political Representation over Time." Politics \& Gender 4, no. 02 (2008): 233-64.

Hunt, Swanee. "Let Women Rule." Foreign Affairs, June 2007.

Hunter, Floyd. Community Power Structure: A Study of Decision Makers. Chapel Hill: University of North Carolina Press, 1953.

Institute for Democracy and Electoral Assistance. “Quota Project," 2015.

Institute for Democracy and Electoral Assistance. "Gender Quotas Database." 2015. International Budget Partnership. “Open Budget Index,” 2010.

International Crisis Group. "To Keep the Peace, We Need More Women." The Globa and Mail. November 13, 2017.

International Institute for Democracy and Electoral Assistance. "Translating Women's Participation in Politics into Critical Actions and Influence." Seminar. Accra, Ghana: IDEA, August 28, 2012.

International Labour Organization. “Key Indicators of the Labour Market: ILO," 2010. Inter-Parliamentary Union. "Parliaments at a Glance," 2017. . "Women in Parliament: 20 Years in Review." Geneva, Switzerland: InterParliamentary Union, 2015. 
. “Women in Politics," 2015.

. "Women in Politics," 2017.

Irwin, Neil. "Why the Financial Crisis Hurt Democracy." The Washington Post. April 7, 2013, sec. B.

Iskra, Darlene, Stephen Trainor, Marcia Leithauser, and Mady Wechsler Segal. “Women's Participation in Armed Forces Cross-Nationally: Expanding Segal's Model." Current Sociology 50, no. 5 (2002): 771-97.

Jordanian National Commission for Women. "National Report: Progress of Jordanian Women In Pursuit of Justice, Participation and Equality 2010-2011." Amman, Jordan: 2011.

Kabeer, Naila. The Conditions and Consequences of Choice: Reflections on the Measurement of Women's Empowerment. Vol. 108. UNRISD Geneva, 1999.

Kabeer, Naila. "Reflections on the Measurement of Women's Empowerment in Discussing Women's Empowerment Theory and Practice, SIDA Studies No. 3." Stockholm: Swedish International Development Cooperation Agency, 2001.

Kabeer, Naila. "Resources, Agency, Achievements: Reflections on the Measurement of Women's Empowerment." Development and Change 30, no. 3 (1999): 435-64.

Kabeer, Naila. "Resources, Agency, Achievements: Reflections on the Measurement of Women's Empowerment." (2001).

Kanter, Rosabeth. "Some Effects of Proportions on Group Life: Skewed Sex Ratios and Responses to Token Women." The American Journal of Sociology 82, no. 5 (1977): 965-90.

Kathlene, Lyn. "Position Power versus Gender Power: Who Holds the Floor?" Gender Power, Leadership, and Governance (1995): 167-94.

Katz, Richard S., and Peter Mair. "Changing Models of Party Organization and Party Democracy: The Emergence of the Cartel Party." Party Politics 1, no. 1 (1995): 5-28.

Katz, Richard S., and Peter Mair. "The Cartel Party Thesis: A Restatement." Perspectives on Politics 7, no. 4 (2009): 753-766.

Kaufmann, Daniel, and Aart Kraay. "Governance Indicators: Where Are We, Where Should We Be Going?" The World Bank Research Observer 23, no. 1 (2008): 1-30.

Kaufmann, Daniel, Aart Kraay, and Massimo Mastruzzi. "The Worldwide Governance Indicators: Methodology and Analytical Issues." World Bank Policy Research Working Paper, no. 5430 (2010).

Kenney, Sally J. "Breaking the Silence: Gender Mainstreaming and the Composition of the European Court of Justice." Feminist Legal Studies 10 (2002): 257-70.

. "Critical Perspectives on Gender and Judging." Politics \& Gender 6 (2010): $433-41$.

. "Where Is Gender in Agenda Setting?" Women and Politics 25, no. $1 / 2$ (2003): 179-207. 
. Gender and Justice: Why Women in the Judiciary Really Matter. Routledge, 2013.

Kenworthy, Lane, and Melissa Malami. “Gender Inequality in Political Representation:

A Worldwide Comparative Analysis." Social Forces 78, no. 1 (1999): 235-68.

Kittilson, Miki Caul. Challenging Parties, Changing Parliaments: Women and Elected

Office in Contemporary Western Europe. Ohio State University Press, 2006.

Klasen, Stephan. “Guest Editor's Introduction." Journal of Human Development 7, no. 2 (2006): 145-59.

. “UNDP's Gender-related Measures: Some Conceptual Problems and Possible Solutions." Journal of Human Development 7, no. 2 (2006): 243-74.

Knudsen, Susanne V. "Intersectionality - A Theoretical Inspiration in the Analysis of Minority Cultures and Identities in Textbooks." Caught in the Web or Lost in the Textbook 53 (2006): 61-76.

Koch, Michael T., and Sarah A. Fulton. "In the Defense of Women: Gender, Office Holding, and National Security Policy in Established Democracies." The Journal of Politics 73, no. 01 (2011): 1-16.

Kristof, Nicholas, and Sheryl WuDunn. Half the Sky: Turning Oppression into Opportunity for Women Worldwide. New York: Alfred A. Knopf, 2009.

Krook, Mona Lena. "Reforming Representation: The Diffusion of Candidate Gender Quotas Worldwide." Politics and Gender 2(3) 2006. 303-327

. Quotas for Women in Politics: Gender and Candidate Selection Reform Worldwide. Oxford University Press, 2010.

. "Gendering Comparative Politics: Achievements and Challenges." Politics $\mathcal{E}$ Gender 7, no. 1 (March 8, 2011): 99-105.

Krook, Mona Lena, and Diana O'Brien. "All the President's Men? The Appointment of Female Cabinet Ministers Worldwide." Presented at the Midwest Political Science Association National Conference, Chicago, IL, 2011.

Kuehnast, Kathleen. “Why Women's Involvement in Peacebuilding Matters." Foreign Service Journal, April 2011.

Kurtzman Group. “Opacity Index,” 2009.

Latino Barometer Secretariate. “Global Barometer." 2011.

Lawless, Jennifer L. "Introduction: Where We've Been and Where We're Going." Politics \& Gender 7, no. 01 (2011): 91-93.

- "Women, War, and Winning Elections: Gender Stereotyping in the PostSeptember 11th Era." Political Research Quarterly 57, no. 3 (2004): 479-90.

Lijphart, Arend. Patterns of Democracy: Government Forms and Performance in ThirtySix Countries. Yale University Press, 2012.

Lindberg, Staffan I. "Women's Empowerment and Democratization: The Effects of Electoral Systems, Participation, and Experience in Africa." Studies in Comparative International Development 39, no. 1 (2004): 28-53. 
Llanos, Beatriz, and Kristen Sample. "Years of Democracy: Riding the Wave." Women's Political Participation in Latin America: Institute for Democratic and Electoral Assistance (30).

Longley, Lawrence D., and Roger H. Davidson. "Parliamentary Committees: Changing Perspectives on Changing Institutions," The Journal of Legislative Studies 4, no. 1 (1998): 1-20.

Lopez-Claros, Augusto, and Saadia Zahidi. “Women's Empowerment: Measuring the Global Gender Gap." World Economic Forum Geneva, 2005.

Lovenduski, Joni, and Pippa Norris. "Westminster Women: The Politics of Presence." Political Studies 51 (2003): 84-102.

Lovett, Jo, and Liz Kelly. "Different Systems, Similar Outcomes? Tracking Attrition in Reported Rape Cases across Europe." London: Child and Women Abuse Studies Unit, London Metropolitan University, 2010.

Lukes, Steven. Power: A Radical View-The Original Text with Two Major New Chapters. New York: Palgrave Macmillan, 2005.

Lynch, Gabrielle, and Gordon Crawford. "Democratization in Africa 1990 - 2010: An Assessment." Democratization 18, no. 2 (2011): 275-310.

Malhotra, Anju, Sidney Ruth Schuler, and Carol Boender. "Measuring Women's Empowerment as a Variable in International Development." World Bank, 2002. Mansbridge, Jane. "Quota Problems: Combating the Dangers of Essentialism." Politics \& Gender 1, no. 04 (2005): 622-38.

- "Should Blacks Represent Blacks and Women Represent Women? A Contingent 'Yes.'” The Journal of Politics 61, no. 03 (1999): 628-57.

Marks, Gary, and Liesbet Hooghe. "Types of multi-level governance." European Integration online Papers 5, no. 11 (2001): 31.

Martin, Patricia Yancey. “Gender as Social Institution.” Social Forces 82, no. 4 (2004): 1249-1273.

Mathiason, John, and Loveena Kookhony. Women in Governmental Decision-Making in the Early $21^{\text {st }}$ Century: What Has - and Has Not - Been Achieved in the Post-Beijing Period. 2006.

Matland, Richard E., and Donley T. Studlar. “The Contagion of Women Candidates in Single-Member District and Proportional Representation Electoral Systems: Canada and Norway." The Journal of Politics 58, no. 03 (1996): 707-33.

Mattson, Ingvar, and Kaare Strøm. "Parliamentary Committees." Parliaments and Majority Rule in Western Europe, 249-307, 1995.

Meier, Petra. "A Gender Gap Not Closed by Quotas." International Feminist Journal of Politics 10, no. 3 (2008): 329-47.

- "The Mutual Contagion Effect of Legal and Party Quotas A Belgian Perspective." Party Politics 10, no. 5 (2004): 583-600. 
Meier, Petra, Emanuela Lombardo, Maria Bustelo, and M. Pantelidou Maloutas. "Gender Mainstreaming and the Benchmarking Fallacy of Women in Political Decision-Making." The Greek Review of Social Research 117, no. B (2005): 35-61.

Meier, Petra, Emanuela Lombardo, Maria Bustelo, and M. Pantelidou Maloutas. "Women in Political Decision-Making and Gender Mainstreaming: Obvious Partners?" In 2nd Pan-European Conference on EU Politics of the ECPR Standing Group on the EU. Bologna, 2004.

Melander, Erik. "Gender Equality and Intrastate Armed Conflict." International Studies Quarterly 49, no. 4 (2005): 695-714.

Milliken, Jennifer, and Keith Krause. "State Failure, State Collapse, and State Reconstruction: Concepts, Lessons and Strategies." Development and Change 33, no. 5 (2002): 753-74.

Mills, C. Wright. The Power Elite. New York: Oxford University Press, 1956.

Mo Ibrahim Foundation. "Ibrahim Index of African Governance," 2013.

Mosedale, Sarah. "Assessing Women's Empowerment: Towards A Conceptual Framework." Journal of International Development 17, no. 2 (2005): 243-57.

Murray, Rainbow. Parties, Gender Quotas and Candidate Selection in France. Palgrave Macmillan Basingstoke, 2010.

Narayan, Deepa, ed. Measuring Empowerment: Cross-Disciplinary Perspectives. Washington DC: The World Bank, 2005.

Nardo, Michela, Michaela Saisana, Andrea Saltelli, Anders Hoffman, and Enrico Giovannini. Handbook on Constructing Composite Indicators: Methodology and User Guide. OECD Publishing: 2005.

Nardo, M., M. Saisana, A. Saltelli, and S. Tarantola. “Tools for Composite Indicators Building. European Commission Joint Research Centre." Institute for the Protection and the Security of the Citizen, Econometrics and Statistical Support to Antifraud Unit, I-21020 Ispra (VA) Italy, Report Number: EUR 21682 (2005).

National Democratic Institute. "Democracy and the Challenge of Change: A Guide to Increasing Women's Political Participation," 2010.

National Democratic Institute. "Women and Local Executive Office," 2015.

National Taiwan University. “Asian Barometer," 2008.

Nomthandazo, Mankazana. "SADC Gender Protocol 2015: South Africa." Gender Links, 2014.

Norris, Pippa, and Joni Lovenduski. "'If Only More Candidates Came Forward: Supply-Side Explanations of Candidate Selection in Britain." British Journal of Political Science 23, no. 3 (1993): 373-408.

Norris, Pippa, and Joni Lovenduski, eds. Gender and Party Politics. Sage Publications, 1993.

Norris, Pippa, and Ronald Inglehart. "Cultural Obstacles to Equal Representation." Journal of Democracy 12, no. 3 (July 2001): 126-40. 
Norris, Pippa, and Mona Lena Krook. "Gender Equality in Elected Office: A Six-Step Action Plan." Organization for Security and Cooperation in Europe, September 9, 2011.

North, Douglass C. “Institutions." The Journal of Economic Perspectives 5, no. 1 (1991): 97-112.

Nzomo, Maria. "Representational Politics in Kenya," 2012.

Organisation for Economic Co-operation and Development. "Gender, Institutions and Development Database," 2009. . "Social Institutions and Gender Index," 2014.

Parpart, Jane L., Shirin M. Rai, and Kathleen A. Staudt. Rethinking Empowerment: Gender and Development in a Global/Local World. Routledge, 2003.

Paxton, Pamela, and Melanie M. Hughes. Women, Politics, and Power. Pine Forge Press, 2007.

Paxton, Pamela, Melanie M. Hughes, and Jennifer L. Green. "The international women's movement and women's political representation, 1893-2003." American Sociological Review 71, no. 6 (2006): 898-920.

Paxton, Pamela, and Sheri Kunovich. "Women's Political Representation: The Importance of Idealogy." Social Forces 82, no. 1 (2003): 87-113.

Paxton, Pamela, Sheri Kunovich, and Melanie M. Hughes. "Gender in Politics." Annual Review of Sociology 33 (2007): 263-84.

Permanyer, Iñaki. "The Measurement of Multidimensional Gender Inequality: Continuing the Debate." Social Indicators Research 95, no. 2 (2010): 181-98.

Petchesky, Rosalind. "Critical Perspectives on Empowerment." Development 53, no. 2 (2010): 181-83.

Pew Research Center. "Views of Presidential Traits: Positives and Negatives." Survey. Pew Research Center, May 2014.

Phillips, Anne. "Democracy and Representation: Or, Why Should It Matter Who Our Representatives Are?" Feminism and Politics, 1998, 224-40. . The Politics of Presence. Oxford University Press, 1995.

Pitkin, Hanna Fenichel. The Concept of Representation. University of California Press, 1967.

Plantenga, Janneke, Chantal Remery, Hugo Figueiredo, and Mark Smith. “Towards a European Union Gender Equality Index." Journal of European Social Policy 19, no. 1 (2009): 19-33.

Puwar, Nirmal. Space Invaders: Race, Gender and Bodies out of Place. Berg, 2004.

Rahat, Gideon. "Candidate Selection: The Choice before the Choice." Journal of Democracy 18, no. 1 (2007): 157-170.

Rai, Shirin M. "Analysing Ceremony and Ritual in Parliament." The Journal of Legislative Studies 16, no. 3 (2010): 284-97. 
Regan, Patrick M., and Aida Paskeviciute. “Women's Access to Politics and Peaceful States." Journal of Peace Research 40, no. 3 (2003): 287-302.

Reynolds, Andrew. "Women in the Legislatures and Executives of the World: Knocking at the Highest Glass Ceiling." World Politics 51, no. 4 (July 1, 1999): $547-72$.

Robeyns, Ingrid. "Sen's Capability Approach and Gender Inequality: Selecting Relevant Capabilities." Feminist Economics 9, no. 2-3 (2003): 61-92.

Rule, Wilma. "Parliaments of, by, and for the People: Except for Women?" Contributions in Political Science 338 (1994): 15-15.

Saltelli, Andrea. "Composite Indicators between Analysis and Advocacy." Social Indicators Research 81, no. 1 (2007): 65-77.

Sanematsu, Marisa. "Accessing Justice: Models, Strategies and Best Practices on Women's Empowerment." International Development Law Organization, 2013.

Sassen, Saskia. "Beyond Party Politics: The New President and the Growth of Executive Power." Dissent 56, no. 1 (Winter 2009): 5-6.

Scheppele, Kim Lane. "Law in a Time of Emergency: States of Exception and the Temptations of 9/11." University of Pennsylvania Journal of Constitutional Law 6 (2004): 1001-83.

. "The International State of Emergency: Challenges to Constitutionalism after September 11." Schmooze'tickets', 2006: 49.

Schüler, Dana. "The Uses and Misuses of the Gender $\square$ Related Development Index and Gender Empowerment Measure: A Review of the Literature." Journal of Human Development 7, no. 2 (2006): 161-81.

Schwindt-Bayer, Leslie A., and William Mishler. "An Integrated Model of Women's Representation." Journal of Politics 67, no. 2 (2005): 407-28.

Scribner, Druscilla, and Priscilla A. Lambert. "Constitutionalizing Difference: A Case Study Analysis of Gender Provisions in Botswana and South Africa." Politics $\mathcal{E}$ Gender 6, no. 01 (2010): 37-61.

Seager, Joni. Women in the World. Fourth Edition. Penguin Books, 2009.

Segal, Mady Wechsler. “Women's Military Roles Cross-Nationally: Past, Present, and Future." Gender \& Society 9, no. 6 (1995): 757-75.

Sen, Amartya. Development as Freedom. Oxford University Press, 2001.

Shah, Bina. "National Security Policy and Feminism Don't Have to Be Incompatible." Defense One, April 7, 2015.

Social Watch. “Gender Equity Index," 2012. . "Social Watch Report: Means and Ends." Uruguay: 2014.

Kenney, Sally Jane. Gender and Justice: Why Women in the Judiciary Really Matter. Routledge, 2013. 
Studlar, Donley T., and Ian McAllister. "Does a Critical Mass Exist? A Comparative Analysis of Women's Legislative Representation since 1950." European Journal of Political Research 41 (2002): 233-53.

Sugarman, David B., and Murray A. Straus. "Indicators of Gender Equality for American States and Regions." Social Indicators Research 20, no. 3 (1988): 229-70.

Sundström, Aksel, Pamela Paxton, Wang Yi-ting, and Staffan I. Lindberg. “Women's Political Empowerment: A New Global Index, 1900-2012." World Development 94 (2017): 321-35.

Sweet, Alec Stone. Governing with Judges: Constitutional Politics in Europe. Oxford University Press, 2000.

Swers, Michele L. The Difference Women Make: The Policy Impact of Women in Congress. University of Chicago Press, 2002.

Tamerius, Karin L. "Sex, Gender, and Leadership in the Representation of Women." Women, Gender, and Politics: A Reader (2010): 243-50.

Tate, C. Neal, and Torbjorn Vallinder. The Global Expansion of Judicial Power. NYU Press, 1995.

Taylor, Paul. Men Or Women: Who's the Better Leader?. Pew Research Center, 2008.

Tekle, Tesfa-Alem. "Somalia: Ethiopia Decides to Join Amisom Force in Somalia." Sudan Tribune. November 12, 2013.

Teune, Henry. "Local Government and Democratic Political Development." The Annals of the American Academy of Political and Social Science 540, no. 1 (1995): 11-23.

Thames, Frank C., and Margaret S. Williams. Contagious Representation: Women's Political Representation in Democracies Around the World. NYU Press, 2012.

Tirman, John. "UNSCR 1325: Slow Progress, Uncertain Prospects." Foreign Service Journal, April 2011.

Transparency International. “Bribe Payers Index,” 2008. . "Corruption Perceptions Index," 2011.

Tremblay, Manon. "The Substantive Representation of Women and PR: Some Reflections on the Role of Surrogate Representation and Critical Mass." Politics $\mathcal{E}$ Gender 2, no. 4 (2006): 502-11.

Tripp, Aili. "Women's Political Empowerment in Statebuilding and Peacebuilding: A Baseline Study." Madison, Wisconsin: University of Wisconsin-Madison, November 2012.

Turquet, Laura. "Progress of the World's Women: In Pursuit of Justice." (2011).

United Cities and Local Governments. The Equality Agenda of United Cities and Local Governments. United Cities and Local Governments. (2013)

United Nations. “Millennium Development Goals," 2011. . "Beijing Declaration and Platform of Action, adopted at the Fourth World Conference on Women," New York: 1995. 
. "Facts and Figures: Leadership and Political Participation." New York: 2017. . "The Millennium Development Goals Report 2015." New York: 2015. . "UN Gender Statistics." New York: 2016.

. “UN Security Council Resolution 1325." New York: 2000.

. “UN Women in Peacekeeping." New York: 2017.

United Nations Development Fund for Women. "ACC Task Force on Basic Social Services for All: Guidelines on Women's Empowerment." New York: 1997.

United Nations Development Program. "Gender Inequality Index." New York: 2010. . "Global Report on Gender Equality in Public Administration." New York: 2014.

. "UNDP Governance Indicators: A User's Guide (2nd Edition)." New York: 2007.

- "Women's Political Participation and Good Governance: 21st Century Challenges." New York: 2000.

United Nations Economic Commission for Africa. "The African Gender and Development Index," 2011.

United Nations General Assembly. "Universal Declaration of Human Rights, Resolution 217 A (III)." United Nations, December 10, 1948.

United Nations General Assembly. "Convention on the Elimination of All Forms of Discrimination Against Women." United Nations, Treaty Series, vol. 1249, p.13, December 18, 1979.

United Nations Secretary-General's Report on Women and Political Participation (2013). "Measures taken and progress achieved in the promotion of women and political participation," A/68/184.

United Nations Security Council. Resolution 1325 (2000), 2000.

UN Women. "Beijing Declaration and Platform for Action." In Fourth World Conference on Women, Vol. 15, 1995.

. "Progress of the World's Women: In Pursuit of Justice." 2011.

United States Agency for International Development. "Implementation of the United States National Action Plan on Women, Peace, and Security." Washington DC, 2012.

. "Women's Leadership as a Route to Greater Empowerment: Desktop Study." Washington DC: USAID, October 2014.

United States State Department / Embassy Kigali. "Rwanda Supports Women's Role in Peace and Security." September 23, 2011.

University of Maryland. "Polity IV Project," 2010.

Van Haute, Emilie, Anissa Amjahad, Arthur Borriello, Caroline Close, and Giulia Sandri. "Party Members in a Pillarised Partitocracy. An Empirical Overview of Party Membership Figures and Profiles in Belgium." Acta Politica 48, no. 1 (2013): 68-91. 
Verloo, Mieke. “Displacement and Empowerment: Reflections on the Concept and Practice of the Council of Europe Approach to Gender Mainstreaming and Gender Equality." Social Politics: International Studies in Gender, State \& Society 12, no. 3 (2005): 344-65.

Walby, Sylvia. "Gender Mainstreaming: Productive Tensions in Theory and Practice." Social Politics: International Studies in Gender, State \& Society 12, no. 3 (2005): 321-43.

Wängnerud, Lena. The Principles of Gender-Sensitive Parliaments. Routledge, 2015.

Watt, Edward David. Authority. New York: St. Martin's Press, 1982.

Weber, Max, and Charles Wright Mills. From Max Weber: Essays in Sociology. Translated, Edited, and with an Introduction by HH Gerth and C. Wright Mills. Edited by Hans Gerth. New York, Oxford University Press [1973], 1946.

White House. "United States National Action Plan on Women, Peace and Security." Washington D.C., 2011.

Weisman, Jonathan, and Jennifer Steinhauer. "Senate Women Lead in Effort to Find Accord." New York Times, October 14, 2013.

Weldon, S. Laurel. "Beyond Bodies: Institutional Sources of Representation for Women in Democratic Policymaking." Journal of Politics 64, no. 4 (2002): 115374.

Williams, Margaret S., and Frank C. Thames. "Women's Representation on High Courts in Advanced Industrialized Countries." Politics \& Gender 4, no. 03 (2008): 451-71.

Wilson, Marie C. Closing the Leadership Gap. New York: Penguin Books, 2007.

Wilson, Woodrow. Congressional Government, 1885, quoted in the Joint Committee on the Organization of Congress Final Report.

Wollack, Kenneth. "Women as Agents of Change: Advancing the Role of Women in Politics and Civil Society," Testimony before the United States Congressional House Committee on Foreign Affairs (2010).

“Women and Local Executive Office." National Democratic Institute for International Affairs: Washington D.C., March 2015.

Women's Environment and Development Organization. “50-50 Campaign: Getting the Balance Right in National Cabinets," 2007.

World Bank Group. World Development Indicators 2014. World Bank Publications, 2014.

. "Women, Business and the Law," 2015.

. "GenderStats." 2011.

."Worldwide Governance Indicators," 2010.

World Economic Forum. “Global Gender Gap Index,” 2015.

Yllö, Kersti. "The Status of Women, Marital Equality, and Violence against Wives a Contextual Analysis." Journal of Family Issues 5, no. 3 (1984): 307-20. 
Yoder, Janice D. “Rethinking Tokenism: Looking beyond Numbers." Gender \& Society 5, no. 2 (1991): 178-92.

Yoon, Mi Yung. “Explaining Women's Legislative Representation in Sub-Saharan Africa." Legislative Studies Quarterly 29, no. 3 (2004): 447-68.

Zhang, Xiaobo. "Fiscal Decentralization and Political Centralization in China: Implications for Growth and Inequality." Journal of Comparative Economics 34, no. 4 (2006): 713-726.

Zenger, J., and J. Folkman. "A Study in Leadership: Women Do It Better than Men." Orem, Utah: Zenger Folkman Inc., 2012. 


\section{ADDENDUM ON VALORIZATION OF THE DISSERTATION}

\section{Research Relevance}

This research effort attempts to demonstrate how new measurement approaches can effectively capture increased data detailing women's access to positions of formal political decision-making across differing regions and political systems. The design of the tool (Diamond Index), and goal in mapping it in 40 countries - many of them recognized as "data scarce" - was to test the premise that not only could a more nuanced measurement approach be developed, but quality data could be reliably gathered on a global scale. The challenge was, therefore, to not only broaden and deepen the selection of indicators, but to also ensure that: 1) indicators selected were similar across all political systems and regions, 2) the data was of high quality, and 3) the data could be collected effectively on a global scale.

The ability to include a wider array of data, including from less-researched countries, can help stakeholders gain a more thorough understanding of women's formal political representation. Fast-track quotas across the whole of government, years of authoritarianism, one-party rule, civil war, and tribal violence are factors less accounted for in the current academic and development literature surrounding women's political descriptive representation. Expanding our views to account for the many ways women are moving into the political arena is needed to not only challenge Western assumptions, but to ensure a more accurate reflection of what is happening globally. With better data - in particular if gathered over time-interested parties can begin to weave a much richer narrative in relation to women's presence in the political space.

\section{Research Target Groups}

As a democracy practitioner working for a development agency, the genesis of this academic undertaking grew out of frustration with the lack of available data on women in the political space. An explicit goal of this research was to create a tool that that could be replicated by a variety of stakeholders, including governments, civil society organizations, and development practitioners. Using publically available data to the greatest extent possible, the methodology for collecting, weighting, calculating, and aggregating the data was designed to be logical and straightforward in its application. The intent in designing the index was to provide a tool that any group or individual could replicate according to their own need and timeframe. Rather than await the annual publication of gender indexes that focus on 
a few global measures, stakeholders are empowered to replicate the tool in their own respective countries as part of a wider gender or political-economy analysis - or simply to better measure and track women's representational progress. In essence, the design of the Diamond Index measurement tool attempted to strike a balance between academic rigor, data accessibility, and practical application.

My particular interest in developing the Diamond Index was to measure women's political representation. Other groups may find value, however, in redefining the tool as a measurement for representing an array of categories: tribes, religions, persons with disabilities, or youth in decision-making positions across government. The index is easily adaptable for descriptively measuring a variety of marginalized or targeted groups of interest.

\section{Research Innovation}

This research builds off previous efforts undertaken by the United Nations, World Economic Forum, Organization for Economic Cooperation and Development, Social Watch, and the European Institute of Gender Equality, among others. Findings of the research demonstrated that a new measurement approach, aimed at expanding the available data on women political decision-makers, was viable. This research project was able to collect $86.7 \%$ of all measures attempted. Excluding the security domain, where the majority of gaps existed, the measurement index was able to gather $94.4 \%$ of the data points. Much of this data -9 of the 12 indicators - was new information previously not collected at the level of detail offered in this research. Eight of the 12 indicators were considered of high quality. Equally important, the information was culled from a wide variety of countries. The more traditional countries of study including those based in Scandinavia, Western Europe, or most of North America - were not included. As a result, a number of low-income countries excluded from other global indexes, many of them considered data-scarce and off the academic grid, were successfully included.

The design of the index reinforces the need to reach across all government branches from a horizontal perspective to better identify percentages of women. While acknowledging that higher percentages of women are important, the measurement tool then takes the additional step of assigning differing decision-making authority to selected positions based on a weighting system. This arrangement of data, examined through both a horizontal and vertical lens, holds the potential for combining data in different ways to identify trends and patterns that have not been fully examined through current gender indexes. With this information academics, governments, practitioners, and advocates can begin to explore, for example, where women are 
accessing elected verses appointed positions, what level of position, in what type of regime, and under what conditions.

Another area of innovation is the amount of data collected on women leaders in the security sector. To date, most information available represents overall numbers of women in an institution, such as the military or police. By focusing on the leadership hierarchy within national police forces, the Diamond Index paints a more robust picture of potential influence women have in the chain of command. Given the importance of this sector in the lives of women and children, it seems likely based on predicted upheaval from future climate change, conflict across regions, and ongoing terrorism threats - that the issue of security will grow in importance. In particular, how women are represented in decision-making roles, and its relation to high levels of insecurity, remains understudied in the academic and development literature. This research effort provides new data for this field of study.

\section{Research Products}

The Diamond Index also adds value as an advocacy and benchmarking tool with which to hold government accountable. Its detailed presentation of women's descriptive representation allows for more targeted advocacy around specific branches of government or within institutions themselves. For example, in one country we may see large numbers of women parliamentarians elected but a small percentage of women holding committee leadership positions. Rather than arguing for more elected women, the point of advocacy may be to narrow the disparity in women committee chairs. In instances where commitments are not being met, the index is an easily understood visualization of where the country is falling behind. In instances where a country is exceeding expectations, the tool can be used to leverage greater awareness of gains being made to the local population or a wider global audience.

The Diamond Index has been introduced and used by the United States Agency for International Development to better document women's participation in the political space in select countries. This analysis has been used to help design country strategies and program activities. Several "spin-off" activities have also evolved from the original research work undertaken on the Diamond Index. This includes a joint research project between the United Nations Development Program and the Graduate School of Public and International Affairs at the University of Pittsburgh. Between September 2015 and November 2017, more than 70 graduate students logged over 7,000 person-hours to help UNDP collect, visualize, and analyze countrylevel data on women's leadership in public administration. This information will be 
used, in part, to support progress of the UN Sustainable Development Goals. Efforts to expand the use of the Diamond Index as a measurement and analytical gender tool continue at the United States Agency for International Development. 


\section{BIOGRAPHY}

Ms. Lott began her professional career as a journalist, working for a variety of publications in the United States and Africa. Human interest stories, travel, and politics across the Horn of Africa were the primary areas of reporting. Ms. Lott's work as a journalist in Somalia led to her embarking on a second career in international development. After working as a consultant and professional with several non-governmental organizations, she joined the United States Agency for International Development as a democracy and governance specialist. Ms. Lott has worked on development projects across the globe, from Africa to Latin America to Asia. Areas of expertise include gender, civil society, and elections. Ms. Lott is currently the Deputy Mission Director for USAID/Malawi, where she resides with her two teenage daughters. Ms. Lott holds a Bachelor of Arts from the University of California, Santa Barbara; Master of Arts from Syracuse University, New York; and Doctor of Philosophy from Maastricht University, Netherlands. 


\section{UNU-MERIT/MGSoG Dissertation Series}

2019

Ana Cristina Calderon Ramirez

Public Management Reforms

Three stories about public procurement agencification in Latin America

UNU-MERIT/MGSoG Dissertation

Series № 226

\section{Camilo Nicanor Carrillo Purin}

Teachers' in-service training and student achievement:

The effect of in-service training of

Peruvian teachers on student

achievement

UNU-MERIT/MGSoG Dissertation

Series № 225

\section{Hugo Confraria}

Developing scientific capacity in the

Global South

UNU-MERIT/MGSoG Dissertation

Series № 224

\section{Alison Cathles}

Educational Pathways and Skills:

Past, Present, and Future

UNU-MERIT/MGSoG Dissertation

Series № 223
Ibrahima Sory Kaba

Aggregate Fluctuations and

Development: Essays on

Macroeconomic Volatility and

Economic Growth

UNU-MERIT/MGSoG Dissertation

Series № 222

\section{Charlotte Keijser}

Firm Participation, Learning and

Innovation in Heterogenous Value

Chains of IT-enabled Services

UNU-MERIT/MGSoG Dissertation

Series № 221

\section{Salih Çevikarslan}

Innovation Strategies and Their

Implications for Technological Change

and Market Outcomes:

An Evolutionary Multi-Agent Based

Modelling Approach

UNU-MERIT/MGSoG Dissertation

Series № 220

Wondimagegn Mesfin Tesfaye

Essays on the Impacts of Climate-

Smart Agricultural Innovations on

Household Welfare

UNU-MERIT/MGSoG Dissertation

Series № 219 


\section{Tatevik Poghosyan}

How Board Networks Affect Firm

Performance and Innovation Incentives

in Transition Economies: The Case of

Armenia

UNU-MERIT/MGSoG Dissertation

Series № 218

\section{Arip Muttaqien}

Essays on Inequality and Polirization:

Empirical Studies in Developing Asia

UNU-MERIT/MGSoG Dissertation

Series № 217

2018

\section{Katrin Marchand}

Essays on Forced Migration and

Labour Market Participation in

Developing Countries

UNU-MERIT/MGSoG Dissertation

Series № 216

\section{Ortrun Merkle}

The Myth of Gender Neutral Power:

Corruption and Gender Norms

UNU-MERIT/MGSoG Dissertation

Series № 215

\section{Biljana Meshkovska}

Life after Trafficking:

(re)integration processes of women that have been trafficked for the purpose of sexual exploitation in Europe

UNU-MERIT/MGSoG Dissertation

Series № 214

\section{Vincenzo Vinci}

The Relevance of Institutions and

People's Preferences for Social

Protection

UNU-MERIT/MGSoG Dissertation

Series № 213

\section{Silke Heuser}

The Effectiveness of Environmental

Policies on Reducing Deforestation in

the Brazilian Amazon

UNU-MERIT/MGSoG Dissertation

Series № 212

\section{Jennifer Waidler}

Social Assistance and Remittances and Their Role in the Fight Against

Poverty

UNU-MERIT/MGSoG Dissertation

Series № 211

\section{Choolwe Muzyamba}

The role of community mobilization in the promotion of maternal health of women living with HIV in Zambia UNU-MERIT/MGSoG Dissertation Series № 210

\section{Juan Carlos A. Castillo Sánchez}

Assessing the Role of the Export Sector in Mexican Economic

Development,1965-2014

UNU-MERIT/MGSoG Dissertation

Series № 209

\section{Tareq Abuelhaj}

Food Security Policy Impact Analysis:

The Econometrics of Cash and Food

Assistance Cost Effectiveness

UNU-MERIT/MGSoG Dissertation

Series № 208 
Marta Férnandez de Arroyabe Arranz

Essays on MEAS and Innovation

UNU-MERIT/MGSoG Dissertation

Series № 207

\section{Clotilde Mahé}

Essays on Migration and Occupational Choice

UNU-MERIT/MGSoG Dissertation Series № 206

\section{Simone Sasso}

Talent on the move. Essays on Human Capital, Graduate Mobility and

Economic Development

UNU-MERIT/MGSoG Dissertation

Series № 205

\section{Khaled Walid Rajab}

Strategic Planning under Fragility

UNU-MERIT/MGSoG Dissertation

Series № 204

\section{Mutinta Hambayi Nseluke}

A Tall Order: Improving Child Linear Growth

UNU-MERIT/MGSoG Dissertation

Series № 203

\section{Elvis Korku Avenyo}

Innovations and Firm Performance

in sub-Saharan Africa: Empirical

Analyses

UNU-MERIT/MGSoG Dissertation

Series № 202

\section{Ni Zhen}

Employment Dynamics, Firm

Performance and Innovation

Persistence in the Context of

Differentiated Innovation Types:

Evidence from Luxembourg

UNU-MERIT/MGSoG Dissertation

Series № 201

\section{Caroline Wehner}

Too Scared to Achieve: The Relation

Between Neuroticism,

Conscientiousness

and Socioeconomic Outcomes

UNU-MERIT/MGSoG Dissertation

Series № 200

\section{Stefania Innocenti}

On Institutional Persistence

UNU-MERIT/MGSoG Dissertation

Series № 199

\section{Hassen Abda Wako}

Economic Globalization, Institutions and Development: Essays on Aid, Foreign Direct Investment and Trade UNU-MERIT/MGSoG Dissertation Series № 198

\section{7}

\section{Hans-Erik Edsand}

Winds of Change

UNU-MERIT/MGSoG Dissertation Series № 197

\section{Ana Patricia Silva Vara}

Redressing the Gender Gap

UNU-MERIT/MGSoG Dissertation

Series № 196 


\section{Andrés Iván Mideros Mora}

Essays on the Economic Effects of Noncontributory Social Protection

UNU-MERIT/MGSoG Dissertation

Series № 195

\section{Tobias Broich}

New Actors in the Global Economy

UNU-MERIT/MGSoG Dissertation

Series № 194

\section{Bernard Nikaj}

From No-government to E-government

UNU-MERIT/MGSoG Dissertation

Series № 193

\section{Ali Safarnejad}

Prioritizing the HIV Response

UNU-MERIT/MGSoG Dissertation

Series № 192

\section{Clovis Freire}

Diversification and Structural

Economic Dynamics

UNU-MERIT/MGSoG Dissertation

Series № 191

\section{Michael Verba}

Innovation and Knowledge Dynamics:

Essays on the Knowledge Economy

UNU-MERIT/MGSoG Dissertation

Series № 190

\section{Pui Hang Wong}

The Hearts and Minds in Conflict and

Peace: The Economics of

Counterinsurgency and the Psychology of Reconstruction

UNU-MERIT/MGSoG Dissertation

Series № 189

\section{Brenda Yamba}

Schooling Despite All Odds: Evidence from Lesotho on Female Child Carers who Stayed in School

UNU-MERIT/MGSoG Dissertation Series № 188

\section{Sheng Zhong}

Moving towards An Energy Efficient

Future: Essays on Energy Efficiency,

Technology and Development

UNU-MERIT/MGSoG Dissertation

Series № 187

\section{Julieta Marotta}

Access to Justice and Legal

Empowerment of Victims of Domestic

Violence through Legal Organizations

in the City of Buenos Aires: A

Qualitative Empirical Legal Study

UNU-MERIT/MGSoG Dissertation

Series, № 186

\section{Andrea Franco-Correa}

On the Measurement of

Multidimensional Poverty as a Policy

Tool: Empirical Applications to Chile,

Colombia, Ecuador and Peru

UNU-MERIT/MGSoG Dissertation

Series, № 185

\section{6}

\section{Yesuf Awel}

Insurance for Growth: Empirical

Essays on Insurance Demand and

Impacts in Africa

UNU-MERIT Dissertation Series,

№ 108 
Tigist Mekonnen Melesse

Grow More Food using Fewer

Resources: Agricultural Technology

Adoption and Innovation Practices for

Inclusive and Sustainable

Development

UNU-MERIT Dissertation Series, № 107

\section{Eleni Yitbarek}

Getting Ahead or left Behind? Essays

on Poverty Dynamics and Social

Mobility in Africa

UNU-MERIT Dissertation Series, № 106

\section{Thuy Dieu Nguyen}

Firm-Level Theory and Evidence of

Corruption

UNU-MERIT Dissertation Series,

№ 105

\section{Raquel Tsukada Lehman}

Essays on Household Production with

Labor-Saving Technology

UNU-MERIT Dissertation Series,

№ 104

\section{Eva Barteková}

Multi-Problem Challenges for a

Renewable Future: Empirical Studies

on Competitive Disadvantages from

Electricity Price Differentials and

Mineral Supply Risk in an Open

Economy

UNU-MERIT Dissertation Series,

№ 103

\section{Jocelyn Olivari}

Entrepreneurial Traits and Innovation:

Evidence from Chile

UNU-MERIT Dissertation Series,

№ 102

\section{Muhammad Shafique}

Essays on the role of knowledge, RED, and Technology-based Firms in the Evolution of Socio-techno-economic System

UNU-MERIT Dissertation Series, № 101

\section{Serdar Türkeli}

Governance of Innovation Policy:

Empirical Studies on Applied Political Economy by Multi-Methods Analysis UNU-MERIT Dissertation Series, № 100

\section{Ayokunu Adedokun}

Pathways to Sustainable Peace

building in Divided Societies: Lessons

and Experiences from Mozambique

MGSoG Dissertation Series, № 75

\section{Luiz Rothier Bautzer}

Organizing Concurrent Engineering through ICT Platforms

Blueprinting Product Lifecycle

Management Platforms across

Disciplinary Agencies

MGSoG Dissertation Series, № 74 


\section{Natalia Popova}

Migration in the Periphery of the

European Union:

Determinants of Successful and

Sustainable Labour Market Integration of Return Migrants in Albania, Egypt, Moldova and Tunisia

MGSoG Dissertations Series, № 73

\section{Richard A. Martina}

Uncertainty and Resource Constraint in the Small Island Developing States: Essays in Entrepreneurial Cognition MGSoG Dissertations Series, № 72

\section{Cécile Cherrier}

The Expansion of Basic Social

Protection in Low-income Countries:

An Analysis of Foreign Aid Actors'

Role in the Emergence of Social

Transfers in Sub-Saharan Africa

MGSoG Dissertations series, № 71

\section{Paul Caldron}

The Tacit Bargain in Short-Term

Medical Missions: Why U.S.

physicians go and what it costs

MGSoG Dissertation Series, № 70

\section{Mahmut Kobal}

Customs E Excellence: A Comparative Approach on Administrative and Regulatory Compliance Perspectives of the EU-Turkey Customs Union MGSoG Dissertation Series, № 69

\section{Craig Loschmann}

Essays on Conflict-related Migration and Development in the Case of

Afghanistan

MGSoG Dissertations Series, № 68

\section{Andrea Milan}

Rural Livelihoods, Location and

Vulnerable Environments: Approaches

to Migration in Mountain areas of

Latin America

MGSoG Dissertation Series, № 67

\section{Farida Lada}

On Guarding the Welfare of Clinical

Trial Subjects While Promoting Novel

Drug Innovation

A Game Theoretical Approach

MGSoG Dissertation Series, № 66

\section{5}

\section{Hibret Belete Maemir}

Dissecting Aggregate Productivity:

International Integration and Growth with Heterogeneous Firms

UNU-MERIT Dissertation Series, № 96

\section{Giorgio Triulzi}

Looking for the Right Path: Technology

Dynamics, Inventive Strategies and

Catching-up in the Semiconductor

Industry

UNU-MERIT Dissertation Series, № 95
Abdul Baseer Qazi
Knowledge flows and networks in the
ICT sector: The case of Pakistan
UNU-MERIT Dissertation Series, № 94 


\section{Ajay Thutupalli}

Technology Paradigm Shifts in

Agriculture: Drivers of Sustainability

and Catch up

UNU-MERIT Dissertation Series, № 93

\section{Eduardo Urias}

Improving access to HIV/AIDS

treatment in Brazil: When are

Compulsory Licenses effective in Price

Negotiations?

UNU-MERIT Dissertation Series, № 92

\section{Francesca Guadagno}

Why have so few Countries

Industrialised?

UNU-MERIT Dissertation Series, № 91

\section{Daniel Opolot}

The Evolution of Beliefs and Strategic

Behaviour

UNU-MERIT Dissertation Series, № 90

\section{Alejandro Lavopa}

Structural Transformation and

Economic Development: Can

Development Traps be Avoided

UNU-MERIT Dissertation Series, № 89

\section{Jinjin Zhao}

Urban water management reform: The

Case of China

UNU-MERIT Dissertation Series, № 88

\section{Simona Vezzoli}

Borders, Independence and Post-

colonial Ties: the Role of the State in

Caribbean Migration

MGSoG Dissertation Series, № 65

\section{Silvia Consuelo Gómez Soler}

Civil Conflict and Education: How

Does Exposure to Civil Conflict Affect

Human Capital Accumulation?

Evidence from Standardized Exit

Exams in Colombia

MGSoG Dissertation Series, № 64

\section{Paula Nagler}

Occupational Choice in the Developing

World

MGSoG Dissertation Series, № 63

\section{Jasmin Kientzel}

Determinants of Professional

Commitment to Environmental

Sustainability

MGSoG Dissertation Series, № 62

\section{Mehmet Güney Celbiş}

Regional Policies: Convergence, Trade, and the Allocation of Public Capital MGSoG Dissertation Series, № 61

\section{Florian Henning}

Living Up to Standard:

Interoperability Governance and

Standards Adoption in Government

Information Networks

MGSoG Dissertation Series, № 60 
Niels P. Groen

2014

The Never-Ending Project

Understanding E-Government Project

Escalation

MGSoG Dissertation Series, № 59

\section{Derek Copp}

Teacher-Based Reactivity to Provincial

Large-scale Assessment in Canada

MGSoG Dissertation Series, № 58

\section{Michaella Vanore}

Family-Member Migration and the

Psychosocial Health Outcomes of

Children in Moldova and Georgia

MGSoG Dissertation Series, № 57

\section{Sonja Fransen}

The Economic and Social Effects of

Remittances and Return Migration in

Conflict-Affected Areas: The Case of

Burundi

MGSoG Dissertation Series, № 56

\section{Ibrahim Khalil Conteh}

The Impact of Floods on Primary

School Education in Zambia

MGSoG Dissertation Series, № 55

\section{Richard Bluhm}

Growth Dynamics and Development

Essays in Applied Econometrics and

Political Economy

MGSoG Dissertation Series, № 54

\section{Nevena P. Zhelyazkova}

Work-Family Reconciliation and Use of Parental Leave in Luxembourg:

Empirical Analysis of Administrative Records

MGSoG Dissertation Series, № 53

\section{Dirk Crass}

The Impact of Brands on Innovation and Firm Performance: Empirical Evidence from Germany

UNU-MERIT Dissertation Series, № 87

\section{Samyukta Bhupatiraju}

The Geographic Dimensions of Growth and Development

UNU-MERIT Dissertation Series, № 86

\section{François Lafond}

TheEvolution of Knowledge Systems UNU-MERIT Dissertation Series, № 85

\section{Annalisa Primi}

Promoting Innovation in Latin

America: What Countries Have

Learned (and What They Have Not) in

Designing and Implementing

Innovation and Intellectual Property

Policies

UNU-MERIT Dissertation Series,

№ 84

\section{Fatoumata Lamarana Diallo}

Evaluation of Meal and Deworming

Programs for Primary Schools in Rural Senegal

UNU-MERIT Dissertation Series, № 83 


\section{Sachin Kumar Badkas}

Metachoice and Metadata: Innovating with Environmental Policy Analysis in Europe

MGSoG Dissertation Series, № 52

\section{Irina S. Burlacu}

An Evaluation of Tax-Benefit Systems Impact on the Welfare of Frontier

Worker:

The Case of Luxembourg and Belgium MGSoG Dissertation Series, № 51

\section{Özge Bilgili}

Simultaneity in Transnational

Migration Research: Links Between

Migrants' Host and Home Country

Orientation

MGSoG Dissertation Series, № 50

\section{Yulia Privalova Krieger}

Reshaping the Big Agenda:

Transnational Politics and Domestic ResistanceFinancial crisis and social protection reform in Bosnia and

Herzegovina

MGSoG Dissertation Series, № 49

\section{Marieke van Houte}

Moving Back or Moving Forward?

Return migration after Conflict

MGSoG Dissertation Series, № 48

\section{Oxana Slobozhan}

Global Governance in the Management of Natural Resources: The Case of the Extractive Industries Transparency Initiative (EITI)

MGSoG Dissertation Series, № 47

\section{Luis Bernardo Mejia Guinand}

The Changing Role of the Central

Planning Offices in Latin America: A

Comparative Historical Analysis

Perspective (1950-2013)

MGSoG Dissertation Series, № 46

\section{Cheng Boon Ong}

Ethnic Segregation in Housing,

Schools and Neighbourhoods in the

Netherlands

MGSoG Dissertation Series, № 45

\section{Luciana V. Cingolani}

Bureaucracies for Development:

Oxymoron or Reality? Studies on State

Capacity in Challenging Governance

Contexts

MGSoG Dissertation Series, № 44

\section{Carlos Cadena Gaitán}

Green Politics in Latin American

Cities - Sustainable Transport Agendas

MGSoG Dissertation Series, № 43

\section{Katie Kuschminder}

Female Return Migration and

Reintegration Strategies in Ethiopia

MGSoG Dissertation Series, № 42

\section{Metka Hercog}

Highly-Skilled Migration and New

Destination Countries

MGSoG Dissertation Series, № 41

\section{Margaret Agaba Rugadya}

Can Remittances Influence the Tenure and Quality of Housing in Uganda?

MGSoG Dissertation Series, № 40 


\section{Ilire Agimi}

New Governance Under Limited

Statehood: The Case of Local

Government Reform in Kosovo

MGSoG Dissertation Series, № 39

\section{3}

Anant Kamath

Information Sharing through Informal

Interaction in Low-Tech Clusters

UNU-MERIT Dissertation Series, № 82

\section{Flavia Pereira de Carvalho}

What we talk about when we talk about

Brazilian Multinationals: An

Investigation on Brazilian FDI,

Economic Structure, Innovation and

the Relationship between them

UNU-MERIT Dissertation Series, № 81

\section{Jun Hou}

Complementarity in Innovation and

Development: A Cross-country

Comparison

UNU-MERIT Dissertation Series, № 80

\section{Rufin Baghana}

Impacts of Government Incentives to $R \mathcal{E} D$, Innovation and Productivity: A Microeconometric Analysis of the Québec Case

UNU-MERIT Dissertation Series, № 79

\section{Lilia I. Stubrin}

High-Tech Activities in Emerging

Countries: A Network perspective on

the Argentinean Biotech Activity

UNU-MERIT/MGSoG Dissertation

Series, № 78

\section{Kristine Farla}

Empirical Studies on Institutions,

Policies and Economic Development

MGSoG Dissertation Series, № 38

\section{Marina Petrovic}

Social Assistance and Activation in the

Pursuit of Happiness: Shedding New

Light on Old Policy Solutions to Social

Exclusion

MGSoG Dissertation Series, № 37

\section{Laura Torvinen}

Assessing Governance Assessments:

The Case of Mozambique: Governance Assessments in the Context of Aid

Effectiveness Discourse

MGSoG Dissertation Series, № 36

\section{Biniam Egu Bedasso}

Institutional Change in the Long

Shadow of Elite: Essays on

Institutions, Human Capital and

Ethnicity in Developing Countries

MGSoG Dissertation Series, № 35

\section{Sepideh Yousefzadeh Faal}

\section{Deghati}

Childhoods Embargoed: Constructing

and Reconstructing Multidimensional

Child Poverty in Iran 1984-2009

MGSoG Dissertation Series, № 34 


\section{Robert Bauchmüller}

Investing in Early Childhood Care and

Education: The Impact of Quality on

Inequality

MGSoG Dissertation Series, № 33

\section{Martin Rehm}

Unified Yet Separated: Empirical

Study on the Impact of Hierarchical

Positions within Communities of

Learning

MGSoG Dissertation Series, № 32

\section{2}

\author{
Abdul Waheed \\ Innovation Determinants and \\ Innovation as a Determinant: Evidence \\ from Developing Countries \\ UNU-MERIT Dissertation Series, \\ № 77
}

\section{Bilal Mirza}

Energy Poverty and Rural Energy

Markets in Pakistan

UNU-MERIT Dissertation Series, № 76

\section{Benjamin Engelstätter}

Enterprise Software and Video Games:

An Empirical Analysis

UNU-MERIT Dissertation Series,

№ 75

\section{Fulvia Farinelli}

Natural Resources, Innovation and

Export Growth: The Wine Industry in

Chili and Argentina

UNU-MERIT Dissertation Series

\section{Rodolfo Lauterbach}

Innovation in Manufacturing: From

Product Variety and Labor

Productivity Growth to Economic

Development in Chile

UNU-MERIT Dissertation Series

\section{Kirsten Wiebe}

Quantitative Assessment of

Sustainable Development and Growth in Sub-Saharan Africa

UNU-MERIT Dissertation Series, № 74

\section{Julio Miguel Rosa}

Organizational Strategies, Firms'

Performance and Spatial Spillovers:

The Canadian Case in Research and

Development.

UNU-MERIT Dissertation Series, № 73

Johannes Wilhelmus Marie Boels Joseph Schumpeter, Honderd Jaar Economische Ontwikkeling: Een Historisch-theoretische Beschouwing. UNU-MERIT Dissertation Series

\section{Dorcas Mbuvi}

Utility Reforms and Performance of the Urban Water Sector in Africa

MGSoG Dissertation Series, № 31

\section{Lina Salanauskaite}

Distributional Impacts of Public

Policies: Essays in Ex-Ante and Ex-

Post Evaluation

MGSoG Dissertation Series, № 30 


\section{Esther Schüring}

To Condition or not - is that the

Question?

An Analysis of the Effectiveness of ExAnte and Ex-Post Conditionality in

Social Cash Transfer Programs

MGSoG Dissertation Series, № 29

\section{Joe Abah}

Strong Organisations in Weak States:

Atypical Public Sector Performance in

Dysfunctional Environments

MGSoG Dissertation Series, № 28

\section{Zina Samih Nimeh}

Social Citizenship Rights: Inequality and Exclusion

MGSoG Dissertation Series, № 27

2011

\section{Daniel Vertesy}

Interrupted Innovation: Emerging

Economies in the Structure of the

Global Aerospace Industry

UNU-MERIT Dissertation Series,

№ 72

\section{Tina Saebi}

Successfully Managing Alliance

Portfolios: AnAlliance Capability View

UNU-MERIT Dissertation Series,

№ 71

\section{Nora Engel}

Tuberculosis in India: A Case of

Innovation and Control

UNU-MERIT/MGSoG Dissertation

Series, № 70

\section{Evans Mupela}

Connectivity and growth in Sub-

Saharan Africa: The Role of

Communication Satellites

UNU-MERIT Dissertation Series, № 69

\section{Nantawan Kwanjai}

Cross Cultural Intelligence amid

Intricate Cultural Webs: A Tale of the

UnDutchables in the Land of 1002

Smiles

UNU-MERIT Dissertation Series, № 68

\section{Lina Sonne}

Innovation in Finance to Finance

Innovation: Supporting Pro-poor

Entrepreneur-based Innovation

UNU-MERIT Dissertation Series, № 67

\section{Lenka Eisenhamerová}

Legitimacy of 'Humanitarian Military Intervention'

MGSoG Dissertation Series, № 26

\section{Sonila Tomini}

Informal Payments for Health Care

Services in Albania

MGSoG Dissertation Series, № 25

\section{Jinjing Li}

Dynamic Microsimulation in Public

Policy Evaluation

MGSoG Dissertation Series, № 24 


\section{Aziz Atamanov}

Rural Nonfarm Employment and International Migration as

Alternatives to Agricultural

Employment: The Case of Kyrgyzstan

MGSoG Dissertation Series, № 23

\section{Frieda Vandeninden}

Poverty Alleviation: Aid and Social

Pensions

MGSoG Dissertation Series, № 22

\section{Juliana Nyasha Tirivayi}

The Welfare Effects of Integrating

AIDS Treatment with Food Transfers:

Evidence from Zambia

MGSoG Dissertation Series, № 21

\section{Agnieska Ewa Sowa}

Who's Left Behind? Social Dimensions of Health Transition and Utilization of Medical Care in Poland

MGSoG Dissertation Series, № 20

\section{Emmanaouil Sfakianakis}

The Role of Private Actors in the

Provision of Public Goods with

Applications to Infrastructure and

Financial Stability

MGSoG Dissertation Series, № 19

\section{Siu Hing Lo}

White Collars Green Sleeves: An Interorganizational Comparison of

Determinants of Energy-Related

Behaviors among Office Workers

MGSoG Dissertation Series, № 18

\section{Treena $\mathbf{W u}$}

Constraints to Human Capital

Investment in Developing Countries:

Using the Asian Financial Crisis in

Indonesia as a Natural Experiment

MGSoG Dissertation Series, № 17

\section{Henry Espinoza Peña}

Impact Evaluation of a Job-Training

Programme for Disadvantaged Youths:

The Case of Projoven

MGSoG Dissertation Series, № 16

2010

Fernando Santiago

Human Resources Management

Practices and Learning for Innovation in Developing Countries:

Pharmaceutical Firms in Mexico

UNU-MERIT Dissertation Series,

№ 66

\section{Zakaria Babutsidze}

Essays on Economies with

Heterogeneous Interacting Consumers

UNU-MERIT Dissertation Series,

№ 65

\section{Bertha Vallejo}

Learning and Innovation Under

Changing Market Conditions: The

Auto Parts Industry in Mexico

UNU-MERIT Dissertation Series,

№ 64 


\section{Donatus Ayitey}

Technical Change, Competitiveness and Poverty Reduction: A Study of the Ghanaian Apparel Industry

UNU-MERIT Dissertation Series, № 63

\section{Sergey Filippov}

Multinational Subsidiary Evolution:

Corporate Change in New EU Member States

UNU-MERIT Dissertation Series, № 62

\section{Asel Doranova}

Technology Transfer and Learning under the Kyoto Regime: Exploring the Technological Impact of CDM Projects in Developing Countries

UNU-MERIT Dissertation Series, № 61

\section{Florian Tomini}

Between Family and Friend:

Understanding the Interdependency of Private Transfers

MGSoG Dissertation Series, № 15

\section{Michał Polalowski}

The Institutional Transformation of Social Policy in East Central Europe: Poland and Hungary in Comparative and Historical Perspective MGSoG Dissertation Series, № 14

\section{Maha Ahmed}

Defining, Measuring and Addressing Vulnerability: The Case of Post

Conflict Environments MGSoG Dissertation Series, № 13

\section{Pascal Beckers}

Local Space and Economic Success: The Role of Spatial Segregation of Migrants in the Netherlands

MGSoG Dissertation Series, № 12

\section{Victor Cebotari}

Conflicting Demands in Ethnically

Diverse Societies: Ethno political

Contention and Identity Values in

Europe

MGSoG Dissertation Series, № 11

\section{Dennis Gyllensporre}

Competing and Complementary Perspectives on the EU as a Crisis Management Actor:

An Examination of the Common Security and Defence Policy through the Lenses of Idealism and Realism MGSoG Dissertation Series, № 10

\section{Judit Vall Castello}

Business Cycle and Policy Effects on Labour Market Transitions of Older and Disabled Workers in Spain MGSoG Dissertation Series, № 9

\section{Keetie Roelen}

False Positives or Hidden Dimensions:

The Definition and Measurement of

Child Poverty

MGSoG Dissertation Series, № 8

\section{Denisa Maria Sologon}

Earning Dynamics in Europe

MGSoG Dissertation Series, № 7 


\section{Melissa Siegel}

Money and Mobility: Migration and Remittances

MGSoG Dissertation Series, № 6

\section{Jessica S. Hagen-Zanker}

Modest Expectations: Causes and

Effects of Migration on Migrant

Households inSource Countries

MGSoG Dissertation Series, № 5

2009

\begin{abstract}
Alexis Habiyaremye
From Primary Commodity Dependence to Diversification and Growth:

Absorptive Capacity and Technological Catch Up in Botswana and Mauritius. UNU-MERIT Dissertation Series, № 60
\end{abstract}

\section{Yoseph Getachew}

The Role of Public Capital in Economic Development

UNU-MERIT Dissertation Series, № 59

\section{Sandra Leitner}

Embodied Technological Change and

Patterns of Investment in Austrian

Manufacturing

UNU-MERIT Dissertation Series, № 58

\section{Semih Akçomak}

The Impact of Social Capital on Economic and Social Outcomes UNU-MERIT Dissertation Series, № 57

\author{
Abraham Garcia \\ The Role of Demand in Technical \\ Change \\ UNU-MERIT Dissertation Series, \\ № 56
}

\section{Saurabh Arora}

Coherence in Socio-technical Systems: A Network Perspective on the Innovation Process

UNU-MERIT Dissertation Series, № 55

\section{Mirtha R. Muniz Castillo}

Human Development and Autonomy in Project Aid: Experiences from four bilateral projects in Nicaragua and El Salvador

MGSoG Dissertation Series, № 4

\section{Christiane Arndt}

Governance Indicators

MGSoG Dissertation Series, № 3

\section{Britta Augsburg}

Microfinance: Greater Good or Lesser Evil?

MGSoG Dissertation Series, № 2

\section{8}

\section{Rutger Daems}

Medicines for the Developing World UNU-MERIT Dissertation Series, № 54 
Johannes Hanel

Assessing Induced Technology:

Sombart's Understanding of Technical

Change in the History of Economics

UNU-MERIT Dissertation Series,

\section{№ 53}

\section{Rifka Weehuizen}

Mental Capital: the Economic

Significance of Mental Health

UNU-MERIT Dissertation Series, № 52

\section{Danielle Cloodt}

The Relationship between RED

Partnership Formation, Social

Embeddedness and Innovative

Performance

UNU-MERIT Dissertation Series, № 51

\section{Sabine Fuss}

Sustainable Energy Development

under Uncertainty

UNU-MERIT Dissertation Series, № 50

\section{Geranda Notten}

Measuring and Managing Poverty

Risks

MGSoG Dissertation Series, № 1

2007

\section{Tobias Kronenberg}

Reconciling Environmental

Conservation with Economic

Prosperity: The Feasibility of Double

Dividends in the Short and Long Run

UNU-MERIT Dissertation Series, № 49

\section{Viktoria Kravtsova}

Assessing the Impact of Foreign Direct Investment in Transition Economies UNU-MERIT Dissertation Series, № 48

\section{Suhail Sultan}

The Competitive Advantage of Small and Medium Sized Enterprises: The Case of Jordan's Natural Stone Industry

UNU-MERIT Dissertation Series, № 47

2006

\section{Bulat Sanditov}

Essays on Social Learning and Imitation

UNU-MERIT Dissertation Series, № 46

\section{Mamata Parhi}

Dynamics of New Technology Diffusion: A Study of the Indian Automotive Industry UNU-MERIT Dissertation Series, № 45

\section{Andreas Reinstaller}

Social Structures and the Innovation Process: Their Role in the Demand of Firms and Consumers

UNU-MERIT Dissertation Series, № 44 


\section{Rose Kiggundu}

Innovation systems and Development:

The Journey of a Beleaguered Nile

Perch Fishery in Uganda

UNU-MERIT Dissertation Series,

№ 43

\section{Thomas Pogue}

The Evolution of Research

Collaboration in South African Gold

Mining: 1886-1933

UNU-MERIT Dissertation Series,

№ 42

\section{Geoffrey Gachino}

Foreign Direct Investment, Spillovers and Innovation: The Case of Kenyan

Manufacturing Industry

UNU-MERIT Dissertation Series, № 41

\section{Önder Nomaler}

Technological Change, International

Trade and Growth: An Evolutionary,

Multi-Agents-Based Modeling

Approach

UNU-MERIT Dissertation Series, № 40

\section{5}

\section{Samia Satti Osman Mohamed-}

Nour

Change and Skill Development in the Arab Gulf Countries

UNU-MERIT Dissertation Series, № 39

\section{Elad Harison}

Intellectual Property Rights:

Economics and Policy Analysis

UNU-MERIT Dissertation Series, № 38

\section{Daniel Dalohoun}

Learning to innovate: agricultural innovation and entrepreneurship: the case of Songhaï farmers in Benin UNU-MERIT Dissertation Series, № 37

\section{Müge Ozman}

Networks, Organizations and

Knowledge

UNU-MERIT Dissertation Series,

№ 36

\section{Bas Straathof}

Product Variety and Economic

Growth: The Counteracting Effects of Scale and Idiosyncrasy

UNU-MERIT Dissertation Series, № 35

\section{Wilfred Schoenmakers}

Knowledge Flows between

Multinational Companies: A Patent

Data Analysis

UNU-MERIT Dissertation Series, № 34

\section{Myriam Cloodt}

Mergers and Acquisitions ( $M$ and As) in High-Tech Industries: Measuring the Post-M and A Innovative Performance of Companies

UNU-MERIT Dissertation Series, № 33 


\section{Paola Criscuolo}

$R \mathcal{E D}$ Internationalisation and

Knowledge Transfer: Impact on MNEs and their Home Countries

UNU-MERIT Dissertation Series, № 32

\section{Maarten Verkerk}

Trust and Power on the Shop Floor UNU-MERIT Dissertation Series, № 31

\section{Gottfried Leibbrandt}

Adoption, Harmonization and Succession of Network Technologies across Countries

UNU-MERIT Dissertation Series, № 30

\section{Mark Sanders}

Skill Biased Technical change: Its Origins, the Interaction with the Labour Market and Policy Implications UNU-MERIT Dissertation Series, № 29

2003

\section{Nadine Roijakkers}

Inter-firm Cooperation in High-tech Industries: a Study of RED

Partnerships in Pharmaceutical Biotechnology UNU-MERIT Dissertation Series, № 28
Speed, Scale and Sustainability

UNU-MERIT Dissertation Series, № 27

\section{Masaru Yarime}

From End-of-Pipe Technology to Clean Technology

UNU-MERIT Dissertation Series, № 26

\section{Stéphane Malo}

The Combinatorial Chemistry

Revolution: Sustaining a Superior

Performance Position through

Technological Learning

UNU-MERIT Dissertation Series, № 25

2002

\section{Annelies Hogenbirk}

Determinants of Inward Foreign

Direct Investment: the Case of the

Netherlands

UNU-MERIT Dissertation Series, № 24

\section{Bastiaan Johan terWeel}

The Computerization of the Labour Market

UNU-MERIT Dissertation Series 
2001

\section{John Adeoti}

Technology Investment in Pollution Control in Sub-Saharan Africa: The Case of the Nigerian Manufacturing Industry

UNU-MERIT Dissertation Series, № 23

\section{Edward Huizenga}

Innovation Management: How

Frontrunners Stay Ahead: An

Empirical Study on Key Success

Factors in the ICT sector

UNU-MERIT Dissertation Series, № 22

2000

\section{Machiel van Dijk}

Technological Change and the

Dynamics of Industries: Theoretical Issues and Empirical evidence from

Dutch Manufacturing

UNU-MERIT Dissertation Series, № 21

1999

\section{Jan Cobbenhagen}

Managing Innovation at the Company Level: A Study on Non-Sector-Specific Success Factors UNU-MERIT Dissertation Series, № 20

\section{Marjolein Caniëls}

Regional Growth Differentials: The Impact of Locally Bounded Knowledge Spillovers

UNU-MERIT Dissertation Series, № 19

\section{8}

\begin{abstract}
Aldo Geuna
Resource Allocation and Knowledge production: Studies in the Economics of University Research
\end{abstract}

UNU-MERIT Dissertation Series, № 18

1996

\section{Reinoud Joosten}

Dynamics, Equilibria, and Values UNU-MERIT Dissertation Series, № 17

\section{Hugo Kruiniger}

Investment, $R \mathcal{E} D$, and the Financing

Decisions of the Firm

UNU-MERIT Dissertation Series, № 16

\section{5}

\section{Hans van Meijl}

Endogenous Technological Change: The Case of Information Technology, Theoretical Considerations and

Empirical Results

UNU-MERIT Dissertation Series, № 15 


\section{René Kemp}

Environmental Policy and Technical

Change: A Comparison of the

Technological Impact of Policy

Instruments

UNU-MERIT Dissertation Series, № 14

\section{Rohini Acharya}

The Impact of New Technologies on

Economic Growth and Trade: A Case

Study of Biotechnology

UNU-MERIT Dissertation Series, № 13

\section{Geert Duysters}

The Evolution of Complex Industrial Systems: The Dynamics of Major IT Sectors

UNU-MERIT Dissertation Series, № 12

\section{Marjan Groen}

Technology, Work and Organisation: A Study of the Nursing Process in Intensive Care Units

UNU-MERIT Dissertation Series, № 11

1994

\section{Huub Meijers}

On the Diffusion of Technologies in a Vintage Framework: Theoretical Considerations and Empirical Results UNU-MERIT Dissertation Series, № 10

\section{Theon van Dijk}

The Limits of Patent Protection: Essays on the Economics of Intellectual

Property Rights

UNU-MERIT Dissertation Series, № 9

\section{Hans Voordijk}

Naar Integrale Logistiek in

Bedrijfsketens: Ontwikkelingen in de Bouw

UNU-MERIT Dissertation Series, № 8

\section{3}

\section{Paul Diederen}

Technological Progress in Enterprises and Diffusion of Innovation:

Theoretical Reflections and Empirical Evidence

UNU-MERIT Dissertation Series, № 7

\section{Ben Dankbaar}

Economic Crisis and Institutional Change: The Crisis of Fordism from the Perspective of the Automobile Industry UNU-MERIT Dissertation Series, № 6

\section{Hanno Roberts}

Accountability and Responsibility: The Influence of Organisation Design on Management Accounting UNU-MERIT Dissertation Series, № 5 
1992

\section{Bart Verspagen}

Uneven Growth between

Interdependent Economies: An

Evolutionary View on Technology

Gaps, Trade and Growth

UNU-MERIT Dissertation Series,

№ 4

\section{Sjoerd Romme}

A Self-organization Perspective on

Strategy Formation

UNU-MERIT Dissertation Series,

№ 3

1989

\section{John Spangenberg}

Economies of Scale, and Atmosphere in

Research Organisations

UNU-MERIT Dissertation Series,

№ 2

1988

\section{John Hagedoorn}

Evolutionary and Heterodox

Innovation Analysis: A Study of

Industrial and Technological

Development in Process Control and

Information Technology

UNU-MERIT Dissertation Series, № 1 